Universidad Politécnica de Madrid

Escuela Técnica Superior de Arquitectura de Madrid

\title{
SOSTENIBILIDAD Y DURABILIDAD DE ELEMENTOS ESTRUCTURALES SUPERFICIALES EN BASE MADERA: \\ EL CASO DEL CLT
}

Tesis Doctoral

\author{
Jorge Galván Rodríguez \\ Ingeniero de Montes \\ Máster en Investigación Forestal Avanzada
}



Departamento de Estructuras

Escuela Técnica Superior de Arquitectura de Madrid

Universidad Politécnica de Madrid

\title{
SOSTENIBILIDAD Y DURABILIDAD DE ELEMENTOS ESTRUCTURALES SUPERFICIALES EN BASE MADERA: \\ EL CASO DEL CLT
}

Tesis Doctoral

\author{
Jorge Galván Rodríguez \\ Ingeniero de Montes \\ Máster en Investigación Forestal Avanzada
}

Directores

Ignacio de Oteiza San José

Enrique Martínez Sierra 



\section{(3) \\ POLITÉCNICA}

Tribunal nombrado por el Sr. Rector Magfco. de la Universidad Politécnica de Madrid, el día de de 20

Presidente:

Vocal:

Vocal:

Vocal:

Secretario:

Suplente:

Suplente:

Realizado el acto de defensa y lectura de la Tesis el día de de 20 en la E.T.S./Facultad

Calificación

EL PRESIDENTE LOS VOCALES 




\section{Agradecimientos}

En esta tesis doctoral, he contado con el apoyo de muchas personas, y no me gustaría olvidarme de nadie, así que con este objetivo y tratando de ser escueto, voy a hacer los agradecimientos por empresas y centros de investigación.

Como excepción a lo dicho voy a personalizar en mis directores, Ignacio Oteiza y Enrique Martínez, a los que agradezco su colaboración y su fe en este proyecto.

A Stora Enso, por creer en este proyecto desde el principio, facilitando todo el material y la ayuda necesaria para su desarrollo. A Rothoblaas por su colaboración y por estar siempre dispuesto a embarcarse en cualquier proyecto que les propongo.

Al Instituto de Ciencias de la Construcción "Eduardo Torroja" - CSIC (IETCC), centro que ha financiado esta investigación y donde se ha desarrollado, donde he aprendido todo lo necesario y más, donde dejo grandes profesionales y amigos. Nunca podré agradeceros todo lo que me habéis aportado. Gracias al laboratorio del DIT, que me abrió sus puertas, me ofreció su conocimiento y toda la ayuda necesaria.

Al Instituto Nacional de Investigación y Tecnología Agraria y Alimentaria (INIA), en especial al Departamento de Productos Forestales, sin cuyo apoyo la tesis no se hubiera podido realizar, gracias por todo el aporte científico y personal que me habéis dado.

Al Instituto de Tecnologías Físicas y de la Información "Leonardo Torres Quevedo" - CSIC (ITEFI), donde se hizo todo el desarrollo tecnológico de la tesis, y donde no solo he conocido grandes profesionales sino grandes personas, gracias por vuestra implicación sin ningún tipo de medida.

Al Instituto de Recursos Naturales y Agrobiología de Sevilla - CSIC (IRNAS) y a la Universidad Católica de Ávila (UCA), por facilitarme en todo lo posible la instalación de mis probetas y por ayudarme en todo el seguimiento, vuestro trato y disposición han sido magníficos.

Al Institut Technologique Forêt Cellulose Bois-Construction Ameublement (FCBA), por compartir su conocimiento y cederme el uso de sus laboratorios, hicieron fácil un trabajo que sin ellos no hubiera sido posible.

Al programa COST, y en especial a la acción FP1303, por todos los conocimientos y el apoyo aportado, por hacerme crecer como investigador y abrirme el horizonte.

A la convocatoria Trees4Future, que me permitió llevar a cabo mis ensayos en el FCBA, financiando mi estancia mediante una beca, gracias por creer en este proyecto.

Al servicio de estadística del CSIC, donde la alta cualificación y el gran nivel humano han permitido que mis resultados fueran lo que son, gracias por la dedicación y el trato.

Por último, y no por ello menos importante, a todas las personas que forman parte de mi Universo personal y que en todo momento me han apoyado y han creído en mí. A mi familia de sangre y a la que la vida me ha dado, y a todas esas personas que me aprecian y me lo demuestran día a día. GRACIAS. 



\section{Resumen}

Debido a la actual crisis del sector inmobiliario y a las políticas de eficiencia energética procedentes de Europa, materiales de construcción como la madera, que presentan una gran versatilidad en el ámbito de la rehabilitación y unas capacidades técnicas y credenciales medioambientales inmejorables, se postulan como el material idóneo de construcción.

Aunque la madera es un gran material de construcción, presenta limitaciones como el resto de materiales. Estas limitaciones, van más allá de los típicos tabúes como resistencia estructural, resistencia frente al fuego o deforestación, actualmente superados gracias a la normalización llevada a cabo.

Actualmente las investigaciones sobre la madera se centran en su durabilidad, especialmente en su comportamiento al exterior. Ya que en interiores o con las debidas protecciones (clases de servicio 1 y 2) estos aspectos están resueltos.

En la normalización llevada a cabo en la madera, y debido al gran avance tecnológico de los últimos tiempos en la fabricación de productos técnicos de madera para la construcción, se puede observar la aparición de ciertos productos innovadores de madera que no han contado con una norma armonizada propia, este es el caso del CLT (Cross laminated timber). Al no tener norma armonizada, los ensayos que se realizaban a este tipo de productos no eran específicos para ellos, lo que se ha traducido en el caso del CLT, en ensayos que penalizan al producto al no estar adaptados a sus características.

El objetivo de esta tesis es analizar la aptitud al uso del CLT como paramento vertical para su uso en exterior, en clase de servicio 3 y clase de uso 3.1. Para ello se plantea la necesidad de envejecerlo y evaluar la pérdida de resistencia estructural del producto. Se plantea el estudio de la durabilidad estructural por la degradación de agentes abióticos. No se tiene en cuenta la degradación de agentes bióticos, ya que se considera que un material tan masivo como el CLT, se puede asimilar en este aspecto, al comportamiento de la madera maciza.

Para llevar a cabo este objetivo se realiza un envejecimiento representativo del material, con ensayos de laboratorio en los que se producirá envejecimiento artificial, con dos tipologías diferentes, y con ensayos de exterior en los que se producirá un envejecimiento natural en tres tipologías climáticas representativas. En ambos casos el envejecimiento se produce mediante la introducción de un gradiente de humedad, que genera tensiones en el producto, y fruto de estas tensiones pueden surgir fendas y delaminaciones

Con respecto a la durabilidad, y a la captación de humedad se sabe que la especie de madera utilizada es un factor decisivo, por ello para llevar a cabo este estudio, se han elegido dos especies diferentes de madera, ambas muy utilizadas en el sector de la construcción, una por su aptitud para los procesos de encolado, y la otra por su aptitud para los tratamientos protectores en profundidad.

Posteriormente se tratará de relacionar la pérdida de propiedades estructurales con la variabilidad climática y con la orientación, para ver cómo afectan al producto, y si es apto para su uso en clase de servicio 3 como paramento vertical. 



\begin{abstract}
Due to the current crisis in the real estate sector and the energy efficiency policies coming from Europe, construction materials such as timber, which have great versatility in the rehabilitation of existing buildings and excellent technical and environmental characteristics. For these reason timber can be considered as the ideal construction material.

Although wood is a great construction material, it presents limitations like all other materials. These limitations go beyond the typical preconceptions, such as low structural resistance, bad resistance to fire or deforestation. These bias are being overcome thanks to the normalization of this material.

Currently research on wood focuses on its durability, especially on its behaviour outdoor. Wood destined for Interiors, or with the appropriate protections (classes of service 1 and 2) have these aspects resolved.
\end{abstract}

In the standardization of wood, and due to great technological advances in recent times in the manufacture of wood technical products for construction, the appearance of certain innovative products of wood that do not have harmonized standards has increased. This is the case of CLT (Cross laminated timber). Since there was no harmonized standard, the tests carried out on this type of product were not specific to them, which as a consequence in the case of the CLT lead to the penalizing of the product as the tests are not adapted to it characteristics.

The objective of this thesis is to analyse the performance of CLT as vertical facing for outdoor uses, service class 3 and use class 3.1. For this, the need to age and evaluate the loss of structural resistance of the product is proposed. The study of the structural durability by degradation of abiotic agents is considered but the degradation of biotic agents is not taken into account, since it is considered that a material such as CLT can be assimilated in this aspect to the behaviour of solid wood.

To carry out this objective, representative aging of the material is performed, with laboratory tests in which artificial aging will be produced, with two different typologies, and with external tests in which natural aging will occur, in three representative climatic typologies. In both cases the aging is produced by the introduction of a moisture gradient, which generates stresses in the product, and as a result of these stresses cracks and delamination may occur.

With respect to durability, and to the capture of moisture it is known that the wood species used is a decisive factor, therefore to carry out this study, two different wood species have been selected. These species are both widely used in construction, one for its suitability for the gluing processes, and the other for deep protective treatments.

Subsequently the relation of the loss of structural properties with climatic variability and orientation is investigated, to determine how they affect the product, and if it is suitable for use in service class 3 as vertical facing. 



\section{Índice general}

1. Introducción $\quad 21$

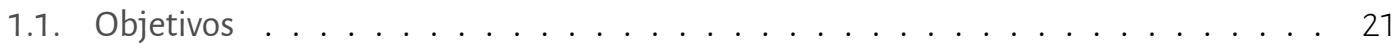

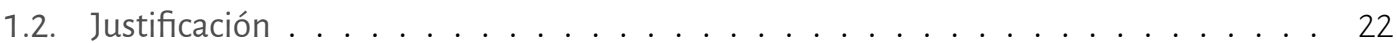

2. La madera y los productos de madera para la construcción 25

2.1. La madera como material . . . . . . . . . . . . . . . . . . . . . . 25

2.1.1. La estructura de la madera . . . . . . . . . . . . . . . . . . . 26

2.1.2. Humedad en la madera . . . . . . . . . . . . . . . . . . . . . 29

2.1.3. Comportamiento de la madera . . . . . . . . . . . . . . . . . . . 32

2.1.4. Clima exterior y humedad de la madera . . . . . . . . . . . . . . 38

2.2. Durabilidad de la madera y los materiales de madera para la construcción . . . . . . 41

2.2.1. Durabilidad natural y conferida de la madera . . . . . . . . . . . . . 43

2.2.2. Clases de uso de la madera . . . . . . . . . . . . . . . . . . . . . . 46

2.2.3. Clases de servicio de la madera . . . . . . . . . . . . . . . . . . . . . 47

2.2.4. Durabilidad del CLT . . . . . . . . . . . . . . . . . . . . . . 49

2.3. Evolución de los productos de madera para la construcción . . . . . . . . . . . . . 52

2.3.1. Desarrollo de los adhesivos . . . . . . . . . . . . . . . 54

2.3.2. Desarrollo de la industrialización de productos . . . . . . . . . . . . . 55

2.3.3. La madera contralaminada CLT . . . . . . . . . . . . . . . . . . 58

2.4. Normativa de ensayo de la madera contralaminada . . . . . . . . . . . . . . . 62

$\begin{array}{lr}\text { 3. Construcción con madera } & \mathbf{6 7}\end{array}$

3.1. Historia de la construcción con madera . . . . . . . . . . . . . . . . . . . 67

3.1.1. Construcción con madera en el mundo . . . . . . . . . . . . . . . . . . . 68

3.1.1.1. Edad Antigua . . . . . . . . . . . . . . . . . . 68

3.1.1.1.1. Viviendas temporales ............ 69

3.1.1.1.2. Viviendas semipermanentes ... . . . . . . . . 70

3.1.1.1.3. Viviendas permanentes .............. 70

3.1.1.2. Edad Moderna . . . . . . . . . . . . . . . . . . 71

3.1.1.2.1. Construcción con entramado de madera . . . . . . . . 72

3.1.1.2.2. Sistemas constructivos de madera . . . . . . . . . . 73

3.1.2. Construcción con madera en Europa . . . . . . . . . . . . . . . . . . . . . 75 
3.1.3. Construcción con madera en España . . . . . . . . . . . . . . . . 76

3.2. Construcción con CLT . . . . . . . . . . . . . . . . . . . . . . 77

3.2.1. Posibilidades del CLT . . . . . . . . . . . . . . . . . . . . . 78

3.2.2. Proceso de construcción y montaje . . . . . . . . . . . . . . . . . . 80

3.2.3. Ejemplos de construcción con CLT . . . . . . . . . . . . . . . . . 81

3.3. Normativa en materia de construcción con madera . . . . . . . . . . . . . . . . . 85

3.3.1. Directiva de Productos de la Construcción 89/106/CE de 1992 . . . . . . . . 86

3.3.2. Eurocódigos. Bases de cálculo de estructuras EN 1990:2002 . . . . . . . . . 87

3.3.3. Eurocódigo 5 UNE-EN 1995-1-1 (2016) . . . . . . . . . . . . . . . 87

3.3.4. Código Técnico de la Edificación CTE de $2006 \ldots \ldots$. . . . . . . . . . 88

3.3.5. Documento básico SE-M de 2009 . . . . . . . . . . . . . . . . 88

3.3.6. Reglamento de Productos de la Construcción (UE) No305/2011 de 2011 . . . 89

4. Desarrollo metodológico del trabajo experimental 91

4.1. Consideraciones previas . . . . . . . . . . . . . . . . . . . . . . . . . . 92

4.2. Características del producto y selección de especies . . . . . . . . . . . . . . . . 94

4.2.1. Material suministrado . . . . . . . . . . . . . . . . . . . . 96

4.3. Descripción de los ensayos . . . . . . . . . . . . . . . . . . . . 96

4.3.1. Tamaño de las probetas . . . . . . . . . . . . . . . . . . . . . 999

4.3.2. Selección de las probetas . . . . . . . . . . . . . . . . . 100

4.3.2.1. Selección de las probetas procedentes del envejecimiento natural. 101

4.3.2.2. Selección de las probetas destinadas al envejecimiento artificial . 101

4.3.2.3. Selección general de las probetas (eliminación de defectos) . . 103

4.4. Envejecimiento natural . . . . . . . . . . . . . . . . . . . . . . . . . 104

4.4.1. Tipos climáticos . . . . . . . . . . . . . . . . . . . . 105

4.4.1.1. Climatología general . . . . . . . . . . . . . . 105

4.4.1.1.1. Temperatura . . . . . . . . . . . . 106

4.4.1.1.2. Precipitación . . . . . . . . . . . . 107

4.4.1.1.3. Otros elementos climáticos . . . . . . . . . . . . 109

4.4.1.2. Climatología en el CTE . . . . . . . . . . . . . . . . 117

4.4.1.3. Climas seleccionados . . . . . . . . . . . . . . . . 117

4.4.2. Diseño de los prototipos . . . . . . . . . . . . . . . . 120

4.4.3. Monitorización . . . . . . . . . . . . . . . . . . . 125

4.4.3.1. Sistema de monitorización . . . . . . . . . . . . 127

4.4.3.2. Parámetros de monitorización . . . . . . . . . . . . 128

4.4.3.3. Tecnología empleada . . . . . . . . . . . . . . . 128

4.4.3.4. Anomalías del sistema . . . . . . . . . . . . . . . . . . 131

4.4.3.5. Adaptación de las medidas . . . . . . . . . . . . . . 134

4.5. Envejecimiento artificial . . . . . . . . . . . . . . . . . . . . . 138

4.5.1. Preparación de las probetas . . . . . . . . . . . . . . . . . . 141

4.5.2. Rueda de envejecimiento . . . . . . . . . . . . . . . . . . . . . . 1442

4.5.2.1. Aparatos . . . . . . . . . . . . . . . . 142

4.5.2.2. Procedimiento . . . . . . . . . . . . . . . 144 
4.5.2.3. Selección de los ciclos a aplicar . . . . . . . . . . . . . . . . . . 144

4.5.3. Cámara climática . . . . . . . . . . . . . . . . . . . 145

4.5.3.1. Aparatos................... 146

4.5.3.2. Procedimiento . . . . . . . . . . . . . . . . 148

4.5.3.3. Selección de los ciclos a aplicar . . . . . . . . . . . . . . . . . 149

4.6. Ensayo de tracción . . . . . . . . . . . . . . . . . . . . . . . 150

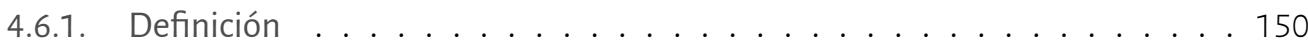

4.6.2. Tipos de mordazas para el ensayo . . . . . . . . . . . . . . . . . . . . . . 151

4.6.2.1. Mordazas tipo A, fijación por agarre mecánico plano, según UNE-

EN 319:1994 . . . . . . . . . . . . . . . . . . . 152

4.6.2.1.1. Variante de ensayo de las mordazas tipo A, con unión

química madera-madera . . . . . . . . . . . . . 156

4.6.2.2. Mordazas tipo B, fijación por agarre mecánico cóncavo según UNE-

EN 302-3:2013 . . . . . . . . . . . . . . . . . . . . 157

4.6.2.3. Mordazas tipo C, fijación por agarre químico plano, según UNE-

EN 408:2010 . . . . . . . . . . . . . . . . . . . . 159

4.6.3. Preparación de las probetas . . . . . . . . . . . . . . . . . . . 161

4.6.4. Aparatos ........................ . 164

4.6.5. Procedimiento ........................ 165

4.7. Ensayo de delaminación . . . . . . . . . . . . . . . . . . . 165

4.8. Tratamiento de los datos . . . . . . . . . . . . . . . . . . . . . . . . . . . . . . 168

5. Desarrollo y aplicación del método 173

5.1. Análisis generales de los envejecimientos . . . . . . . . . . . . . . . . . . . . . . . 174

5.1.1. Resultados para el abeto . . . . . . . . . . . . . . . . . . . . . 174

5.1.1.1. Ensayo de referencia . . . . . . . . . . . . . . . . 174

5.1.1.2. Análisis descriptivo de los diferentes métodos de envejecimiento 175

5.1.1.2.1. Envejecimiento natural . . . . . . . . . . . . 175

5.1.1.2.2. Envejecimiento artificial . . . . . . . . . . . . . . 177

5.1.1.3. Análisis de contraste de hipótesis de los diferentes métodos de envejecimiento . . . . . . . . . . . . . . . . . 179

5.1.1.4. Resumen de los resultados sobre el comportamiento del CLT de Abeto .................... . . 182

5.1.2. Resultados para el pino . . . . . . . . . . . . . . . . . 182

5.1.2.1. Ensayo de referencia . . . . . . . . . . . . . . 183

5.1.2.2. Análisis descriptivo de los diferentes métodos de envejecimiento 183

5.1.2.2.1. Envejecimiento natural . . . . . . . . . . . . . 183

5.1.2.2.2. Envejecimiento artificial . . . . . . . . . . . . . 185

5.1.2.3. Análisis de contraste de hipótesis de los diferentes métodos de envejecimiento . . . . . . . . . . . . . . 187

5.1.2.4. Resumen de los resultados sobre el comportamiento del CLT de Pino ................... . 190

5.2. Análisis del envejecimiento natural . . . . . . . . . . . . . . . . . . . . . . . . 190 
5.2.1. Resultados para el abeto . . . . . . . . . . . . . . . . . . . . . . . . . 191

5.2.1.1. Análisis descriptivo del envejecimiento natural . . . . . . . . . . 191

5.2.1.1.1. Carga máxima abeto . . . . . . . . . . . . . . 191

5.2.1.1.2. Delaminación abeto . . . . . . . . . . . . . 192

5.2.1.2. Análisis de contraste de hipótesis del envejecimiento natural . . 193

5.2.1.2.1. Carga máxima abeto . . . . . . . . . . . . 193

5.2.1.2.2. Delaminación abeto . . . . . . . . . . . . 200

5.2.1.3. Resumen de los resultados del CLT de abeto . . . . . . . . . 207

5.2.2. Resultados para el pino (Pinus sylvestris) . . . . . . . . . . . . . . 208

5.2.2.1. Análisis descriptivo del envejecimiento natural . . . . . . . . . 208

5.2.2.1.1. Carga máxima pino . . . . . . . . . . . . . . 210

5.2.2.1.2. Delaminación pino . . . . . . . . . . . . . . . . 210

5.2.2.2. Análisis de contraste de hipótesis del envejecimiento natural . 210

5.2.2.2.1. Carga máxima pino . . . . . . . . . . . . . . 210

5.2.2.2.2. Delaminación pino . . . . . . . . . . . . . 215

5.2.2.3. Resumen de los resultados del CLT de pino . . . . . . . . . . . 221

5.3. Análisis del envejecimiento artificial . . . . . . . . . . . . . . . . . . 222

5.3.1. Resultados para el abeto (Picea abies) . . . . . . . . . . . . . . . 222

5.3.1.1. Análisis descriptivo FCBA . . . . . . . . . . . . . . . . 223

5.3.1.2. Análisis descriptivo del método INIA . . . . . . . . . . . 223

5.3.1.3. Análisis de contraste de hipótesis . . . . . . . . . . . . . . . 224

5.3.1.3.1. Carga máxima . . . . . . . . . . . . . . . . 224

5.3.1.3.2. Delaminación . . . . . . . . . . . . . . . 227

5.3.2. Resultados para el pino (Pinus sylvestris) . . . . . . . . . . . . . . 230

5.3.2.1. Análisis descriptivo del método FCBA . . . . . . . . . . . . . 230

5.3.2.2. Análisis descriptivo para el método INIA . . . . . . . . . . . 230

5.3.2.3. Análisis de contraste de hipótesis . . . . . . . . . . . . . . . . 231

5.3.2.3.1. Carga máxima . . . . . . . . . . . . . . . . 231

5.3.2.3.2. Delaminación . . . . . . . . . . . . . 234

5.4. Análisis de variables climáticas y degradación . . . . . . . . . . . . . . . 236

5.4.1. Análisis descriptivo de clima y degradación . . . . . . . . . . . . . 236

5.4.2. Análisis de componentes principales para datos categóricos abeto . . . . . 239

5.4.2.1. Análisis de componentes principales para datos categóricos de la

carga máxima . . . . . . . . . . . . . . . . . . . 241

5.4.2.2. Análisis de componentes principales para datos categóricos de la delaminación . . . . . . . . . . . . . . . 244

5.4.3. Análisis de los componentes principales para datos categóricos del pino . . 246

5.4.3.1. Análisis de componentes principales para datos categóricos de la carga máxima . . . . . . . . . . . . . . . . . 248

5.4.3.2. Análisis de componentes principales para datos categóricos de la delaminación . . . . . . . . . . . . . 250

5.5. Análisis comparativo de la degradación respecto al método aplicado . . . . . . . . . 252

5.5.1. Degradación según el método aplicado . . . . . . . . . . . . . . . 253 
5.5.2. Comparativa entre métodos ... . . . . . . . . . . . . . . 255

6. Conclusiones 259

6.1. Conclusiones parciales sobre el abeto . . . . . . . . . . . . . . . . . . 259

6.2. Conclusiones parciales sobre el pino . . . . . . . . . . . . . . . . . . . . . . 261

6.3. Conclusiones generales . . . . . . . . . . . . . . . . . . . 263

7. Futuras líneas de investigación 265

$\begin{array}{lr}\text { 8. Îndices de calidad de la tesis } & 267\end{array}$

$\begin{array}{lr}\text { Bibliografía } & 273\end{array}$

Îndice de figuras $\quad 291$

$\begin{array}{lr}\text { Índice de tablas } & 297\end{array}$ 



\section{Capítulo 1}

\section{Introducción}

\subsection{Objetivos}

La madera contralaminada o CLT, siglas procedentes del término que la denomina en inglés Cross Laminated Timber, es un producto denominado innovador según la antigua directiva de productos de la construcción.

Cabe mencionar que durante el desarrollo de la presente tesis doctoral se publicó la tan esperada norma armonizada del CLT, aunque al ser este estudio previo a dicha publicación no se considera en el texto lo establecido en dicha norma. No se ha considerado necesario incluir dicho análisis ya que la citada norma armonizada sigue sin responder (mediante metodologías de ensayo), a la cuestión que en este trabajo se plantea, si es apto el CLT para las condiciones de uso propias de una clase de uso 3.1, equivalente a la clase de servicio 3 para usos verticales con capacidad de drenado de agua.

Los ensayos que se le practican a este tipo de productos para certificar sus propiedades mediante un DITE (actualmente ETE), son ensayos de otros productos similares que se consideran válidos para ellos, pero que no han sido desarrollados ad hoc. Esto hace que en ocasiones estos ensayos penalicen al producto, ya que no tienen en cuenta sus particularidades de fabricación o conformación del producto.

Actualmente el CLT está normalizado para clases de servicio 1 y 2, pero no para clase de servicio 3. En teoría la durabilidad de este material es la misma que la de la madera maciza, pero al tratarse de un producto complejo hay que tener en cuenta otros parámetros, como las colas y la disposición de las piezas que ayudan a conformar el producto.

Como objetivos de esta tesis se plantean los siguientes:

- Analizar la aptitud al uso de CLT para su uso al exterior como paramento vertical en clase de servicio 3.

- Analizar la influencia del clima en la degradación de las colas que conforman el CLT.

- Analizar la influencia del clima en la degradación de las especies de madera que conforman el CLT objeto de estudio. 
- Estudio de un sistema de ensayo adaptado al CLT para evaluar su durabilidad para clase de servicio 3, siempre como paramento vertical.

- Comparación de dos sistemas de envejecimiento artificial con el envejecimiento natural en tres tipologías climáticas representativas de la península ibérica.

- Avanzar en el conocimiento del comportamiento al exterior del CLT.

- Profundizar en la propuesta de soluciones innovadoras que ayuden a cumplir las condiciones necesarias para el uso en clase de servicio 3 del CLT.

\subsection{Justificación}

Durante la historia del hombre, desde que este salió de las cavernas y se construyó su primer refugio para poder soportar las inclemencias del tiempo, su evolución y la de la construcción, han ido unidas, adaptándose las diferentes técnicas a las necesidades según la zona y costumbres. Está visión de la construcción de adaptarse a las necesidades del hombre, empezó a ampliarse cuando apareció el concepto de sostenibilidad. La aparición de este concepto, nos hizo darnos cuenta que en la construcción no sólo podíamos centrarnos en cubrir las necesidades del usuario, sino que había unas necesidades aún más importantes que eran las del planeta que habitamos.

Cuando hablamos de sostenibilidad tenemos en cuenta muchos factores, no solo el ambiental, y tras muchas experiencias y estudios, somos conscientes de que este tipo de construcción es posible. En estos términos, uno de los materiales que se postula como favorito es la madera, que si bien no siempre es el material idóneo, si lo es en muchos casos en los que por diferentes motivos no es utilizado.

Por diferentes razones, el uso de la madera ha sido denostado en nuestro país en los últimos tiempos. Sin embargo, se trata de un material empleado en construcción de viviendas desde el Neolítico. Una de las dificultades con las que se encontraba este material para su uso en construcción era la falta de normativa, la cual hasta hace casi 30 años era prácticamente inexistente. Quizás esta falta de regulación radique en que tradicionalmente la madera se ha usado en la construcción de elementos, por un lado dispares, y por otro de revestimiento y acabado.

Los productos de madera, al igual que las técnicas constructivas, han evolucionado mucho en los últimos tiempos, consiguiendo gracias a la tecnología, poner en el mercado productos técnicamente competitivos con otros materiales y que cuentan con unas credenciales medioambientales francamente buenas. De entre los productos que han surgido por la evolución de la tecnología de la madera nos encontramos con el tablero contralaminado, denominado CLT por su nombre inglés Cross laminated timber.

El CLT es un producto que hasta el cambio de normativa con respecto a la normalización de productos de la construcción, de documento de idoneidad técnica DITE a ETE, era denominado producto innovador. El antiguo Documento de Idoneidad Técnica Europeo (DITE), actualmente DEE, es uno de los instrumentos utilizados por los fabricantes de productos de madera destinados a la construcción para demostrar la idoneidad técnica de este material por su innovación como productos de la construcción. 
El CLT surge en la década de los 90 en la zona de Austria, donde se unieron distintos centros tecnológicos para desarrollar un nuevo producto que incentivara el consumo de la madera como materia prima en la construcción. La industria con sus posibilidades y potencial se unió a centros de investigación como la universidad de Graz, que junto con su Institute of Timber Engineering and Wood Technology desarrollaron lo que hoy en día llamamos Tablero Contralaminado (TCL), Cross Laminate Timber (CLT), X-Lam, Panneaux de Bois Massif o Brettsperrholz (BSP). Propusieron una técnica similar a la de los contrachapados, Ilevado a escala estructural para edificación, generando tableros estructurales de gran formato, dando como resultado estructuras superficiales.

Es un sistema constructivo basado en "patentes" donde la información independiente casi no existe. La información disponible se obtiene a partir de las empresas que lo producen, y algunos centros de investigación y desarrollo relacionados con la industria maderera. Este producto se ha ido legalizando a través de certificaciones ETA (European Technical Approval), DITE en España, y es un producto estructural que no se contempla dentro de las normativas (Eurocódigo 5, UNE-EN 1995-1-1, 2016).

Su funcionamiento como sistema está más que demostrado, de forma normativa y empírica, ya que se han realizado todo tipo de construcciones, desde viviendas unifamiliares hasta edificios de más de 10 plantas.

Como se ha comentado, el CLT es un producto ampliamente caracterizado en cuanto a sus propiedades mecánicas, sus propiedades acústicas y en su comportamiento frente al fuego, pero con respecto a su durabilidad nos encontramos con que solo es apto para su uso en clase de servicio 1 o 2 .

Teniendo en cuenta las posibilidades de este sistema constructivo, entre ellos la rehabilitación, y que no solo presenta unas buenas credenciales medioambientales, sino un gran comportamiento energético, ya que este tipo de construcción encaja muy bien con el estándar Passiv House, parece necesario investigar sobre todas las posibilidades de uso, ya que todas las políticas procedentes de Europa nos hablan de sostenibilidad y eficiencia energética, ámbitos en los que este producto presenta grandes posibilidades.

Es por ello que se plantea la investigación del CLT en materia de durabilidad teniendo en cuenta variables de sostenibilidad. Por ello la presente tesis doctoral se propone mediante este estudio promover el diseño y uso sostenible de elementos constructivos de madera, proporcionar información técnica y ambiental fiable del uso de la madera en construcción, potenciar y poner en valor el uso de sistemas constructivos de madera en la rehabilitación, y promover la innovación y el desarrollo técnico de nuevos productos.

Esta investigación busca poner en evidencia el valor de la madera y especialmente la madera industrializada como material constructivo, generando un nuevo abanico de posibilidades a la hora de la inserción de este material en la construcción española.

Lo importante de esta investigación es que de alguna forma, al mostrar las capacidades de este material mediante su durabilidad, puede producir impulso del uso de la madera a futuro cuando España siga el rumbo de un crecimiento constante el sector de la construcción, y se pueda ver en la madera una alternativa para hacer edificios de estructuras mixtas, generando innovación tecnológica que a su vez origine construcciones sostenibles. 
Cabe destacar el carácter totalmente innovador de este trabajo de investigación, dado que no existe hasta el momento otro estudio de carácter nacional que, evalúe y cuantifique la degradación del CLT al exterior para su aptitud al uso en clase de servicio 3 como paramento vertical, aplicando una metodología adaptada al material.

El sector de la edificación representa el 40 \% del consumo energético total de la Unión Europea (UE). La reducción del consumo de energía en este ámbito constituye, por lo tanto, una prioridad en el marco de los objetivos "20-20-20" en materia de Eficiencia Energética.

Casi la mitad de los materiales utilizados en la Unión Europea están destinados a la construcción y mantenimiento de edificios. Por ello, la elección de materiales y soluciones constructivas de bajo impacto ambiental en todo su ciclo de vida se convierte en tema clave en el proceso de conseguir una Construcción más Sostenible y alcanzar cumplir los objetivos de reducción de emisiones ya planteados.

Además, la Directiva Europea de Edificios de Consumo de Energía Casi Nulo nos obliga a replantear nuestros procesos y soluciones constructivas en la búsqueda de una mayor Eficiencia Energética y la mejor integración de las energías renovables.

Por todo ello es necesario avanzar en el conocimiento de materiales sostenibles y a la vez energéticamente eficientes, como es el caso de los productos técnicos de madera, ayudando así a Arquitectos, Ingenieros y otros actores del sector a su utilización en el sector de la construcción, garantizando su mayor durabilidad, consiguiendo así un mejor ciclo de vida del producto. 


\section{Capítulo 2}

\section{La madera y los productos de madera para la construcción}

La madera y sus derivados juegan un papel doble en la mejora medioambiental del proceso edificatorio. Por un lado, al ser un producto que de forma natural fija carbono atmosférico durante su proceso de elaboración (por el árbol) y requerir muy poca energía para su transformación y puesta en obra, los balances de la huella ecológica del proceso constructivo resultan mucho más positivos y acordes con las nuevas regulaciones ambientales. Por otro lado, al ser un material cuasi aislante, su empleo en la construcción de las envolventes térmicas de los edificios ayuda a reducir decisivamente el consumo energético en uso de los edificios. Finalmente, debido a su higroscopicidad, la madera influye también, de manera positiva, en el clima de los habitáculos que conforma, ayudando así a conseguir el confort del usuario (Teischinger, 1987).

Estos factores han logrado que la madera avance en el desarrollo de productos para la construcción, y su uso vuelva a la escena constructiva de manera progresiva. Pero el uso de la madera y los productos derivados de la madera, requieren el conocimiento tanto del material como del producto para una correcta utilización.

\subsection{La madera como material}

Para comprender el funcionamiento de los productos de construcción derivados de la madera, hay que hacer una primera aproximación hacia el material base, la madera, y una segunda hasta el producto.

Se llama madera al conjunto de tejidos del xilema que forman el tronco, las raíces y las ramas de los vegetales leñosos, excluida la corteza. Desde el punto de vista comercial, únicamente se aprovecha la madera de los árboles, es decir, vegetales leñosos de ciertas dimensiones (García et al., 2003). 


\subsubsection{La estructura de la madera}

Para analizar la madera, hay que comprender su proceso de crecimiento, y para ello hay que remitirse al árbol. En la sección transversal del árbol se pueden observar diferentes partes, la parte más visibley externa es la corteza, parte muerta, que tiene la función de proteger las partes vivas del árbol.

Tras la corteza la primera capa que se presenta es el cambium, tejido meristemático encargado de la producción celular. El cambium produce en su parte externa células que darán lugar a la corteza, y en su parte interior células que darán lugar a la madera. Este tejido que se conforma hacia el interior del cambium es el tronco, donde se encuentran los tejidos vivos del árbol encargados de distribuir los nutrientes a lo largo del mismo.

Dependiendo de la especie de la que se trate, este tejido que el cambium genera hacia el interior del tronco llamado madera, puede diferenciarse a su vez en albura, duramen y médula, nombrados desde el exterior al interior del tronco.

Estos tres tipos de madera o tres partes que conforman la madera, que no están presentes en todas las especies, tendrán una composición diferente y unas propiedades estructurales diferentes, que afectará entre otras cosas a su durabilidad.

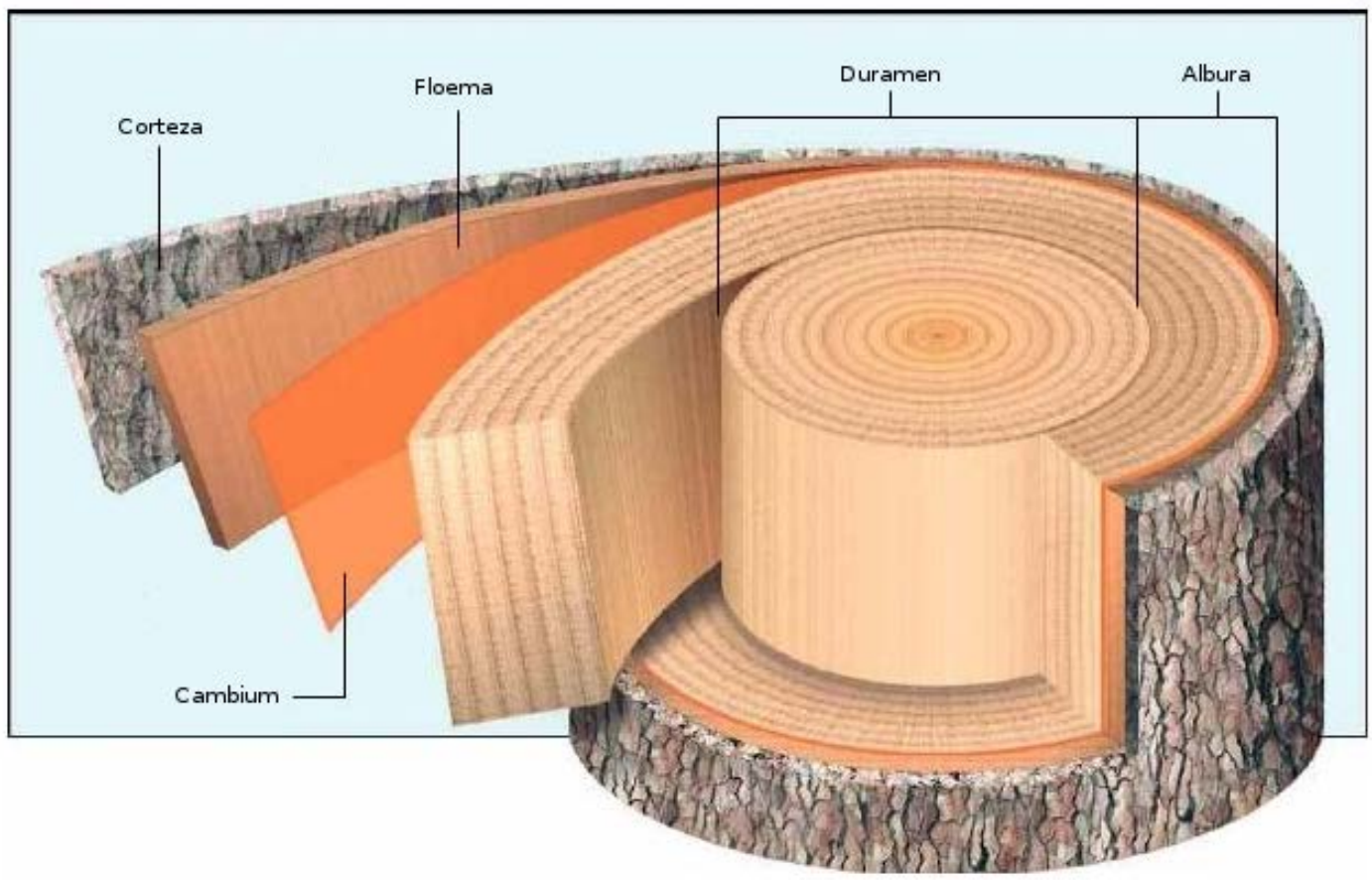

Figura 2.1: Esquema de las partes del tronco

En los climas templados, la madera que se produce durante la primavera, difiere de la producida en la época de verano y otoño. La madera que se produce durante la primavera, también llamada madera temprana (earlywood en inglés), es la responsable del transporte, y la madera de verano y otoño, tam- 
bién llamada madera tardía (latewood en inglés), es la que soporta mecánicamente el tronco. Debido a las paredes celulares más gruesas y los lúmenes más pequeños, las células de la madera tardía tienen una densidad más alta que conduce a un color más oscuro y hace que el anillo anual sea visible a simple vista (figura 2.2). Las diferencias en el ancho radial de los anillos de crecimiento se deben tanto a las condiciones ambientales durante el período de crecimiento, como al suelo y clima.
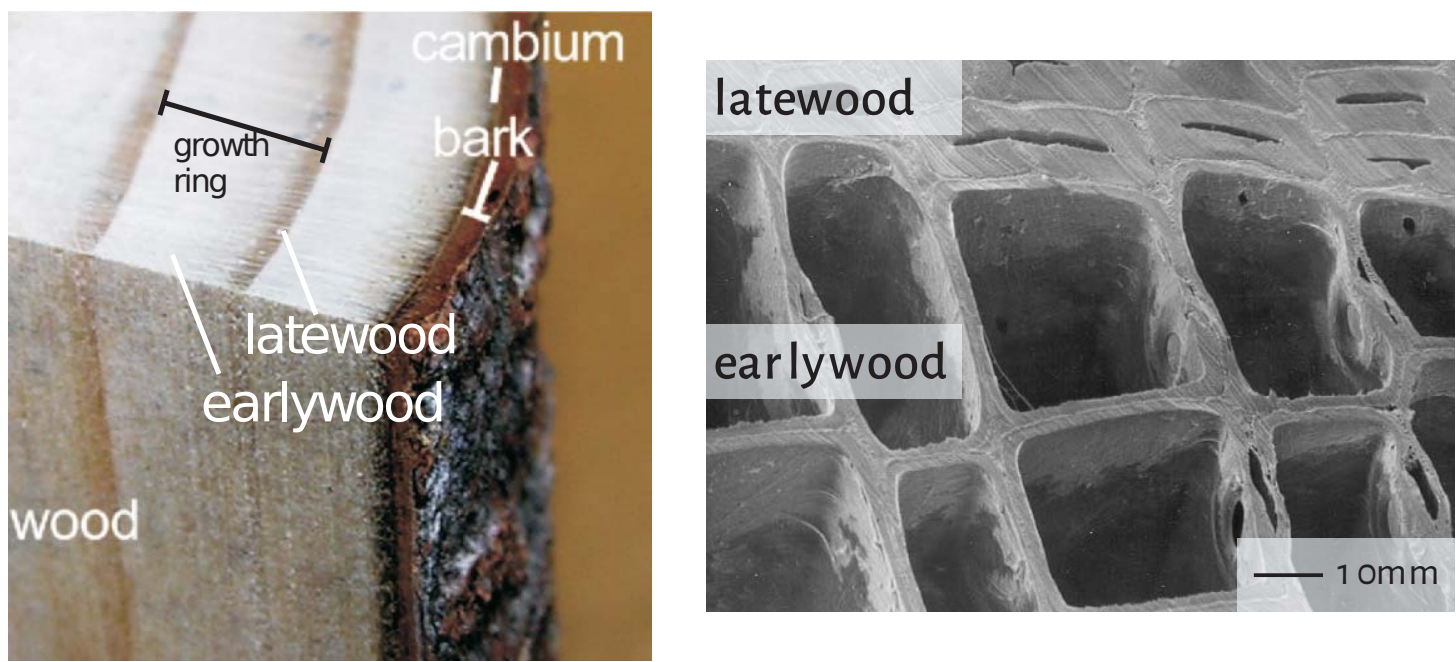

Figura 2.2: Lado izquierdo: Pinus radiata, (Walker, 2006). Lado derecho: Picea abies, muestra claramente las traqueidas de madera tardía de pared más gruesa y las traqueidas de madera temprana de pared más delgada

El material que compone el tronco son las células de madera. En el caso de las maderas blandas o coníferas, como el abeto o el pino, el 90-95\% del volumen de madera está compuesto de células llamadas traqueidas, fibras o grano. Las principales funciones de las traqueidas son el soporte mecánico y el transporte de fluidos. Estas se encuentran alineadas longitudinalmente en la dirección del tronco.

Existen otro tipo de células, denominadas parénquima, que están alineadas en la dirección radial, que es la dirección que se dibuja desde la médula, centro del tronco, hasta la corteza. Son los elementos básicos que componen los radios de la madera, y su función en el tronco es el almacenamiento de nutrientes. Se supone que los radios refuerzan el tallo en la dirección radial, lo que ha sido demostrado para maderas duras por Burgerty Eckstein (2001).

Una traqueida es una célula que consiste en una pared celular que encierra un lumen. La pared celular es la parte estructural de la célula, siendo la luz de la célula la cavidad de esta donde se transportan los fluidos. La pared celular está compuesta por la pared primaria (P) y la pared secundaria compuesta (S).

La pared secundaria a su vez consta de tres capas: la capa externa $S_{1}$, la capa media $S_{2}$ y la capa interna $S_{3}$ (figura 2.3). Estas capas y la pared primaria difieren en la orientación de sus microfibrillas, que son unidades de celulosa similares a hilos. En la delgada pared primaria $\mathrm{P}(0,1 \mu \mathrm{m})$ las microfibrillas están orientadas aleatoriamente. En la pared secundaria S, las microfibrillas giran alrededor de la céIula en un patrón helicoidal en un cierto ángulo con respecto al eje longitudinal de la célula, este es el denominado ángulo de microfibrilla (AMF).

Dentro de pared secundaria, la capa más externa $S_{1}$, tiene un espesor que oscila entre 0,1 a 0,3 $\mu \mathrm{m}$, y 


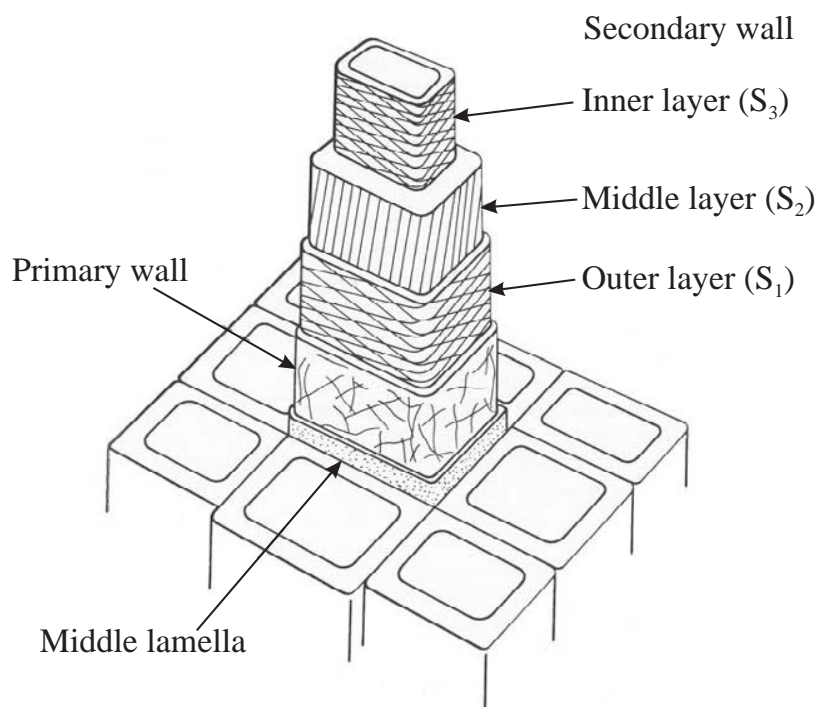

Figura 2.3: La estructura de la pared celular, Dinwoodie (1975)

su AMF varía de $50^{\circ}$ a $70^{\circ}$ dependiendo de la especie de madera (Dinwoodie, 1975; Kollmann y Côté, 1968). El espesor de la capa $S_{2}$ varía entre la madera temprana (1-4 $\left.\mu \mathrm{m}\right)$ y la madera tardía (3-8 $\left.\mu \mathrm{m}\right)$. La capa $\mathrm{S}_{2}$ constituye aproximadamente el 70-80 \% del grosor total de la pared celular. El AMF puede variar de $10^{\circ}$ a $30^{\circ}$ dependiendo de la especie, la edad y la procedencia de la célula, ya sea de madera temprana o de madera tardía (Dinwoodie, 1975; Kollmann y Côté, 1968). La estructura de la capa $\mathrm{S}_{2}$ tiene una fuerte influencia sobre propiedades celulares como la rigidez y la contracción (Persson, 2000), e incluso sobre las propiedades mecánicas de la madera (por ejemplo Burgert et al., 2002; Cave y Walker, 1994; Keunecke, 2008; Lindström et al., 2002; Reiterer et al., 1999). La capa $S_{3}$ de 0,1 $\mu \mathrm{m}$ de espesor es la parte interna de la pared secundaria S, tiene un AMF de $60^{\circ}$ a $90^{\circ}$ (Wardrop, 1964). Las células están interconectadas por la lámina central que está libre de fibrillas de celulosa. Se puede ver una discusión más profunda sobre las células que componen la madera en Bodig y Jayne (1993), Dinwoodie (1989) y Kollmann y Côté (1968).

Los anillos de crecimiento que conforman la madera crean una estructura cilíndrica. Esto provoca que ciertos parámetros del material como la rigidez, la resistencia y la contracción tengan una fuerte dependencia de la dirección. La disposición longitudinal de las fibras hacia el eje del tronco provoca, por ejemplo, a una gran rigidez en la dirección de las fibras y a su vez una rigidez considerablemente baja en dirección perpendicular a la misma. Las propiedades incluso varían significativamente entre las direcciones transversales. Típicamente, en la dirección radial (de la médula a la corteza), la rigidez es el doble que la tangencial a la dirección de los anillos de crecimiento.

Además, la hinchazón y contracción inducida por la humedad es considerablemente más pequeña en la dirección longitudinal que en las direcciones radial y tangencial a los anillos de crecimiento.

Las maderas blandas típicas, las coníferas como el pino y el abeto, se hinchan y se contraen dos veces más tangencialmente que radialmente. Esto desempeña un papel significativo, por ejemplo, en 
el secado de la madera aserrada, y en la resistencia de los encolados en los productos derivados de la madera. Debido a la estructura cilíndrica y a las diferencias radiales/tangenciales, la deformación de los tableros después del secado depende de la posición dentro del tronco donde fueron aserradas las piezas que lo componen (Ormarsson, 1999).

\subsubsection{Humedad en la madera}

La madera es un material higroscópico, que responde a los cambios en el contenido de humedad del aire. Las moléculas de agua se unen por enlaces de hidrógeno a los grupos $\mathrm{OH}$ de los componentes de la pared celular, en particular a la celulosa (Spalt, 1958). La cantidad de vapor de agua absorbido por una pieza de madera dependerá en gran medida de la cantidad de grupos $\mathrm{OH}$ que estén expuestos. El acceso a los grupos puede ser bloqueado por extractivos dentro de la madera (Skaar, 1988), y se ha demostrado que la eliminación de estos aumenta la higroscopicidad (Wangaardy Granados, 1967). Por lo tanto, la madera con alto contenido en extractivos tenderá a tener un bajo contenido de humedad en equilibrio.

El agua que es sostenida por las fuerzas moleculares dentro de la madera se llama "agua ligada". La adsorción del vapor de agua sobre los componentes de la pared celular continúa hasta que no pueden aceptar más y este punto, que es generalmente aceptado para las especies de madera que nos conciernen a un contenido de humedad del 28-30\%, se conoce como "saturación de fibra" (Tiemann, 1906). El punto de saturación de fibra es en realidad bastante variable, y puede variar más de 20-40\%, dependiendo de las especies de madera. Una vez que este nivel de humedad se excede el "agua libre" comenzará a llenar las cavidades de las células. La saturación total rara vez se produce en la mayoría de las situaciones debido a las burbujas de aire atrapado en las cavidades de las células.

La incorporación de agua en la pared celular llena todas las cavidades de la pared celular que están presentes y empuja las microfibrillas de celulosa, de manera que se producen cambios dimensionales. Estos cambios estarán en ángulo recto con el eje largo de las microfibrillas y, como éstas son casi paralelas al eje largo del árbol, los cambios longitudinales en la madera madura serán mínimos. Las cifras publicadas para las maderas blandas y las maderas duras europeas sugieren que los hinchamientos radiales y tangenciales son 10 y 20 veces mayores, respectivamente, que el hinchamiento longitudinal. Sin embargo, si las microfibras son menos verticales, como en la madera juvenil, puede producirse hinchamiento longitudinal significativo (Harris y Meylan, 1965). La diferencia de hinchazón entre las direcciones radial y tangencial (anisotropía) puede resultar en distorsión en lugar de la simple expansión y contracción del área de la sección transversal (Barbery Meylan, 1964; Barber, 1968).

Es importante recordar que la hinchazón ocurre dentro de las paredes de la célula y es por lo tanto una consecuencia de un aumento en el agua ligada. El agua libre dentro de las cavidades celulares no tiene ningún efecto adicional, de modo que ni el hinchamiento ni el encogimiento ocurren por encima del punto de saturación de la fibra.

Debido a que la contracción y la hinchazón están asociadas con la pared celular, y con los grupos $\mathrm{OH}$ expuestos en las moléculas celulosa / hemicelulosa, la madera es bastante variable en su respuesta. Las maderas duras tienden a tener un contenido de celulosa más al to y un contenido más bajo de lignina que las maderas blandas y son por lo tanto, más propensas al cambio dimensional. Esto puede 

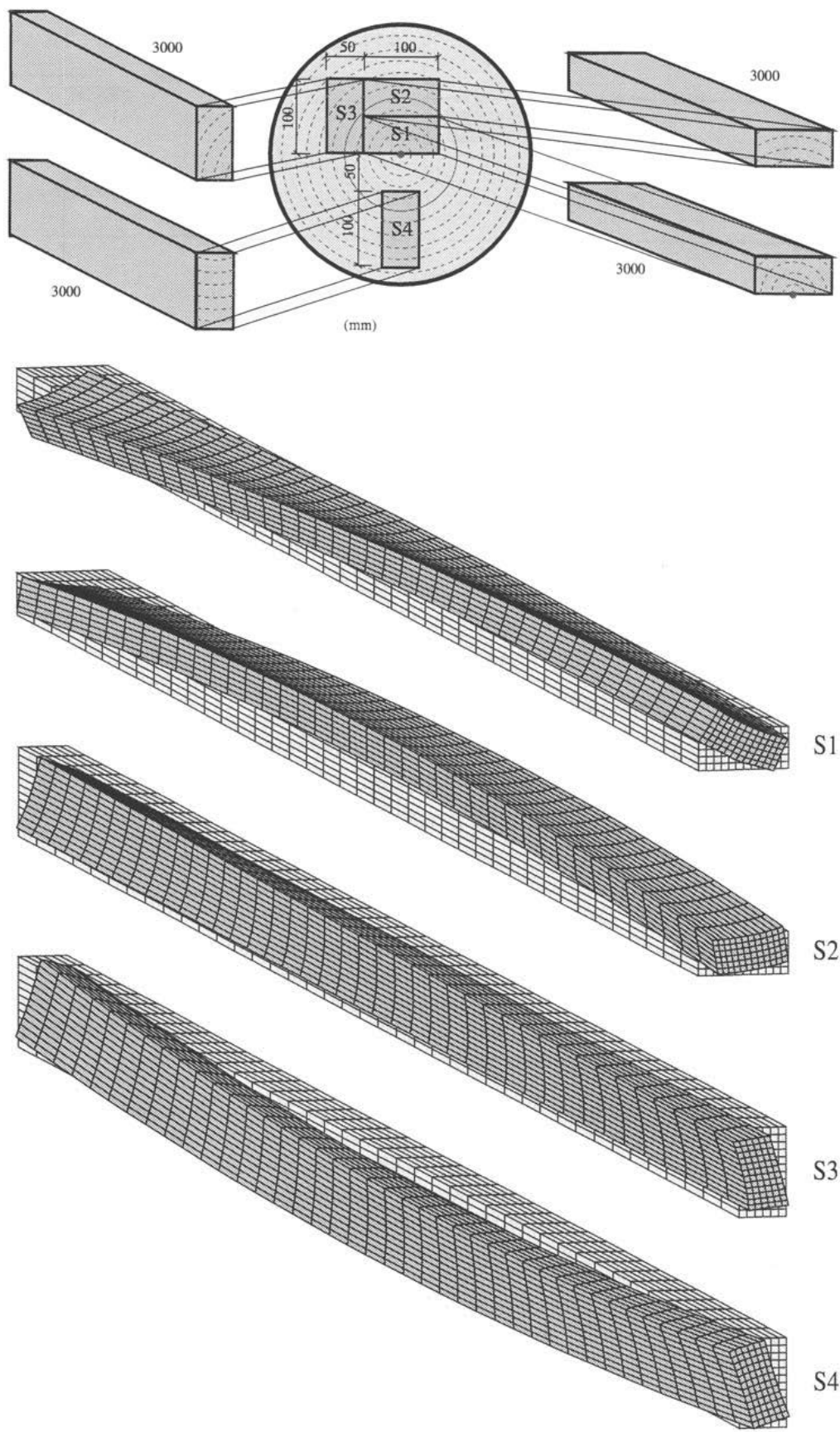

Figura 2.4: Deformaciones producidas por el secado en tablones procedentes de distintas partes del tronco (Ormarsson, 1999)

ser compensado en algunas especies de madera dura por un alto contenido de extractivos, que bloquearán el movimiento del agua (Skaar, 1988), y muchas maderas duras tropicales son por lo tanto 
dimensionalmente bastante estables

Sobre los procesos del transporte de humedad se ha realizado una amplia gama de investigaciones. Las obras generales relacionadas con los fenómenos del transporte en madera son escritas por Von Kollmann (1963), Siau (1984), Siau (1995), Skaar (1988), Stamm (1967a) y Stamm (1967b).

La humedad en la madera existe como agua unida en las paredes celulares higroscópicas o como agua libre (en forma líquida o de vapor de agua) en el lumen celular. El contenido de humedad de la madera $w(\%)$, denominada generalmente MC por sus siglas en inglés moisture content, se suele expresar en forma porcentual, y se define como la masa de humedad en la madera expresada como una fracción de la masa de madera seca $m_{0}(\mathrm{~kg})$ :

$$
w(t)=\frac{m(t)-m_{0}}{m_{0}} \times 100
$$

La masa de humedad es la masa de la muestra húmeda $m(t)(\mathrm{kg})$ en el momento $t(\mathrm{~s})$ menos la masa de la muestra seca. La relación entre la concentración $c\left(\mathrm{~kg} \mathrm{~m}^{-3}\right)$ y el contenido de humedad es:

$$
c(t)=\frac{m(t)-m_{0}}{V_{0}}=w(t) \rho_{0}
$$

La concentración de agua se indica con el volumen seco de madera $V_{0}\left(\mathrm{~m}^{-3}\right)$ como referencia. Por lo tanto, los efectos de los cambios de volumen debido a la hinchazón se omiten del balance de masas. El contenido de humedad y la concentración están en equilibrio con la humedad relativa (\%) del aire ambiente. Este contenido de humedad en equilibrio aumenta con el aumento de la humedad relativa $(\mathrm{RH})$ desde básicamente $0 \%$ en aire seco hasta el punto de saturación de fibra de 28-32\% a aproximadamente $98 \%$ de HR (paredes celulares saturadas) y teóricamente saturación completa del lumen a 100 \% RH. Las isotermas de sorción (figura 2.5) muestran la relación entre el contenido de humedad de la madera y la humedad relativa para temperaturas constantes. El efecto del contenido de humedad de equilibrio de la madera es mayor en la desorción que en la absorción, esto se denomina histéresis de sorción. Por lo tanto, el contenido de humedad a una humedad relativa dada depende de la historia del contenido de humedad.

El transporte de humedad en madera por debajo del punto de saturación de fibra es un proceso gobernado por difusión: difusión de agua en las paredes celulares y difusión de vapor de agua en la luz de la célula (Kollmann, 1955; Siau, 1995).

Si el flujo de aire en la superficie de la madera es lento, hay que considerar la resistencia superficial a la difusión.

Como se puede observar según lo expuesto, el contenido de humedad de la madera es un parámetro ampliamente estudiado y que depende de diferentes factores, esto hace que el análisis de la incorporación del agua en la madera y los efectos que produce el gradiente de humedad consecuencia de su exposición al exterior, sea un proceso complejo que requiera de cierta acotación para poder estudiar sus efectos. 


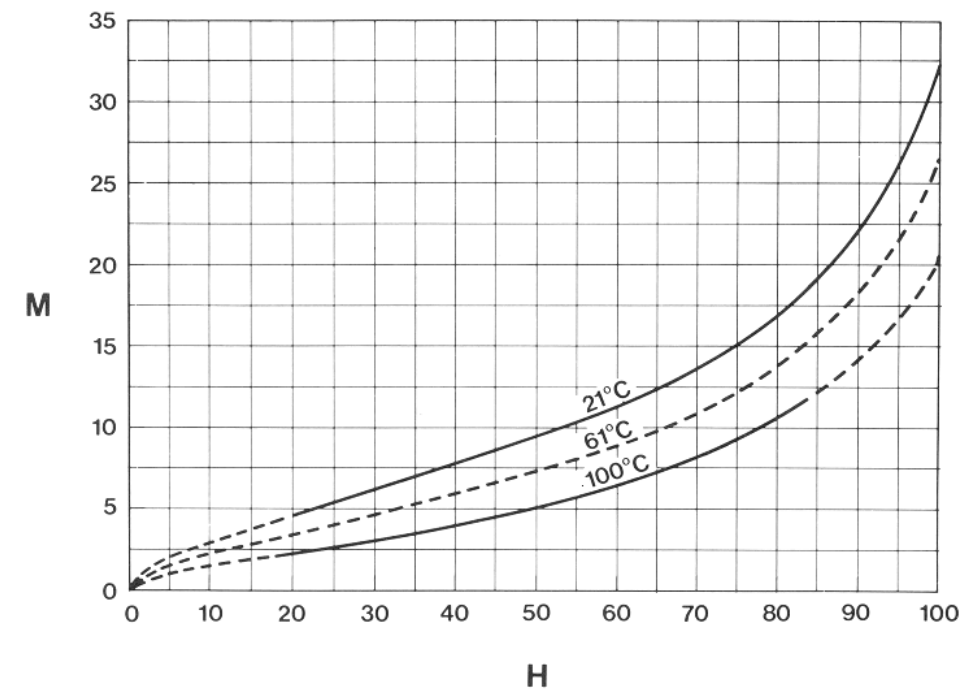

Figura 2.5: Isotermas de sorción ( $M$ : humedad de madera, $\mathrm{H}$ : humedad relativa)

\subsubsection{Comportamiento de la madera}

El comportamiento de la madera como material va a estar muy influenciado por la humedad que, como hemos visto anteriormente, puede presentarse en la madera de diferentes formas. La velocidad en que la humedad se incorpora o sale de la estructura de la madera, también va a condicionar su comportamiento y durabilidad a largo plazo.

Como se ha comentado, el contenido de humedad es un parámetro importante, que afecta a varias propiedades físicas, mecánicas y reológicas de la madera incluyendo durabilidad, procesos de contracción e hinchazón, módulo de elasticidad, y propiedades de resistencia (Gereke y Niemz, 2010).

La microestructura y la forma cilíndrica de las células que conforman la madera implican propiedades anisótropas. Esto, referido a los ejes de simetría y descrito con coordenadas cilíndricas, se simplifica comúnmente como comportamiento ortotrópico (figura 2.6(a)).

Un factor adicional que afecta significativamente el estado de tensión de la madera es el gradiente de humedad. La difusión de la humedad en la madera es un proceso bastante lento en comparación con el flujo de calor por ejemplo.

Los gradientes de humedad en las secciones de madera se crean cuando existe una diferencia en el valor del contenido de humedad en el seno de la sección transversal. Los gradientes en la mayoría de los casos se producen por cambios en el contenido de humedad de la superficie de las piezas motivados por acusados cambios en las condiciones higrotérmicas del medio circundante. Estos cambios tan intensos se suelen producir o en los procesos de secado de la madera o debidos al agua de lluvia en los usos del material al exterior. Por el contrario, los gradientes debidos a cambios en la humedad relativa atmosférica son mucho menos acusados y requieren mucho más tiempo para su establecimiento. Los cambios de humedad, cuando son superiores al $2 \%$, inducen procesos de contracción (humedad decreciente) o de hinchazón (humedad creciente) en la madera, que inducen a su vez tensiones en las 
secciones de madera. Estas tensiones se denominan tensiones inducidas por la humedad y pueden dar lugar a grietas en la superficie o en la parte central de las secciones de madera ya que la anisotropía anteriormente mencionada hace que la contracción (o hinchamiento) tangencial sea mayor que la radial.

Este comportamiento varía según las especies de madera, tienen diferentes coeficientes de contracción en el sentido radial y en el tangencial, lo que conlleva un diferente coeficiente de anisotropía. El coeficiente de anisotropía indica la facilidad de agrietamiento de la especie. Como se indica en el cuadro 2.1, la picea es una de las especies que mayor coeficiente de anisotropía tiene, lo que quiere decir que se fenda fácilmente ante el cambio dimensional producido por la variación de la humedad. La anisotropía absoluta indica el tamaño de las grietas que se producen por estos cambios dimensionales, a mayor coeficiente mayor tamaño de grietas, en este caso las mayores grietas se producen en los pinos.

Esta característica nos da una idea de la elasticidad o plasticidad que posee una especie, en el caso del pino y el abeto, las especies más utilizadas en productos estructurales de madera para la construcción, el abeto se presenta como una especie más plástica, y por tanto más propensa al fendado por los cambios de humedad.

Cuadro 2.1: Coeficientes de contracción dimensional y riesgo de atejado de algunas especies (adaptado de Alvarez y Fernández-Colfin, 1996)

\begin{tabular}{lccccc}
\hline \multirow{2}{*}{ ESPECIES } & \multicolumn{2}{c}{ Coef. Contracción $C_{\mathrm{D}}(\%)$} & & \multicolumn{2}{c}{ Anisotropía } \\
\cline { 2 - 3 } \cline { 6 - 6 } \cline { 5 - 6 } & Radial $C_{\mathrm{r}}$ & Tangencial $C_{\mathrm{t}}$ & & Coeficiente & Absoluta \\
\hline Pino radiata & 0,16 & 0,25 & & 1,8 & 3,3 \\
Pino pinaster & 0,13 & 0,26 & & 1,9 & 3,3 \\
Pino silvestre & 0,16 & 0,33 & & 1,8 & 3,2 \\
Pino laricio & 0,11 & 0,20 & & 1,8 & 2,8 \\
Alerce europeo & 0,10 & 0,20 & & 2,2 & 1,3 \\
Pino de Oregón & 0,18 & 0,28 & & 1,6 & 1,5 \\
Hemlock (Tsuga) & 0,19 & 0,34 & & 2,1 & 2,4 \\
Picea abies & 0,15 & 0,32 & & 2,6 & 3,0 \\
Pino palustris & 0,25 & 0,32 & & 1,4 & 1,4 \\
Abeto (Abies) & 0,13 & 0,23 & & 2,7 & 2,5 \\
Picea sitchensis & 0,15 & 0,28 & & 2,3 & 2,6 \\
Cedro rojo (Tuja) & 0,08 & 0,20 & & 2,9 & 1,8 \\
\hline
\end{tabular}

Las propiedades reológicas de la madera, es decir, la fluencia y la sorción mecánica, están marcadamente afectadas por el contenido de humedad, y la cuantía de su variación tiene un papel importante en el desarrollo de tensiones internas, ya que generalmente disminuyen las magnitudes de resistencia (Toratti, 1992; Hanhijärvi, 1995; Toratti y Svensson, 2000).

Sin embargo, como se ha comentado no sólo el nivel de contenido de humedad es importante, los cambios rápidos, provocan gradientes de humedad en la madera que inducen tensiones perpendiculares a la fibra y que pueden ocasionar grietas en la madera. Además, las variaciones de humedad tienen efectos negativos sobre la resistencia y rigidez de la madera sometida a carga a largo plazo (Ranta-Maunus, 2003). 
El mencionado comportamiento ortotrópico, debido a la microestructura y a la forma cilíndrica de la madera implican propiedades mecánicas diferentes en los distintos ejes de simetría, estos se puede ver descritos con coordenadas cilíndricas en la figura 2.6(a).

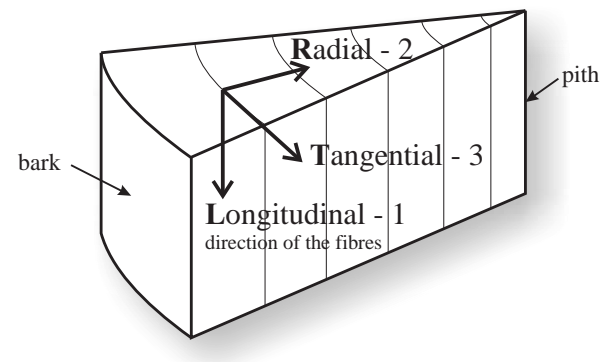

(a)

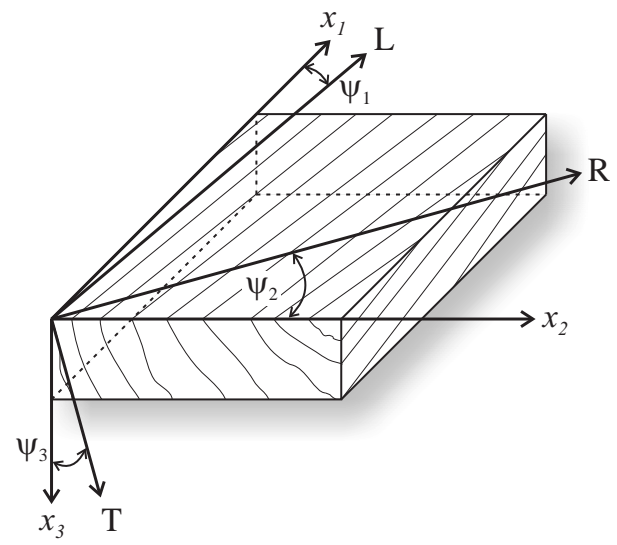

(b)

Figura 2.6: Direcciones de madera ortotrópicas (según Bodig y Jayne, 1993)

La interrelación existente entre carga y deformación se describe por la ley de elasticidad de Hooke.

Cuando se habla de madera estructural es muy importante el comportamiento reológico de la madera, que afecta directamente a la fluencia (denominada creep en terminología anglosajona). La fluencia es la tensión dependiente del tiempo, que se desarrolla cuando la madera durante un período corto o largo de tiempo, se expone a un estrés constante bajo condiciones ambientales constantes. Este fenómeno ha sido estudiado por muchos investigadores, véase, por ejemplo, Hanhijärvi (1995), Hartnack (2005), Morlier (2004) y Toratti (1992).

Deformation

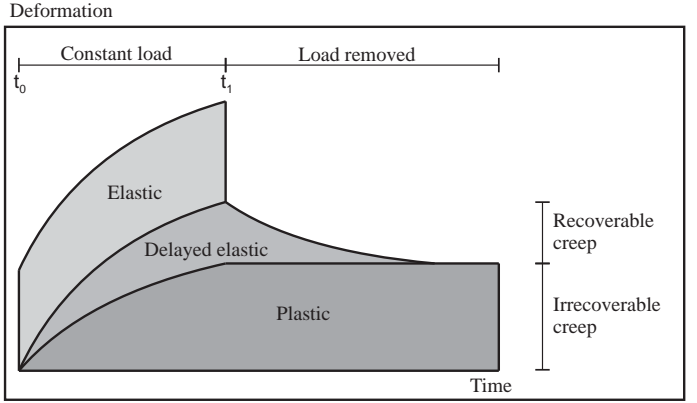

(a) Deformaciones debidas a una carga constante y después de la descarga, Dinwoodie (1989)

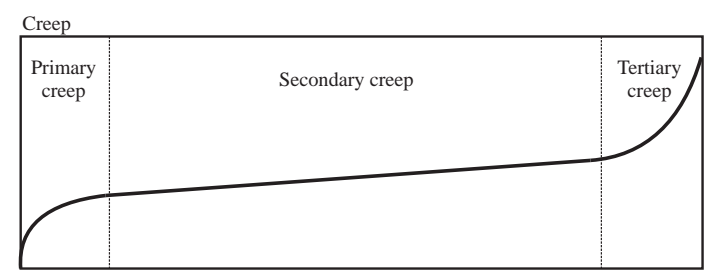

(b) Fluencia debido al esfuerzo uniaxial constante y las fases de fluencia, Niemz (1993)

Figura 2.7: Ilustración de fluencia

La carga con una tensión constante en el tiempo to, provoca una deformación elástica instantánea (figura 2.7(a)). Una deformación de fluencia, es la que se desarrolla cuando se mantiene la tensión cons- 
tante. Si la carga se retira en el instante $t_{1}$, la parte elástica de la deformación desaparecerá, y una cierta cantidad de la tensión de fluencia se recuperará. Sin embargo, esta deformación de recuperación es sólo una parte de la deformación total de fluencia ya que no se produce la recuperación total de la deformación por fluencia. Los dos componentes de fluencia son a menudo llamados fluencia elástica y plástica.

Si se aplica una tensión constante durante un tiempo prolongado, la deformación por fluencia puede dividirse en tres partes (figura 2.7(b)). En primer lugar, la fluencia aumenta considerablemente durante las primeras horas después de la carga, esto se conoce como fluencia primaria. A continuación, la deformación por fluencia se caracteriza por una velocidad de deformación decreciente, sigue un largo período de tensión lentamente creciente (fluencia secundaria) y justo antes del fallo, la deformación aumenta rápidamente (fluencia terciaria). Una muestra cargada puede fallar debido a la fluencia terciaria, dependiendo de la cantidad de la carga aplicada.

El efecto de que la deformación de una muestra seca cargada es significativamente mayor que la suma de las deformaciones de una muestra cargado en condiciones ambientales constantes, y la deformación de una muestra seca no sometida a carga se denomina efecto mecano-sortivo (figura 2.8). Esto se ha observado experimentalmente por Mårtensson (1992), Ranta-Maunus (1990) y Svensson (1997). El efecto mecano-sortivo es mayor cuanto mayor es el contenido de humedad Ranta-Maunus (1975), Liu (1994) y Toratti (1992). Es algo incierto si la mecano-sorción depende de la velocidad de incorporación del contenido de humedad.

Por último y relacionado con todos los aspectos explicados hasta el momento, con el objetivo de acabar de comprender el comportamiento de la madera como material, hay que tener en cuenta las tensiones inducidas por la humedad en la madera. La variación de la humedad relativa ambiente provoca un cambio de humedad en la sección transversal. Debido a su anatomía y al mencionado comportamiento ortotrópico, una distribución no uniforme de la humedad conduce a diferentes movimientos de hinchazón y contracción. En el caso de materiales derivados de la madera, como es el caso del CLT, el hecho de que las áreas estén restringidas por áreas adyacentes, es decir, áreas bajo proceso de hinchazón/merma estén restringidas en su movimiento por la existencia de áreas adyacentes estables, provoca tensiones internas en la madera. Dado que la resistencia mecánica es mucho más baja en dirección perpendicular a la fibra que en la dirección de la fibra, debido a la propia estructura de la madera, las tensiones en la dirección transversal desempeñan un papel importante en la utilización de la madera (riesgo de grietas)

En los últimos años, se han llevado a cabo muchos trabajos sobre la respuesta mecánica de la madera a los cambios de humedad, como los de Dill-Langer (2004), Hanhijärvi (1995) y Mårtensson (1992). En estos trabajos se ha predicho la respuesta del estrés a una historia climática específica, pero no se ha confirmado mediante mediciones in situ.

Existen diferentes técnicas para medir la tensión generada por la humedad, la técnica denominada de corte en rodajas fue empleada por Behnke y Militzer (1994), Jönsson (2005b), McMillen (1955), Niemz y Wang (2002) y Svensson y Toratti (2002). Esta técnica fue desarrollada originalmente por Peck (1940), en ella los esfuerzos se determinan cortando las muestras en rodajas y midiendo el cambio de longitud. El material procedente de madera de tensión se contrae durante el cortado y el material procedente de madera de compresión se expande en el cortado. 

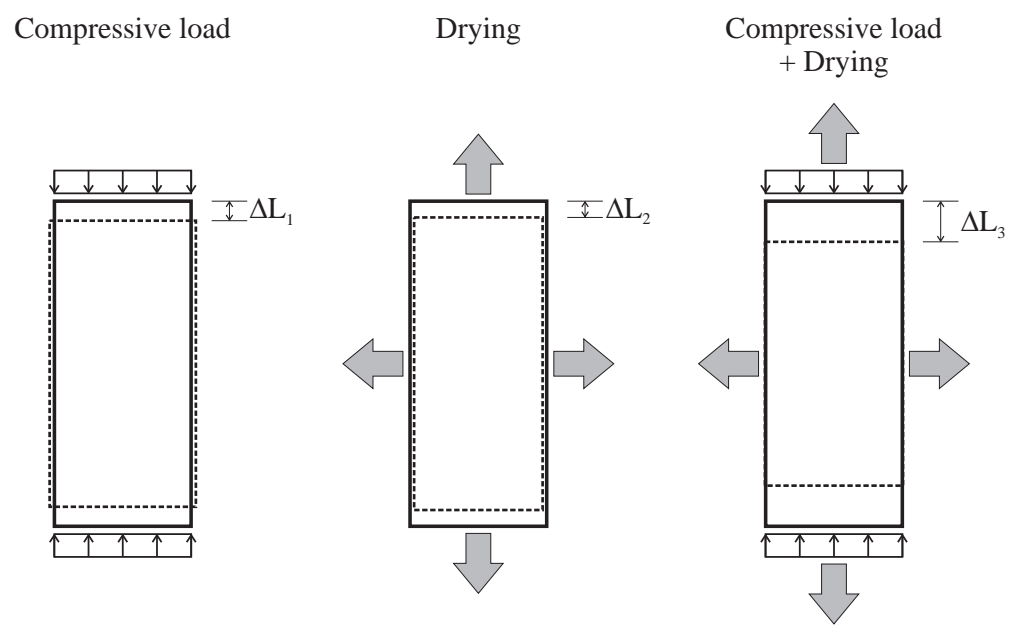

$\square$ Way of water

$\downarrow \downarrow \downarrow \downarrow \downarrow$ Direction of load

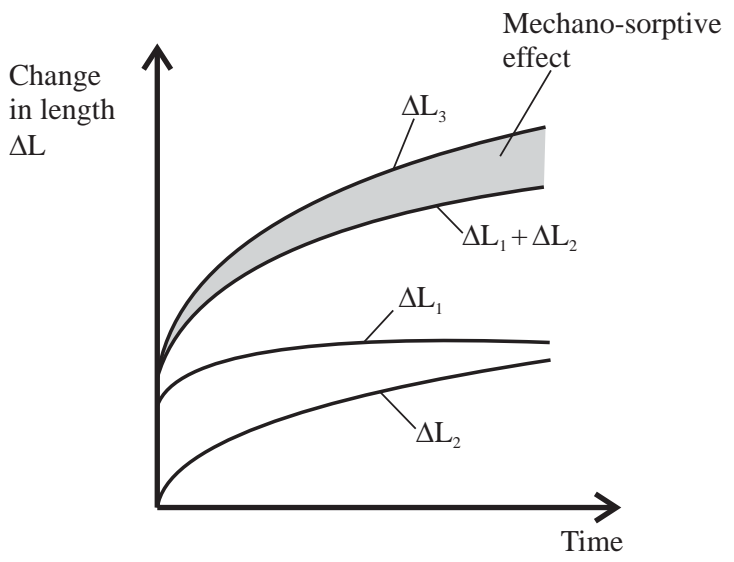

Figura 2.8: Ilustración del efecto mecano-sortivo

La medición de estas tensiones, denominadas cementado, se lleva a cabo mediante el proceso descrito en la norma UNE-CEN/TS 14464 (2010) Madera aserrada. Método de medición del cementado, donde también se describen los aparatos necesarios para su medición.

Svensson y Toratti (2002) determinaron tensiones en muestras de madera de abeto (Picea abies). El equipo utilizado se muestra en la figura 2.9. Las deformaciones liberadas se midieron mediante cinco transductores colocados contra el extremo de la muestra. Jönsson (2005b) (véase también jönsson, 2004; Jönsson, 2005a; ]önsson y Svensson, 2004), aplicó una técnica libre de contacto. Las deformaciones liberadas de las muestras de madera laminada se midieron mediante una cámara digital. Comparó la posición de los marcadores que fueron fotografiados antes y justo después de serrar en rodajas.

McMillen (1955) probó tensiones en roble rojo (Quercus rubra) durante el secado al aire. Los resultados, trazados en la figura 2.10, muestran que, en primer lugar, se desarrollan tensiones de tracción en las 


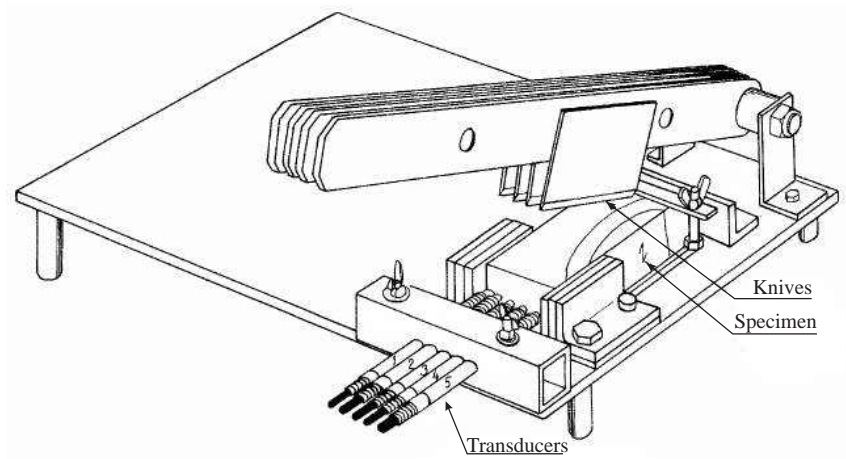

Figura 2.9: Equipo para cortary medir deformaciones liberadas en madera, Svensson y Toratti (2002)

partes exteriores y tensiones de compresión en la parte interna. La contracción de las partes externas es obstaculizada por la parte interior, que todavía no se ve afectada por el secado. Posteriormente, las tensiones disminuyen debido a una distribución de humedad más equilibrada. Además, en el proceso de secado, la parte interior de secado está restringida por las partes exteriores excesivamente estiradas Welling (1988). La distribución de estrés cambia de signo. Este fenómeno se conoce como reversión del esfuerzo o endurecimiento.

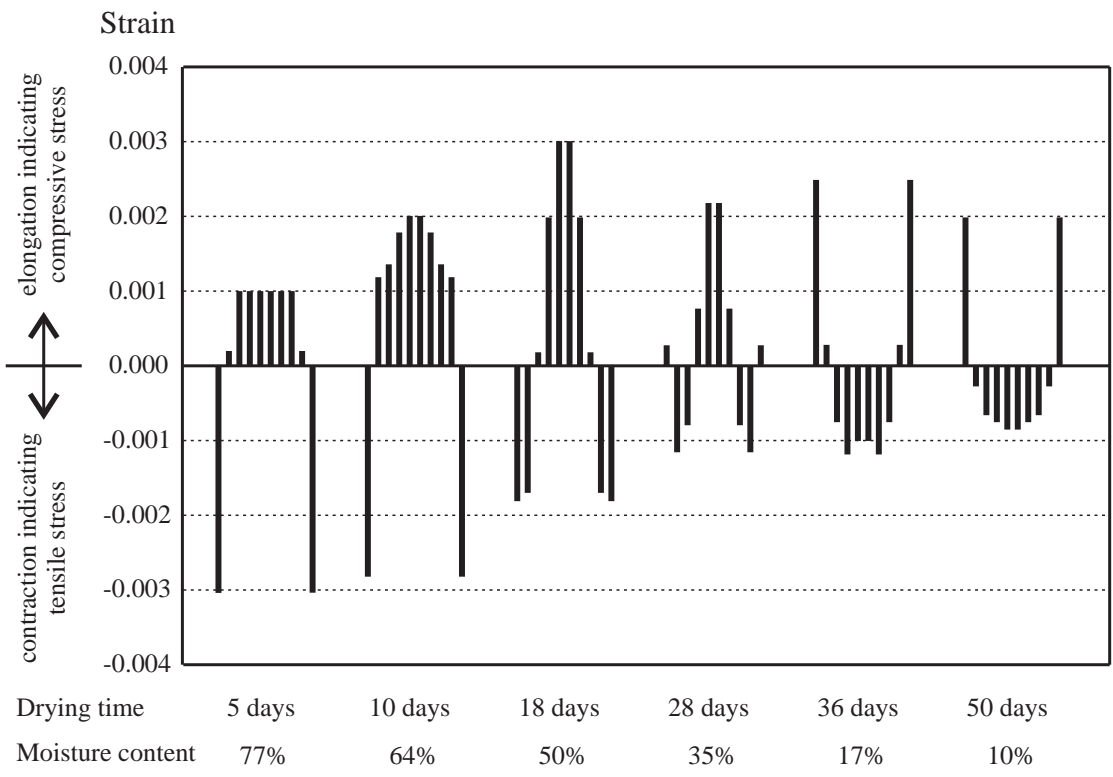

Figura 2.10: Distribución de la deformación en roble rojo de $50 \mathrm{~mm}$ (Quercus rubra) durante el secado al aire, gráfico según McMillen (1955)

En todo lo expuesto, se pone de relevancia la importancia del contenido de humedad en la madera, tanto para su funcionamiento como material de construcción, ya sea como material o como producto 
derivado de la madera, como para la conformación del producto, es por esto que la normativa referente a la fabricación de productos derivados de la madera es tan específica con los contenidos de humedad de los materiales destinados a la fabricación de productos derivados de la madera.

Además, este contenido de humedad no solo afecta a las propiedades estructurales de la madera, sino que debido a los cambios dimensionales y a la consiguiente generación de grietas, afecta directamente a la durabilidad del material y de los productos derivados de la madera, es normal por tanto que sea la humedad el parámetro condicionante a la hora de diferenciar entre las clases de uso y de servicio de la madera como material estructural de construcción.

\subsubsection{Clima exterior y humedad de la madera}

La madera es un material higroscópico que absorbe o desorbe agua, ya sea como vapor de agua por sorción del aire circundante o como agua líquida por las fuerzas capilares, tratando así de mantener el equilibrio del estado de humedad con el aire circundante. Como consecuencia, el contenido de humedad de la madera es diferente en diferentes condiciones climáticas (Ranta-Maunus, 2003)

La exposición externa de estructuras de madera, denominado como "carga de humedad", se puede subdividir en varias categorías tales como las condiciones externas, ya sea o no protegidos por la precipitación y radiación solar, y las condiciones interiores de edificios con o sin calefacción. También se pueden subdividir en relación con la actividad que tiene lugar en el interior del edificio (Fragiacomo et al., 2011)

Cuando se habla de madera al exterior, la "carga de humedad" que principalmente afecta al material madera y a los productos derivados de la madera es el agua líquida, como se muestra entre otras investigaciones en Fernández-Colfin et al. (2017).

Ya se ha comentado la influencia del nivel de contenido de humedad en la resistencia de la madera, esta ha sido ampliamente estudiada para el diseño de estructuras de madera. Los nuevos trabajos encaminados a su inclusión en normas de diseño, tienen en cuenta las variaciones de humedad con respecto al clima, ya que este contenido de humedad transitorio, relacionado con la madera aumenta el riesgo de fracaso del elemento y debe ser considerado como una carga extra de la estructura (RantaManaus, 2001).

La parametrización del comportamiento de la madera con respecto a su comportamiento al exterior en función del clima y el diseño constructivo, es el nuevo reto que en investigación con respecto a durabilidad de la madera expuesta al exterior como material de construcción se plantea. Con el fin de lograr este objetivo hay múltiples investigaciones, tanto en el continente europeo como en el americano, sin embargo a veces estos estudios son o muy complejos o demasiado generalistas, en España cabe destacar el trabajo realizado por Alvarez y Fernández-Colfin (1996).

Por ejemplo en el Wood Handbook (Simpson y TenWolde, 1999) se han publicado los valores medios a largo plazo del contenido de humedad de equilibrio (denominado por sus siglas en inglés, equilibrium moisture content, EMC), de la madera expuesta al exterior en diferentes climas de los Estados Unidos. En el clima del norte, el máximo de EMC, se produce durante el invierno, y el mínimo durante el verano. En el clima continental, en el Norte (Missoula, Minnesota), el rango va desde el 9,8 a 17,6\%. En las 
zonas meridionales se alcanza el máximo durante el verano y el mínimo durante el invierno, como en Los Ángeles (EMC $=12$ a $15 \%$ ). Además, hay zonas con contenido de humedad bastante constante que van desde los climas desérticos secos (por debajo del 10\%) a zonas costeras húmedas (14-15\% en Nueva Orleans).

Estos datos ayudan entre otras cosas a determinar el contenido de humedad idóneo para la puesta en obra de la madera según la zona, para evitar en la medida de lo posible la variación volumétrica de las piezas de madera, consecuencia de la variación de humedad, lo que redunda en una mayor vida útil, al disminuir su degradación. Como ejemplo en la figura 2.11 se muestran las recomendaciones americanas en contenidos de humedad a la que se deben secar la madera cuando se utiliza en interiores.

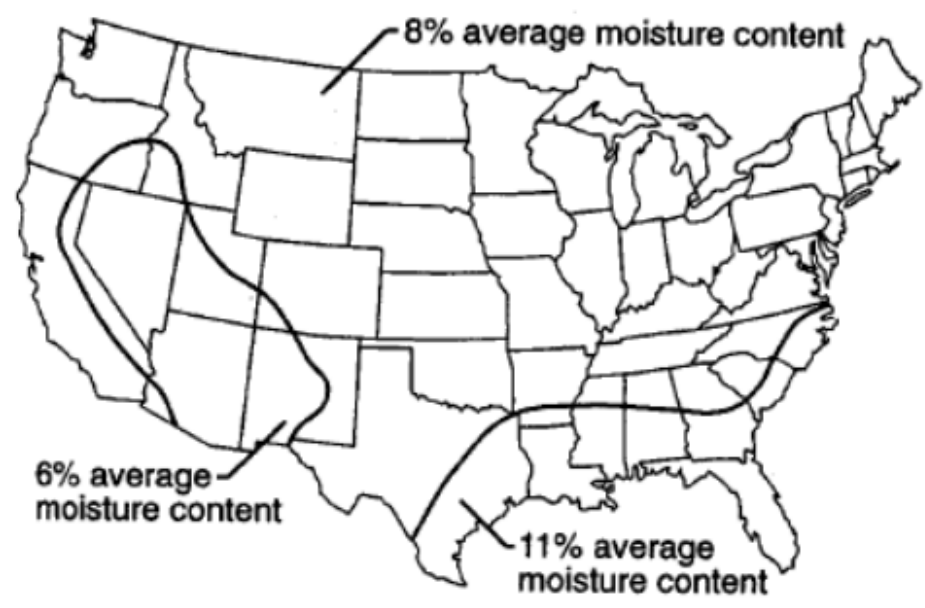

Figura 2.11: Recomendaciones americanas en contenidos de humedad

En entornos europeos, en el clima nórdico, el contenido medio de humedad de la madera es a menudo un $12 \%$ durante el verano, y un $6 \%$ durante el invierno. De acuerdo con ello, la madera debe secarse a esta gama, y se recomienda a menudo $8 \%$ (Ranta-Manaus, 2001).

Ya se ha comentado el efecto que tiene la humedad con respecto a las propiedades estructurales de la madera, estos efectos a menudo se expresan de una manera simplificada: cambio en la propiedad (\%) causadas por el cambio del uno por ciento de contenido de humedad. En la tabla 3.1 se muestran estos resultados para la madera blanda (Hoffmeyer, 1995b), la madera en rollo (Ranta-Maunus, 1999) y los valores adoptados en la norma UNE-EN 384 (2016) para ajustar los valores de percentil $5^{\circ}$ de madera aserrada.

Al igual que se ha visto en los estudios anteriores, existen estudios sobre la exposición en condiciones externas sin protección de la precipitación ni la radiación solar. La exposición varía de acuerdo con el clima, y en Fragiacomo et al. (2011) sólo se consideran climas europeos, en general estas consideraciones climáticas son a gran escala. Hay una necesidad de investigar la influencia de la humedad en el rendimiento de las estructuras de madera. Se han estudiado las fendas observadas en las estructuras 
Cuadro 2.2: Efecto del cambio de contenido de humedad a las propiedades mecánicas de las maderas blandas ( \% / \%) entre 8 y $20 \%$ MC. Los valores de la madera clara y madera redonda son los efectos promedio, los valores de la madera aserrada son los valores característicos (Ranta-Manaus, 2001)

\begin{tabular}{lccc}
\hline Property & Clear wood & Round timber & Sawn timber (EN 384) \\
\hline Compression strength $(/ /$ and $\perp$ ) & 5 & 5 & 3 \\
Bending strength & 4 & 1 & 0 \\
Tension strength $(/ /)$ & 2,5 & & 0 \\
Tension strength $(\perp)$ & 2 & & \\
Shear strength & 3 & & 2 \\
Impact bending strength $(/ /)$ & 0,5 & & \\
Modulus of elasticity $(/ /)$ & 1,5 & & \\
\hline
\end{tabular}

de madera expuestas a condiciones de exterior y protegidos de la lluvia, en las regiones de conexión y adyacentes a las fuentes de calor (Frühwald et al., 2007).

Una regla práctica seguida en Alemania considera que el agrietamiento ocurrido en una viga de madera aserrada sometida a flexión es aceptable si la profundidad de la grieta no exceda de 1/6 de la anchura (Frech y Möhler, 1987; Radovic y Wiegand, 2005).

La modelización del comportamiento de la madera al exterior es un tema de interés hoy día, de hecho existe una acción COST dedicada expresamente a esto, COST Action E55 (http://www.cost-e55.ethz.ch/), con el título; "Modelización del comportamiento de las estructuras de madera". Uno de sus objetivos es investigar el efecto de la humedad en estructuras de madera, con especial énfasis en las tensiones perpendiculares a la fibra inducidas por la humedad. La influencia de los diferentes climas se investiga dividiendo Europa en una serie de regiones climáticas y mediante la identificación de historias representativas de la humedad relativa y la temperatura. Los resultados en términos de variaciones contenido de humedad y las tensiones que se derivan, e analizaron usando un modelo implementado en el paquete de software Abaqus, 2008 (Hibbit, Karlsson \& Sorensen, 2009; ó Fragiacomo et al., 2011).

En esta acción COST se considera el estrés inducido por la humedad, pero no los efectos de la radiación solar o la lluvia. Se buscan regiones climáticas europeas con condiciones ambientales bastante homogéneas, ayudados por la clasificación climática de Köppen-Geiger (Kottek et al., 2006). Sobre la base de la clasificación Köppen-Ceiger, se definen nueve regiones climáticas europeas (véase el cuadro 2.3).

Cuadro 2.3: Köppen-Ceiger climate type classification of Europe (Kottek et al., 2006)

\begin{tabular}{lll}
\hline Abbreviation & Type of climatic region & Examples of cities within the climatic region \\
\hline BSK & Cold semi-arid climate & Madrid, Salamanca, Albacete \\
CSA & Warm mediterranean climate & Lisbon, Florence, Cagliari, Palermo, Athens \\
CSB & Temperate mediterranean climate & Potenza, Marsilla, Coruna, Porto \\
CFA & Warm oceanic/humid subtropical climate & Zagreb, Brescia, Torino, Bologna, Roma, Foggia \\
CFB & Temperate oceanic climate & Stuttgart, Paris, London \\
DFA & Warm/humid continental climate & Moscow, Warsaw, Helsinki \\
DFC & Cool continental climate/subartic climate & Rovaniemi, Lulea, Tampere \\
ET & Tundra climate & Chambery, Zürich, Sofia \\
\hline
\end{tabular}


En Fragiacomo etal. (2011) se describe un estudio de las tensiones internas perpendicular a la fibra producidas en la madera por las variaciones de contenido de humedad que son causadas por la exposición a los diferentes climas. Un modelo de elementos finitos tridimensional implementado en Abaqus que combina un modelo de Fick de la transferencia de la humedad y un modelo mecánico para el comportamiento dependiente del tiempo de la madera, y con esto se llevaron a cabo simulaciones numéricas.

Las deformaciones y tensiones inducidas por la humedad juegan un papel importante en la aplicación de paneles de madera contralaminados, en Cereke y Niemz (2010) se estudiaron las deformaciones y tensiones mediante pruebas experimentales y simulaciones numéricas mediante tres escenarios de humedad, que causan problemas en la práctica, pero al igual que en otros estudios se hace necesario el uso de datos reales que puedan confirmar esas simulaciones.

Como se puede observar hay múltiples estudios relacionados con la humedad de la madera en condiciones de exposición exterior. Pero al analizar la bibliografía existente se observa por un lado que las zonificaciones que se realizan para el estudio son demasiado generalistas y en ningún caso son representativas de la enorme variabilidad climática que existe en España, y por otro lado los estudios llevados a cabo en este tema suelen ser a través de simulaciones, no con datos reales.

\subsection{Durabilidad de la madera y los materiales de madera para la construcción}

Un aspecto que cobra especial importancia cuando se habla de madera como material estructural de construcción es la durabilidad. Si bien la durabilidad de las especies de madera se encuentra definida por normativa, ya sea durabilidad natural, que es la durabilidad intrínseca a cada especie de madera, o sea durabilidad conferida, que es la que se consigue aplicando un método de tratamiento, hay que tener en cuenta que la puesta en obra y las medidas de diseño son determinantes para una correcta durabilidad durante la vida de servicio del material o del producto.

En general, la calidad de los componentes se equipara con la durabilidad del producto, por tanto, es conveniente definir el término "durabilidad". En la norma UNE-EN 350 (2016) y la UNE-EN 1001-2 (2007), la durabilidad es "la resistencia de la madera a la destrucción por los organismos degradadores de la madera". Por el contrario, en la norma ISO 15686-7 (2011) se define la durabilidad no como la propiedad del material, sino como la "capacidad de un edificio o de sus partes para llevar a cabo la función requerida durante un período determinado de tiempo bajo la influencia de los agentes existentes en servicio" (Brischke et al., 2006).

Al leer estas definiciones, se puede observar que en tema de durabilidad hay dos ámbitos en los que la durabilidad afecta a la madera, uno sería su durabilidad biótica o biológica, en la que se tiene en cuenta la resistencia de la madera o producto derivado de la madera frente al ataque de organismos xilófagos, y la otra sería su durabilidad abiótica, en la que la madera o producto derivado de la madera mantiene su integridad como elemento estructural de construcción.

Cuando se hace referencia a productos derivados de la madera, hay que tener en cuenta que son productos compuestos, y generalmente encolados, como es el caso del CLT. En estos casos, hay que contemplar que estos productos pueden sufrir dos tipos de degradación, debido a su origen compuesto, 
pueden sufrir degradación en la materia base, la madera, o en el agente aglomerante que ayuda a conformar el producto, las colas.

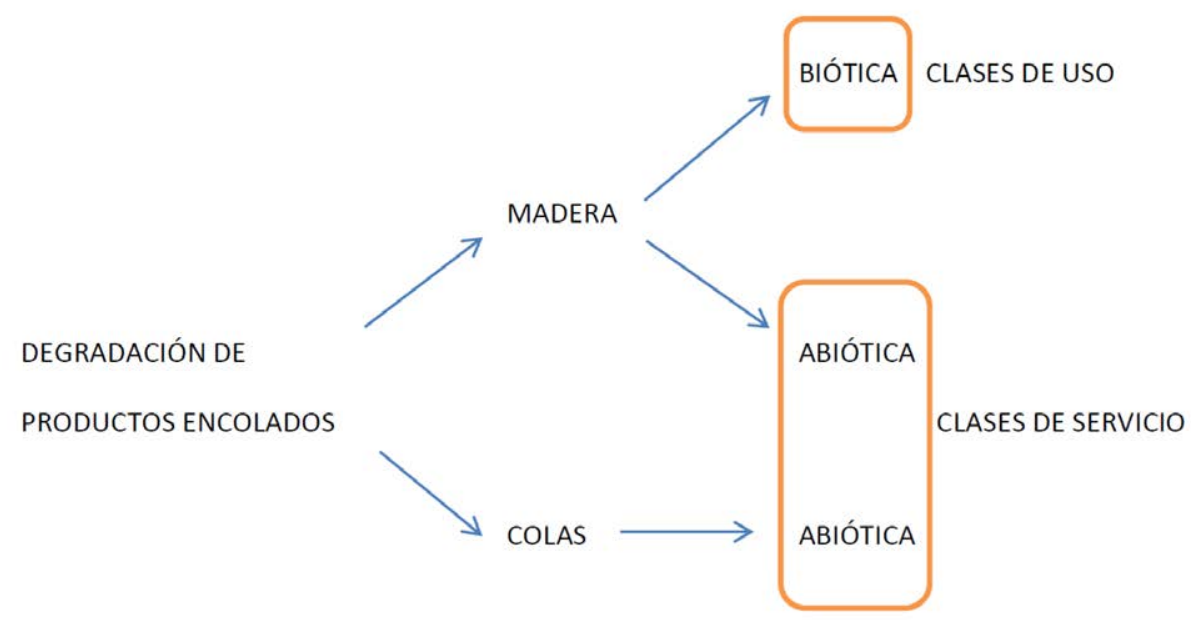

Figura 2.12: Esquema de la degradación de los productos encolados (elaboración propia)

La degradación en la madera a su vez puede ser de dos tipos, degradación biótica, cuando la degradación producida en el material es a través de agentes bióticos (hongos, termitas, etc.), y en este caso está directamente relacionado con las clases de uso (UNE-EN 335, 2013, Durabilidad de la madera y de los productos derivados de la madera. Clases de uso: definiciones, aplicación a la madera maciza y a los productos derivados de la madera), o degradación abiótica, cuando la degradación que se produce en el material se produce a través de agentes abióticos (agua, sol, etc.), y en este caso está directamente relacionado con las clases de servicio (UNE-EN 1995-7-1, 2016, DB-SE-M Seguridad Estructural Madera del Código Técnico de la Edificación).

Tanto las clases de uso como las clases de servicio en la madera, se basan en el contenido de humedad de la misma, y los escenarios de exposición que se proponen en las normas que regulan tanto las clases de uso como las clases de servicio se basan en la humedad.

La necesidad de investigación en el campo de la planificación de la vida útil y su predicción, en la maderay los productos derivados de la madera, emana de la Directiva Europea de Productos de Construcción (Directiva 89/106/CEE, 1989), actualmente derogada por la publicación de su correspondiente reglamento, relativa a la aproximación de las disposiciones legales, reglamentarias y de los estados miembros sobre los productos de construcción, así como de un gran interés por parte de la industria de la construcción (Brischke et al., 2006).

La durabilidad natural de la madera como material está ampliamente estudiada y normalizada, pero cuando hablamos de productos derivados de la madera, productos compuestos como se ha comentado, quizás no siempre están recogidas sus peculiaridades en la normativa. Para el estudio de la aptitud al uso del CLT como paramento al exterior, hay que hacer unas acotaciones con respecto a la durabilidad, debido al amplio espectro del ámbito de estudio.

Se parte de la premisa de que el CLT en temas de durabilidad biológica se puede asimilar a la madera 
maciza, que actualmente está ampliamente estudiada por diversos autores, y la necesidad actual de estudio se centra en los agentes abióticos que afectan a la durabilidad de la madera, y a la integridad del CLT como producto, centrándose estos agentes en los factores climáticos, que aún no se encuentran completamente recogidos en la normativa y que afectan severamente a las clasificaciones existentes de clases de uso y clases de servicio.

\subsubsection{Durabilidad natural y conferida de la madera}

Según Brischke et al. (2006) existen amplios estudios con respecto a la durabilidad natural de la madera como material, refiriéndose a diferentes aspectos. Por ejemplo, la durabilidad natural de la madera como material, varía según la parte del tronco a la que haga referencia. El duramen, gracias a sus sustancias extractivas, aumenta su resistencia frente a hongos, insectos y microorganismos (Fengel y Wegener, 1989), al contrario de lo que sucede en la albura. Estas sustancias extractivas pueden ser tóxicas, o pueden simplemente influir en la dinámica de la humedad (Stirling y Morris, 2006). Diferentes estudios muestran que las sustancias extractivas varían según la posición en el tronco, encontrándose su máximo en la periferia del duramen (Cartwright, 1942; Scheffery Hopp, 1949; Gardnery Barton, 1958; Gardnery Barton, 1960; Piirto y Wilcox, 1981; Haupt et al., 2003; Hillis, 2012).

Todo esto hace que la durabilidad natural de la madera se vea afectada por diferentes factores, estos, determinarán la mayor o menor vida útil de la madera o producto derivado de la madera puesto en obra. Pero todos estos parámetros, ya se encuentran contemplados en la normativa que define la durabilidad de la madera en función de su especie.

La norma UNE-EN 350 (2016) expone que la durabilidad de una especie de madera o de un material derivado de la madera frente a los diversos agentes de degradación biológica, se evalúa con los métodos de ensayo descritos en las normas europeas correspondientes. Además, contiene tablas en las que se clasifican las diferentes especies en muy durable, durable, medianamente durable, poco durable y no durable, frente a hongos, insectos y xilófagos marinos.

También se encuentran en esta norma, ensayos de campo para evaluar la durabilidad de la madera y los materiales derivados de la madera, en ubicaciones por encima del suelo (clase de uso 3), que es el caso más común en que se suele encontrar actualmente la madera en construcción, y el que contempla esta tesis. Ya en esta norma, se hace la observación de que este tipo de ensayos deben repetirse en diferentes localizaciones geográficas, mostrando así la importancia del clima en una misma clase de uso.

En el anexo B de la citada norma, se orienta sobre la durabilidad del duramen de la madera de especies seleccionadas, frente a una gama de agentes de degradación biológica (norma UNE-EN 350, 2016, anexo B tablas B1-B4). En estas tablas, entre otros datos, se muestra la impregnabilidad de albura y duramen de las diferentes especies, tema de vital importancia, a la hora de intentar alargar la durabilidad biológica natural de una especie mediante un tratamiento, la conocida como durabilidad conferida.

En el anexo C de la misma norma, se trata de la impregnabilidad con productos protectores hidrosolubles, esta impregnabilidad o facilidad con la que una madera puede ser penetrada por un líquido, queda clasificada en la tabla $\mathrm{C} 1$ del citado anexo. 
La durabilidad de la madera se puede mejorar mediante muchas técnicas diferentes, por lo que la resistencia de la madera frente a los organismos que la destruyen, ya no se basa únicamente en las propiedades de la madera natural (Brischke et al., 2006).

Pero tanto la durabilidad natural como conferida, ofrecen resistencia a la madera frente al ataque biótico o de organismos biológicos, pero en ningún caso aumentan su durabilidad frente a agentes abióticos, o al menos no lo hacen de una forma significativa.

Otra posible vía de protección de la madera es la protección mediante el diseño, que es el paso más importante hacia la protección efectiva de la madera. Los diferentes detalles del diseño de un edificio, de las partes que lo componen y hasta de los productos, afectan indirectamente a la vida útil de la madera, ya que determinan el nivel de riesgo.

La durabilidad de un componente de madera o de los productos derivados de la madera, depende de sus condiciones de uso. Por lo tanto, la distancia al suelo, la presencia de aleros y cornisas, la exposición solar o a los vientos dominantes de lluvia, y otros detalles de diseño, deben ser considerados a la hora de garantizar la durabilidad de un producto de madera (Schmidt, 2005). Las medidas de diseño, afectan la durabilidad de la madera, sus productos y soluciones en todos sus ámbitos, tanto en el biótico como el abiótico.

Como se ha comentado, el contenido de humedad de la madera, en función de la humedad del aire, la precipitación y la absorción de agua, ya sea por medio de contacto con el suelo, o debido a fugas, parece ser uno de los factores de desintegración decisivos, tanto de la parte biológica (Schmidt, 2006), como estructural, por la degradación de las colas, a causa de la merma e hinchazón de la madera. La relevancia sobresaliente que tiene el contenido de humedad de la madera, en la disminución de la durabilidad, se ha señalado en muchos estudios sobre la durabilidad de la madera y sus productos derivados (por ejemplo Viitanen y Ritschkoff, 1991; Rapp et al., 2000; Rydell et al., 2005), y se fija en diferentes normas (por ejemplo UNE-EN 335, 2013; UNE-EN 460, 1995).

En relación a la humedad, hay que tener en cuenta que tanto el diseño como la precipitación van s ser determinantes en el comportamiento de la madera. En el caso de las precipitaciones, Scheffer (1971) supone que la frecuencia de las precipitaciones es un factor más importante que la suma de precipitaciones. Por lo tanto, el desarrollo de índices climáticos sigue siendo deseable, pero tiene que ser mejorado por una consideración de los factores de desintegración directos (Brischke et al., 2006).

La temperatura de la madera es la segunda influencia más importante en la actividad fúngica. En diferentes estudios (por ejemplo Beesley et al., 1983; Creemers et al., 2002; Crinda y Carey, 2004; Augusta et al., 2004) se demostró influencia sinérgica de la precipitación y la temperatura del aire en las tasas de descomposición en las pruebas de durabilidad de campo.

Pero la temperatura no solo afecta a la actividad fúngica, también afecta al movimiento del agua en la madera y al gradiente que en esta se produce. Esta velocidad en los cambios de volumen genera fendas, que no solo afectan a la degradación biótica, sino a la abiótica también, ya que los cambios volumétricos como se ha comentado pueden producir daños en las colas que componen los productos derivados de la madera, así como en la propia madera, disminuyendo sus propiedades estructurales y su vida útil. 
Hay múltiples estudios para determinar la vida útil de la madera, en los que los parámetros climáticos, el contenido de humedad de la madera y su temperatura combinados, han conducido a una función de dosis-respuesta factible, resultando una base útil para la predicción de la vida en servicio (Brischke y Rapp, 2010). Se han adoptado diferentes enfoques para establecer índices climáticos, y poder así estimar el potencial deterioro de un sitio específico (Scheffer, 1971; Beesley et al., 1983; Creemers et al., 2002; Grinda y Carey, 2004), pero todos fallaron, al intentar establecer un nivel suficientemente fuerte de correlación entre los datos climáticos y la degradación, que les permitieran ser utilizados para una predicción fiable de la vida de servicio (Degroot, 1982; Norén, 2001; Brischke et al., 2008).

La predicción de la vida útil de los componentes de madera, es una tarea que engloba a muchos grupos diferentes; científicos de la madera, arquitectos, prescriptores, ingenieros civiles, carpinteros y constructores de casas. En cualquier momento durante la fase de construcción, cuando deben tomarse decisiones acerca de las soluciones más adecuadas, la durabilidad, y por tanto, la vida útil esperada de un material o de un componente, debe tomarse en consideración (Brischke et al., 2011). Actualmente los esfuerzos en la investigación sobre la predicción de vida útil se han intensificado en varios países.

En Australia, CSIRO y Timber Queensland Ltd., adoptaron un enfoque muy amplio, en el que la información proporcionada para la estimación de la vida útil de la madera con respecto a diferentes exposiciones, se basaba en varios modelos relativos a la desintegración en y por encima del suelo, y el ataque por termitas y xilófagos marinos. Este estudio, dio como resultado la elaboración de una "Cuía de diseño de vida útil de la madera" (Mackenzie et al., 2007; Wang et al., 2008) y un programa de software acorde a la guía "TimberLife".

En Europa, diferentes proyectos se centran también en la predicción de la vida útil de la madera y los productos derivados de la madera, pero están siguiendo concepciones y enfoques experimentales muy diferentes para la modelización (Brischke, 2007; Kuilen, 2007; Kutnik, 2008; Viitanen et al., 2008; Viitanen et al., 2009; Bulcke et al., 2009; Gobakken y Lebow, 2010; Thelandersson et al., 2009).

Por último, varios estudios de América del Norte y Asia, abordan también las estimaciones del riesgo de degradación, y otros problemas de la predicción de vida útil (por ejemplo Morris, 2005; Lacasse et al., 2007; Wang et al., 2007; Iwamae y Suzuki, 2008; Larkin y Laks, 2008; Lebow e Highley, 2008; Morris y Wang, 2008a).

Durante los últimos años se observan notables progresos en la planificación y predicción de la vida útil de diferentes materiales, pero es evidente que todavía es necesario avanzar en la metodología de ensayos (Lacasse, 2008) y finalmente, se carece de bases de datos completas que contengan registros de vida útil para los diversos materiales y productos de construcción. Uno de los mayores desafíos para lograr esto, es hacer que los resultados sean comparables, especialmente cuando han sido obtenidos por diferentes investigadores, con diferentes métodos de ensayo y en diferentes localizaciones. Por lo tanto, se necesitan procedimientos de ensayo armonizados, así como criterios de calidad claros, no sólo para los registros de la vida útil, sino también para los esquemas de clasificación resultantes (Brischke et al., 2017).

En todos los estudios mencionados anteriormente, la investigación se centra en la degradación biótica de la madera. Además, están centrados en climas muy diferentes al clima español, por lo que los resultados en este caso tampoco son extrapolables. Cuando se buscan estudios sobre la degradación 
abiótica de la madera y la pérdida de propiedades estructurales, los estudios se reducen mucho y en el caso del CLT se vuelven prácticamente inexistentes.

Aunque es una práctica común el determinar el contenido de humedad de la madera en los ensayos de degradación de laboratorio, no es así en las pruebas de campo, ni siquiera en los estudios sobre los productos básicos integrales, construcciones o edificios. Por el contrario, hay muchos estudios conocidos sobre la dinámica de la humedad y la carga de humedad resultante de los respectivos materiales de construcción, en el campo de la física de la construcción. Por ejemplo, mediciones in situ en la pared de montaje, construcción, o uniones de muros cortina de lluvia (Ceving y Uvsløkk, 2000; Ceving et al., 2006; Derome et al., 2007; Class y TenWolde, 2007; Hubbs y Branch, 2007; Rasmussen y Nicolajsen, 2007; Buxbaum et al., 2009). El sector de la durabilidad de la madera, por el contrario, tiene que ponerse al día, y debe tomar más ventaja de la información adicional proporcionada por mediciones del contenido de humedad de la madera (Brischke et al., 2011).

Es un hecho generalmente aceptado, que las pruebas de campo proporcionan condiciones de ensayo más realistas, pero a menudo son pruebas con duraciones inaceptablemente largas. La aparición de degradación en ensayos sin contacto con el suelo, a menudo tienen una repercusión significativa después de 5 años, y la vida de servicio no puede ser calculada antes de que pasen décadas (Wang et al., 2008; Brischke et al., 2012).

Por todo lo expuesto, es necesario el ensayo de durabilidad de CLT con datos reales, de envejecimiento al exterior, y métodos de ensayo adecuados al material, y que pueden reproducir las degradaciones que se generan por la exposición al exterior del producto. Además, como se ha comentado, hay una gran investigación en cuanto a durabilidad frente a ataques bióticos, pero en el campo de los daños abióticos y la durabilidad de la madera, la investigación es más limitada, y cuando centramos la investigación en productos derivados de la madera de carácter innovador, se observa que la carencia es notable.

\subsubsection{Clases de uso de la madera}

Es inevitable hablar del uso de la madera y los productos derivados de la madera en construcción y no hacer referencia a las clases de uso, que vienen reguladas en la norma UNE-EN 335 (2013). Esta norma establece las definiciones generales de las clases de uso en diferentes situaciones de servicio, y es de aplicación tanto para la madera como para sus productos derivados.

Al igual que sucedía con la durabilidad natural y conferida de la madera, en las clases de uso se hace referencia a los agentes bióticos, pero no hay ninguna referencia a los agentes abióticos, aunque se suponen tenidos en cuenta en la planificación de las mencionadas clases.

En esta norma se establecen cinco clases de uso que hacen referencia a diferentes situaciones de servicio a las que puede estar expuesta la madera y sus productos derivados y a los agentes bióticos que pueden actuar en cada caso.

Las diferencias entre las clases de uso están asociadas a las diferencias de exposición medioambiental que pueden hacer a la madera o a los materiales derivados de la madera susceptibles de ataque biológico, y según esto se dividen en: 
- Clase de uso 1 (CU1): situación en la que la madera o el material derivado de la madera se utiliza en el interior de una construcción y no expuesto a la intemperie ni la humidificación.

- Clase de uso 2 (CU2): situación en la que la madera o material derivado de la madera se encuentra bajo cubierta y no expuesto a la intemperie (en particular a la lluvia horizontal) pero en la que puede estar sometido a una humidificación ocasional pero no persistente. Puede producirse condensación superficial pero en momentos esporádicos.

- Clase de uso 3 (CU3): situación en la que la madera o material derivado de la madera está por encima del suelo y expuesto a la intemperie (en particular lluvia). El grado de exposición puede ser muy diferentes por lo que según los casos, la clase de uso 3 se puede subdividir en dos subclases: la clase uso 3.1 y la clase de uso 3.2

Subclase 3.1 (CU3.1): situación en la que los productos de madera y materiales derivados de la madera no permanecen húmedos durante largos periodos. El agua no se acumula.

Subclase 3.2 (CU3.2): situación en la que los productos de madera y materiales derivados de la madera permanecen húmedos durante largos periodos. El agua puede acumularse.

- Clase de uso 4 (CU4): situación en la que la madera o los materiales derivados de la madera están en contacto directo con el suelo y/o el agua dulce.

- Clase de uso 5 (CU5): situación en la que la madera o los materiales derivados de la madera están sumergidos en agua salada (es decir agua de mar o agua salina) de forma regular o permanente.

Como resumen de las clases de uso, en la norma UNE-EN 335 (2013), se presenta el cuadro 2.4, en la que se presentan las 5 clases de uso con los agentes biológicos que pueden aparecer en cada una de ellas.

En la norma UNE-EN 335 (2013) en su anexo A, se presenta una tabla en la que expone la correspondencia entre las clases de servicio y las clases de uso, ya que las clases de uso en principio no contemplan la humedad de la madera de una forma numérica, aunque este implícito en las diferentes exposiciones.

Esta tabla aporta información sobre la clase de uso probable que se corresponde con cada una de las clases de servicio.

En todo caso, como se ha comentado, las clases de uso clasifican la maderay los productos derivados de la madera según el riesgo de ataque biológico que puedan sufrir en función de la situación de servicio en la que se encuentren, pero no tiene en cuenta de forma explícita el contenido de la humedad de la madera o los productos derivados de la madera en cada una de estas situaciones de servicio, y más importante aún, no presenta ningún tipo de índice climático que modifique la clase de uso. Esto último es muy importante, ya que una misma clase de uso teórica, según el clima en el que se sitúe puede dar lugar a una clase de uso real muy diferente.

\subsubsection{Clases de servicio de la madera}

La norma UNE-EN 1995-1-1 (2016) define las tres clases de servicio a tener en cuenta por el calculista para asignar valores de resistencia y calcular las deformaciones de los elementos de madera que se 
Cuadro 2.4: Resumen de las clases de uso y de los agentes biológicos que atacan la madera y los materiales derivados de la madera

\begin{tabular}{|c|c|c|c|c|c|c|}
\hline \multirow{2}{*}{$\begin{array}{l}\text { Clase } \\
\text { de uso }\end{array}$} & \multirow{2}{*}{ Situación general de uso } & \multicolumn{5}{|c|}{ Aparición de agentes biológicos } \\
\hline & & $\begin{array}{l}\text { Hongos } \\
\text { cromógenos }\end{array}$ & $\begin{array}{l}\text { Hongos } \\
\text { xilófagos }\end{array}$ & Coleópteros & Termitas & $\begin{array}{l}\text { Xilófagos } \\
\text { marinos }\end{array}$ \\
\hline 1 & En interior, seco & - & - & $U$ & $L$ & - \\
\hline 2 & $\begin{array}{l}\text { En interior o bajo cubierta, } \\
\text { no expuesto a la } \\
\text { intemperie. Posibilidad de } \\
\text { condensación de agua }\end{array}$ & $U$ & $\cup$ & $U$ & $\mathrm{~L}$ & - \\
\hline 3 & $\begin{array}{l}\text { Al exterior por encima del } \\
\text { suelo, expuesto a la } \\
\text { intemperie. } \\
\text { Se subdivide en: } \\
\text { 3.1 Condiciones de } \\
\text { humidificación breve } \\
\text { 3.2 Condiciones de } \\
\text { humidificación } \\
\text { prolongada }\end{array}$ & $U$ & $\cup$ & $U$ & $\mathrm{~L}$ & - \\
\hline 4 & $\begin{array}{l}\text { Al exterior en contacto con } \\
\text { el suelo y/o con agua dulce }\end{array}$ & $\cup$ & $\cup$ & $\cup$ & $L$ & - \\
\hline 5 & $\begin{array}{l}\text { Sumergido en agua salada } \\
\text { de forma regular o } \\
\text { permanentemente }\end{array}$ & $U$ & $\cup$ & $U$ & $\mathrm{~L}$ & $U$ \\
\hline
\end{tabular}

$\mathrm{U}=$ Universalmente presente en Europa y territorios de la UE.

$\mathrm{L}=$ Localmente presente en Europa y territorios de la UE.

Cuadro 2.5: Posible correspondencia entre clases de servicio y clases de uso

\begin{tabular}{ll}
\hline Clase de servicio según la norma EN 1995-1-1 & Clase de uso probable según la norma EN 335 \\
\hline Clase de servicio 1 & Clase de uso 1 \\
\hline Clase de servicio 2 & Clase de uso 1 \\
& Clase de uso 2 si el elemento está en una situación \\
& en la que es susceptible de humidificarse ocasional- \\
& mente, por ejemplo, por condensación \\
\hline Clase de servicio 3 & Clase de uso 2 \\
& Clase de uso 3 o mayor en caso de aplicación exterior \\
\hline
\end{tabular}

aplicarán en la construcción. Estas clases de servicio se asignan por el contenido de humedad de la madera que se corresponde con la humedad y temperatura previstas en servicio.

Pero el concepto de clase de servicio tiene una aplicación que va más allá del cálculo estructural, ya que tiene influencia destacada en la prescripción de los productos en los que hacen acto de presencia los adhesivos ya que la humedad, junto con la temperatura, son los dos principales agentes de su degradación (abiótica).

El contenido de humedad de la madera, como se ha comentado, es también un factor importante res- 
pecto a los agentes biológicos, pero el sistema de clases de servicio según la norma UNE-EN 1995-7-1 (2016) y el sistema de clases de uso de la norma UNE-EN 335 (2013) no tienen el mismo enfoque respecto a los efectos de la humedad y por tanto las clases de uso y de servicio no son equivalentes. La equivalencia de ambas clasificaciones se puede ver en cuadro 2.5 .

Las estructuras deben asignarse a una de las clases de servicio definidas en la norma UNE-EN 1995-7-1 (2016). El objeto principal del sistema de clases de servicio es la asignación de los valores de resistencia y el cálculo de las deformaciones bajo condiciones ambientales determinadas, este sistema establece las siguientes clases de servicio:

- Clase de servicio 1 (CS1): se caracteriza por un contenido de humedad en los materiales correspondiente a una temperatura de $20^{\circ} \mathrm{C}$ y una humedad relativa del aire que sólo supere el $65 \%$ durante unas pocas semanas al año. En esta clase de servicio el contenido de humedad medio en la mayoría de las coníferas no excede del $12 \%$.

- Clase de servicio 2 (CS2): se caracteriza por un contenido de humedad en los materiales correspondiente a una temperatura de $20^{\circ} \mathrm{C}$ y una humedad relativa del aire que sólo supere el $85 \%$ durante unas pocas semanas al año. En esta clase de servicio el contenido de humedad medio en la mayoría de las coníferas no excede del $20 \%$.

- Clase de servicio 3 (CS3): se caracteriza por unas condiciones climáticas que conduzcan a contenidos de humedad mayores que en la clase de servicio 2 .

Como se observa en las definiciones de las clases de servicio, la clase de servicio 3 es un cajón desastre donde se contemplan todos los casos que no se contemplan en la clase se servicio 2. Esta clasificación conlleva que en la clase de servicio 3 se encuentren casos muy diferentes dentro de la exposición de la madera al exterior.

Al igual que pasaba en las clases de uso, en las clases de servicio no hay ningún tipo de factor de clima que modifique la clase de servicio o que lo contemple, y esto es determinante en el uso de la madera y los materiales de madera al exterior, ya que la circunstancias de $20{ }^{\circ} \mathrm{C}$ y $85 \%$ de humedad solo en algunas semanas al año equivalente a la clase de uso 2 , se puede dar simultáneamente en dos climas muy diferentes y por tanto obtener de la madera o de sus productos derivados comportamientos muy diferentes, que lleven a durabilidades y vidas útiles muy dispares.

\subsubsection{Durabilidad del CLT}

Según lo expuesto en el apartado 2.2 Durabilidad de la madera y los materiales de madera para la construcción, el CLT es un material derivado de la madera y compuesto, que es susceptible de sufrir degradación biótica y abiótica. Teniendo en cuenta que el CLT es un producto derivado de la madera muy masivo, se decide equiparar su durabilidad biológica a la madera maciza, y por tanto será equivalente a la durabilidad de la especie de madera de la que está compuesto.

Con respecto a la durabilidad abiótica, en el CLT, al igual que en la madera, los parámetros que más van a influir son la humedad y la temperatura, que son los más influyentes en el proceso degradativo que sufre el CLT por su exposición al exterior. 
La exposición a la humedad es un factor muy importante para la vida en servicio y capacidad de carga de los elementos y sistemas estructurales de madera. Es de gran importancia no sólo en contenido de humedad de la madera, sino también la variación de este, para la realización de estructuras de madera y productos derivados de la madera como puede ser el CLT. Un factor crítico es la variación de la humedad relativa $(\mathrm{RH})$ en el aire ambiente, que induce a la aparición de tensiones perpendiculares a la fibra (Häglund, 2007). Estas tensiones pueden provocar grietas perpendiculares a la fibra, que al evolucionar, reducen la capacidad de carga del elemento de madera de forma individual y por tanto de toda la construcción (Gustafsson et al., 1998; Morliery Ranta-Maunus, 1998). Los efectos de la tensión perpendicular a la fibra son una causa muy frecuente de fallo estructural (Gustafsson, 2003).

Las propiedades mecánicas de la madera están sujetas al contenido de humedad de la madera (MC), denominado así por sus siglas en inglés Mositure Content. El módulo de elasticidad (MOE) en la dirección de la fibra en la madera sin defectos se reduce en aproximadamente un 1,5\%, si la humedad de la madera se incrementa en un $1 \%$ (Hoffmeyer, 1995a). Según Kufner (1978) las variaciones de MOE como una función de la MC para diferentes especies de madera son similares.

Además, se produce agrietamiento de las capas de recubrimiento, durante el secado de los paneles (Niemz y Wang, 2002; Niemz et al., 2005), lo que se traduce en una reducción de MOE perpendicular a la dirección de la fibra de las capas de recubrimiento.

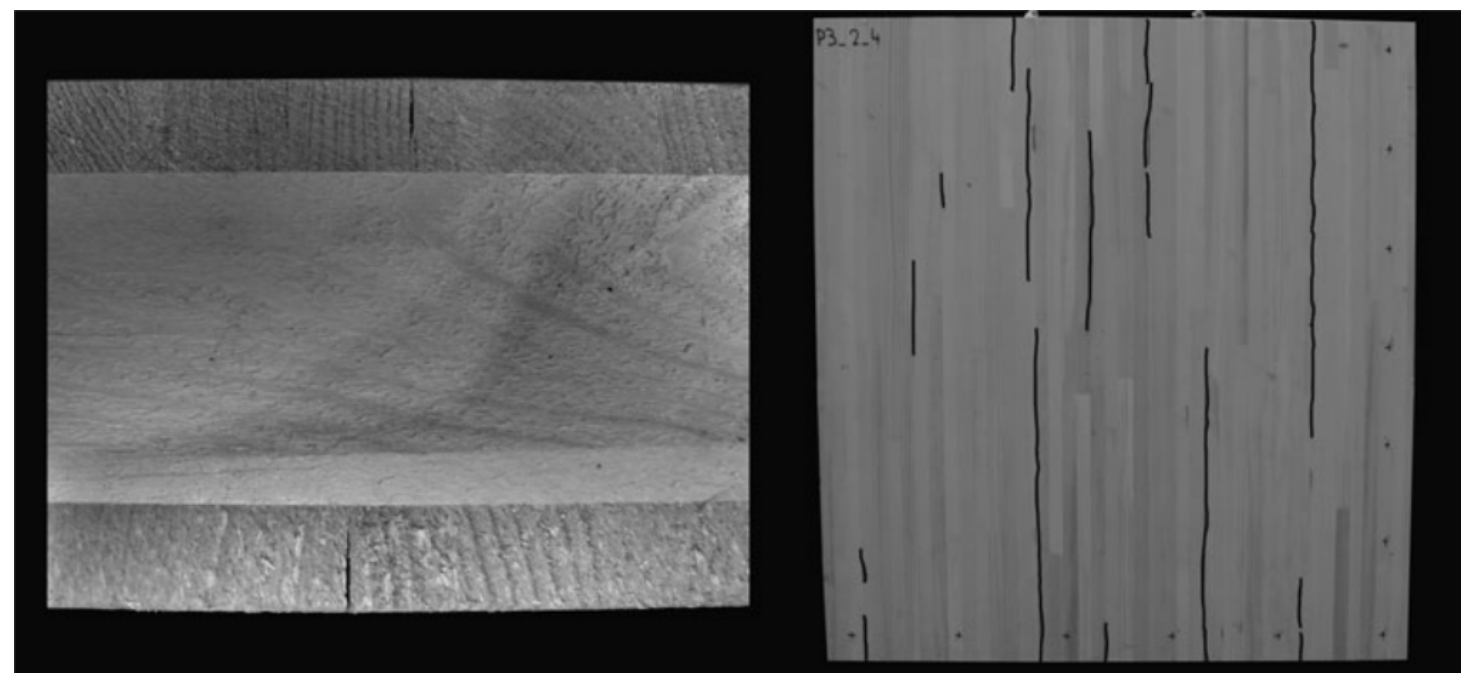

Figura 2.13: Las grietas en las capas de recubrimiento después de secar las muestras CLT a un contenido de humedad del $10 \%$ (Gülzow et al., 2011)

De los ensayos para estudiar el impacto de los cambios de humedad de la madera (MC) en los parámetros de rigidez de los paneles de madera contralaminada (CLT), se extrae que cuando aumenta el MC del clima de referencia $\left(20^{\circ} \mathrm{C}, 65 \% \mathrm{HR}\right)$, todos los parámetros de rigidez investigados disminuyen su nivel medio, y que el secado puede causar grietas en todas las capas del CLT, que, como resultado puede conducir a una reducción de la MOE perpendicular a la fibra de las capas de recubrimiento (Gülzow et al., 2011).

Para asegurar la durabilidad a largo plazo del CLT, es necesario investigar su rendimiento higrotérmico. 
Aunque es cierto que ha habido bastantes estudios sobre CLT y otros productos derivados de la madera usando simulaciones higrotérmicas, pocos de ellos incluyen verificaciones con mediciones en campo (Häglund, 2007; Coto et al., 2011; Kalamees y Vinha, 2003; Hameury, 2005). La mayoría de estos estudios utilizan programas de simulación computacional existentes, generalmente WUFI, un programa comercial de simulación higrotérmica basado en la ley de Fick para modelar el vapor y la ley de Darcy para el transporte de líquidos (McClung et al., 2014).

Aunque este programa (WUFI) se ha verificado para una amplia gama de materiales de construcción, incluyendo productos derivados de la madera, tales como madera contrachapada y OSB, existen dificultades y limitaciones conocidas para modelar el comportamiento higrotérmico de la madera utilizando sólo un modelo de Fick, particularmente para condiciones de alta humedad relativa (HR) y condiciones cambiantes (Håkansson, 1998; Ruut, 2003; Wang et al., 2014; Wadsö, 1994; Engelund et al., 2013). Esto es debido al efecto de absorción retardado a altas HR descrito por Håkansson (1998).

Las simulaciones comentadas se hicieron con un enfoque determinista, que se utiliza comúnmente en los estudios sobre mojado y secado de las uniones de muros de madera (Häglund, 2007; Goto et al., 2011; Kalamees y Vinha, 2003; Hameury, 2005). Sin embargo, los factores que influyen en las respuestas higrotérmicas son de naturaleza estocástica, tales como la variabilidad de las propiedades del material, condiciones de contorno, así como las cargas ambientales. Las incertidumbres de los parámetros de entrada pueden dar lugar a una desviación entre los resultados de la simulación y el rendimiento real de las uniones de los muros (Künzel y Kiessl, 1996; Li et al., 2009), en consecuencia, puede dar lugar a diseños defectuosos (Wang y Ce, 2016).

Este enfoque estocástico se ha aplicado en varios estudios que investigan la influencia de las propiedades del material y las condiciones de contorno a través de simulaciones higrotérmicas (Salonvaara et al., 2001; Holm y Kuenzel, 2002; Defraeye et al., 2013; Zhao et al., 2011). La influencia de las condiciones ambientales, tales como la lluvia y las ganancias internas de humedad en el comportamiento higrotérmico de las uniones de los muros también se ha investigado con estudios paramétricos (Cornick et al., 2010) y con el análisis de distintos escenarios (Pallin, 2013). Sin embargo, estos estudios realizados a través de análisis estocásticos se limitan a configuraciones de pared y orientaciones fijas sin la consideración de los factores de riesgo tales como la lluvia (Wang y Ge, 2016).

Este enfoque estocástico investiga más a fondo las causas de las discrepancias entre las mediciones y simulaciones identificadas en los estudios anteriores (McClung et al., 2014), y permite tener en cuenta las incertidumbres de las propiedades del material y las condiciones de contorno con diferentes cargas ambientales y configuraciones de diseño (Wang y Ge, 2016).

La exposición prolongada a la humedad durante la construcción y en la vida en servicio de los productos de madera, en referencia a su durabilidad, es una cuestión de gran importancia para la mayoría de productos de madera, incluyendo CLT. En concreto, los paneles CLT en obras de construcción sin protección pueden estar expuestos a la lluvia, lo que puede producir la entrada de agua en el producto, conduciendo a niveles indeseablemente altos de humedad incorporada una vez ensamblados. Si esta humedad incorporada no puede secar en un plazo de tiempo razonable, se puede producir un daño potencial (McClung et al., 2014).

McClung et al. (2014) ha evaluado aspectos como el riesgo de humedad durante el proceso construc- 
tivo en el Sur de Ontario, o Serrano et al. (2014) que lo llevó a cabo en Suecia, lugares donde se ha demostrado que la humectación puntual durante el proceso constructivo no es un factor determinante en la resistencia del sistema estructural.

El almacenamiento de la humedad es una propiedad importante de material que influye en el contenido de humedad del panel de CLT, en los niveles más bajos de MC, donde domina la difusión del vapor, la función de almacenamiento de humedad tiene una influencia positiva, mientras que en los niveles superiores de MC, superiores al $20 \%$, donde gobierna el transporte de líquidos, la influencia de la función de almacenamiento es menor y tiene una influencia negativa (Stürzenbecher y Hofstetter, 2017).

Aunque la madera como material no es ni perfectamente homogénea, ni isotrópica, es racional no tener en cuenta la anisotropía en las direcciones transversales, es decir, la madera se trata matemáticamente como isotrópica en las direcciones transversales. Los experimentos en madera de coníferas han demostrado que los coeficientes de difusión son prácticamente los mismos en la dirección tangencial y radial (Rosenkildey Arfvidsson, 1997; Hedenblad, 1996), comentado también por Hukka (1999). Hay que tener en cuenta que el transporte de la humedad en la dirección longitudinal es muy diferente (Häglund, 2007).

Los cambios rápidos de humedad, afectan a la parte externa de la madera, pero dejan las partes internas del elemento intactas. Sin embargo, los cambios lentos, como las variaciones anuales, afectan a todo el elemento. Existen diferencias notables entre los lugares con respecto a la respuesta debida a un contenido de humedad variable (Häglund, 2007).

Las estructuras compuestas son muy sensibles al estrés higrotermico-elástico, esto es debido a su heterogeneidad intrínseca, tanto a escala micro como macroscópica, y está relacionado con la diferencia de las propiedades higrotermico-elásticas de las entidades adyacentes; colas y madera, y se agudiza más cuando en el caso de la madera contralaminada las capas adyacentes están alineados con diferentes orientaciones de las fibras (Gigliotti et al., 2007).

Con todo lo expuesto se pone de manifiesto la importancia de la humedad en el CLT, y la necesidad de estudios no teóricos mediante simulación, sino de estudios que se complementen con datos reales y experiencias en campo para confirmar los resultados de las simulaciones. También hay que ser consciente de las diferencias climáticas de los países mediterráneos, totalmente diferentes a la realidad climática de centro-europa, que hace que la mayoría de estudios existentes no sean válidos para estas latitudes.

\subsection{Evolución de los productos de madera para la construcción}

Hombre y tecnología han evolucionado a lo largo de su existencia de forma paralela. La necesidad de dominar el medio le confirió al hombre el descubrimiento y conocimiento de los materiales que la naturaleza le ofrecía (García, 1999). Pero es realmente con la incorporación de la industria cuando evoluciona y progresa el sistema, que se produce con mayor auge donde la materia prima es abundante, en América (García-Navarro y Peña, 2001b). La revolución industrial significó también un hito en el empleo estructural de este material, muchas veces silenciado por el evidente protagonismo del acero 
y el hormigón, y también por la decadencia que en casi toda Europa tuvo este material(Carcía-Navarro y Peña, 2003).

La revolución tecnológica e industrial que introdujo nuevos materiales estructurales en el proceso constructivo como el acero y el hormigón, es la que ha permitido en los últimos tiempos el desarrollo de materiales técnicos de madera que la han vuelto a posicionar en el mercado como un material estructural vanguardista.

La puesta al día de la madera como material de construcción consistió en la paulatina sustitución de la madera maciza por materiales industrializados, es decir, la aparición de un nuevo material estructural que puede denominarse como "madera industrializada" (García-Navarro y Peña, 2003).

Como se ha comentado anteriormente, en principio se produjo un gran desarrollo en materia de productos de madera para construcción en países con abundancia de materia prima, pero el segundo y más reciente desarrollo en productos industrializados de madera, se produjo en países con menos abundancia de materia prima, que querían optimizar el uso de la madera, y darle así un valor añadido a maderas de pequeñas dimensiones, más abundantes en este momento. Este desarrollo comenzó a finales del s.XIX, con el uso de colas y resinas sintéticas.

A partir de 1930 comenzó con la aplicación de las colas termoendurecibles, que hicieron posibles las unidades estructurales continuas, constituidas por pequeños elementos estructurales de madera, incluso con diferentes propiedades. La transformación fundamental ha consistido en la sustitución de la madera por productos derivados de ella, que han mejorado sus propiedades mecánicas para ponerlas a la altura de las del más cualificado material estructural. Como ejemplo se pueden nombrar la madera laminada encolada (CLUELAM), la madera microlaminada (LVL-Laminated Veneer Lumber), la madera reconstituida (PSL-Parallel Strand Lumber) o los tableros de virutas orientadas (OSB-Oriented Strand Board), sistemas todos ellos que surgen con el objetivo de aprovechar al máximo la producción forestal, mediante el empleo de partes de la madera que hasta ahora habían sido desechadas (GarcíaNavarro y Peña, 2003).

La fabricación de todos estos productos no hubiera sido posible sin el desarrollo de la tecnología del encolado, que comenzó con colas fuertes hacia el año 4000 a.C., hasta nuestros días. Los últimos desarrollos han aumentado la durabilidad de la madera, generando una amplia familia de nuevos productos que han rebasado las limitaciones de ésta en su forma original gracias a las colas, y han contribuido al diseño de unos medios de unión capaces de transmitir mayores cargas con una fiabilidad superior (García-Navarro y Martínez, 1996).

En lo explicado se observa como la madera como material se adapta a las diferentes necesidades y conocimientos que el hombre ejerce sobre ella, desde su utilización directa como troncos sin apenas transformación, hasta su moderna transformación en modernos productos de construcción que permiten el desarrollo de estructuras que con otros materiales sería impensable, y con un coste medioambiental muy bajo o incluso negativo. 


\subsubsection{Desarrollo de los adhesivos}

Para poder comprender la evolución de los productos de madera para la construcción desde el rollizo hasta materiales tan avanzados como el CLT, hay que comprender también el desarrollo de las colas.

Actualmente los productos de madera para la construcción, son en su mayoría productos derivados de madera, conocidos como "Wood based products" en inglés, se componen de madera como materia base, y de un agente aglomerante o cola, que ayuda a conformar el producto.

Las colas, cola de hueso, cola de pescado y cola de almidón, entre otras, supusieron el primer avance en la tecnología del encolado y por tanto en productos derivados de la madera. Tras este primer avance el descubrimiento de la casina supuso un paso importante, llegando su fabricación industrial en 1895 en EEUU. En 1900 se extrae industrialmente la gelatina. Entre 1910 y 1915 aparecen las primeras colas a base de la disolución de caucho natural. La caseína experimenta un desarrollo importante entre 1913 y 1917, primero por el uso en carpintería y a continuación por su utilización en aviación. Las colas a base de soja suponen en 1926 la fabricación de los primeros contrachapados. En 1930 las colas de resorcina (EEUU) y de urea-formol encuentran sus primeros usos. En ese mismo año las colas vinílicas y las de neopreno (Dupont de Nemours) son formuladas. Los primeros adhesivos a base de cauchos sintéticos son fabricados en 1938 (USA). En 1949 se fabrican los primeros adhesivos epoxys. Los adhesivos vinílicos de un sólo componente se formulan en 1950, y no es hasta 1964 cuando aparecen los primeros termofusibles. Desde ese año la química de adhesivos ha estado dirigida al estudio de los vinílicos de dos componentes y a los poliuretanos termofusibles (García, 1999).

Este desarrollo en el campo de las colas, permitió la construcción de diferentes ejemplos, que fabricando los productos de un modo artesanal, dejaban entrever las posibilidades de la madera como producto de construcción.

Entre las primeras experiencias conocidas sobre la utilización de la madera laminada encolada en Europa, está la construcción de un Auditorio en Basilea (Suiza), en 1893. La estructura se resuelve a base de arcos, utilizando probablemente caseína como resina de encolado. Más adelante, la madera laminada encontró también aplicación en otros campos tecnológicamente avanzados como la aviación y reafirmó sus posibilidades en el sector de la construcción. Con el desarrollo de colas estables, en la década de los cincuenta, se hizo posible su utilización en puentes, construcciones marinas y ambientes agresivos. En cuanto a la forma y tamaño de las piezas, no existen otras limitaciones que las dictadas por el transporte, manipulación y puesta en obra. Las láminas en la pieza terminada se pueden disponerverticalmente, aunque lo más frecuente es hacerlo de forma horizontal. Con arcos, se han llegado a salvar luces por encima de los 100 metros En piezas rectas, no es raro sobrepasar los 30 metros (GarcíaNavarro y Martínez, 1996).

Todo este desarrollo por un lado de la tecnología del encolado, y por otro de la aplicación de los primeros productos de madera encolados, ha hecho que a día de hoy se encuentre en el mercado una gran familia de productos derivados de la madera para el sector de la construcción. Tras todo el avance llevado a cabo, los productos derivados de la madera de la actualidad, son productos con una alta industrialización y totalmente normalizados, lo que permite que tengan una fácil utilización por parte de los prescriptores. 


\subsubsection{Desarrollo de la industrialización de productos}

Durante el siglo XX, se ha producido un gran desarrollo en toda la familia de tableros de madera gracias a la mejora de la química de adhesivos, que unida al avance en la tecnología de la madera y a la industrialización del proceso de fabricación, han permitido la gran variedad y calidad de estos productos.

Siguiendo la cronología expuesta por García-Navarro y Martínez (1996) y haciendo una breve reseña por los principales productos de madera para la construcción, el primero en aparecery más destacado por su uso fue el tablero contrachapado. Es un tablero que se obtiene por la superposición de chapas de madera encoladas, las chapas se unen de forma que cada chapa forma un ángulo de $90^{\circ}$ con la chapa adyacente, logrando así que las direcciones de la fibra estén perpendiculares y aportando una mayor estabilidad al tablero, además esta conformación dota al tablero de una mayor resistencia a la flexión.

El tablero contrachapado fue usado por primera vez en construcción en los años 30, es el primer tablero que se fabricó para obtener madera en formato superficial de gran tamaño, tiene una gran versatilidad de usos, y una utilización con fabricación rudimentaria bastante previa a los años 30. La variedad de usos de este tablero es enorme, pero quizás cabe destacar su uso en el sector de la aeronaval, donde fue utilizado para el fuselaje de los aviones (figura 2.14).
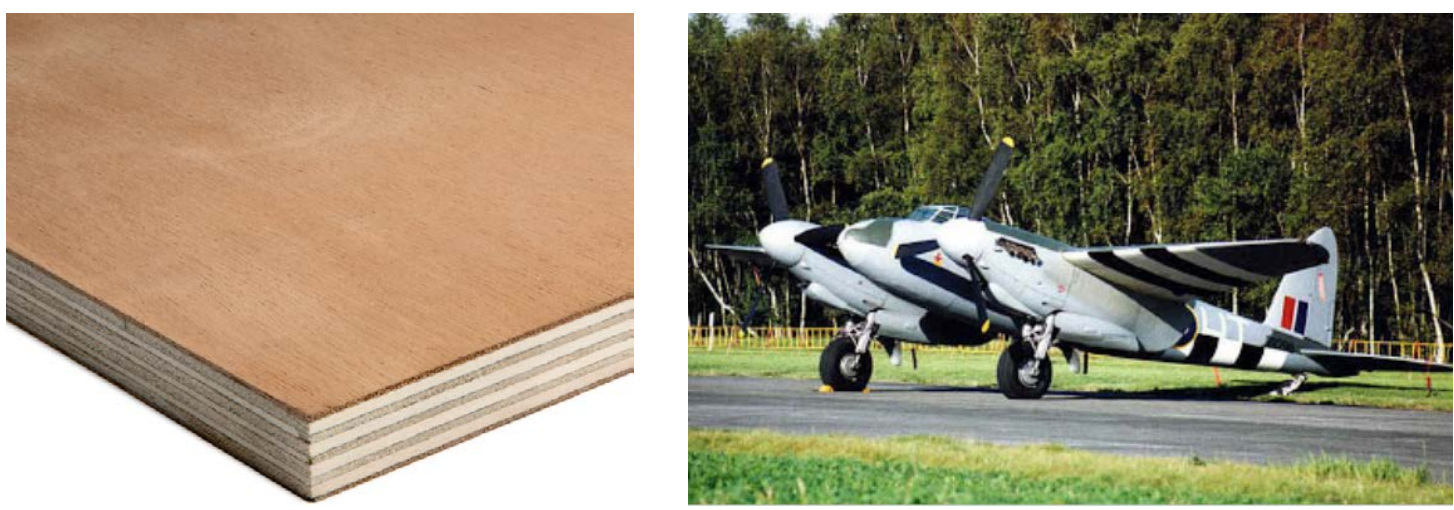

Figura 2.14: Tablero contrachapado y mosquito segunda guerra mundial

Tras el tablero contrachapado, también en la década de los 30, comenzó la producción industrial del tablero de partículas, impropiamente llamado tablero aglomerado (figura 2.15). El tablero de partículas se obtiene de la aplicación de presión y calor sobre partículas de madera y/o de otros materiales lignocelulósicos en forma de partículas, a las que se ha añadido previamente un adhesivo. Estos tableros también presentan multitud de usos, y multitud de variedades, además de por el tamaño de partículas por los diferentes aditivos que se le aplican y que permiten modificar las propiedades del tablero.

Seguidamente en los años 40, aparece el tablero de fibras duro (figura 2.16), con un concepto parecido, pero con características bien diferenciadas. Al igual que ocurre en el proceso de fabricación del tablero de partículas, el tablero de fibras duro procede de la aplicación de calor y/o presión a una manta que en este caso está compuesta por fibras lignocelulósicas, a diferencia de en el caso anterior que estaba compuesta por partículas. 


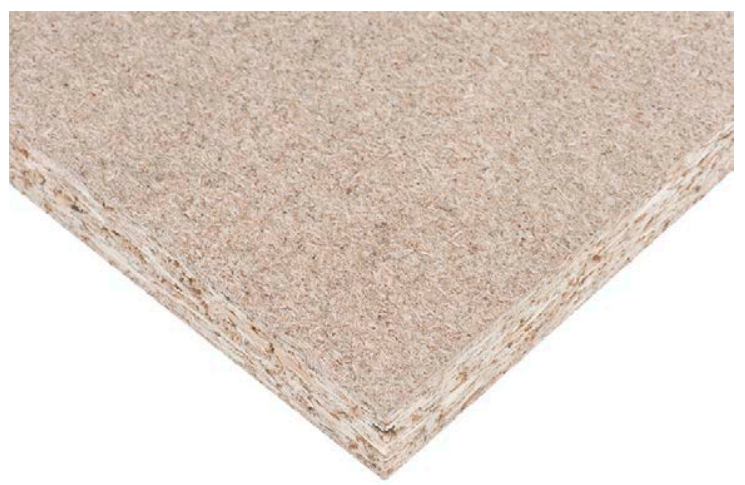

Figura 2.15: Tablero de partículas

Estos tableros también poseen una gran versatilidad en cuanto a usos, y gracias a los aditivos que se les pueden incorporar en el proceso de fabricación, existen también multitud de variedades con diferentes propiedades.

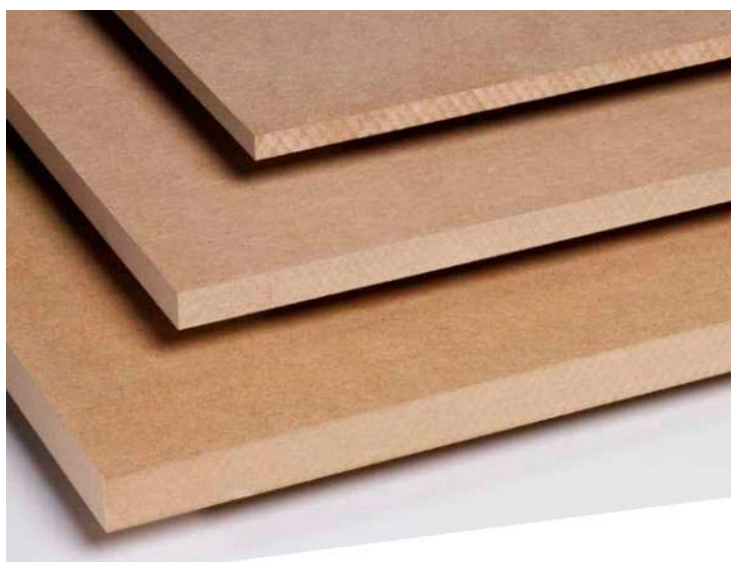

Figura 2.16: Tablero de fibras duro

A comienzos de los 70 se incorpora al mercado el tablero de densidad media (figura 2.17). El tablero de densidad media se obtiene aplicando calor y presión a las fibras de la madera a las que se ha añadido previamente un adhesivo. Se caracteriza por tener una densidad igual o superior a $450 \mathrm{~kg} / \mathrm{m}^{3}$ (UNE-EN $316,2009)$. Según la normativa su nombre correcto sería tableros de fibras fabricadas por el proceso seco, pero debido a la complejidad del nombre se suelen conocer por las siglas de su nombre en inglés MDF (Medium Density Fiberboards), o también como DM, denominación del todo incorrecta ya que se corresponde con una marca comercial.

Al igual que se ha comentado en los tableros anteriores, son tableros muy versátiles y permiten modificar sus propiedades mediante aditivos.

En la misma década de los 70, comienzan los ensayos del tablero de virutas de disposición orientada (figura 2.18). Este tablero se obtiene aplicando presión y calor a virutas de madera encoladas: Las virutas que conforman el tablero son irregulares y tienen una forma y un espesor variables, y se ali- 


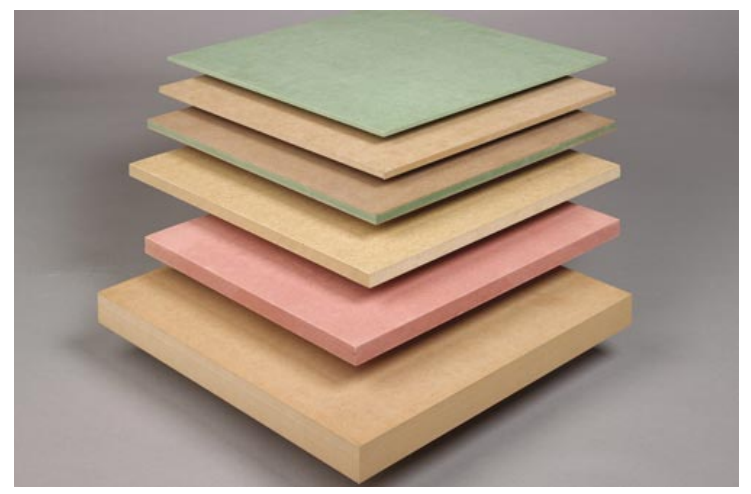

Figura 2.17: Tablero de fibras de densidad media

nean formando capas. Las capas exteriores están orientadas mayormente en el sentido longitudinal del tablero y la capa o capas interiores tanto perpendicular como paralelas o longitudinales al tablero. Normalmente se disponen en 3 capas y raramente en 5 .

Se suele denominar por las siglas de su nombre en inglés OSB (Oriented Strand Board), y es junto con el tablero contrachapado el tablero con más uso estructural. El tablero OSB proviene de la búsqueda de un tablero con propiedades similares al contrachapado pero más barato y con un mayor aprovechamiento de la madera.

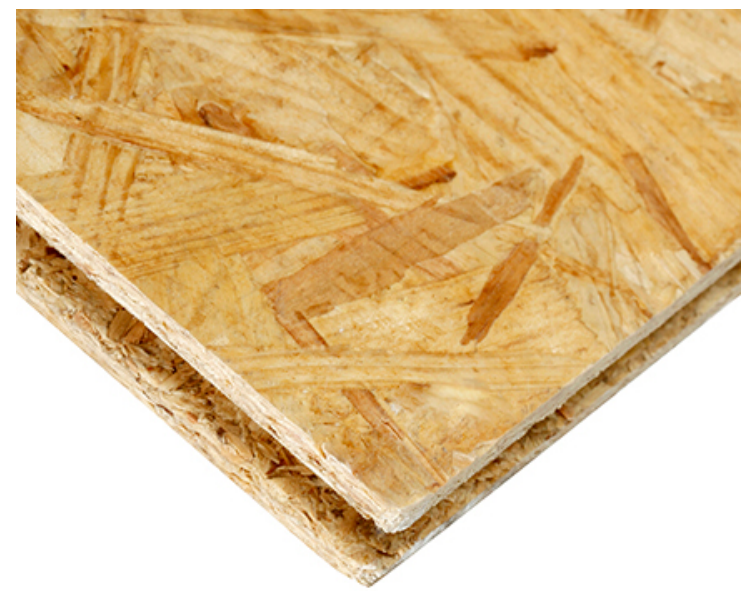

Figura 2.18: Tablero de virutas OSB

Posteriormente el OSB se incorpora a la familia de tableros el tablero de partículas-cemento, dotado de propiedades claramente diferenciadas del resto (figura 2.19). Los tableros madera-cemento, están formados por partículas de madera, cemento Portland y aditivos químicos que se encargan de acelerar el proceso de fraguado del cemento. Al igual que los tableros de partículas suelen estar formados por tres capas. Para la conformación del tablero hay que aplicar presión a las partículas de madera que han sido previamente aglomeradas con mortero de cemento

Estos tableros se suelen denominar también CBPB, siglas que proceden de su denominación inglesa 
Cement Bonded Particle Board.

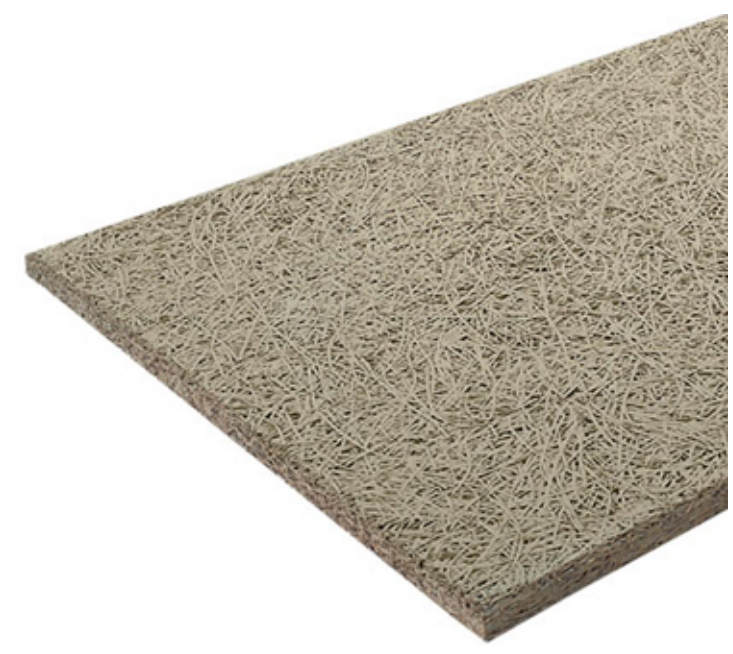

Figura 2.19: Tablero de partículas de madera-cemento

Los productos de madera para la construcción descritos, permiten la eliminación de nudos, grietas y características propias de la madera joven, mientras que la tasa de aprovechamiento de la materia prima es más alta. Es decir, se necesita menos volumen de fibra bruta para obtener las mismas o mayores producciones, y con superiores prestaciones que con madera maciza. Estos materiales, de los que se conocen con exactitud sus prestaciones, mejoran las características del elemento equivalente en madera y, en muchos casos, de otros sistemas de construcción convencional de uso similar (García-Navarro y Martínez, 1996).

El más novedoso de estos productos de construcción de la familia de los tableros estructurales es la madera contralaminada, más conocida como CLT, por sus siglas en inglés Cross Laminated Timber, y que se describe en el siguiente apartado.

\subsubsection{La madera contralaminada CLT}

La búsqueda de la eficiencia en el aprovechamiento de la madera, ha llevado a la obtención de productos que aprovechen al máximo la materia prima, y mejoran el rendimiento estructural de la madera eliminando sus defectos.

El nacimiento de la madera contralaminada CLT, surge en un momento, en el que el uso de la madera como material de construcción se había reducido, ya que se usaba prácticamente como revestimiento, y estructuralmente como elementos lineales. Sin embargo, en los últimos 10 años más o menos, la madera ha recuperado cuota de mercado en el ámbito de los materiales de construcción sólida a base de minerales, en diferentes campos en el ámbito de la construcción (Brandner etal., 2016). Parte de este resurgimiento se debe al lanzamiento comercial de un producto innovador conocido como madera contralaminada (CLT) 
El término alemán "Brettsperrholz" (BSP) fue utilizado por primera vez por Dröge y Stoy (1981) para describir un producto utilizado preferentemente para crear una red de vigas de madera maciza, seguido por Steurer (1989) que lo usó para referirse a los tableros usados en los puentes de madera, y que finalmente fue traducido al inglés por el término "Cross Laminated Timber" (CLT) por Schickhofer y Hasewend (2000).

El desarrollo del CLT en la década de 1990 fue motivada por la necesidad de la industria del aserrío de encontrar un uso a madera de pequeñas dimensiones (Guttmann, 2008). Austria llevó a cabo un esfuerzo de investigación académico-industrial conjunto que dio como resultado el desarrollo del CLT (García-Navarro y Peña, 2001b). Tras un lento inicio, la construcción con CLT aumentó significativamente en la década del 2000, impulsado por el movimiento de construcción verde, las mejores eficiencias de este tipo de construcción, la homologación de productos, y la mejora de los canales de comercialización y distribución (Mohammad et al., 2012).

La contribución de la normativa específica en el ámbito de la construcción con madera, sobre todo en el fomento de la $\mathrm{I}+\mathrm{D}+\mathrm{i}$, ha permitido a la madera posicionarse como un material competitivo, aunque por el desconocimiento prescriptivo aún queda una gran labor de promoción. Esto ha hecho que los productos innovadores en madera en Europa son en primer lugar los sistemas de edificación, seguidos de los elementos estructurales (Oteiza et al., 2013).

La idea de la madera contralaminada no es nueva, está basada en otros productos existentes en carpintería como el contrachapado. La principal ventaja que aporta es su estabilidad dimensional, debido al uso de madera saneada y de la disposición de las piezas que conforman el producto, y la principal diferencia es el grosor de las láminas, que lo hacen apto para ser un producto de construcción estructural (Brandner et al., 2016). Como ejemplo de que la madera contralaminada no es una idea nueva, se puede citar la investigación llevaba a cabo en el INIA con madera de chopo en la década de los 60 (Nájera, 1960), en la que ya aparece con el nombre de madera contralaminada.

Los productos derivados de la madera (EWP's) fueron desarrollados por una parte para hacer frente a la variabilidad inherente del material y por otra para utilizarlo de manera más eficiente. Entre los ejemplos de EWP más utilizados se encuentran los paneles orientados Oriented Strand Board (OSB), los tableros de fibra de madera de densidad media Medium Density Fiber (MDF), y madera laminada Cluelam (CL). Estos productos se fabrican para conseguir unas propiedades de ingeniería específicas, tales como alta resistencia, durabilidad mejorada y consistencia. Los EWP también ayudan a hacer un uso más eficiente de la madera con el uso de árboles de pequeño diámetro y bajo valor (Ross, 2010; Woodall et al., 2011; McKeever, 1997; APA, 2013). El desarrollo y la mejora de las tecnologías de adhesión, las conexiones mecánicas, y la tecnología de clasificación, se han traducido en EWP's que extienden en gran medida las posibilidades de construcción con productos derivados de la madera (Canadian Wood Council, 2010).

Como se ha comentado, una de las más recientes innovaciones en EWP, es el desarrollo de la madera contralaminada (CLT). Estos paneles (también referidos como "X-Lam”, "madera maciza” o "Cross-Lam”), son un producto de ingeniería de madera compuesto por laminación longitudinal de piezas más pequeñas, de aproximadamente 20-60 mm (0,75 a 2,5 pulgadas) de espesor. Estas tablas se pegan lateralmente en una sola capa, y después se adhieren a las capas adyacentes en ángulo recto, las capas de madera se unen alternando la dirección de la veta entre capas, con el fin de que el panel resistir la 
carga en ambas direcciones (Laguarda Mallo y Espinoza, 2015). De la madera descrita anteriormente se conforma el tablero que se puede observar en la figura 2.20.

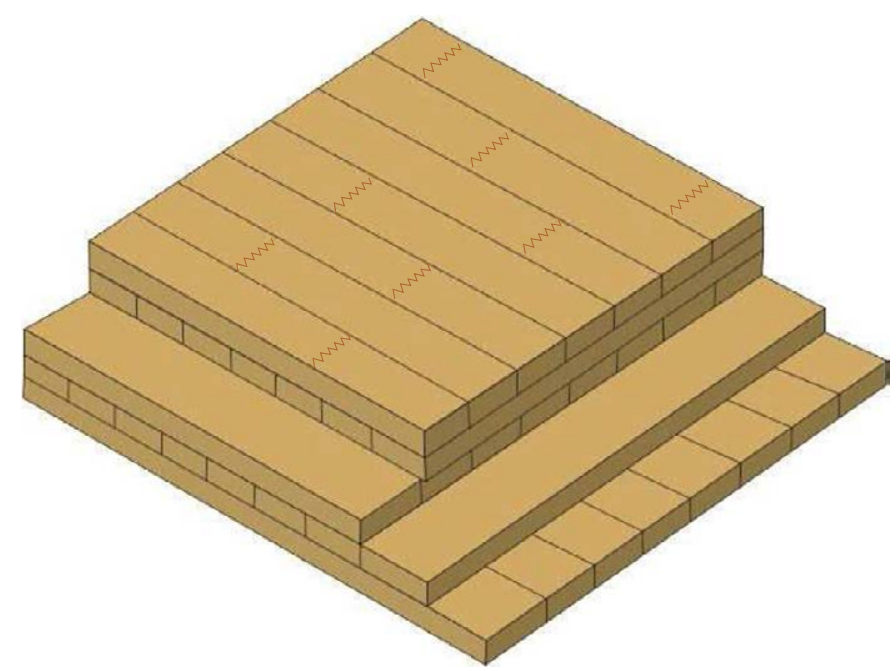

Figura 2.20: Vista esquemática de la configuración de capas del CLT

Un proceso típico de fabricación de CLT incluye la selección de la madera que conformará el producto, el cepillado de la madera, la aplicación de adhesivos, la superposición de las capas que conformarán el panel y el prensado, seguidamente se llevará a cabo el corte del producto, su marcado y envasado (García, 1999).

La clave para la resistencia del CLT está en la calidad de la madera utilizada, y en la calidad de la unión adhesiva. Para evitar las variaciones dimensionales y las grietas, la madera se seca en horno hasta un $12 \pm 3 \%$ de contenido de humedad. El tiempo de proceso de montaje varía de 15 minutos a 1 hora dependiendo del equipo y el adhesivo. Una vez aplicado el adhesivo, el conjunto se presiona mediante prensas hidráulicas (más común), o de vacío y aire comprimido, dependiendo del grosor del panel y adhesivo utilizado. Posteriormente los paneles ensamblados se cepillan y lijan para obtener finalmente una superficie lisa. Los paneles se mecanizan cortándose a medida y abriendo huecos de puertas y ventanas, todo ello con una gran precisión gracias a las máquinas de control numérico.

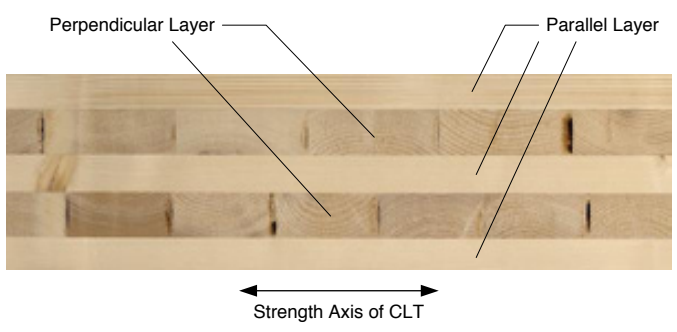

Figura 2.21: Sección transversal de un panel de CLT de cinco capas

Se requieren pruebas de control de calidad en planta estrictas para asegurar que los productos finales de CLT serán aptos para las aplicaciones previstas (Mohammad et al., 2012). Esto conlleva tanto un 
control de calidad en fábrica, como un control externo que verifique el proceso. Como consecuencia del proceso de fabricación descrito, se obtiene un compuesto cuasi rígido, un producto de ingeniería de madera en forma de panel, capaz de soportar cargas tanto dentro y como fuera del plano y de competir con los materiales que tiempo atrás le robaron a la madera su papel como material estructural de construcción (Brandner et al., 2016).

Esta contra-laminación destinada a mejorar la rigidez, la estabilidad, y las propiedades mecánicas (Evans, 2013), ha hecho que este material muestre una gran variedad de posibilidades en construcción, lo que ha fomentado su uso, y permitido que haya ido ganando popularidad en aplicaciones residenciales y no residenciales, principalmente en Europa (Gagnon, 2011). El éxito cosechado por el CLT en las últimas dos décadas (Lehmann, 2012) ha hecho que la producción de CLT en Europa aumentara de $25.000 \mathrm{~m}^{3}$ en 1996 a $340.000 \mathrm{~m}^{3}$ en 2010 (Crespell y Gagnon, 2010), y en 2014, el volumen de producción en todo el mundo aumentó a $625.000 \mathrm{~m}^{3}$ (Plackner, 2014). Según el pronóstico, a finales de 2015 se espera un volumen de $700.000 \mathrm{~m}^{3}$, véase la figura 2.22 .

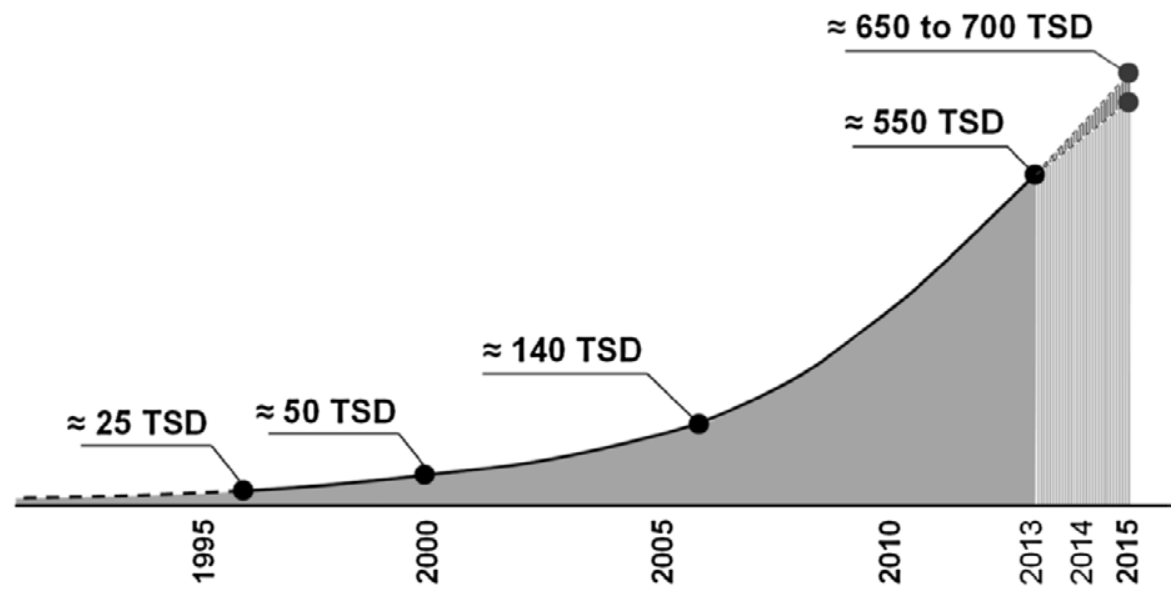

Figura 2.22: Desarrollo del volumen mundial de producción de CLT hasta 2013 y las previsiones hasta el año 2015 en $\mathrm{m}^{3}$ (Brandner et al., 2016) (TSD: miles)

Actualmente el CLT es un producto demandado, y con una amplia investigación sobre sus propiedades. Al ser un producto normalizado, es de fácil manejo en los cálculos para arquitectos e ingenieros, y debido a su alta industrialización permite el diseño de todas las partes del edificio para su prefabricación.

Por otra parte, el diseño asistido por ordenadory los desarrollos en la tecnología de la madera aplicados a la producción, permiten alcanzar los más altos estándares de calidad y mejorar las posibilidades del producto mediante la personalización del mismo, de acuerdo con las necesidades específicas de cada edificio (véanse las figuras 2.23(a) y 2.23(b) de Staib et al., 2008).

Hoy día el CLT es una alternativa real para la construcción sostenible, y los retos que actualmente se le presentan son el desconocimiento por gran parte del sector de la construcción, en países como España. Llegar a una cultura de construcción en madera, rompiendo con los tabúes existentes, es una tarea mucho más lenta y difícil de lo que en principio puede parecer, pero teniendo en cuenta las credenciales 


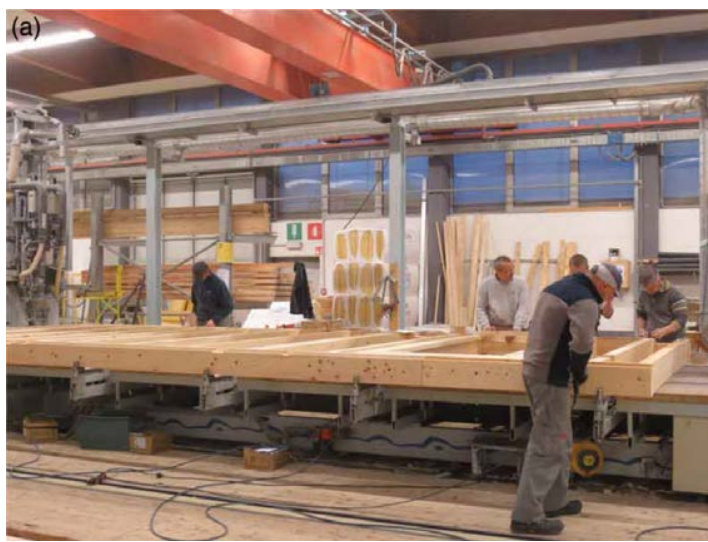

(a)

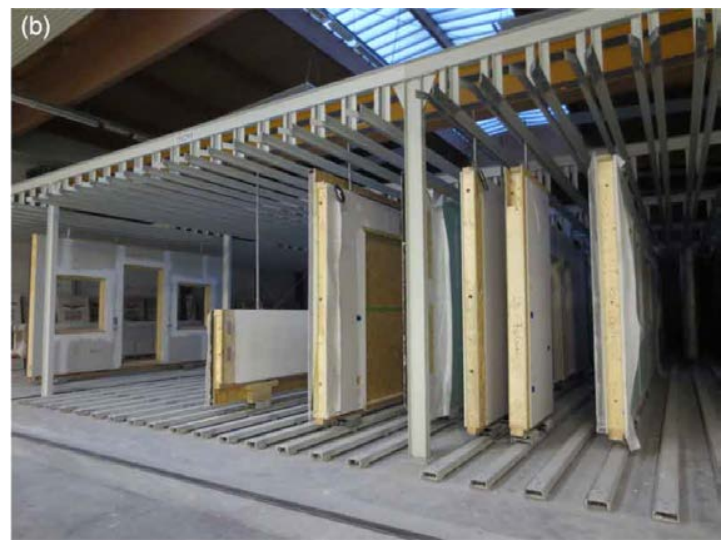

(b)

Figura 2.23: Proceso de mecanizado de los paneles de CLT

técnicas y medioambientales que presenta este material hoy en día, merece la pena intentarlo (Oteiza et al., 2013).

\subsection{Normativa de ensayo de la madera contralaminada}

Como se ha comentado anteriormente, la construcción con madera ha evolucionado mucho desde sus orígenes, tanto desde el punto de vista de la tipología constructiva, como desde el desarrollo de la tecnología de los productos empleados. Al ser la madera un recurso natural renovable, ha sido aprovechada en la mayor parte de los países y usada extensivamente en forma industrializada para la construcción de viviendas.

Ha sido un material importante para la construcción de edificios a través de la historia mundial. Los países industrializados (EEUU, Canadá, Inglaterra, Alemania y Francia, entre otros), han utilizado desde hace muchos años la madera como material de construcción, bien sea sola o en combinación con otros materiales.

La madera es un producto natural susceptible de industrialización, lo que permite establecer estándares de producción y clasificación, dando lugar a productos con unas especificaciones y controles muy rigurosos. Esto ha permitido un desarrollo de productos técnicos orientados al sector de la construcción, compitiendo en igualdad de condiciones con otros materiales y tecnologías. Todo este desarrollo junto con el desarrollo de la normativa ha conseguido que hoy día se encuentren en el mercado productos innovadores como el CLT.

Teniendo en cuenta el desarrollo, así como el creciente interés e importancia que el CLT ha tomado para arquitectos, ingenieros y otras partes interesadas, se espera un aumento acelerado en el volumen de producción en todo el mundo en la próxima década; en particular, en países como Canadá, Estados Unidos y Japón. Por lo tanto, es necesario el desarrollo de procesos de homogeneización, que comprenda normas de producto, ensayos, diseño, uniones, así como ejecución y final de uso, por ello se 
recomienda el establecimiento de un conjunto armonizado de normas en todo el mundo (Brandner et al., 2016).

En Europa, la normalización de los productos innovadores derivados de la madera, como es el CLT, llegó a través de la directiva de productos de la construcción (Directiva 89/106/CEE, 1989), derogada posteriormente por el correspondiente reglamento de productos de la construcción (Reglamento 305/2011/UE, 2011). Esta directiva daba la opción de conseguir el marcado CE para productos que no tuvieran norma armonizada.

La mencionada directiva tenía por objeto garantizar la libre circulación de todos los productos de construcción en la Unión Europea mediante la armonización de las legislaciones nacionales relativas a los requisitos esenciales de estos productos en materia de salud, seguridad y bienestar, en el contexto de una Europa sin fronteras económicas ni políticas. Una de sus principales innovaciones era el establecimiento de los procedimientos necesarios para el marcado CE de productos de construcción, incluidos aquellos productos innovadores contemplados en las Guías DITE.

La directiva se aplicaba a los productos de construcción, es decir, los productos destinados a incorporarse permanentemente a las obras de construcción. Estos productos debían ser conformes a los requisitos esenciales, sólo se podrían comercializar si eran idóneos para el uso al que se destinaban. Los requisitos esenciales se concretaron en primer lugar mediante documentos interpretativos elaborados por comités técnicos para, a continuación, desarrollarse en forma de especificaciones técnicas, que podían ser:

- Normas armonizadas europeas adoptadas por los organismos europeos de normalización (CEN - CENELEC), con arreglo a mandatos de la Comisión y previa consulta del Comité Permanente de Construcción

- Documentos de Idoneidad Técnica Europeo (DITE), que valoraran la idoneidad de un producto para su uso. Se aplicaban en los casos para los cuales no existía ni una norma armonizada, ni una norma nacional reconocida, ni un mandato de norma europea, y con respecto a los cuales la Comisión considerara, previa consulta a los Estados miembros en el seno del Comité Permanente de Construcción, que no se podía —o que todavía no se podía — elaborar una norma.

Esta directiva contaba con unos anexos que facilitaban información detallada sobre: Requisitos Esenciales, Documento de Idoneidad Técnica Europeo (DITE), Certificado de conformidad con las especificaciones técnicas y Organismos Notificados.

El Documento de Idoneidad Técnica Europeo DITE (European Technical Approval, ETA), que en resumen era una evaluación técnica favorable de la idoneidad de un producto para un uso asignado, derivado del cumplimiento de los requisitos esenciales que debía satisfacer ese producto en la obra en que fuera utilizado, fue la vía de obtención del marcado CE para los productos no normalizados de acuerdo con la DPC, y fue el camino utilizado para la introducción en el mercado europeo del CLT.

Este procedimiento conllevaba la aplicación de normas de productos similares para la realización de los ensayos de aptitud al uso, y mediante esta normativa se elaboraba un CUAP con los ensayos necesarios para normalizar estos productos. En muchas ocasiones estos ensayos no se adaptaban totalmente a 
las características de los productos evaluados, y penalizaban al producto por ser demasiado exigentes, como ocurría en el caso del CLT.

En el caso de América del Norte, donde se han iniciado líneas de producción de CLT, y se han construido varias estructuras usando paneles CLT fabricados allí, se encontraban con que debido a la falta de estándares de CLT, estas estructuras eran generalmente diseñadas y construidas bajo la firma de un ingeniero, y aprobadas por el organismo regulador sobre una base caso por caso (Yeh et al., 2012).

Como se ve en el ejemplo de América del Norte, para la aceptación de materiales de construcción innovadores como es el CLT, es necesaria una norma de producto basada en el consenso entre diseñadores y organismos reguladores. En este caso se llevó a cabo una norma binacional entre los EE.UU. y Canadá, desarrollada por el proceso de la APA-The Engineered Wood Association como redactor de estándares acreditado por el American National Standards Institute (ANSI), y que dio lugar a la norma ANSI/APA PRG 320 (2017) sobre el rendimiento de la madera contralaminada. Esta norma no es una norma de fabricación de CLT y no aborda cuestiones específicas de la fabricación tales como la fluencia, duración de la carga, efecto de los cambios de volumen, efecto de la humedad, resistencia de carga lateral, uniones, fuego, etc. Para muchos de estos aspectos se llevó a cabo el Manual de CLT publicado en Canadá (Gagnon y Pirvu, 2011), y se desarrolló un esfuerzo similar para desarrollar un Manual de CLT en los EE.UU.

Con la publicación de la norma CLT basado en el consenso, ANSI/APA PRG 320 (2011), en América del Norte, la industria de productos de madera reconstituida ha dado un paso muy importante hacia la comercialización de los productos y sistemas de CLT.

En Canadá, la adopción de las ediciones 2005 y 2010 del Código Nacional de Construcción (NBCC), que son códigos basados en objetivos, ayudó a eliminar el sesgo inherente contra la madera en los códigos prescriptivos anteriores (1995 y anteriores). El nuevo formato reconoce tanto "soluciones aceptables" $y$ "soluciones alternativas", que fomentan el uso de materiales innovadores, productos y sistemas (NRC, 2010). Del mismo modo, en los EE.UU., hay códigos de construcción basados en el rendimiento que establecen un nivel de rendimiento esperado, y hay disposiciones en los códigos de construcción basados en normas prescriptivas que permiten el uso de métodos y materiales alternativos (Mohammad et al., 2012).

En el caso de España, y anterior a la normativa y legislación en materia de construcción con madera, nos encontramos con una serie de normas y sellos de calidad, que ayudaron al desarrollo de la tecnología de la madera como material de construcción, y colaboraron con el desarrollo de normativa específica gracias a la normalización del material. En primer lugar se produce una normalización de la madera y los productos derivados de la madera para la construcción, que se llevó a cabo mediante la elaboración de diferentes normas mediante los pertinentes comités de normalización.

Pero aparte de algunos documentos de solicitud nacionales para cumplir con el Eurocódigo 5, por ejemplo DIN-EN 1995-1-1 (2013) y ONORM B 1995-1-1:2014 (2014), las normas de diseño para elementos de CLT no existían entre las normas de diseño europeas. En este transcurso de tiempo en que el CLT existía en el mercado y no había norma armonizada, el CLT tenía que ser diseñado como se ha comentado de acuerdo a numerosas especificaciones de producto, y documentos de idoneidad técnica. 
Era imprescindible la armonización de estos procedimientos de diseño y la previsible revisión del Eurocódigo 5. Hasta 2016, estaban disponibles algunas pautas basadas en el concepto de diseño que emana de los códigos de diseño europeos y que resume los hallazgos de numerosos proyectos de investigación, por ejemplo Schickhofer et al. (2010), Wallner-Novak et al. (2013) y Harris et al. (2013). Por otra parte, también se ha mencionado que hay directrices basadas en otros conceptos de diseño y escritas para países fuera de Europa, por ejemplo, el Manual de CLT para el mercado canadiense (Gagnon y Pirvu, 2011) y para el mercado de Estados Unidos (Karacabeyli y Douglas, 2013) basado en los estándares norteamericanos.

Pero es en Febrero de 2016, cuando se publica la norma armonizada de madera contralaminada (UNEEN 16351, 2016), hasta entonces, las propiedades mecánicas del CLT como material, como por ejemplo las propiedades de resistencia y rigidez, estaban reguladas de una forma no del todo compatible con el material por los documentos de idoneidad técnica. Era necesaria una norma de CLT donde se regulasen los requisitos esenciales de este producto, y según Gagnon y Pirvu (2011) se puede considerar una primera versión de esta norma el documento de nacionalidad austriaca ONORM B 1995-1-1:2014 (2014)

En definitiva, en el caso de España, tanto el nuevo código técnico de la edificación, basado en un enfoque prestacional, como el desarrollo de la normativa específica de la madera y los materiales derivados de la madera, han contribuido a la innovación en productos de madera y sus derivados para la construcción. Aun así sigue quedando pendiente investigación en el ámbito de la durabilidad de la madera y los productos derivados de la madera, sobre todo en lo perteneciente a su comportamiento al exterior, factor que influye directamente en su vida útil.

Aún queda mucho por hacer para situar al CLT a un nivel similar al del acero y el hormigón, y para lograr este objetivo es necesario que toda la industria trabaje al unísono (Zumbrunnen y Fovargue, 2012). Parte de este trabajo es la armonización de los métodos de ensayo, evaluación y diseño para mantener la coherencia, lo que proporcionaría una verificación adecuada, fiable y reproducible de propiedades y características, que constituye un requisito previo para el pleno desarrollo del CLT como sistema de construcción establecido a nivel internacional (Brandner et al., 2016). También es necesaria la adaptación de los códigos técnicos de la edificación de algunos países para la construcción con CLT en altura (Schmidty Griffin, 2013). 



\section{Capítulo 3}

\section{Construcción con madera}

Para comprender la evolución de la madera como material de construcción, y la posterior aparición de los materiales de construcción derivados de la madera, es necesario hacer un breve repaso sobre la historia de la construcción con madera, y observar como la madera se ha ido adaptando a las necesidades socioeconómicas a lo largo de la historia.

Se empieza por el uso prácticamente directo del árbol, y de un uso masivo de la madera, tanto por la masividad de los productos utilizados, como por su cantidad de uso, y se tiende con la evolución a un uso menos masivo en ambos sentidos.

En este uso y evolución de la madera como material de construcción, ha tenido un gran peso la cultura y la tradición, además de la disponibilidad de la materia prima.

\subsection{Historia de la construcción con madera}

La preferencia por la madera desde los inicios de la historia de la construcción y su persistencia incluso en circunstancias adversas parecen indicar que existe una afinidad especial entre el hombre y este material, por encima de su simple disponibilidad (Carcía-Navarro y Peña, 2001a). Las propiedades y prestaciones de la madera como material, que el hombre ha utilizado desde siempre, son menos conocidas que las de otros materiales, debido a la utilización casi directa que el hombre ha hecho de ella (Guinard, 2000).

La evolución en su uso desde la cultura grecorromana, han hecho que la investigación y el paulatino desarrollo de su tecnología, con el fin de aprovechar al máximo sus propiedades, consigan que hoy día se posea un amplio conocimiento sobre este material.

La construcción en madera ha vivido hasta ahora dos grandes cimas. La primera se produjo en el imperio romano, y especialmente en las cubiertas de las basílicas paleocristianas. La segunda se produjo durante la edad media, cuando la técnica maderera en general alcanzo un elevado perfeccionamiento y desarrollo estructural, del que se vivió hasta principios del siglo XIX (García-Navarro y Peña, 2003). 
En un primer momento el desarrollo del oficio, permitió construir obras espectaculares de hasta seis y siete plantas, como el Ayuntamiento de Esslingen (Alemania, 1430), de seis alturas (García-Navarro y Peña, 2001 b) (véase figura 3.1). Posteriormente, la colonización de América, en lo que a la tecnología de la construcción se refiere, provoca la exportación de los sistemas constructivos europeos al nuevo continente, con ejemplos en el norte como los de Massachusetts (1636) o Nueva Inglaterra (edificio de la Bolsa, 1651). En el cono sur, de colonización española y portuguesa, se incorpora la arquitectura colonial propia de una cultura más mediterránea, y un uso menos masivo de la madera (García-Navarro y Peña, 2002).

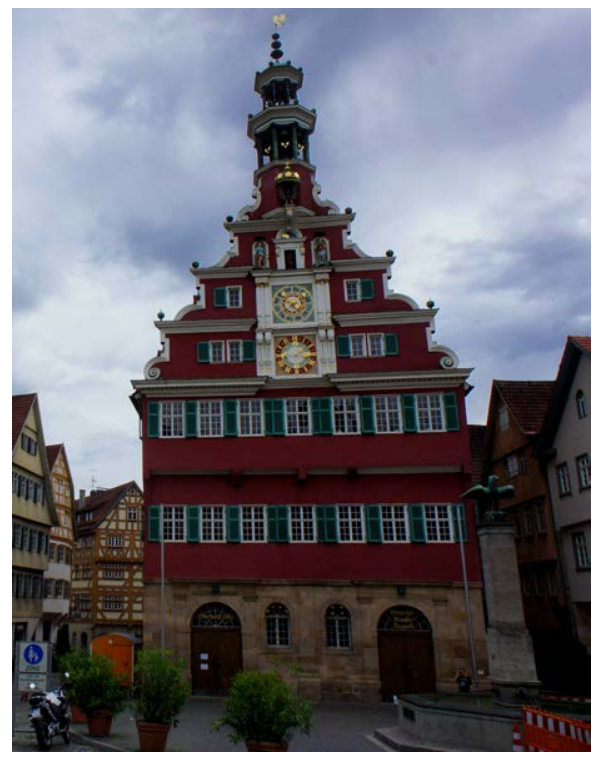

Figura 3.1: Antiguo ayuntamiento de Esslingen

Tal y como señala Graciani García (1995), los cambios en la técnica constructiva de la madera se refieren sobre todo sobre todo a los sistemas de unión de las piezas entre si y al modo de trabajarla.

\subsubsection{Construcción con madera en el mundo}

\subsubsection{Edad Antigua}

La construcción se inicia en el Neolítico con los primeros asentamientos, y es la madera acompañada de la piedra, uno de los primeros materiales que se emplea para ello. Es por tanto la madera, junto con la piedra, el material con más derecho a denominarse tradicional. Se inicia este tipo de construcción neolítica en el Cercano Oriente, y se extiende por toda Europa. A finales del Neolítico era la construcción con madera una forma dominante de construcción en toda Europa excepto en el extremo norte, el Mediterráneo occidental y la zona atlántica de Inglaterra, en estos dos últimos, era la piedra la que cobraba mayor importancia como material de construcción.

Inicialmente, los postes se clavaban en el suelo, situados a cierta distancia, y los espacios entre ellos se tejían con zarzas o se rellenaban de barro y paja. A finales del Neolítico, en la zona de Jutlandia, 
los postes se clavaban en el suelo sin ningún tipo de espacio, para conseguir más calor en el interior. Este tipo de construcción en que los elementos de madera se situaban de forma vertical se extendió de una manera lenta, no llegando a Rusia hasta 300 años antes de Cristo, y a Inglaterra hasta la época anglosajona.

La evolución de la construcción con madera, partiendo de estos métodos rudimentarios, ha llevado a la creación de diferentes técnicas, en las que la madera se ha asociado con otros materiales para conformar distintas tipologías constructivas, muchas de ellas han evolucionado junto con la tecnología del material hasta nuestros días.

Antes de abordar la exposición cultural del empleo estructural o resistente de la madera a lo largo de la Historia, conviene apuntar una serie de consideraciones según el grado de estabilidad y durabilidad de las construcciones (García-Navarro y Peña, 2001a)

\subsection{Viviendas temporales}

Se pueden distinguir viviendas con una temporalidad efímera, derivada del modo de vida de los primeros pobladores, que tenían un carácter trashumante. En esta tipología se pueden citar vestigios de viviendas datados en el 4000 a.C. en la aldea de Panpo o (China), también se encuentran ejemplos más cercanos pero muy similares a las tipologías primitivas en los skerm de los habitantes del desierto del Kalahari, en los que un entramado de ramas arrancadas de algún árbol cercano, formando un arco, soporta una cubierta vegetal sujeta por una cuerda atada perimetralmente (figura 3.2). Se pueden encontrar ejemplos similares como la cabaña de los pigmeos bambutis (Selva Ituri, África), más elaboradas por necesidad de durabilidad o por condiciones climatológicas más severas como los tupiq inuit y las tiendas cónicas de los indios de las llanuras americanas.

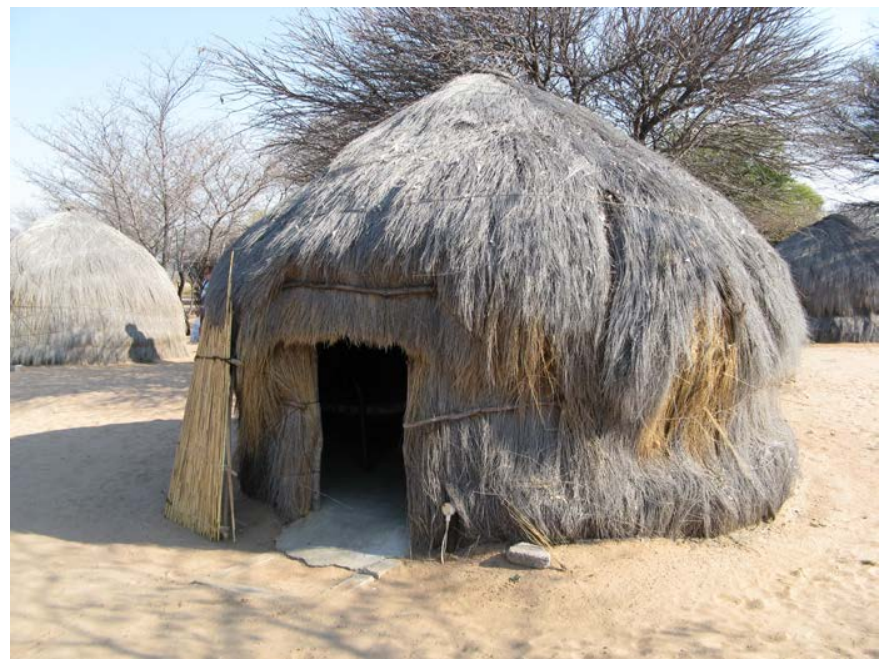

Figura 3.2: Skerm del desierto del Kalahari

Estas sencillas estructuras, con independencia de su carácter más o menos eventual, se van progresivamente complicando en función de las exigencias de sus habitantes. 


\subsection{Viviendas semipermanentes}

Las culturas más sedentarias han dado a sus construcciones un carácter más estable y han producido, por tanto, un trabajo más cuidado. Normalmente se trata de pueblos agricultores o de ganadería doméstica, mucho más vinculados al terreno. Un primer ejemplo podría ser el de las aldeas neolíticas construidas sobre palafitos, descubiertas en el lago suizo de Neuchâtel en 1885, que estaban formadas por casas de madera cuya duración limitada — de seis a doce años— provocaba su reconstrucción periódica. Las viviendas se levantaban sobre unas plataformas apoyadas sobre palos empotrados en el fondo de los lagos, ríos o pantanos donde se ubicaban.

En las viviendas babilónicas de la Baja Mesopotamia, en concreto en los restos de Katal Hüyük (Anatolia, 6000 a.C.) se han encontrado viviendas colectivas hechas con ladrillos de adobe y un ligero entramado de madera, a las que se accede desde el techo mediante una escalera también de madera, ya que una gran parte de la vida se desarrollaba en la terraza. Estos techos eran por tanto planos, construidos mediante tiras de caña recubiertas de espesas capas de fango, y se apoyaban sobre vigas de madera.

Mucho más recientes, con sistemas provenientes de la antigua civilización Anasa pero que perduran en la actualidad, los pueblos indios (Arizona y Nuevo Méjico, América del Norte) desarrollan unas construcciones en forma de graderío, caracterizadas por muros de ladrillo de adobe o piedra sobre mortero, con grandes vigas de madera de cedro de $30 \mathrm{~cm}$ de diámetro que se apoyan en los muros, y viguetas transversales muy juntas entre sí apoyadas a su vez sobre las vigas. Las vigas principales no se cortan dada su escasez y en previsión de su posterior reutilización, de forma que sobresalen por la fachada en una imagen característica de estos núcleos.

\subsection{Viviendas permanentes}

Cuando la cultura vinculada a la tierra alcanza importantes grados de desarrollo, la vivienda necesita ser mucho más duradera y prolongar su vida a varias generaciones. Se construyeya necesariamente con materiales duraderos (madera o mampostería), y cuando la zona está expuesta a cambios climáticos importantes que requieran una especial adaptación, se recurre a materiales aislantes. En esta línea se ha comprobado que incluso en el Neolítico había construcciones permanentes de troncos.

Los arquitectos fenicios eran expertos en edificación con piedra y madera, y construyeron en torno al siglo X a.C. casas más altas que las de Roma. Los escitas, según Herodoto, utilizaron troncos para la construcción de las cámaras funerarias de sus reyes, en una época coetánea, en torno al año 1000 a.C. escritores romanos como Tácito hablan ya de construcciones en Alemania con estructura de troncos cortados, de sección cuadrangular (Schoenauer, 1984).

Capítulo aparte merecen los sistemas de cimentación de estas viviendas que, precisamente por su disposición enterrada, se han conservado mejor que muchas estructuras al aire libre. Se observan tanto tipologías de apoyo superficial como de apoyo profundo. Entre las primeras, el apoyo puntual mediante postes cortos de madera encajados en el terreno fue el sistema más característico de toda la Prehistoria (desde el Paleolítico hasta la Edad de Hierro), y podía llegar a encontrarse tanto en asentamientos temporales como permanentes. También se empleaba el apoyo lineal sobre el terreno, mediante troncos acostados horizontalmente, y el apoyo profundo de los palafitos en terrenos húmedos y pantanosos. 
En definitiva, la utilización de la madera estructural era desde los orígenes del hombre un recurso generalizado, principalmente condicionado no tanto a la estabilidad del asentamiento como a la disponibilidad de este material. Estaba claramente ligada a las zonas de bosques abundantes, que permitían y potenciaban la madera como material de construcción básico.

Cuando era asequible, la cultura de su utilización y el oficio para su manipulación se desarrollaban sin más problemas.

\subsubsection{Edad Moderna}

Centrándose en la construcción de carácter permanente, y haciendo una breve reseña por la evolución de la construcción con madera, como se ha comentado, se pueden observar las influencias que la tipología de la construcción europea ha tenido en el continente americano. Se puede afirmar que ninguna tipología constructiva anterior a 1850 se originó en América, y aunque las técnicas fueron modificadas es innegable su origen europeo.

Partiendo de la base de que EEUU es un país rico en madera, en la expansión hacia el oeste de América entre 1790 y 1850 la madera, se convirtió en un material de construcción más importante aún de lo que había sido en el litoral, donde este tipo de construcción era predominante. Sin embargo, se puede observar que todos los métodos de construcción empleados tenían un significativo antecedente europeo.

En aquellos momentos de exuberancia, impulsados por un suministro interminable de madera, los métodos de construcción se reanudaron, ya que no eran más que un vestigio de los métodos tradicionales utilizados en gran parte de Europa occidental, se trataba de construir con maderas verticales u horizontales muy juntas.

A principios del período colonial con la política de ahorro de madera, era bastante común el uso del entramado de madera, que luego sería ampliamente practicado en Europa occidental, donde era bastante común.

La casa de madera se consideró durante un tiempo como una estructura temporal, algo tradicional que podía ser reemplazado cuando las circunstancias lo permitieran. Sólo en las tierras altas del Sur esta práctica de construcción fue totalmente aceptada.

Desde 1850, ha habido grandes cambios en el sector de la construcción, en los materiales y formas utilizadas para construir. Sin embargo, una encuesta de la vivienda agrícola realizada en EEUU y publicada en 1939 reveló que el $97 \%$ de las viviendas rurales de la muestra fueron construidas en madera, 1,8 \% fueron construidas de ladrillo, 0,5 \% de piedra, 0,4 \% de tierra, y el 0,4 \% restante de hormigón. Por lo tanto, fiel a la tradición, la madera era el material de construcción abrumadoramente dominante, por lo menos en el caso de las viviendas más modestas.

La América europea ha conocido tres métodos generales de construcción en madera: con paredes de entramado (una estructura de madera cuadrada que actúa como esqueleto, con madera situada horizontal, vertical y diagonalmente); con paredes de troncos verticales, y con paredes de troncos horizontales. 
En Asia se puede disfrutar de ejemplos de construcción que abarcan tres milenios de la tradicional arquitectura oriental en madera, se encuentran todo tipo de construcciones que van desde templos budistas hasta palacios, entre ellos también construcciones que figuran en la lista de la Herencia Cultural de la Humanidad.

La madera ha sido utilizada por los seres humanos durante muchos miles de años si se ha utilizado para un material de construcción o para crear un elemento útil. Entre las estructuras más antiguas están las estructuras de madera chinas que datan de hace aproximadamente 7000 años (Steinhardty Fu, 2002).

En el caso de China, modelos de templos budistas, complejos de palacios antiguos y edificios seculares típicos de diferentes regiones fueron construidos con extrema precisión por aprendices o para objetivos documentales a finales del siglo XIX y principios del siglo XX, basados en edificios reales o reconstruidos, así como en estructuras ideales de la dinastía Tang (siglos VII y X) y de la dinastía Ming (siglos XIV y XVII).

En Japón se encuentra otra larga tradición de construcción con madera, que ha perdurado en el tiempo entre otros motivos por el excelente comportamiento que tienen las construcciones con madera frente a los movimientos sísmicos.

La construcción en sus inicios ha estado muy vinculada a la cultura popular de la zona, en los países industrializados con el tiempo, el modelo constructivo se ha globalizado, aunque se muestre ligeramente influenciado por la cultura y muy influenciado por el clima.

\subsection{Construcción con entramado de madera}

El entramado en Europa tiene una tradición tan larga que se convirtió en el método dominante de construcción en los asentamientos litorales ingleses.

Es tipológicamente más avanzado que la construcción vertical de la que se deriva. Los entramados fueron construidos de maderas muy pesadas, con un factor de seguridad muy por encima de cualquier posible demanda, esta es una de las razones por la que muchas de las casas más antiguas han sobrevivido.

No fue hasta el año 1830 en que apareció el llamado balloon frame, utilizando maderas mucho más pequeñas y ligeras. El balloon frame en viviendas comenzó a ser importante sólo después de 1850; en principio era muy utlizado en graneros, y no fue hasta bien entrado el siglo XX en que su uso se extendió a todo tipo de construcciones.

La madera se utilizaba ampliamente en las colonias inglesas y holandesas, hasta el punto que era casi el único método de construcción utilizado. Excepto en las tierras altas del sury su periferia, esta estructura se transmitió hacia el oeste y se convirtió en la forma casi universal de construcción, reemplazando rápidamente la casa de troncos pionera. Fueron cambios muy significativos, se pasó de una construcción pesada a un entramado de madera (ballom frame) con un simple revestimiento.

El entramado de madera consistía en una pesada estructura de madera cuadrada con relleno de paja, entre otros, de esta forma estaba construido la mayoría del patrimonio cultural que dejaron los europeos en Estados Unidos en el momento de la Revolución. El relleno (denominado nogging) era a veces 
de ladrillo (figura 3.3(a)), a veces de barro que se adhería a la estructura, y se colocaba vertical u horizontalmente entre la estructura de madera (figura 3.3(b)). En ocasiones, el relleno era de piedra, de zarza o de listones unidos. Esta construcción con la estructura de madera en forma de esqueleto de la construcción acabó con la necesidad de utilizar una gran cantidad de madera, y es probablemente la razón por la que ha tenido una amplia utilización en Europa.

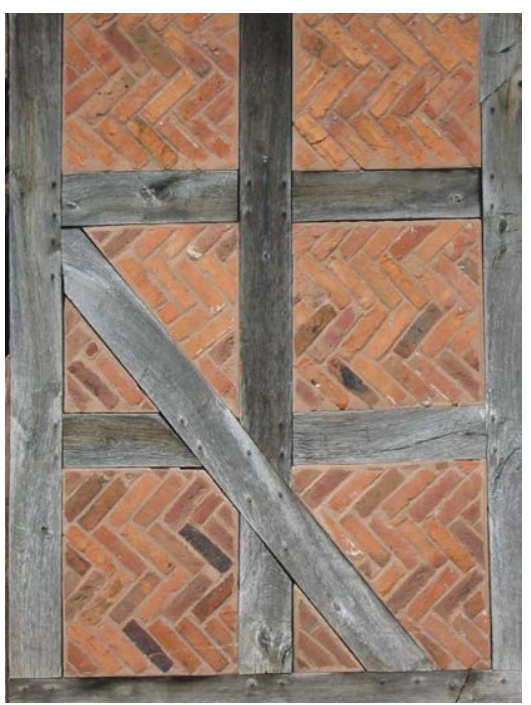

(a) nogging de ladrillo

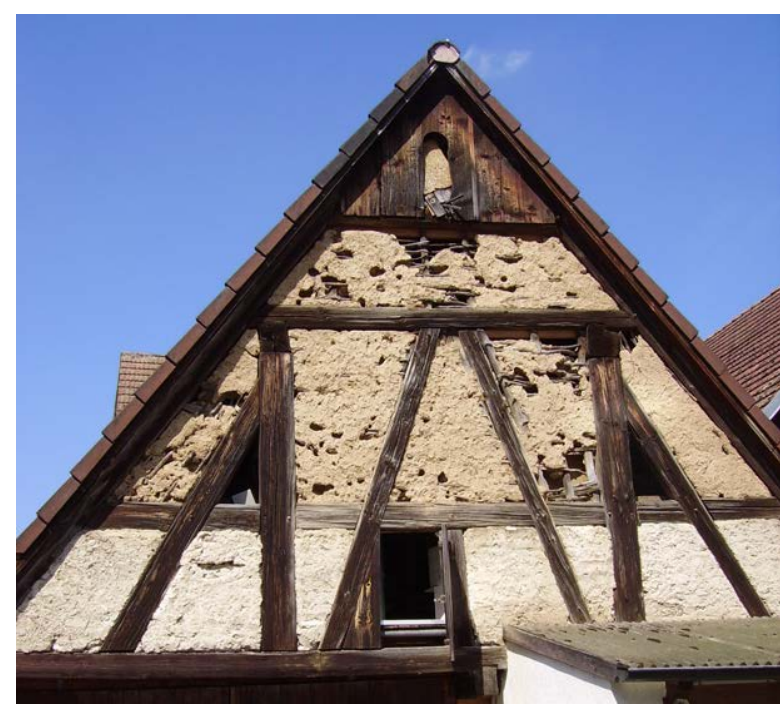

(b) nogging de barro

Figura 3.3: Entramado de madera con relleno o nogging de ladrillo o barro

El entramado de madera era común en los primeros asentamientos litorales, y la madera utilizada en este tipo de construcciones solía ser de mala calidad, por ello con frecuencia fueron cubiertas, al igual que ocurrió con el antiguo techo de paja mundialmente utilizado, que dio paso a las tejas de madera. Finalmente se suspendió el uso de nogging (pero no, como a veces se ha sugerido, exclusivamente debido al bajo contenido de cal de arcillas de América).

Aunque los ejemplos sobrevivientes de entramado de madera son bastante comunes en los estados orientales, no se llevó hacia el oeste en gran medida. Sin embargo, inmigrantes alemanes del siglo XIX introdujeron el entramado de madera en zonas como Ohio, Wisconsin, Missouri, y Tejas, donde se ha mantenido esta práctica casi hasta el presente.

\subsection{Sistemas constructivos de madera}

Como se ha comentado anteriormente, la construcción con madera ha evolucionado mucho desde sus orígenes, tanto desde el punto de vista de la tipología constructiva, como desde el del desarrollo de la tecnología del material.

Uno de los sistemas constructivos más antiguos es el del Kiwari japonés, cuyo primer manual de carpintería conocido data del año 1608 (Shomei). De gran influencia en la arquitectura moderna por su 
rigurosa composición geométrica, el Kiwari basa su modelación en el Ken, la dimensión estándar entre columnas que equivale a 6-6,5 Sakhu o pies (unos 183-198 cm) que luego de divide en módulos menores. Este sistema se extendió rápidamente por todo el país, implicando un cierto grado de prefabricación en la vivienda que a mediados del siglo XVIII ya alcanzaba a buena parte de la estructura de madera y a las carpinterías. Si bien es cierto que la regularidad de las medidas y la repetición de los componentes permitían optimizar el uso de los materiales, el Kiwari no puede ser considerado un sistema prefabricado ya que muchas de las partes de la vivienda se realizaban in situ y además cada proyecto básico de los manuales de carpintería debía ser adaptado a las preferencias de los clientes por lo que la repetición y la estandarización no eran muy frecuentes. Desde el punto de vista del clima y la eficiencia energética, el kiwari presenta una adaptación curiosa. Los muros exteriores removibles y los interiores correderos permitían una sobre ventilación cruzada, muy útil en verano, aunque no en invierno (Wadel, 2009).

Al ser la madera un recurso natural renovable, ha sido explotada en la mayor parte de los países y usada extensivamente en forma industrializada para la construcción de viviendas. Ha sido un material importante para la construcción de edificios a través de la historia de todas las regiones del mundo. En los Estados Unidos y Canadá donde la construcción de viviendas tiene el mismo grado de industrialización que la industria automovilística, la producción de viviendas unifamiliares de madera constituye el $90 \%$ del total edificado.

Los países industrializados (EEUU, Canadá, Inglaterra, Alemania y Francia, entre otros), han utilizado desde hace muchos años la madera como material de construcción, bien sea sola o en combinación con otros materiales. Sin embargo, en Venezuela, país con amplios recursos forestales, los sistemas constructivos que se han empleado tradicionalmente para la construcción de los programas habitacionales se han fundamentado principalmente en el uso de materiales de construcción como el hormigón y el acero, entre otros.

Sin embargo, se puede ver el trabajo realizado por Barrios et al. (2011) en el que se realiza el diseño estructural y la evaluación económica de un sistema constructivo modular en madera, capaz de ser industrializado para viviendas prefabricadas, lo que permite una solución rentable al problema habitacional como respuesta a la necesidad de tener acceso a una vivienda digna y confortable, pues los procesos y fabricación en volúmenes, abaratan sustancialmente los costos de manufactura. Demostrando de esta forma que la construcción en madera es más económica que la construcción tradicional.

Este sistema constructivo ideado por un grupo de investigación de la Universidad Central de Venezuela demuestra que la madera es una alternativa más que posible en términos técnicos frente a las construcciones de acero y hormigón, y potencialmente mejor en el plano medioambiental.

Los sistemas constructivos han ido desarrollándose con el avance de la tecnología de la madera y de la industria, que ha dado lugar a nuevos productos capaces de solventar las necesidades de los usuarios, y con un alto nivel de industrialización, que hace a estos productos idóneos para la prefabricación.

Uno de los productos más novedosos, aunque lleva prácticamente 30 años en el mercado, es la madera contralaminada, un producto altamente industrializado, perfecto para la prefabricación, y que permite el desarrollo de sistemas constructivos basados en él, debido a su gran versatilidad de fabricación. 


\subsubsection{Construcción con madera en Europa}

En efecto, como hemos comentado la construcción de poste vertical parece haberse originado en el Cercano Oriente en el Neolítico, y posteriormente se extendió por toda Europa, excepto en el extremo norte, el Mediterráneo occidental, y la zona atlántica de Inglaterra.

La construcción con entramado de madera se practica en Cran Bretaña, Francia y Alemania, y hacia el norte en el sur de Suecia, como áreas más representativas de construcción con madera.

La construcción con madera en Europa ha evolucionado siempre tendiendo a un uso menos masivo del material, es decir a tratar de optimizar el uso de la madera. Desde las primeras construcciones de troncos más masivas y rudimentarias a las construcciones de entramado ligero, en las que la cantidad de madera es menor. Todas las tipologías constructivas utilizadas en Europa fueron exportadas al continente americano, y aunque se puede ver su influencia, tuvieron evoluciones diferentes.

Se puede observar en la actualidad que en el uso de la madera en construcción hay una clara diferencia entre los países del Norte y del Sur de Europa. Aunque en los inicios toda construcción tenía madera, la aparición del acero y el hormigón, hicieron que la cultura de construcción con madera se conservara de diferente forma en los países europeos.

Como norma general, la construcción con madera se ha conservado más en climas fríos (países del Norte de Europa), que en climas cálidos (países Mediterráneos), entre otras cosas por las propiedades aislantes de la madera, y por la mayor degradación que sufre la madera en climas cálidos.

La tendencia a la optimización en el uso de la madera, y el poder dar un valor añadido a las maderas de pequeñas dimensiones, han generado una investigación muy amplia en este campo, que ha dado lugar al desarrollo de nuevos productos de construcción, queal igual que pasó antaño con las tipologías constructivas, han sido exportadas al continente americano.

Productos como el CLT están devolviendo a la madera a la escena constructiva como producto de construcción, no solo por las posibilidades de un material que aporta la misma resistencia que el acero en relación a su peso, sino con una carga medioambiental muy pequeña con la que no puede competir ningún otro material de construcción.

Un indicador sobre este desarrollo en los productos de construcción son los denominados "productos de construcción innovadores", que son aquellos productos que obtienen el marcado CE mediante los documentos de idoneidad técnica (DITE), que con la implantación del nuevo reglamento pasan a ser documentos de evaluación europeos (DEE). Aunque con el nuevo reglamento se deja de distinguir entre productos innovadores y tradicionales, no cabe duda de la innovación que existe en los productos de madera para la construcción que han obtenido un DITE (Oteiza et al., 2013).

El incremento de productos innovadores en madera con DITE creció en Europa de manera continuada de 2007 a 2011. En el año 2012 la disminución fue considerable, lo que puede estar ligado a la crisis del sector de la construcción en Europa.

Dentro de Europa, Alemania es el país con mayor número de productos innovadores en base madera en cuanto a DITE, y España se encuentra en el cuarto lugar en cuanto a productos innovadores de madera, dato curioso teniendo en cuenta la baja influencia de la construcción con madera en España. 


\subsubsection{Construcción con madera en España}

Como se ha comentado la madera en la construcción, ha formado parte total o parcialmente en edificaciones desde que el hombre se perfeccionó en el manejo de las herramientas. En aquellos lugares donde los refugios o abrigos naturales no le proporcionaban la seguridad suficiente, el hombre comienza a fabricar sus casas utilizando materiales como piedra y madera (García, 1999).

La construcción con madera ha tenido una gran evolución desde el tratado más antiguo sobre construcción que ha llegado hasta nosotros, datado en el siglo I a.C. y obra del arquitecto e ingeniero romano Marco Vitruvio, titulado De architectura. En él se recogen las primeras descripciones sobre la composición, cualidades y usos de la madera, mostrando un especial interés sobre la influencia de la época de corta y su influencia en las características de la madera frente a agentes xilófagos.

En España, debido a las diferentes invasiones sufridas, se cuenta con una gran diversidad cultural en todos los ámbitos, entre ellos la construcción. Se pueden encontrar ejemplos de construcción de casi todas las culturas que han pasado por España, y todas han usado la madera como material de construcción.

España cuenta con un gran patrimonio histórico, con grandes obras como el Monasterio del Escorial. Hay que tener en cuenta que toda construcción anterior a 1900 en España incorpora madera en su sistema constructivo de una u otra forma. Dentro de este patrimonio, nos encontramos con palacios, monasterios, catedrales, y un sinfín de tipologías constructivas.

De entre las tipologías constructivas en España, se podría destacar el caserío, que es el tipo de casa tradicional de los labradores del País Vasco. Los ejemplares conservados de mayor antigüedad datan de los últimos años del siglo XV y todavía siguen en pie más de un millar de edificios construidos en el periodo que discurre entre esa fecha y mediados del siglo XVI. Junto a este tipo de construcciones encontramos a los hórreos, que son graneros suspendidos de madera, para preservar el trigo de la humedad y los roedores, y que encontramos también en otros lugares de la geografía norte española.

Pero si hay un forma de construir a destacar en sería la carpintería de lacería española. Los carpinteros medievales que trabajaron en los reinos de Castilla y León, convivieron con un mundo musulmán en cuyas decoraciones proliferaban esquemas geométricos muy sofisticados. La especial habilidad de estos carpinteros en el arte de construir armaduras, y su gran dominio de la técnica carpintera les permitieron adaptar nuevos esquemas geométricos orientales a las estructuras que realizaban especialmente en pisos y en armaduras de cubiertas, logrando unas soluciones sin igual en el resto de carpinterías europeas.

Esta técnica que perduró durante siglos por casi todo nuestro territorio y arraigó firmemente en las Islas Canarias, e incluso llegó con fuerza al continente americano poco después del descubrimiento, se le atribuye generalmente un origen islámico, aunque parece más probable que la técnica sea de origen visigodo (Nuere Matauco, 1998).

Desde la antigüedad y hasta la aparición del acero y el hormigón armado, la madera ha sido el material de construcción más usado en España. Con la aparición del acero, y el hormigón armado y pretensado, se tiende a sustituir a la madera en sus aplicaciones estructurales con ventajas económicas y 
constructivas, hasta tal punto, que en muchos países como España, se prohíbe el empleo de elementos estructurales de madera en las viviendas acogidas a planes nacionales (Cassinello, 1973).

Eso fue un hecho hasta la década de los 80, como ejemplo se pueden citar las I Jornadas Nacionales de la Madera en la Construcción, en las que al referirse a la normativa existente con respecto a la madera en construcción se expone que puede resumirse en dos palabras "NO HAY". A consecuencia de la falta de conocimiento sobre el material existente entre los prescriptores, que dio lugar a una mala praxis en reformas de edificios con estructura de madera, se puede entender el desuso que el material ha sufrido en los últimos tiempos. Esta situación relegó a la madera a ámbitos secundarios dentro de la construcción, como elementos dispares, o de revestimiento y acabado.

Uno de los aspectos a los que la Administración presta atención preferente dentro del ámbito legislativo de la construcción es la seguridad, lo que ha restringido mucho el uso de la madera por su cualidad de material combustible, a pesar de ser resistente al fuego. Esto unido a la expuesta falta de normativa hizo que la madera fuera desapareciendo de la escena constructiva.

La madera ha sido la gran olvidada del siglo XX, hacia los 80 se volvió la vista a la madera, pero sigue habiendo recelos a su uso (Nuere Matauco, 2017).

La madera es un producto natural susceptible de industrialización, lo que permite establecer estándares de producción y clasificación, dando lugar a productos con unas especificaciones y controles muy rigurosos. Esto ha permitido un desarrollo de productos técnicos orientados al sector de la construcción, compitiendo en igualdad de condiciones con otros materiales y tecnologías.

En países como España, donde la construcción con madera ha sufrido un progresivo abandono, es difícil llegar a una cultura de construcción en madera, rompiendo con los tabúes existentes. Es una tarea mucho más lenta y difícil de lo que en principio puede parecer, pero teniendo en cuenta las credenciales técnicas y medioambientales que presenta este material hoy en día, merece la pena intentarlo.

\subsection{Construcción con CLT}

Como se ha comentado la construcción en madera ha vivido hasta ahora dos grandes cimas. La primera se produjo en el imperio romano, la segunda se produjo durante la edad media y llegó hasta el siglo XIX, y tras su abandono en muchos países, como puede ser el caso de España, parece que según el escenario actual, la era contemporánea puede ser la tercera cima de la madera como material de construcción.

En esta ocasión la madera vuelve a la escena constructiva con los deberes hechos, ya que se presenta como un material altamente industrializado y totalmente normalizado, con unas características técnicas bien definidas que lo hacen un material con grandes prestaciones, y con la ventaja entre otras de su comportamiento medioambiental, tanto en su fase de desarrollo como sumidero de carbono, como durante su vida útil como almacén del mismo.

De entre todos los materiales de construcción derivados de la madera, actualmente, y tras años de introducción en el mercado se está viendo la implantación por peso propio de la madera contralaminada, uno de los antiguamente llamados productos innovadores por la directiva de productos de la 
construcción, y que hoy día está plenamente integrado en muchos países de Europa y con expansión en otros continentes como América u Oceanía.

\subsubsection{Posibilidades del CLT}

EL CLT se ha convertido en un producto de interés mundial, que actualmente se está fabricando fuera de Europa. Ha habido numerosas actividades globales de investigación en materia de desarrollo, producción, uso y normalización, en países como Canadá, Estados Unidos, Australia, Japón, China y Nueva Zelanda (Brandner et al., 2016)

La principal barrera a cualquier nuevo movimiento, como puede ser la introducción del CLT como material de construcción, es el conocimiento, y parece que a pesar de haber una conciencia adecuada sobre el CLT, hay una falta de conocimiento generalizada sobre sus atributos y capacidades. Tras varios estudios sobre la introducción del CLT en diferentes mercados, se observa que una vez que el público objetivo conoce las capacidades del CLT se siente seguro para usarlo como alternativa viable frente al hormigón postensado en viviendas multifamiliares, incluso en la construcción de rascacielos (Laguarda Mallo y Espinoza, 2015).

Un caso a resaltar es el de Reino Unido, donde el primer proyecto que utilizó CLT lo hizo como elementos de cubierta como parte de un edificio de construcción convencional. El éxito del CLT es no sólo el éxito de un producto, ha sido también muy importante para la industria de la madera en su conjunto, convirtiéndose en una verdadera alternativa al hormigón y al acero. Se puede decir que el Reino Unido es en la actualidad un mercado clave para el CLT, al convertirse en un sistema de construcción reconocido. Este éxito se puede ver en los diferentes proyectos que se han construido en los últimos años (Zumbrunnen y Fovargue, 2012).

El edificio Stadthaus tuvo un gran impacto en todo el mundo, pero también tuvo un gran impacto a nivel local. Este edificio ubicado en Hackney, un municipio de Londres de 250.000 habitantes situado al norte de la ciudad, y construido en 2009, ha sido el precursor de múltiples obras con distintos usos, construidas con CLT en este mismo municipio, lo que ha llevado a que ya en 2015 se contaran con 13 edificios construidos en CLT y 5 en construcción (véase figura 3.4).

El proceso de introducción de un producto, es un proceso complejo, largo y con muchos condicionantes. Como ejemplos se puede citar el caso de Suecia, que a pesar de ser un país con amplia tradición en gestión de bosques y construcción con madera, está teniendo una lenta introducción del CLT, en este caso, los reglamentos contra incendios se cambiaron en base al comportamiento del material en el año 1994, lo que permitió la utilización de materiales combustibles, incluidos la madera, en estructuras con más de dos pisos (Falk, 2013). A pesar de esto el CLT se presenta como un material de construcción alternativo para construcciones de media altura en Suecia (Hameury, 2005).

Sin embargo, se encuentran con casos como el de Australia, donde sin una amplia tradición maderera, y donde pese a unas demandas del cliente, unas condiciones climáticas, un desarrollo industrial, y unos sistemas de producción previos radicalmente diferentes de los que se pueden encontrar en Europa central, el CLT ha tenido una gran acogida (Falk, 2013). Aunque se encuentran barreras en relación al contexto económico y cultural del tipo de construcción y de mantenimiento (Bylund, 2012). 


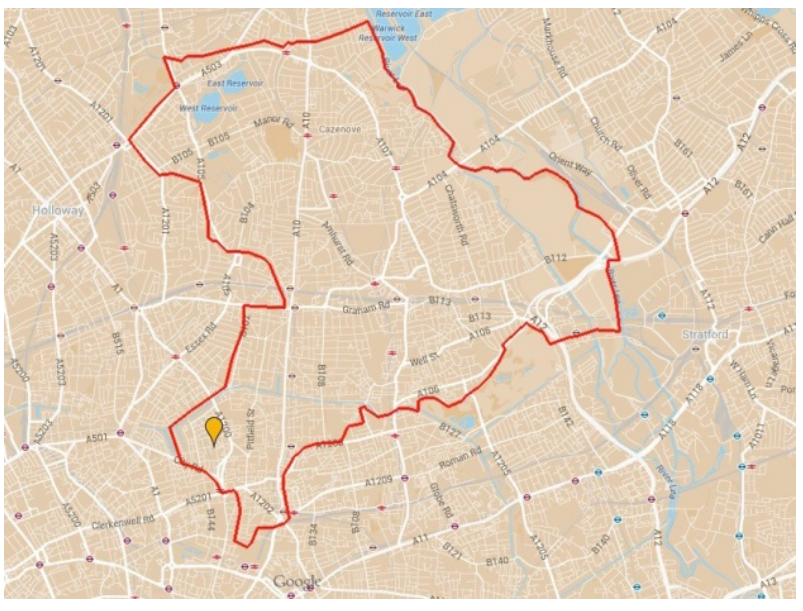

(a) 2009

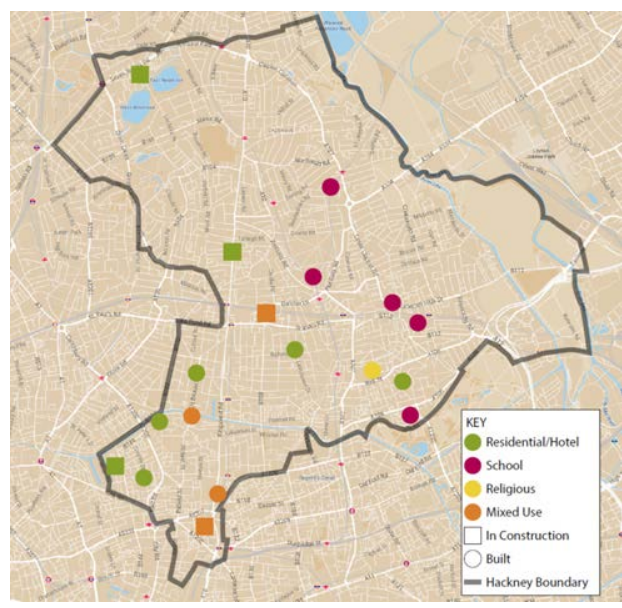

(b) 2015

Figura 3.4: Ejemplo de la evolución de la construcción con CLT en Hackney (norte de Londres). Imagen cedida por Waugh Thistleton Architects Ltd.

En Australia Occidental la tecnología de la construcción que prevalece para edificios residenciales se basa principalmente en el concepto de una doble pared de ladrillo, que se ha convertido en una tradición arraigada, lo que dificulta la competitividad del CLT, al igual que ocurre en Dinamarca, donde los esfuerzos hasta ahora para la introducción del CLT y sus productos han dejado aún pocos ejemplos en el entorno construido (Falk, 2013).

En EE.UU las barreras percibidas para la adopción del CLT como material de construcción son su disponibilidad en el mercado, cuestiones de costes y compatibilidad con el código de construcción (Laguarda Mallo y Espinoza, 2015). A pesar de esto el CLT tiene un mercado potencial en América del Norte para la construcción de altura media o incluso estructuras más altas debido a su buen rendimiento de seguridad estructural y el fuego, la capacidad de almacenamiento de carbono, peso ligero, y la naturaleza prefabricada (Gagnon y Pirvu, 2011; Karacabeyli y Douglas, 2013).

Como se ha comentado los elementos que juegan un papel importante en la adopción de un nuevo producto como el conocimiento, las percepciones y la voluntad de adoptar el nuevo sistema de construcción, son áreas que han recibido poca consideración. Teniendo en cuenta los casos y estudios citados anteriormente, se prevé que el éxito de la construcción basada en madera contralaminada en los Estados Unidos dependerá en gran parte de la información sobre los beneficios del material de llegar al público objetivo, en este caso, la comunidad arquitectónica (Laguarda Mallo y Espinoza, 2015).

El caso de Nueva Zelanda, que se encuentra en una zona de terremotos, da al CLT una buena posibilidad para su introducción en el mercado. Ya que el CLT ha demostrado ampliamente su comportamiento frente al sismo (Ellis y Bougard, 2001; Reynolds et al., 2015), tanto desde el punto de vista de la construcción, como de sus componentes, ya sea con ensayos directos o con diferentes tipos de modelización (Lindt et al., 2011; Folz y Filiatrault, 2001; Filiatrault et al., 2009; Judd y Fonseca, 2005; Tomasi et al., 2015; He et al., 2001; Casagrande et al., 2016) 
El comportamiento de CLT en un terremoto es excepcionaly se ha demostrado con la reconstrucción de L'Aquila, en Italia, su comportamiento sísmico ha sido rigurosamente probado en diferentes proyectos de investigación y trae oportunidades únicas para la construcción en zonas de terremotos en todo el mundo. El mercado de Nueva Zelanda tiene una apariencia similar al de Australia, y el mayor potencial se centra en el sector de mediana altura, donde los principales competidores son el acero y el hormigón (Zumbrunnen y Fovargue, 2012).

Tanto en el mercado australiano como en el neozelandés el trabajo realizado ayudará a fomentar en mercado del CLT, pero tarde o temprano será importante conseguir producción local, en lugar de depender de los paneles importados. Las últimas investigaciones confirman la idoneidad de las especies de coníferas nativas de Australia la producción de CLT, y en Nueva Zelanda en la actualidad, ya existe una planta de fabricación CLT cerca de Nelson (Zumbrunnen y Fovargue, 2012).

Con todo lo expuesto se pueden ver las inmensas posibilidades que tiene el CLT como material de construcción, siempre y cuando puedan vencerse las barreras normativas, hecho que parece que tiene una solución sencilla en comparación con la mayor barrera, el conocimiento del material por parte de prescriptores y usuarios.

\subsubsection{Proceso de construcción y montaje}

Una de las grandes ventajas que presenta el CLT como material de construcción es la simplicidad de instalación, que se rige principalmente por las conexiones utilizadas durante la construcción. Los paneles se ensamblan utilizando sistemas de sujeción mecánica, tales como tornillos autoperforantes roscados (Evans, 2013).

Otra de las características más atractivas del CLT como un sistema de construcción se refiere a la velocidad en que los edificios CLT se pueden erigir, en gran parte debido a su naturaleza prefabricada. Esto permite una alta precisión (las aberturas en los paneles se llevan a cabo mediante máquinas de control numérico), una terminación más rápida, una mayor seguridad, menos interrupciones en el entorno, y menos generación de residuos en obra (Evans, 2013; Karacabeyli y Douglas, 2013).

En la figura 3.5 se observan el CLT como producto y varios ejemplos de aplicación.
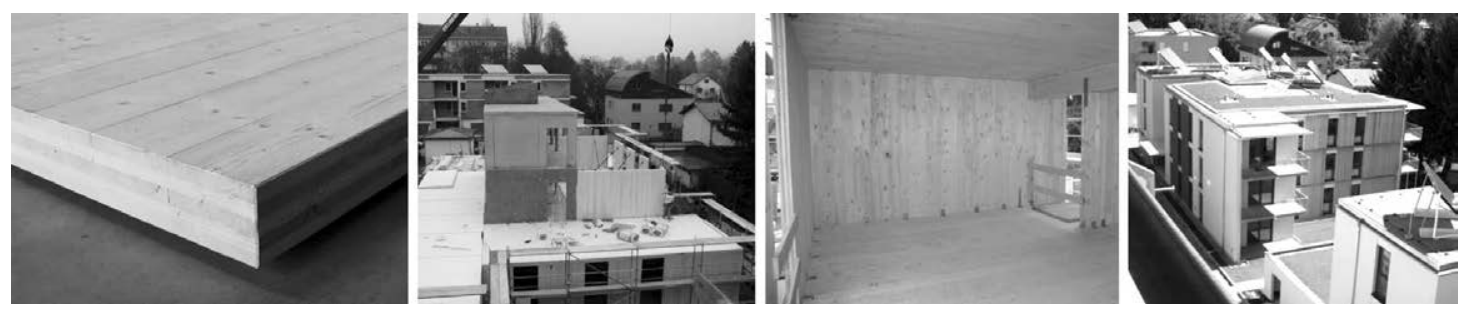

Figura 3.5: (izquierda) Panel de CLT de 5 capas; (del medio a la derecha) Imágenes del proyecto Wittenbauerstraße/Craz/Austria: dos edificios residenciales de tres plantas (Brandner et al., 2016)

En la figura 3.6 podemos ver diferentes conformaciones del producto, ya que, otra de las ventajas que presenta el CLT es que se puede fabricar prácticamente a medida, no solo con respecto a las dimensiones, si no, y más importante aún, con respecto a las solicitaciones estructurales, favoreciendo así 
las propiedades del panel en el sentido que se necesite. También se pueden observar en la figura 3.6 diferentes combinaciones de CLT con otros productos estructurales.

MINIMUM walls, secondary constructions

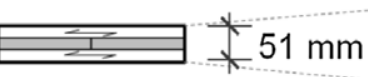

e.g. $17|17| 17 \mathrm{~mm}$ 3 layers
STANDARD walls, floors (span $\leq 5.5 \mathrm{~m}$ )
MAXIMUM floors, bridge decks

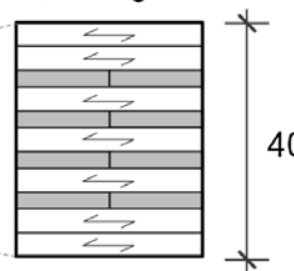

$400 \mathrm{~mm}$

e.g. $2 \times 40|30| 40|30| 40 \mid \ldots \mathrm{mm}$ 11 layers

CLT | GLT rib floor

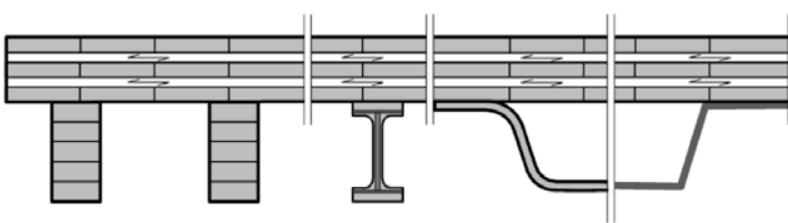
CLT | GLT/CLT box girder

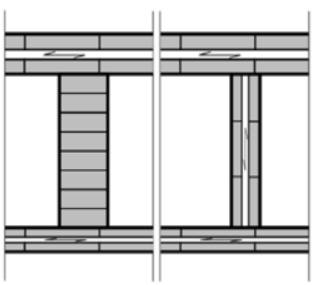

CLT | concrete comp. floor

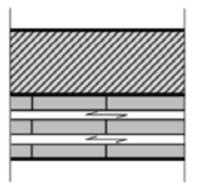

Figura 3.6: (arriba) Ejemplos de composición de capas para fines determinados; (Parte inferior) Ejemplos de estructuras de materiales compuestos de CLT y madera laminada encolada (CLT), de ultra alto rendimiento de madera contrachapada (UHPP), acero u hormigón; adaptado de Schickhofer (2015)

\subsubsection{Ejemplos de construcción con CLT}

En la última década, la construcción en madera ha alcanzado un consenso cada vez mayor dentro del panorama del mercado de la construcción, tratando de forma competitiva con otros materiales de construcción, tales como hormigón y acero, incluso en el caso de proyectos a gran escala. (Timmer, 2011; Abrahamsen y Malo, 2014). Esto es debido por una parte a rasgos intrínsecos de la madera, tales como su bajo peso y su fabricación sencilla, que la hacen adecuada para la realización de componentes prefabricados para la construcción (Smith, 2014).

El CLT se utiliza cada vez más para muros y forjados en edificios residenciales y como planchas de pavimento en construcciones de puentes (Pohlmann y Mohr, 1999; Schickhofery Hasewend, 2000; Schickhofer, 2002; Schickhofer y Bernasconi, 2002; Gülzow et al., 2007).

Los recientes desarrollos en el campo de la tecnología de los productos de madera han planteado nuevas ideas y posibilidades para el diseño de edificios en altura que utilizan la madera como principal material de construcción (Timmer, 2011; Abrahamsen y Malo, 2014). Consiguiendo así que produzca 
un cambio en la mayor parte del uso de la madera estructural en Europa en el último siglo, pasando de la construcción de casas de una y dos plantas a la construcción en altura con madera.

Estudios exhaustivos sobre este tema muestran cómo la construcción de edificios en altura con madera hoy en día no sólo es posible, gracias a sus excelentes propiedades mecánicas y comportamientos estructurales de sus nuevos productos, sino también segura, eficiente, económica y ambientalmente sostenible (Chapman et al., 2012; Chapman, 2012; Fleming et al., 2014; Chapman, 2014).

En principio cuando la madera se va a utilizar en edificios altos, es probable que se utilice en combinación con otros materiales, tales como acero u hormigón (Reynolds et al., 2016), y aunque es una alternativa viable y muy interesante, no es necesaria, ya que hay diversos estudios que demuestran que, con materiales como el CLT, se pueden construir edificios utilizando únicamente madera como material estructural de hasta 20 pisos (Chapman, 2014), e incluso de 30 cumpliendo con el Eurocódigo (Chapman et al., 2012; Chapman, 2012).

Desde un punto de vista arquitectónico hay que tener en cuenta que, aparte de los beneficios medioambientales mencionados anteriormente, y económicos referidos a la ejecución de la obra, la construcción con madera destaca por la versatilidad de diseño que permite como material, y que en ciertos

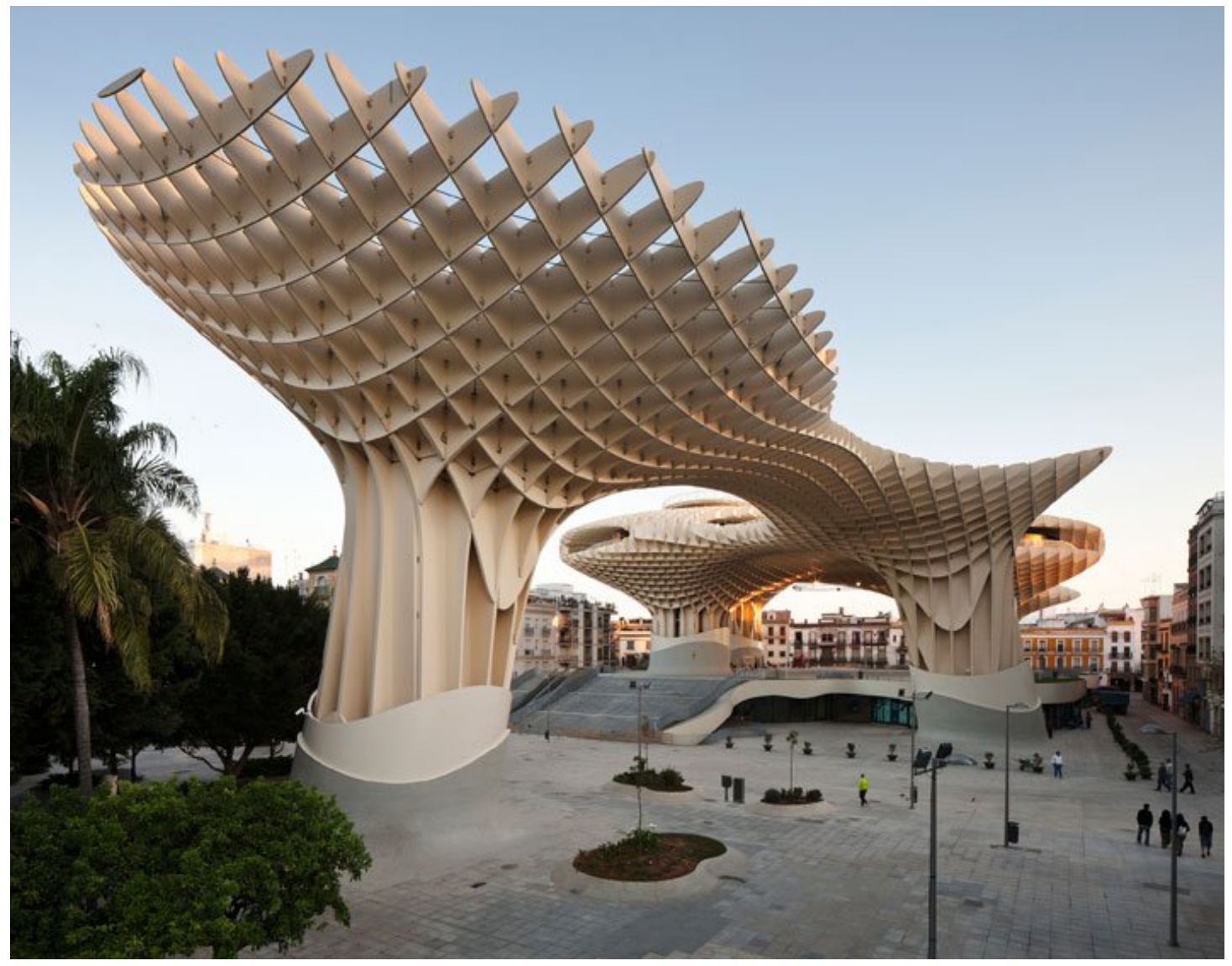

Figura 3.7: Metropol parasol, “las Setas", Sevilla (]ürgen Mayer, 2011) 
proyectos la hace destacar como material de construcción frente a los tradicionales. Como ejemplo se puede ver el Metropol Parasol (Sevilla), la estructura más grande del mundo en madera, proyectada en principio en hormigón, y que termino construyéndose en madera porque no era técnicamente posible llevarla a cabo en hormigón (figura 3.7).

Un ejemplo de la calidad de las construcciones con CLT se puede ver en el edificio de 5 plantas de la calle Waterson (London, UK), que fue en 2005 la estructura más alta del mundo completamente construida en CLT, y el primer edificio de CLT que entró en la categoría 2B, una de las categoría más exigentes ante el riesgo frente al colapso desproporcionado, tras la clasificación de los edificios en la norma BS EN 1991-1-7 (Zumbrunnen y Fovargue, 2012).

El aumento de las preocupaciones del cambio climático y las emisiones de dióxido de carbono asociadas con la construcción hacen que exista un interés mundial en edificios de varios pisos de madera, debido a las ventajas medioambientales de la construcción en madera, en comparación con los edificios de hormigón y acero, gracias al secuestro de $\mathrm{CO}_{2}$ que se produce en los árboles (Chapman, 2014; Chapman, 2012; Chapman et al., 2012; Fleming et al., 2014).

Arquitectos, ingenieros e investigadores por igual a menudo citan razones prácticas para la construcción con madera, ya que permite diseñar y construir con una velocidad y escala sin precedentes (Fleming et al., 2014), siendo esta una de las cualidades más apreciadas en la construcción con CLT (Gardino, 2011; Lehmann, 2012). Esto, por ejemplo, ha sido el caso en dos edificios muy conocidos en el campo de la construcción en madera (figura 3.8): la Stadthaus (9 pisos) en Londres (2009) (Lehmann, 2012) y el edificio Forté (10 pisos) en Melbourne (2012) (Waugh et al., 2010), este último demostró los beneficios del proceso constructivo con CLT, lo que hizo que fuera propuesto como material para la realización de viviendas sociales (Hough et al., 2012). Para ambos proyectos, la tecnología de la madera contralaminada se prefirió frente al hormigón, de acuerdo con una evaluación preliminar del desarrollo del proyecto que puso de relieve las ventajas del sistema CLT en términos de aspectos ambientales (reducción de emisiones de $\mathrm{CO}_{2}$ equivalente) y ahorro de tiempo de construcción (Gasparri

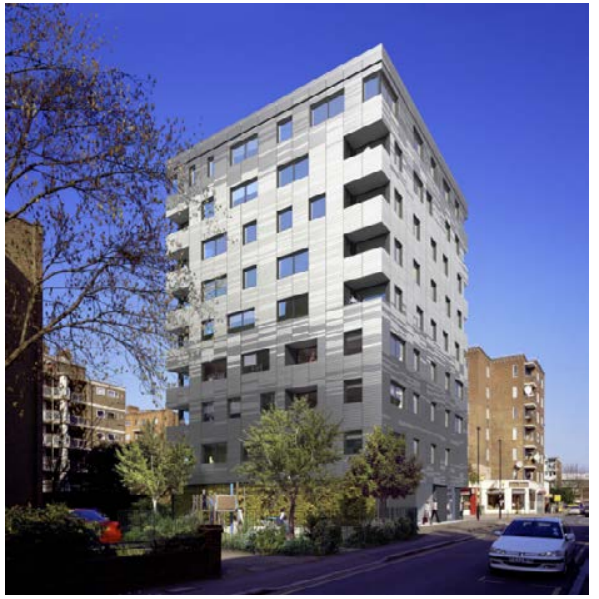

(a) Edificio Stadthaus, Londres (2009)

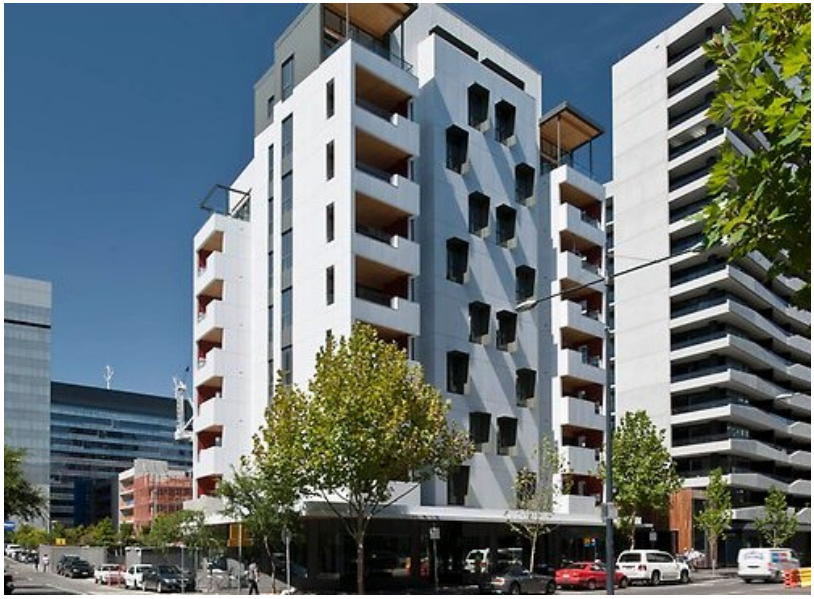

(b) Edificio Forté, Melbourne (2012)

Figura 3.8: Dos destacados edificios construidos con CLT 
et al., 2015).

Estudios previos (Gasparri et al., 2015) prueban que la prefabricación de elementos en el caso del CLT, permite una reducción significativa de los costes, eso sin tener en cuenta los costes de andamiaje. Esto si se centra en los costes directos, es decir, derivados de ahorro de recursos en términos de material, mano de obra y herramientas, si además, consideramos los ahorros indirectos derivados de organización mejor emplazamiento de la obra y otros aspectos relacionados ciertamente reducir aún más los costes totales (Gasparri et al., 2015). Este ahorro en términos de tiempo y costes, mejora de forma general la calidad del proceso de construcción.

Pero arquitectos e ingenieros necesitan ir más allá de la idea del secuestro de carbono en la construcción con madera con respecto a la construcción con acero y hormigón (Fleming et al., 2014). El CLT se ha extendido recientemente en los mercados internacionales de todo el mundo, debido al potencial que ofrece desde muy diferentes puntos de vista, no solo el ambiental, aspectos tales como su comportamiento estructural, sísmico, y la ya mencionada velocidad de ejecución que aporta al proceso constructivo (Zumbrunnen y Fovargue, 2012; Laguarda Mallo y Espinoza, 2015).

A pesar de todo el trabajo que se ha hecho para la promoción del CLT como material de construcción, y de todo el trabajo de normalización del producto, hoy día sigue siendo necesaria la difusión de sus propiedades y utilidades, ya que como se ha mencionado, existe mucho desconocimiento aun entre prescriptores y usuarios.

Los diseñadores interesados en el uso de la madera en edificios de mediana y gran altura se encuentran a menudo con escepticismo sobre la resistencia al fuego y otras cuestiones técnicas. El Murray Grove Stadthaus, seleccionado para la adjudicación del RIBA President's Award for Research en 2010, fue uno de los proyectos del Reino Unido pioneros para mostrar cómo masiva madera estructural es técnica y económicamente competitiva con el acero y el hormigón (Fleming et al., 2014).

Como regla general, se puede afirmar que el esfuerzo de diseño necesario desde el comienzo de fabricación del producto o componente y la concepción del edificio es mayor cuando aumenta el nivel de prefabricación (Sarja, 2003; Lessing, 2006; Smith, 2015). Pero este esfuerzo en la fase de diseño redunda en una mayor calidad del edificio, y un mayor control durante la ejecución. Cabe comentar con respecto a la construcción con CLT, que su desmonte y demolición al final del ciclo de vida es también es un valor añadido del producto (]ensen, 2013).

Por todas estas cualidades, en el norte de Europa el CLT se presenta como un producto de construcción consolidado en el mercado. En los últimos tiempos, se puede notar incluso un cierto auge del producto en España, con múltiples ejemplos tanto en rehabilitación como en obra nueva. Entre las obras Ilevadas a cabo con CLT en rehabilitación se puede destacar la "Ca la Dona", donde se llevó a cabo proceso de rehabilitación con criterios de sostenibilidad, realizando una intervención estructural innovadora consistente en una sustitución funcional de forjados existentes con panel de madera contralaminada (E. Hormias, 2012). Y con respecto a la obra nueva, cabe destacar la construcción de 65 pisos de protección oficial en Hondarribia (figura 3.9), que se plantea como un referente de construcción sostenibley el inmueble más grandey de mayor altura hecho en madera en todo el suroeste de Europa (Ormazabal, 2017). 


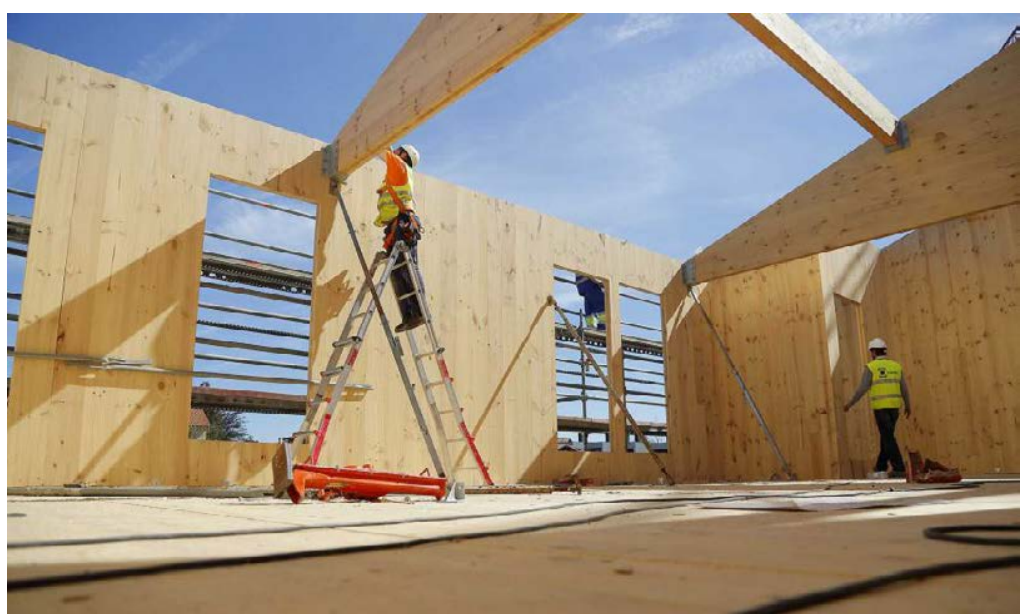

Figura 3.9: Operarios realizando tareas de montaje en las viviendas de Hondarribia, Gipuzkoa (Fotografía: Javier Hernández)

Por todo lo expuesto se puede ver la gran evolución del CLT como material de construcción, también se puede ver el camino que queda por recorrer en cuanto a la formación de arquitectos y prescriptores, y la concienciación de las bondades del material entre los usuarios. Con respecto a la parte técnica, al igual que pasa con la madera y todos sus materiales derivados, aún hace falta investigación en el ámbito de la durabilidad, que actualmente afecta sobre todo a su exposición al exterior, condicionante importante en la vida en servicio del producto, que afectará a su vida útil.

\subsection{Normativa en materia de construcción con madera}

Como se ha comentado anteriormente, en España la normativa en materia de construcción con madera ha sido cuanto menos controvertida, ha pasado desde la prohibición en el uso de elementos estructurales de madera en las viviendas acogidas a planes nacionales (Cassinello, 1973), hasta la inexistencia de su regulación hasta prácticamente la década de los 90, ya que como dijo de Miguel (1985) en las primeras Jornadas Nacionales de la Madera en la Construcción, el problema de la normativa en materia de construcción con madera es que "NO HAY".

Esta falta de normativa y uso por parte de los prescriptores ha llevado al abandono de la madera como material de construcción en su vertiente de material estructural, y quedó relegada a ámbitos secundarios dentro de la construcción, como elementos dispares, o de revestimiento y acabado.

Otro de los aspectos también comentado es la cualidad de la madera de ser un material combustible, y que pese a ser resistente al fuego, la ha restringido mucho en su uso, debido a la atención preferente que se muestra dentro del ámbito legislativo de la construcción a la seguridad. Cuando un edificio posee estructura de madera y sufre un incendio, es para la opinión pública el causante, sin embargo sabemos que no es así, hay ejemplos como el de Canadá, hoy día se dan hipotecas para la construcción con madera, tras descubrirse que la principal causa de incendio no este material, sino los textiles. 
Otra causa de los grandes incendios con madera en zonas urbanas, es a veces el agolpamiento de las construcciones y la mala planificación urbanística, y no la madera.

Hoy día estos aspectos parecen superados, ya que técnicamente la madera y los productos derivados de la madera están totalmente normalizados y caracterizados, quedando pendiente únicamente profundizar algo más en la investigación en el ámbito de la durabilidad con respecto a la vida útil de los productos, y la necesidad de una promoción del material para que se convierta en un material familiar para arquitectos, prescriptores y usuarios.

Respecto a la madera como producto estructural, no hay que olvidar que actualmente el modelo europeo implica el uso extensivo de la madera en cubiertas, en casi todos los países; en forjados en muchos de ellos, y aún en muros y fachadas en otros.

En el caso particular de la madera en España, muchos han sido los motivos por los que se abandonó la construcción con madera. Entre las barreras que frenaban su vuelta a la escena constructiva como material en la época contemporánea, además del desconocimiento prescriptivo, se encontraba la falta de normativa referente al mismo.

Con respecto al avance de la normativa en materia de construcción en referencia a la madera podemos destacar la siguiente legislación cronológicamente:

\subsubsection{Directiva de Productos de la Construcción 89/106/CE de 1992}

La Directiva de Productos de la Construcción (Directiva 89/106/CEE, 1989) tiene por objeto garantizar la libre circulación de todos los productos de construcción en la Unión Europea mediante la armonización de las legislaciones nacionales relativas a los requisitos esenciales de estos productos en materia de salud, seguridad y bienestar, en el contexto de una Europa sin fronteras económicas ni políticas. Una de las principales innovaciones de esta reglamentación es el establecimiento de los procedimientos necesarios para el marcado CE de productos de construcción, que ya va siendo una realidad en el ámbito europeo y en nuestro país, incluidos aquellos productos innovadores contemplados en las nuevas Guías DITE.

La Directiva se aplica a los productos de construcción, es decir, los productos destinados a incorporarse permanentemente a las obras de construcción. Estos productos deben ser conformes a los requisitos esenciales, sólo se podrán comercializar si son idóneos para el uso al que se destinan. Los requisitos esenciales se concretarán en primer lugar mediante documentos interpretativos elaborados por comités técnicos para, a continuación, desarrollarse en forma de especificaciones técnicas, que pueden ser:

- Normas armonizadas europeas adoptadas por los organismos europeos de normalización (CEN - CENELEC), con arreglo a mandatos de la Comisión y previa consulta del Comité Permanente de Construcción.

- Documentos de Idoneidad Técnica Europeo (DITE), que valoren la idoneidad de un producto para su uso. Se aplican en los casos para los cuales no existen ni una norma armonizada, ni una norma nacional reconocida, ni un mandato de norma europea, y con respecto a los cuales la 
Comisión considere, previa consulta a los Estados miembros en el seno del Comité Permanente de Construcción, que no se puede - o que todavía no se puede- elaborar una norma.

Esta directiva cuenta con unos anexos que nos facilitan información detallada sobre: Requisitos Esenciales, Documento de Idoneidad Técnica Europeo (DITE), Certificado de conformidad con las especificaciones técnicas y Organismos Notificados.

El Reglamento de Productos de la Construcción (Reglamento 305/2011/UE, 2011), del que se hablará más adelante, deroga dicha directiva.

\subsubsection{Eurocódigos. Bases de cálculo de estructuras EN 1990:2002}

Los Eurocódigos surgen con el objetivo de la eliminación de las barreras técnicas al comercio en la Comunidad Europea, y servir para la armonización de las especificaciones técnicas en el sector de la construcción. Establecen un conjunto de reglas técnicas armonizadas para el proyecto de las construcciones que, en una primera etapa, sirviera como alternativa a las reglas nacionales en vigor en los Estados Miembros y, finalmente, las pudiera reemplazar.

La preparación de los Eurocódigos se le transfirió al Comité Europeo de Normalización (CEN), que fue el que preparó y publicó los Eurocódigos, con el fin de dotarlos de un estatus de Norma Europea (EN). Esto vinculó a los Eurocódigos con las disposiciones de todas las Directivas del Consejo y Decisiones de la Comisión que hacen referencia a las normas europeas, por ejemplo, la Directiva 89/106/CEE (1989) sobre productos de construcción.

Los Eurocódigos sirven como documentos de referencia para demostrar el cumplimiento de las obras de edificación y de ingeniería civil con los Requisitos Esenciales de la Directiva de Productos de la Construcción, como base para especificar los contratos de las construcciones y de los servicios de ingeniería correspondientes, y como marco para redactar las especificaciones técnicas armonizadas de productos de construcción (ENs y DITEs).

\subsubsection{Eurocódigo 5 UNE-EN 1995-1-1 (2016)}

Entre las normas que comprende el programa de Eurocódigos estructurales, se encuentra la norma UNE-EN 1995-1-1 (2016) Eurocódigo 5: Proyecto de estructuras de madera, en la que se puede ver todo lo referente a las estructuras de madera.

El Eurocódigo 5 se aplica al proyecto de edificios y obras de ingeniería civil con madera (madera maciza, aserrada, escuadrada o en forma de poste, madera laminada encolada o productos derivados de la madera con uso estructural, por ejemplo, la madera microlaminada LVL) o con tableros derivados de la madera unidos con adhesivos o medios de fijación mecánicos. Dicho Eurocódigo cumple los principios y requisitos para la seguridad y servicio de las estructuras y las bases de proyecto y verificación definidas en la Norma Europea EN 1990:2002 de Eurocódigos: Bases de cálculo de estructuras.

El Eurocódigo 5 sólo afecta a los requisitos de resistencia mecánica, adecuación al servicio, durabilidad y resistencia al fuego de las estructuras de madera. Otros requisitos, como por ejemplo el aislamiento térmico y acústico, no se consideran. 


\subsubsection{Código Técnico de la Edificación CTE de 2006}

Desde 1957 las normas técnicas que regulaban el sector de la edificación, conocidas como normas MV, eran competencia del Ministerio de la Vivienda. Estas reglas se transformaron en las Normas Básicas de la Edificación (NBE) en 1977. Además de las NBE, surgieron otras especificaciones técnicas no obligatorias entra las que destacaron las Normas Tecnológicas de la Edificación (NTE). Estas normas complementarían en el campo de las soluciones constructivas convencionales o tradicionales a los Documentos de Idoneidad Técnica (DIT), evaluaciones técnicas favorables para las soluciones innovadoras otorgadas por el Instituto de Ciencias de la Construcción Eduardo Torroja.

En 1999 se publica la Ley 38/1999 de 5 de noviembre de Ordenación de la Edificación, que tiene como principal objetivo el de regular el sector de la edificación. Esta ley insta a la aprobación de un Código Técnico de la Edificación que establezca las exigencias que deben cumplir los edificios en relación con los requisitos básicos de seguridad y habitabilidad.

El Código Técnico de la Edificación (CTE) es el marco normativo que establece las exigencias a cumplir por los edificios en relación con los requisitos básicos de seguridad y habitabilidad establecidos en la Ley 38/1999 de 5 de noviembre, de Ordenación de Ordenación de la Edificación (LOE), en materias de seguridad: estructural, contra incendios, y de utilización; y habitabilidad: salubridad, protección frente al ruido y ahorro de energía.

Una de las principales novedades que introduce CTE respecto a la legislación anterior de la edificación en España fue el enfoque por objetivos o prestaciones, que son el conjunto de características objetivas de un edificio que contribuyen a determinar su aptitud de uso. Hasta su aparición, la regulación había sido de carácter prescriptivo. Este nuevo enfoque supone en la práctica, la eliminación de una serie de barreras técnicas que obstaculizaban la aplicación de innovaciones tecnológicas al proceso de edificación.

De esta forma, el CTE favorece el desarrollo de tareas de investigación, desarrollo e innovación (I+D+i), así como un aumento del uso de las nuevas tecnologías en el sector de la construcción, al integrar de forma más directa los avances logrados gracias a estas actividades. Así, el enfoque de prestaciones permite la utilización de innovaciones técnicas sin perder de vista los elementos tradicionales del método de la construcción, lo que en el caso de la madera ha permitido grandes aportaciones al proceso constructivo.

\subsubsection{Documento básico SE-M de 2009}

El "Documento Básico. Seguridad Estructural. Estructuras de Madera" del Código Técnico de la Edificación (CTE DB SE-M), es una trascripción casi literal del "EUROCÓDICO 5: Proyecto de estructuras de madera. Parte 1-1: Reglas generales y reglas para edificación" publicado en 2006.

El campo de aplicación de este documento básico es el de la verificación de la seguridad de los elementos estructurales de madera en edificación. La satisfacción de otros requisitos (aislamiento térmico, acústico, o resistencia al fuego,) quedan fuera del alcance de este documento. Los aspectos relativos a la fabricación, montaje, control de calidad, conservación y mantenimiento se tratan en la medida necesaria para indicar las exigencias que se deben cumplir en concordancia con las bases de cálculo. 
La aplicación de los procedimientos de este documento básico se llevará a cabo de acuerdo con las condiciones particulares que en el mismo se establecen, con las condiciones particulares indicadas en el documento básico de seguridad estructural y con las condiciones generales para el cumplimiento del CTE, las condiciones del proyecto, las condiciones en la ejecución de las obras y las condiciones del edificio que figuran en los artículos 5, 6, 7 y 8 respectivamente de la parte I del CTE.

\subsubsection{Reglamento de Productos de la Construcción (UE) Nº 305/2011 de 2011}

Los productos de construcción están sujetos a las normas de libre circulación de mercancías en la Unión Europea (UE) así como a las normas relativas a la seguridad de los edificios, la salud, la sostenibilidad, la economía energética y la protección del medio ambiente. Este reglamento pretende simplificar el marco jurídico aplicable a los productos de construcción, y establecer las condiciones relativas a la introducción en el mercado de productos de construcción. Define, asimismo, criterios para evaluar las prestaciones de dichos productos así como las condiciones de utilización del marcado CE.

Hace referencia a aspectos como; la declaración de prestaciones y marcado CE, las obligaciones de los agentes económicos (fabricantes, importadores y distribuidores), especificaciones técnicas armonizadas, Organismos de Evaluación Técnica (OET), autoridades notificantes y organismos notificados y vigilancia del mercado. Cabe comentar que este reglamento deroga la Directiva 89/106/CEE. Para la mejor comprensión y aplicación del nuevo reglamento, el Ministerio de Industria, Energía y Turismo ha elaborado una "Cuía para la preparación de la documentación a elaborar por el fabricante para el marcado CEy la documentación a emitir por los organismos notificados".

Una vez revisada la legislación referente a la construcción con madera, se puede observar cómo la evolución de la normativa ha ido dirigida a fomentar la investigación en el sector de la construcción, a la fabricación de productos innovadores que pudieran cumplir con la normativa existente en pro de una construcción más sostenible en el más amplio significado de la palabra.

En este apartado se puede ver la evolución que han tenido los productos de madera en el sector de la construcción en los últimos tiempos. Esta evolución va unida a un gran avance tecnológico en la fabricación de los productos de madera, y al cumplimiento de unos exigentes controles de calidad.

Aun así como se ha comentado, queda pendiente investigación en el uso de la madera y los productos derivados de la madera al exterior. Uno de los problemas principales en este ámbito es que la climatología predominante en los países centro y nor europeos es muy diferente a la predominante en los países mediterráneos, así sucede que países como Suecia, en diferentes ubicaciones no encuentren condicionantes que afecten en cuanto a los códigos de diseño (Häglund, 2007), sin embargo existen países como puede ser el caso de España, en los que los códigos de diseño pueden ser determinante para la vida en servicio de una estructura de madera.

Es importante la determinación de perfiles de contenido de humedad debido a las variaciones de la humedad del ambiente con el fin de comprender mejor y cuantificar cómo estas variaciones afectan a la madera. Los códigos de diseño actuales utilizan clases de servicio para tener en cuenta efectos de la humedad inducida, pero se basan en niveles de equilibrio previstos, la naturaleza de la madera expuesto a la humedad no se refleja totalmente (Häglund, 2007). Es necesario para mejorar estos códigos 
y que las cargas de humedad puedan ser tratadas como una carga de diseño ordinario para poder ser combinados con los efectos de otras cargas, por ejemplo la nieve y la carga de viento (Ranta-Maunus, 2003). Además, los experimentos realizados en madera laminada encolada en función de las condiciones climáticas exteriores protegidas han demostrado que las variaciones climáticas pueden inducir significativamente altas tensiones en el intervalo de dos tercios del valor de resistencia característica (Aichery Dill-Langer, 1997), o incluso más alta (Jönsson, 2004).

Por todo lo expuesto se plantea que la normativa ha tenido un desarrollo correcto en España, y como se ha expuesto a apostado por la innovación, lo que ha permitido el desarrollo de la madera y los productos derivados de la madera, aun así sigue quedando pendiente una regulación con respecto al uso de la madera y los productos derivados de la madera al exterior, ya que la normativa actual derivada de la europea no recoge la casuística que se presenta en países como España. 


\section{Capítulo 4}

\section{Desarrollo metodológico del trabajo expe- rimental}

Evaluar la vida en servicio de un producto o material, es estudiar su durabilidad, refiriéndose en el caso de materiales de construcción estructurales, al tiempo en que el material o producto mantiene las propiedades para las que fue prescrito. Es importante evaluar la durabilidad de los diferentes productos y sistemas constructivos como base para un eficaz uso de los mismos, es importante conocer la adecuación al uso en función de la durabilidad de los diferentes productos y sistemas constructivos. Esta adecuación dependerá de diferentes factores, aunque quizás uno de los principales sea el clima.

Esta adecuación al uso, nos permitirá una utilización correcta del material, que conseguirá obtener del producto o sistema constructivo la máxima durabilidad, lo que redundará en una construcción más sostenible. La construcción sostenible es una realidad cada día más cercana, y es aquí donde la declaración ambiental de edificios de cuna a tumba es una herramienta de primer orden, y en la cual la madera y los productos derivados de la madera pueden jugar un papel crucial.

Para estudiar la durabilidad de este material con el objetivo de ver su aplicabilidad en clase de servicio 3 , se plantean diferentes tipos de envejecimiento, y el posterior ensayo de las muestras con la finalidad de hacer un estudio completo que permita evaluar su aptitud para el uso.

El envejecimiento a aplicar a las muestras puede ser de dos tipos, envejecimiento natural con exposición directa del material al exterior permitiendo su degradación por los diferentes agentes meteorológicos, y envejecimiento artificial producido en laboratorio mediante diferentes técnicas.

No existe ninguna equivalencia real para la comparación entre un envejecimiento natural y uno artificial, por tanto para la evaluación de la durabilidad, o de la aptitud al uso de los diferentes materiales de construcción, se utilizan métodos que tratan de reproducir las peores condiciones a las que se podría enfrentar en material o producto durante su vida en servicio. Estos métodos, siempre son más agresivos que la realidad a la que se enfrenta un material o producto en su exposición al exterior. 


\subsection{Consideraciones previas}

A la hora de plantear una metodología de ensayo para un material como el CLT aparece el hándicap de la ausencia de normativa referente al mismo. Este tipo de productos denominados innovadores (Directiva 89/106/CEE, 1989), y en concreto el CLT, que obtiene el marcado CE mediante procedimiento CUAP, se encuentra con la falta de ensayos normalizados específicos para él (Oteiza et al., 2013). Durante el desarrollo de esta tesis ha sido publicada la norma armonizada del CLT (UNE-EN 16351, 2016), aunque siguen sin plantearse ensayos específicos orientados hacia la evaluación de la calidad de encolado en condiciones de clase de servicio 3.

Si bien en la bibliografía encontramos diferentes ensayos de durabilidad para madera maciza y productos en base madera no encontramos ninguno específico para este tipo de producto.

Con la metodología que se plantea se pretende avanzar en el conocimiento del comportamiento funcional y la durabilidad del CLT, en condiciones de uso exterior fuera del contacto con el suelo (fachadas, muros, pasarelas, etc.), y como paramento, relacionando entre sí el "clima del material" (temperatura y contenido de humedad de la madera) medido, con la "dosis" de degradación acumulada inherente a cada climatología o condición específica de uso. Nos planteamos, pues, evaluar si el material podría ser aplicado en condiciones de uso típicas de una clase de uso 3.1 (elementos verticales que no almacenan agua de lluvia).

En la actualidad nos encontramos que los proyectistas que trabajan con madera, no poseen herramientas y metodologías fiables que les permitan valorar adecuadamente el efecto que sobre el comportamiento funcional de la madera y de los elementos estructurales de madera tienen, no sólo la climatología local sino también el diseño adoptado y las variables inherentes al material (especie, dimensiones).

La existencia de guías, e incluso programas, desarrollados para el Centro y Norte de Europa, CNE, (Thelandersson et al., 2011; Jermer, 2011), e incluso Australia, donde se plantea la evaluación del diseño adoptado desde el punto de vista de su durabilidad (Wang et al., 2007), no resuelven el problema nacional, ya que los sistemas constructivos nacionales son muy diferentes, y nuestro clima es muy variable y diferente al de estas regiones. Por estos motivos las recomendaciones de diseño propuestas, no producen el adecuado comportamiento funcional (en términos de durabilidad) del elemento de madera usado en la construcción en un clima como el de la península ibérica.

Por desgracia, la falta de conocimiento en el ámbito de la durabilidad, afecta a aspectos fundamentales a la hora de analizar la funcionalidad de un producto y diseño dados:

- El efecto del clima, tanto general, por las diferencias que nos encontramos en las diferentes regiones geográficas de la península ibérica, como local, debido a las diferentes exposiciones a las que puede estar sometido el producto.

- El efecto de variables inherentes al material, que dependerán de la especie, dimensiones, fendas, etc., según se adapten mejor o peor a esas condiciones climáticas generales y locales.

- El efecto del diseño, un aspecto muy importante, y que afectará de forma decisiva a la durabilidad de un producto de madera al exterior. 
Derivada de esta falta de conocimiento respecto de su comportamiento funcional, existe otro aspecto que queda comprometido con la actual carencia de información como es el de la predicción de la vida en servicio, aspecto éste de gran trascendencia a la hora de llevar a cabo evaluaciones ambientales tanto a nivel de producto (según UNE-EN 15804, 2012; pr-EN 16485, 2012) como a nivel de edificio (según UNE-EN 15643-1, 2012; UNE-EN 15643-2, 2011; UNE-EN 15643-3, 2012; UNE-EN 15643-4, 2012; UNE-EN 15978, 2011).

La aproximación metodológica efectuada en estos trabajos llevados a cabo a nivel europeo es eminentemente fundamental ya que va dirigida hacia la formulación de modelos del tipo dosis-respuesta, más (Brischke et al., 2011; Brischke y Hansson, 2011) o menos (Jermer, 2011; Thelandersson et al., 2011) complejos, que permitan no solo modelizary, por ello cuantificar el efecto de las distintas variables en el proceso degradativo de la madera sino, también, determinar la vida esperada en servicio mediante el cálculo de los umbrales críticos (estados límites de servicio) en los que la degradación hace acto de presencia (Thelandersson, 2013).

Fuera de Europa son de señalar los trabajos llevados a cabo en Australia por Mackenzie et al. (2007) y Wang et al. (2008), en Norte América por Scheffer (1971), Eslyn et al. (1985), Setliff (1986), Morris y Wang (2008b) y Carll (2009) así como en Asia por Hasegawa (1996). La naturaleza de estos últimos trabajos no-europeos es mucho más práctica y empírica ya que la gran mayoría de ellos se basan en la aplicación del sencillo índice Scheffer (Scheffer, 1971), formulado de forma más o menos modificada según las condiciones climatológicas nacionales.

La mayor crítica que se puede hacer a los estudios efectuados a nivel europeo radica tanto en la multiplicidad de dispositivos experimentales empleados por los diversos autores para la obtención de los datos básicos de la degradación y del efecto del "clima del material" (puesta de manifiesto en los recientes trabajos de Brischke et al. (2013a) y Meyer et al. (2013)), como en el marcado carácter centronor-europeo (CNE) de los climas analizados. Esto hace que en la formulación y diseño de sus modelos, no se tengan suficientemente en cuenta las particularidades introducidas por las especiales características climáticas de los países mediterráneos, en los que la existencia de prolongados periodos de sequía asociados a elevadas temperaturas, hacen que el proceso degradativo no sólo se pare sino que se revierta en determinadas épocas del año.

De hecho, en uno de sus últimos trabajos, Brischke et al. (2013b) pone de manifiesto que en sus modelos de dosis respuesta el efecto de la variable temperatura es el dominante, lo que puede explicarse en parte porque las estaciones experimentales por ellos empleadas se encontraban ubicadas en lugares con climatologías tales, que hacían que el contenido de humedad de la madera fuera casi permanentemente elevado durante todo el año. De hecho, cuando tales modelos se aplican a, por ejemplo, la climatología española los índices de degradación que resultan son exageradamente elevados, precisamente por el magnificado efecto de la temperatura en ellos. Esta conclusión por si sola pone de manifiesto la necesidad de reformular tales modelos, integrando en ellos datos tomados en zonas con climatologías más variables, como la española, en las que existen prolongados tiempos de secado del material que paran, e incluso invierten, el proceso degradativo.

Como se puede observar en los estudios previos, no hay ningún estudio que se adapte a la climatología de nuestro país, y para poder evaluar el comportamiento al exterior del CLT es necesario un tipo de estudio que tenga en cuenta el CLT como producto, ya que los estudios mencionados se refieren a 
madera como material, pero en el caso del CLT al comportamiento del material madera hay que añadir el comportamiento del producto, ya que es un "producto en base madera", en el que además del material, influye el aglomerante (adhesivo) y la tecnología utilizada para conformar el producto, máxime cuando en el caso del CLT es la unión de las láminas mediante el adhesivo, el principal inconveniente en su comportamiento al exterior.

A los aspectos relacionados con la climatología, que afectan al envejecimiento natural, hay que añadir que, como se ha comentado anteriormente, el CLT no posee una metodología de ensayo propia, al tratarse de un producto denominado innovador según la antigua directiva de productos de la construcción, por lo que para la obtención del marcado CEy su normalización como producto de la construcción se han usado normas de productos similares, con diferentes ensayos.

En la propuesta de ensayos se llevan a cabo ensayos más cercanos a la naturaleza del producto, por su conformación y demás factores, que permita evaluar el producto, tratando de no penalizarlo por tratarse de ensayos no adaptados a él.

Para analizar la durabilidad del producto al exterior, se seleccionan tres tipos climáticos representativos de la península ibérica, esta exposición provocará un envejecimiento en las muestras que posteriormente será analizado, llevando a cabo ensayos de tracción perpendicular a la fibra, en lo que podremos analizar la pérdida de capacidad del CLT en este ambiente.

Como complemento a estos ensayos, se realizan ensayos en laboratorio, tratado de acelerar el proceso de envejecimiento, y poder evaluar el comportamiento del CLT a largo plazo para poder así analizar su durabilidad. El envejecimiento artificial se lleva a cabo con dos variantes, una en la que se tiene en cuenta el efecto de la radiación solar y otra en la que se simula el efecto lluvia. Tras ambos envejecimientos, y al igual que en el envejecimiento natural llevado a cabo al exterior se lleva a cabo en ensayo a tracción perpendicular a las fibras de las muestras envejecidas.

Con los tres tipos de envejecimiento planteados se pretende analizar el comportamiento del CLT en su uso exterior, tratando de evaluar que parámetros le afectan, y saber tanto si es apto para su uso en clase de servicio 3, así como las posibles mejoras que se pueden introducir para aumentar su resistencia en esta exposición.

\subsection{Características del producto y selección de especies}

En principio cualquier especie de madera puede ser susceptible de convertirse en CLT, de hecho son muchas con las que se intenta fabricar el producto. Aunque conceptualmente todas las especies de madera podrían ser usadas en la fabricación de este producto, la verdad es que hay factores que priorizan a unas maderas frente a otras. Su encolabilidad, la rectitud de su fibra, la estabilidad dimensional, la homogeneidad, la resistencia y el precio son factores que han de ser tenidos en cuenta a la hora de conformar un producto eficaz y competitivo.

Debido al origen centroeuropeo y a su facilidad de trabajo y abundancia en el entorno, las primeras y principales especies con que se ha fabricado este producto pertenecen al grupo de las coníferas. Nos podemos encontrar CLT fabricado con pino silvestre (Pinus sylvestris), con pino radiata (Pinus radiata), con picea (Picea abies) o abeto (Abies alba), o incluso con el árbol del caucho (Hevea brasiliensis), con el 
que ya se fabrican vigas de madera laminada (Nadir et al., 2014). Existen, incluso, referencias respecto del uso de la madera de chopo en la fabricación de este tipo de productos en España ya hacia los años 60 del siglo pasado (Nájera, 1960).

La elección de la especie de madera es un paso fundamental, ya que cada especie engloba en su seno tanto el efecto de la anisotropía, que se refleja en la tendencia de la especie al alabeo, a la generación de fendas y a la capacidad de atrapar agua, como el efecto de la porosidad, que se refleja en una mayor velocidad de sorción o desorción y, por tanto, en el tiempo en que la humedad permanece en la madera, haciendo que el material o producto que conforma se mantenga en un clima de "riesgo". Todo esto junto con la acción concomitante de la distinción entre duramen y albura, ya que cada una de estas partes del tronco presenta una porosidad, anisotropía e incluso durabilidad natural propias dentro de una misma especie.

Bien es cierto, que aunque hay gran variedad de especies aptas para la fabricación del CLT, tanto coníferas como frondosas, definidas en la norma EN 14081-1, por diferentes motivos destacan las coníferas. Entre las especies más utilizadas se encuentra la picea (Picea abies) y el abeto (Abies alba), que por ser indistinguibles entre sí se comercializan conjuntamente bajo el nombre genérico de abeto, madera que resulta idónea en los procesos de encolado, pero que por su dificultad de tratamiento no se muestra en principio adecuada para su uso exterior. Otro género habitual en la fabricación del CLT es el Pinus spp. y dentro de este género se pueden encontrar diferentes especies, entre ellas el pino silvestre (Pinus sylvestris), una de las más habituales y comerciales.

Teniendo en cuenta la representatividad comercial y de uso, y su aplicabilidad en la realidad constructiva, se selecciona el abeto (Picea abies/ Abies alba), que como se ha comentado es quizás la madera más utilizada en la producción de productos laminados, entre otros factores por su estabilidad y facilidad de encolado, y por otro lado se selecciona al pino (Pinussylvestris), al igual que en el caso del abeto por su representatividad en la producción de productos de madera encolados, y por su facilidad para recibir tratamientos protectores que prolongan la durabilidad de la madera.

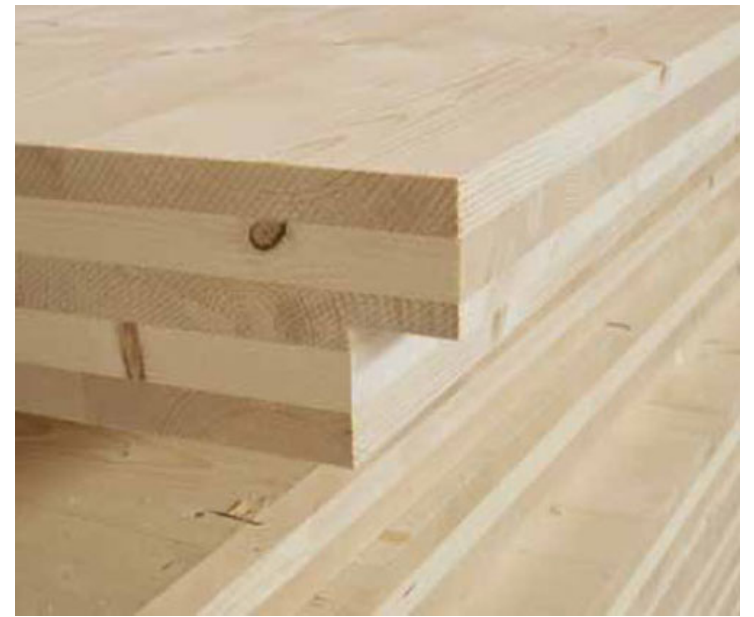

Figura 4.1: Ejemplo de CLT tricapa de grosor 1000 mm (300 - 400 - 300) 
Una vez seleccionadas las especies para llevar a cabo el estudio teniendo en cuenta los factores inherentes a la especie, se procede a seleccionar el producto a utilizar. Para ello hay que tener en cuenta la geometría y masividad del elemento, ya que esto afecta a la capacidad de acumulación interna de agua y el tiempo hasta el secado (desorción) completo, del elemento de madera. Si bien es cierto que el producto a utilizar es el CLT, hay que tener en cuenta que existen muchas posibilidades de conformación del producto, tanto en número de capas como en grosor de las mismas como en la propia conformación.

En principio la idea es seleccionar el producto más sencillo posible, para intentar introducir la mínima cantidad de variables en el estudio. El CLT más sencillo es el tricapa, formado por tres capas de madera, con las exteriores paralelas entre sí, y la central perpendicular a ellas.

Con respecto al grosor de las capas hay una disyuntiva, el producto más homogéneo sería tener las tres capas del mismo grosor, que según los estándares de fabricación y de mercado sería el CLT tricapa de $300 \mathrm{~mm}$ por capa. Pero si atendemos a la utilización del producto y al uso comercial realmente no es este el producto más utilizado, y menos si tenemos en cuenta el uso exterior. Por tanto atendiendo a la finalidad del estudio y a la demanda de mercado se decide optar por un CLT tricapa con las capas exteriores de $300 \mathrm{~mm}$ y la interior de $400 \mathrm{~mm}$, lo que conforma un grosor total de producto de 1000 mm (figura 4.1).

\subsubsection{Material suministrado}

Tanto en la elección de especie como de producto para llevar a cabo el estudio hay que tener en cuenta cuestiones prácticas como la demanda del mercado, la producción del producto, etc., para que el estudio refleje la realidad de uso del producto.

A la hora de solicitar el material necesario para llevar a cabo el estudio, hay que tener en cuenta criterios de producción para ser lo más eficiente posible y así optimizar el uso del material. Teniendo en cuenta tanto la construcción de los prototipos de exterior, como las probetas que se necesitan para el envejecimiento en laboratorio, y teniendo en cuenta criterios de producción, se cuenta con una cantidad total de $5,33 \mathrm{~m}^{3}$ de madera, de los cuales la mitad es de madera de abeto (Picea abies), y la otra mitad es de pino (Pinus sylvestris).

La madera suministrada se reparte según su utilización para en abeto como se refleja en el cuadro 4.7, y en la figura 4.2, se puede observar el despiece de los paneles de forma que se optimice la producción del tablero (en la página 97).

En el cuadro 4.2 se refleja la madera suministrada de pino según su utilización, y en la figura 4.3, se puede observar el despiece de los paneles de forma que se optimice la producción del tablero (en la página 98).

\subsection{Descripción de los ensayos}

Para poder ser capaces de responder a la pregunta sobre la durabilidad del CLT en aplicaciones de exterior es necesario, o ensayar material que haya estado en estas condiciones durante largo tiempo, ex- 
Cuadro 4.1: Detalle de los paneles de abeto según su uso previsto

\begin{tabular}{|c|c|c|c|c|c|c|c|c|c|}
\hline Etiqueta & Piezas & Descripción del producto & $x[\mathrm{~cm}]$ & $y[\mathrm{~cm}]$ & Crosor $[\mathrm{cm}]$ & Área [m2] & Volumen $\left[\mathrm{m}^{3}\right]$ & Peso $[\mathrm{kg}]$ & Uso Previsto \\
\hline 05WA_Fichte-1-1 & 1 & CLT 100 NVI C3S WW C24 SAN & 120,0 & 120,0 & 10,0 & 1,44 & 0,14 & 71 & Paramento prototipo \\
\hline 05WA_Fichte-1-2 & 1 & CLT 100 NVI C3S WW C24 SAN & 120,0 & 120,0 & 10,0 & 1,44 & 0,14 & 71 & Paramento prototipo \\
\hline 05WA_Fichte-1-3 & 1 & CLT 100 NVI C3S WW C24 SAN & 120,0 & 120,0 & 10,0 & 1,44 & 0,14 & 71 & Paramento prototipo \\
\hline 05WA_Fichte-1-4 & 1 & CLT 100 NVI C3S WW C24 SAN & 120,0 & 120,0 & 10,0 & 1,44 & 0,14 & 71 & Paramento prototipo \\
\hline 05WA_Fichte-2-1 & 1 & CLT 100 NVI C3S WW C24 SAN & 120,0 & 120,0 & 10,0 & 1,44 & 0,14 & 71 & Paramento prototipo \\
\hline 05WA_Fichte-2-2 & 1 & CLT 100 NVI C3S WW C24 SAN & 120,0 & 120,0 & 10,0 & 1,44 & 0,14 & 71 & Paramento prototipo \\
\hline 05WA_Fichte-2-3 & 1 & CLT 100 NVI C3S WW C24 SAN & 120,0 & 120,0 & 10,0 & 1,44 & 0,14 & 71 & Paramento prototipo \\
\hline 05WA_Fichte-2-4 & 1 & CLT 100 NVI C3S WW C24 SAN & 120,0 & 120,0 & 10,0 & 1,44 & 0,14 & 71 & Paramento prototipo \\
\hline 05WA_Fichte-3-1 & 1 & CLT 100 NVI C3S WW C24 SAN & 120,0 & 120,0 & 10,0 & 1,44 & 0,14 & 71 & Paramento prototipo \\
\hline 05WA_Fichte-3-2 & 1 & CLT 100 NVI C3S WW C24 SAN & 120,0 & 120,0 & 10,0 & 1,44 & 0,14 & 71 & Paramento prototipo \\
\hline 05WA_Fichte-3-3 & 1 & CLT 100 NVI C3S WW C24 SAN & 120,0 & 120,0 & 10,0 & 1,44 & 0,14 & 71 & Paramento prototipo \\
\hline 05WA_Fichte-3-4 & 1 & CLT 100 NVI C3S WW C24 SAN & 120,0 & 120,0 & 10,0 & 1,44 & 0,14 & 71 & Paramento prototipo \\
\hline 10DE_Fichte-1 & 1 & CLT 100 NVI C3S WW C24 SAN & 130,0 & 130,0 & 10,0 & 1,69 & 0,17 & 83 & Cubierta Prototipo \\
\hline 10DE_Fichte-2 & 1 & CLT 100 NVI C3S WW C24 SAN & 130,0 & 130,0 & 10,0 & 1,69 & 0,17 & 83 & Cubierta Prototipo \\
\hline 10DE_Fichte-3 & 1 & CLT 100 NVI C3S WW C24 SAN & 130,0 & 130,0 & 10,0 & 1,69 & 0,17 & 83 & Cubierta Prototipo \\
\hline 995O_Fichte-1 & 1 & CLT 100 NVI C3S WW C24 SAN & 110,0 & 130,0 & 10,0 & 1,43 & 0,14 & 70 & Probetas \\
\hline 995O_Fichte-2 & 1 & CLT 100 NVI C3S WW C24 SAN & 110,0 & 130,0 & 10,0 & 1,43 & 0,14 & 70 & Probetas \\
\hline 99SO_Fichte-3 & 1 & CLT 100 NVI C3S WW C24 SAN & 110,0 & 130,0 & 10,0 & 1,43 & 0,14 & 70 & Probetas \\
\hline
\end{tabular}

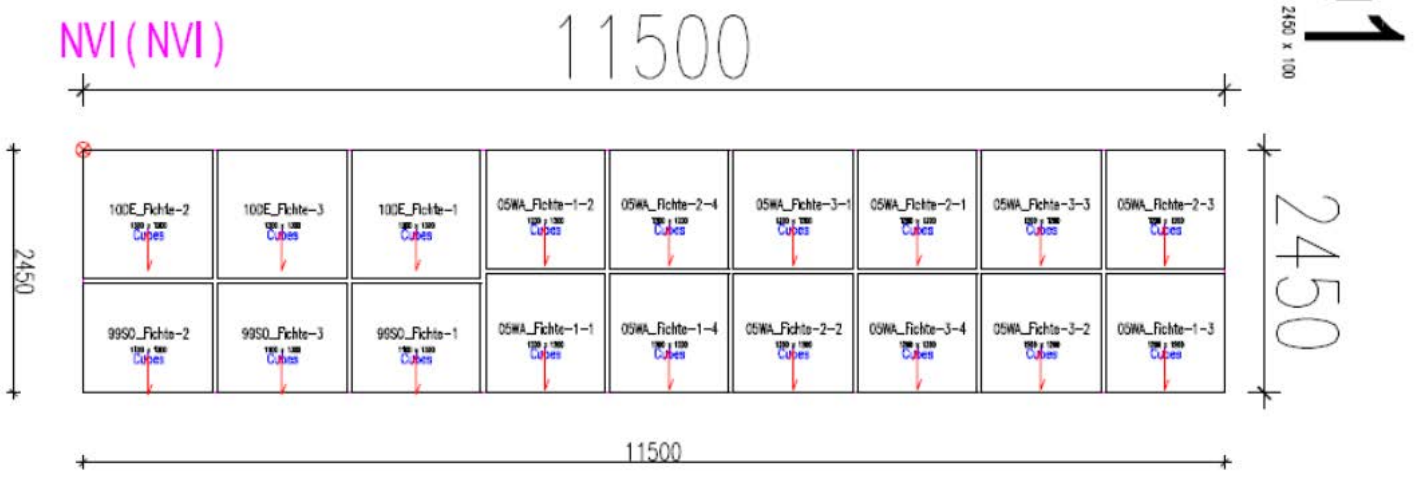

Figura 4.2: Despiece para la mecanización y optimización de los paneles de CLT de abeto

tremo este que no es posible, o hacer uso de material envejecido artificialmente, de forma acelerada, lo que permite evaluar la pérdida de propiedades que sufre el material.

Al plantearse envejecer un material, hay que tener en cuenta que no existe ningún proceso universalmente aceptado que pueda imitar las condiciones reales de exposición y a su vez acelerar este proceso en el tiempo. Por tanto lo que se obtiene con envejecimientos artificiales es una estimación de la degradación que la exposición al exterior produce en el material.

Por lo comentado anteriormente, se plantea llevar a cabo dos tipos de envejecimiento, por una parte un envejecimiento natural o real, mediante la exposición directa del material al exterior, y por otra parte 
Cuadro 4.2: Detalle de los paneles de pino

\begin{tabular}{|c|c|c|c|c|c|c|c|c|c|}
\hline toprule Etiqueta & Piezas & Descripción del producto & $x[\mathrm{~cm}]$ & $y[\mathrm{~cm}]$ & Grosor $[\mathrm{cm}]$ & Área [m2] & Volumen $\left[\mathrm{m}^{3}\right]$ & Peso $[\mathrm{kg}]$ & Uso Previsto \\
\hline 05WA_Kiefer-1-1 & 1 & CLT 100 NVI C3S WW C24 SAN & 120,0 & 120,0 & 10,0 & 1,44 & 0,14 & 71 & Paramento prototipo \\
\hline 05WA_Kiefer-1-2 & 1 & CLT 100 NVI C3S WW C24 SAN & 120,0 & 120,0 & 10,0 & 1,44 & 0,14 & 71 & Paramento prototipo \\
\hline 05WA_Kiefer-1-3 & 1 & CLT 100 NVI C3S WW C24 SAN & 120,0 & 120,0 & 10,0 & 1,44 & 0,14 & 71 & Paramento prototipo \\
\hline 05WA_Kiefer-1-4 & 1 & CLT 100 NVI C3S WW C24 SAN & 120,0 & 120,0 & 10,0 & 1,44 & 0,14 & 71 & Paramento prototipo \\
\hline 05WA_Kiefer-2-1 & 1 & CLT 100 NVI C3S WW C24 SAN & 120,0 & 120,0 & 10,0 & 1,44 & 0,14 & 71 & Paramento prototipo \\
\hline 05WA_Kiefer-2-2 & 1 & CLT 100 NVI C3S WW C24 SAN & 120,0 & 120,0 & 10,0 & 1,44 & 0,14 & 71 & Paramento prototipo \\
\hline 05WA_Kiefer-2-3 & 1 & CLT 100 NVI C3S WW C24 SAN & 120,0 & 120,0 & 10,0 & 1,44 & 0,14 & 71 & Paramento prototipo \\
\hline 05WA_Kiefer-2-4 & 1 & CLT 100 NVI C3S WW C24 SAN & 120,0 & 120,0 & 10,0 & 1,44 & 0,14 & 71 & Paramento prototipo \\
\hline 05WA_Kiefer-3-1 & 1 & CLT 100 NVI C3S WW C24 SAN & 120,0 & 120,0 & 10,0 & 1,44 & 0,14 & 71 & Paramento prototipo \\
\hline 05WA_Kiefer-3-2 & 1 & CLT 100 NVI C3S WW C24 SAN & 120,0 & 120,0 & 10,0 & 1,44 & 0,14 & 71 & Paramento prototipo \\
\hline 05WA_Kiefer-3-3 & 1 & CLT 100 NVI C3S WW C24 SAN & 120,0 & 120,0 & 10,0 & 1,44 & 0,14 & 71 & Paramento prototipo \\
\hline 05WA_Kiefer-3-4 & 1 & CLT 100 NVI C3S WW C24 SAN & 120,0 & 120,0 & 10,0 & 1,44 & 0,14 & 71 & Paramento prototipo \\
\hline 10DE_Kiefer-1 & 1 & CLT 100 NVI C3S WW C24 SAN & 130,0 & 130,0 & 10,0 & 1,69 & 0,17 & 83 & Cubierta Prototipo \\
\hline 10DE_Kiefer-2 & 1 & CLT 100 NVI C3S WW C24 SAN & 130,0 & 130,0 & 10,0 & 1,69 & 0,17 & 83 & Cubierta Prototipo \\
\hline 10DE_Kiefer-3 & 1 & CLT 100 NVI C3S WW C24 SAN & 130,0 & 130,0 & 10,0 & 1,69 & 0,17 & 83 & Cubierta Prototipo \\
\hline 995O_Kiefer-1 & 1 & CLT 100 NVI C3S WW C24 SAN & 110,0 & 130,0 & 10,0 & 1,43 & 0,14 & 70 & Probetas \\
\hline 995O_Kiefer-2 & 1 & CLT 100 NVI C3S WW C24 SAN & 110,0 & 130,0 & 10,0 & 1,43 & 0,14 & 70 & Probetas \\
\hline 99SO_Kiefer-3 & 1 & CLT 100 NVI C3S WW C24 SAN & 110,0 & 130,0 & 10,0 & 1,43 & 0,14 & 70 & Probetas \\
\hline
\end{tabular}

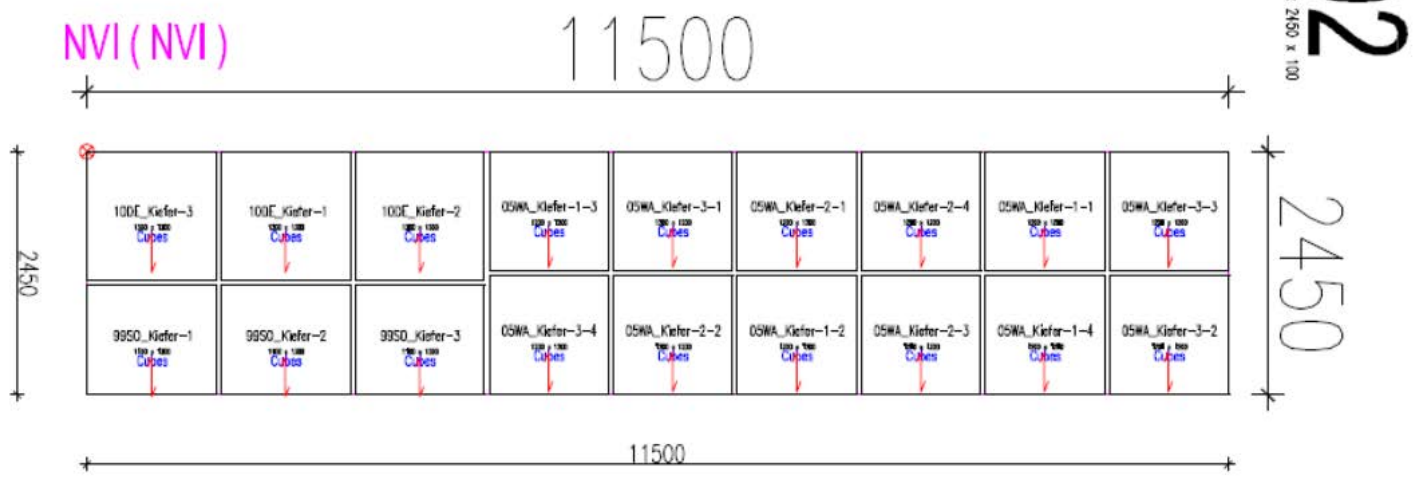

Figura 4.3: Despiece para la mecanización y optimización de los paneles de CLT (Fuente: Stora Enso)

un envejecimiento artificial o inducido, que se llevará a cabo en laboratorio, tratando de reproducir las condiciones reales que el material sufriría en su exposición al exterior.

Debido a motivos de acotación del trabajo de investigación, y a la variabilidad climática española, en el presente estudio se han seleccionado tres tipologías climáticas que se consideran representativas de la climatología española, para el envejecimiento al exterior.

Con respecto al envejecimiento artificial, se llevará a cabo el envejecimiento atendiendo a dos metodologías diferentes, en ambos se trata de reproducir el efecto de la lluvia y el posterior secado de este agua aportada al material. En un método el aporte de agua se realiza mediante riego por goteo, y seca- 
do mediante ciclos, ya que se lleva a cabo en cámara climática, y en el otro el aporte de agua se realiza mediante inmersión en agua osmotizada, y el secado por exposición al ambiente exterior añadiendo el efecto de la radicación solar en el proceso.

Los ensayos que se van a describir a continuación pretenden demostrar la aptitud al uso del CLT como producto de construcción válido para su utilización en clase de servicio 3 y clase de uso 3.1 como paramento.

En todos los casos, el envejecimiento provocado al material consiste en la introducción de un gradiente en el contenido de humedad de la madera para crear tensiones internas. Esto dará como resultado tensiones de tracción perpendiculares a las líneas de cola. Con esto se podrá comprobar si es adecuada la adhesión de las láminas y si la cola resiste las tensiones generadas.

Tras aplicar al material los envejecimientos descritos, se realiza en las probetas envejecidas, un ensayo de tracción perpendicular a la fibra, lo que permite evaluary comparar entre los diferentes métodos, las pérdidas de propiedades estructurales y el comportamiento del adhesivo en el material, permitiendo estimar la aptitud al uso de la clase de servicio planteada para el CLT.

Esta pérdida de propiedades estructurales se evaluará teniendo en cuenta dos parámetros, la carga máxima soportada por el producto y la delaminación producida en el mismo.

\subsubsection{Tamaño de las probetas}

El tamaño de las probetas va a estar condicionado por el tipo de ensayo que se va a llevar a cabo con ellas, no es el mismo tamaño para realizar un ensayo de cortante o de tracción perpendicular a la fibra.

Hasta ahora y al no haber norma específica, los ensayos se han venido haciendo con la norma UNE-EN 408 Estructuras de madera. Madera aserrada y madera laminada encolada para uso estructural. Determinación de algunas propiedades físicas y mecánicas (UNE-EN 408, 2012). Esta norma en realidad no contempla el CLT, pero al ser un producto normalizado mediante CUAP, se adoptan ensayos de las normas que más se puedan asemejar al producto.

Partiendo de la base de la ausencia de normativa del CLT como producto, para seleccionar el tamaño de muestra para llevar a cabo los ensayos, se puede partir de la norma UNE-EN 13354 Tableros de madera maciza. Calidad de encolado. Método de ensayo (UNE-EN 13354, 2009), en la que nos indican un tamaño de muestra para tableros multicapa, en este caso, el tablero de madera maciza de tres capas se puede asimilar al tablero contralaminado de tres láminas que se va a utilizar en los ensayos, aunque son tableros con propiedades y modos de fabricación diferentes.

Otra opción es la norma UNE-EN 16351:2016 Estructuras de madera. Madera contralaminada. Requisitos (UNE-EN 16351, 2016), que es la norma de madera contralaminada, publicada durante el desarrollo de la presente tesis doctoral, en esta norma se utiliza un tamaño de probeta diferente, sensiblemente mayor y que por diferentes opciones se considera más adecuado.

Dependiendo de que las probetas a ensayar sean cilíndricas o cúbicas, las medidas serán $95 \pm 5 \mathrm{~mm}$ de diámetroy $100 \pm 5 \mathrm{~mm}$ de lado respectivamente, y con una zona de visión ortogonal de al menos 10.000 $\mathrm{mm}^{2}$. El espesor de las muestras deberá cumplir con el espesor de la madera contralaminada de la que 
han sido tomadas (UNE-EN 16351, 2016). Esto sería en el caso de los ensayos de tracción perpendicular a la fibra, que son los que se van a llevar a cabo en las muestras de referencia, sin envejecimiento, y en las demás muestras tras los distintos procesos de envejecimiento.

La norma armonizada UNE-EN 16351 (2016) no incluye la evaluación de la resistencia del encolado mediante la realización del ensayo a tracción perpendicular, propiedad esta que sí es habitualmente empleada en el control de calidad de gran cantidad de familias de tableros (partículas, fibras) y que puede arrojar luz sobre el comportamiento del encolado durante el proceso de envejecimiento. La metodología del ensayo es similar a la contemplada en las normas UNE-EN 408 (2012, apartado 16) y UNE-EN 789 (2006, apartado 9) si bien en este caso adoptamos un tamaño de probeta propio.

Este estudio se lleva a cabo con un panel tricapa de $100 \mathrm{~mm}$ de espesor, y para el ensayo de resistencia a tracción las muestras a ensayar tendrán unas dimensiones de $100 \times 100 \times 100$ mm.

Se trata de probetas cúbicas, en las que la testa de la madera ocupa la mayor cantidad de la misma, aspecto que se comenta en el apartado 4.5 Envejecimiento artificial.

En el caso del ensayo de delaminación, el tamaño de la probeta no es tan relevante, ya que lo que se evalúa es el porcentaje de madera, para poder determinar si ha habido un fallo en el encolado y si se ha producido la delaminación en este caso, por la degradación del producto.

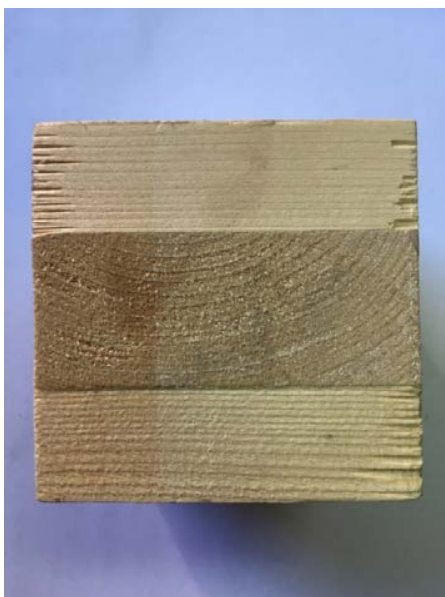

Figura 4.4: Probeta de abeto

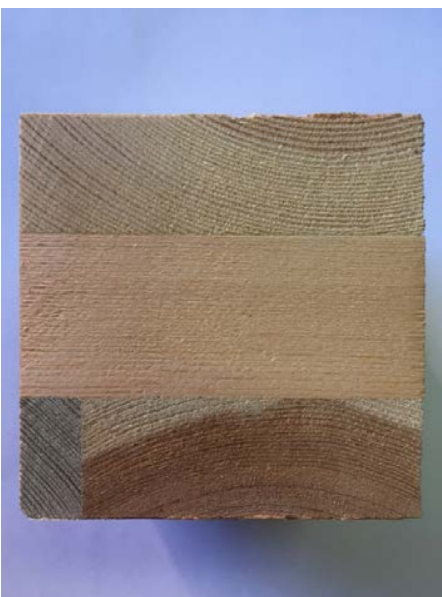

Figura 4.5: Probeta de pino

Por tanto el tamaño de probeta seleccionado es válido tanto para el ensayo de tracción perpendicular a la fibra como para el ensayo de delaminación.

\subsubsection{Selección de las probetas}

Para la selección de las probetas hay que tener en cuenta en primer lugar si se han sometido a envejecimiento previo a su mecanización, caso del envejecimiento natural llevado a cabo en exterior, o si por el contrario van a ser sometidas al envejecimiento tras su mecanización, caso del envejecimiento artificial llevado a cabo en laboratorio, ya que en cada caso el proceso de extracción de las probetas del panel será diferente. 
Una vez extraídas las probetas del panel, se llevará a cabo una segunda selección para eliminar fallos que se consideren no admisibles, y que puedan llevar a cabo a resultados erróneos en los ensayos.

\subsubsection{Selección de las probetas procedentes del envejecimiento natural.}

Tras el periodo de exposición al exterior en las tres ubicaciones seleccionadas, los prototipos son retirados y llevados al laboratorio del INIA, donde se procede a la extracción por corte de las probetas que posteriormente se someten al ensayo de tracción perpendicular a la fibra.

Como se ha visto en el apartado 4.3.1 Tamaño de las probetas, las probetas para el ensayo de tracción perpendicular a la fibra que se realiza tras aplicar los diferentes envejecimientos son de $100 \times 100 \times 100$ $\mathrm{mm}$. Los paneles de exterior presentan unas medidas de $1200 \times 1200 \mathrm{~mm}$, excepto el panel superior que se usa como protección y que tiene unas medidas de $1300 \times 1300 \mathrm{~mm}$, pero que no será objeto de ensayo, ya que de partida se descarta la utilización del CLT para exterior como elemento horizontal sin protección.

En principio de cada panel se pueden extraer 144 probetas, pero debido al efecto borde y a la relación testa/cara del material, no serían representativas del comportamiento del producto. Se decide seleccionar las probetas de la parte central del panel, un total de 10 probetas por panel para llevar a cabo el ensayo. La extracción de las probetas se lleva a cabo según el patrón que se muestra en la figura 4.6.

Una vez extraídas las probetas se procede a su numeración para poder identificarlas durante todo el proceso de ensayos y así tener claro a que probeta se le asigna cada resultado. En la nomenclatura de las probetas se tendrá en cuenta la especie de la que está compuesta el producto, la ciudad donde ha estado expuesto, la orientación a la que pertenece, y su numeración, que se compone de un número y una letra según el patrón de la figura 4.6.

En la nomenclatura de las especies de madera que conforman el producto se mantiene la nomenclatura de origen, por tanto la letra K (kiefer) se refiere al pino, en este caso Pinus sylvestris, y la nomenclatura $\mathrm{F}$ (fietche) se refiere al abeto, en este caso Picea abies.

Para las ciudades seleccionadas la nomenclatura se corresponde con la letra M para Madrid, SE para Sevilla y A para Ávila. En el caso de las orientaciones se usa la inicial de la orientación en mayúscula, así $\mathrm{N}$ corresponde a la orientación Norte de la ubicación, S a la Sur, E a la este y O a la Oeste.

Por último el número y la letra definen la situación dentro del panel de la probeta. Un ejemplo de probeta con la correspondiente nomenclatura se puede ver en la figura 4.7.

\subsubsection{Selección de las probetas destinadas al envejecimiento artificial}

Antes de llevar a cabo los envejecimientos artificiales hay que mecanizar las probetas. A diferencia de en el caso del envejecimiento exterior, en el envejecimiento de laboratorio y debido a las limitaciones dimensionales que tienen las máquinas de ensayo hay que mecanizar las probetas previamente al envejecimiento. 


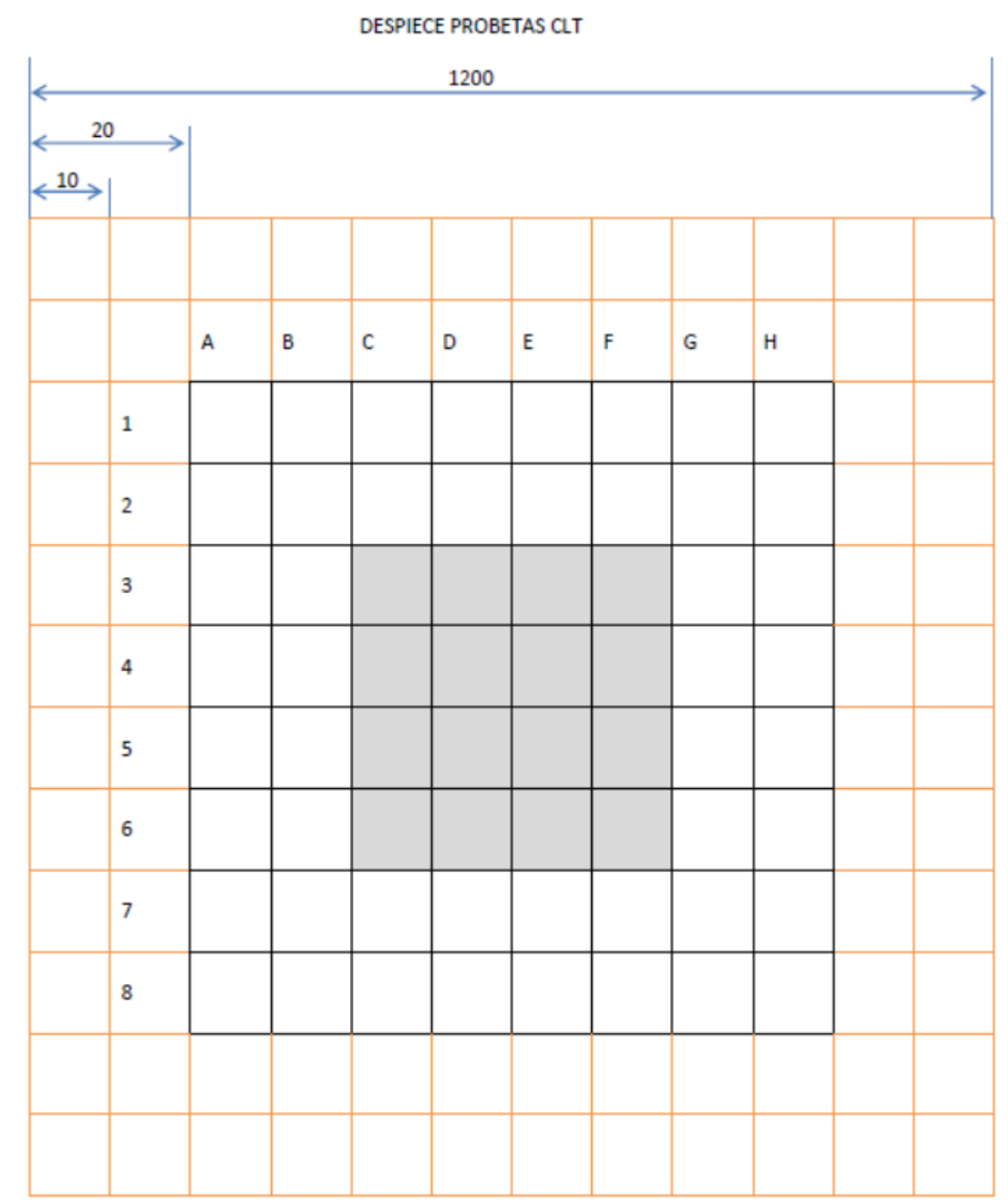

Figura 4.6: Despiece de los paneles de CLT expuestos al exterior para la obtención de probetas

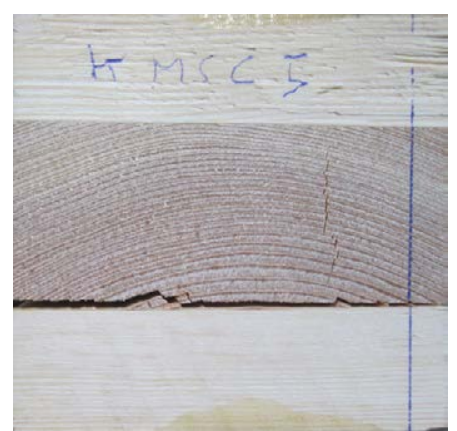

Figura 4.7: Probeta de pino, ubicada en Madrid, expuesta a la orientación Sur y situada en el panel en la posición C5, con su correspondiente nomenclatura 
Teniendo en cuenta que tras el envejecimiento el ensayo que se lleva a cabo es el de tracción perpendicular a la fibra, se mecanizan las probetas con el tamaño necesario para este ensayo, que como se describe en el apartado 4.3.1 Tamaño de las probetas es de $100 \times 100 \times 100 \mathrm{~mm}$.

Las probetas se extraen de los paneles de CLT de pino (Pinus sylvestris) y abeto (Picea abies) de $1100 \mathrm{x}$ $1300 \mathrm{~mm}$, se realizan cortes paralelos a la dirección de la fibra de las caras externas, obteniendo unas tiras de $100 \times 1100 \mathrm{~mm}$, y mediante corte perpendicular se obtienen 10 probetas por tira.

En este caso para evitar la entrada de agua por la testa, debido al efecto borde de la madera, y a la proporción testa/cara que tienen las probetas de CLT de este tamaño, que pueden hacer que el comportamiento de las probetas sea poco representativo del comportamiento real que tendría el producto en su exposición al exterior, las probetas se tratan como se describe en el apartado 4.5.1 Preparación de las probetas.

\subsubsection{Selección general de las probetas (eliminación de defectos)}

Tanto las probetas procedentes del envejecimiento natural, como las probetas utilizadas para el envejecimiento artificial deben ser seleccionadas, en el primer caso posteriormente al envejecimiento y en el segundo de manera anterior.

Esta selección trata de eliminar defectos del material y del producto, que puedan ocasionar que las probetas no sean representativas del material o producto, ya que debido a su tamaño este tipo de defectos tienen una repercusión mayor de la que tendrían en una aplicación real del producto.

La probetas objeto de ensayo deberán estar libres de defectos, por tanto las probetas seleccionadas no deben presentar fallas ni defectos, y debe tener su eje longitudinal paralelo a la dirección de la fibra.

Para la selección de las probetas se tienen en cuenta tanto defectos del material, como son los nudos saltadizos, las gemas, etc., como defectos del producto, como pueden ser los fallos de encolado.

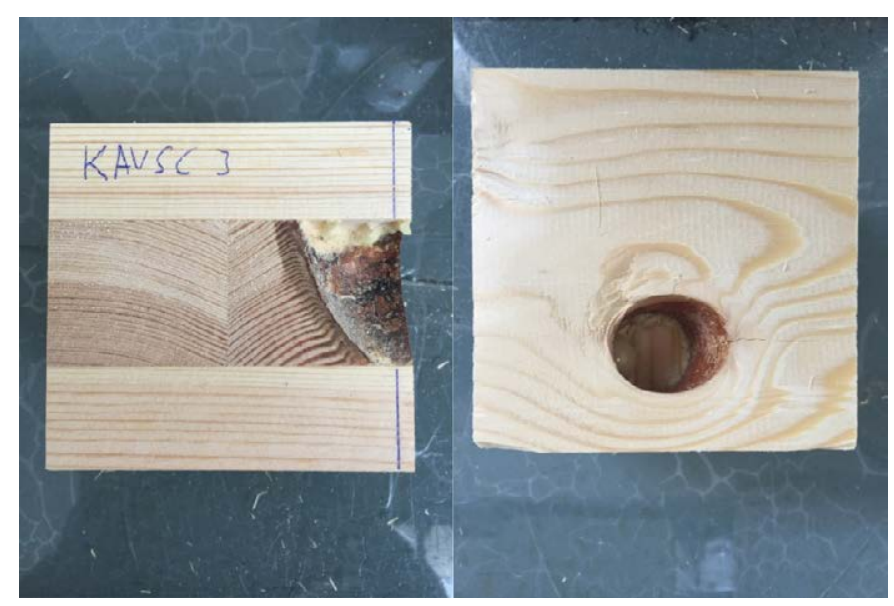

Figura 4.8: Defectos del material por gema y nudo saltadizo 


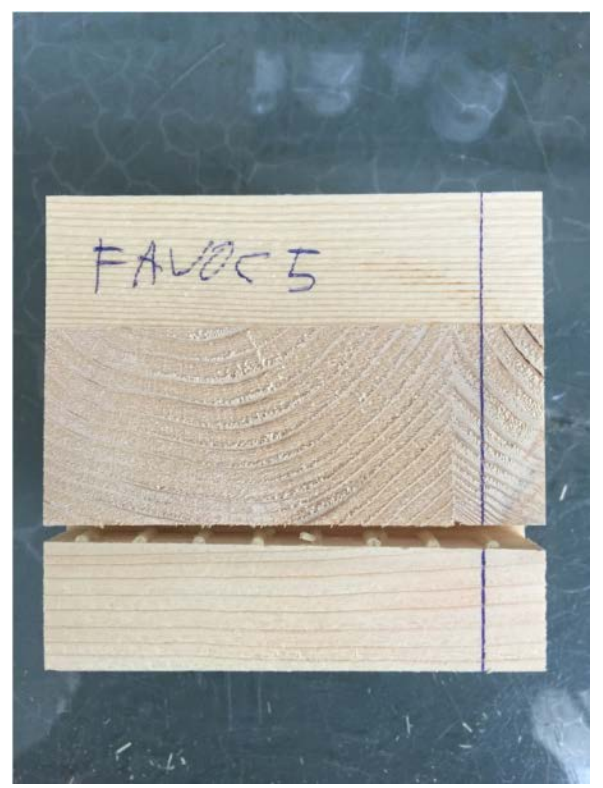

Figura 4.9: Defectos del producto por fallo de encolado

\subsection{Envejecimiento natural}

El clima del material, entendido como la combinación de temperatura y contenido de humedad, es el factor clave para la degradación biótica y abiótica tanto de la madera como de sus productos derivados. El objetivo del presente trabajo es el de analizar la degradación abiótica del tablero contralaminado (CLT) ya que la degradación biótica de este material puede ser asimilada a la de la madera maciza.

Considerando un régimen de temperaturas normales (las que tienen lugar en nuestro entorno geográfico), la degradación abiótica del CLT se produce fundamentalmente por cambios en el contenido de humedad de la madera, los cuales generan fuertes tensiones rasantes en las líneas de cola (especialmente por la arquitectura cruzada de las láminas) a la vez que producen un fuerte agrietamiento en la madera, especialmente en la/s cara/s exteriores. El agrietamiento de la madera no tiene mayor importancia salvo en el caso de los usos horizontales ya que son espacios de embalsamiento de agua, lo que aumenta el tiempo de retención de la misma y tiene efecto sobre el contenido de humedad máximo. No obstante lo anterior y dado que en el presente trabajo sólo se plantean aplicaciones con disposiciones de tipo vertical (típicas de una clase de uso 3.1), este agrietamiento tampoco se considera trascendente y es por ello por lo que en el presente trabajo nos centraremos en el análisis del estado de conservación de las líneas de encolado.

El envejecimiento natural o mediante exposición al exterior cuenta con diferentes agentes atmosféricos que ayudan a introducir el gradiente en el contenido de humedad de la madera. Este gradiente va a generar una serie de tensiones internas en el material madera, que provocarán tensiones perpendiculares a las líneas de cola, lo que puede comprometer la durabilidad estructural del CLT como producto.

España es un país rico en variedades climáticas, y no es posible estudiar toda la tipología presente en la península ibérica, ya que la variedad climática es muy vasta, y se hace inabarcable si tenemos en 
cuenta además la variedad microclimática.

Para poder abarcar el estudio del efecto de la exposición al exterior de este producto hay que hacer una selección representativa y diferenciada de las variedades climáticas de la península ibérica, así como seleccionar los agentes atmosféricos más representativos, o que mayor influencia pueden tener en la degradación del producto.

Es necesario para poder evaluar el efecto del clima, la monitorización de los prototipos expuestos al exterior, conocer el clima del material y poder compararlo con el clima al que están expuestos los prototipos, y poder evaluar de esta forma cuales son los factores que afectan de forma directa a la degradación de este producto.

\subsubsection{Tipos climáticos}

Existen innumerables clasificaciones climáticas. Actualmente, en España, coexisten, con mayor o menor arraigo la clásica de Köppen (1918, 1923, 1930), recogida en numerosos atlas, la de Miller (1950), la de Papadakis (1966) utilizada con profusión en el ámbito agronómico, la de Rivas Martínez (1980, 1987), seguida generalmente por botánicos y fitosociólogos, y las dos de Allué $(1966,1990)$ muy apreciadas en el sector forestal y basadas en los climodiagramas de Waltery Lieth (1960), a su vez inspirados en el diagrama ombrotérmico de Gaussen (1954).

Todas ellas pretenden tener un carácter fitológico, es decir, que las unidades que definen coincidan, siquiera aproximadamente, con los grandes biomas del mundo o, al menos, con la vegetación potencial que podría identificarse con dichas unidades climáticas.

En general, todas utilizan datos pluviométricos y datos térmicos más o menos combinados tendiendo a definir umbrales que condicionan la vida de determinadas formaciones vegetales por exceso de frío o de calor, o por sequía en distintas épocas del año.

Para definir los tipos climáticos necesarios para la evaluación en exterior de un producto como el CLT en una climatología tan variada como es la española, tenemos que tener en cuenta parámetros como por ejemplo el alcance del estudio. Sería muy interesante poder estudiar todas las tipologías climáticas en España, con todas sus variables, como pueda ser la altitud, o la cercanía a la costa, y como no teniendo en cuenta cuestiones fundamentales como puede ser el diseño.

Por diversas razones, entre ellas de tiempo y presupuesto, se considera necesario acotar este estudio, y con el objeto de producir un resultado que pueda ser representativo y útil, se han llevado a cabo una serie de limitaciones con respecto al campo de actuación en referencia a las localizaciones geográficas en las que se desarrolla el estudio.

\subsubsection{Climatología general}

A la hora de definir un clima nos encontramos con dos parámetros fundamentales, como son la temperatura y la precipitación, y otros elementos climáticos como son; la radiación solar, la insolación, la nubosidad, la humedad del aire, la presión atmosférica y los vientos. 
Cuando hablamos de clima del material, que es el que afecta a su durabilidad en ambiente exteriory en definitiva a su vida en servicio, se observa que aunque la península cuenta con un amplio abanico de temperaturas, su variabilidad no es tan significativa a la hora de hablar del clima del material como lo pueden ser las precipitaciones, a diferencia de lo que ocurre en otros climas norte y centroeuropeos, donde la variable condicionante es la temperatura.

Estos parámetros o factores climáticos, como son la temperatura y la precipitación tienen un efecto en la madera como material y en el CLT como producto. Este efecto varía según el clima, como comentábamos anteriormente en la diferencia entre clima norte y centro europeo y clima del sur de Europa, pero también según las diferentes combinaciones que se producen entre estos factores.

Cuando analizamos un clima concreto y a la hora de compararlo con otro, no se pueden evaluar estos factores de forma independiente, al menos no podemos hacerlo para ver su efecto en la madera, ya que climas diferentes pueden dar comportamientos similares en el material madera y en el producto CLT dependiendo de las combinaciones que se den entre ellos.

A continuación se hace una breve descripción de los distintos parámetros climáticos que configuran el clima en la península ibérica, y del posible efecto que pueden producir en la madera, ya sea de forma aislada o en combinación con otros factores.

\subsection{Temperatura}

Es junto con la humedad uno de los factores básicos a la hora de definir un clima, y también a la hora de observar el comportamiento de la madera al exterior.

Uno de los parámetros que definen la temperatura es la temperatura media anual, que podemos ver representado mediante isotermas medias anuales en el mapa hipsométrico, donde podemos ver claramente las diferencias de latitud entre el norte y el sur la península ibérica.

Además de la temperatura media, se suele tener en cuenta para la caracterización de un clima las temperaturas medias del mes más frío, que en la península es Enero como norma general, y la del mes más cálido que se suele repartir entre Julio y Agosto. Si nos fijamos en las temperaturas extremas que se pueden alcanzar en la península ibérica vemos que le rango es muy amplio, y va desde los -30 a los $50^{\circ} \mathrm{C}$, con una amplitud térmica media anual de más de $20^{\circ} \mathrm{C}$, lo que nos da una idea de la marcada continentalidad de la mayor parte de la península ibérica, sin contar obviamente las zonas costeras.

La marcada continentalidad de la mayor parte de la península ibérica, junto con el tipo de material objeto de estudio, la madera, van a marcar las pautas a la hora de definir los tipos climáticos a seleccionar en el estudio de envejecimiento natural.

En el caso de la madera, la temperatura es un factor muy importante, ya que su efecto en combinación con otros factores va desde la rápida salida del agua de la madera con las correspondientes tensiones y formación de fendas, hasta el desarrollo de organismos patógenos que provocan la degradación del material.

Es la temperatura en combinación con el viento la que va a marcar la velocidad de salida del agua de la madera, y esta velocidad será la causa principal para la formación de fendas, ya que lo que marca la 


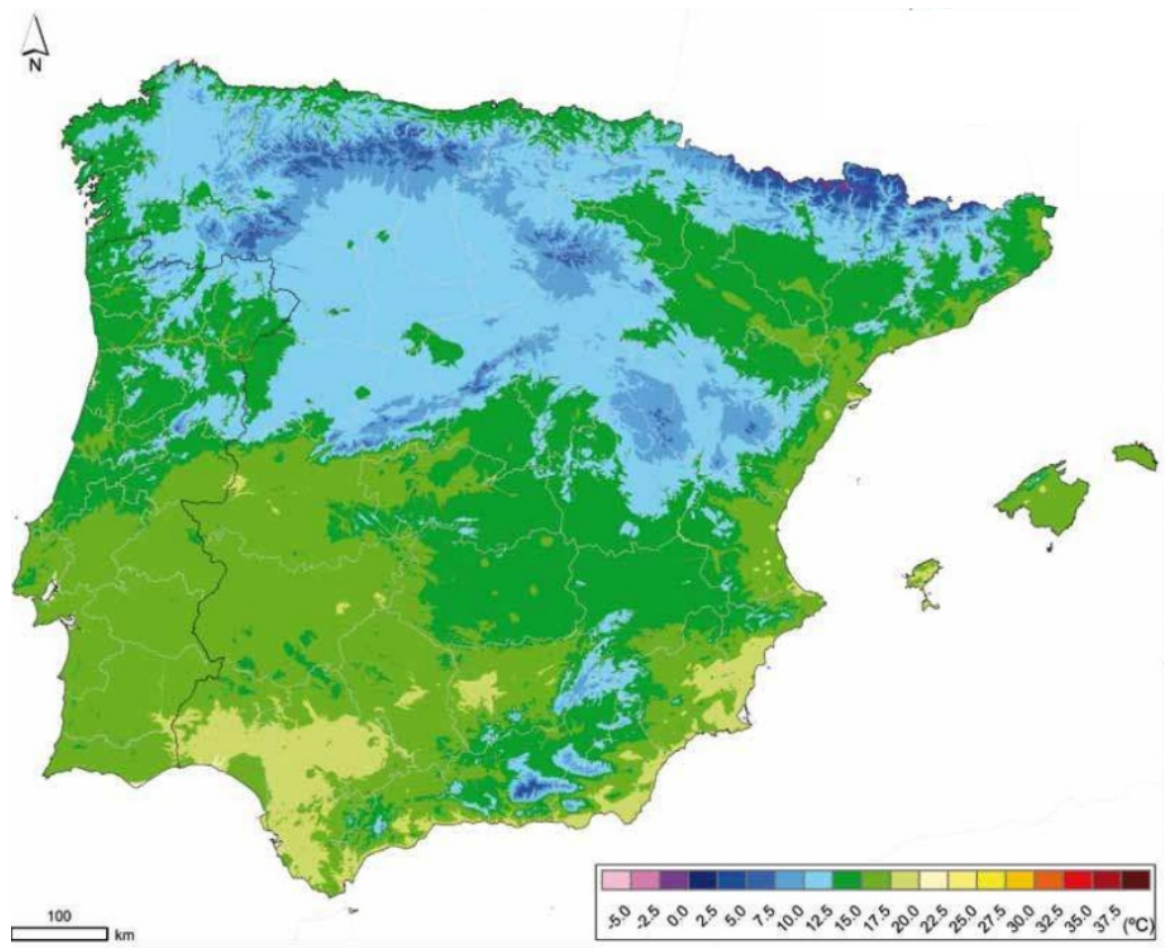

Figura 4.10: Temperatura media del aire en la Península Ibérica e Islas Baleares 1971-2000 (Ref. Atlas)

agresividad a la hora de la formación de fendas es más la velocidad de entrada y salida del agua en el material que realmente la variación de volumen.

\subsection{Precipitación}

Como comentábamos anteriormente, es junto con la temperatura uno de los factores básicos a la hora de definir un clima, y como no a la hora de observar el comportamiento de la madera al exterior. Suele ser el mayor aportante de contenido de humedad de la madera cuando esta se encuentra expuesta al exterior.

La precipitación es el elemento climático más importante en España, tanto desde un punto de vista climático como en su consideración de recurso, dadas su modesta cuantía en gran parte del territorio y su elevada variabilidad temporal y espacial.

El total medio anual ha servido tradicionalmente para distinguir tres grandes áreas: la España lluviosa, seca y semidesértica. El mapa de precipitación media anual de España es muy complejo, con muchos enclaves de alta o baja pluviometría relativa insertos en comarcas de signo opuesto (figura 4.11).

A una escala de conjunto, la precipitación anual en la Península Ibérica disminuye de norte a sury de oeste a este, por lo que en la diagonal imaginaria que une Galicia y Almería se produce el contraste pluviométrico extremo. 


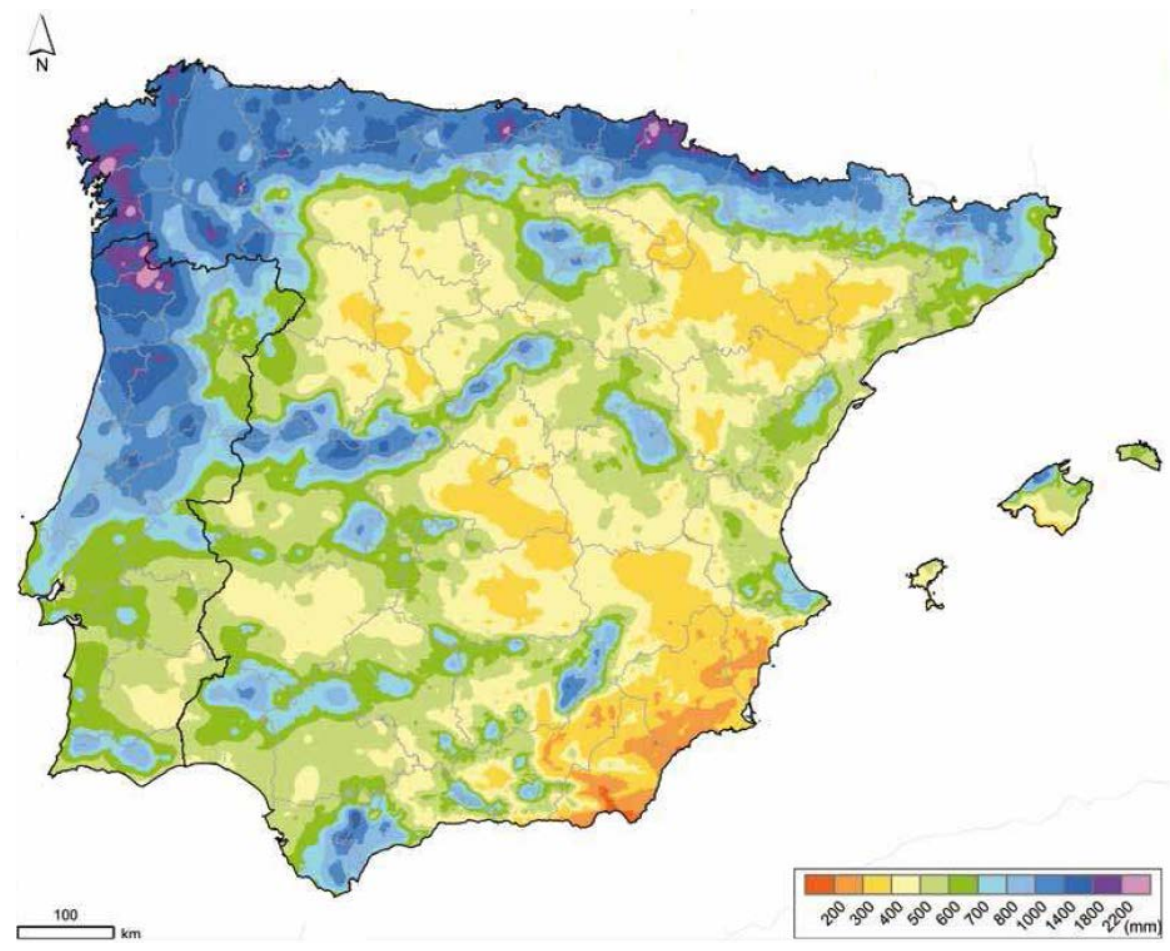

Figura 4.11: Precipitación media anual (mm)(1971-2000) (Elaborado por el INM)

Consustancial con los climas mediterráneos, la pluviometría de gran parte de España se caracteriza por su elevada variabilidad interanual. Tenemos un umbral del coeficiente de variación anual que varía del 20 al $40 \%$, lo que indica que hay zonas con una variabilidad interanual muy alta. A esto hay que añadir que hay una extraordinaria variedad de regímenes pluviométricos estacionales.

Al igual que sucede con la precipitación anual en términos de cuantía, en la península ibérica podemos afirmar que el número medio anual de días con precipitación apreciable disminuye con claridad de norte a sur, y algo de oeste a este y que hay una gran variabilidad según la zona en el número de días con lluvia al año, que oscila entre los más de 100 y menos de 50 días.

Si se usa el umbral de $1 \mathrm{~mm}$ para considerar un día de precipitación, parte del Sureste peninsular contabiliza menos de 30 días al año, mientras que en el norte llegan aún a sobrepasarse los 140 días. En consecuencia, la frecuencia de la precipitación en gran parte de la península puede calificarse de relativamente baja a muy baja (Moreno, 2008).

Con respecto a la nieve se puede afirmar que es un fenómeno poco frecuente en gran parte de la península; sólo en las grandes cordilleras peninsulares el número de días de nieve adquiere relevancia.

La precipitación en forma de lluvia es el principal aporte de agua en general en la península ibérica, y el que afecta en mayor medida a las estructuras de madera expuestas al exterior. Al igual que ocurría con la temperatura, el aporte de agua en la madera tiene un efecto diferente dependiendo de la combinación que tenga con otros factores como son la temperatura, el viento, etc. 
Se pueden encontrar zonas con precipitación similary diferente comportamiento de la madera expuesta al exterior, y zonas con diferente precipitación y comportamientos similares, dependiendo de cómo este factor se combina con los demás.

\subsection{Otros elementos climáticos}

Como se comentaba anteriormente, la precipitación y la temperatura son los principales factores para definir un clima, pero nos encontramos con otros elementos que lo conforman, y que pueden modificar el comportamiento de los materiales de construcción al exterior al asociarse con los anteriormente mencionados.

\section{Radiación solar}

La península ibérica, recibe una apreciable cantidad de radiación solar, con valores inferiores a los que se registran en las latitudes tropicales bajo las altas presiones homónimas, pero similares a los que se observan en la zona ecuatorial.

\section{Insolación}

En la España peninsular la insolación media anual presenta también una amplia variación, pues los valores prácticamente se duplican entre Bilbao y Cádiz, observatorio este último en el que se rebasan las 3000 horas de sol al año. La mayor parte de la península ibérica recibe una abundante insolación.

La insolación produce un claro efecto en la madera, ya que degrada intensamente la lignina, lo que lleva a un agrisamiento general del conjunto de toda la madera. Con el tiempo se puede llegara observar que la madera tardía de los anillos de crecimiento expuestos empieza lentamente a desaparecer (por efecto combinado de la luz solary del arrastre del agua de lluvia), produciéndose los "peines de madera" tan típicos en maderas históricas al exterior (puertas, ventanas, dinteles, cabezas de vigas, etc.). En general tanto la degradación del color (agrisamiento) como los "peines" no tienen efecto sobre las propiedades estructurales de la madera.

\section{Nubosidad}

Con los datos de insolación y de número de días de cielo despejado y de cielo cubierto se estima que el número medio anual de días despejados está comprendido entre sólo 25,8 (aeródromo de Vitoria) y 155,8 (Cádiz), lo que permite hacerse una idea de los contrastes en la península ibérica.

A nivel de material la madera afecta de manera indirecta en el caso de la insolación, que se ve reducida, aunque no tiene un efecto directo, y de manera directa cuando viene acompañada de humedad y se produce la precipitación, pero en principio es un efecto menor. 


\section{Humedad del aire}

Los valores de la humedad relativa media anual varían entre el 88 y el $49 \%$, siendo el norte de la España peninsulary los litorales los espacios con mayor humedad relativa; por el contrario, son las tierras más alejadas del mar, Madrid y sus alrededores, las de menor promedio anual.

La alta humedad el aire afecta al material cuando se encuentra expuesto al exterior, como se sabe la madera es un material higroscópico y tiende a estar en equilibrio con el medio circundante, pero el efecto de la humedad ambiental para que se refleje en el material, y máxime a una profundidad que pueda afectar a un material como el CLT, debe ser prolongada y en ausencia de otros factores como la temperatura, la insolación o el viento, que podrían minimizar su efecto.

Es en zonas de costa donde este nivel de humedad es suficiente para tener un efecto perceptible en el comportamiento de la madera al exterior.

\section{Presión atmosférica}

La presión atmosférica muestra en una buena parte de España su máximo mensual en invierno, casi siempre en enero, y los valores más bajos en primavera, sobre todo abril, y verano, patrón que puede parecer el opuesto al esperado.

La altitud es otro factor que puede influir en el comportamiento de la madera al exterior, entre otros factores por la diferencia de presión atmosférica, que condiciona la entrada y salida de agua en la madera.

\section{Vientos}

La orografía de la península ibérica favorece la existencia de vientos regionales y locales que se constituyen en elementos de significación climática en las áreas en que soplan. Como vientos regionales pueden destacarse, entre otros, el cierzo, la tramontana, el levante, el poniente y el ábrego. Al margen de ellos, el régimen de brisas marinas caracteriza la atmósfera de los litorales durante la mitad cálida del año y en otras jornadas estables.

Teniendo en cuenta que España es el país más montañoso de la península ibérica después de Suiza, nos encontramos con una gran variabilidad de climatología tanto por la diferencia de latitud y longitud, como por la diferencia altitudinal.

El viento puede influir en la evaporación del agua en la madera, pero no solo afecta en este caso, también hay que tener en cuenta los vientos dominantes de lluvia, que en el caso que nos ocupa pueden condicionar el comportamiento del material. Uno de los factores a tener en cuenta a la hora de diseñar una estructura de madera al exterior son los vientos dominantes de lluvia, para tratar de minimizar su efecto con las medidas de diseño. 


\subsubsection{Climatología en el CTE}

Para establecer una clasificación climática de la Península Ibérica, algunos autores, como KöppenCeiger, han utilizado indicadores básicos meteorológicos, basados en el empleo de las precipitaciones anuales y de las temperaturas medias, para establecer una clasificación biogeográfica del lugar. Para delimitar los distintos climas se establecen intervalos de temperatura y precipitación, basados en la incidencia del clima sobre la vegetación y la actividad humana.

Otros autores, como el meteorólogo y climatólogo Inocencio Font Tullot, establecen una clasificación climática de la Península Ibérica basada en otros indicadores factores como el índice de continentalidad y el régimen pluviométrico.

Para poder realizar estudios de eficiencia energética y establecer las limitaciones reglamentarias sobre un edificio es necesario poder parametrizar de una forma simplificada el comportamiento del clima a través de sus variables meteorológicas más significativas.

Esta parametrización del clima debe ser lo suficientemente precisa como para poder establecer diferencias entre unas y otras zonas climáticas, además de ser, las metodologías empleadas, lo suficientemente simplificadas, como para poder operar de forma sencilla con las diferentes variables climatológicas que se emplean, de manera que se puedan obtener resultados representativos de cada localidad geográfica de una forma operativa y suficientemente aproximada a la realidad.

Una forma simplificada de poder trabajar con el clima del lugar es emplear el concepto de severidades climáticas, que desarrolla el Documento de Ahorro de Energía del Código Técnico de la Edificación (CTE), y con el que se permite conocer la caracterización climática del lugar (Larrumbide et al., 2013).

Para entender las clasificaciones climáticas que se establecen en el DB-HE del CTE, se deben tener claros una serie de conceptos, como son:

- Zona climática: zona para la que se definen unas solicitaciones exteriores comunes a efectos de cálculo de la demanda energética. Se identifica mediante una letra, correspondiente a la severidad climática de invierno, y un número, correspondiente a la severidad climática de verano.

- Clima de referencia: clima normalizado que define los parámetros climáticos (temperatura, radiación solar...) representativos de una zona climática concreta para el cálculo de la demanda. Permite estandarizar las solicitaciones exteriores.

- Severidad climática: cociente entre la demanda energética de un edificio en una localidad y la correspondiente al mismo edificio en una localidad de referencia. En la reglamentación actual se ha tomado Madrid como localidad de referencia, siendo, por tanto, su severidad climática la unidad. Se define una severidad climática de verano y otra de invierno.

Como apoyo al DB HE, y para definir las zonas climáticas, se expone a continuación, a título informativo, las correlaciones que relacionan algunos parámetros climáticos con las severidades climáticas de verano e invierno, así como los intervalos de valores empleados para definir las zonas climáticas del DB HE.

Este documento de apoyo al DB HE describe los parámetros que caracterizan los climas de referencia del DB HE, las correlaciones que se han establecido para determinar las severidades climáticas estacio- 
nales y los intervalos de severidades climáticas considerados para definir los climas de referencia del DB HE.

El clima de referencia define las solicitaciones exteriores de cálculo para un año tipo a través de una serie de parámetros (temperatura, humedad, radiación solar...), representativos de una zona climática.

Para el cálculo numérico de la severidad climática se determinan dos formulaciones basadas en correlaciones para el periodo de invierno y para el de verano. El periodo de verano se considera el intervalo comprendido de junio a septiembre, ambos inclusive, mientras que el periodo de invierno para la determinación de la severidad climática, se considera el intervalo de diciembre a febrero, ambos meses también incluidos.

\section{Severidad climática de invierno}

Para definir la severidad climática de invierno, en el documento de apoyo al DB HE, podemos ver la siguiente expresión:

$$
S C I=a \cdot C D+b \cdot \frac{n}{N}+c \cdot C D^{2}+d \cdot\left(\frac{n}{N}\right)^{2}+e
$$

donde:

CD es la suma de los grados-día de invierno en base 20 para los meses que van desde octubre a mayo

$\frac{n}{N} \quad$ es el cociente entre número de horas de sol y el número de horas de sol máximas, sumadas cada una de ellas por separado para los meses que van desde octubre a mayo

$a, b, c, d, e \quad$ son los coeficientes de regresión, cuyos valores se indican en el cuadro 4.3

Cuadro 4.3: Coeficientes de regresión para la severidad climática de invierno (SCI)

\begin{tabular}{ccccc}
\hline $\mathrm{a}$ & $\mathrm{b}$ & $\mathrm{c}$ & $\mathrm{d}$ & $\mathrm{e}$ \\
\hline $3,546 \cdot 10^{-4}$ & $-4,043 \cdot 10^{-1}$ & $8,394 \cdot 10^{-8}$ & $-7,325 \cdot 10^{-2}$ & $-1,137 \cdot 10^{-1}$ \\
\hline
\end{tabular}

Severidad climática de verano

El cálculo de la severidad climática de verano se obtiene mediante la siguiente expresión:

$$
\mathrm{SCV}=a \cdot C D+b \cdot C D^{2}+c
$$

donde:

GD es la suma de los grados-día de verano en base 20 para los meses que van desde junio a septiembre

$a, b, c \quad$ son los coeficientes de regresión, cuyos valores se indican en el cuadro 4.4 
Cuadro 4.4: Coeficientes de regresión para la severidad climática de verano (SCV)

\begin{tabular}{ccc}
\hline a & b & c \\
\hline $2,990 \cdot 10^{-3}$ & $-1,1597 \cdot 10^{-7}$ & $-1,713 \cdot 10^{-1}$ \\
\hline
\end{tabular}

\section{Definición de zonas climáticas}

La zonificación climática de invierno y de verano de la península ibérica se obtiene mediante la aplicación de las expresiones anteriores.

La zona climática de invierno se determina en función de la severidad climática de invierno (SCI), correspondiendo a cada zona climática de invierno del DB-HE (A, B, C, D y E) al intervalo indicado en el cuadro 4.5.

Cuadro 4.5: Intervalos para la zonificación de invierno

\begin{tabular}{cccccc}
\hline$\alpha$ & A & B & C & D & E \\
\hline $\mathrm{SCl} \leq 0$ & $0<\mathrm{SCl} \leq 0,23$ & $0,23<\mathrm{SCl} \leq 0,5$ & $0,5<\mathrm{SCl} \leq 0,93$ & $0,94<\mathrm{SCl} \leq 1,51$ & $\mathrm{SCl}>1,51$ \\
\hline
\end{tabular}

La zona climática de verano se determina en función de la severidad climática de verano (SCV), correspondiendo cada zona climática de verano del DB-HE $(1,2,3,4)$ al intervalo indicado en el cuadro 4.6.

Cuadro 4.6: Intervalos para la zonificación de verano

\begin{tabular}{cccc}
\hline 1 & 2 & 3 & 4 \\
\hline$S C V \leq 0,5$ & $0,5<S C V \leq 0,83$ & $0,83<S C V \leq 1,38$ & $S C V>1,38$ \\
\hline
\end{tabular}

En el DB HE 2006, para la asignación de la severidad climática se establece una combinación de los grados-día, en base a una temperatura determinada, y de la radiación solar de la localidad considerada, de forma que se puede considerar que cuando dos localidades tienen la misma severidad climática de invierno (SCl), la demanda energética de calefacción de un mismo edificio situado en ambas localidades es sensiblemente igual. Lo mismo es aplicable para la severidad climática de verano (SCV).

De esta forma para cada capital de provincia se define una combinación formada por una letra y un número. La letra corresponde a la clasificación para el invierno y el número a la clasificación del verano.

De forma simplificada, en función de la altitud de la localidad, se establece su asignación climática. De esta manera para cualquier localidad o capital de provincia de la Península Ibérica, islas Baleares, islas Canarias o las ciudades autónomas de Ceuta y Melilla, se define esta combinación de letras y números.

Para el invierno se han definido los climas A, B, C, D y E; y para el verano se determinan los climas 1, 2, 3 y 4. El clima más suaves del periodo de invierno es el A; los más fríos son el clima D y el E; y los climas B y C, son climas medios. Para el verano el más suave es el clima 1, el más extremo el 4, y los climas 2 y 3 son climas intermedios de severidad climática.

Combinando las 5 divisiones de invierno con las 4 de verano se obtendrían 20 zonas distintas, de las cuales se han establecido únicamente 12 en las cuales se ubican las localidades españolas. 
De forma gráfica las 12 zonas definidas se identifican mediante una letra, correspondiente a la división de invierno, y un número, correspondiente a la división de verano, como se muestra en el cuadro 4.7.

Cuadro 4.7: Esquema de agrupación climática de la Península Ibérica, islas Baleares, Canarias y ciudades autónomas de Ceuta y Melilla. DB HE 2006

\begin{tabular}{|l|l|l|l|}
\hline A4 & B4 & C4 & \\
\hline \multirow{2}{*}{ A3 } & \multirow{3}{*}{ B3 } & C3 & D3 \\
\cline { 3 - 4 } & & C2 & E1 \\
\cline { 3 - 4 } & & C1 & D1 \\
\end{tabular}

Avanzando en el estudio de las diferentes zonas climáticas nos encontramos con la posible problemática que se pueden producir en los cerramientos de la envolvente térmica, ante la verificación de la limitación del riesgo de formación de condensaciones intersticiales, cuya aparición puede tener importantes incidencias.

Para el cálculo de las condensaciones intersticiales en todas las capitales de provincia se aplican los criterios establecidos en Documento de Apoyo, DA DB-HE/2, relativo a la comprobación de limitación de condensaciones superficiales e intersticiales en los cerramientos (Larrumbide et al., 2014).

En la figura 4.12, se representan gráficamente las zonas climáticas de la Península Ibérica con las capitales de provincia junto a los nuevos climas de referencia definidos por el actual DB HE de 2013, donde se puede ver las posiciones relativas, desde el punto de vista climático, entre las capitales más frías y las más cálidas.

El Código Técnico de la Edificación establece en el actual Documento Básico de Ahorro de Energía DB HE de 2013, que se deben limitar los riesgos debidos a procesos que produzcan una merma significativa de las prestaciones térmicas o de la vida útil de los elementos que componen la envolvente térmica, tales como las condensaciones.

Se entiende por contenido de humedad crítico de un material, como la cantidad de agua por encima de la cual empieza la transferencia de humedad en fase líquida, pudiendo esta agua condensada, migrar hacia las capas de un lado y otro de la interfase en la que se produzcan las condensaciones intersticiales.

El contenido de humedad crítico que se emplea para realizar el estudio es el definido en el cuadro 4.8.

Cuadro 4.8: Contenido crítico de agua

\begin{tabular}{lc}
\hline Material & $\mathrm{kg} / \mathrm{m}^{3}$ \\
\hline Hormigón celular & 120 \\
\hline Ladrillo & $60-130$ \\
\hline Mortero de cemento & 180 \\
\hline Hormigón & 125 \\
\hline Ladrillo silicio-calcareo & $80-110$ \\
\hline
\end{tabular}




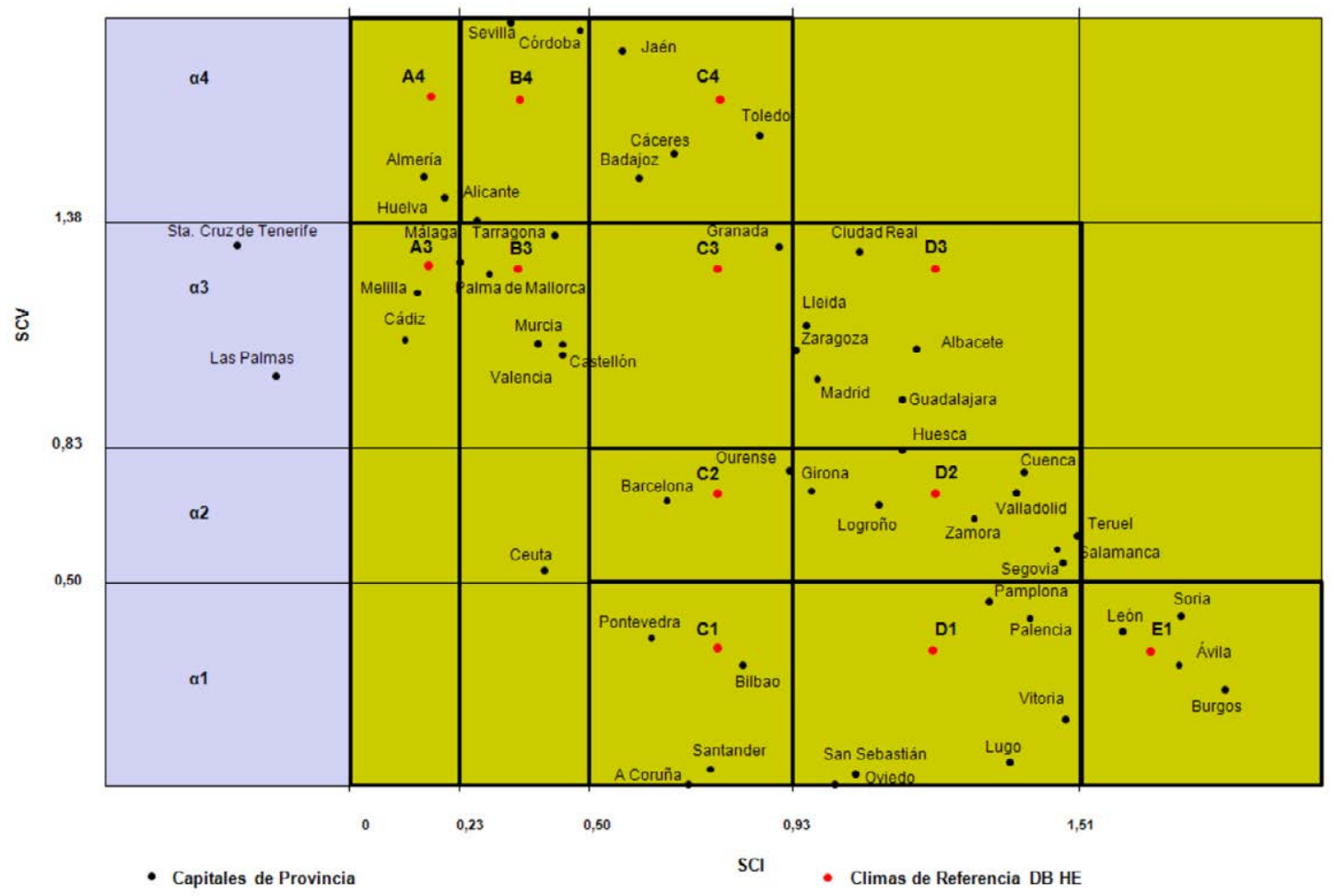

Figura 4.12: Zonas climáticas peninsulares con capitales de provincia y climas de referencia (Fuente: Larrumbide et al., 2014)

Como se observa en el cuadro 4.8, en ningún caso se contempla la madera como material de construcción, sin embargo, el riesgo de condensaciones intersticiales le afecta también a este material, y es un factor de riesgo para productos como el CLT, en el cual se puede ver afectada su vida en servicio.

A continuación, se muestra en la figura 4.13, un representación gráfica por zonas climáticas y capitales de provincia del mayor o menor riesgo de formación de condensaciones intersticiales.

En esta figura se aprecia cómo los mayores riesgos de formación de condensaciones intersticiales se manifiestan en las capitales de provincia que no son costeras, con alta severidad climática de invierno.

A la hora de analizar el riesgo de formación de las condensaciones intersticiales, no solo se debe cuidar que la presencia de agua condensada no se manifieste en la capa en la que se dispone el aislamiento térmico, sino que es importante evitar que el contenido de agua condensada no sea superior al contenido de agua crítico que admite la solución constructiva prevista, evitándose con ello las posibles patologías derivadas de la presencia de agua en el cerramiento constructivo.

\subsubsection{Climas seleccionados}

A la hora de definir los tipos climáticos representativos de un país como España, nos encontramos que por su compleja orografía y su situación geográfica, posee una notable variedad climática. Las diferen- 


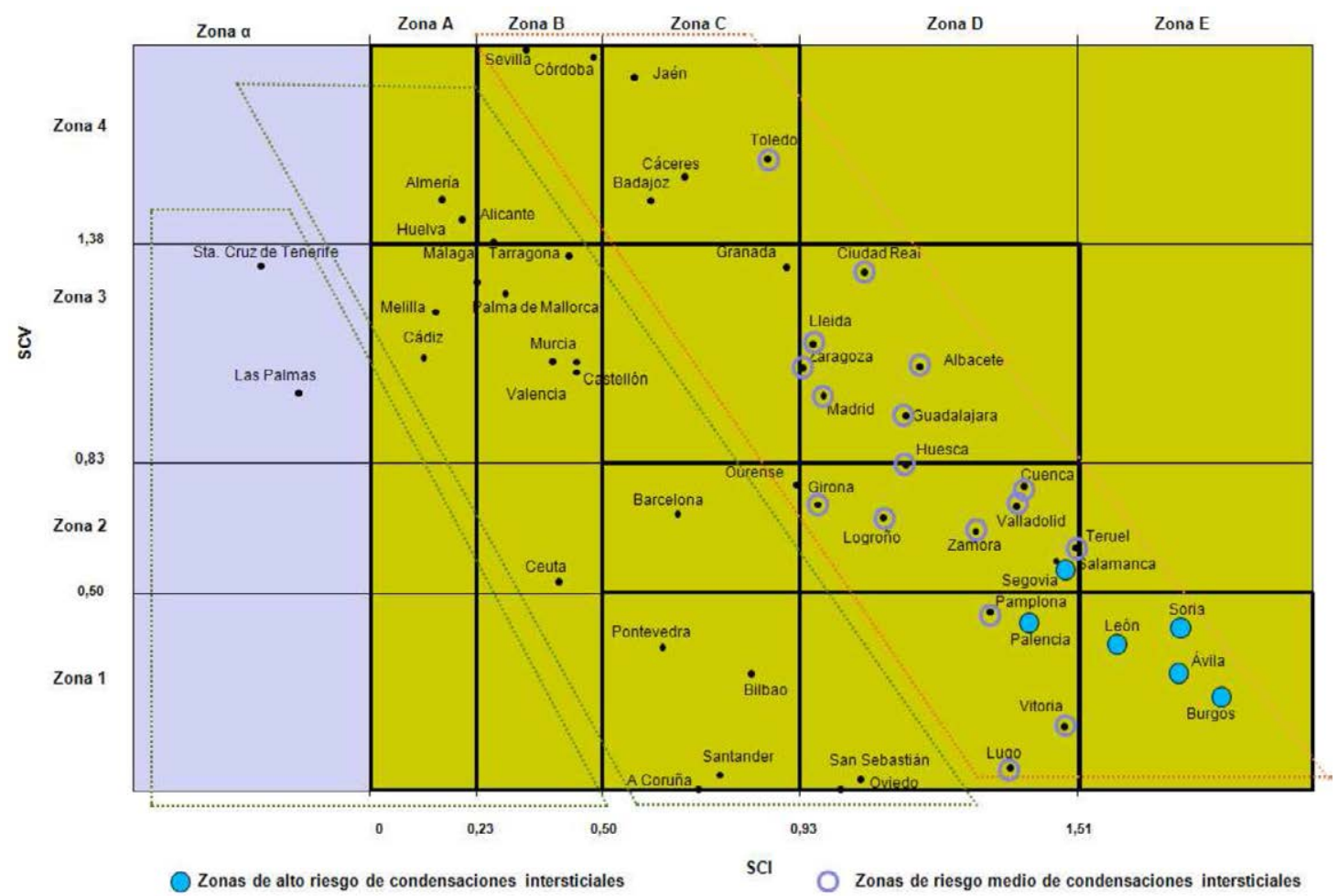

Figura 4.13: Capitales de provincia con riesgo de formación de condensaciones intersticiales (Fuente: Larrumbide et al., 2014)

cias espaciales de los valores térmicos medios anuales superan los $18^{\circ} \mathrm{C}$ en el territorio peninsular y el rango de precipitación anual promedio abarca desde apenas $150 \mathrm{~mm}$ a más de $2500 \mathrm{~mm}$.

A ello hay que añadir la elevada variabilidad climática interanual y la notable amplitud de valores diarios extremos. Así, por ejemplo, la variabilidad pluviométrica alcanza coeficientes superiores al $20 \%$ en las regiones mediterráneas y el archipiélago canario, y las secuencias de días consecutivos sin lluvia llegan a rebasar los 4 meses en la mitad meridional. La variabilidad interanual está fundamentalmente condicionada por diversos patrones de la circulación general de la atmósfera en el hemisferio norte, entre los que destaca la llamada Oscilación del Atlántico Norte (índice NAO). Por otra parte, los valores térmicos diarios extremos abarcan un intervalo de $-40^{\circ} \mathrm{Ca}+50^{\circ} \mathrm{Cy}$ los máximos de precipitación diaria llegan a superar los $500 \mathrm{~mm}$ (Moreno, 2008).

Desde el punto de vista reglamentario, según el Documento de Ahorro de Energía DB HE 2013, del Código Técnico de Edificación (CTE), se necesitan definir las diferentes zonas climáticas para el cálculo de la demanda energética, que lleve a una mayor eficiencia en el uso de los recursos. Para la cuantificación de la demanda energética es necesario definir unas condiciones de contorno, es decir, tener en cuenta unas determinadas condiciones climáticas exteriores propias de cada lugar.

Existen diversos indicadores climáticos que se emplean como elementos de medida para establecer diferentes caracterizaciones climatológicas del lugar. El DB HE emplea las variables climatológicas de temperatura y radiación solar para caracterizar las zonas climáticas (Larrumbide et al., 2014). 
Si quisiéramos hacer una selección de climas representativos de España, nos encontraríamos con una casuística muy variada debido a las diferencias señaladas. En todo caso la selección debe tener en cuenta que el estudio del CLT es el estudio de un producto dedicado a la construcción.

Teniendo en cuenta todo lo anteriormente expuesto y haciendo una primera aproximación, se decide acotar los tipos climáticos a la España peninsular, dejando aparte los diferentes archipiélagos, debido a su peculiaridad climática.

También se tiene en cuenta en esta selección, el riesgo de condensaciones intersticiales, que puede llevar como sea mencionado anteriormente a que el contenido de agua condensada sea superior al contenido de agua crítico que admite la solución constructiva prevista, lo que conlleva el riesgo de que ciertos procesos degradativos produzcan una merma significativa de las prestaciones de la vida útil de los elementos que componen la envolvente de un edificio.

En un principio se decide que los climas seleccionados no estén en la costa ya que como se ha comentado anteriormente en la costa se produce un efecto muy particular en la madera al exterior debido a la alta humedad del ambiente todo el año.

Teniendo en cuenta las apreciaciones con respecto al clima que se observan en el código técnico de la edificación y en función de los datos climáticos ya disponibles por trabajos anteriores (Noves y Cuijarro, 1984) y de la logística disponible para efectuar los trabajos campo, se consideran "a priori" las siguientes localizaciones.

- Madrid, logísticamente es la mejor ubicación ya que el centro de investigación donde se desarrolla este trabajo es allí. Se trata del clima usado como clima de referencia en el código técnico de la edificación, lo que hace que sea un clima interesante para su posterior comparación con cualquier otro clima. Según el CTE sería un clima con invierno frío (D) y con un verano intermedio (3) tirando a duro.

- Ávila, teniendo en cuenta la logística, Ávila es una ubicación relativamente cercana al centro de investigación donde se realiza el trabajo. Según el CTE sería un clima con invierno muy frío (E) y con un verano suave (1).

- Sevilla, sería la ubicación que logísticamente está más alejada del centro de investigación, pero ya que ninguno de los tipos climáticos restantes se encontraban cerca, Sevilla era un lugar con fácil comunicación. Según el CTE sería un clima con invierno medio (B) tirando a suave, y con un verano extremo (4).

En esta primera aproximación teniendo en cuenta la logística y los tipos climáticos del CTE de la edificación, se observa que las tres localidades seleccionadas, son ubicaciones claramente diferenciadas y representativas de tres climatologías diferentes, y se corresponden con climas continentales, para evitar el efecto costa comentado anteriormente.

Siguiendo con la normativa en construcción, en una segunda aproximación, si atendemos al riesgo de condensaciones intersticiales, se puede observar que según los criterios establecidos en el Documento de Apoyo, DA DB-HE/2, relativo a la comprobación de limitación de condensaciones superficiales e intersticiales en los cerramientos (Larrumbide et al., 2014), estas tres ubicaciones representan los tres casos que se contemplan: 
- Madrid, con un tipo climático D3, invierno correspondiente a zona D, y verano correspondiente a zona 3, presenta un riesgo medio de condensaciones intersticiales.

- Ávila, con un tipo climático E1, invierno correspondiente a zona E, y verano correspondiente a zona 1 , presenta un riesgo alto de condensaciones intersticiales.

- Sevilla, con un tipo climático B4, invierno correspondiente a zona B, y verano correspondiente a zona 4 , presenta un riesgo bajo de condensaciones intersticiales.

Por tanto y como se ha comentado, el CLT es un producto de construcción, por lo que es muy importante la visión climática que nos aporta el código técnico de la edificación, y publicaciones complementarias como las de Larrumbide et al. $(2013,2014)$, atendiendo a las mismas, podemos reafirmarnos en la selección de las provincias objeto de estudio, ya que con respecto al concepto de severidad climática nos encontramos con tres zonas completamente diferentes y representativas de la península ibérica. Y si se atiende al riesgo de condensaciones intersticiales, se observa que con esta selección contemplamos toda la posible casuística.

Además como suma a lo anteriormente mencionado si se observa el cuadro 4.9, correspondiente a la clasificación climática en función del régimen térmico y del régimen hídrico, de las capitales de provincia españolas (Gandullo et al., 1998), se observa que se corresponden con tres tipos climáticos totalmente diferentes, tanto desde el punto de vistas del régimen hídrico como del régimen térmico.

Encontrándonos con una clasificación climática que da unas tipologías similares a las del CTEy que en todo caso diferencia claramente a las tres ubicaciones escogidas.

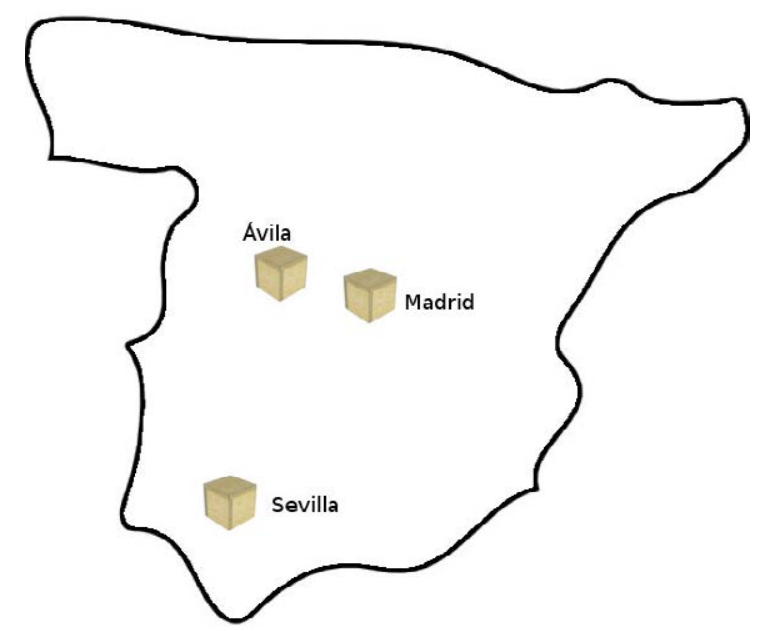

Figura 4.14: Situación de las probetas en los climas representativos seleccionados 
Cuadro 4.9: Clasificación climática de las capitales de provincia (Fuente: Gandullo et al., 1998, Tabla VII)

\begin{tabular}{|c|c|c|}
\hline Ciudad & Régimen Térmico & Régimen Hídrico \\
\hline Almería & templado-cálido de inviernos tibios & árido estricto \\
\hline Cádiz & templado-cálido de inviernos tibios & mesoxérico a perxérico \\
\hline Córdoba & templado-cálido de inviernos tibios & euxérico a semiárido \\
\hline Granada & templado-cálido de inviernos tibios & euxérico a semiárido \\
\hline Huelva & templado-cálido de inviernos tibios & perxérico a semiárido \\
\hline Jaén & templado-cálido de inviernos tibios & euxérico a semiárido \\
\hline Málaga & templado-cálido de inviernos tibios & perxérico a semiárido \\
\hline Sevilla & templado-cálido de inviernos tibios & euxérico a semiárido \\
\hline Huesca & templado-frío de inviernos frescos & oligoxérico a euxérico \\
\hline Teruel & templado-frío de inviernos frescos & euxérico estricto \\
\hline Zaragoza & templado-cálido de inviernos frescos & semiárido estricto \\
\hline Oviedo & templado-frío de inviernos tibios & subxérico a oligoxérico \\
\hline Palma de Mallorca & templado-cálido de inviernos tibios & perxérico estricto \\
\hline Las Palmas & cálido & árido estricto \\
\hline Santa Cruz de Tenerife & cálido & árido estricto \\
\hline Santander & templado-frío de inviernos tibios & axérico a subxérico \\
\hline Ávila & templado-frío de inviernos fríos & perxético estricto \\
\hline Burgos & templado-frío de inviernos frescos & oligoxérico a mesoxérico \\
\hline León & templado-frío de inviernos frescos & oligoxérico a euxérico \\
\hline Palencia & templado-frío de inviernos frescos & euxérico a perxérico \\
\hline Salamanca & templado-frío de inviernos frescos & euxérico a perxérico \\
\hline Segovia & templado-frío de inviernos frescos & mesoxérico a euxérico \\
\hline Soria & templado-frío de inviernos fríos & oligoxérico a mesoxérico \\
\hline Valladolid & templado-frío de inviernos frescos & mesoxérico a euxérico \\
\hline Zamora & templado-frío de inviernos frescos & perxérico estricto \\
\hline Albacete & templado-frío de inviernos frescos & perxérico estricto \\
\hline Ciudad Real & templado-cálido de inviernos frescos & euxérico a semiárido \\
\hline Cuenca & templado-frío de inviernos frescos & oligoxérico a euxérico \\
\hline Guadalajara & templado-frío de inviernos frescos & euxérico a perxérico \\
\hline Toledo & templado-cálido de inviernos tibios & perxérico a semiárido \\
\hline Barcelona & templado-cálido de inviernos tibios & mesoxérico estricto \\
\hline Girona & templado-cálido de inviernos tibios & subxérico a oligoxérico \\
\hline L7eida & templado-cálido de inviernos frescos & perxérico estricto \\
\hline Tarragona & templado-cálido de inviernos tibios & euxérico estricto \\
\hline Alicante & templado-cálido de inviernos tibios & semiárido estricto \\
\hline Castellón & templado-cálido de inviernos tibios & perxérico estricto \\
\hline Valencia & templado-cálido de inviernos tibios & perxérico estricto \\
\hline Badajoz & templado-cálido de inviernos tibios & euxérico a semiárido \\
\hline Cáceres & templado-cálido de inviernos tibios & perxérico a semiárido \\
\hline La Coruña & templado-frío de inviernos tibios & subxérico a oligoxérico \\
\hline Lugo & templado-frío de inviernos frescos & subxérico a mesoxérito \\
\hline Orense & templado-frío de inviernos tibios & oligoxérico a euxérico \\
\hline Pontevedra & templado-frío de inviernos tibios & subxérico a oligoxérico \\
\hline Logroño & templado-frío de inviernos frescos & euxérico estricto \\
\hline Madrid & templado-cálido de inviernos frescos & euxérico a perxérico \\
\hline Murcia & templado-cálido de inviernos tibios & árido estricto \\
\hline Pamplona & templado-frío de inviernos frescos & subxérico a oligoxérico \\
\hline Bilbao & templado-frío de inviernos tibios & axérico a subxérico \\
\hline San Sebastián & templado-frío de inviernos tibios & axérico estricto \\
\hline Vitoria & templado-frío de inviernos frescos & subxérico a oligoxérico \\
\hline
\end{tabular}




\subsubsection{Diseño de los prototipos}

Para llevar a cabo el diseño de los prototipos que se van a situar al exterior debemos tener en cuenta la finalidad del estudio, que es la evaluación del comportamiento al exterior como paramento vertical sin contacto con el suelo, del CLT.

Lo primero a la hora de diseñar el prototipo para exterior es definir el tamaño y la forma. Aunque el CLT como producto presenta una gran versatilidad, lo que permite casi cualquier forma geométrica no curva, para la investigación se selecciona la forma más simple que pueda cumplir con las necesidades de estudio.

Con el objetivo de analizar profundamente el comportamiento del CLT al exterior, y hacer este estudio de durabilidad lo más completo posible, se plantea la posibilidad de estudiar la influencia de la orientación en la degradación del producto expuesto al exterior. Para ello se plantea que el prototipo tenga exposición a las cuatro orientaciones. Teniendo en cuenta las premisas mencionadas, la forma geométrica más sencilla que me permite tener en cuenta las cuatro orientaciones es el cubo.

Al someter a exposición exterior un producto como el CLT, la entrada de humedad en la madera en general, y en este producto en particular, no se produce a la misma velocidad ni en la misma cuantía en la cara que en la testa, factor que hay que tener en cuenta a la hora de calcular el tamaño de los prototipos que se colocarán al exterior, para tratar de minimizar el efecto borde que se produce en productos de madera como el CLT.

Cuando se habla del efecto borde de la madera, se hace referencia a que la estructura tubular marcadamente longitudinal de la madera, hace que la circulación de líquidos sea mucho más sencilla en dirección longitudinal que en dirección trasversal. Esto hace que cuando se exponen al clima exterior elementos lineales de madera se observe que el agua penetra fundamentalmente por las testas (que pone al aire la estructura longitudinal del material), lo que explica la causa por la cual lo que se suelen pudrir son las cabezas de las vigas en una longitud variable pero no superior a $50 \mathrm{~cm}$ y que en la madera de uso rural los piquetes de madera se pudran por la parte insertada en el suelo y algunos centímetros más arriba (por ascensión capilar).

Por tanto, en los tableros contralaminados no es esperable que el agua penetre en su estructura de forma rápida a través de las caras pero sí a través de las testas de las piezas de madera que conforman cada una de las láminas, lo que hace que la degradación biótica y abiótica del material se concentre en la periferia del elemento, especialmente en aquellas zonas más expuestas al agua de lluvia.

El montaje de estos prototipos se llevará a cabo de forma manual, y su transporte en una furgoneta de transporte standard, por lo que el tamaño y peso de estos prototipos no puede ser demasiado elevado, para facilitar así su transporte y montaje. Además hay que tener en cuenta el factor de producción en fábrica, tratando de escoger un tamaño que nos permita tener el mínimo residuo posible.

Teniendo en cuenta lo explicado anteriormente, a continuación vemos el tamaño de las piezas necesarias para conformar el prototipo de exterior de CLT. Según vemos en la figura 4.15, mencionado anteriormente, se propone un tamaño de panel de 1,20 x 1,20 m, para el paramento vertical que se expondrá en las cuatro orientaciones, y un panel de 1,30 × 1,30 m para la parte superior, ya que debido a 
la disposición de los paneles, para poder tapar los cantos laterales de uno de los lados, la longitud total de cada lado es de $1,30 \mathrm{~m}$.

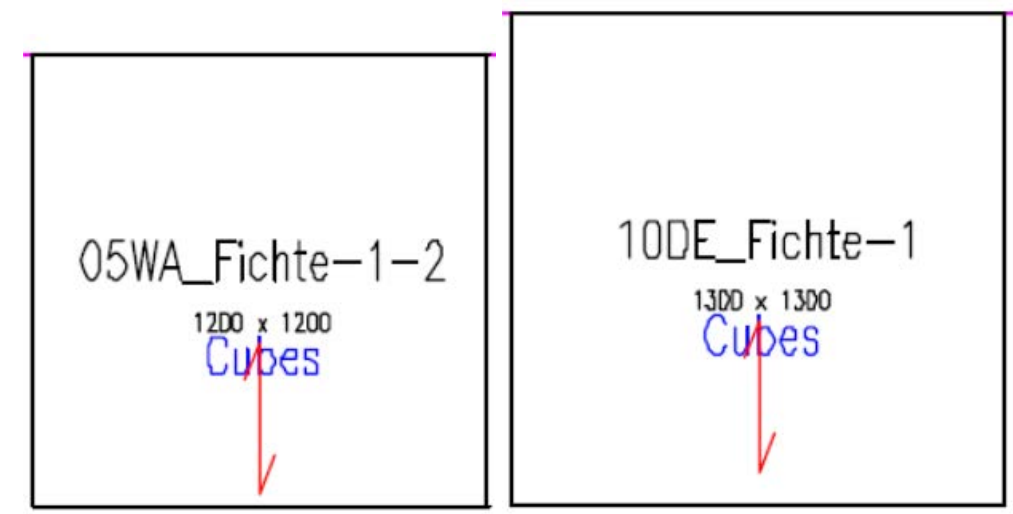

Figura 4.15: Dibujo de los paneles verticales (paramento) y el panel horizontal (cubierta)

En la figura 4.16, podemos ver la conformación del prototipo con los paneles de la figura 4.15.

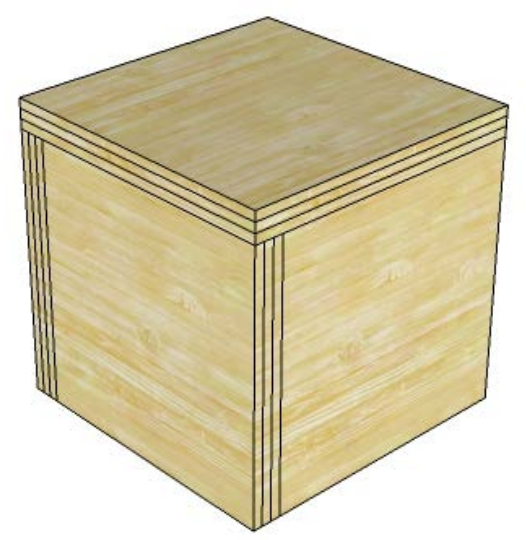

Figura 4.16: Prototipo de ensayo de CLT para su exposición al exterior

Como se puede observar en la figura anterior, los paneles de CLT que conforman el prototipo, tienen todos únicamente una testa expuesta. La testa superior queda protegida por la tapa que cierra el prototipo, y las inferiores quedan al descubierto pero aisladas del suelo. En cuanto a las laterales, solo queda una testa de cada panel expuesta, ya que la otra que protegida con el siguiente panel debido a la colocación. No obstante parte de la testa expuesta queda protegida por una cinta que se coloca entre las uniones de los paneles del prototipo para poder evaluar la degradación estética que sufre el mismo.

Otro factor a tener en cuenta a la hora de diseñar el prototipo es el aislamiento con respecto al suelo del mismo. Como se puede observar en las diferentes clases de uso, la degradación de la madera como material y por tanto del CLT como producto derivado de la madera, varía si este se encuentra en 
contacto con el suelo o no. En nuestro estudio vamos a considerar que la madera se encuentra aislada del contacto con el suelo por dos razones, una de estas razones es que es práctica constructiva habitual aislar la madera del contacto con el suelo, y otra, el poder simplificar los factores que afectan a la degradación del producto para así poder ver claramente la influencia de las distintas ubicaciones y orientaciones

En la figura 4.17, se muestra el diseño de la bancada que sirve como base para situar las probetas de CLT, aislándolas del suelo. Es una bancada de hierro, formada por dos vigas paralelas, unidas perpendicularmente por unas viguetas de menor tamaño. De estas vigas principales parten cuatro patas de hierro soldadas, donde se sitúan unas placas también soldadas (figura 4.18), que son el lugar donde se anclan mediante tornillería los paneles.

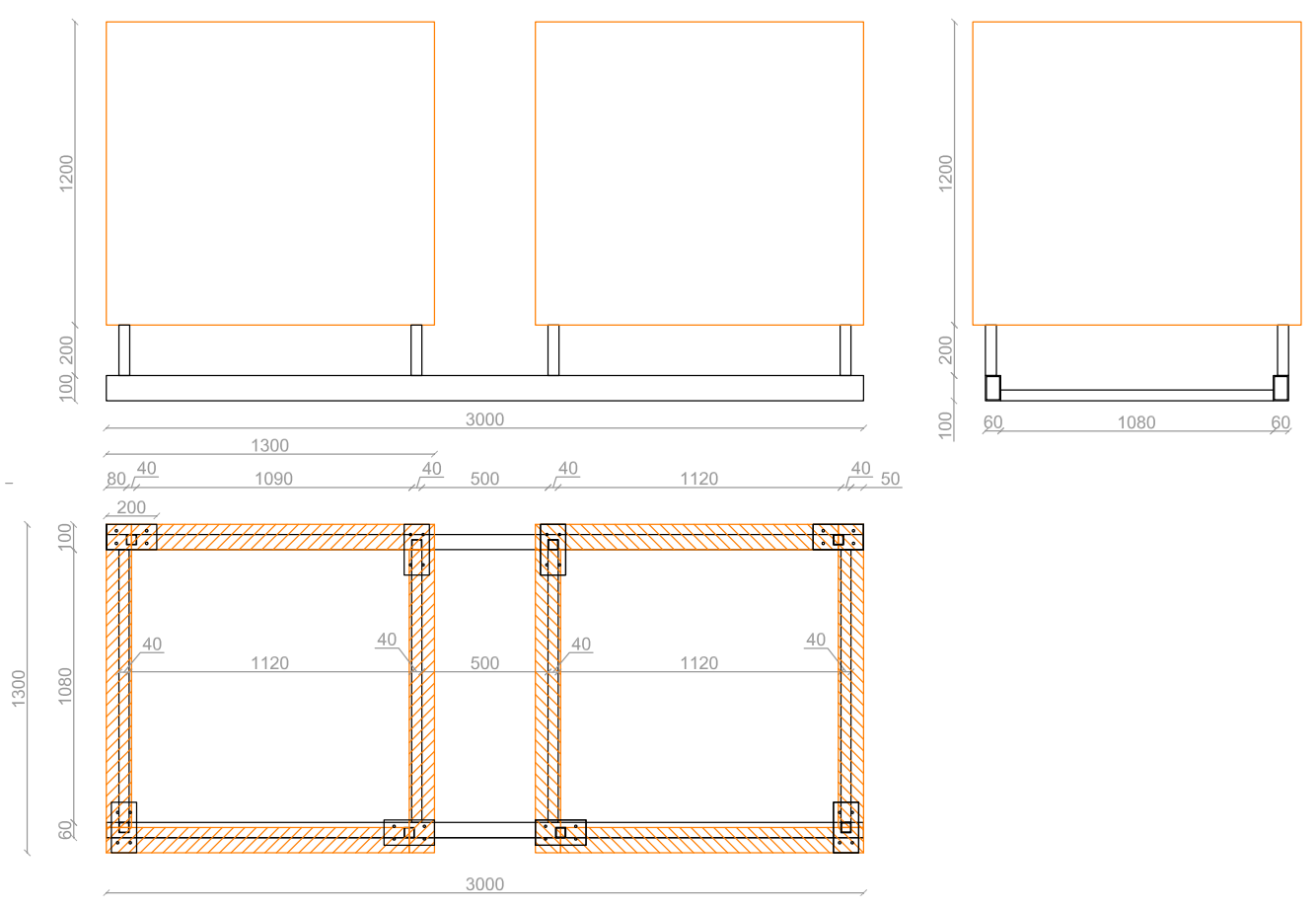

Figura 4.17: Bancada de hierro donde se colocan los prototipos al exterior

Para la conformación del prototipo y la unión del mismo a las placas de la bancada, se utiliza tornillería y herrajes típicos de la construcción con madera. Para la unión entre paneles se opta por el uso de dos angulares de acero por cada encuentro, en la figura 4.20 podemos ver sus características.

Este tipo de angulares de acero para la construcción tienen un esquema de fijación que permite la unión entre madera/madera y hormigón/madera, y a su vez diferentes esquemas de fijación, figura 4.21, dependiendo de que la unión sea parcial o total. En el esquema de fijación, los puntos negros representan los tornillos necesarios para llevar a cabo un apuntalamiento parcial, y los puntos negros sumados a los rojos serían los tornillos necesarios para llevar a cabo un apuntalamiento total. 


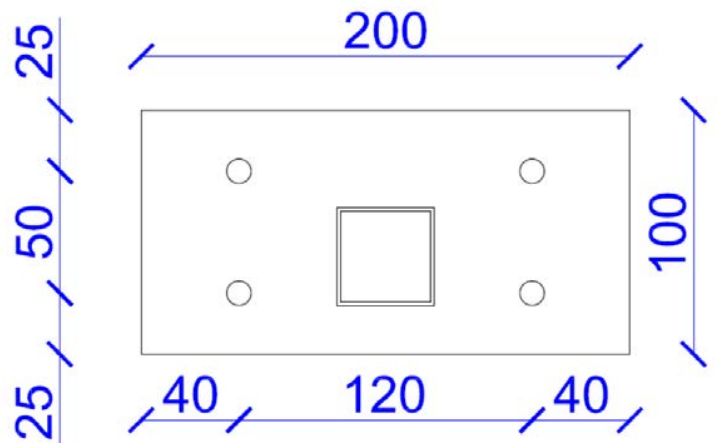

Figura 4.18: Detalle de la placa de sujeción de los paneles de CLT

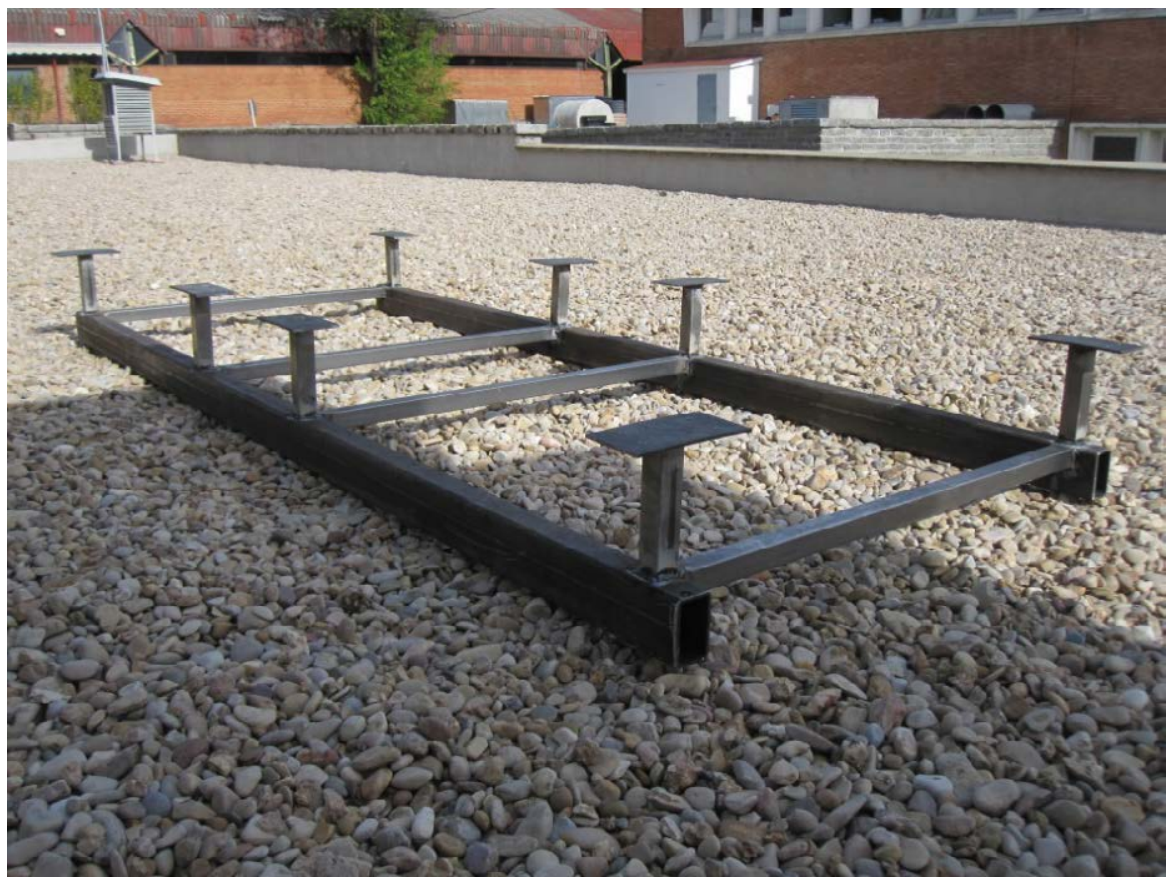

Figura 4.19: Fotografía de la bancada de hierro

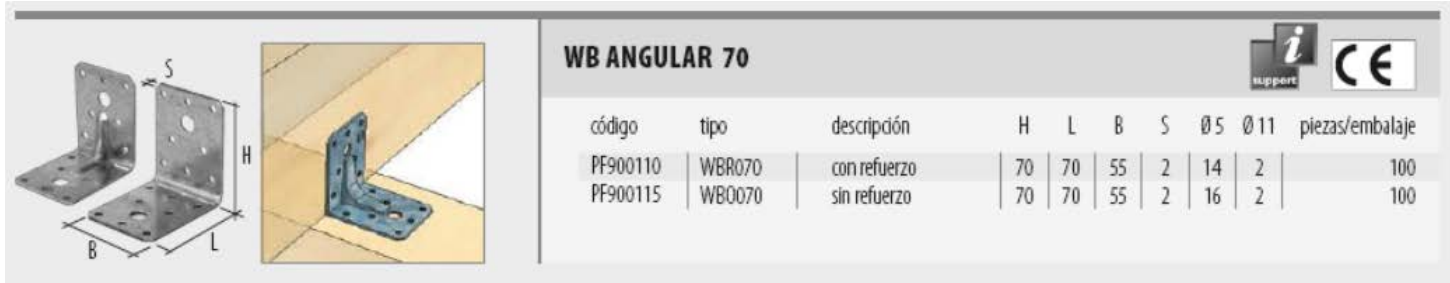

Figura 4.20: Angular de acero y sus variantes (utilizado para la unión de los paneles de CLT)

Dependiendo de la carga a la que se someta el angular y los tipos de materiales que una, llevará diferente tornillería, tanto en número como en tipo. Esto se puede observar en la figura 4.22. 

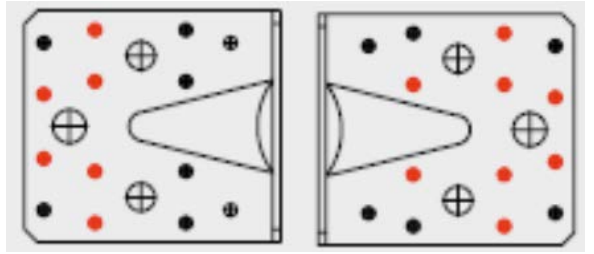

Figura 4.21: Esquema de fijación del angular para su unión madera/madera

\begin{tabular}{|c|c|c|c|c|c|}
\hline Código & Unión & $\begin{array}{c}\text { Clavos Anker } \\
\emptyset 4,0 \times 60 \\
\text { [pza.] }\end{array}$ & $\begin{array}{c}\text { Andajes } \\
\text { SKR } \emptyset 10 \times 100 \\
\text { [pza.] }\end{array}$ & $\begin{array}{c}\mathrm{R}_{2 / 3, \text { zul }} \\
\text { (admisible) } \\
\text { [KN] }\end{array}$ & $\begin{array}{c}\mathrm{R}_{2 / 3, \mathrm{k}} \\
\text { (caracteristico) } \\
{[\mathrm{KN}]}\end{array}$ \\
\hline PF900110 & Madera/Madera & 12 & - & 1,8 & 3,9 \\
\hline PF900110 & Hormigón/Madera & 5 & 1 & 0,9 & 1,8 \\
\hline PF900115 & Madera/Madera & 13 & - & 1,9 & 4,3 \\
\hline PF900115 & Hormigón/Madera & 5 & 1 & 0,9 & 2,0 \\
\hline
\end{tabular}

Figura 4.22: Valores estáticos para la unión de corte en el caso de un apuntalamiento total

Tanto para la unión de los paneles a la base donde se ubicarán al exterior, como para la unión entre paneles mediante angulares, se utilizará el mismo tipo de tornillo. Un tornillo de acero de la empresa Rothoblaas cuyas características se pueden ver en la figura 4.23.

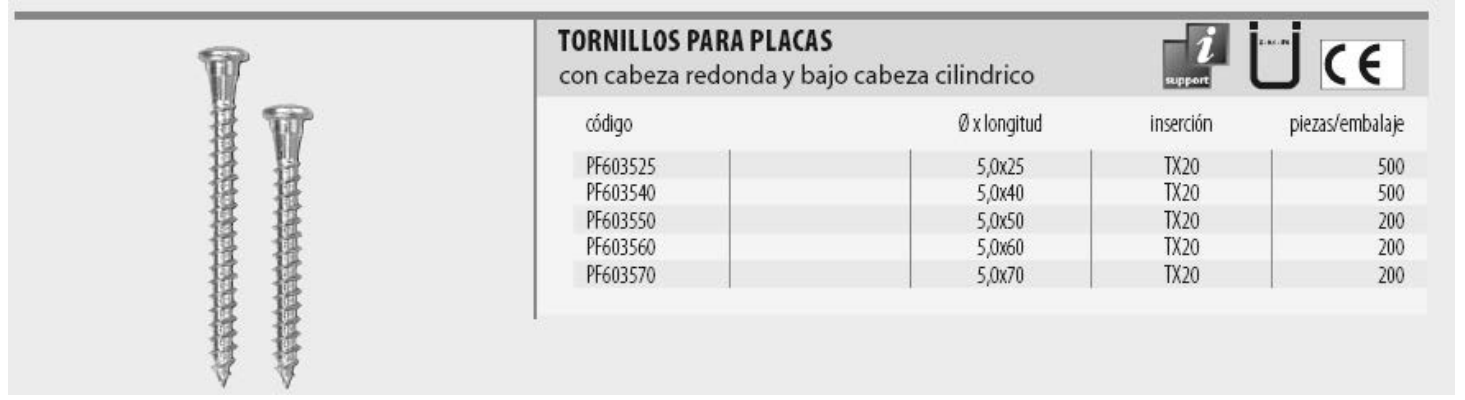

Figura 4.23: Tornillo de acero y sus variantes (utilizado para la unión de los paneles de CLT)

En la figura 4.24, se muestran los valores estáticos para los tornillos elegidos según el espesor de la placa del angular utilizado.

\begin{tabular}{|c|c|c|c|c|c|c|}
\hline \multirow[t]{2}{*}{ Espesor placa } & \multirow{2}{*}{$\begin{array}{c}\mathrm{V}_{\text {zul }} \text { admis. } \\
{[\mathrm{kNV}]} \\
5,0 \mathrm{xL}\end{array}$} & \multicolumn{5}{|c|}{$\begin{array}{c}\mathrm{R}_{\mathrm{v}, \mathrm{k}} \text { Característico } \\
{[\mathrm{kN}]}\end{array}$} \\
\hline & & $5,0 \times 25$ & $5,0 \times 40$ & $5,0 \times 50$ & $5,0 \times 60$ & $5,0 \times 70$ \\
\hline $\mathrm{s}=2,00 \mathrm{~mm}$ & 0,53 & 0,96 & 1,51 & 1,70 & 1,79 & 1,89 \\
\hline $\mathrm{s}=3,00 \mathrm{~mm}$ & 0,53 & 1,28 & 1,85 & 1,97 & 2,07 & 2,16 \\
\hline $\mathrm{s}=5,00 \mathrm{~mm}$ & 0,53 & 1,31 & 1,91 & 2,03 & 2,13 & 2,22 \\
\hline
\end{tabular}

Figura 4.24: Valores estáticos para los tornillos unión de corte madera - acero

Tanto los angulares como los tornillos escogidos presentan unos valores de resistencia muy superiores 
a los requerimientos que en realidad van a tener del prototipo, por lo que se decide utilizar un apuntalamiento parcial utilizando únicamente 4 tornillos por angular. Para la unión de los paneles de CLT se utilizan dos angulares en cada encuentro. Con respecto a la fijación de los paneles a la estructura metálica se utilizarán todos los tornillos que aparecen en el diseño de la placa de sujeción (figura 4.18).

Además de lo comentado anteriormente, y con el fin de evitar la entrada de agua por la testa superior, se colocaran unos vierte aguas de aluminio, que se fijaran al panel superior de CLT del prototipo, mediante la tornillería explicada anteriormente. De igual manera y con el fin de evitar la entrada excesiva de agua por la testa inferior del panel, se colocará una cinta americana en la parte inferior del panel que hará las veces de goterón. En la figura 4.25 se puede apreciar tanto el goterón inferior, como el vierte aguas de la parte superior.

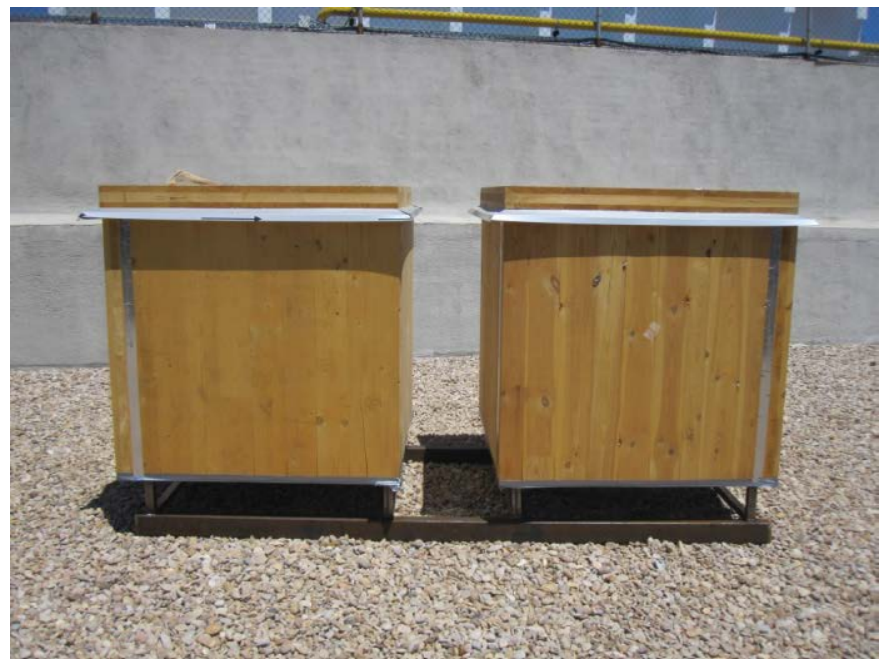

Figura 4.25: Prototipos de CLT (Madrid)

El montaje de los prototipos se llevó a cabo de forma manual, como se puede observar en la figura 4.26.

\subsubsection{Monitorización}

El conocimiento de las condiciones ambientales puede suponer una estrategia de prevención de daños, en tanto en cuanto permite detectar variaciones ambientales que pueden favorecer el deterioro de un material, esta detección permite tomar medidas de protección antes de que este deterioro ocurra, con el consiguiente ahorro de costes a largo plazo (Aparicio et al., 2014).

Las tecnologías inalámbricas WSNs (Wireless Sensor Networks) se están empleando actualmente en una variedad de aplicaciones reales. Las redes de sensores inalámbricos consisten en dispositivos embebidos, sin cables, capaces de emplear gran variedad de sensores electrónicos. La característica más atractiva de las redes de sensores inalámbricos es su autonomía evitando la necesidad de un costoso y desagradable cableado entre nodos.

La investigación y el desarrollo en la tecnología WSN se inició en los años 90 mediante sensores integrados para la monitorización de estructuras (Structural Health Monitoring, SHM). SHM se refiere a 


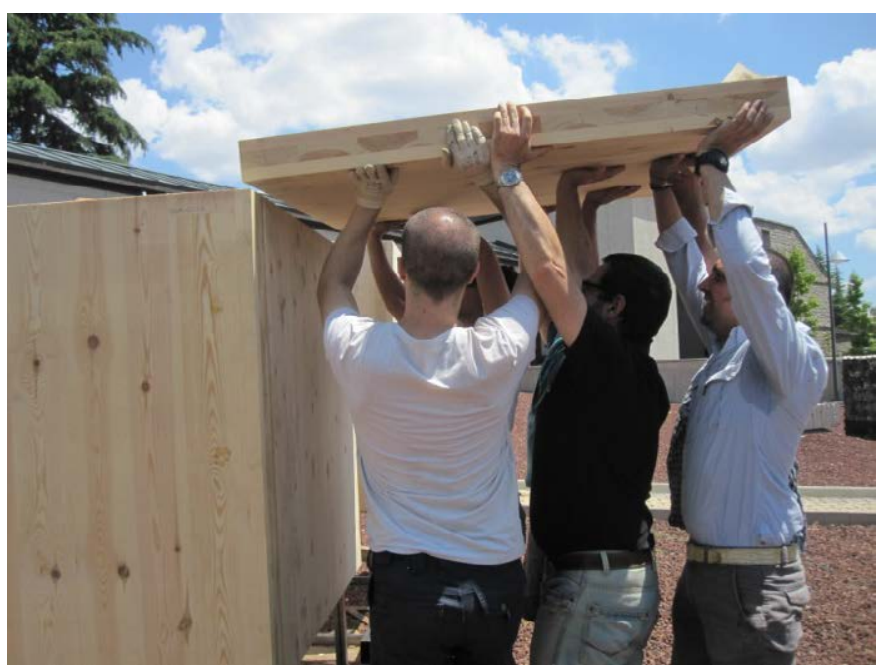

Figura 4.26: Montaje manual de los prototipos exteriores (Ávila)

sensores, instrumentación y métodos para la monitorización "in situ" de la integridad de estructuras críticas tales como aviones, puentes y edificios. Para distinguir entre los efectos producidos por factores externos y los inducidos por la degradación intrínseca de la estructura, se requiere el análisis a largo plazo (Phares et al., 2005).

Hay numerosas publicaciones sobre el estudio de las WSN para la evaluación de la integridad estructural (Santana-Sosa et al., 2006; Grosse y Krüger, 2006), y se han obtenido resultados prometedores en la monitorización de diferentes estructuras, pero se requiere más trabajo para mejorar su fiabilidad para su uso en la evaluación estructural. En Lynch y Loh (2006) se puede encontrar un análisis exhaustivo sobre WSN usados en la monitorización y seguimiento de estructuras.

Conocer el clima del material es necesario para poder analizar la aptitud al uso del CLT, saber si durante su exposición cambia de clase de uso y los valores de humedad y temperatura que el material posee son necesarios para poder posteriormente analizarlos y saber si la posible degradación se puede relacionar con el clima del material o con el clima exterior.

Dada la complejidad que supone el estudio del deterioro de un material a través de las condiciones microclimáticas y medioambientales existentes, es de vital importancia la elección de los parámetros a monitorizar y el diseño de la red para tal efecto (Aparicio et al., 2014).

Respecto de la técnica de monitorización para analizar la evolución de la temperatura y la humedad de la madera con el tiempo, existen numerosos y recientes trabajos (Kasal y Anthony, 2004; Saïd, 2007; Dyken y Klepp, 2010; Tannert et al., 2010; Tannert et al., 2011; Martínez Garrido et al., 2011; Dietsch et al., 2012) que han puesto de manifiesto la conveniencia y posibilidad de llevar a cabo dicha monitorización de forma continuada y remota mediante sistemas basados en la transmisión inalámbrica de datos. De esta forma los resultados quedan registrados de forma permanente en bases de datos de rápido acceso, que son de utilidad para posteriores análisis, lanzamiento de alarmas, y evaluaciones en campo por parte del personal destinado a ello. 
La implantación y desarrollo de redes de sensores inalámbricas facilita la adquisición de datos y la monitorización de las variaciones en las condiciones ambientales que puedan conducir a daños de los materiales en un estadio muy inicial al permitir detectar cambios en las propiedades.

Para ser realmente útiles en la detección continua del riesgo de degradación de elementos estructurales, de carpinterías y hasta de elementos decorativos en edificios históricos de madera (por ejemplo, cubiertas y elementos en madera de difícil acceso en edificios históricos, edificios remotos, etc.), los sensores de estos sistemas remotos tipo data-logger, deben ser ajustados (o rediseñados) para la adecuada medida del contenido de humedad de las maderas habitualmente presentes en nuestro entorno, ya que la conversión de las medidas de resistencia eléctrica en medidas de humedad de la madera la efectúan dichos data-loggers de acuerdo con curvas internas de tipo genérico que llevan a errores muy groseros cuando se trata de estimar la humedad de nuestras maderas, ya que las curvas de fábrica difieren notablemente de las adecuadas a nuestras maderas (Fernández-Colfín et al., 2012)

Por otra parte, las variaciones climáticas (y por consiguiente las variaciones en el contenido de humedad) en nuestra geografía nacional son mucho más extremas que las que hacen acto de presencia en el Centro y Norte de Europa, lo que obliga a ajustar los límites de medición de los aparatos empleados (y su rediseño). Un ejemplo de la inadecuación a nuestra realidad de los equipos usados en los trabajos efectuados en CNE radica en el hecho de que los data-loggers de humedad de madera tenían un umbral inferior de medición del $11 \%$, mientras que en nuestro entorno y en verano podemos encontrar valores del 7-8 \%, lo cual supone pasar de medir resistencias eléctricas en el entorno de 500 Mohms a 500 Cohms (cambios tecnológicos éstos importantes en el diseño del aparato).

\subsubsection{Sistema de monitorización}

Los sistemas utilizados generalmente para medir la humedad de la madera, como se ha visto en el apartado 4.1 Consideraciones previas, son sistemas de resistencia eléctrica. Como se ha comentado, para ciertos valores de humedad se requieren resistencias eléctricas muy sensibles, esto, entre otras cosas hace que las medidas sean muy exactas pero muy puntuales a la vez, es decir, que miden con mucha exactitud en un punto determinado, pero a veces, debido a que la madera no es un material homogéneo, esta medida puede no ser representativa de toda la pieza, como en el caso de los paneles de CLT.

En monitorizaciones a largo plazo, son más estables sistemas de monitorización por capacitancia, utilizados en otros estudios como (Dyken y Klepp, 2010). Estos sistemas, cuentan con sensores ambientales de humedad y temperatura, que si se colocan en unas cavidades de pequeño tamaño, dan la temperatura y la humedad ambiental a la que se encuentran el material en el que están embebidos.

Estos datos de humedad y temperatura ambiental facilitados por estos sensores capacitivos requieren de una conversión. Al igual que sucedía con los datos facilitados por los sensores por resistencia eléctrica los datos de humedad ambiental obtenidos se convertirán a datos de humedad de madera.

En definitiva se ha optado para este estudio del uso de una red de sensores mixta, que incorpora sensores capacitivos capaces de medir humedad y temperatura ambiental, que van unidos mediante cable en el interior del prototipo, pero el intercambio de información entre el mote que registra los datos de 
los sensores y la base que los incorpora al ordenador se logra a través de la emisión de ondas de radio, teniendo una transmisión inalámbrica de los datos.

\subsubsection{Parámetros de monitorización}

Como se ha comentado anteriormente en el apartado de climatología, la precipitación y la temperatura son los parámetros fundamentales para definir un clima, en el caso del clima del material estos parámetros son la humedad y la temperatura, y son los que se van a monitorizar para su posterior análisis.

La medición de esta temperatura y humedad del material se llevará a cabo mediante unos sensores de humedad y temperatura ambiental de tipo capacitivo situados dentro del material, se colocan en las cuatro orientaciones para poder evaluar este efecto en el envejecimiento del CLT.

El modelo de sensor que utilizado es el SHT75 de Sensirión. Estos sensores, calibrados de fábrica, proporcionan la información digitalizada mediante una comunicación 12C, lo cual tiene la ventaja de que la precisión y ruido de medida sea independiente de la longitud del cable y facilita su incorporación a las WSN.

Solo se situarán sensores en el interior del material, y no en el exterior, ya que los datos climáticos de ambiente exterior se tomarán de estaciones climatológicas cercanas.

Se disponen cuatro sensores en cada prototipo, estos se sitúan en el centro del panel y embebidos en el material a mitad del espesor. Para la correcta evaluación de la entrada de la humedad por la cara, el orificio que albergará los sensores se realizará desde el interior hacia al exterior.

El orificio que alberga el sensor tendrá el tamaño minimo posible para conseguir que el equilibrio de humedad y temperatura ambiental de la cavidad y el de la madera logren un rápido equilibrio, detectando así los cambios de una forma más rápida.

El efecto que se produce en la cavidad del sensor, debido a la tendencia de la madera a estar en equilibrio higroscópico con el medio (Alvarez y Fernández-Colfin, 1996), es un estado de equilibrio entre la humedad de la madera y la humedad del aire de la cavidad, o lo que es lo mismo entre la presión de agua de la cavidad y la de los poros de la madera que conectan con la cavidad. Esta relación se estudia mediante experimentos de calibración en cámara climática.

\subsubsection{Tecnología empleada}

Para cada una de las ubicaciones seleccionadas se van a utilizar ocho sensores, cuatro por cada especie objeto de estudio, atendiendo a las cuatro orientaciones que se evalúan. Para adquirir las señales de estos 8 sensores se ha adoptado una solución técnica que permitiera abaratar el sistema. Dada la cercanía entre las diferentes posiciones de los sensores en vez de utilizar un nodo de la WSN por cada uno de los sensores se optó por utilizar un el sistema WILTemp diseñado por el ITEFI del CSIC que permite conectar a un solo nodo hasta 16 sensores, cuatro individuales y 12 más mediante la utilización de tarjetas multiplexoras diseñadas específicamente para este proyecto. 

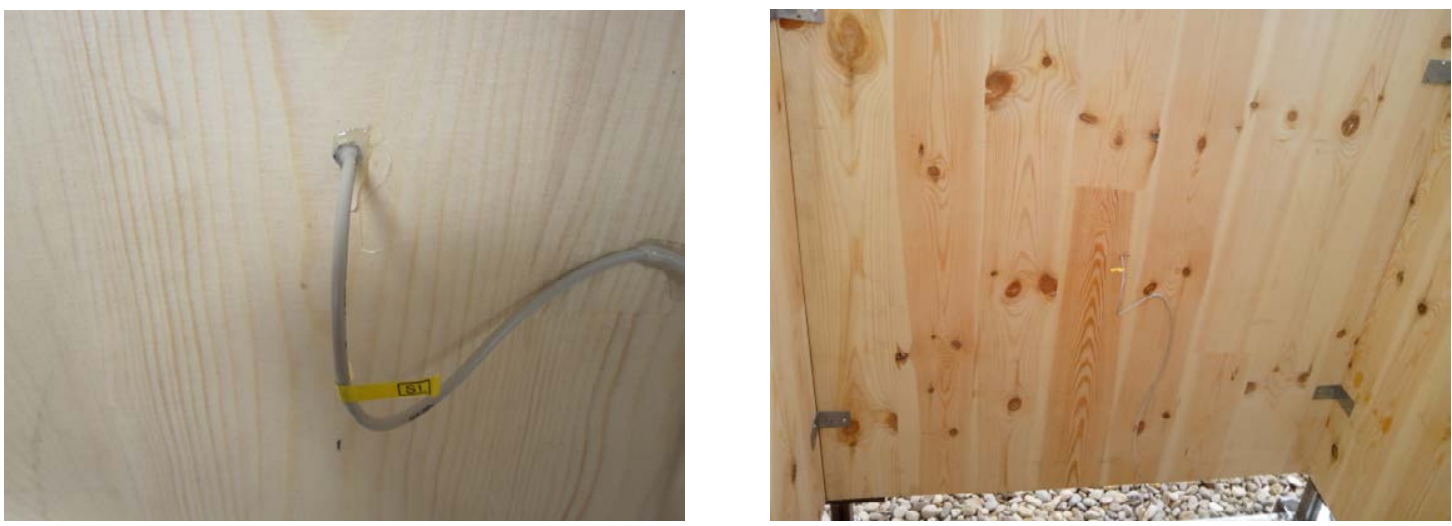

Figura 4.27: Vista desde el interior del prototipo de un sensor de temperatura y humedad embebido en la madera
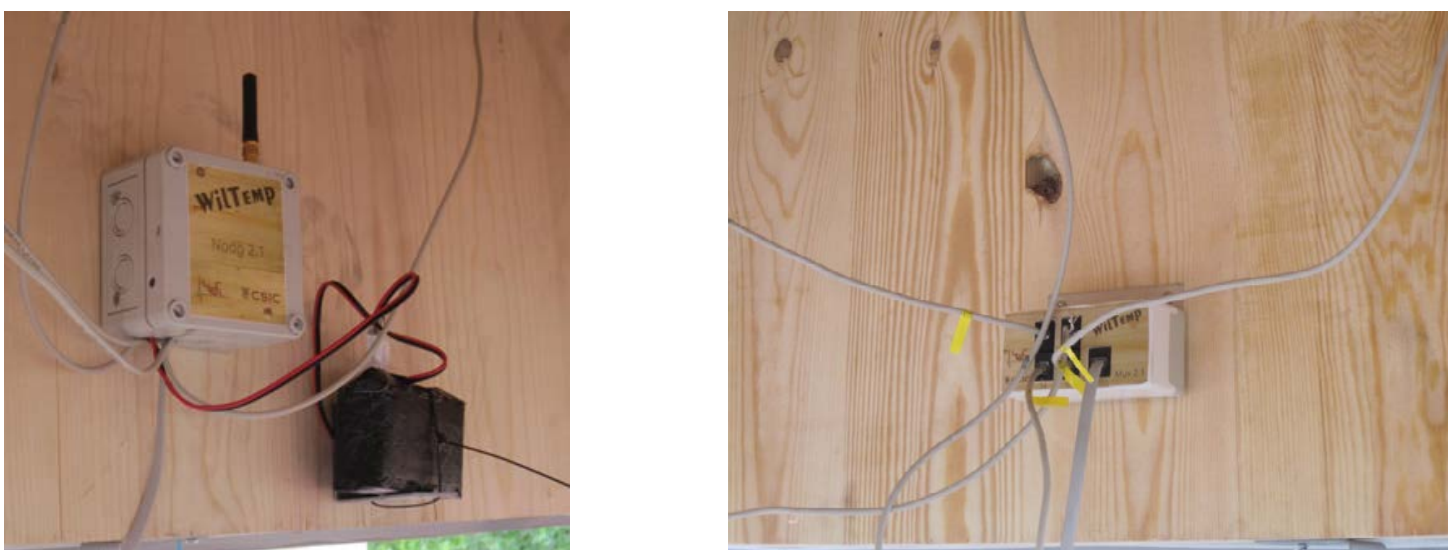

Figura 4.28: Mote y multiplexor instalados en el interior de los prototipos

La longitud de los cables tiene que ser menor de $3 \mathrm{~m}$. Por tanto para poder conectar los 8 sensores, en cada ubicación es necesario contar con un mote de Mica2, que admite cuatro sensores, y un multiplexor que admite otros cuatro. Estos nodos están basados en el mote IRIS de la compañía MEMSIC.

Los datos obtenidos en los diversos prototipos se contrastarán con las de estaciones meteorológicas cercanas con el fin de generalizar en lo posible la relación de estas medidas con condiciones ambientales normalizadas que son las que se utilizan en los diferentes estudios de durabilidad.

Con respecto a la energía para el funcionamiento de la red de sensores, y con el objetivo de facilitar la instalación de los prototipos en cualquier lugar a la intemperie, se dota a la red de un sistema autónomo de energía (pilas) que permite un funcionamiento desatendido el tiempo estimado suficiente entre revisiones de los equipos. Con doce pilas AA de $1.5 \mathrm{v}$ se consigue que la red de 8 sensores funcione por un periodo superior de 6 meses en las tres ubicaciones seleccionadas.

Es necesario que los datos adquiridos por la WSN se transmitan de forma inalámbrica a una base situada en un edificio cercano a la zona de exposición de los prototipos, en cada una de las ubicaciones.

La base receptora está conectada a un ordenador donde se almacena toda la información que se ad- 

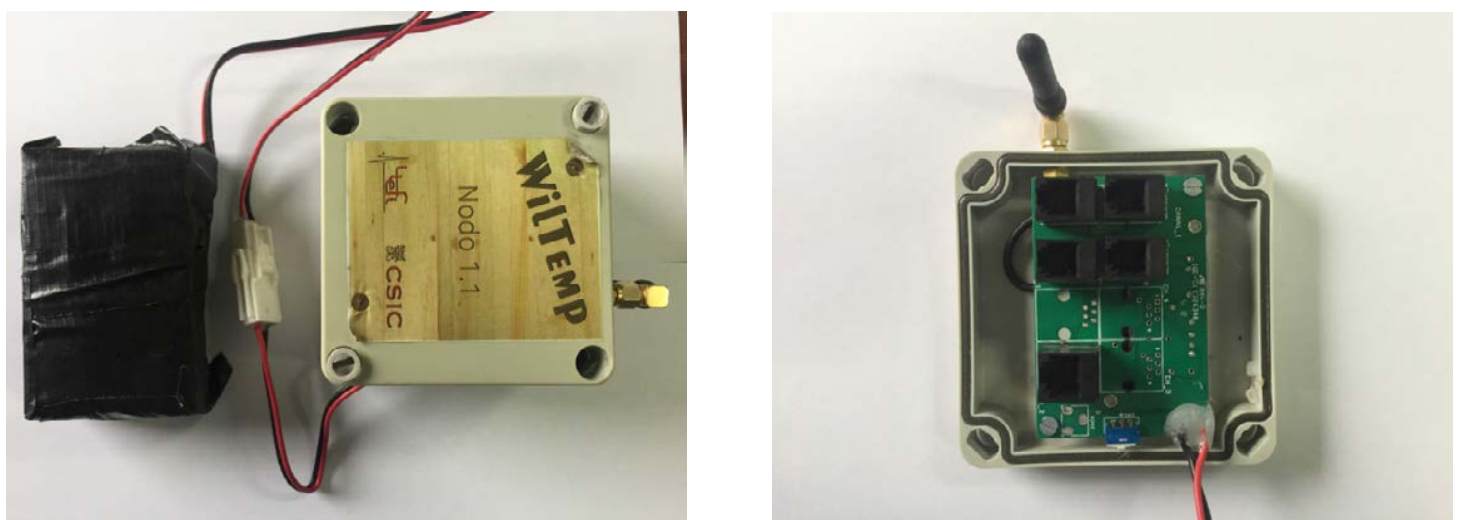

Figura 4.29: A la izquierda el MOTE con la batería y a la derecha el circuito del mote
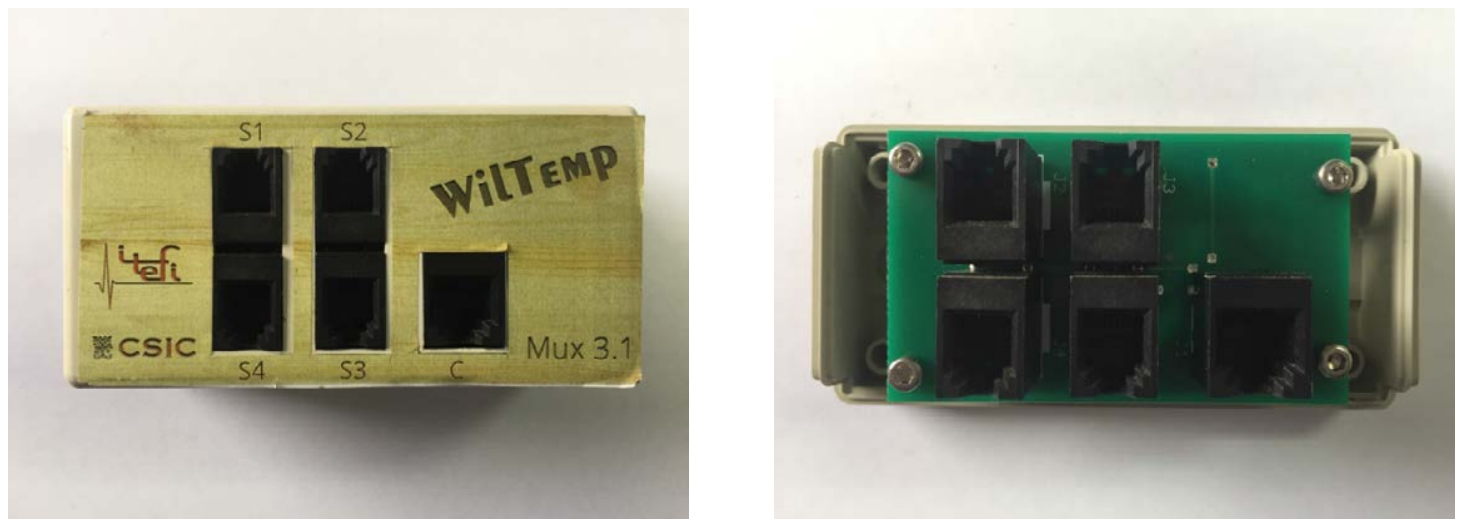

Figura 4.30: A la izquierda el Multiplexor, y a la derecha su circuito interno
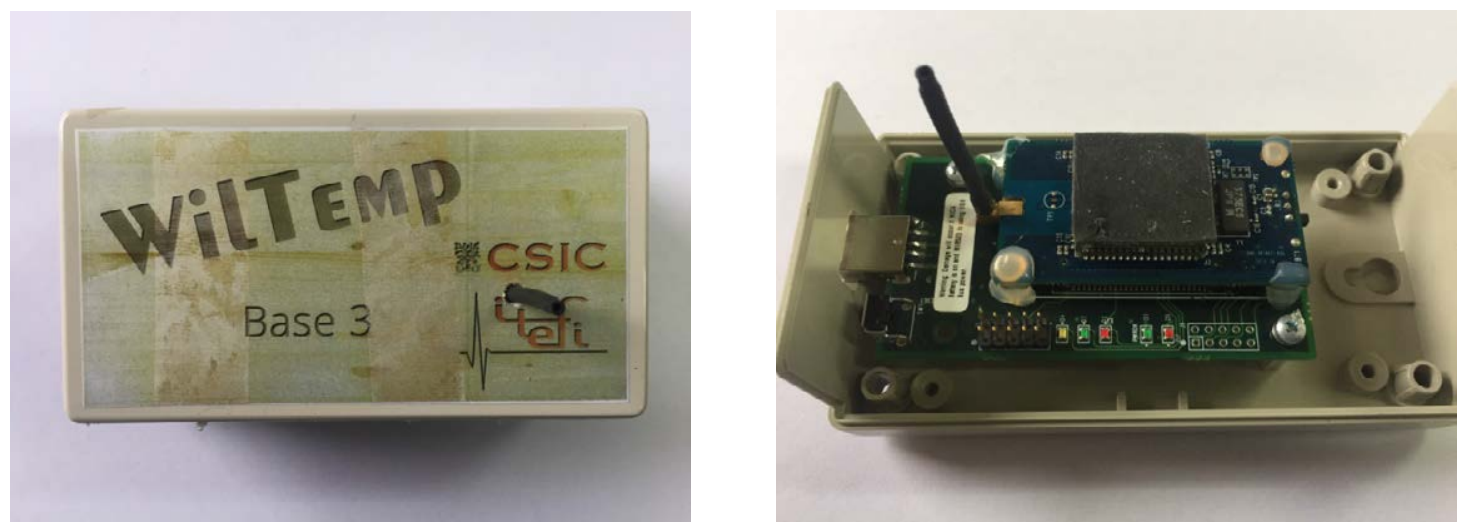

Figura 4.31: A la izquierda la base receptora, y a la derecha su circuito interno

quiere de la red. La información se guarda en el disco duro del ordenador a la vez que se adquiere de modo que no se pierda si se produce un fallo en la energía del ordenador. Hecho que se produjo en todas las ubicaciones seleccionadas. 
La conexión a internet de los ordenadores base en todas las ubicaciones donde se colocaron los prototipos, ha permitido dos utilidades adicionales, por una parte se ha podido consultar en tiempo real la adquisición de los datos y por otra los datos se han almacenado automáticamente en la "nube" para evitar una pérdida de los datos adquiridos ante una posible avería catastrófica del ordenador base.

Para el control remoto de los ordenadores se ha utilizado un programa de difusión gratuita para uso personal (Teamviewer(), que ha permitido ver las mediciones en tiempo real de temperatura y humedad, vigilar el nivel de carga de las baterías de la WSN, y detectar posibles fallos en el ordenador base o en la red. Para el almacenamiento automático de los datos en la "Nube" se ha utilizado la aplicación "Dropbox@" también de manera gratuita.

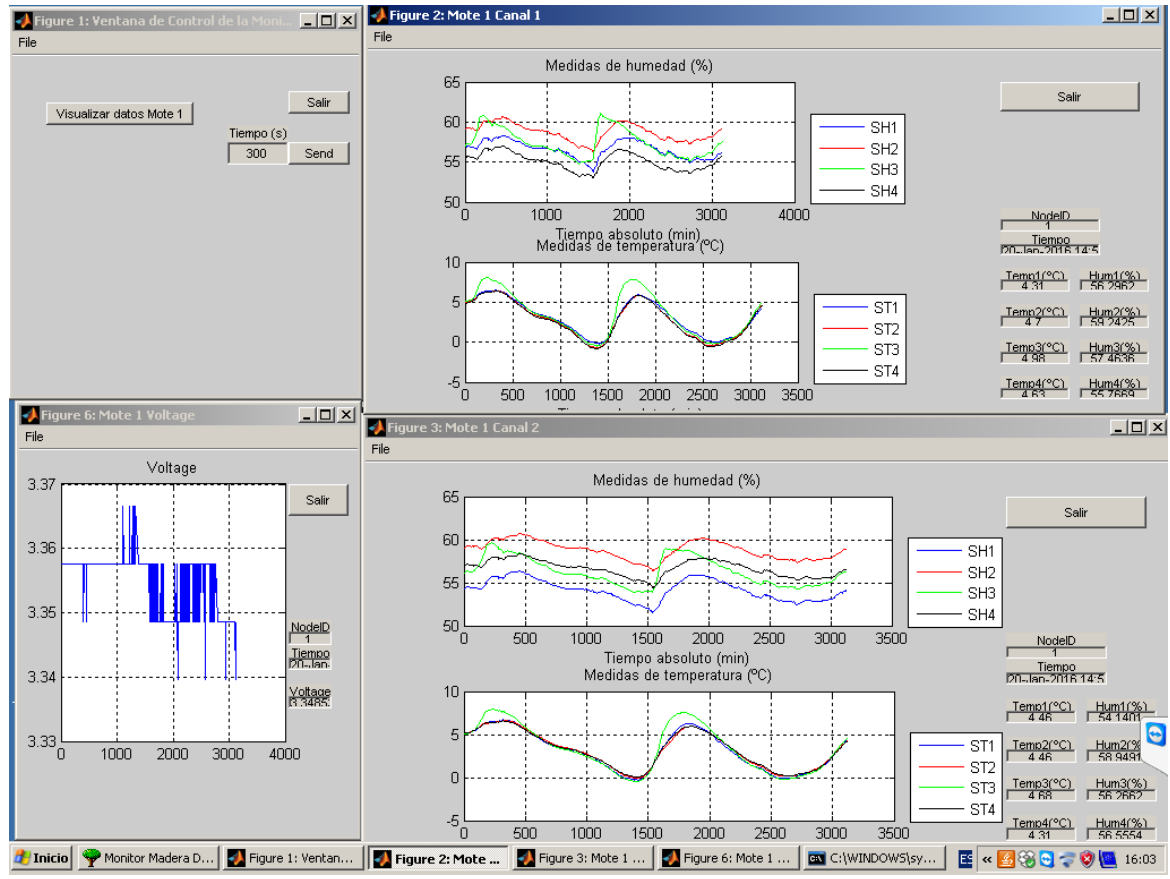

Figura 4.32: Pantallazo del ordenador en el que se muestran todos los parámetros en tiempo real

A continuación se muestran tres esquemas con la ubicación de las probetas y los sistemas de medición en las tres localizaciones seleccionadas (figuras 4.33, 4.34 y 4.35).

En resumen con una conexión a internet y con diferentes programas de uso gratuito se ha conseguido un sistema de monitorización remota que ha permitido ver lo que está sucediendo en cada momento, lo que nos ha permito detectar averías en el sistema y poder solucionarlas a la mayor brevedad, además de salvaguardar los datos ante una avería catastrófica. Esto muestra la versatilidad del sistema así como la multiplicidad de utilidades que puede tener este tipo de monitorización.

\subsubsection{Anomalías del sistema}

El sistema completo es capaz de monitorizar dos prototipos de madera, uno de abeto y otro de pino, con una programación que permite tomar una medida de temperatura y humedad cada 5 minutos. El 


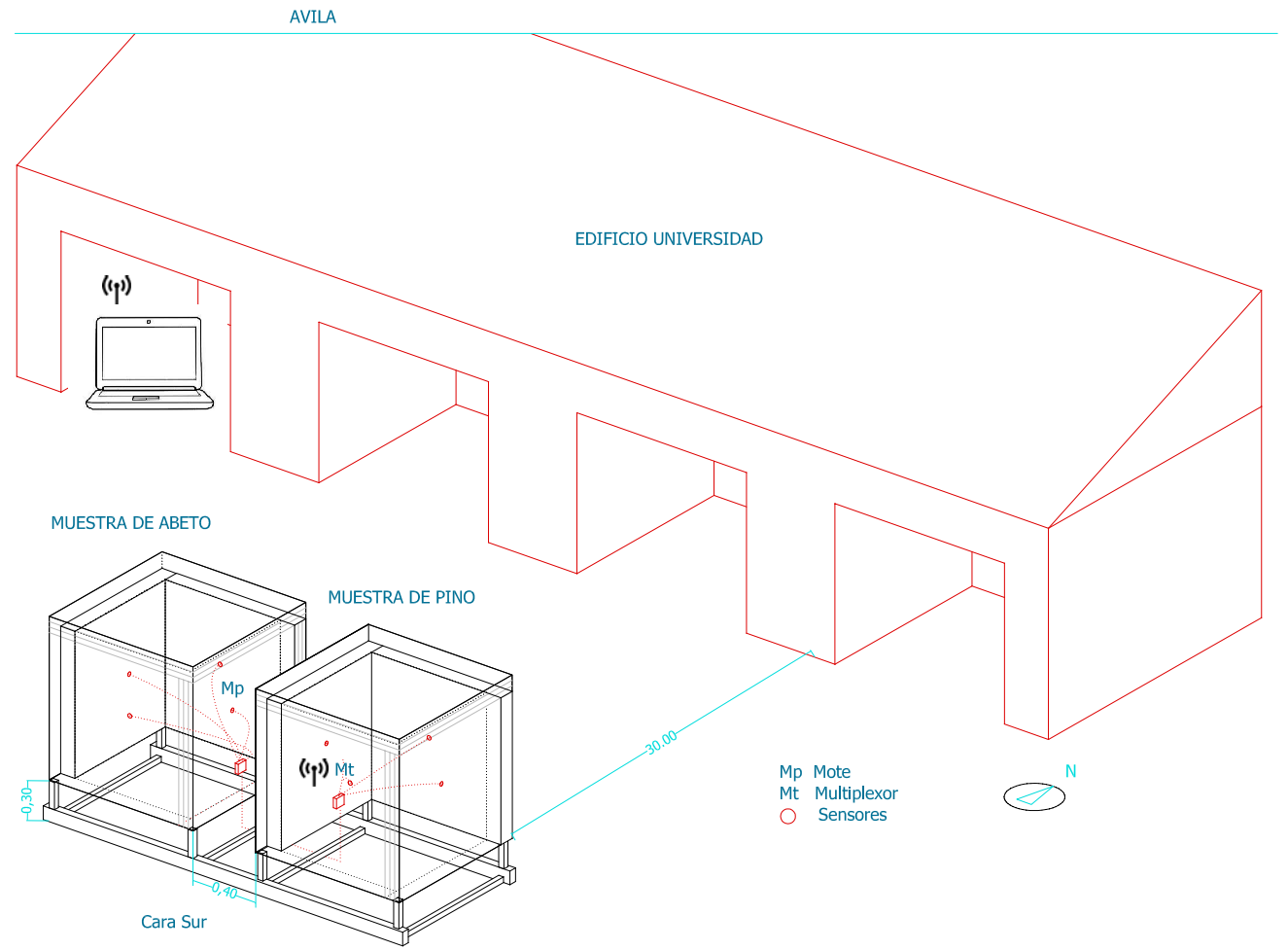

Figura 4.33: Esquema de los prototipos y los sistemas de medición en Ávila

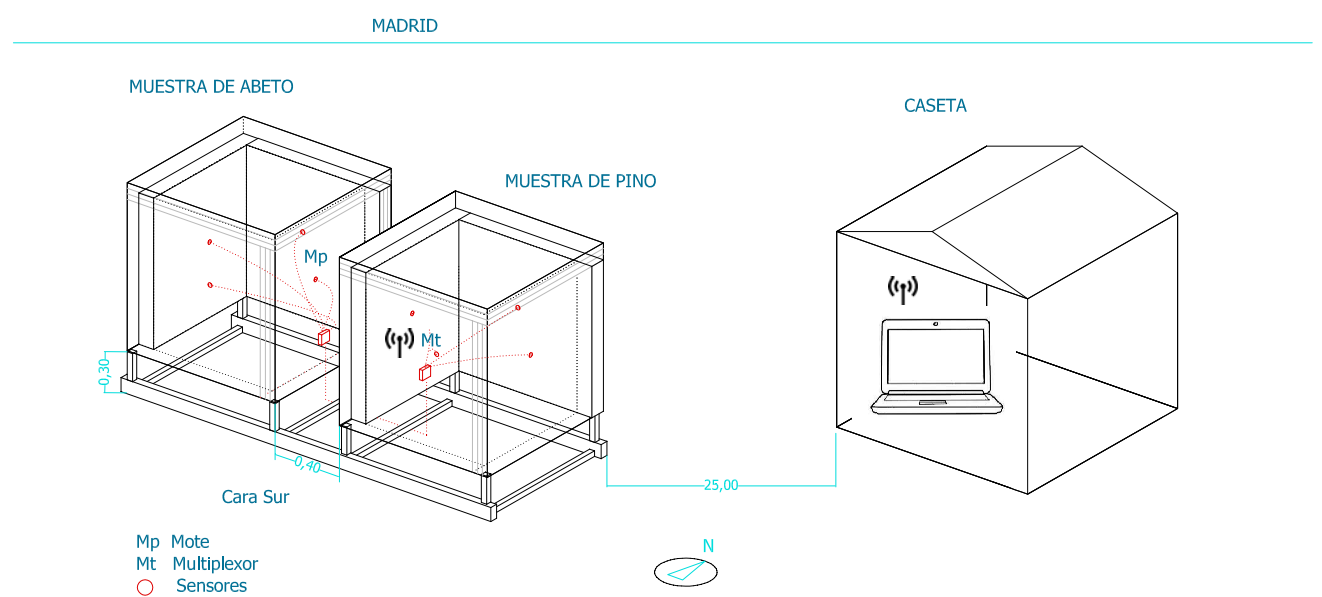

Figura 4.34: Esquema de los prototipos y los sistemas de medición en Madrid

equipo se compone de un sistema de 8 sensores de temperatura y humedad por localización, que como comentamos en el apartado anterior están embebidos en las paredes de madera de los prototipos, en 


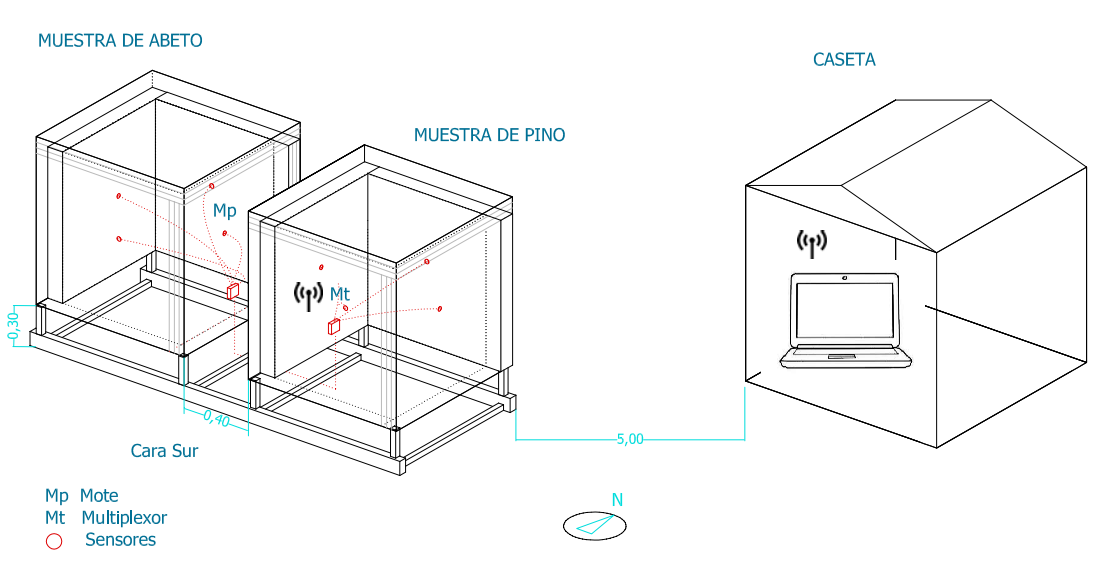

Figura 4.35: Esquema de los prototipos y los sistemas de medición en Sevilla

cada una de las orientaciones.

Durante el año que se lleva a cabo la monitorización, se registran una serie de problemas en el sistema, que gracias a su consulta en tiempo real, hace que se puedan solucionar a la mayor brevedad posible, algunos de manera telemática y otros de forma presencial.

Los errores más comunes registrados en el sistema se enumeran a continuación, explicando además las posibles soluciones adoptadas:

- Corte del suministro eléctrico de los ordenadores de base: Esta problemática está asociada a la todas las instalaciones, debido al tipo de equipos utilizado. Este tipo de problemas se ha detectado rápidamentey se ha solucionado en pocas horas, lo que no ha conllevado una gran pérdida de datos. El problema radica en que los ordenadores convencionales no se reinician una vez se restablece el suministro eléctrico. La solución para prevenir este tipo de incidencias pasa por utilizar ordenadores de bajo consumo con alimentación independiente, que permitan al equipo mantenerse operativos durante el corte de suministro.

- Problemas en la comunicación entre la base y el nodo: Este problema solo se ha dado en la instalación llevada a cabo en Madrid, la hipótesis más probable es la utilización de inhibidores de frecuencia debido a la proximidad de instalaciones militares. La solución se ha basado en instalar repetidores entre la base y el nodo para aumentar la potencia de la señal transmitida.

- Averías en los sensores por entrada de agua: Este problema solo se ha producido una vez, en que la cavidad que aloja el sensor, se llenado de agua, produciendo una avería en el sensor y haciendo que este dejase de funcionar. La solución llevada a cabo ha sido inclinar la cavidad el sensor ligeramente para evitar la acumulación de agua, y sustituir el sensor dañado. En versiones posteriores de este sistema, se usan sensores equipados con filtros de goretex, que permiten la entrada de humedad para su medición, pero no la entrada de agua líquida que satura y daña el 
sensor, obligando a su sustitución.

- Problemas de condensación en la cavidad: Este problema ha surgido de forma puntual en el prototipo ubicado en Sevilla, que climáticamente es la ubicación con la humedad relativa más alta. Se observa que hay un malfuncionamiento cuando debido a la condensación se produce la aparición de agua líquida en la cavidad, pero cuando esta agua desaparece y el sensor se seca vuelve a funcionar con normalidad.

- Condensación: Se ha dado ocasionalmente sobre todo en el sistema de Sevilla que como se puede comprobar tiene la humedad relativa más alta. Cuando se secan vuelven a funcionar normalmente. Como solución a este problema, se cuenta con una nueva generación de sensores de humedad, que presentan un modo de secado, capaz de eliminar la condensación si esta se produce.

- El último problema que presenta el sistema, es la dependencia de la humedad relativa con la temperatura. Por tanto la relación entre la humedad y temperatura de la cavidad, y la humedad de la madera, se va a establecer mediante el procedimiento establecido en Dyken y Klepp (2010), para lo cual será necesario realizar en el laboratorio los experimentos de calibración correspondientes.

A pesar de los problemas mencionados, los sistemas de monitorización instalados han demostrado su utilidad en la aplicación propuesta. Ninguno de los problemas detectados comprometen los resultados del estudio de la variación de las propiedades del CLT en su exposición a la intemperie como paramento, ya que solo se ve afectada la cantidad de datos obtenidos, y de una forma muy limitada que prácticamente no influye en el estudio del comportamiento general.

\subsubsection{Adaptación de las medidas}

El término contenido de humedad de la madera, utilizado en su forma anglosajona "moisture content" (MC), se define como "la cantidad de agua que una pieza de madera contiene", expresada como porcentaje del peso anhidro o secado al horno de la pieza de madera.

Las medias tomadas por los sensores capacitivos del sistema, son temperatura y humedad ambiente. En este caso el valor de humedad ambiente que nos facilita el sensor es humedad relativa, y su valor es dependiente de la temperatura. Para poder convertir estos valores de humedad relativa en humedad de la madera, se lleva a cabo un experimento de calibración en laboratorio, mediante el proceso establecido por Dyken y Klepp (2010).

Según Dyken y Klepp (2010), hay una diferencia significativa entre un pequeño trozo de madera que está en equilibrio de humedad con un gran volumen de aire ambiente y un pequeño volumen de aire dentro de la madera que está en equilibrio de humedad con un gran volumen de madera. En el primer caso la humedad de la madera (MC) se rige por el aire ambiente y en el segundo caso, la humedad relativa $(\mathrm{RH})$ del volumen de aire pequeño dentro de la madera se rige por la humedad de la madera (MC). 
Para establecer esta relación entre la humedad ambiental de una pequeña cavidad en la madera y MC se deben realizar ensayos de calibración. El procedimiento se describe a continuación.

El ensayo se lleva a cabo con una probeta de pino de CLT tricapa con medidas 100x100x100 mm. Tras la humectación de la probeta hasta saturarla de humedad, se procede a su mecanizado para introducirle el sensor. Una vez instrumentada, ésta se introduce en cámara, donde se cuenta con una balanza de precisión que monitoriza la pérdida de peso de la probeta. Tanto la balanza como el equipo de monitorización de temperatura y humedad se conectan a un ordenador que registra y guarda los datos de manera automática durante la duración del ensayo. Para medir la temperatura y humedad se debe utilizar el mismo tipo de sensores y equipamiento equivalente al utilizado en los prototipos de exterior. Los datos y el funcionamiento del equipo pueden seguirse en tiempo real online.

Una vez colocados los sistemas de monitorización de humedad, temperatura y peso, se procede a la aplicación de los ciclos de secado. La probeta se someterá a tres ciclos de secado, en todos habrá en cámara una temperatura y humedad constante, y se irá registrando la pérdida de peso de la probeta.

Cuadro 4.10: Ciclos de humedad y temperatura para el ensayo

\begin{tabular}{lcc}
\hline & Humedad (\%) & Temperatura $\left({ }^{\circ} \mathrm{C}\right)$ \\
\hline Ciclo 1 & 30 & 30 \\
\hline Ciclo 2 & 30 & 20 \\
\hline Ciclo 3 & 30 & 13 \\
\hline
\end{tabular}

Para los tres ciclos se ha mantenido la cámara climática a una humedad constante del $30 \%$. Las temperaturas se han mantenido constante a $30^{\circ} \mathrm{C}, 20^{\circ} \mathrm{C}$ y $13^{\circ} \mathrm{C}$ en cada uno de los tres ciclos. La humedad de la cámara se ha seleccionado al $30 \%$ para acelerar en lo posible el secado, pero dentro de una humedad ambiental que se pueda dar en los ambientes exteriores donde se van a realizar los experimentos de envejecimiento de este tipo de materiales.

Con respecto a las temperaturas seleccionadas hay que indicar que hubiera interesado cubrir en lo posible el rango de temperaturas que se han dado en el interior de la madera en los ensayos de envejecimiento exterior, $0-35^{\circ} \mathrm{C}$. Sin embargo debido a un procedimiento técnico que se da en la mayoría de las cámaras climáticas, los ciclos desescarchado se ha optado que seleccionar la temperatura mínima a $13^{\circ} \mathrm{C}$. Estos ciclos se realizan de manera periódica cuando la temperatura de la cámara es inferior o igual a $10^{\circ} \mathrm{C}$ y producen un aumento rápido de la humedad y temperatura, por lo que impiden mantener la humedad y la temperatura de la cámara constante.

La fórmula para calcular el contenido de humedad es:

$$
M C(\%)=\frac{(\text { Peso de madera húmeda }- \text { Peso de madera anhidra })}{\text { Peso de madera anhidra }} \cdot 100
$$

En la fórmula anterior, el peso de la madera anhidra o secada al horno, se calcula secando la madera en estufa a una temperatura de $103^{\circ} \mathrm{C}$ hasta que su contenido de humedad es $0 \%$. 
Con los pesos obtenidos en cada uno de los ciclos de secado, y con el peso anhidro de la probeta, se procede a calcular los valores del contenido de humedad de la madera. Estos valores de humedad en peso de madera se relacionan con la humedad relativa medida por los sensores de la cavidad, que se reflejan en la figura 4.36 como puntos.

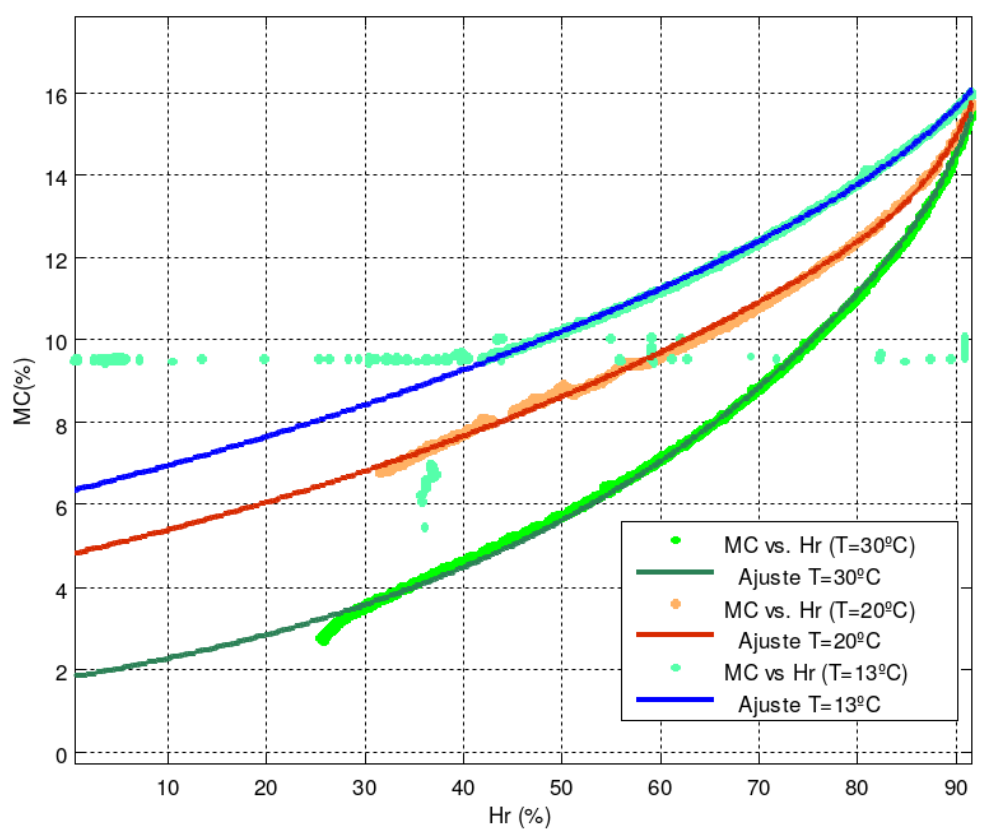

Figura 4.36: Curvas de ajuste de humedad de madera

Posteriormente se prueban diferentes funciones de ajuste con la herramienta de MATLAB cftools hasta que se obtiene un coeficiente de correlación aceptable. Para llevar a cabo el ajuste, como es usual, no se han tenido en cuenta los errores de medida, que corresponden a los puntos dispersos que aparecen en la gráfica, y han sido debidos a que el ensayo a $13^{\circ} \mathrm{C}$, se produjeron fallos de comunicación con la balanza.

A partir de esos valores se comprobó que el mejor ajuste para las funciones de contenido de humedad de madera (MC), en función de la humedad relativa y la temperatura de la cavidad, es la función:

$$
M C(T, H r)=a \cdot T \cdot e^{b \cdot T \cdot H r}+c \cdot T \cdot e^{d \cdot T \cdot H r}
$$

donde

T

$\mathrm{Hr}$

$a, b, c y d$ es la temperatura expresada en ${ }^{\circ} \mathrm{C}$

es la humedad expresada en \%

son coeficientes obtenidos por ajuste que se muestra en la figura 4.36 
Con los correspondientes coeficientes para la ecuación de la humedad de la madera que se muestran en el cuadro 4.17.

Cuadro 4.11: Coeficientes para la ecuación de la humedad de la madera

\begin{tabular}{lccccc}
\hline $\mathrm{T}\left({ }^{\circ} \mathrm{C}\right)$ & $\mathrm{a}$ & $\mathrm{b}$ & $\mathrm{c}$ & $\mathrm{d}$ & $\mathrm{R}^{2}$ \\
\hline 13 & 6,359 & 0,0094 & $5,77 \cdot 10^{-6}$ & 0,1311 & 0,9997 \\
\hline 20 & 4,765 & 0,01176 & $1,341 \cdot 10^{-9}$ & 0,2285 & 0,9977 \\
\hline 30 & 1,787 & 0,02276 & $1,694 \cdot 10^{-13}$ & 0,321 & 0,9986 \\
\hline
\end{tabular}

De la monitorización llevada a cabo en la cámara climática con la probeta de CLT de pino, se han obtenido tres curvas correspondientes a las tres temperaturas programadas, que nos relacionan la humedad ambiental medida por el sensor y la humedad de la madera.

$M C_{13}=f\left(13^{\circ} \mathrm{C}, \mathrm{Hr}\right)$

$M C_{20}=f\left(20^{\circ} \mathrm{C}, \mathrm{Hr}\right)$

$M C_{30}=f\left(30^{\circ} \mathrm{C}, \mathrm{Hr}\right)$

Para obtenervalores de humedad de madera MC a temperaturas diferentes de las programadas se hace una interpolación o extrapolación lineal mediante los tres valores obtenidos con las curvas ajustadas. Por consiguiente a partir de las medidas de humedad y temperatura de la cavidad, se puede estimar la humedad de la madera. Se comprobó que para las medidas de CLT de abeto las curvas obtenidas eran prácticamente iguales, por lo que se optado por utilizar los mismos parámetros para los dos tipos de madera.

A partir de estos cálculos se puede obtener un mapa de color que nos relaciona la humedad relativa y la temperatura medida por el sensor con la humedad de la madera y así comprobar si la relación establecida entre la medida del ambiente de la cavidad y MC.

La figura 4.37 es un mapa de color que muestra la humedad de la madera en cualquier medida de temperatura y humedad de la cavidad dentro del rango de medidas de los sensores que se han obtenido de los ensayos de envejecimiento en el exterior. La interpretación de este mapa es la siguiente, dada una medida del sensor de temperatura y humedad, la humedad de la madera (MC) se corresponderá con el color del mapa correspondiente a esas coordenadas.

Por ejemplo, si el sensor mide una humedad del $60 \%$ y una temperatura de -5 grados, la humedad de la madera es cercana al $15 \%$ (azul oscuro), pero si esa medida está a $40^{\circ} \mathrm{C}$, la humedad de la madera estaría cercana al $4 \%$ (naranja).

En definitiva lo que nos muestra el mapa de color es que si la temperatura está alta, la cavidad va a tender a "quitar" agua a la madera, por tanto si solo tiene el $60 \%$, es que la madera tiene poca agua. $\mathrm{O}$ lo que es lo mismo si la madera tuviera un $15 \%$ de humedad a $40^{\circ} \mathrm{C}$ la cavidad alcanzaría una humedad relativa superior al 90 \% (azul oscuro). Esta relación entre la humedad relativa y temperatura de la cavidad con respecto a la humedad de la madera (MC) es análoga a la obtenida en el estudio de Dyken y Klepp (2010). 


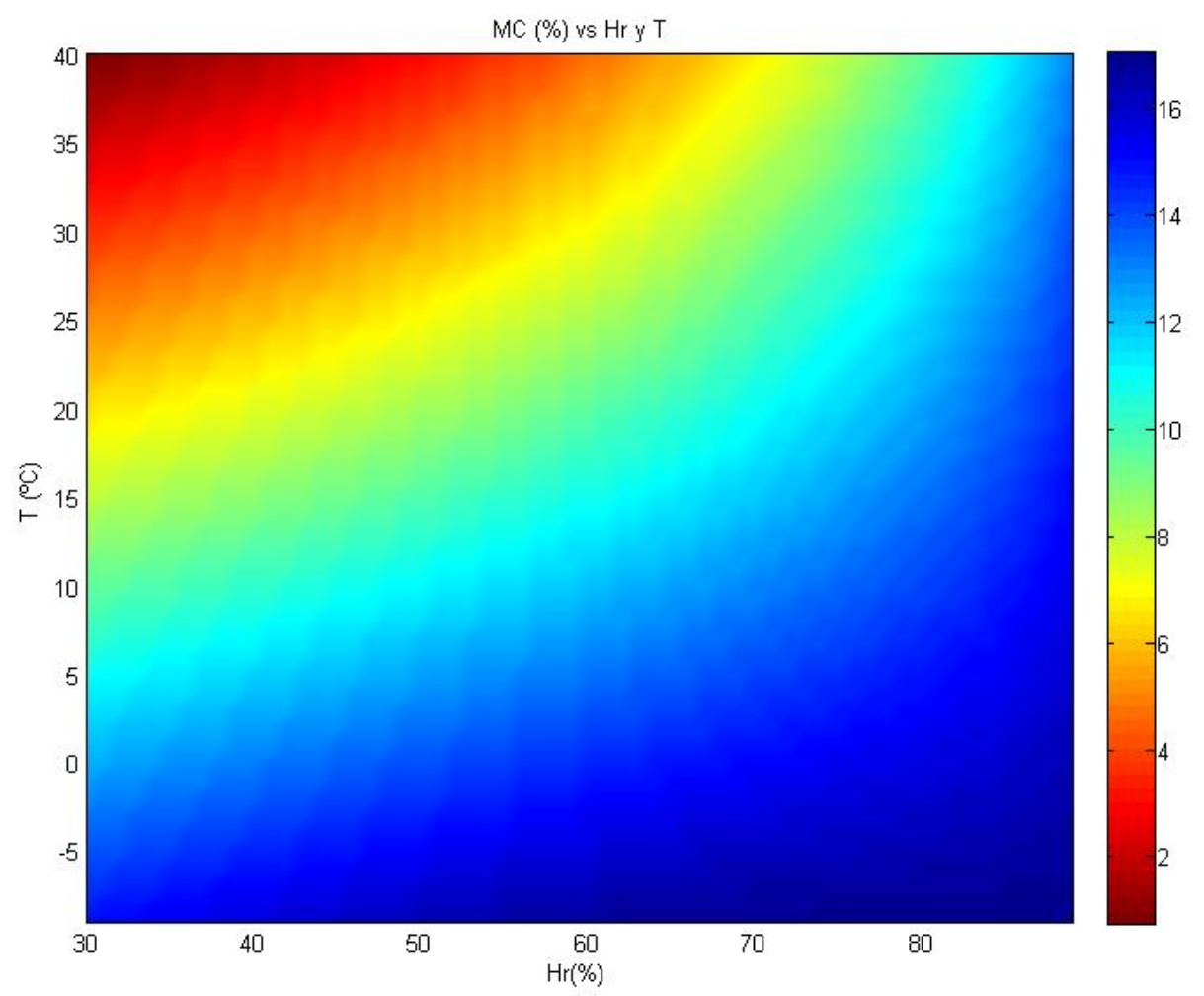

Figura 4.37: Mapa de color de la humedad de la madera

Como conclusión, mediante esta relación podemos estudiar el comportamiento de la humedad de la madera (MC) en los prototipos exteriores a partir de las medidas de $\mathrm{Hr}$ y $\mathrm{T}^{\mathrm{a}}$ obtenidas mediante los sensores incorporados a los sistemas de monitorización.

\subsection{Envejecimiento artificial}

Como complemento al envejecimiento natural llevado a cabo al exterior en las tres ubicaciones seleccionadas, se plantea la aplicación de otros tipos de envejecimiento al CLT, con el objetivo de relacionar la degradación del material con alguno de los factores ambientales a los que se suele exponer al exterior.

No existe un patrón para reproducir en laboratorio las condiciones ambientales a las que se encuentra sometido un material al exterior, en primer lugar porque habría que tener en cuenta muchas variables, y porque estas variables serían muy cambiantes dependiendo del clima de cada localidad y del año. Además en una climatología tan diversa como la presente en la península ibérica, y ya comentada en el apartado 4.4.1 Tipos climáticos, la casuística sería enorme.

Unido a la enorme combinatoria de factores que se han mencionado para reproducir un clima, está la 
necesidad de acelerar el ensayo, para poder predecir del comportamiento que un material tendrá en uno, cinco o cincuenta años.

Hasta el momento no hay aceptado para el CLT ningún ciclo acelerado que pueda reproducir fielmente la degradación climática que se produce mediante la exposición al exterior. En los productos de la madera normalmente se aplican ciclos que tratan de reproducir el efecto de las principales variables climáticas que afectan a la degradación física del material: la temperatura, la humedad y la insolación. Con el fin de acelerar los procesos degradativos del material estas variables son reproducidas en laboratorio con mucha mayor intensidad y/o frecuencia. La insolación, normalmente reproducida mediante el empleo de lámparas de UV, es una variable que en nuestro caso no emplearemos ya que asumimos que el CLT puesto al exterior en todos los casos deberá incorporar un acabado superficial.

Por tanto, el tipo de envejecimiento que se plantea se basa en el empleo de ciclos de humedad y temperatura. En el caso del CLT, el ciclo que se propone para estimar su durabilidad para clase de servicio 3 , es el que se utiliza para evaluar los tableros de madera maciza denominados así según la clasificación presente en la norma UNE-EN 12775 (2001), que pueden tener uso en ambiente seco, húmedo y exterior, dependiendo a la clase de servicio a la que esté destinada, según lo definido en la norma UNE-EN 1995-1-1 (2016).

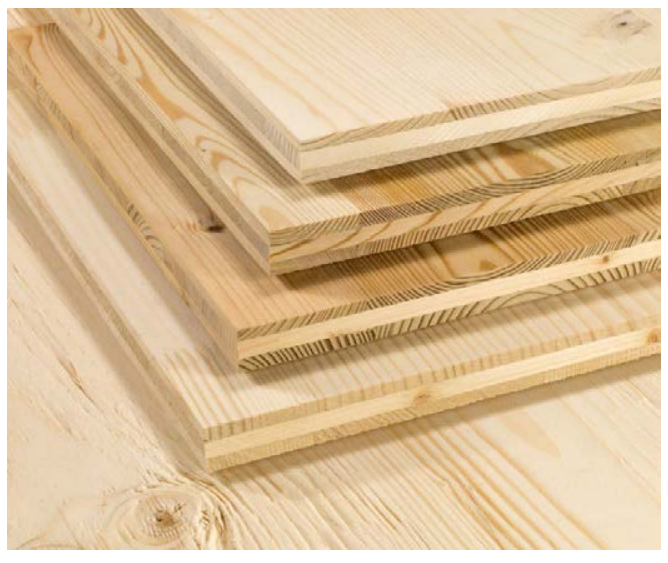

Figura 4.38: Tablero de madera maciza tricapa (SWP)

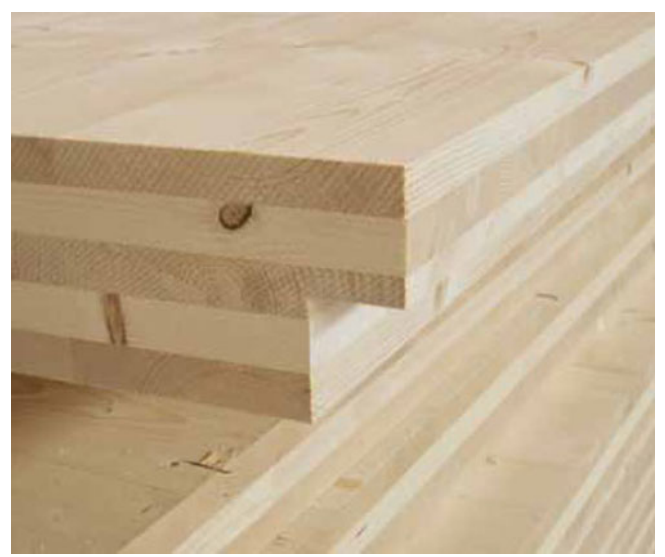

Figura 4.39: Tablero de madera contralaminada tricapa (CLT)

Aunque en principio el tablero contralaminado objeto de estudio, formado por tres capas de madera de coníferas encoladas en capas sucesivas perpendiculares entre sí, puede asemejarse a un tablero de madera maciza tricapa, definido por la norma UNE-EN 13353:2009+A1:2011 (2011), el CLT se diferencia de los tableros de madera maciza, de tipo alistonado o tricapa (SWP, Solid Wood Panels), por sus dimensiones muy superiores, tanto en espesor como en longitud, lo que implica técnicas de fabricación diferentes, y unas prestaciones estructurales y físicas diferentes.

Lo expuesto anteriormente hace que presumiblemente su comportamiento al exterior varíe respecto del de los tableros de madera maciza y que, por tanto, el método aceptado para este último no sea plenamente aceptable para evaluar la cinética de la degradación al exterior de los tableros CLT.

En el caso de estudio, CLT al exterior como paramento, se trata del uso de un tablero para aplicaciones de exterior a la intemperie, como se define para la clase de servicio 3 de la norma UNE-EN 1995-7-7 
(2016) y para la clase de uso 3 según la norma UNE-EN 335 (2013). Son tableros capaces de resistir una exposición prolongada a la intemperie y al agua, ya sea líquida o en forma de vapor, en un entorno húmedo pero ventilado, donde puede alcanzar frecuentemente un contenido de humedad superior al $20 \%$.

Actualmente la aptitud del encolado al uso exterior en clase de servicio 3 de los tableros de madera maciza se evalúa mediante la aplicación de la norma UNE-EN 13354 (2009), mediante la evaluación del encolado se obtiene la integridad estructural del producto, y este proceso es el que se ha venido utilizando hasta la aparición de la norma UNE-EN 16351 (2016) para la evaluación del CLT.

Según esta norma, las muestras a ensayar, se someten a un penetramiento acorde con la clase de servicio definida en la norma UNE-EN 1995-1-1 (2016), correspondiente a la clase de servicio que se desea evaluar. Tras cortar las probetas, se someten al penetramiento adecuado en función del uso previsto, ambiente seco, húmedo o exterior, aplicando el correspondiente ciclo.

El tipo y duración del ciclo dependerá del uso previsto, y en el caso de ambiente exterior consistirá en un penetramiento tipo 3, que consiste en la inmersión de las probetas en agua hirviendo durante cuatro horas, posteriormente se somete a secado a una temperatura de $60^{\circ} \mathrm{C}$, con un margen de más menos $3^{\circ} \mathrm{C}$ durante un periodo comprendido entre 16 y 20 horas, de nuevo se vuelven a hervir las muestras durante cuatro horas y finalmente se somete a un enfriamiento en agua a $20^{\circ} \mathrm{C}$ con un margen de más menos $3^{\circ} \mathrm{C}$ (UNE-EN 1995-7-1, 2016, Tabla 1).

El ensayo descrito es excesivo para un producto como el CLT, que por una parte tiene una conformación y un grosor de lámina diferente al SWP, y por otro lado la parte de testa que queda sometida al exterior es mucho mayor de la que quedaría en la realidad. El CLT es un producto estructural superficial, y si trabajara al exterior como paramento, ya sea muro o fachada, la parte expuesta sería la cara, ya que de canto debido a las dimensiones que suele tener este producto la superficie sería mínima. En el ensayo descrito aproximadamente un $67 \%$ del CLT expuesto es testa, mientras que el resto es cara.

La velocidad de entrada y salida del agua por la estructura longitudinal de la madera (testa) es notablemente superior que por la estructura transversal (caras), dependiendo esta diferente velocidad de ciertas variables anatómicas (tamaño de los lúmenes, textura, densidad de radios leñosos, etc.) cuyo análisis está fuera del presente trabajo. Por otra parte, en el uso constructivo habitual de los tableros de madera la relación "superficie de testa/superficie de tablero" es mucho más reducida en CLT que en SWP (ya que el formato de los tableros SWP es mucho menor) lo que hace que el efecto testa en tablero CLT pueda ser considerado en muchos casos despreciable. Por dicho motivo y para evitar magnificar el efecto testa, que en nuestro caso sería especialmente pernicioso, los ensayos de envejecimiento artificial sobre tableros CLT se llevaron a cabo sobre probetas con sus cantos sellados mediante tres capas de pintura plástica.

Para llevar a cabo el envejecimiento en laboratorio se emplearon dos sistemas diferentes aunque llevados a cabo sobre probetas de las mismas características.

Ambos sistemas de envejecimiento difieren en el mecanismo de entrada del agua líquida en el interior del material ya que mientras en uno, que denominaremos de rueda de envejecimiento, la entrada se produce mediante inmersiones muy cortas en el otro, que denominaremos de cámara, la humectación se lleva a cabo mediante riego por goteo (imitando la acción del agua de lluvia). El sistema de "Rueda 
de envejecimiento" difiere también en la metodología de secado posthumectación ya que ésta se lleva a cabo por acción de rayos UV, que imitan la acción de los rayos solares, mientras que en el sistema de "Cámara" el secado se efectúa por aire climatizado.

Tras su envejecimiento, por uno u otro método, las probetas fueron ensayadas mecánicamente a tracción perpendicular a las caras (perpendicular a los planos de encolado), evaluándose como variables la carga máxima, el tipo de rotura (por cola o por madera) y el porcentaje de delaminación.

\subsubsection{Preparación de las probetas}

La finalidad del ensayo a tracción es analizar la pérdida de propiedades estructurales que tiene el CLT tras el envejecimiento debido a las tensiones originadas por los cambios de humedad producidos. Como el planteamiento de uso del material es en clase de servicio 3 como paramento, se pretende que la entrada de agua se produzca por la cara del material que en condiciones de uso estaría expuesta al exterior, por lo que se lleva a cabo una preparación previa con este objetivo.

Como se ha comentado en el apartado 4.4.2 Diseño de los prototipos en el caso del envejecimiento natural o exposición directa al exterior, en los prototipos se llevará a cabo la protección de las testas con detalles de diseño en el caso de las testas superiores e inferiores, y parcialmente con una cinta en el caso de las testas laterales. Además, se minimizará el efecto de absorción de agua por las testas con el sistema de selección de las probetas descrito en el apartado 4.3.2.1 Selección de las probetas procedentes del envejecimiento natural.

Para conseguir que en el envejecimiento artificial o de laboratorio, se produzca la mayor parte de la entrada de agua por la cara de las probetas, se sellan las testas, minimizando así la entrada de agua por esta vía.

Una vez cortadas las probetas como se describe en el apartado 4.3.2.2 Selección de las probetas destinadas al envejecimiento artificial, se les da un cepillado superficial, son numeradas, y se meten en cámara en condiciones de ambiente normalizadas $\left(20^{\circ} \mathrm{C} \pm 2^{\circ}, \mathrm{HR} 65 \% \pm 5 \%\right)$, que equivale al $12 \%$ correspondiente al equilibrio higroscópico de la madera, para su estabilización hasta su ensayo.

Tras lograr el equilibrio higroscópico, las probetas son lijadas, para posteriormente aplicarles una protección en las testas con una pintura especial para madera apta para la intemperie y que protege contra los rayos ultravioleta, con el fin de que la entrada de humedad en la madera, y la acción de los rayos ultravioleta (en el caso de las muestras sometidas a la rueda de envejecimiento), se produzca por la zona que en el caso de paramento al exterior estaría realmente expuesta.

Tras 24 horas de secado de la primera capa protectora, se vuelve a repetir la operación otra vez más, y 24 horas después se aplica una tercera capa para aquellas partes más porosas que no han logrado quedar totalmente cubiertas. Con un total de 3 capas se asegura la impermeabilización de las testas garantizando que la mayor parte de la entrada de agua, se produce por la cara de la probeta.

Si tras esta operación de sellado mediante pintura persiste algún orificio en la madera, se procede a sellarlos con silicona blanca. 
Finalmente y 24 horas antes de empezar con el ensayo, se lleva a cabo un lijado de las caras para eliminar restos de pintura y que la humedad pueda penetrar por la cara de una manera normal.

\subsubsection{Rueda de envejecimiento}

La rueda de envejecimiento es un aparato que posee el FCBA para la evaluación del rendimiento de los protectores de la madera que se aplican a productos de madera o productos derivados de la madera que van a estar expuestos al exterior. Ceneralmente este estudio de la durabilidad de los protectores se aplica a carpinterías de madera, siguiendo la especificación técnica propia NF P 23-305 (2014).

En el ensayo que se lleva a cabo en la rueda de envejecimiento, la introducción del gradiente en el contenido de humedad de la madera para crear tensiones internas, se realizará mediante inmersión de las probetas en una cubeta con agua osmotizada. Este ensayo además de tener en cuenta la entrada y salida de humedad de la madera, tiene en cuenta el deterioro producido por los rayos ultravioleta, gracias a las lámparas que posee la rueda de envejecimiento.

\subsubsection{Aparatos}

El envejecimiento artificial Ilevado a cabo en el FCBA, se realiza en un aparato llamado "ageing wheel" o rueda de envejecimiento artificial (figura 4.40).

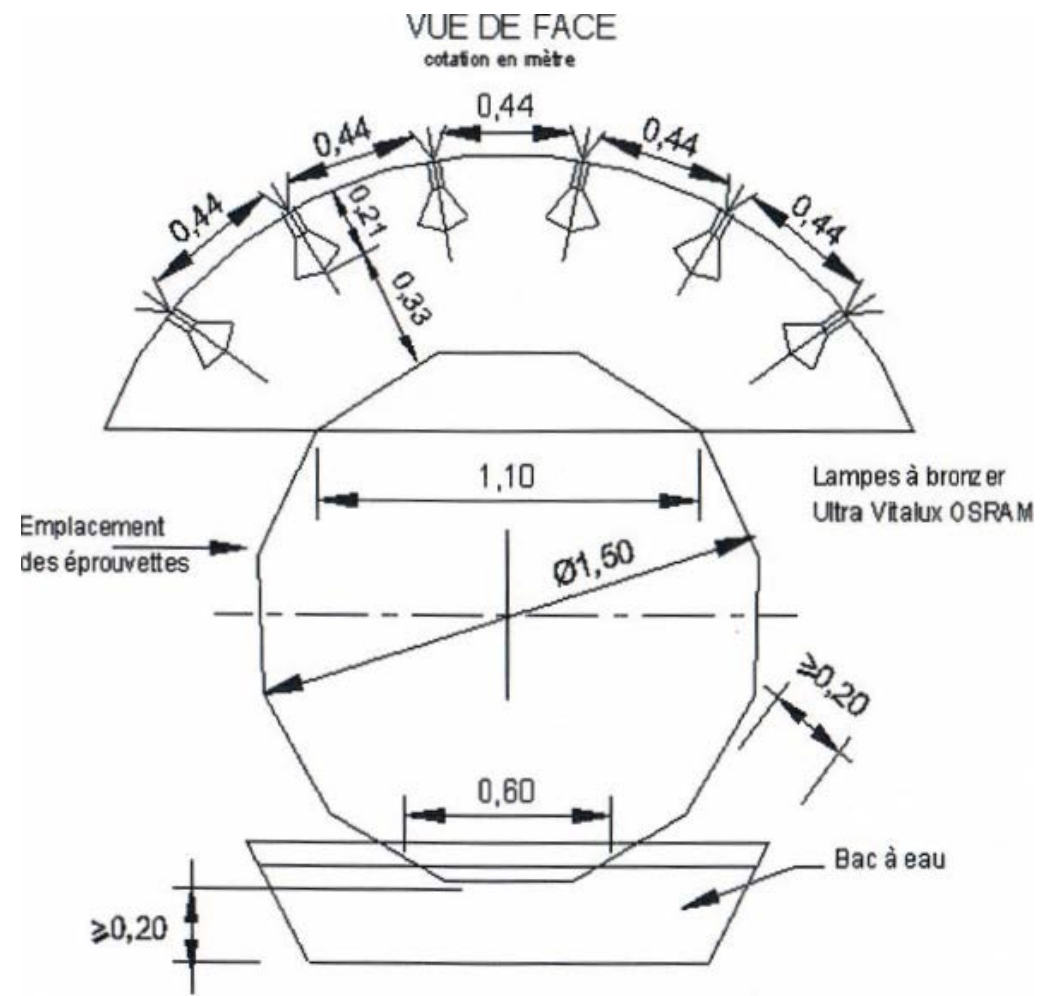

Figura 4.40: Esquema de la "Ageing wheel" o rueda de envejecimiento artificial, FCBA (Burdeos) 


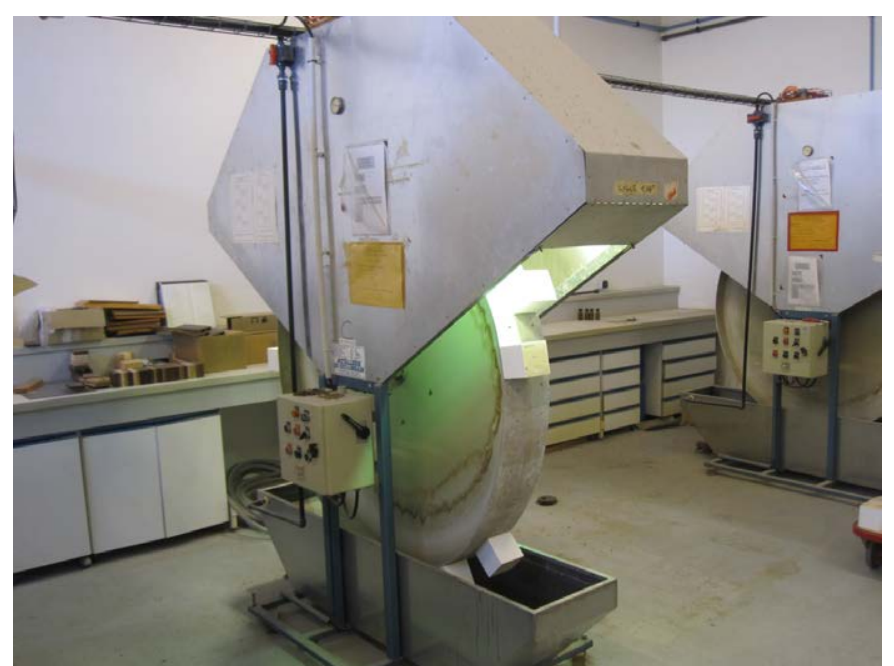

Figura 4.41: Fotografía de la "Ageing wheel" o rueda de envejecimiento artificial, FCBA (Burdeos)

El aparato consta de una rueda giratoria que en su parte exterior posee un espacio para colocar las probetas a ensayar. Una cubeta inferior rellena de agua, donde se produce la humectación de las probetas, y un arco superior, provisto de unas lámparas ultravioletas donde las probetas se exponen a los efectos de la degradación de los rayos ultravioleta.

El arco donde se produce la degradación por efecto ultravioleta, contribuye con el secado de las probetas por el efecto de la temperatura, está provisto de 6 lámparas UV / IR referencia OSRAM Ultravitalux E 27 (300 W), ver figura 4.42.
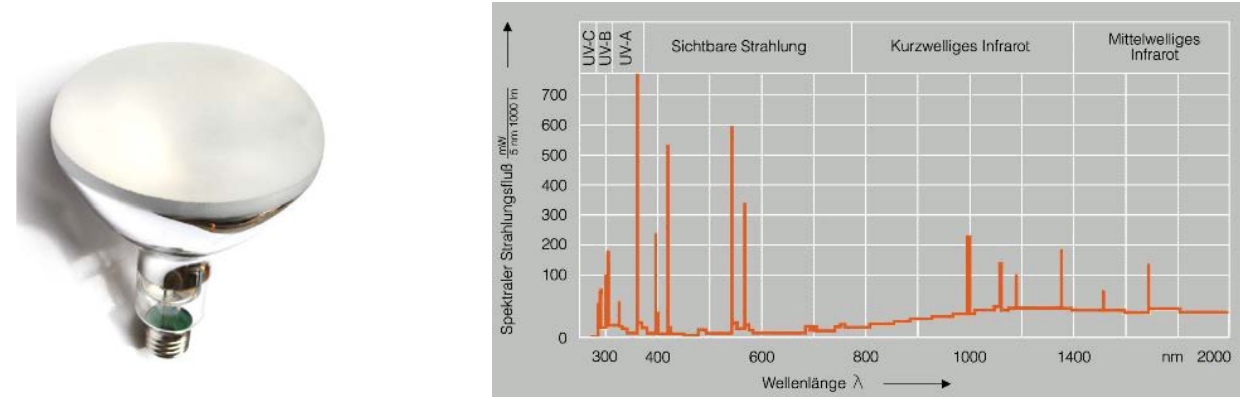

Figura 4.42: Lámpara OSRAM y gráfica de la potencia de radiación espectral de la lámpara

Las lámparas que componen el sistema de irradiación se cambian preferiblemente cada 500 horas de uso, y la sustitución se realiza por grupos de dos como se indica en la figura 4.43.

El sistema de irradiación descrito es comparable a la utilización de 2 lámparas IR 375 CH 230/950 de 375 w E 27, junto con 4 lámparas UV HPR de 125 vatios de luz encuadradas en la parte central del arco (Informe del estudio de intercomparación LNE, mayo de 1999). 


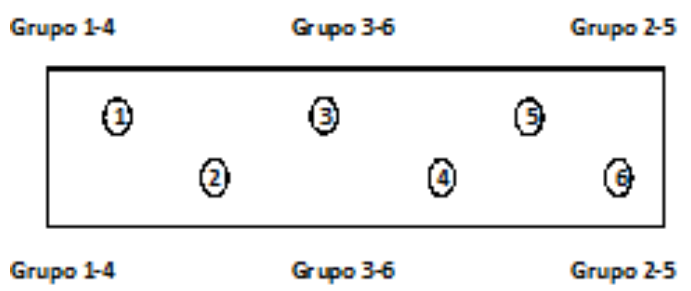

Figura 4.43: Disposición de las lámparas en el arco de irradiación

\subsubsection{Procedimiento}

La cubeta se rellena de agua osmotizada de forma que cuando la probeta pase por ella la cubra hasta el $50 \%$ del espesor de la misma, consiguiendo así que el agua se introduzca por la cara exteriory desprotegida, tratando de simular la entrada de agua que se produciría en un panel de CLT que estuviera expuesto al exterior y se estuviera utilizando como paramento y sin protección.

Una vez rellena la cubeta y preparadas las probetas como se describe en el apartado 4.5.1 Preparación de las probetas, se procede a la colocación de las probetas en la rueda de envejecimiento.

Al poner en marcha la rueda de envejecimiento, se inicia el proceso de envejecimiento, en primer lugar las probetas se sumergen en la cuba de agua osmotizada durante un periodo de 12 minutos, lo que supone el tiempo de humectación del ciclo, seguidamente se exponen al aire ambiente durante 27 minutos, lo que inicia su tiempo de secado, a continuación pasan por el arco de irradiación, donde se exponen durante 24 minutos a las lámparas ultravioletas, continuando con su proceso de secado, y por último y cerrando el ciclo, vuelven a exponerse durante 27 minutos al aire ambiente, finalizando así el tiempo de secado del ciclo.

Cuadro 4.12: Resumen del ciclo que realiza la rueda de envejecimiento (FCBA)

\begin{tabular}{|c|c|c|c|c|c|}
\hline & \multirow[b]{2}{*}{ Efecto } & \multirow{2}{*}{$\frac{\text { Fase de Humectación }}{\text { Cubeta }}$} & \multicolumn{3}{|c|}{ Fase de secado } \\
\hline & & & Ambiente & Arco & Ambiente \\
\hline \multirow{3}{*}{ Tiempo (min) } & Humectación & 12 & - & - & - \\
\hline & Secado & - & 27 & - & 27 \\
\hline & Radiación & - & - & 24 & - \\
\hline
\end{tabular}

\subsubsection{Selección de los ciclos a aplicar}

Como se ha comentado en el apartado 4.5 Envejecimiento artificial, no existe ninguna equivalencia para equiparar los ciclos de envejecimiento acelerado con la exposición al exterior. En este caso para establecer los ciclos a aplicar, se van a tener en cuenta los ciclos que se aplican en el FCBA con la rueda de envejecimiento, y la precipitación en un clima determinado, los días de lluvia por año. 
En el procedimiento propio del FCBA para la rueda de envejecimiento, aplicando el ciclo de 90 minutos descrito en el apartado anterior, dependiendo del acabado de la muestra a ensayar, se plantean dos temporalidades diferentes:

- 1 semana (equivalente a 112 ciclos), indicado para evaluar la durabilidad de carpinterías de madera o productos derivados de la madera con acabado de lasur monocapa o producto protector, que necesitará una posterior renovación de la protección.

- 6 semanas (equivalente a 672 ciclos) indicado para evaluar la durabilidad de las carpinterías de madera o productos derivados de la madera, con acabado de lasur o producto protector de tres capas, que no necesitará una posterior renovación de la protección.

Consultando los datos existentes en AEMET, para Madrid, utilizado como clima de referencia, y siendo escogido como uno de los climas para la exposición al exterior, se observa que en el periodo comprendido entre 1970 al 2000, en la estación meteorológica correspondiente a Madrid existe un promedio de 79,6 días de lluvia al año, considerando día de lluvia aquel en que la precipitación es superior a 0,2 mm (Fernandez-Colfin et al., 2016).

Si se considera que cada vuelta en el ciclo de envejecimiento es un episodio de lluvia con su correspondiente secado, se puede establecer la equivalencia de que 80 episodios de lluvia equivalen a un año de exposición al exterior en un clima de referencia como el de Madrid.

Por lo tanto y estimando que suceden 80 días de lluvia al año, se plantean los siguientes ciclos a aplicar en la rueda de envejecimiento del FCBA:

- Primer ciclo, o ciclo corto, aplicación de 80 ciclos de envejecimiento, que simulan los 80 episodios de lluvia que suceden en un año en el clima de referencia (Madrid), y que equivale a tener las muestras 5 días en la rueda de envejecimiento.

- Segundo ciclo, o ciclo largo, aplicación de 480 ciclos de envejecimiento, que simulan los 480 episodios de lluvia que suceden en seis años en el clima de referencia (Madrid), y que equivale a tener las muestras 30 días en la rueda de envejecimiento.

Con la duración seleccionada para los ciclos, se consigue adaptar para el caso de España, y más concretamente para el clima de referencia de Madrid, el ensayo de la rueda de envejecimiento, pero además se mantiene la relación de envejecimiento que se establece en el FCBA para los dos acabados, es decir, el ciclo largo es 6 veces superior en duración al ciclo corto.

\subsubsection{Cámara climática}

La cámara climática, es el aparato más comúnmente utilizado para simular climas y así envejecer los materiales. En estas cámaras se controla la temperatura y la humedad, y mediante ciclos se someten las muestras introducidas en ellas a un envejecimiento acelerado.

En Fernandez-Colfin et al. (2016) se pone de manifiesto que la temperatura y humedad relativa por sí solas no producen el cambio de clase de servicio 2 a CS3, motivo por lo cual para que este cambio se 
produzca y así evaluar las consecuencias estructurales que este conlleva es necesario incorporar agua líquida en el proceso de envejecimiento.

\subsubsection{Aparatos}

El equipo utilizado en el INIA para llevar a cabo el envejecimiento artificial es una cámara climática, capaz de hacer ciclos de temperatura y humedad, marca ControlTécnica modelo CP 10/500 con las siguientes características técnicas para ensayos climáticos:

- Rango de temperatura $+10^{\circ} \mathrm{Ca}+50^{\circ} \mathrm{C}$

- Fluctuación de temperatura en condiciones de estabilidad temporal $\pm 0,5 \mathrm{~K}$

- Rango de humedad $10 \%$ a $90 \%$ humedad relativa

- Rango de punto de rocío $1+7^{\circ} \mathrm{Ca}+45^{\circ} \mathrm{C}$

- Rango de punto de rocío $2-5^{\circ} \mathrm{Ca}+7^{\circ} \mathrm{C}$

- Fluctuación de humedad en condiciones de estabilidad temporal de $\pm 1 \mathrm{a} \pm 3 \%$

Todos los valores son medios y han sido obtenidos a temperatura ambiente de $+25^{\circ} \mathrm{C}$ con un voltaje nominal de $230 \mathrm{~V} / 50 \mathrm{~Hz}$, sin muestra, sin radiación y sin accesorios.

- Sistema de control y visualización por microprocesador de 32 bits

- Selección digital de temperatura en ${ }^{\circ} \mathrm{C}$ y humedad relativa en \%

- Indicación digital de punto de consigna y valor real de temperatura y humedad relativa

- Cenerador de programas integrado, almacenamiento de hasta 100 programas de ciclos de ensayo.

- Software de selección-limitación de temperatura mínima/máxima de la cámara de ensayo

- Funcionamiento en modo manual o automático

Este equipo se calibra en base al procedimiento LC07107 del Laboratorio de Calibración del servicio técnico que la suministra, acreditado por ENAC para la realización de calibraciones en temperatura y humedad.

Mediante este equipo se pueden llevar a cabo ciclos de temperatura y humedad para el envejecimiento del material, pero no posee ningún dispositivo para poder reproducir el efecto de la lluvia, cosa necesaria en el envejecimiento planteado por dos razones, para las probetas de madera que se utilizan, el tiempo que conllevaría el cambio de clase de uso es muy largo, y por otra parte, el efecto que produce la entrada de humedad en las probetas por el efecto de la lluvia es diferente al efecto que produce esta entrada de humedad por el aumento de la humedad relativa, ya que la velocidad con que se introduce el gradiente de humedad en la madera es diferente. 


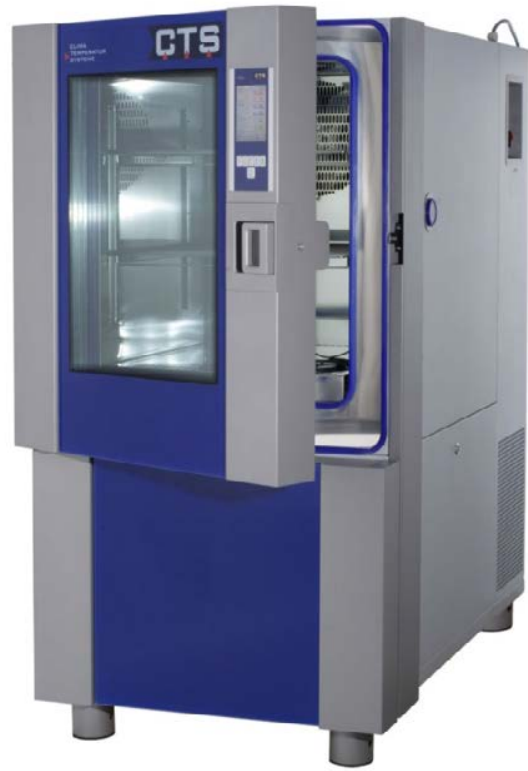

Figura 4.44: Fotografía de la cámara climática utilizada en el ensayo (INIA)

Por tanto para poder llevar a cabo el ensayo planteado hay que hacer una serie de modificaciones en la cámara que nos permitan introducir el efecto de la lluvia en el ensayo. Para ello se propone la instalación de un sistema de riego por goteo en el interior de la cámara.

Se instalan goteros autocompensantes, con una capacidad de caudal de 2 litros por hora, en las bandejas de la cámara climática. La cámara climática posee tres bandejas, lo que nos permite instalar dos sistemas de riego que se hacen independientes con la instalación de unas Ilaves que permiten abrir o cerrar el riego en cada bandeja de forma independiente.
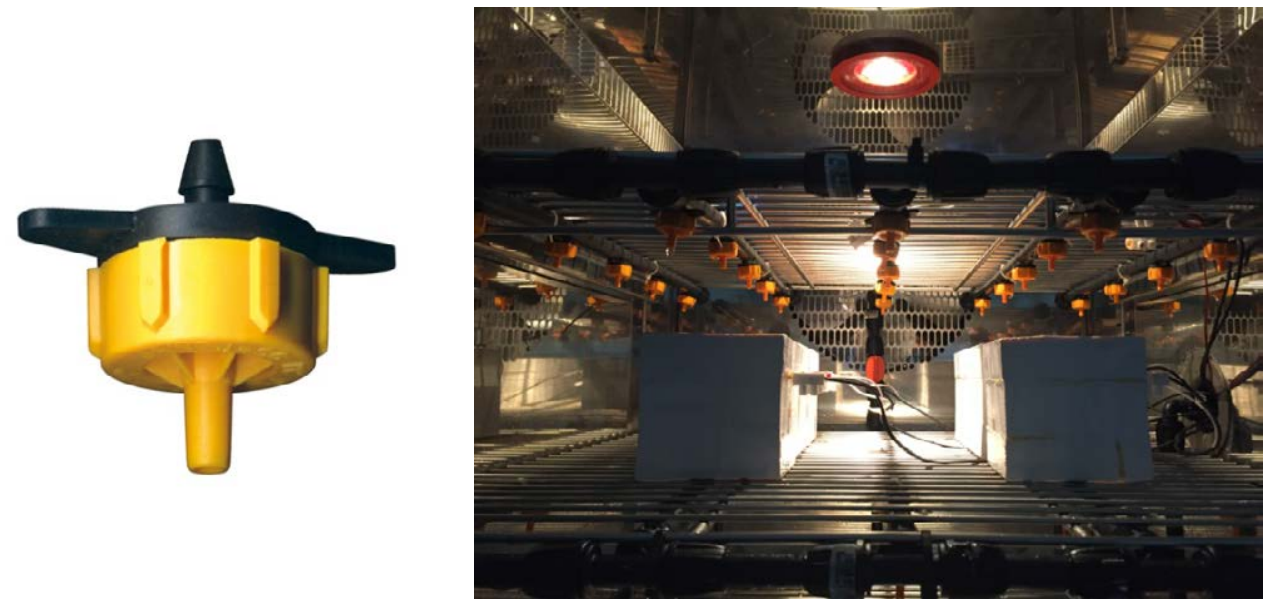

Figura 4.45: Cotero de riego utilizado para la adaptación de la cámara e instalación del mismo 
Se conecta el sistema de riego a la red se suministro de agua, y esto se hace mediante un programador que permite establecer los periodos de riego definidos en el apartado 4.5.3.3 Selección de los ciclos a aplicar.

\subsubsection{Procedimiento}

Se rellena el tanque de agua de la cámara climática, y se conecta el riego por goteo instalado, para así mediante el riego conseguir que el agua se introduzca por la cara exterior y desprotegida, tratando de simular la entrada de agua que se produciría en un panel de CLT que estuviera expuesto al exteriory se estuviera utilizando como paramento y sin protección.

Una vez preparada la cámara, y preparadas las probetas como se describe en el apartado 4.5.1 Preparación de las probetas, se introducen las probetas de CLT en la cámara, con la cara enfrentada al riego por goteo, antes de poner en marcha la cámara y el riego, se colocan encima de las probetas unos cuadrados de fieltro de lana natural $100 \%$ y 6 mm de espesor, con las mismas dimensiones de la cara 100×100 $\mathrm{mm}$, de forma que el agua aportada por parte de los atomizadores, se reparte de madera uniforme por la superficie de la cara.

Al poner en marcha la cámara con el correspondiente riego, se inicia el proceso de envejecimiento, en el que las probetas se someterán a un periodo húmedo, y posteriormente a otro seco, esta aplicación alternativa de periodo húmedo y seco que componen el ciclo, permite que las probetas aumenten su humedad lo suficiente para que se produzca un cambio en la clase de servicio, y así producir una degradación similar a la que se produciría en su aplicación exterior como paramento.

En el caso del ciclo que se pretende aplicar en el INIA, no hay un ensayo previo en el que basarnos como sucedía en el FCBA, simplemente una serie de ensayos cortos llevados a cabo, que muestran que cuando se somete a las probetas de CLT con la preparación previamente descrita a riego, durante dos días, con una frecuencia de un minuto de riego cada hora, se produce un aumento suficiente en la humedad de la probeta para que haya un cambio de clase de servicio.

Con el ciclo aplicado se consigue que las probetas pasen de clase de servicio 1, condiciones en las que se introducen en la cámara, a clase de servicio 3, condiciones a las que llega tras la aplicación del riego por goteo. Este cambio de clase de servicio permite que se produzca una degradación similar a la que sufriría el CLT si se expusiera al exterior como paramento.

El ciclo húmedo consistirá la programación de un riego de un minuto de duración cada hora, durante dos días, con se logra que las probetas que previamente se encontraban en condiciones de clase de servicio 1 pasen a condiciones de clase de servicio 3.

El ciclo seco se inicia con el apagado y apertura de la cámara durante 24 horas, para conseguir una rápida pérdida de humedad, sin que se produzca la saturación de la cámara. Tras comprobar mediante los empapadores que se ha producido la evaporación del agua, se programa la cámara con una humedad relativa del $56 \%$ y $23^{\circ} \mathrm{C}$ de temperatura durante 24 horas, a continuación se baja la humedad relativa al $50 \%$ manteniendo la temperatura, y se mantiene en estas condiciones 72 horas, completando así el ciclo y consiguiendo llevar las probetas a las condiciones iniciales de clase de servicio 1. 
Cuadro 4.13: Ciclo semanal seleccionado para el envejecimiento en cámara del CLT (INIA)

\begin{tabular}{|c|c|c|c|c|c|c|c|c|}
\hline \multirow[b]{2}{*}{ Dispositivo } & \multirow[b]{2}{*}{ Parámetro } & \multicolumn{2}{|c|}{ Fase de humectación } & \multicolumn{5}{|c|}{ Fase de secado } \\
\hline & & Lunes & Martes & Miércoles & Jueves & Viernes & Sábado & Domingo \\
\hline Riego & Agua & $1 \mathrm{~min} /$ hora & $1 \mathrm{~min} /$ hora & - & - & - & - & - \\
\hline \multirow{2}{*}{ Cámara } & Humedad & $96 \%$ & $96 \%$ & - & $56 \%$ & $50 \%$ & $50 \%$ & $50 \%$ \\
\hline & Temperatura & $23^{\circ} \mathrm{C}$ & $23^{\circ} \mathrm{C}$ & - & $23^{\circ} \mathrm{C}$ & $23^{\circ} \mathrm{C}$ & $23^{\circ} \mathrm{C}$ & $23^{\circ} \mathrm{C}$ \\
\hline
\end{tabular}

\subsubsection{Selección de los ciclos a aplicar}

Si bien se ha comentado que no existe ninguna equivalencia entre los ciclos de envejecimiento aplicados y el efecto que produce la degradación por la exposición a la intemperie, en el caso del envejecimiento llevado a cabo en el FCBA existía una metodología, aplicada a otros productos de madera, que se adaptó para el CLT con la climatología del clima de referencia.

En el caso del ciclo que se pretende aplicar en el INIA, contamos con el ciclo definido en el apartado anterior, que conlleva el cambio de clase de uso del material. Teniendo definido el ciclo a aplicar, se procede a calcular el número de ciclos a aplicar, de forma que sean comparativos con el año de exposición que los prototipos van a estar al exterior, y con el otro método de envejecimiento artificial aplicado en el FCBA.

Según lo establecido en el apartado 4.5.2.3 Selección de los ciclos a aplicar, en un clima como el de Madrid se produce un promedio de 80 episodios de lluvia al año, podemos equiparar cada episodio de Iluvia con un periodo de riego, que como se establece se lleva a cabo en cámara climática durante 1 minuto, y con la presencia de un empapador, que ayuda a uniformizar el aporte de agua, y la retiene para favorecer su penetración en la probeta.

Por lo tanto y estimando que suceden 80 días de lluvia al año, se plantean los siguientes ciclos a aplicar en la cámara climática del INIA:

- Primer ciclo, o ciclo corto, aplicación de 2 ciclos de envejecimiento, que simulan los 80 episodios de lluvia que suceden en un año en el clima de referencia (Madrid), y que equivale a tener las muestras 2 semanas en la cámara climática. La aplicación de estos ciclos lleva al cambio de clase de servicio del producto, que pasa de la clase de servicio 1 inicial a clase de servicio 3 tras la aplicación de la fase húmeda del ciclo, y vuelve a clase de servicio 1, tras la aplicación de la fase seca del ciclo, con lo que en la aplicación del ciclo durante dos semanas se consigue reproducir los episodios de lluvia necesarios para completar un año, y cuatro cambios de clase de servicio del material.

- Segundo ciclo, o ciclo largo, aplicación de 10 ciclos de envejecimiento, que simulan los 480 episodios de lluvia que suceden en seis años en el clima de referencia (Madrid), y que equivale a tener las muestras 10 emanas en la cámara climática. La aplicación de estos ciclos Ileva al cambio de clase de servicio del producto, que pasa de la clase de servicio 1 inicial a clase de servicio 3 tras la aplicación de la fase húmeda del ciclo, y vuelve a clase de servicio 1, tras la aplicación de la fase seca del ciclo, con lo que en la aplicación del ciclo durante diez semanas se consigue 
reproducir los episodios de lluvia necesarios para completar seis años, y veinte cambios de clase de servicio del material.

Aplicando estos ciclos de envejecimiento, se reproduce el envejecimiento que se lleva a cabo en un año de exposición al exterior del producto como paramento, y los datos obtenidos en el ciclo corto en el FCBA y en el INIA serían comparables, y a su vez ambos serían comparables con el año de exposición al exterior que se lleva a cabo con el envejecimiento natural.

Al aplicar el ciclo durante 10 semanas, se están reproduciendo 480 episodios de lluvia, el equivalente a la degradación sufrida durante 6 años de exposición al exterior, y los datos obtenidos en este ciclo largo, son comparables con el ciclo largo de envejecimiento aplicado en el FCBA.

\subsection{Ensayo de tracción}

La actual y reciente norma armonizada para los tableros CLT, UNE-EN 16351 (2016), no contempla el ensayo de tracción perpendicular a la hora de evaluar la calidad del encolado sino que emplea el ensayo de cortante, que fue específicamente diseñado para la madera laminada y empleado también con los tableros SWP en la norma UNE-EN 13354 (2009). La experiencia de laboratorio habida con este ensayo aplicado en los tableros SWP plantea la duda de si el efecto del cruzamiento de la dirección de las fibras entre las distintas capas produce un envejecimiento muy superior al real y si el diferente valor de resistencia al cortante paralelo y rodante no induce innecesariamente roturas sobre madera, lo que no ocurre con la madera laminada en la que en todas sus capas la fibra sigue la misma dirección.

Por dicho motivo es hipótesis del presente trabajo que el ensayo de tracción perpendicular, aunque más complejo en su ejecución, puede arrojar más luz sobre el proceso de envejecimiento real de las líneas de cola, tal y como pasa con los tableros de partículas y fibras en los que este ensayo se efectúa rutinariamente tras someter al material a ciclos de envejecimiento.

Debido a esto, los ensayos de tracción perpendicular se efectuaron tanto sobre material sin envejecer como sobre material envejecido de acuerdo con los diversos sistemas de envejecimiento anteriormente analizados.

Otra hipótesis de este trabajo es la de que los procesos de envejecimiento producen tensiones rasantes en el seno de las líneas de cola que generen en ellas microfisuras que lleven a menores valores de la resistencia última a la tracción perpendicular.

\subsubsection{Definición}

Cuando se caracteriza un producto laminado encolado para aplicaciones resistentes, como es el CLT, se evalúan una serie de características esenciales, como son el módulo de elasticidad a flexión y la resistencia a la flexión, a la compresión, a la tracción y al cortante.

El ensayo de tracción perpendicular a la fibra, se basa en aplicar una carga continua de tracción en dirección perpendicular a las fibras de la madera hasta llegar al punto de fallo de la probeta. La máquina de ensayo utilizada para este ensayo cuenta con un dispositivo que nos permite regular la velocidad del 
ensayo, que se realizará a velocidad constante. A esta máquina se le acoplan dos mordazas que sirven para fijar la probeta, la cual no debe presentar fallos ni defectos.

El valor característico de la resistencia a tracción perpendicular en la madera conífera es muy bajo, del orden de $0,4 \mathrm{~N} / \mathrm{mm}^{2}$, inferior en todo caso al de las frondosas, que se sitúa en el orden de $0,6 \mathrm{~N} / \mathrm{mm}^{2}$. Esta baja resistencia de la madera de conífera en la dirección perpendicular se debe a que su estructura anatómica es fundamentalmente longitudinal por lo que la resistencia transversal la otorga el mayor o menor contenido en lignina así como las características compositivas, la frecuencia y tamaño de los radios leñosos (que discurren en sentido transversal y, por ello, efectúan una función de "atado" de la estructura longitudinal). Esto es así por cuanto el árbol en servicio no tiene que enfrentar grandes solicitaciones de este tipo y sí en dirección longitudinal.

Sin embargo este tipo de solicitaciones sí tienen gran importancia en la aplicación estructural de los productos de la madera, especialmente en las uniones y en las piezas curvadas

La metodología y equipamiento necesario para efectuar el ensayo de tracción perpendicular en madera sólida y productos laminados queda reflejada en las normas UNE-EN 408 (2012) y UNE-EN 302-3 (2013).

\subsubsection{Tipos de mordazas para el ensayo}

Atendiendo a la diferente normativa existente en materia de ensayo de productos de madera, existen tres tipos de mordazas para la realización del ensayo de tracción perpendicular a la fibra:

- Mordazas de tipo cóncavo, de acuerdo con la norma UNE-EN 302-3 (2013) con las que la carga puede transmitirse a la probeta por medio de placas de acero con unas mordazas cóncavas. Las probetas de madera han de mecanizarse para poder ser insertadas en las mordazas.
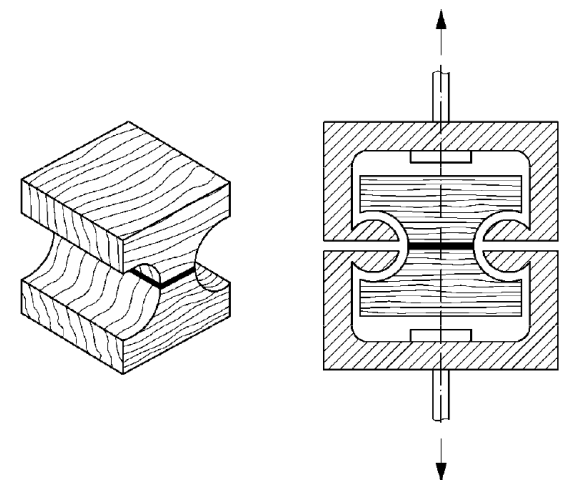

Figura 4.46: Mordaza de tipo cóncavo

- Mordazas de tipo placa, de acuerdo con la norma UNE-EN 408 (2012).

- Mordazas de tipo ranura-lengüeta, de acuerdo con la norma UNE-EN 319 (1994).

En Fernandez-Colfin et al. (1988) se compara en tableros de particular los resultados obtenidos con el empleo de mordazas tipo ranura y lengüeta respecto de los obtenidos con el empleo de mordazas tipo 


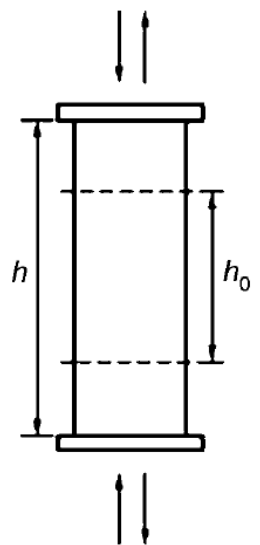

Figura 4.47: Mordaza de tipo placa
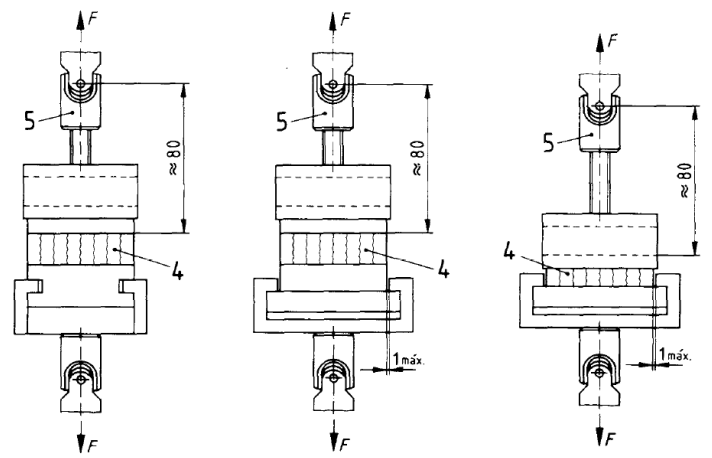

1 Bloque metálico

2 Bloque en forma de $T$ (metal, madera de frondosas o contrachapado de frondosas) 3 Bloque en contrachapado de frondosas (no aconsejable para tableros delgados) 4 Probeta.

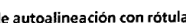

Figura 4.48: Mordaza de tipo ranura-lengüeta

plano concluyéndose sobre la conveniencia de emplear estas últimas y proponiendo un diseño para conseguir la autoalineación de las placas.

A continuación se lleva a cabo un análisis, para evaluar qué tipo de garras es el más adecuado para llevar a cabo el ensayo de tracción perpendicular a la fibra en las probetas de CLT. Para ello se llevarán a cabo unos ensayos previos y se tendrán en cuenta parámetros como la dificultad de mecanizado, el tipo de cola empleada y los resultados obtenidos.

\subsubsection{Mordazas tipo A, fijación por agarre mecánico plano, según UNE-EN 319 (1994)}

Este tipo de mordazas requiere practicar un ranurado lateral en las probetas, que permitan la fijación a las mordazas, y la transmisión de la fuerza de tracción para poder llevar a cabo el ensayo. Presenta 


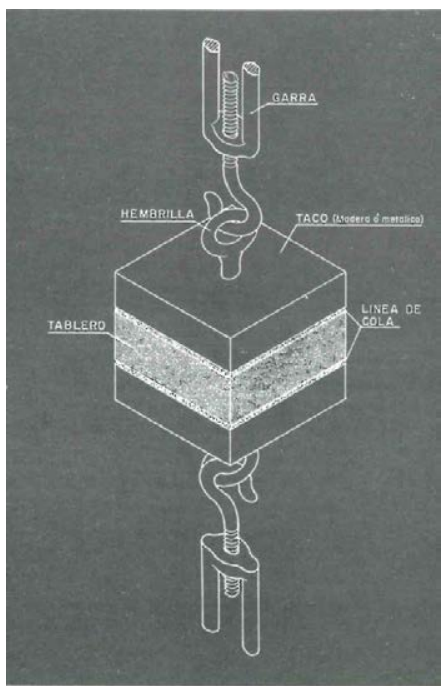

Figura 4.49: Ejemplo de fijación de la mordaza
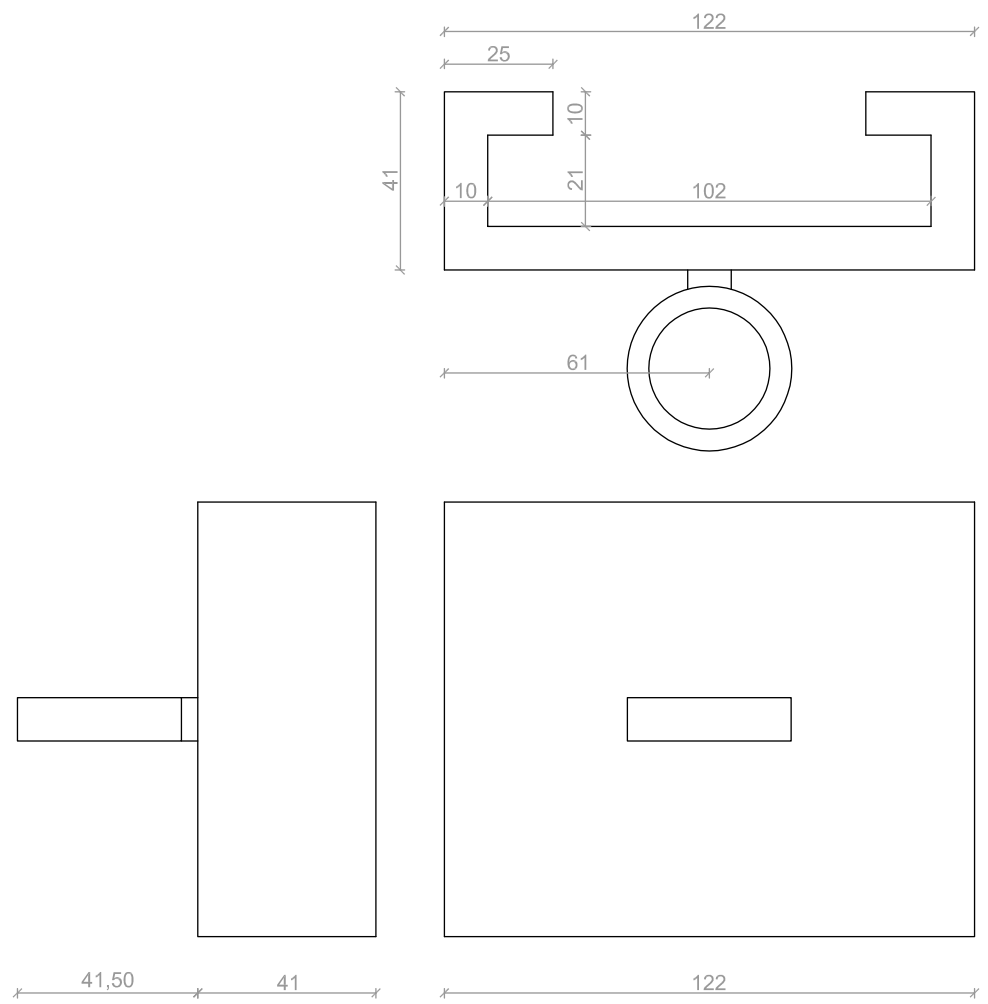

Figura 4.50: Plano de mordazas tipo A de agarre plano

la ventaja de que es una mecanización sencilla, pero en contrapunto reduce la sección de la probeta y deja la zona lateral muy debilitada.

Siguiendo la metodología de ensayo para el ensayo a tracción perpendicular a la fibra según UNE- 
EN 408 (2012), con las mordazas tipo A, con tres probetas de Pinus nigra con unas dimensiones de 100×100×100 mm (CLT tricapa), a una velocidad de 0,5 mm/min, se obtienen los resultados del cuadro 4.14.

Cuadro 4.14: Resultados del ensayo a tracción perpendicular a la fibra con mordazas tipo A

\begin{tabular}{lccc}
\hline & CARGA.MAX $(\mathrm{N})$ & DESP.MAX $(\mathrm{mm})$ & MODULO $(\mathrm{MPa})$ \\
\hline Probeta 1 & 6304,09 & 0,83 & 102,38 \\
Probeta 2 & 5696,33 & 1,36 & 85,78 \\
Probeta 3 & 6800,14 & 3,85 & 31,38 \\
\hline Media & 6266,85 & 2,01 & 73,18 \\
\hline Desviación estándar & 552,85 & 1,61 & 37,14 \\
\hline
\end{tabular}

A continuación se muestran las gráficas correspondientes a la curva del esfuerzo de tracción hasta la rotura de la probeta, y unas fotografías que muestran el tipo de rotura sucedido en cada probeta:

Probeta 1 a 1

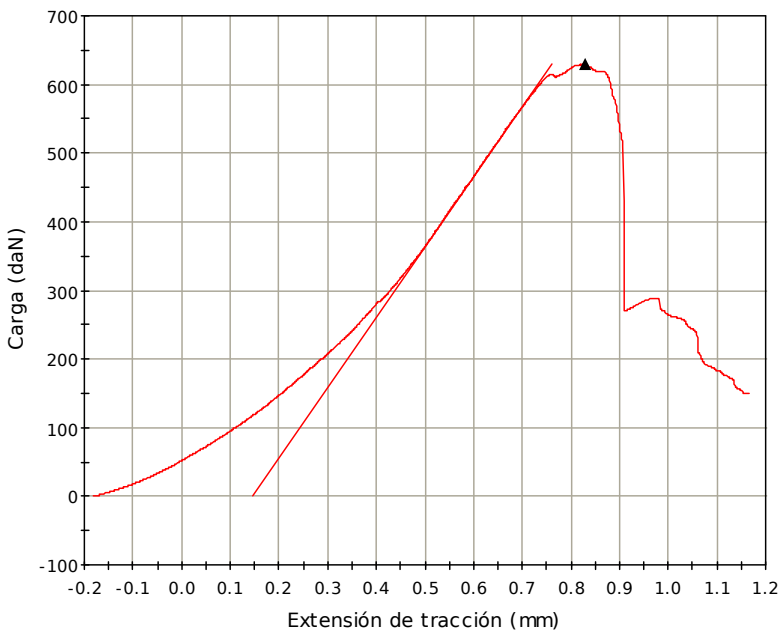

Figura 4.51: Esfuerzo de tracción hasta falla de probeta 1 de CLT con mordazas tipo A

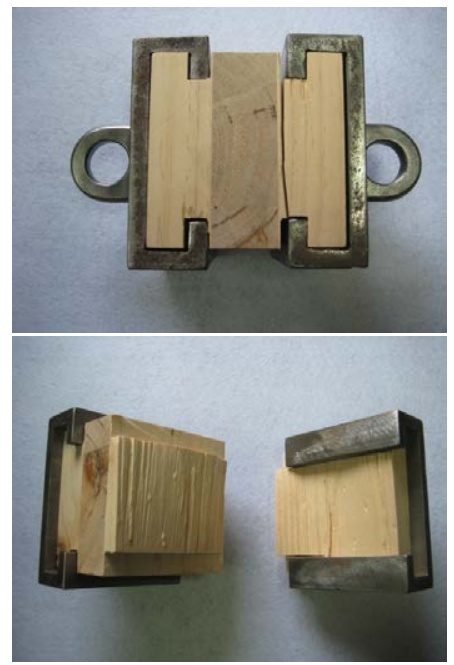

Figura 4.52: Rotura de la probeta 1 por ensayo de tracción perpendicular a la fibra con mordazas tipo $\mathrm{A}$ 
Probeta 2 a 2

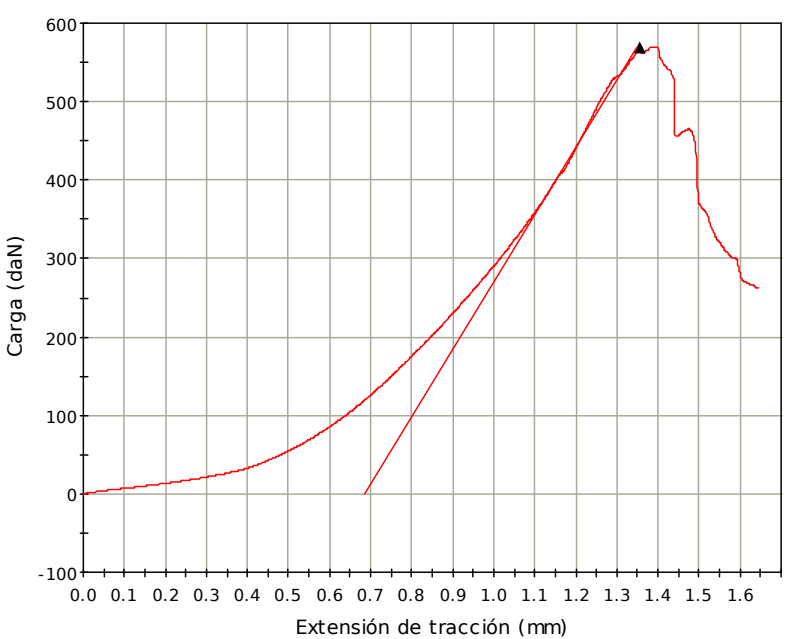

Figura 4.53: Esfuerzo de tracción hasta falla de probeta 2 de CLT con mordazas tipo $\mathrm{A}$

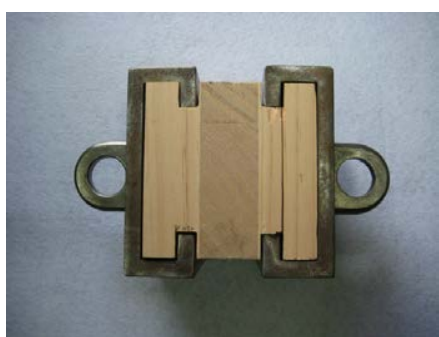

\begin{tabular}{c} 
Probeta n.ㅇ․ \\
$-\quad 2$ \\
\hline
\end{tabular}

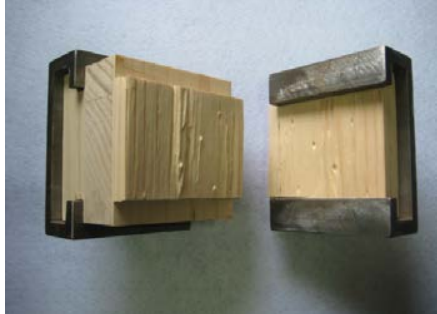

Figura 4.54: Rotura de la probeta 2 por ensayo de tracción perpendicular a la fibra con mordazas tipo A
Probeta 3 a 3

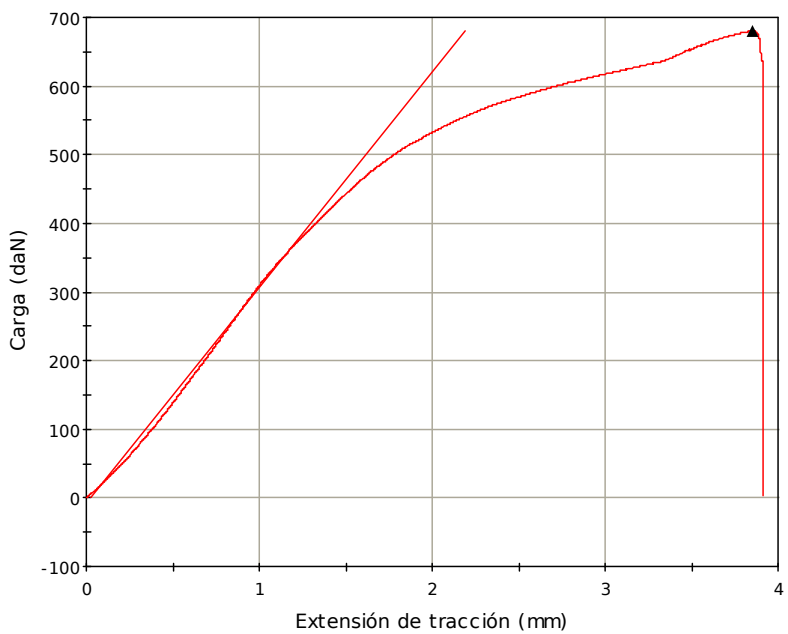

Figura 4.55: Esfuerzo de tracción hasta falla de probeta 3 de CLT con mordazas tipo A

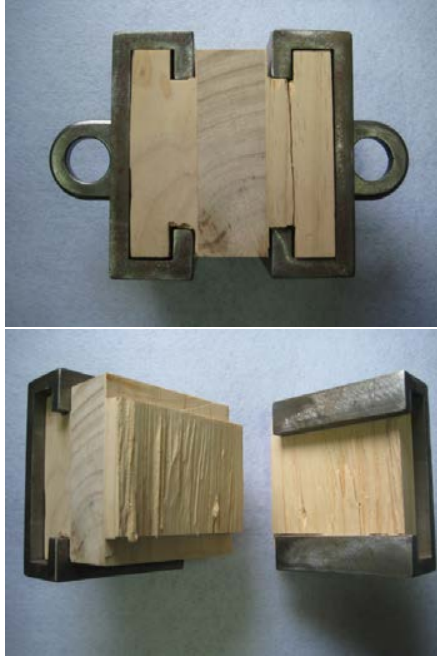

Figura 4.56: Rotura de la probeta 3 por ensayo de tracción perpendicular a la fibra con mordazas tipo A 


\subsection{Variante de ensayo de las mordazas tipo A, con unión química madera-madera}

A la vista de los resultados obtenidos en la mordaza tipo A, se decide probar con otro método para llevar a cabo el ensayo a tracción. En lugar de mecanizar las probetas a ensayar, se decide fijar las probetas mediante encolado con resina epoxi a unos trozos de haya mecanizados para este tipo de garras, obteniéndose el siguiente resultado:

Cuadro 4.15: Resultados del ensayo a tracción perpendicular a la fibra con mordazas tipo A, en su variante química madera-madera

\begin{tabular}{lccc}
\hline & CARGA.MAX $(\mathrm{N})$ & DESP.MAX $(\mathrm{mm})$ & MODULO $(\mathrm{MPa})$ \\
\hline Probeta 1 & 14455,01 & 2,3 & 79,04 \\
\hline Media & 14455,01 & 2,3 & 79,04 \\
\hline Desviación estándar & - & - & - \\
\hline
\end{tabular}

En las fotografías podemos ver la probeta encolada con las piezas de haya mecanizadas, antes y después del ensayo.

Probeta 1 a 1

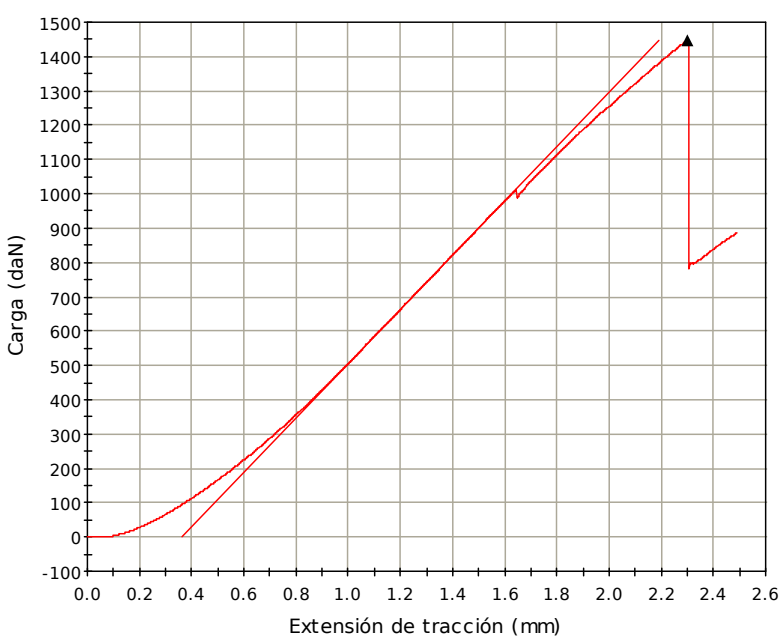

Figura 4.57: Esfuerzo de tracción hasta falla de probeta de CLT con la variante de mordazas tipo A

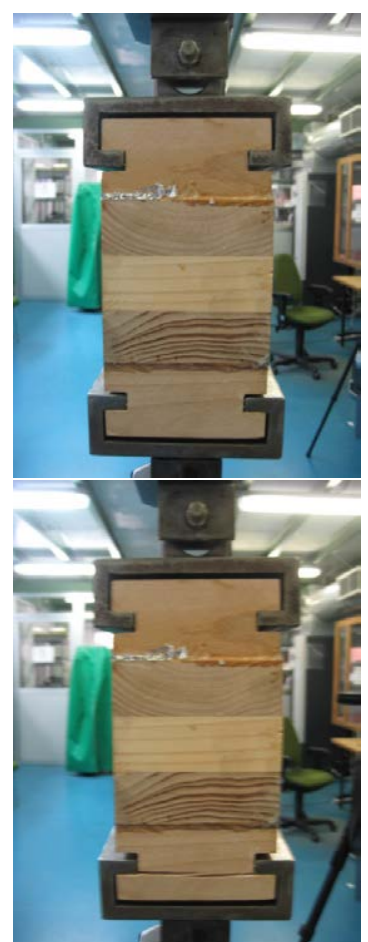

Figura 4.58: Rotura de la probeta por ensayo de tracción perpendicular a la fibra con la variante de mordazas tipo A

Atendiendo a las resultados obtenidos de los dos tipos de ensayos realizados con la mordaza de tipo A de ranura plana, observamos que en el segundo caso, cuando encolamos la probeta a la pieza de 
haya mecanizada, la carga máxima que soporta antes de la rotura es sustancialmente mayor, aunque la rotura se sigue produciendo en la misma zona que en el primer caso.

Observando la zona de rotura en el primer caso, en que los cabezales tractores estaban más fijos, se está produciendo un fallo por hienda (Fernandez-Colfin et al., 1988), sin embargo en el segundo caso en el que se utilizaron unos pasadores y otro tipo de cabezales, que permitían en propio autoajuste de la probeta al esfuerzo de tracción la rotura se produce de una manera más uniforme.

\subsubsection{Mordazas tipo B, fijación por agarre mecánico cóncavo según UNE-EN 302-3 (2013)}
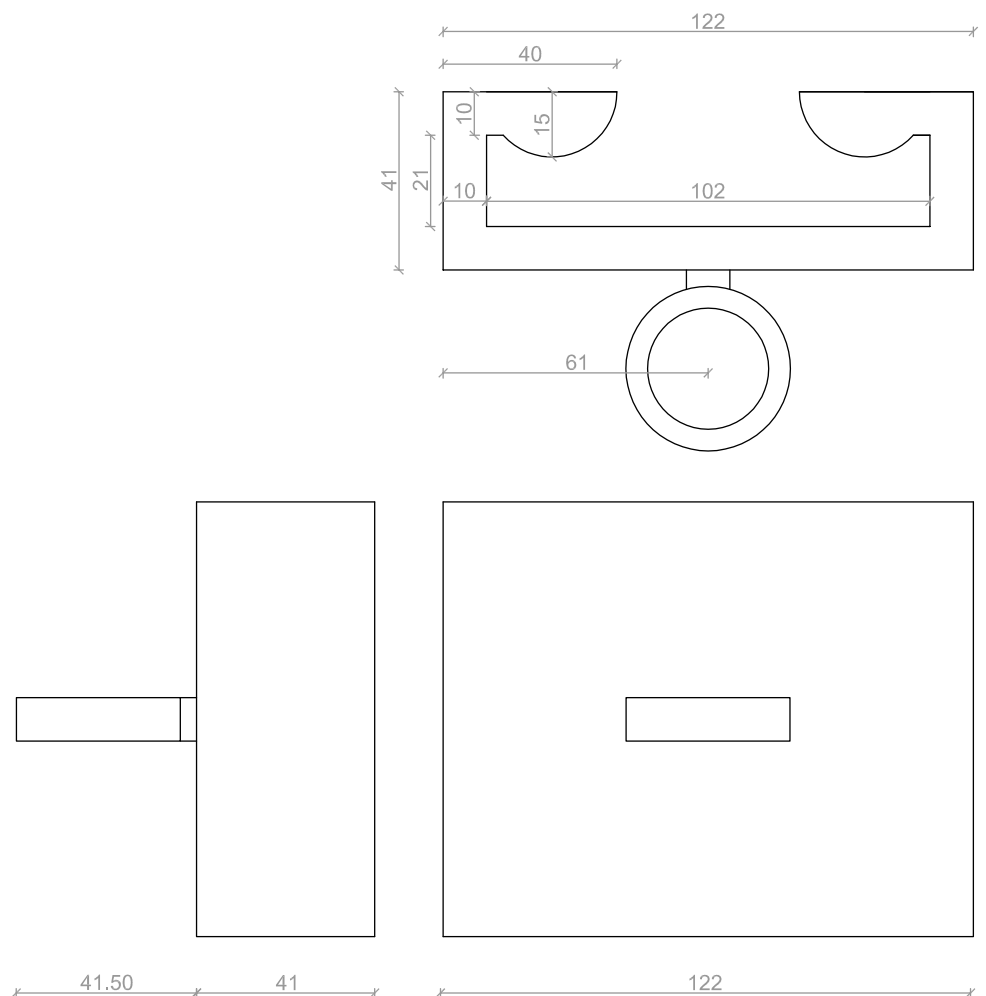

Figura 4.59: Plano de mordazas tipo B de agarre cóncavo

Este tipo de mordaza requiere practicar un ranurado lateral en las probetas, que permiten la fijación a las mordazas, y transmitirán la fuerza de tracción para poder llevar a cabo el ensayo. Presenta la ventaja en principio de que se reparten las fuerzas de una forma más uniforme que en el ejemplo anterior, pero en contrapartida, sufre una gran reducción de la sección de ensayo y presenta una mecanización de las probetas muy compleja, de hecho no ha sido viable la mecanización de las probetas con los medios disponibles.

Este ensayo no se pudo llevar a cabo debido a la imposibilidad de mecanización de las probetas con los medios existente. A continuación se muestra una foto de uno de los intentos llevados a cabo para su mecanización. 

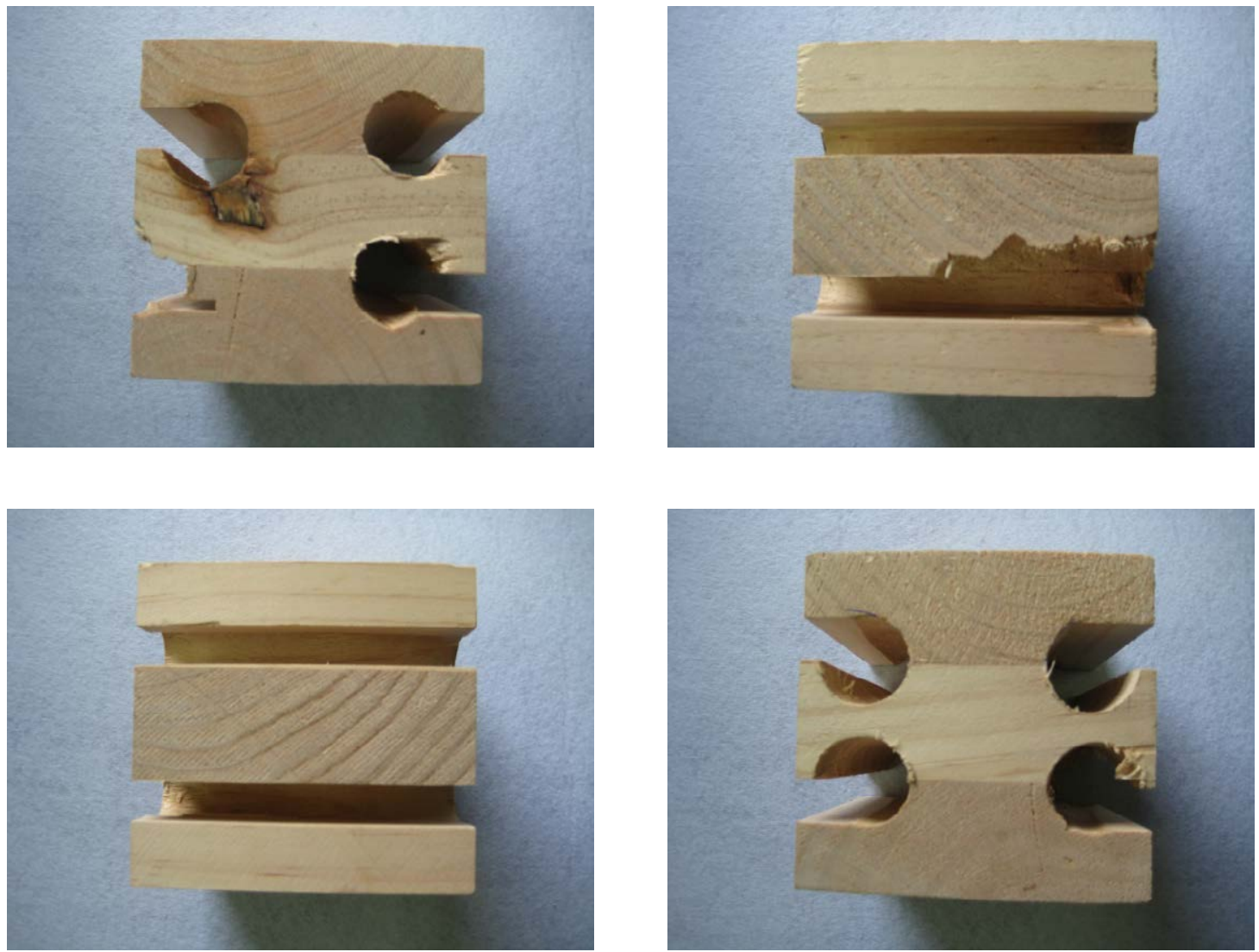

Figura 4.60: Intento de mecanización de las probetas 
4.6.2.3. Mordazas tipo C, fijación por agarre químico plano, según UNE-EN 408 (2012)
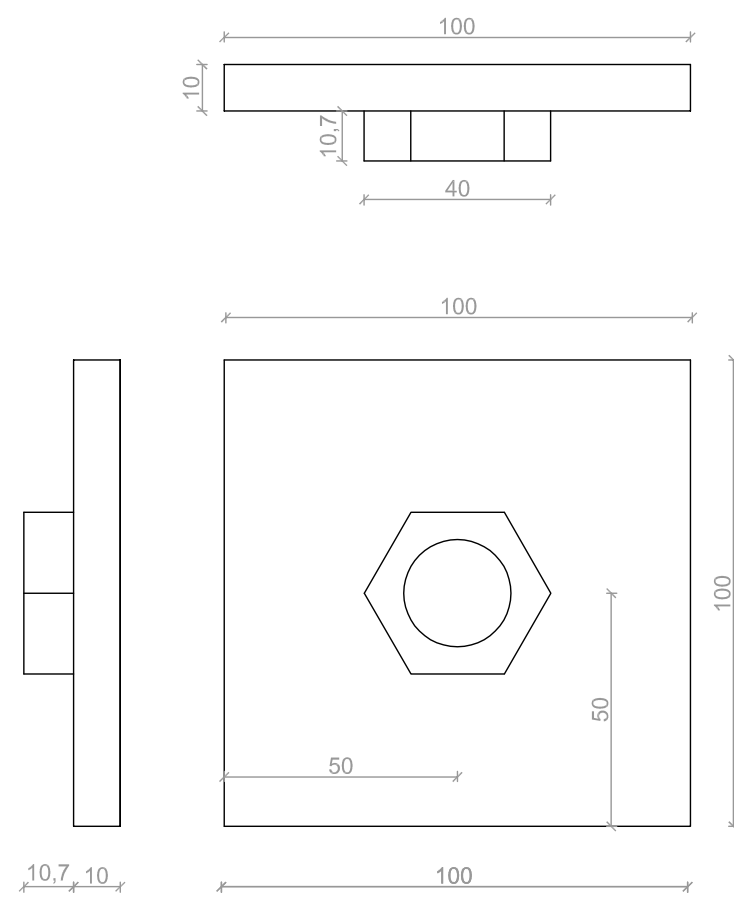

Figura 4.61: Plano de mordaza de tipo C de agarre químico

Es el modelo de mordaza más sencillo de los tres que se plantean en principio, con el hándicap de que la fijación de las probetas se debe realizar mediante encolado con resina epoxi, lo que requiere un proceso laborioso, pero a cambio permite el ensayo de toda la sección de la probeta.

Siguiendo la metodología de ensayo para el ensayo a tracción perpendicular a la fibra según UNEEN 408 (2012), con las mordazas tipo C, con tres probetas de Pinus nigra con unas dimensiones de $100 \times 100 \times 100 \mathrm{~mm}$ (CLT tricapa), a una velocidad de $0,5 \mathrm{~mm} / \mathrm{min}$, se obtienen los resultados del cuadro 4.16 .

Cuadro 4.16: Resultados del ensayo a tracción perpendicular a la fibra con mordazas tipo C

\begin{tabular}{lccc}
\hline & CARGA.MAX $(\mathrm{N})$ & DESP.MAX $(\mathrm{mm})$ & MODULO $(\mathrm{MPa})$ \\
\hline Probeta 1 & 29082,35 & 2,24 & 196,69 \\
Probeta 2 & 13959,82 & 0,85 & 217,99 \\
Probeta 3 & 28346,25 & 2,05 & 205,62 \\
\hline Media & 23796,14 & 1,71 & 206,77 \\
\hline Desviación estándar & 8526,45 & 0,75 & 10,7 \\
\hline
\end{tabular}

PROBETA 1:

Atendiendo a las fotografías y la gráfica de la probeta 1, se puede observar que presenta un buen valor de resistencia a la rotura a tracción, aunque por la forma de la rotura y teniendo en cuenta que los cabe- 
Probeta 1 a 1

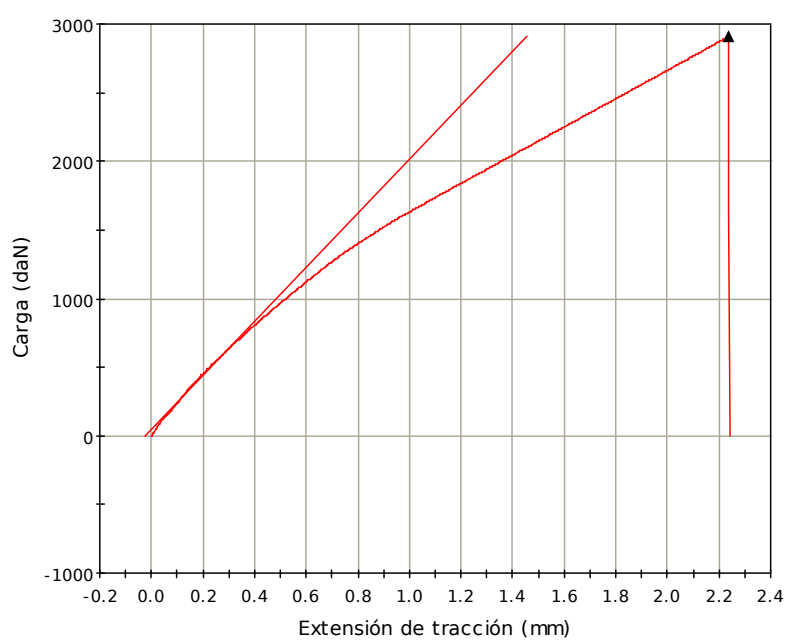

Figura 4.62: Esfuerzo de tracción hasta falla de probeta 1 de CLT con mordazas tipo $\mathrm{C}$

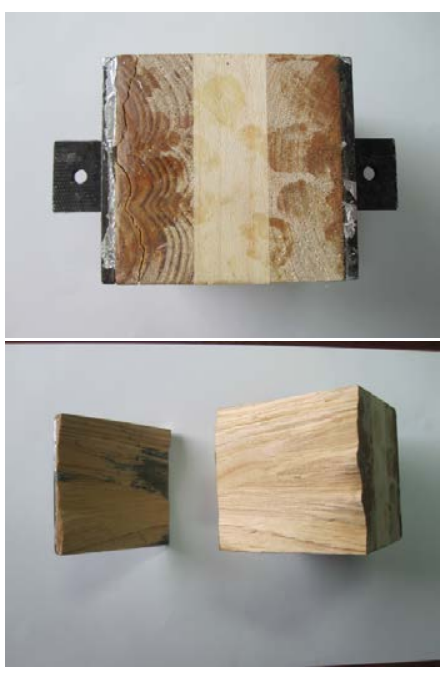

Figura 4.63: Rotura de la probeta 1 por ensayo de tracción perpendicular a la fibra con mordazas tipo $\mathrm{C}$

zales tractores son los mismos que los usados en el caso anterior, se puede apreciar que sigue habiendo muestras de hienda en la rotura.

PROBETA 2:

Probeta 2 a 2

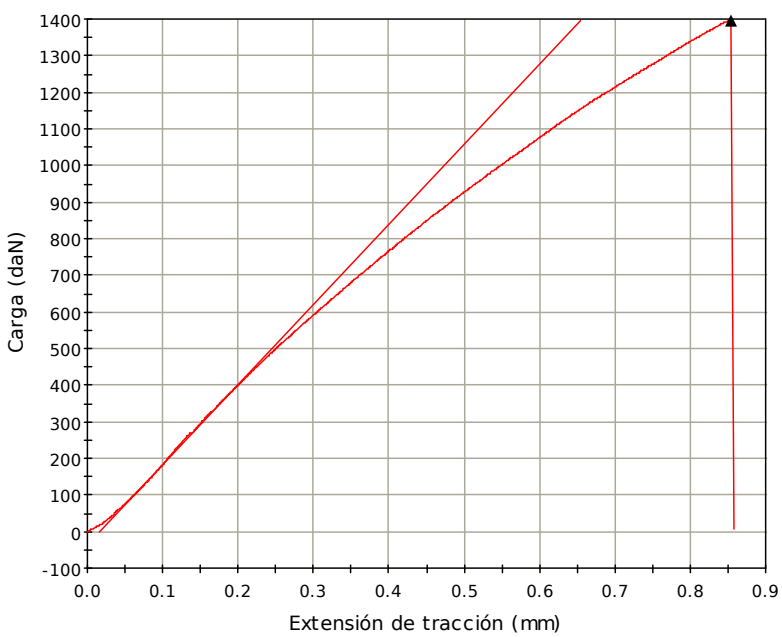

Figura 4.64: Esfuerzo de tracción hasta falla de probeta 2 de CLT con mordazas tipo $\mathrm{C}$

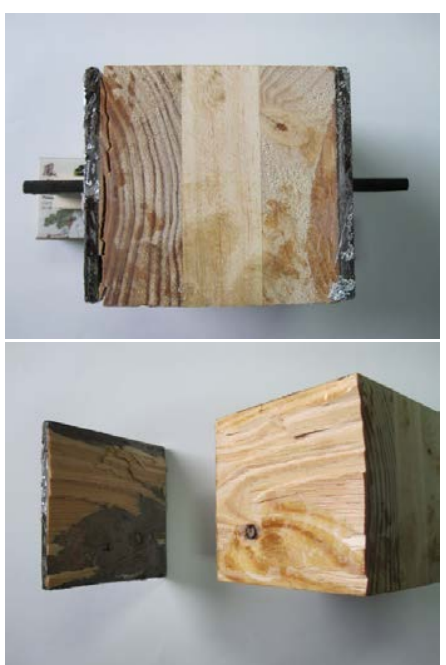

Figura 4.65: Rotura de la probeta 2 por ensayo de tracción perpendicular a la fibra con mordazas tipo $\mathrm{C}$

Atendiendo a las fotografías y la gráfica de la probeta 2 , se puede observar que presenta un valor bajo de resistencia a la rotura a tracción, aunque por la forma de la rotura y teniendo en cuenta que los cabezales tractores son los mismos que los usados en el caso anterior, se puede apreciar que en este caso 
el efecto de la hienda es más acusado, además del fallo de la cola que en este caso es de un porcentaje mayor que en el resto.

PROBETA 3:

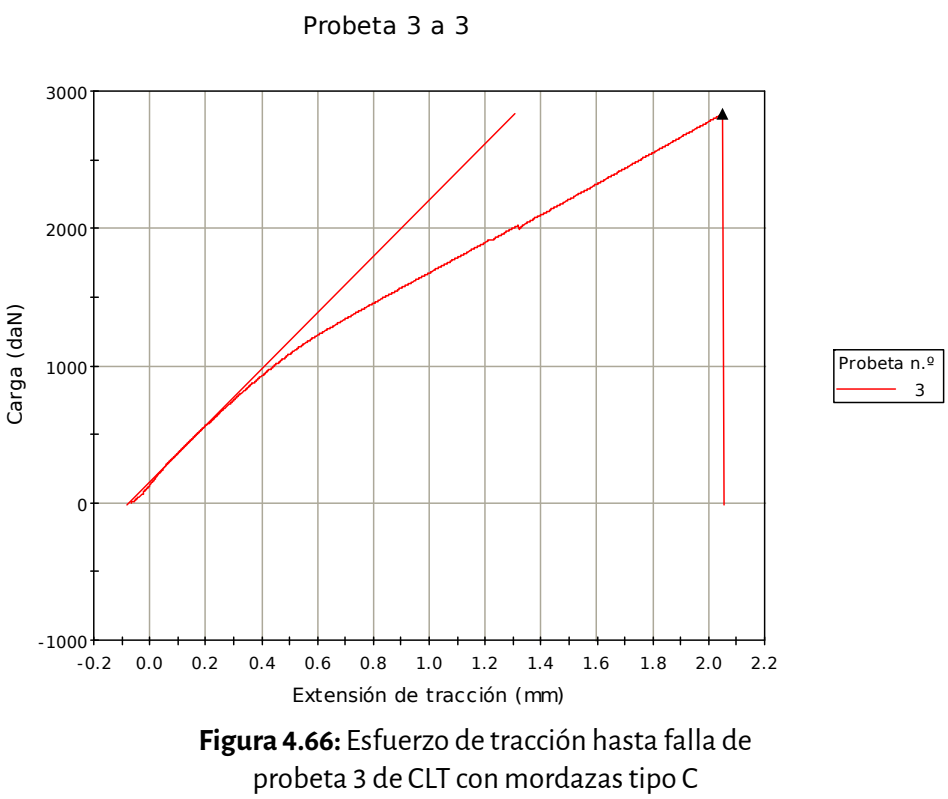

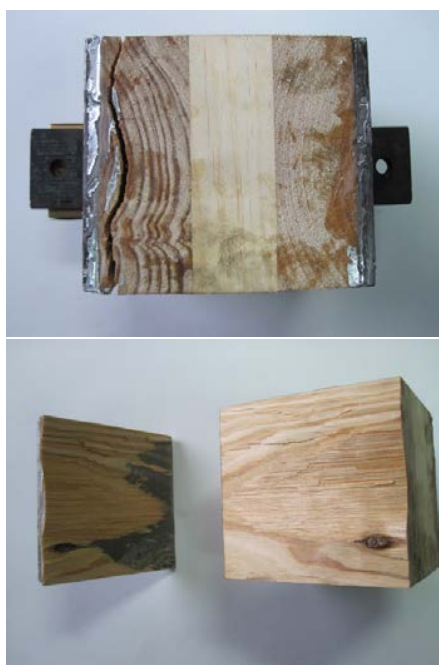

Figura 4.67: Rotura de la probeta 3 por ensayo de tracción perpendicular a la fibra con mordazas tipo $\mathrm{C}$

Atendiendo a las fotografías y la gráfica de la probeta 3 , se puede observar que presenta un buen valor de resistencia a la rotura a tracción, aunque por la forma de la rotura y teniendo en cuenta que los cabezales tractores son los mismos que los usados en el caso anterior, se puede apreciar que sigue habiendo muestras de hienda en la rotura.

Tras el ensayo con los tres tipos de garras propuesto para el ensayo a tracción perpendicular a la fibra, se concluye que el tipo de garras más adecuado para este ensayo son las garras planas tipo C con fijación química. Aunque este tipo de garras es el que conlleva un proceso de ensayo más laborioso, por la preparación de las probetas, es el que se considera más adecuado. También se percibe que hay indicios de rotura por hienda, por lo que se proponen ciertos cambios en las mordazas de la máquina de ensayo.

\subsubsection{Preparación de las probetas}

Una vez seleccionado el modelo de garras más adecuado para llevar a cabo el ensayo de tracción perpendicular a la fibra, se describe a continuación el proceso de preparación de las probetas.

Las propiedades elastomecánicas de los productos de madera, como es caso del CLT, varían en función del contenido de humedad. Así, si aumenta el tanto por ciento de humedad, bajan la resistencia y el módulo de elasticidad. Este efecto se produce por variaciones en el contenido de humedad hasta el punto de saturación de la fibra, a partir de este momento los valores se estabilizan y no sufren variación. Esta es la razón por la que los ensayos se realizan bajo condiciones de ambiente normalizadas, con 
una temperatura de $20^{\circ} \mathrm{C} \pm 2^{\circ} \mathrm{C}$, y con una humedad relativa del $65 \% \pm 5 \%$, que equivale al $12 \%$ de humedad en madera, cifra que se corresponde con el equilibrio higroscópico de la madera (UNE-EN 384, 2016).

Se recomiendo por tanto que las muestras antes de ser ensayadas se estabilicen en cámara climática en un periodo comprendido entre 7 y 10 días en condiciones de ambiente normalizadas. Por tanto, tras la aplicación de los diferentes ciclos de envejecimiento y antes de llevar a cabo los ensayos de tracción perpendicular a la fibra, las muestras se estabilizan en cámara climática durante 7 días en unas condiciones de $20^{\circ} \mathrm{C}$ y $65 \%$ de humedad (UNE-EN 384, 2016).

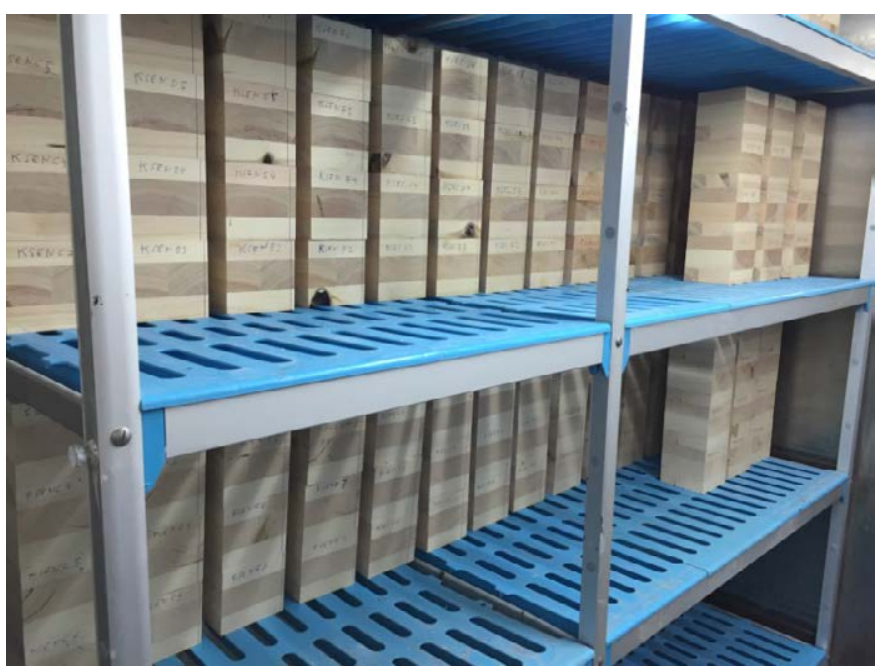

Figura 4.68: Muestras estabilizándose en cámara climática en ambiente normalizado

Tras el periodo de estabilización de la humedad de las probetas, y antes de unirlas a las garras, se lleva a cabo una selección de las mismas según lo descrito en el apartado 4.3.2 Selección de las probetas, para que las probetas ensayadas sean representativas de la muestra.

Hay que prestar especial atención en la preparación de piezas de ensayo para asegurar que las superficies cargadas son lisas y paralelas entre sí y perpendiculares a la dirección de la línea de cola. Por lo cual, y una vez estabilizadas las probetas, se procede a un lijado superficial de las caras, que además contribuirá a favorecer la acción del adhesivo epoxi bicomponente que se aplica para la fijación química de las probetas a las garras de ensayo. Una vez lijadas las probetas se limpian con un disolvente universal, para eliminar las impurezas de la superficie y asegurar una correcta unión con la garra. La garra también se limpia con este disolvente universal con el fin de eliminar posibles impurezas.

Seguidamente se procede a la preparación del adhesivo epoxi utilizado para la unión química entre la garra y la probeta. Se trata de un adhesivo bicomponente, se realiza la mezcla al $50 \%$ entre los dos componentes, y una vez que esta mezcla es homogénea, se procede a la aplicación de una fina capa tanto en la superficie de la probeta como en la superficie de la garra.

A continuación se procede a la unión de las garras con las caras de las probetas. En el proceso de fraguado del adhesivo, se producen movimientos que hacen que la garra se desplace sobre la superficie 

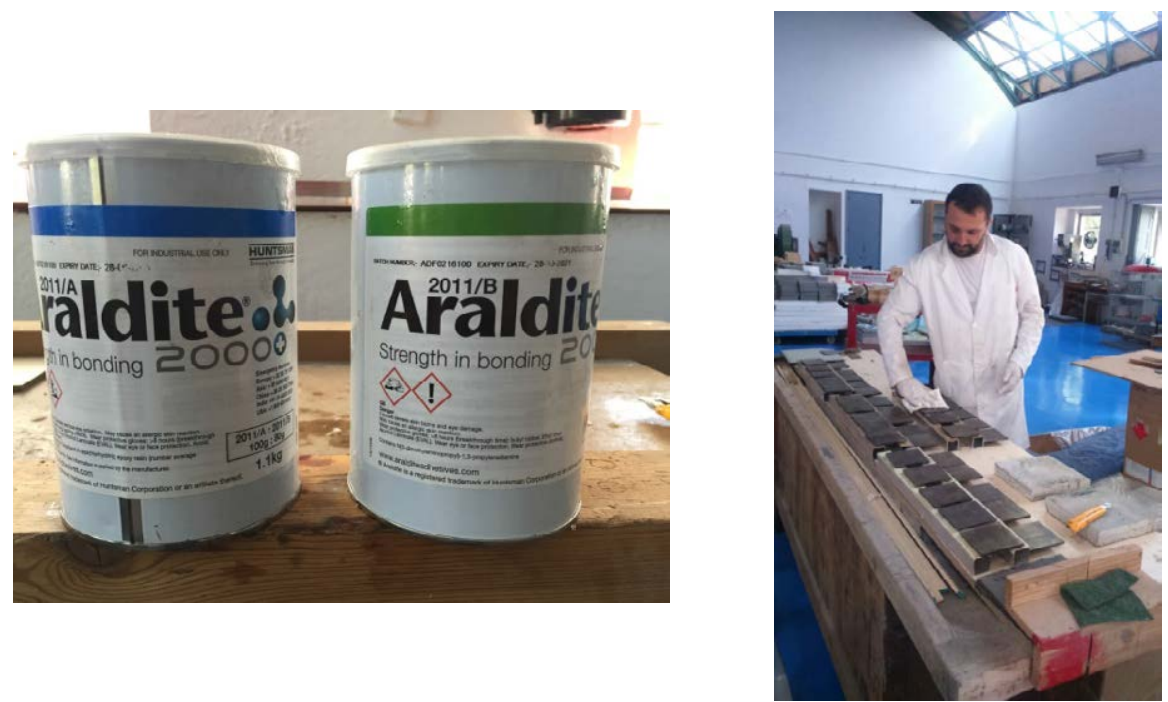

Figura 4.69: Adhesivo epoxi y su aplicación

de la cara de la probeta, para evitar esto y que la unión sea lo más uniforme posible, se rodea la probeta unida a las garras con cinta americana, lo que permite mantener la garra en la posición fijada.

Una vez concluido todo el proceso de pegado, y debido al tipo de adhesivo utilizado hay que esperar 24 horas para poder llevar a cabo el ensayo de tracción, este tiempo de fraguado se lleva a cabo en el laboratorio con las probetas a humedad y temperatura ambiente.

Tras la realización del ensayo, se lleva a cabo la limpieza de las probetas para poder iniciar de nuevo el proceso. Esta limpieza se lleva a cabo en primer lugar con la retirada de la madera de las probetas de la superficie de las garras, debido a la fuerte unión que se crea con el uso del adhesivo, es necesario en primer lugar el uso de un formón para madera y un martillo. Una vez retirados los restos de mayor tamaño, se procede a la eliminación total de los restos de cola y de madera que permanecen en la superficie de las garras.
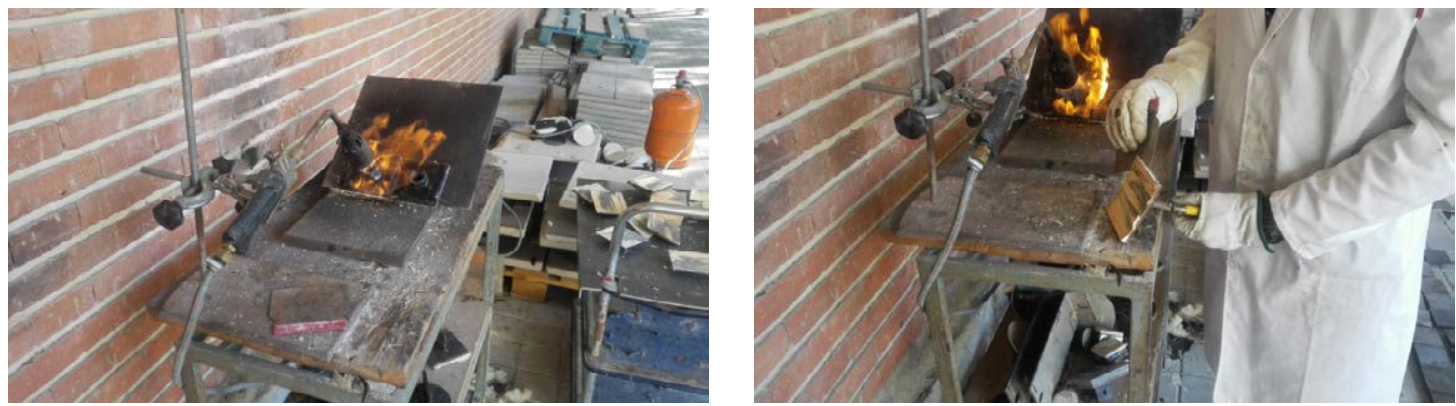

Figura 4.70: Limpieza de las probetas

Este segundo paso se lleva a cabo sometiendo a las probetas a la acción del calor, esto se hace con un soplete de gas, se calienta la superficie, y con la ayuda de una espátula, se retiran los restos de madera y cola. Para asegurarnos la retirada total de los restos, la superficie es cepillada con un cepillo de bronce, 
que nos asegura la retirada total de residuos. Tras este proceso, las garras estarían de nuevo listas para comenzar el proceso de pegado descrito anteriormente.

\subsubsection{Aparatos}

Para la realización de este ensayo se han seguido las indicaciones establecidas en la norma UNE-EN 408 (2012). Los ensayos se realizan conforme a las especificaciones establecidas en la norma de referencia en una maquina universal de ensayo electromecánica, son las más comúnmente utilizadas para la realización de ensayos estáticos de tracción/compresión.

En este caso el equipo utilizado es un flexodinamómetro marca Instron modelo 5582 de 100 KN de capacidad con las siguientes características:

- Sistema digital de control del puente móvil con ajuste de velocidad variable

- Control digital de bucle cerrado y adquisición de datos

- Controladores de extensión y de carga

- Captura de datos a $40 \mathrm{kHz}$ de velocidad de muestreo con una transferencia al ordenador a $500 \mathrm{~Hz}$ sincrónicamente de hasta 4 canales

- Husillos de recirculación de bolas

- Espacio doble de ensayo

- Tarjeta de acondicionador de sensor con función de adquisición de datos y control de bucle cerrado para transductores

- Programa de ensayos de materiales basado en Windows y con interface gráfico del usuario. El programa proporciona una plataforma que sirve para realizar mediciones básicas, control de ensayo e informe del ensayo, genera gráficos y tabla de resultados de los datos procesados

- Control y resultados de ensayo: preciclado, precarga, dos velocidades de ensayo con cambio automático en punto especificado por el usuario, control de creep y relajación, pretension, control de mordazas y detección del fin del ensayo por rotura, detección de puntos preseleccionado, valores picos, corección de deslizamientos y creep/relajación (total y delta)

Este equipo se clasifica como Clase 0,5 según la calibración anual por laboratorio externo certificado, conforme a la norma UNE-EN ISO 7500-1 (2016), con las siguientes características:
Error relativo de precisión
$q= \pm 0,5$
Error relativo de repetibilidad
$b=0,5$
Error relativo de reversibilidad
$v= \pm 0,75$
Error relativo de cero
$f 0= \pm 0,05$
Resolución relativa
$\mathrm{a}=0,25$ 


\subsubsection{Procedimiento}

El ensayo se realiza con una velocidad de desplazamiento del puente móvil de $0,5 \mathrm{~mm} / \mathrm{min}$, dicha velocidad se estableció en las pruebas iniciales para asegurar los tiempos de rotura en $300 \pm 120$ s, conforme a la norma de referencia.

En dicha norma se especifica el procedimiento para la realización de los ensayos a tracción y establece que: "La probeta se debe cargar por medio de mordazas que permitan en la medida de lo posible la aplicación de una carga de tracción, sin provocar flexión. Se deben registrar las características de las mordazas y las condiciones de carga realmente usadas".

Para el cumplimiento de este requisito hicimos uso de dos acoplamientos, uno a cada lado de ensayo de la probeta, del tipo "junta universal o cardan" ya que permite unir dos ejes no colineales eliminando las flexiones, lo que minimiza el efecto de rotura por hienda detectado en los ensayos previos para la elección de las garras a utilizar.

La principal característica de las juntas universales es su capacidad de trabajar con elevadas desalineaciones paralelas y están diseñadas para aplicaciones exigentes y en las que las condiciones externas son desfavorables para otros tipos de acoplamientos.

\subsection{Ensayo de delaminación}

Como se ha comentado, para evaluar la aptitud al uso del CLT como paramento en clase de servicio 3, en condiciones de uso compatibles con una clase de uso 3.1 de la norma UNE-EN 335 (2013). Se tendrán en cuenta dos parámetros: la carga máxima, que hace referencia a la resistencia a tracción perpendicular a las fibras de las muestras ensayadas, y el ensayo de delaminación, que hace referencia a la integridad del CLT como producto.

La norma UNE-EN 16351 (2016) propone unos métodos de evaluación para los componentes y los productos utilizados para la conformación del CLT. En estos métodos, se plantea la evaluación de la madera que compone el CLT, del adhesivo usado para las uniones, y del CLT como producto.

Según la citada norma los encolados pueden considerarse duraderos y fiables si se satisfacen los requisitos mínimos de fabricación (UNE-EN 16351, 2016, Anexo I), y define la resistencia del encolado como:

- Resistencia del encolados de los empalmes por unión dentada de las láminas

- Resistencia del encolado de los planos de encolado entre capas

- Resistencia de los encolados de canto entre láminas

- Resistencia del encolado de los empalmes por unión macrodentada

Propone diferentes ensayos para evaluar las diferentes resistencias, la resistencia de los planos de encolado entre capas se evalúa mediante el ensayo de delaminación (UNE-EN 16351, 2016, Anexo C), en el que explica cómo se deben medir las delaminaciones y que se debe considerar delaminación. 
El ensayo de delaminación de los planos de encolado consiste, en medir las líneas de cola tras el proceso de envejecimiento, que tiene como objetivo crear tensiones internas en la madera mediante un gradiente en su contenido de humedad.

Según describe el Anexo C, una calidad de encolado defectuosa tendrá como resultado la aparición de delaminaciones en los planos de encolado, además se describe cómo medir estas delaminaciones.

La delaminación total viene definida en forma porcentual por la fórmula:

$$
\text { Delam }_{\text {tot }}=\frac{I_{\text {tot,delam }}}{I_{\text {tot, linea cola }}} \text { en } \%
$$

donde

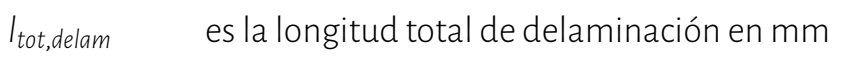

$I_{\text {tot,linea cola }}$ es la suma de las longitudes de todas las líneas de cola en una probeta de delaminación en mm

La delaminación máxima vive definida igualmente de forma porcentual por la fórmula:

$$
\text { Delam }_{\text {max }}=100 \cdot \frac{I_{\text {max delam }}}{l_{\text {linea cola }}} \text { en } \%
$$

donde

Imax,delam es la longitud máxima de delaminación en mm

$l_{\text {linea cola }}$ es la longitud de una línea de cola en $\mathrm{mm}$

Atendiendo a las fórmulas expresadas anteriormente, la resistencia del encolado de los planos de encolado entre capas, se considera suficiente si la longitud máxima de delaminación no supera el $40 \%$ de la longitud total de una línea de cola, y si la longitud total de delaminación no supera el 10 \% de la suma de longitudes de todas la líneas de cola.

Cuando la longitud máxima de delaminación o la longitud total de delaminación superan los límites especificados anteriormente, o cuando las longitudes de delaminación no pueden evaluarse a causa de una calidad inadecuada de las superficies de corte, cada plano de encolado debe ser abierto. El porcentaje de fallo por madera de cada zona encolada abierta debe ser al menos el $50 \%$, y el porcentaje de fallo por madera de todas las zonas encoladas abiertas debe ser del 70 \% como mínimo.

En este estudio, se va a suponer que las líneas de delaminación son insuficientes, ya que se considera más objetiva la evaluación de toda la superficie de encolado, que únicamente las líneas de cola. Además en el caso del envejecimiento artificial, las probetas se sellan con pintura plástica para forzar la entrada de agua por la cara y no por la testa, lo que dificulta la evaluación de las líneas de encolado. Por lo expuesto se lleva a cabo la segunda parte del procedimiento de evaluación descrito. 
Una vez las muestras han sido sometidas al ensayo de tracción perpendicular a la fibra, serán abiertas totalmente, para ello se aprovecha que las muestras están fijadas a las garras planas y se separaran gracias a la fuerza de tracción perpendicular que se puede ejercer con la máquina de ensayo.

Con las muestras abiertas completamente y con la finalidad de determinar en qué porcentaje se ha producido la rotura por madera o por cola, se le aplica a ambas caras de la rotura una solución de safranina.

La safranina es un colorante que colorea la celulosa, y en este caso de roturas por los planos de encolado permite determinar que parte de la superficie es celulosa y por tanto corresponde a una rotura por fallo de madera, y que parte es cola y por tanto la rotura se debe a un fallo en el plano de encolado.

Las muestras son impregnadas con safranina mediante una brocha, se impregna toda la superficie de las dos caras que forman parte de la rotura y se esperan 24 horas para llevar a cabo la evaluación.

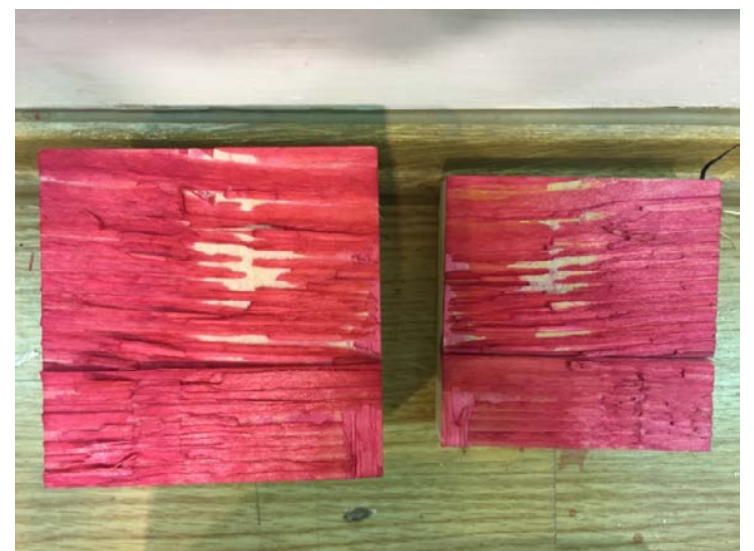

Figura 4.71: Detalle de rotura tras su impregnación con safranina

La determinación de la superficie de rotura que pertenece a rotura por cola o rotura por madera, se lleva a cabo mediante la utilización de una plantilla de acetato transparente cuadriculada. Cada cuadrícula de esta plantilla se corresponde con un $5 \%$ de superficie.

Una vez transcurridas las 24 horas necesarias para que la coloración de la celulosa sea clara y con ayuda de la plantilla de acetato, se determina el porcentaje de madera de la rotura. Para ello se sitúa la plantilla sobre la cara más desfavorable y se mide la superficie de madera.

El resultado del ensayo de delaminación llevado a cabo tras el ensayo de tracción perpendicular a la fibra, en el que se obtienen datos de la resistencia mecánica del material, indica si el valor de carga máxima que utilizamos para evaluar la pérdida de propiedades se ha debido a una pérdida de propiedades del CLT como producto, si la delaminación es menor del $70 \%$, o por el contrario es una pérdida de propiedades debido al material, a la especie de madera utilizada, si la delaminación se encuentra por encima del $70 \%$.

En caso del que la rotura por madera en los planos de encolado sea superior al $70 \%$, se supone que el encolado es seguro y duradero, ya que se ha mantenido íntegro durante el periodo de estudio, o al menos así lo expresa la norma UNE-EN 301 (2014), para elementos estructurales pertenecientes a las 


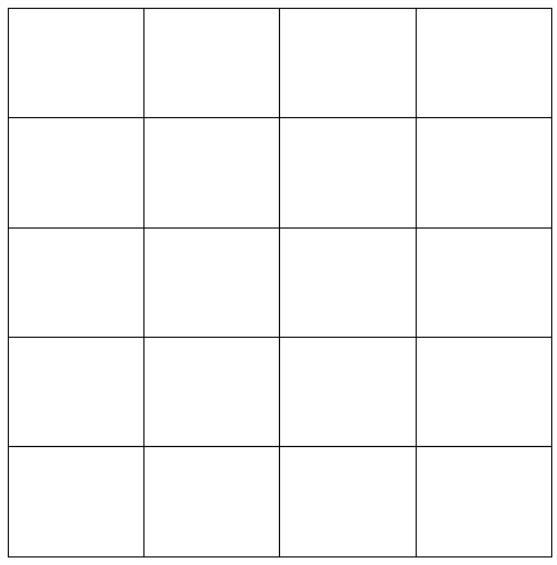

Figura 4.72: Plantilla para evaluación de fallo

clases de servicio 1 y 2 , y comenta que para estructuras de madera pertenecientes a la clase de servicio 3 se deben tomar precauciones especiales, como por ejemplo emplearse adhesivos resistentes al agua.

\subsection{Tratamiento de los datos}

Con los datos obtenidos de los diferentes métodos de envejecimiento, se van a llevar a cabo una serie de cálculos para poder obtener resultados. Estos cálculos se efectuarán mediante dos tipos de análisis, que se llevaran a cabo con dos programas diferentes.

El primer tipo de análisis es el que se ha denominado "análisis descriptivo", que consiste en un análisis general llevado a cabo mediante la hoja de cálculo Excel. En este análisis se describirán los resultados obtenidos en los diferentes métodos de envejecimiento mediante el uso de parámetros descriptivos habituales como las medias y la desviación estándar de los datos.

En este estudio la media utilizada o promedio, es la correspondiente a la media aritmética. También se conoce como esperanza matemática. Proporciona una medida de posición de los datos indicando el valor entorno al cual están centrados -su centro de gravedad. Aporta por si mismo una información muy útil, aunque incompleta como veremos al no dar indicaciones sobre la dispersión de los datos, sobre la población. En nuestro caso se puede ver como un valor representativo que muestra el efecto de cada uno de los envejecimientos.

La desviación estándar o desviación típica es una medida de dispersión para variables de razón y de intervalo, definida como la raíz cuadrada de la varianza de la variable. Permite conocer con detalle un conjunto de datos, ya que no basta con conocer las medidas de tendencia central o promedio calculado previamente, sino que se necesita conocer también la desviación que presentan estos datos en su distribución respecto de la media aritmética de dicha distribución, con objeto de tener una visión de los mismos más acorde con la realidad al momento de describirlos e interpretarlos para la toma de decisiones. En el caso de la madera la desviación estándar es un parámetro importante, debido a la variabilidad del material. 
Con este primer análisis, se obtiene una visión general descriptiva de lo que le está sucediendo al producto y al material con respecto al envejecimiento aplicado.

Para poder afirmar que las tendencias observadas en el análisis anterior son estadísticamente significativas se lleva a cabo un segundo tipo de análisis. Estos análisis se han llevado a cabo mediante el programa estadístico especializado SPSS y forman dos grandes grupos. En primer lugar se han realizado algunos contrastes de hipótesis sobre las diferencias entre los distintos tratamientos aplicados (envejecimiento natural y envejecimientos artificiales). Por otro lado se han realizado "análisis de componentes principales para datos categóricos".

Para el primer tipo de análisis, en primer lugar se establece un modelo en el que la variable respuesta (carga máxima o delaminación) sea explicada mediante algún factor como puede ser la ubicación u orientación o el tipo de envejecimiento artificial. Una vez comprobada la validez de la o las variables explicativas, es decir, que con un nivel de significación dado (en general 0,05) su coeficiente en el modelo es distinto de cero, se procede a realizar siempre las siguientes pruebas:

- Prueba de Levene o de homogeneidad de varianzas, que servirá para considerar las varianzas dentro de cada grupo iguales o diferentes-lo que determinará el tipo de los análisis posteriores.

- Test ANOVA, o análisis de varianza, para contrastar la hipótesis de que no haya diferencia significativa entre los grupos

Cuando el Test ANOVA arroja diferencias significativas entre los grupos, debe analizarse donde se dan estas diferencias - el ANOVA no lo hace- por lo que hay que recurrir a análisis de comparaciones múltiples post hoc. Se elegirán unos u otros en función de la homogeneidad o no de las varianzas y de si se desea comparar con los grupos entre sí o con un grupo de referencia, utilizando los siguientes análisis, para los que se obtiene el intervalo de confianza, en este caso del $95 \%$, en el que se encuentra la diferencia entre las medias de los grupos considerados. Cuando en este intervalo se encuentre el cero, no se puede afirmar, con ese nivel de confianza, que la diferencia de medias sea distinta de cero, o lo que es lo mismo, que hay diferencia significativa entre esos dos grupos.

La elección de los análisis post hoc se hace de la siguiente manera. Si se puede asumir que las varianzas son iguales se pueden Ilevar a cabo los siguientes análisis de comparaciones múltiples:

- Análisis de comparación múltiple de Dunnett si se desea comparar con los grupos con un grupo de referencia. Esta prueba realiza comparaciones múltiples por parejas comparando un conjunto de tratamientos respecto a una única media de control. Mediante esta prueba se puede comprobar que la media de cualquier nivel del factor (excepto la categoría de control) difiere significativamente de la categoría de control.

- Análisis de comparación múltiple de Bonferroni si se desea comparar todos los grupos entre sí y las varianzas se pueden considerar iguales. Esta prueba realiza comparaciones por pares entre las medias de los grupos, pero controla la tasa de error global estableciendo que la tasa de error de cada prueba sea igual a la tasa de error por experimento dividida entre el número total de contrastes. Así, se corrige el nivel de significación observado por el hecho de que se están realizando múltiples comparaciones. 
En el caso de que no se pueda considerar que las varianzas son iguales, se podrían llevar a cabo las pruebas de comparaciones múltiples de Tamhane, T3 de Dunnett, y C de Dunnett. En este trabajo se ha optado siempre por la prueba de Tamhane. Se trata de una prueba conservadora de comparación por parejas basada en la prueba t.

También se ha llevado a cabo el criterio de información de Akaike (AIC), que es una medida de la calidad relativa de un modelo estadístico, para un conjunto dado de datos. Como tal, el AIC proporciona un medio para la selección del modelo.

AIC maneja un trade-off entre la bondad de ajuste del modelo y la complejidad del modelo. Se basa en la entropía de información: se ofrece una estimación relativa de la información perdida cuando se utiliza un modelo determinado para representar el proceso que genera los datos.

AIC no proporciona una prueba de un modelo en el sentido de probar una hipótesis nula, es decir AIC puede decir nada acerca de la calidad del modelo en un sentido absoluto. Si todos los modelos candidatos encajan mal, AIC no dará ningún aviso de ello.

Finalmente se ha realizado un análisis de componentes principales para datos categóricos que cuantifica simultáneamente las variables categóricas a la vez, lo que reduce la dimensionalidad de los datos. El análisis de componentes principales categórico se conoce también por el acrónimo CATPCA, del inglés CATegorical Principal Components Analysis.

El objetivo de los análisis de componentes principales es la reducción de un conjunto original de variables en un conjunto más pequeño de componentes no correlacionados que representen la mayor parte de la información encontrada en las variables originales. La técnica es más útil cuando un extenso número de variables impide una interpretación eficaz de las relaciones entre los objetos (sujetos y unidades). Al reducir la dimensionalidad, se interpreta un pequeño número de componentes en lugar de un extenso número de variables.

El análisis estándar de componentes principales asume relaciones lineales entre las variables numéricas. Por otra parte, el método de escalamiento óptimo permite escalar las variables a diferentes niveles. Las variables categóricas se cuantifican de forma óptima en la dimensionalidad especificada. Como resultado, se pueden modelar relaciones no lineales entre las variables.

Mediante este análisis con dos dimensiones se puede explicar una gran cantidad de varianza, y nos ofrece resultados de la varianza explicada por variable y por dimensión, las cuantificaciones de las categorías para las variables seleccionadas y estadísticos descriptivos para las variables seleccionadas.

A continuación se muestra una relación de las técnicas utilizadas y de los diferentes análisis llevados a cabo:

1. Análisis descriptivos univariantes de los parámetros o variables aleatorias dependientes y que son el objetivo del estudio.

Cálculo de estadísticos centrales y de dispersión en la población general y para cada subpoblación definida por los principales factores de variabilidad (Especie, Experimento, Ubicación, Orientación). Estudio gráfico de las distribuciones de probabilidad. 
2. Modelos Lineales Cenerales para cada especie (Abeto, Pino). Las variables dependientes (Carga máxima, Delaminación) son transformadas logarítmicamente para normalizarlas.

Los modelos principales han sido:

a) ANOVA de una vía para estudiar el efecto general del experimento

b) ANOVA de una vía para estudiar el efecto general de la ubicación en todos los experimentos

c) ANOVA de una vía para estudiar el efecto de la ubicación en el envejecimiento natural

d) ANOVA de una vía para estudiar el efecto de la orientación en el envejecimiento natural para cada ubicación

e) ANOVA de una vía para estudiar el efecto de cada experimento en envejecimiento artificial

f) ANOVA de una vía para estudiar el efecto de cada experimento en envejecimiento artificial, contrastando sobre la referencia

g) ANOVA de una vía para estudiar el efecto de cada experimento en envejecimiento artificial, contrastando sobre el conjunto de datos de envejecimiento natural tomados conjuntamente

h) Modelo lineal general para estudiar el efecto de la ubicación y la orientación jerarquizada a la ubicación en el envejecimiento natural

i) Modelo general para estudiar el efecto de los tres factores principales: experimento, ubicación, orientación en las principales variables dependientes de respuesta

En todos los casos se ha comprobado la homogeneidad de varianza por el test de Levene. En los modelos de un solo factor se han realizado pruebas a posteriori pareadas:

- Bonferroni en caso de homogeneidad de varianza

- Tamhane en caso de no homogeneidad de varianza

En aquellos modelos ANOVA en los que había un control, se ha calculado el test de Dunnet sobre el control.

3. Análisis multivariantes para relacionar parámetros de respuesta principales y condiciones ambientales en envejecimientos al exterior. Análisis de Componentes Principales para variables categóricas (CatPCA)

a) Carga máxima, Delaminación y variables climáticas

b) Carga máxima y variables climáticas

c) Delaminación y variables climáticas

Los contrastes de hipótesis de han hecho para un nivel de confianza del $95 \%$. Los análisis se han realizado con el programa IBM SPSS Statistics V23 



\section{Capítulo 5}

\section{Desarrollo y aplicación del método}

Para llevar a cabo el análisis de cómo afecta el envejecimiento al CLT por los distintos métodos aplicados a las dos especies objeto de estudio, se va a realizar un análisis de los datos por especie, de forma independiente.

Con el fin de evaluar la degradación en los análisis se tienen en cuenta dos características importantes estructuralmente hablando para un material como el CLT, como son la delaminación y la resistencia a la tracción perpendicular a la fibra. Con el ensayo de tracción perpendicular a la fibra obtenemos valores de carga máxima soportada por las probetas sometidas a ensayo, el módulo de elasticidad de las mismas y el desplazamiento máximo. De estas tres variables vamos a tomar la carga máxima soportada, que es la variable más representativa a nivel de comportamiento estructural.

Mediante la delaminación se evaluará el envejecimiento del CLT como producto, la integridad que presenta en su exposición al exterior, y mediante la carga máxima soportada, se evaluará la resistencia del producto, y en el caso de que los ensayos de delaminación muestren integridad de producto, estos resultados reflejarán la integridad del material madera en relación a la especie utilizada para conformar el producto.

Los análisis Ilevados a cabo se van a centrar en un análisis general de los envejecimientos, que mostraran en relación a los valores de referencia la degradación que ha sufrido el material con los distintos métodos de envejecimiento en términos generales. Tras este primer análisis se realiza una aproximación sobre el envejecimiento natural, para comprobar que sucede en el producto por su exposición al exterior. Seguidamente en una segunda aproximación se analiza lo que sucede en el envejecimiento artificial. Y por último se trata de analizar qué variables climáticas son las que influyen en la degradación del CLT.

Los mencionados análisis van a constar de dos partes, la primera parte es un análisis descriptivo que define lo que está sucediendo con el producto al aplicarle cada uno de los métodos de envejecimiento. Y la segunda parte es un análisis de contraste de hipótesis en el caso del análisis general de los envejecimientos, en el análisis del envejecimiento natural, y en el caso del envejecimiento artificial, y un análisis de componentes principales para datos categóricos en el caso del análisis de las variables cli- 
máticas y la degradación, con esta segunda parte se trata de confirmar estadísticamente los resultados obtenidos en el análisis descriptivo.

A la hora de analizar los resultados, y dependiendo de lo que se pretende evaluar, se llevarán a cabo análisis en lo que se incluye la referencia, y sirven para ver el nivel de degradación producido por cada tipo de envejecimiento frente al valor control o de referencia, y análisis que no incluyen la referencia, para comparar los distintos métodos de envejecimiento y modalidades dentro de cada método, que en el caso del envejecimiento natural serán las orientaciones y ubicaciones, y en el caso del envejecimiento artificial será el método aplicado y la duración del mismo.

Los análisis mencionados conducen a la evaluación del CLT como producto estructural en uso de clase de servicio 3 y clase de uso 3.1, mostrando la aptitud al uso como material de construcción al exterior usado como paramento.

Para poder llevar a cabo las comparaciones, y evaluar el envejecimiento producido en este producto, se realizan unos ensayos con el material sin ningún tipo de envejecimiento, lo que nos permitirá hacer una breve caracterización del mismo que posteriormente utilizaremos como valores de referencia para la intercomparación.

\subsection{Análisis generales de los envejecimientos}

En este análisis general se realiza una comparación de todos los métodos de envejecimiento con todas sus modalidades, comparándolos con la referencia, para obtener una primera aproximación del proceso degradativo que está sufriendo el CLT. Este análisis al igual que el resto se va a llevar a cabo por especie.

\subsubsection{Resultados para el abeto}

A continuación se muestran los valores obtenidos en los ensayos de tracción perpendicular a la fibra y delaminación para las muestras de referencia del CLT de abeto, y seguidamente los resultados medios obtenidos para las muestras que han sido envejecidas mediante los diferentes métodos, con las diferentes modalidades. El análisis general se realiza con comparaciones frente a la referencia, para evaluar la degradación producida por cada uno de los envejecimientos. Se hace un primer análisis descriptivo, que muestra qué está sucediendo en cada uno de los procesos, y un segundo análisis de contraste de hipótesis para ver la representatividad estadística de los resultados.

\subsubsection{Ensayo de referencia}

En el cuadro 5.1, se muestran los valores medios de carga máxima, desplazamiento máximo, módulo

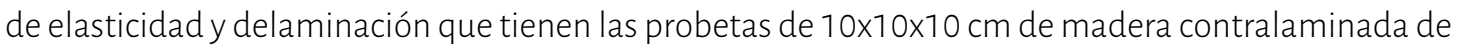
abeto, sometidas al ensayo de tracción perpendicular a la fibra y de delaminación, cuando no han sido sometidas a ningún tipo de tratamiento que pudiera envejecer la madera o deteriorar el producto. 
Cuadro 5.1: Ensayo de referencia Abeto

\begin{tabular}{lcccc}
\hline MEDIDA & CARGA MÁX. (N) & DESP. MÁX. (mm) & MÓDULO (Mpa) & DELAMINACIÓN (\%) \\
\hline Media & 14172,35 & 1,27 & 117,02 & 82,00 \\
\hline Desv. Estan. & 1241,98 & 0,10 & 29,28 & 16,19 \\
\hline
\end{tabular}

Estos valores son los que se denominan valores de referencia, y que se usan para evaluar la degradación sufrida por el CLT en cada uno de los métodos aplicados.

\subsubsection{Análisis descriptivo de los diferentes métodos de envejecimiento}

\subsection{Envejecimiento natural}

A continuación se muestran los valores obtenidos para las muestras de CLT de abeto que han sido sometidas al ensayo de tracción perpendicular a la fibra y delaminación, a las que previamente se les ha expuesto a un envejecimiento natural, que como se describe en el apartado 4.4 Envejecimiento natural, se ha llevado a cabo en tres localizaciones geográficas de la península ibérica que se han considerado representativas.

\section{Madrid}

Centrándose en el valor medio, en el cuadro 5.2 se puede observar que en Madrid no hay ninguna pérdida en términos de delaminación tras un año de exposición del CLT de abeto al exterior, en comparación con los valores de referencia, sin embargo en la media por orientaciones si se puede observar una pequeña pérdida en la cara Sur.

Cuadro 5.2: Exposición exterior abeto Madrid

\begin{tabular}{clcccc}
\hline ORIENTACIÓN & MEDIDA & CARCA MÁX. (N) & DESP. MÁX. (mm) & MÓDULO (Mpa) & DELAMINACIÓN (\%) \\
\hline \multirow{2}{*}{ NORTE } & Media & 9939,27 & 1,10 & 116,91 & 82,00 \\
\cline { 2 - 6 } & Desv. Estan. & 1588,44 & 0,32 & 13,64 & 7,53 \\
\hline \multirow{2}{*}{ SUR } & Media & 10408,39 & 0,93 & 126,51 & 80,00 \\
\cline { 2 - 6 } & Desv. Estan. & 2602,09 & 0,22 & 6,51 & 9,13 \\
\hline \multirow{2}{*}{ ESTE } & Media & 13662,12 & 1,16 & 135,20 & 84,80 \\
\cline { 2 - 6 } & Desv. Estan. & 2152,53 & 0,13 & 8,76 & 11,02 \\
\hline \multirow{2}{*}{ OESTE } & Media & 11544,83 & 0,98 & 134,10 & 82,50 \\
\cline { 2 - 6 } & Desv. Estan. & 1827,31 & 0,10 & 8,36 & 13,99 \\
\hline \multirow{2}{*}{ Valores medios } & Media & 11388,65 & & & 82,33 \\
\cline { 2 - 6 } & Desv. Estan. & 2042,59 & & & 10,42 \\
\hline
\end{tabular}


Con respecto a los valores medios de carga máxima, si se observa una pérdida de resistencia estructural en términos de valor medio con respecto a la referencia, y además, se puede observar que dicha pérdida está influenciada por la orientación, obteniéndose el peor resultado en la cara Norte y el mejor en la cara Este. Cabe comentar que la orientación Este se encontraba protegida parcialmente por la proximidad de la probeta de pino en esta ubicación, lo que hace que tenga una menor radicación solar y un menor aporte de agua procedente de la lluvia, así como menor influencia del viento.

\section{Sevilla}

Centrándose en el valor medio, en el cuadro 5.3 se puede observar que en Sevilla no hay una pérdida significativa en términos de delaminación tras un año de exposición del abeto al exterior, aunque si se tiene en cuenta que la cara protegida aumenta la media, se puede intuir que hay una pequeña pérdida con respecto a los valores de delaminación de referencia. Si se observa la media por orientaciones, se pueden ver pérdidas en las caras Sury Oeste.

Cuadro 5.3: Exposición exterior abeto Sevilla

\begin{tabular}{clcccc}
\hline ORIENTACIÓN & MEDIDA & CARCA MÁX. (N) & DESP. MÁX. (mm) & MÓDULO (Mpa) & DELAMINACIÓN (\%) \\
\hline \multirow{2}{*}{ NORTE } & Media & 10592,47 & 1,10 & 124,78 & 82,50 \\
\cline { 2 - 6 } & Desv. Estan. & 1917,51 & 0,32 & 18,53 & 15,50 \\
\hline \multirow{2}{*}{ SUR } & Media & 11238,90 & 1,10 & 127,71 & 80,50 \\
\cline { 2 - 6 } & Desv. Estan. & 1616,77 & 0,20 & 3,96 & 10,66 \\
\hline \multirow{2}{*}{ ESTE } & Media & 11926,04 & 1,10 & 139,06 & 84,00 \\
\cline { 2 - 6 } & Desv. Estan. & 2279,52 & 0,32 & 4,85 & 6,99 \\
\hline \multirow{2}{*}{ OESTE } & Media & 12509,15 & 1,12 & 132,25 & 80,50 \\
\cline { 2 - 6 } & Desv. Estan. & 2426,32 & 0,22 & 5,17 & 9,56 \\
\hline \multirow{2}{*}{ Valores medios } & Media & 11566,64 & & & 81,88 \\
\cline { 2 - 6 } & Desv. Estan. & 2060,03 & & & 10,68 \\
\hline
\end{tabular}

Con respecto a los valores medios de carga máxima, sí se observa una pérdida de resistencia estructural en términos de valor medio con respecto a la referencia, y además se puede observar que está condicionado por la orientación, obteniendo el peor resultado en la cara Norte y el mejor en la cara Oeste.

\section{Ávila}

Centrándose en el valor medio, en el cuadro 5.4 se puede observar que en Ávila no solo no hay una pérdida en términos de delaminación, sino que la media es superior a la delaminación de referencia tras un año de exposición del CLT de abeto al exterior. Si se observa la media por orientaciones se puede ver que la cara con una media menor es la Sur, siendo aun así superior al valor de referencia. 
Cuadro 5.4: Exposición exterior abeto Ávila

\begin{tabular}{clcccc}
\hline ORIENTACIÓN & MEDIDA & CARCA MÁX. (N) & DESP. MÁX. (mm) & MÓDULO (Mpa) & DELAMINACIÓN (\%) \\
\hline \multirow{2}{*}{ NORTE } & Media & 12582,28 & 1,11 & 126,30 & 95,50 \\
\cline { 2 - 6 } & Desv. Estan. & 3273,01 & 0,19 & 11,27 & 6,43 \\
\hline \multirow{2}{*}{ SUR } & Media & 14501,97 & 1,36 & 118,05 & 83,50 \\
\cline { 2 - 6 } & Desv. Estan. & 2386,46 & 0,40 & 39,80 & 17,33 \\
\hline \multirow{2}{*}{ ESTE } & Media & 15822,06 & 1,23 & 148,43 & 84,00 \\
\cline { 2 - 6 } & Desv. Estan. & 2210,05 & 0,11 & 7,57 & 9,37 \\
\hline \multirow{2}{*}{ OESTE } & Media & 15727,36 & 1,25 & 138,62 & 89,00 \\
\cline { 2 - 6 } & Desv. Estan. & 2847,79 & 0,13 & 12,14 & 8,76 \\
\hline \multirow{2}{*}{ Valores medios } & Media & 14658,42 & & & 88,00 \\
\cline { 2 - 6 } & Desv. Estan. & 2679,33 & & & 10,47 \\
\hline
\end{tabular}

Con respecto a los valores medios de resistencia a la tracción, se observa que la media de las orientaciones es superior a la media de referencia, lo que refleja que no hay pérdida de resistencia estructural en términos de valores medios. Sí se observan los valores por orientación se puede ver que solo la cara Norte tiene un valor inferior al de referencia, aunque presenta el mejor valor en términos de delaminación.

\subsection{Envejecimiento artificial}

A continuación se muestran los valores obtenidos para las muestras de CLT de abeto, que han sido sometidas al ensayo de tracción perpendicular a la fibra y al ensayo de delaminación, con un envejecimiento artificial previo, que como se describe en el apartado 4.5 Envejecimiento artificial, se ha llevado a cabo mediante dos métodos diferentes y aplicando dos ciclos distintos en cada uno de los métodos.

\section{Envejecimiento artificial FCBA}

En el envejecimiento artificial llevado a cabo en el FCBA mediante la Ageing Wheel, en su modalidad de ciclo corto, se observa que no hay pérdidas en materia de delaminación con respecto a los valores de referencia (véase cuadro 5.5).

Cuadro 5.5: FCBA ciclo corto abeto

\begin{tabular}{lcccc}
\hline MEDIDA & CARCA MÁX. (N) & DESP. MÁX. (mm) & MÓDULO (Mpa) & DELAMINACIÓN (\%) \\
\hline Media & 10039,47 & 0,99 & 117,44 & 85,00 \\
\hline Desv. Estan. & 1764,22 & 0,12 & 13,64 & 8,49 \\
\hline
\end{tabular}

En relación a la carga máxima, se observa que hay una pérdida de resistencia, con respecto al valor de referencia y con respecto a todos los envejecimientos llevados a cabo en exterior. 
En el envejecimiento artificial Ilevado a cabo en el FCBA mediante la Ageing Wheel, en su modalidad de ciclo largo, se observa en el cuadro 5.6 que no hay pérdidas en materia de delaminación con respecto a los valores de referencia, los datos son incluso mejores que en el envejecimiento de ciclo corto, lo que hace pensar que no hay mucha variación entre ambas modalidades de este método de envejecimiento.

Cuadro 5.6: FCBA ciclo largo abeto

\begin{tabular}{lcccc}
\hline MEDIDA & CARGA MÁX. (N) & DESP. MÁX. $(\mathrm{mm})$ & MÓDULO (Mpa) & DELAMINACIÓN (\%) \\
\hline Media & 12251,68 & 1,12 & 126,23 & 91,00 \\
\hline Desv. Estan. & 2867,78 & 0,11 & 17,47 & 8,10 \\
\hline
\end{tabular}

En relación a la carga máxima, se observa que hay una pérdida de resistencia, con respecto al valor de referencia y con respecto a todos los envejecimientos llevados a cabo en exterior, pero curiosamente es menor que en el ciclo corto, aunque presenta una mayor desviación estándar, lo que hace pesar que la modalidad aplicada (duración del ciclo), no afecta a la degradación en este método.

\section{Envejecimiento artificial INIA}

En el envejecimiento artificial llevado a cabo en el INIA mediante cámara climática, en su modalidad de ciclo corto que se muestra en el cuadro 5.7, se observa que hay pérdidas por delaminación, siendo el peor resultado obtenido, aun así sigue estando por encima del $70 \%$, por lo que sería un resultado aceptable para el CLT tras el envejecimiento.

Cuadro 5.7: INIA ciclo corto abeto

\begin{tabular}{lcccc}
\hline MEDIDA & CARCA MÁX. (N) & DESP. MÁX. (mm) & MÓDULO (Mpa) & DELAMINACIÓN (\%) \\
\hline Media & 7643,66 & 0,76 & 116,45 & 76,50 \\
\hline Desv. Estan. & 1831,95 & 0,14 & 14,31 & 18,57 \\
\hline
\end{tabular}

En relación a la carga máxima, se observa que hay una pérdida significativa de resistencia, con respecto al valor de referencia y con respecto a todos los envejecimientos llevados a cabo en exterior y en laboratorio.

En el envejecimiento artificial llevado a cabo en el INIA mediante cámara climática, en su modalidad de ciclo largo que se muestra en el cuadro 5.8, se observa que hay pérdidas por delaminación, y aunque el resultado es de los más bajos obtenidos, está por encima del $70 \%$, y además es superior al obtenido en ciclo corto, por lo que hace pensar que la duración del ciclo no influye en la aplicación del método.

Cuadro 5.8: INIA ciclo largo abeto

\begin{tabular}{lcccc}
\hline MEDIDA & CARGA MÁX. (N) & DESP. MÁX. (mm) & MÓDULO (Mpa) & DELAMINACIÓN (\%) \\
\hline Media & 7693,04 & 0,82 & 111,22 & 77,50 \\
\hline Desv. Estan. & 1237,67 & 0,09 & 12,33 & 5,89 \\
\hline
\end{tabular}


En relación a la carga máxima, se observa que hay una pérdida significativa de resistencia, con respecto al valor de referencia y con respecto a todos los envejecimientos llevados a cabo en exteriory en laboratorio, pero curiosamente es menor que en el ciclo corto, lo que hace pensar que en realidad la duración del ciclo no influye en la aplicación del método.

\subsubsection{Análisis de contraste de hipótesis de los diferentes métodos de envejecimiento}

Tras este primer análisis descriptivo, se procede a realizar el análisis de contraste de hipótesis, para determinar cuáles de los resultados obtenidos tienen representatividad estadística. Para ello se procede a comparar todos los resultados obtenidos en los diferentes envejecimientos llevados a cabo en el CLT de abeto con los resultados obtenidos en las muestras de referencia.

En el cuadro 5.9 se muestran los datos utilizados para el análisis, es una tabla descriptiva en la que se puede ver el número de muestras de cada envejecimiento, con la desviación estándar, el error estadístico, y todos los parámetros necesarios para caracterizar la muestra que se procede a analizar. En la figura 5.1 están representados gráficamente los mismos datos mediantes diagramas de caja y bigotes.

Cuadro 5.9: Valores descriptivos del abeto

\begin{tabular}{|c|c|c|c|c|c|c|c|c|c|}
\hline & & \multirow{2}{*}{$\mathrm{N}$} & \multirow{2}{*}{ Mean } & \multirow{2}{*}{ Std. Dev. } & \multirow{2}{*}{ Std. Err. } & \multicolumn{2}{|c|}{$95 \%$ Conf. Int. for Mean } & \multirow{2}{*}{ Min. } & \multirow{2}{*}{ Max. } \\
\hline & & & & & & Lower B. & Upper B. & & \\
\hline \multirow{9}{*}{ CARGA MÁX. (N) } & Referencia & 10 & 14172,35 & 1241,98 & 392,75 & 13283,89 & 15060,81 & 12731,82 & 17139,98 \\
\hline & Avila & 40 & 14658,42 & 2921,78 & 461,97 & 13723,99 & 15592,84 & 8787,67 & 19766,68 \\
\hline & Madrid & 40 & 11388,65 & 2470,05 & 390,55 & 10598,69 & 12178,61 & 7722,13 & 17003,55 \\
\hline & Sevilla & 40 & 11566,64 & 2131,00 & 336,94 & 10885,11 & 12248,17 & 8167,97 & 15784,02 \\
\hline & FCBA Corto & 10 & 10039,47 & 1764,22 & 557,90 & 8777,42 & 11301,51 & 7522,34 & 13673,82 \\
\hline & FCBA Largo & 10 & 12251,68 & 2867,78 & 906,87 & 10200,20 & 14303,17 & 8842,68 & 16585,08 \\
\hline & INIA Corto & 10 & 7643,66 & 1831,95 & 579,31 & 6333,16 & 8954,15 & 5659,68 & 10555,30 \\
\hline & INIA Largo & 10 & 7693,04 & 1237,67 & 391,39 & 6807,67 & 8578,42 & 5560,19 & 9538,59 \\
\hline & Total & 170 & 11897,35 & 3146,13 & 241,30 & 11421,01 & 12373,70 & 5560,19 & 19766,68 \\
\hline \multirow{9}{*}{$\begin{array}{l}\text { DELAMINACIÓN } \\
(\%)\end{array}$} & Referencia & 10 & 82,00 & 16,19 & 5,12 & 70,42 & 93,58 & 55 & 100 \\
\hline & Avila & 40 & 88,00 & 11,87 & 1,88 & 84,21 & 91,79 & 40 & 100 \\
\hline & Madrid & 40 & 82,33 & 10,42 & 1,65 & 78,99 & 85,66 & 50 & 100 \\
\hline & Sevilla & 40 & 81,88 & 10,78 & 1,71 & 78,43 & 85,32 & 60 & 100 \\
\hline & FCBA Corto & 10 & 85,00 & 8,50 & 2,69 & 78,92 & 91,08 & 70 & 95 \\
\hline & FCBA Largo & 10 & 91,00 & 8,10 & 2,56 & 85,21 & 96,79 & 80 & 100 \\
\hline & INIA Corto & 10 & 76,50 & 18,57 & 5,87 & 63,22 & 89,78 & 30 & 90 \\
\hline & INIA Largo & 10 & 77,50 & 5,89 & 1,86 & 73,28 & 81,72 & 65 & 85 \\
\hline & Total & 170 & 83,58 & 11,84 & 0,91 & 81,78 & 85,37 & 30 & 100 \\
\hline
\end{tabular}

A continuación se ha llevado a cabo un test de Levene o de homogeneidad de la varianza (cuadro 5.10), y tras este se procede a llevar a cabo un test de ANOVA para poder evaluar si existen diferencias significativas entre los distintos envejecimientos (cuadro 5.11).

A la vista de los resultados del test de ANOVA, se puede afirmar que hay diferencias significativas, tanto en la delaminación como en la carga máxima, aunque en el caso de los resultados correspondientes a la delaminación, estas diferencias no menos importantes. 

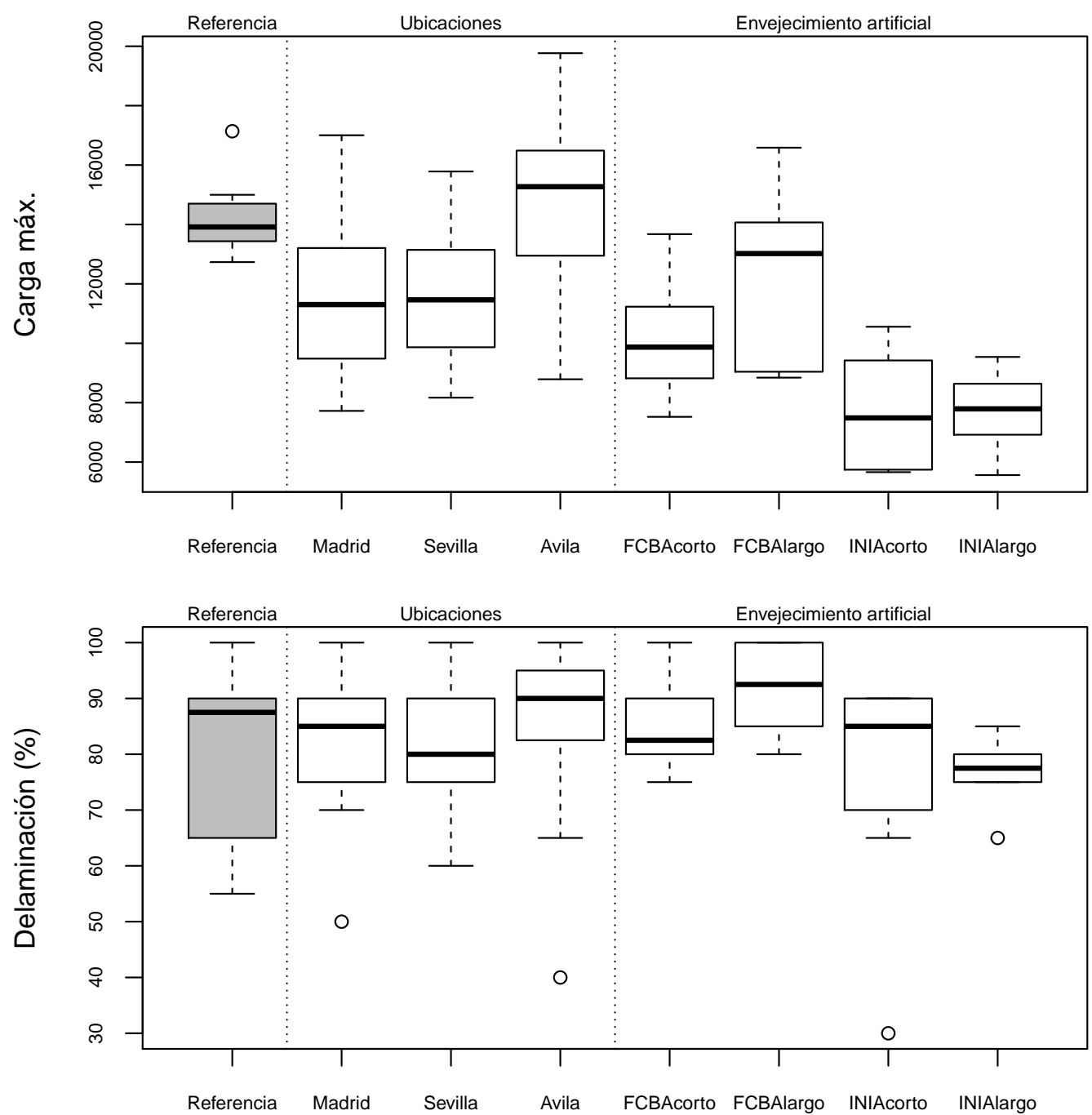

Figura 5.1: Diagramas de caja y bigotes de los valores descriptivos del abeto

Cuadro 5.10: Prueba de homogeneidad de varianza de Levene de la carga máxima y de la delaminación en función del envejecimiento ${ }^{2}$

\begin{tabular}{lrrrr}
\hline & Levene Statistic & df1 & df2 & Sig. \\
\hline CARGA MÁX. (N) & 3,031 & 7 & 162 & 0,005 \\
\hline DELAMINACIÓN (\%) & 1,926 & 7 & 162 & 0,069
\end{tabular}

${ }^{\text {a }}$ Especie $=$ Abeto

Debido a la no homogeneidad de la varianza, y para poder evaluar las diferencias reflejadas en el test de ANOVA, se procede a realizar un test de comparación múltiple de Dunnett, que permite comparar 
Cuadro 5.11: Test ANOVA de la carga máxima y de la delaminación en función del envejecimiento ${ }^{a}$

\begin{tabular}{llrrrrr}
\hline & & Sum of Squares & df & Mean Square & F & Sig. \\
\hline \multirow{3}{*}{ CARCA MÁX. (N) } & Between Groups & 764895486,827 & 7 & 109270783,832 & 19,498 & 0,000 \\
\cline { 2 - 7 } & Within Groups & 907887639,838 & 162 & 5604244,690 & & \\
\cline { 2 - 7 } & Total & 1672783126,665 & 169 & & & \\
\hline \multirow{3}{*}{ DELAMINACIÓN (\%) } & Between Groups & 2427,356 & 7 & 346,765 & 2,641 & 0,013 \\
\cline { 2 - 7 } & Within Groups & 21272,150 & 162 & 131,310 & & \\
\cline { 2 - 7 } & Total & 23699,506 & 169 & & & \\
\hline
\end{tabular}

${ }^{\mathrm{a}}$ Especie $=$ Abeto

todos los resultados obtenidos de los diferentes envejecimientos con los resultados de referencia.

Cuadro 5.12: Análisis de comparación múltiple de Dunnett de la carga máxima y de la delaminación en función del envejecimiento ${ }^{b}$

Dunnett t (2-sided) $)^{\mathrm{a}}$

\begin{tabular}{|c|c|c|c|c|c|c|c|}
\hline \multirow{2}{*}{ Dependent Variable } & \multirow{2}{*}{ (I) Ubicación } & \multirow{2}{*}{ (J) Ubicación } & \multirow{2}{*}{ Mean Diff. (I-J) } & \multirow{2}{*}{ Std. Error } & \multirow{2}{*}{ Sig. } & \multicolumn{2}{|c|}{$95 \%$ Conf. Interval } \\
\hline & & & & & & Lower B. & Upper B. \\
\hline \multirow{7}{*}{ CARGA MÁX. (N) } & Avila & Referencia & 486,06 & 836,98 & 0,981 & $-1677,36$ & 2649,49 \\
\hline & Madrid & Referencia & $-2783,70 *$ & 836,98 & 0,006 & $-4947,13$ & $-620,28$ \\
\hline & Sevilla & Referencia & $-2605,71^{*}$ & 836,98 & 0,012 & $-4769,14$ & $-442,29$ \\
\hline & FCBA Corto & Referencia & $-4132,89^{*}$ & 1058,70 & 0,001 & $-6869,43$ & $-1396,35$ \\
\hline & FCBA Largo & Referencia & $-1920,67$ & 1058,70 & 0,266 & $-4657,21$ & 815,87 \\
\hline & INIA Corto & Referencia & $-6528,70^{*}$ & 1058,70 & 0,000 & $-9265,24$ & $-3792,15$ \\
\hline & INIA Largo & Referencia & $-6479,31^{*}$ & 1058,70 & 0,000 & $-9215,85$ & $-3742,77$ \\
\hline \multirow{7}{*}{ DELAMINACIÓN (\%) } & Avila & Referencia & 6,00 & 4,05 & 0,458 & $-4,47$ & 16,47 \\
\hline & Madrid & Referencia & 0,33 & 4,05 & 1,000 & $-10,15$ & 10,80 \\
\hline & Sevilla & Referencia & $-0,13$ & 4,05 & 1,000 & $-10,60$ & 10,35 \\
\hline & FCBA Corto & Referencia & 3,00 & 5,13 & 0,980 & $-10,25$ & 16,25 \\
\hline & FCBA Largo & Referencia & 9,00 & 5,13 & 0,295 & $-4,25$ & 22,25 \\
\hline & INIA Corto & Referencia & $-5,50$ & 5,13 & 0,750 & $-18,75$ & 7,75 \\
\hline & INIA Largo & Referencia & $-4,50$ & 5,13 & 0,874 & $-17,75$ & 8,75 \\
\hline
\end{tabular}

${ }^{a}$ Dunnett t-tests treat one group as a control, and compare all other groups against it

*The mean difference is significant at the 0.05 level.

${ }^{b}$ Especie $=$ Abeto

Según muestra el cuadro 5.12 (en la figura 5.2 también se representan gráficamente los intervalos de confianza de las diferencias entre las medias), se puede afirmar que en relación los valores de la carga máxima no hay diferencias significativas en el caso de la exposición al exterior de Ávila, y la aplicación del envejecimiento artificial de laboratorio llevado a cabo en el FCBA, en su modalidad de ciclo largo, o lo que es lo mismo, estos dos envejecimientos no han producido la degradación del material. En el resto de los casos y según los datos que muestra la tabla si hay diferencias significativas, y por tanto hay pérdida de propiedades con respecto a la referencia, o lo que es lo mismo se produce degradación.

Con respecto a la delaminación, y según este test, se observa que no hay diferencias significativas en ninguno de los métodos de envejecimiento aplicados, o lo que es lo mismo, que no se produce degradación a nivel de producto. 

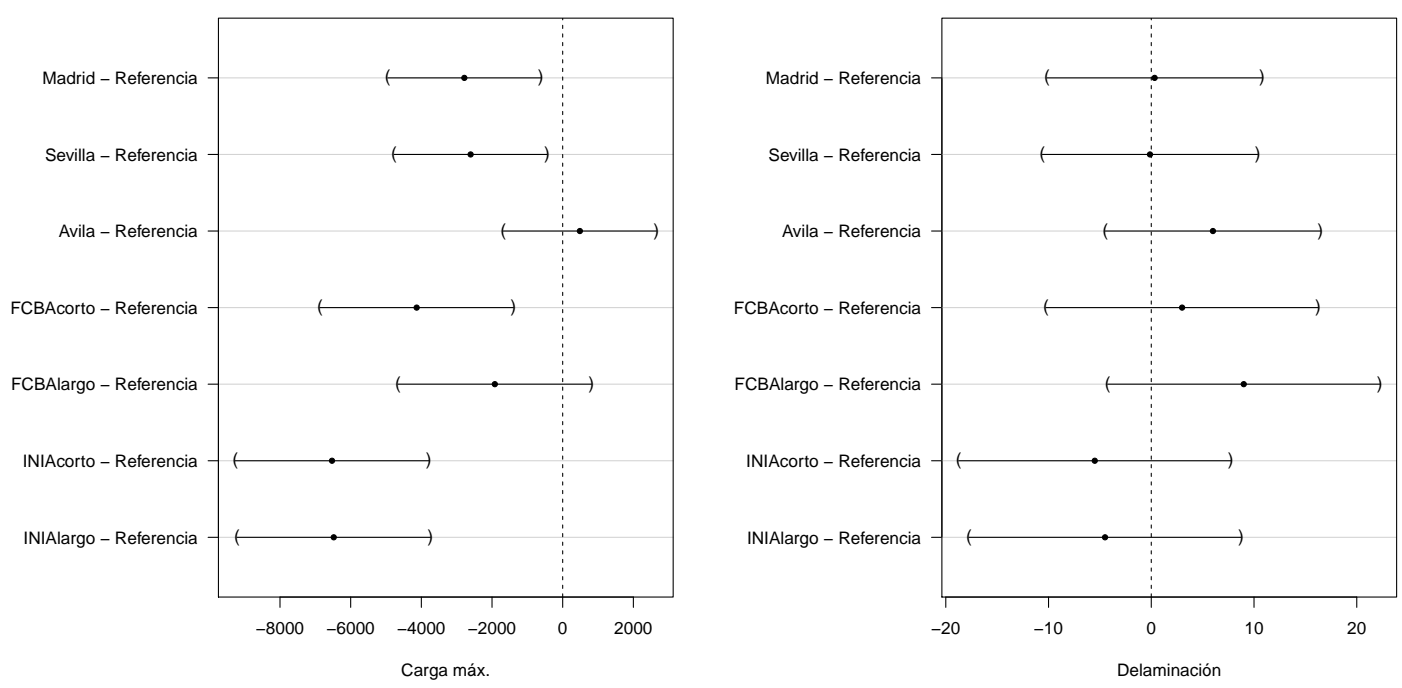

Figura 5.2: Intervalos de confianza del $95 \%$ de las diferencias de medias entre los distintos envejecimientos y la referencia para el abeto según el análisis de Dunnett

\subsubsection{Resumen de los resultados sobre el comportamiento del CLT de Abeto}

Tanto en el primer análisis general descriptivo, como en el segundo de contraste de hipótesis, se observa que el CLT de abeto, no presenta problemas de delaminación, lo que en primera instancia hace pensar, que sería apto para su uso exterior como producto. Sin embargo, atendiendo a los valores de carga máxima, se observa que excepto en Ávila y en la aplicación del envejecimiento artificial en el FCBA en su modalidad de ciclo largo, en todos los demás casos, el CLT de abeto presenta pérdida de su capacidad resistente, expresado en los análisis por el valor de la carga máxima.

Según lo analizado hasta el momento, el CLT de abeto no presenta problemas en su exposición al exterior como producto, si lo hace como material, ya que la madera de abeto pierde propiedades resistentes en su exposición a los diferentes métodos de envejecimiento.

\subsubsection{Resultados para el pino}

A continuación se muestran los valores obtenidos en los ensayos de tracción perpendicular a la fibra y delaminación para las muestras de referencia del CLT de pino, y seguidamente los resultados medios obtenidos para las muestras que han sido envejecidas mediantes los diferentes métodos, con sus diferentes modalidades. El análisis general se realiza con comparaciones frente a la referencia, para evaluar la degradación producida por cada uno de los envejecimientos. Se hace un primer análisis descriptivo, que muestra que está sucediendo en cada uno de los procesos, y un segundo análisis de contraste de hipótesis para ver la representatividad estadística de los resultados. 


\subsubsection{Ensayo de referencia}

En el cuadro 5.13, se muestran los valores medios de carga máxima, desplazamiento máximo, módu-

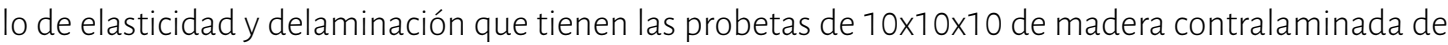
pino, sometidas al ensayo de tracción perpendicular a la fibra y de delaminación, cuando no han sido sometidas a ningún tipo de tratamiento que pudiera envejecer la madera o deteriorar el producto.

Cuadro 5.13: Ensayo de referencia pino

\begin{tabular}{lcccc}
\hline MEDIDA & CARCA MÁX. (N) & DESP. MÁX. (mm) & MÓDULO (Mpa) & DELAMINACIÓN (\%) \\
\hline Media & 19523,09 & 1,42 & 149,12 & 93,00 \\
\hline Desv. Estan. & 1584,80 & 0,20 & 10,19 & 10,06 \\
\hline
\end{tabular}

Estos valores son los que se denominan valores de referencia, y que se usan para evaluar la degradación sufrida por el CLT en cada uno de los métodos aplicados.

\subsubsection{Análisis descriptivo de los diferentes métodos de envejecimiento}

\subsection{Envejecimiento natural}

A continuación se muestran los valores obtenidos para las muestras de CLT de pino que han sido sometidas al ensayo de tracción perpendicular a la fibra y delaminación, a las que previamente se les ha expuesto a un envejecimiento natural, que como se describe en el apartado 4.4 Envejecimiento natural, se ha llevado a cabo en tres localizaciones geográficas de la península ibérica que se han considerado representativas.

\section{Madrid}

Centrándose en el valor medio, en el cuadro 5.14 se puede observar que en Madrid hay pérdidas en términos de delaminación tras un año de exposición del CLT de pino al exterior, en comparación con los valores de referencia. Si se observa la media por orientaciones, se puede ver que la pérdida más significativa se produce en la cara Sur.

Con respecto a los valores medios de carga máxima, también se observa una pérdida de resistencia estructural en términos de valor medio, aunque no se puede considerar significativa. En este caso no se puede afirmar que esté condicionada por la orientación, ya que los datos para las diferentes orientaciones son muy similares, excepto en el caso de la orientación Oeste, donde no hay ninguna pérdida de resistencia estructural. Cabe comentar que la orientación Oeste se encontraba protegida parcialmente por la proximidad de la probeta de abeto en esta ubicación, lo que hace que tenga una menor radicación solar y un menor aporte de agua procedente de la lluvia, así como menor influencia del viento. 
Cuadro 5.14: Exposición exterior pino Madrid

\begin{tabular}{llcccc}
\hline ORIENTACIÓN & MEDIDA & CARCA MÁX. (N) & DESP. MÁX. $(\mathrm{mm})$ & MÓDULO (Mpa) & DELAMINACIÓN (\%) \\
\hline \multirow{2}{*}{ NORTE } & Media & 17628,13 & 1,42 & 144,49 & 82,20 \\
\cline { 2 - 6 } & Desv. Estan. & 2169,59 & 0,14 & 9,76 & 10,66 \\
\hline \multirow{2}{*}{ SUR } & Media & 17374,65 & 1,40 & 144,80 & 78,70 \\
\cline { 2 - 6 } & Desv. Estan. & 2251,02 & 0,13 & 13,61 & 8,77 \\
\hline \multirow{2}{*}{ ESTE } & Media & 17207,12 & 1,40 & 142,35 & 86,90 \\
\cline { 2 - 6 } & Desv. Estan. & 2589,40 & 0,22 & 5,79 & 7,67 \\
\multirow{2}{*}{ OESTE } & Media & 18291,75 & 1,47 & 149,37 & 83,20 \\
\cline { 2 - 6 } & Desv. Estan. & 2520,38 & 0,15 & 9,43 & 9,73 \\
\hline \multirow{2}{*}{ Valores medios } & Media & 17625,41 & & & 82,75 \\
\cline { 2 - 6 } & Desv. Estan. & 2382,60 & & & 9,21 \\
\hline
\end{tabular}

Sevilla

Centrándose en el valor medio, en el cuadro 5.15 se puede observar que en Sevilla hay una pequeña pérdida en términos de delaminación tras un año de exposición del CLT de pino al exterior. Si se observa la media por orientaciones se pueden ver pérdidas significativas en las caras Este y Oeste, esta última a pesar de estar protegida, lo que hace pensar que en términos de delaminación esta sería la peor orientación.

Cuadro 5.15: Exposición exterior pino Sevilla

\begin{tabular}{llcccc}
\hline ORIENTACIÓN & MEDIDA & CARGA MÁX. (N) & DESP. MÁX. $(\mathrm{mm})$ & MÓDULO (Mpa) & DELAMINACIÓN (\%) \\
\hline \multirow{2}{*}{ NORTE } & Media & 19760,69 & 1,61 & 151,25 & 89,00 \\
\cline { 2 - 6 } & Desv. Estan. & 3178,87 & 0,33 & 8,57 & 11,01 \\
\hline \multirow{2}{*}{ SUR } & Media & 20235,87 & 1,44 & 162,37 & 87,50 \\
\cline { 2 - 6 } & Desv. Estan. & 1851,06 & 0,14 & 7,43 & 14,58 \\
\hline \multirow{2}{*}{ ESTE } & Media & 20972,87 & 1,59 & 161,43 & 81,00 \\
\cline { 2 - 6 } & Desv. Estan. & 2287,86 & 0,37 & 9,00 & 12,65 \\
\hline \multirow{2}{*}{ OESTE } & Media & 18944,66 & 1,52 & 151,92 & 82,00 \\
\cline { 2 - 6 } & Desv. Estan. & 2098,59 & 0,27 & 12,35 & 10,33 \\
\hline \multirow{2}{*}{ Valores medios } & Media & 19978,52 & & & 84,88 \\
\cline { 2 - 6 } & Desv. Estan. & 2354,10 & & & 12,14 \\
\hline
\end{tabular}

Con respecto a los valores de carga máxima, no se observa una pérdida de resistencia estructural en términos de valores medios, aunque se puede observar que está condicionada por la orientación, ya que la cara que peores valores presenta es la Oeste a pesar de estar protegida como hemos comentado anteriormente. 
Ávila

Centrándose en el valor medio, en el cuadro 5.16 se puede observar que en Ávila no hay una pérdida significativa en términos de delaminación, aunque si se observa la media por orientaciones se puede ver que la cara con una media menor es la Sur.

Cuadro 5.16: Exposición exterior pino Ávila

\begin{tabular}{llcccc}
\hline ORIENTACIÓN & MEDIDA & CARGA MÁX. (N) & DESP. MÁX. $(\mathrm{mm})$ & MÓDULO (Mpa) & DELAMINACIÓN (\%) \\
\hline \multirow{2}{*}{ NORTE } & Media & 19108,67 & 1,41 & 159,64 & 97,50 \\
\cline { 2 - 6 } & Desv. Estan. & 2539,75 & 0,18 & 8,12 & 5,40 \\
\hline \multirow{2}{*}{ SUR } & Media & 17559,81 & 1,35 & 149,24 & 88,50 \\
\cline { 2 - 6 } & Desv. Estan. & 1673,24 & 0,13 & 5,77 & 12,26 \\
\hline \multirow{2}{*}{ ESTE } & Media & 17909,20 & 1,32 & 150,90 & 89,50 \\
\cline { 2 - 6 } & Desv. Estan. & 3126,46 & 0,21 & 12,65 & 11,17 \\
\hline \multirow{2}{*}{ OESTE } & Media & 16707,12 & 1,28 & 150,65 & 91,50 \\
\cline { 2 - 6 } & Desv. Estan. & 2146,29 & 0,13 & 7,42 & 8,51 \\
\hline \multirow{2}{*}{ Valores medios } & Media & 17821,20 & & & 91,75 \\
\cline { 2 - 6 } & Desv. Estan. & 2371,43 & & & 9,34 \\
\hline
\end{tabular}

Con respecto a los valores de carga máxima, se observa que la media de las orientaciones es inferior a la media de referencia, aunque esta pérdida no parece significativa. Si se observan los datos por orientación se puede ver que la cara Oeste tiene un valor inferior al valor medio.

\subsection{Envejecimiento artificial}

A continuación se muestran los datos obtenidos para las muestras de CLT de pino que han sido sometidas al ensayo de tracción perpendicular a la fibra y al ensayo de delaminación, sometidas previamente a envejecimiento artificial, que como se describe en el apartado 4.5 Envejecimiento artificial, se ha llevado a cabo mediante dos métodos diferentes y aplicando dos ciclos distintos en cada uno de los métodos.

\section{Envejecimiento artificial FCBA}

En el envejecimiento artificial llevado a cabo en el FCBA mediante la Ageing Wheel, en su modalidad de ciclo corto, en el cuadro 5.17 se observa que hay pérdidas en materia de delaminación con respecto a los valores de referencia, siendo uno de los peores valores obtenidos para el pino.

En relación a la carga máxima, se observa que hay una pérdida de resistencia, con respecto al valor de referencia y con respecto a todos los envejecimientos llevados a cabo en exterior. 
Cuadro 5.17: FCBA ciclo corto pino

\begin{tabular}{lcccc}
\hline MEDIDA & CARGA MÁX. (N) & DESP. MÁX. (mm) & MÓDULO (Mpa) & DELAMINACIÓN (\%) \\
\hline Media & 16749,19 & 1,62 & 137,47 & 81,00 \\
\hline Desv. Estan. & 1823,84 & 0,49 & 12,72 & 10,73 \\
\hline
\end{tabular}

En el envejecimiento artificial Ilevado a cabo en el FCBA mediante la Ageing Wheel, en su modalidad de ciclo largo, en el cuadro 5.18 se observa que hay pérdidas en materia de delaminación, y presenta uno de los valores más bajos obtenidos para el pino, y similar al ciclo corto.

Cuadro 5.18: FCBA ciclo largo pino

\begin{tabular}{lcccc}
\hline MEDIDA & CARGA MÁX. (N) & DESP. MÁX. (mm) & MÓDULO (Mpa) & DELAMINACIÓN (\%) \\
\hline Media & 19603,80 & 1,66 & 146,20 & 81,70 \\
\hline Desv. Estan. & 1618,75 & 0,18 & 6,81 & 11,83 \\
\hline
\end{tabular}

En relación a la carga máxima, se observa que no hay una pérdida de resistencia, con respecto al valor de referencia ni con respecto a todos los envejecimientos llevados a cabo en exterior. A pesar de que este ciclo presenta un valor de resistencia mayor, a la vista de los resultados, cabe pensar que los dos ciclos son similares y que en realidad la duración no afecta al envejecimiento.

\section{Envejecimiento artificial INIA}

En el envejecimiento artificial llevado a cabo en el INIA mediante cámara climática, en su modalidad de ciclo corto, en el cuadro 5.19 se observa que hay una pequeña pérdida por delaminación, aunque no se puede considerar significativa, ya que es superior a algunos valores obtenidos en envejecimiento a exteriory está muy cerca del valor de referencia.

Cuadro 5.19: INIA ciclo corto pino

\begin{tabular}{lcccc}
\hline MEDIDA & CARGA MÁX. (N) & DESP. MÁX. (mm) & MÓDULO (Mpa) & DELAMINACIÓN (\%) \\
\hline Media & 17278,93 & 1,34 & 147,43 & 89,50 \\
\hline Desv. Estan. & 2216,02 & 0,13 & 9,11 & 11,89 \\
\hline
\end{tabular}

En relación a la carga máxima, se observa que hay una pérdida de resistencia con respecto al valor de referencia, aunque en este caso es similar a los obtenidos en algunas de las orientaciones a exterior.

En el envejecimiento artificial Ilevado a cabo en el INIA mediante cámara climática, en su modalidad de ciclo largo, en el cuadro 5.20 se observa que con respecto a la delaminación hay pérdidas, aunque el resultado es bastante bueno comparado con los envejecimientos al exterior, y similar al obtenido en ciclo corto.

En relación a la carga máxima, se observa que hay una pérdida significativa de resistencia, con respecto al valor de referencia y con respecto a todos los envejecimientos llevados a cabo en exterior. Según esto 
Cuadro 5.20: INIA ciclo largo pino

\begin{tabular}{lcccc}
\hline MEDIDA & CARCA MÁX. (N) & DESP. MÁX. (mm) & MÓDULO (Mpa) & DELAMINACIÓN (\%) \\
\hline Media & 15866,58 & 1,29 & 134,55 & 88,50 \\
\hline Desv. Estan. & 2601,03 & 0,15 & 22,61 & 10,55 \\
\hline
\end{tabular}

no podemos afirmar que en el caso del pino la duración del ciclo no afecte, aunque las pérdidas entra las dos modalidades de este envejecimiento no sean excesivas.

\subsubsection{Análisis de contraste de hipótesis de los diferentes métodos de envejecimiento}

Tras este primer análisis descriptivo, se procede a realizar un análisis de contraste de hipótesis, para determinar cuáles de los resultados obtenidos tienen representatividad estadística. Para ello se procede a comparar todos los resultados obtenidos en los diferentes envejecimientos llevados a cabo en el CLT de pino con los resultados obtenidos en las muestras de referencia.

En el cuadro 5.21 se muestran los datos utilizados para el análisis, es una tabla descriptiva en la que se puede ver el número de muestras de cada envejecimiento, con la desviación estándar, el error estadístico, y todos los parámetros necesarios para caracterizar la muestra que se procede a analizar. En la figura 5.3 están representados gráficamente los mismos datos mediantes diagramas de caja y bigotes.

Cuadro 5.21: Valores descriptivos del pino

\begin{tabular}{|c|c|c|c|c|c|c|c|c|c|}
\hline & & \multirow{2}{*}{$\mathrm{N}$} & \multirow{2}{*}{ Mean } & \multirow{2}{*}{ Std. Dev. } & \multirow{2}{*}{ Std. Err. } & \multicolumn{2}{|c|}{$95 \%$ Conf. Int. for Mean } & \multirow{2}{*}{ Min. } & \multirow{2}{*}{ Max. } \\
\hline & & & & & & Lower B. & Upper B. & & \\
\hline \multirow{9}{*}{ CARGA MÁX. (N) } & Referencia & 10 & 19523,09 & 1584,80 & 501,16 & 18389,39 & 20656,78 & 17905,45 & 22813,78 \\
\hline & Avila & 40 & 17821,20 & 2493,22 & 394,21 & 17023,83 & 18618,57 & 12744,78 & 23977,38 \\
\hline & Madrid & 40 & 17625,41 & 2333,17 & 368,91 & 16879,23 & 18371,60 & 13053,01 & 21630,70 \\
\hline & Sevilla & 40 & 19978,52 & 2429,75 & 384,18 & 19201,45 & 20755,59 & 15324,30 & 24956,16 \\
\hline & FCBA Corto & 10 & 16749,19 & 1823,84 & 576,75 & 15444,50 & 18053,89 & 14404,40 & 19806,29 \\
\hline & FCBA Largo & 10 & 19603,80 & 1618,75 & 511,89 & 18445,82 & 20761,78 & 16497,67 & 21698,95 \\
\hline & INIA Corto & 10 & 17278,93 & 2216,02 & 700,77 & 15693,68 & 18864,17 & 13879,67 & 20788,90 \\
\hline & INIA Largo & 10 & 15866,58 & 2601,03 & 822,52 & 14005,91 & 17727,24 & 11373,79 & 18745,85 \\
\hline & Total & 170 & 18277,77 & 2587,89 & 198,48 & 17885,95 & 18669,59 & 11373,79 & 24956,16 \\
\hline \multirow{9}{*}{$\begin{array}{l}\text { DELAMINACIÓN } \\
(\%)\end{array}$} & Referencia & 10 & 93,00 & 10,06 & 3,18 & 85,81 & 100,19 & 70 & 100 \\
\hline & Avila & 40 & 91,75 & 9,97 & 1,58 & 88,56 & 94,94 & 70 & 100 \\
\hline & Madrid & 40 & 82,75 & 9,39 & 1,48 & 79,75 & 85,75 & 60 & 98 \\
\hline & Sevilla & 40 & 84,88 & 12,27 & 1,94 & 80,95 & 88,80 & 60 & 100 \\
\hline & FCBA Corto & 10 & 81,10 & 10,73 & 3,39 & 73,42 & 88,78 & 65 & 97 \\
\hline & FCBA Largo & 10 & 81,70 & 11,83 & 3,74 & 73,24 & 90,16 & 65 & 100 \\
\hline & INIA Corto & 10 & 89,50 & 11,89 & 3,76 & 80,99 & 98,01 & 70 & 100 \\
\hline & INIA Largo & 10 & 88,50 & 10,55 & 3,34 & 80,95 & 96,05 & 75 & 100 \\
\hline & Total & 170 & 86,55 & 11,28 & 0,87 & 84,84 & 88,26 & 60 & 100 \\
\hline
\end{tabular}

${ }^{\mathrm{a}}$ Especie $=$ Pino

A continuación se ha llevado a cabo test de Levene o de homogeneidad de la varianza (cuadro 5.22), y tras este se procede a llevar a cabo un test de ANOVA (cuadro 5.23) para poder evaluar si existen diferencias significativas entre las varianzas. 

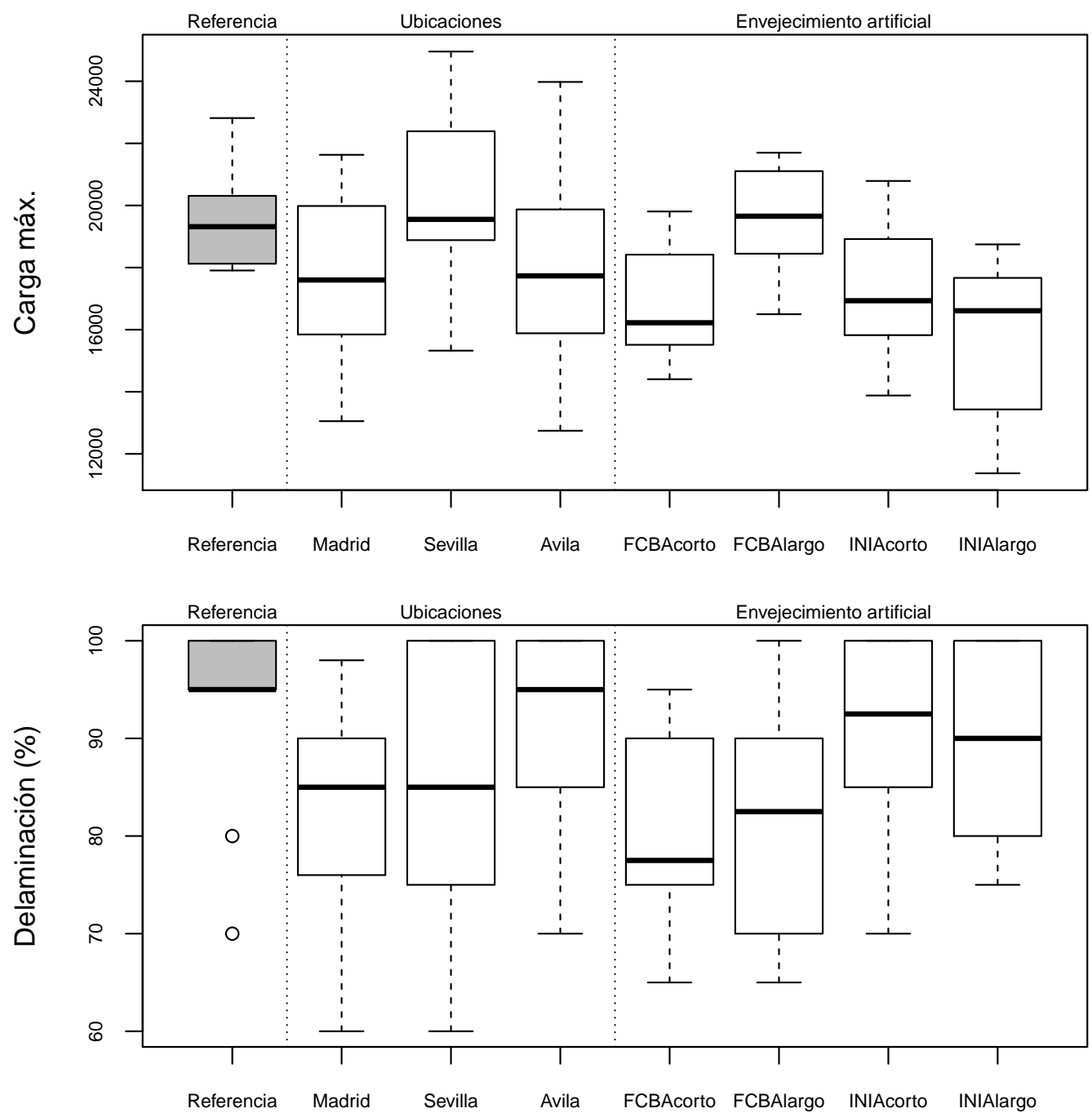

Figura 5.3: Diagramas de caja y bigotes de los valores descriptivos del pino

Cuadro 5.22: Prueba de homogeneidad de varianza de Levene de la carga máxima y de la delaminación en función del envejecimiento ${ }^{a}$

\begin{tabular}{lrrrr}
\hline & Levene Statistic & df1 & df2 & Sig. \\
\hline CARGA MÁX. (N) & 1,007 & 7 & 162 & 0,428 \\
\hline DELAMINACIÓN (\%) & 0,789 & 7 & 162 & 0,597 \\
\hline
\end{tabular}

${ }^{\mathrm{a}}$ Especie $=$ Pino

A la vista de los resultados del test de ANOVA, se puede afirmar que hay diferencias significativas, tanto en la delaminación como en la carga máxima. 
Cuadro 5.23: Test ANOVA de la carga máxima y de la delaminación en función del envejecimiento ${ }^{\mathrm{a}}$

\begin{tabular}{llrrrrr}
\hline & & Sum of Squares & df & Mean Square & F & Sig. \\
\hline \multirow{3}{*}{ CARCA MÁX. (N) } & Between Croups & 265636008,982 & 7 & 37948001,283 & 7,097 & 0,000 \\
\cline { 2 - 7 } & Within Croups & 866186099,222 & 162 & 5346827,773 & & \\
\cline { 2 - 7 } & Total & 1131822108,205 & 169 & & & \\
\hline \multirow{3}{*}{ DELAMINACIÓN (\%) } & Between Groups & 2844,749 & 7 & 406,393 & 3,526 & 0,001 \\
\cline { 2 - 7 } & Within Croups & 18671,375 & 162 & 115,255 & & \\
\cline { 2 - 7 } & Total & 21516,124 & 169 & & & \\
\hline
\end{tabular}

${ }^{\mathrm{a}}$ Especie $=$ Pino

Para poder evaluar las diferencias reflejadas en el test de ANOVA, se procede a realizar un test de comparación múltiple de Dunnett, que nos permite comparar todos los resultados obtenidos de los diferentes envejecimientos con los resultados de referencia.

Cuadro 5.24: Análisis de comparación múltiple de Dunnett de la carga máxima y de la delaminación en función del envejecimiento ${ }^{b}$

\begin{tabular}{|c|c|c|c|c|c|c|c|}
\hline \multirow[t]{2}{*}{ Dependent Variable } & \multirow[t]{2}{*}{ (I) Ubicación } & \multirow[t]{2}{*}{ (J) Ubicación } & \multirow[t]{2}{*}{ Mean Diff. (I-J) } & \multirow[t]{2}{*}{ Std. Err. } & \multirow[t]{2}{*}{ Sig. } & \multicolumn{2}{|c|}{$95 \%$ Conf. Int. } \\
\hline & & & & & & Lower B. & Upper B. \\
\hline \multirow{7}{*}{ CARGA MÁX. (N) } & Avila & Referencia & $-1701,89$ & 817,53 & , 159 & $-3815,05$ & 417,27 \\
\hline & Madrid & Referencia & $-1897,68$ & 817,53 & ,094 & $-4010,83$ & 215,48 \\
\hline & Sevilla & Referencia & 455,43 & 817,53 & 984 & $-1657,72$ & 2568,59 \\
\hline & FCBA Corto & Referencia & $-2773,90 *$ & 1034,10 & 039 & $-5446,85$ & $-100,94$ \\
\hline & FCBA Largo & Referencia & 80,71 & 1034,10 & 1,000 & $-2592,24$ & 2753,67 \\
\hline & INIA Corto & Referencia & $-2244,16$ & 1034,10 &, 132 & $-4917,12$ & 428,79 \\
\hline & INIA Largo & Referencia & $-3656,51^{*}$ & 1034,10 &, 003 & $-6329,46$ & $-983,56$ \\
\hline \multirow{7}{*}{ DELAMINACIÓN (\%) } & Avila & Referencia & $-7,25$ & 3,80 & 999 & $-71,06$ & 8,56 \\
\hline & Madrid & Referencia & $-10,25^{*}$ & 3,80 & 037 & $-20,06$ &,- 44 \\
\hline & Sevilla & Referencia & $-8,13$ & 3,80 &, 140 & $-17,94$ & 1,69 \\
\hline & FCBA Corto & Referencia & $-11,90$ & 4,80 &, 065 & $-24,31$ &, 51 \\
\hline & FCBA Largo & Referencia & $-11,30$ & 4,80 &, 088 & $-23,71$ & 1,11 \\
\hline & INIA Corto & Referencia & $-3,50$ & 4,80 & 942 & $-15,91$ & 8,91 \\
\hline & INIA Largo & Referencia & $-4,50$ & 4,80 & 839 & $-16,91$ & 7,91 \\
\hline
\end{tabular}

a Dunnett t-tests treat one group as a control, and compare all other groups against it.

* The mean difference is significant at the 0.05 level.

${ }^{b}$ Especie $=$ Pino

Según muestra el cuadro 5.24 (en la figura 5.4 también se representan gráficamente los intervalos de confianza de las diferencias entre las medias), se puede afirmar que en relación los valores de la carga máxima hay diferencias significativas en el caso del envejecimiento artificial de laboratorio llevado a cabo en el INIA en su modalidad de ciclo largo, y la aplicación del envejecimiento artificial de laboratorio llevado a cabo en el FCBA, en su modalidad de ciclo corto, o lo que es lo mismo, estos dos envejecimientos han producido la degradación del material. En el resto de los casos y según los datos que muestra la tabla no hay diferencias significativas, y por tanto no hay pérdida de propiedades con respecto a la referencia, o lo que es lo mismo no se produce degradación. 

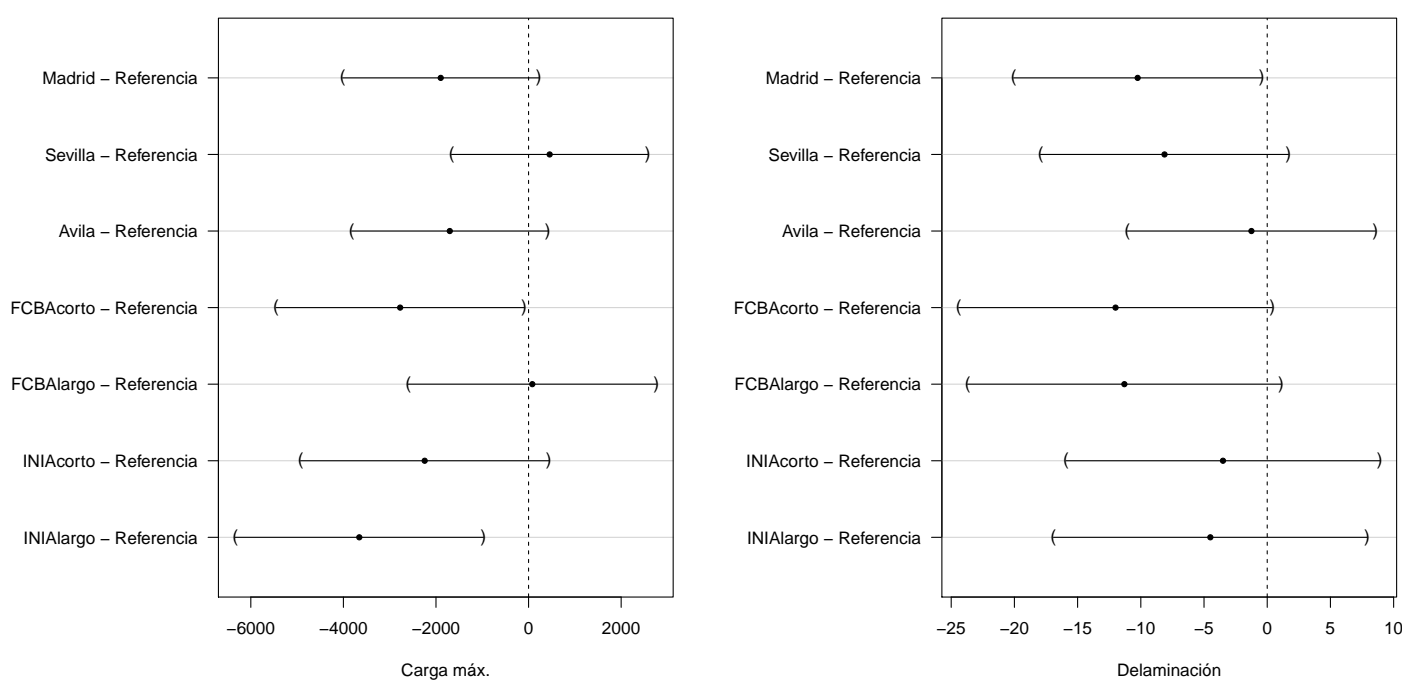

Figura 5.4: Intervalos de confianza del $95 \%$ de las diferencias de medias entre los distintos envejecimientos y la referencia para el pino según el análisis de Dunnett

Con respecto a la delaminación, y según este test, se observa que solo hay diferencias significativas en el caso del envejecimiento natural llevado a cabo en Madrid, aunque esta diferencia es aislada y no se puede ver como una gran diferencia con la referencia.

\subsubsection{Resumen de los resultados sobre el comportamiento del CLT de Pino}

Tanto en el primer análisis general descriptivo, como en el segundo de contraste de hipótesis, se observa que el CLT de pino, no presenta problemas de delaminación, lo que hace pensar, que en principio sería apto para su uso exterior. Sin embargo, atendiendo a los valores de carga máxima, se observa alguna pequeña pérdida de resistencia, tanto en los envejecimientos naturales (en menor medida), como en los artificiales llevados a cabo en laboratorio.

Según lo analizado hasta el momento, el CLT de pino no presenta problemas en su exposición al exterior como producto, si tiene unas pequeñas pérdidas como material, ya que la madera de pino en alguno de los envejecimientos pierde propiedades.

\subsection{Análisis del envejecimiento natural}

Tras la primera aproximación llevada a cabo en el análisis general de los envejecimientos, en la que se han comparado los valores de referencia con los valores obtenidos para el abeto en todos los métodos de envejecimiento aplicados. Se procede a un análisis más específico, centrando este análisis en el envejecimiento natural.

Con esta intercomparación, se trata de evaluar si entre las distintas ubicaciones hay alguna que se considera más favorable para la exposición al exterior del CLT, también evaluar el comportamiento de las 
diferentes orientaciones para valorar si se puede afirmar que exista un efecto orientación en la degradación.

\subsubsection{Resultados para el abeto}

A continuación se lleva a cabo un análisis descriptivo del envejecimiento natural en el que se comparan los resultados obtenidos en este método de envejecimiento con la referencia, para poder ver que está sucediendo en cada una de las ubicaciones y evaluar el efecto orientación, y un segundo análisis de contraste de hipótesis para ver la representatividad estadística de los resultados.

En el análisis de contraste de hipótesis se harán comparaciones con la referencia para evaluar la degradación, y sin la referencia para analizar las diferencias que existen entre los métodos aplicados y poder evaluar la degradación en cada uno de ellos.

\subsubsection{Análisis descriptivo del envejecimiento natural}

Con respecto al abeto, cabe comentar que en referencia a los valores de delaminación, se va a considerar que un valor de delaminación es aceptable cuando se encuentre por encima del 70 \% de madera, según lo descrito en el ensayo de delaminación en el apartado 4.7 Ensayo de delaminación, cosa que en el abeto sucede en todos los resultados obtenidos.

La primera comparación es una aproximación bastante somera en la que se puede ver que el valor de delaminación de referencia del abeto 82,00 \% está por debajo de la media de las delaminaciones de los envejecimientos al exterior $84,07 \%$, lo que en un principio hace ver que las muestras envejecidas al exterior como término medio están al menos igual que las de referencia, y las medias de cada ubicación y orientación no son muy dispares, ya que presentan una desviación estándar de 4,86.

Otra aproximación general pero que también puede servir de indicativo es el valor medio de la carga máxima, atendiendo a los datos, se observa que la carga máxima media para el abeto en las muestras de referencia es de $14.172,35 \mathrm{~N}$, superior a la carga máxima media de todas las ubicaciones y orientaciones. Aquí sin embargo cabe comentar que la desviación típica de la media de las cargas máximas de los envejecimientos exteriores es sensiblemente superior a la desviación estándar de las muestras de referencia, 2004,61, frente a los 1241,98 de las muestras de referencia, lo hace plantearse que puede haber pérdida de capacidad resistente según la ubicación y orientación.

En esta primera aproximación se puede extraer que no hay una influencia significativa en cuanto a términos de delaminación entre las muestras de referencia y las diferentes ubicaciones y orientaciones, pero sí entre los valores de resistencia en la tracción perpendicular a la fibra, expresados en forma de carga máxima soportada.

\subsection{Carga máxima abeto}

Atendiendo a las orientaciones, se observa que la orientación Norte es la peor de las cuatro orientaciones, teniendo en cuenta las tres ubicaciones, seguida de la orientación Sur. La orientación Norte 
Cuadro 5.25: Análisis descriptivo del envejecimiento natural del abeto

\begin{tabular}{|c|c|c|c|}
\hline & & DELAMINACIÓN (\%) & CARGA MÁX. (N) \\
\hline \multirow{2}{*}{ Referencia } & Media & 82,00 & 14172,35 \\
\hline & Desv. Estan. & 16,19 & 1241,98 \\
\hline \multirow{4}{*}{ Madrid } & Norte & 82,00 & 9939,27 \\
\hline & Sur & 80,00 & 10408,39 \\
\hline & Este & 84,80 & 13662,12 \\
\hline & Oeste & 82,50 & 11544,83 \\
\hline \multirow{4}{*}{ Sevilla } & Norte & 82,50 & 10592,47 \\
\hline & Sur & 80,50 & 11238,90 \\
\hline & Este & 84,00 & 11926,04 \\
\hline & Oeste & 80,50 & 12509,15 \\
\hline \multirow{4}{*}{ Avila } & Norte & 95,50 & 12582,28 \\
\hline & Sur & 83,50 & 14501,97 \\
\hline & Este & 84,00 & 15822,06 \\
\hline & Oeste & 89,00 & 15727,36 \\
\hline \multirow{2}{*}{ Media env. } & Media & 84,07 & 12537,90 \\
\hline & Desv. Estan. & 4,34 & 2004,61 \\
\hline \multirow{3}{*}{ Ciudades } & Madrid & EONS & EOSN \\
\hline & Sevilla & ENOS & OESN \\
\hline & Avila & NOES & EOSN \\
\hline \multirow{4}{*}{ Orientaciones } & Norte & ASM & ASM \\
\hline & Sur & ASM & ASM \\
\hline & Este & MSA & AMS \\
\hline & Oeste & AMS & ASM \\
\hline
\end{tabular}

presenta todos los valores por debajo del valor de referencia, y dos de ellos por debajo del valor medio. Atendiendo a las ubicaciones, se observa que Ávila es la mejor ubicación con respecto a los valores de carga máxima, ya que todos sus valores se sitúan por encima del valor medio y todos menos uno por encima de la delaminación de referencia, además de tener los mejores valores en todas las orientaciones, incluida la Oeste que en Ávila no se encuentra protegida, pero si lo está en las otras dos ubicaciones.

\subsection{Delaminación abeto}

Atendiendo a las orientaciones, se observa que la orientación Sur es la peor de las cuatro orientaciones, teniendo en cuenta las tres ubicaciones, ya que en dos de ellas los valores de delaminación se encuentran por debajo de la delaminación media y las tres por debajo de la delaminación de referencia.

Atendiendo a las ubicaciones, se observa que Ávila es la mejor ubicación con respecto a los valores de delaminación, ya que casi todos sus valores se sitúan por encima de la delaminación media y todos por encima de la delaminación de referencia, y por tener los mejores valores en todas las orientaciones, 
ya que aunque en la orientación Este no tiene los valores superiores, se puede considerar que lo son, debido a que es la única ubicación que no tiene esta orientación protegida, obteniendo aun así unos valores muy altos y muy cercanos a las demás ubicaciones que se encontraban protegidas.

\subsubsection{Análisis de contraste de hipótesis del envejecimiento natural}

Tras este primer análisis general descriptivo de los resultados, basado en los valores medios obtenidos, se procede a realizar un análisis de contraste de hipótesis para valorar la representatividad estadística de los resultados.

\subsection{Carga máxima abeto}

Para evaluar la carga máxima, se plantean varios modelos en los que se contrastan los efectos principales, Ubicación (Referencia como control, Madrid, Ávila y Sevilla) y Orientación (Norte, Sur, Este y Oeste). El mejor modelo según su AIC (bondad de ajuste a través del índice de Akaike), es aquel que presenta Ubicación como efecto principal y Orientación como efecto jerarquizado a Ubicación. Los test de efectos del modelo aparecen en el cuadro 5.26.

Cuadro 5.26: Análisis de efectos del modelo de la carga máxima por ubicación y orientación según ubicación ${ }^{2}$

\begin{tabular}{lrrr}
\hline \multirow{2}{*}{ Source } & \multicolumn{3}{c}{ Type III } \\
\cline { 2 - 4 } & Wald Chi-Square & df & Sig. \\
\hline (Intercept) & 4169,892 & 1 &, 000 \\
\hline UBICACION & 64,990 & 3 &, 000 \\
\hline ORIENTACION(UBICACION) & 37,793 & 9 &, 000 \\
\hline Dependent Variable: CARCA MÁX. (N) & & \\
Model: (Intercept), UBICACION, ORIENTACION(UBICACION) \\
a Especie= Abeto
\end{tabular}

Según se muestra en este cuadro, en el caso del Abeto, tanto la ubicación como la orientación son efectos significativos sobre la carga máxima. Por esta razón y para estudiar la posición de la Referencia frente a las ubicaciones físicas se construye un efecto mixto ubicación*orientación (13 niveles, Referencia, MadridEste, MadridOeste, etc.) y se plantea una prueba de homogeneidad de varianza de Levene (cuadro 5.27), un test de ANOVA (cuadro 5.28), y la realización posterior de un análisisde comparación múltiple de Dunnet que permita una comparación por pares de la Referencia.

Cuadro 5.27: Prueba de homogeneidad de varianza de Levene de la carga máxima por ubicación y orientación ${ }^{\mathrm{a}}$

\begin{tabular}{rrrrr}
\hline & Levene Statistic & df1 & df2 & Sig. \\
\hline CARGA MÁX. (N) & 2,607 & 12 & 117 &, 004 \\
\hline
\end{tabular}

\footnotetext{
${ }^{\text {a }}$ Especie $=$ Abeto
} 
Cuadro 5.28: Test ANOVA de la carga máxima por ubicación y orientación ${ }^{\mathrm{a}}$

\begin{tabular}{rlrrrrr}
\hline & & Sum of Squares & df & Mean Square & F & Sig. \\
\hline & Between Croups & 466689131,134 & 12 & 38890760,928 & 7,709 &, 000 \\
\cline { 2 - 7 } CARGA MÁX. (N) & Within Croups & 590265790,817 & 117 & 5045006,759 & & \\
\cline { 2 - 7 } & Total & 1056954921,951 & 129 & & & \\
\hline
\end{tabular}

${ }^{a}$ Especie $=$ Abeto

Los test de Levene y ANOVA muestran como resultado no homogeneidad de varianzas y diferencias significativas entre las medias debidas al factor principal (UxO).

Para poder discutir lo que está sucediendo en el abeto con respecto a la ubicación y la orientación, y teniendo en cuenta la no homogeneidad de la varianza, se realiza un análisis de comparación múltiple de Dunnett.

Cuadro 5.29: Análisis de comparación múltiple de Dunnett de la carga máxima por ubicación y orientación ${ }^{b}$ Dunnett t (2-sided $)^{2}$

\begin{tabular}{lllrrrrr}
\hline \multirow{2}{*}{ Dependent Var. } & (I) obi_ori & (J) obi_ori & Mean Diff. (I-J) & Std. Err. & Sig. & \multicolumn{2}{c}{$95 \%$ Conf. Int. } \\
\cline { 6 - 8 } & & & & & & Lower B. & Upper B. \\
\hline & Avila oeste & Referencia & 1555,007 & 1004,49 &, 612 & $-1269,9225$ & 4379,9365 \\
& Avila norte & Referencia & $-1590,076$ & 1004,49 &, 585 & $-4415,0055$ & 1234,8535 \\
& Avila sur & Referencia & 329,616 & 1004,49 & 1,000 & $-2495,3135$ & 3154,5455 \\
& Avila este & Referencia & 1649,708 & 1004,49 &, 540 & $-1175,2215$ & 4474,6375 \\
& Madrid oeste & Referencia & $-2627,524$ & 1004,49 &, 082 & $-5452,4535$ & 197,4055 \\
CARCA MÁX. (N) & Madrid norte & Referencia & $-4233,085^{*}$ & 1004,49 &, 001 & $-7058,0145$ & $-1408,1555$ \\
& Madrid sur & Referencia & $-3763,965^{*}$ & 1004,49 &, 003 & $-6588,8945$ & $-939,0355$ \\
& Madrid este & Referencia & $-510,232$ & 1004,49 & 1,000 & $-3335,1615$ & 2314,6975 \\
& Sevilla oeste & Referencia & $-1663,199$ & 1004,49 &, 530 & $-4488,1285$ & 1167,7305 \\
& Sevilla norte & Referencia & $-3579,885^{*}$ & 1004,49 &, 005 & $-6404,8145$ & $-754,9555$ \\
& Sevilla sur & Referencia & $-2933,450^{*}$ & 1004,49 &, 037 & $-5758,3795$ & $-108,5205$ \\
& Sevilla este & Referencia & $-2246,317$ & 1004,49 &, 193 & $-5071,2465$ & 578,6125 \\
\hline
\end{tabular}

${ }^{a}$ Dunnett $t$-tests treat one group as a control, and compare all other groups against it.

*The mean difference is significant at the 0.05 level.

${ }^{\mathrm{b}}$ Especie $=$ Abeto

Como se observa en el cuadro 5.29, según el análisis de Dunnett, la orientación tiene influencia en la carga máxima para la especie abeto, en 4 de los 12 casos de ubicación”orientación. Este efecto se produce en las orientaciones Norte y Sur. En la figura 5.5 se muestran los intervalos de confianza de las diferencias entre medias de forma gráfica.

Los resultados anteriores están referenciados a un control. En los análisis siguientes se trata de profundizar en las posibles diferencias que pueda haber en cada una de las Ubicaciones en función de la Orientación, en este caso sin tener en cuenta el valor de referencia o control mencionado anteriormente. 


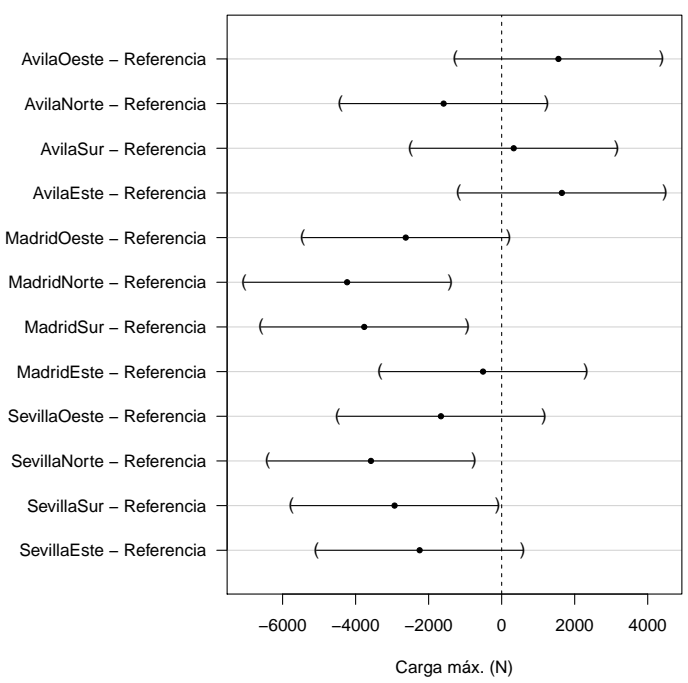

Figura 5.5: Intervalos de confianza del $95 \%$ de las diferencias de medias entre los distintos envejecimientos y la referencia para el abeto según el análisis de Dunnett

Ávila

En primer lugar se lleva a cabo un test de Levene o de homogeneidad de la varianza (cuadro 5.30), y tras comprobar la homogeneidad de la muestra, se lleva a cabo un test de ANOVA que compara cada una de las orientaciones entre ellas dentro de la misma ubicación (cuadro 5.37).

Cuadro 5.30: Prueba de homogeneidad de varianza de Levene de la carga máxima por orientación ${ }^{\text {a }}$

\begin{tabular}{rrrrr}
\hline & Levene Statistic & df1 & df2 & Sig. \\
\hline CARGA MÁX. (N) & 1,822 & 3 & 36 &, 161 \\
\hline
\end{tabular}

${ }^{\text {a }}$ Especie $=$ Abeto, Ubicación $=$ Avila

Cuadro 5.31: Test ANOVA de la carga máxima por orientación ${ }^{2}$

\begin{tabular}{rlrrrrr}
\hline & & Sum of Squares & df & Mean Square & F & Sig. \\
\hline \multirow{3}{*}{ CARGA MÁX. (N) } & Between Groups & 68315397,723 & 3 & 22771799,241 & 3,098 & 039 \\
\cline { 2 - 7 } & Within Groups & 264618606,534 & 36 & 7350516,848 & & \\
\cline { 2 - 7 } & Total & 332934004,257 & 39 & & & \\
\hline
\end{tabular}

${ }^{\text {a }}$ Especie $=$ Abeto, Ubicación $=$ Avila

En el test de ANOVA, se observa que existen diferencias significativas, aunque por el valor que presenta se presupone que no son muy acusadas, entre las distintas orientaciones para el abeto en la ubicación de Ávila. Teniendo en cuenta la homogeneidad de las varianzas, se procede a llevar a cabo un análisis de comparación múltiple de Bonferroni para evaluar lo que está sucediendo (cuadro 5.32). En la figura 5.6 
se muestran gráficamente los intervalos de confianza del $95 \%$ de las diferencias entre medias de las distintas orientaciones.

Cuadro 5.32: Análisis de comparación múltiple de Bonferroni de la carga máxima por orientación ${ }^{2}$ Bonferroni

\begin{tabular}{|c|c|c|c|c|c|c|c|}
\hline \multirow{2}{*}{ Dependent Var. } & \multirow{2}{*}{ (I) Orient. } & \multirow{2}{*}{ (J) Orient. } & \multirow{2}{*}{ Mean Diff. (I-J) } & \multirow{2}{*}{ Std. Err. } & \multirow{2}{*}{ Sig. } & \multicolumn{2}{|c|}{$95 \%$ Conf. Int. } \\
\hline & & & & & & Lower B. & Upper B. \\
\hline \multirow{12}{*}{ CARGA MÁX. (N) } & \multirow{3}{*}{ Oeste } & Norte & 3145,083 & 1212,478 &, 082 & $-240,1221$ & 6530,2881 \\
\hline & & Sur & 1225,391 & 1212,478 & 1,000 & $-2159,8141$ & 4610,5961 \\
\hline & & Este & $-94,701$ & 1212,478 & 1,000 & $-3479,9061$ & 3290,5041 \\
\hline & \multirow{3}{*}{ Norte } & Oeste & $-3145,083$ & 1212,478 &, 082 & $-6530,2881$ & 240,1221 \\
\hline & & Sur & $-1919,692$ & 1212,478 & ,733 & $-5304,8971$ & 1465,5131 \\
\hline & & Este & $-3239,784$ & 1212,478 &, 068 & $-6624,9891$ & 145,4211 \\
\hline & \multirow{3}{*}{ Sur } & Oeste & $-1225,391$ & 1212,478 & 1,000 & $-4610,5961$ & 2159,8141 \\
\hline & & Norte & 1919,692 & 1212,478 & ,733 & $-1465,5131$ & 5304,8971 \\
\hline & & Este & $-1320,092$ & 1212,478 & 1,000 & $-4705,2971$ & 2065,1131 \\
\hline & \multirow{3}{*}{ Este } & Oeste & 94,701 & 1212,478 & 1,000 & $-3290,5041$ & 3479,9061 \\
\hline & & Norte & 3239,784 & 1212,478 &, 068 & $-145,4211$ & 6624,9891 \\
\hline & & Sur & 1320,092 & 1212,478 & 1,000 & $-2065,1131$ & 4705,2971 \\
\hline
\end{tabular}

*The mean difference is significant at the 0.05 level.

${ }^{a}$ Especie = Abeto, Ubicación = Avila

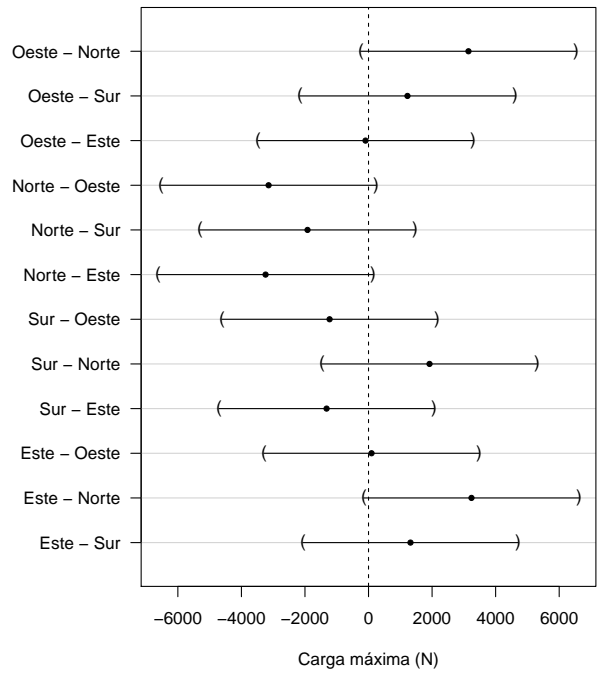

Figura 5.6: Intervalos de confianza del $95 \%$ de las diferencias de medias entre las distintas orientaciones para el abeto en Ávila según el análisis de Bonferroni

Según este análisis, y como se preveía por la baja significación del test de ANOVA, ninguna orientación presenta una diferencia significativa frente a otra. 


\section{Madrid}

En primer lugar se lleva a cabo un test de Levene o de homogeneidad de la varianza (cuadro 5.33), y tras comprobar la homogeneidad de la muestra, se lleva a cabo un test de ANOVA que compara cada una de las orientaciones entre ellas dentro de la misma ubicación (cuadro 5.34).

Cuadro 5.33: Prueba de homogeneidad de varianza de Levene de la carga máxima por orientación ${ }^{a}$

\begin{tabular}{rrrrr}
\hline & Levene Statistic & df1 & df2 & Sig. \\
\hline CARCA MÁX. (N) & 2,100 & 3 & 36 &, 117 \\
\hline
\end{tabular}

${ }^{\mathrm{a}}$ Especie $=$ Abeto, Ubicación $=$ Madrid

Cuadro 5.34: Test ANOVA de la carga máxima por orientación ${ }^{2}$

\begin{tabular}{rlrrrrr}
\hline & & Sum of Squares & df & Mean Square & F & Sig. \\
\hline \multirow{3}{*}{ CARGA MÁX. (N) } & Between Groups & 82546840,384 & 3 & 27515613,461 & 6,374 &, 001 \\
\cline { 2 - 7 } & Within Croups & 155398210,433 & 36 & 4316616,956 & & \\
\cline { 2 - 7 } & Total & 237945050,817 & 39 & & & \\
\hline
\end{tabular}

${ }^{\mathrm{a}}$ Especie $=$ Abeto, Ubicación $=$ Madrid

En el test de ANOVA, se observa que existen diferencias significativas entre las distintas orientaciones para el abeto en la ubicación de Madrid, y teniendo en cuenta la homogeneidad de las varianzas, se procede a llevar a cabo un análisis de comparación múltiple de Bonferroni para evaluar lo que está sucediendo

Cuadro 5.35: Análisis de comparación múltiple de Bonferroni de la carga máxima por orientación ${ }^{a}$ Bonferroni

\begin{tabular}{|c|c|c|c|c|c|c|c|}
\hline \multirow{2}{*}{ Dependent Var. } & \multirow{2}{*}{ (I) Orient. } & \multirow{2}{*}{ (J) Orient. } & \multirow{2}{*}{ Mean Diff. (I-J) } & \multirow{2}{*}{ Std. Err. } & \multirow{2}{*}{ Sig. } & \multicolumn{2}{|c|}{$95 \%$ Conf. Int. } \\
\hline & & & & & & Lower B. & Upper B. \\
\hline \multirow{12}{*}{ CARCA MÁX. (N) } & \multirow{3}{*}{ Oeste } & Norte & 1605,561 & 929,152 &, 555 & $-988,6052$ & 4199,7272 \\
\hline & & Sur & 1136,441 & 929,152 & 1,000 & $-1457,7252$ & 3730,6072 \\
\hline & & Este & $-2117,292$ & 929,152 &, 172 & $-4711,4582$ & 476,8742 \\
\hline & \multirow{3}{*}{ Norte } & Oeste & $-1605,561$ & 929,152 &, 555 & $-4199,7272$ & 988,6052 \\
\hline & & Sur & $-469,120$ & 929,152 & 1,000 & $-3063,2862$ & 2125,0462 \\
\hline & & Este & $-3722,853^{*}$ & 929,152 &, 002 & $-6317,0192$ & $-7128,6868$ \\
\hline & \multirow{3}{*}{ Sur } & Oeste & $-1136,441$ & 929,152 & 1,000 & $-3730,6072$ & 1457,7252 \\
\hline & & Norte & 469,120 & 929,152 & 1,000 & $-2125,0462$ & 3063,2862 \\
\hline & & Este & $-3253,733^{*}$ & 929,152 &, 008 & $-5847,8992$ & $-659,5668$ \\
\hline & \multirow{3}{*}{ Este } & Oeste & 2117,292 & 929,152 &, 172 & $-476,8742$ & 4711,4582 \\
\hline & & Norte & $3722,853^{*}$ & 929,152 &, 002 & 1128,6868 & 6317,0192 \\
\hline & & Sur & $3253,733^{*}$ & 929,152 &, 008 & 659,5668 & 5847,8992 \\
\hline
\end{tabular}

* The mean difference is significant at the 0.05 level.

${ }^{a}$ Especie $=$ Abeto, Ubicación $=$ Madrid 


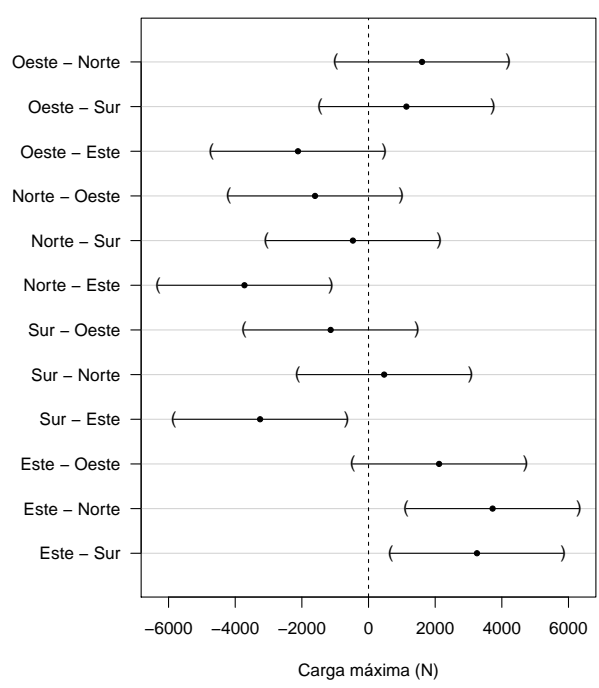

Figura 5.7: Intervalos de confianza del $95 \%$ de las diferencias de medias entre las distintas orientaciones para el abeto en Madrid según el análisis de Bonferroni

Según el análisis de Bonferroni del cuadro 5.35, la orientación que presenta diferencias significativas es la cara Este, con respecto a la Norte y a la Sur, fenómeno que se explica por la protección parcial que tiene la cara Este de abeto por la proximidad del prototipo de pino. En la figura 5.7 se muestran gráficamente los intervalos de confianza del $95 \%$ de las diferencias entre medias de las distintas orientaciones.

\section{Sevilla}

En primer lugar se lleva a cabo un test de Levene o de homogeneidad de la varianza (cuadro 5.36), y tras comprobar la homogeneidad de la muestra, se lleva a cabo un test de ANOVA que compara cada una de las orientaciones entre ellas dentro de la misma ubicación (cuadro 5.37).

Cuadro 5.36: Prueba de homogeneidad de varianza de Levene de la carga máxima por orientación ${ }^{2}$

\begin{tabular}{lrrrr}
\hline & Levene Statistic & df1 & df2 & Sig. \\
\hline CARGA MÁX. (N) &, 933 & 3 & 36 &, 435 \\
\hline a Especie = Abeto, Ubicación = Sevilla & & &
\end{tabular}

En el test de ANOVA, se observa que no existen diferencias significativas entre las distintas orientaciones para el abeto en la ubicación de Sevilla, por lo que no procede a llevar a cabo un análisis de comparación múltiple de Bonferroni.

Por último y para confirmar si existe alguna ubicación preferente para el abeto en relación a la carga máxima, se toman como muestra todos los datos de cada ubicación, es decir, incluyendo las cuatro orientaciones, y se llevan a cabo análisis para valorar este efecto. 
Cuadro 5.37: Test ANOVA de la carga máxima por orientación ${ }^{\mathrm{a}}$

\begin{tabular}{llrrrrr}
\hline & & Sum of Squares & df & Mean Square & F & Sig. \\
\hline \multirow{3}{*}{ CARGA MÁX. (N) } & Between Groups & 20739207,518 & 3 & 6913069,173 & 1,592 & ,208 \\
\cline { 2 - 7 } & Within Croups & 156366364,580 & 36 & 4343510,127 & & \\
\cline { 2 - 7 } & Total & 177105572,098 & 39 & & & \\
\hline
\end{tabular}

\footnotetext{
${ }^{\text {a }}$ Especie $=$ Abeto, Ubicación $=$ Sevilla
}

Cuadro 5.38: Valores descriptivos de carga máxima por ubicación ${ }^{2}$

\begin{tabular}{|c|c|c|c|c|c|c|c|c|c|}
\hline & & \multirow{2}{*}{$\mathrm{N}$} & \multirow{2}{*}{ Mean } & \multirow{2}{*}{ Std. Dev. } & \multirow{2}{*}{ Std. Err. } & \multicolumn{2}{|c|}{$95 \%$ C. I. for Mean } & \multirow{2}{*}{ Min. } & \multirow{2}{*}{ Max. } \\
\hline & & & & & & Lower B. & Upper B. & & \\
\hline \multirow{4}{*}{ CARCA MÁX. (N) } & Avila & 40 & 14658,42 & 2921,78 & 461,97 & 13723,99 & 15592,84 & 8787,67 & 19766,68 \\
\hline & Madrid & 40 & 11388,65 & 2470,05 & 390,55 & 10598,69 & 12178,61 & 7722,13 & 17003,55 \\
\hline & Sevilla & 40 & 11566,64 & 2131,00 & 336,94 & 10885,11 & 12248,17 & 8167,97 & 15784,02 \\
\hline & Total & 120 & 12537,90 & 2925,42 & 267,05 & 12009,11 & 13066,69 & 7722,13 & 19766,68 \\
\hline
\end{tabular}

${ }^{\mathrm{a}}$ Especie $=$ Abeto

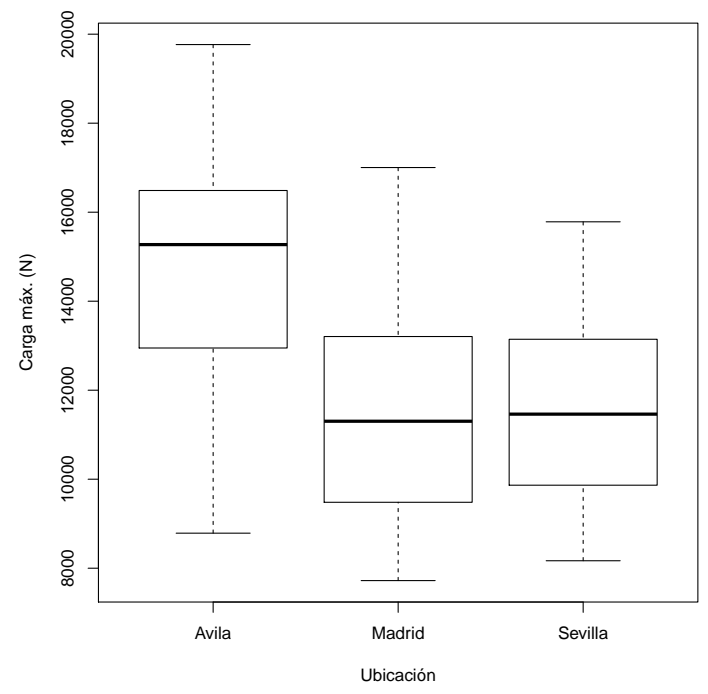

Figura 5.8: Diagramas de caja y bigotes de los valores descriptivos de carga máxima por ubicación del abeto

En el cuadro 5.38 se observan los datos de cada ubicación con sus correspondientes valores de media, desviación estándar, etc., que caracterizan la muestra analizada. En la figura 5.8 se muestran gráficamente estos valores mediante diagramas de caja y bigotes.

En el test de ANOVA (cuadro 5.40), se observa que existen diferencias significativas entre las distintas ubicaciones para el abeto en relación a la carga máxima. Teniendo en cuenta la homogeneidad de las varianzas (cuadro 5.39), se procede a llevar a cabo un análisis de comparación multiple de Bonferroni. 
Cuadro 5.39: Prueba de homogeneidad de varianza de Levene de la carga máxima por ubicación ${ }^{2}$

\begin{tabular}{rrrrr}
\hline & Levene Statistic & df1 & df2 & Sig. \\
\hline CARGA MÁX. (N) & 1,937 & 2 & 117 &, 149 \\
\hline
\end{tabular}

${ }^{\mathrm{a}}$ Especie $=$ Abeto

Cuadro 5.40: Test ANOVA de la carga máxima por ubicación ${ }^{\mathrm{a}}$

\begin{tabular}{llrrrrr}
\hline & & Sum of Squares & df & Mean Square & F & Sig. \\
\hline & Between Croups & 270428356,149 & 2 & 135214178,075 & 21,150 &, 000 \\
\cline { 2 - 6 } CARGA MÁX. (N) & Within Croups & 747984627,172 & 117 & 6393031,001 & & \\
\cline { 2 - 6 } & Total & 1018412983,321 & 119 & & & \\
\hline
\end{tabular}

${ }^{\mathrm{a}}$ Especie $=$ Abeto

Cuadro 5.41: Análisis de comparación múltiple de Bonferroni de la carga máxima por ubicación ${ }^{a}$ Bonferroni

\begin{tabular}{|c|c|c|c|c|c|c|c|}
\hline \multirow{2}{*}{ Dependent Var. } & \multirow{2}{*}{ (I) Ubic. } & \multirow{2}{*}{ (J) Ubic. } & \multirow{2}{*}{ Mean Diff. (I-J) } & \multirow{2}{*}{ Std. Err. } & \multirow{2}{*}{ Sig. } & \multicolumn{2}{|c|}{$95 \%$ Conf. Int. } \\
\hline & & & & & & Lower B. & Upper B. \\
\hline \multirow{6}{*}{ CARGA MÁX. (N) } & \multirow{2}{*}{ Avila } & Madrid & $3269,765^{*}$ & 565,377 &, 000 & 1896,527 & 4643,004 \\
\hline & & Sevilla & $3091,777^{*}$ & 565,377 &, 000 & 1718,538 & 4465,015 \\
\hline & \multirow{2}{*}{ Madrid } & Avila & $-3269,765^{*}$ & 565,377 &, 000 & $-4643,004$ & $-1896,527$ \\
\hline & & Sevilla & $-177,989$ & 565,377 & 1,000 & $-1551,227$ & 1195,250 \\
\hline & \multirow{2}{*}{ Sevilla } & Avila & $-3091,777^{*}$ & 565,377 &, 000 & $-4465,015$ & $-1718,538$ \\
\hline & & Madrid & 177,989 & 565,377 & 1,000 & $-7195,250$ & 1551,227 \\
\hline
\end{tabular}

*The mean difference is significant at the 0.05 level.

a Especie $=$ Abeto

Según muestra el cuadro 5.41, en el análisis de Bonferroni, la ubicación que produce esta diferencia significativa es Ávila, y según los valores de la tabla no solo es diferente, sino que es mejor en términos de carga máxima. En la figura 5.9 se muestran gráficamente los intervalos de confianza del $95 \%$ de las diferencias entre medias de las distintas ubicaciones.

\subsection{Delaminación abeto}

Para evaluar la delaminación, se plantean varios modelos en los que se contrastan los efectos principales, Ubicación (Referencia como control, Madrid, Ávila y Sevilla) y Orientación (Norte, Sur, Este y Oeste). El mejor modelo según su AIC (bondad de ajuste a través del índice de Akaike), es aquel que presenta Ubicación como efecto principal y Orientación como efecto jerarquizado a Ubicación. Los test de efectos del modelo aparecen en el cuadro 5.42.

Según se muestra en el cuadro 5.42, en el caso del abeto, la ubicación es un efecto significativo sobre la delaminación, mientras que no puede afirmarse que la orientación influya significativamente, aunque 


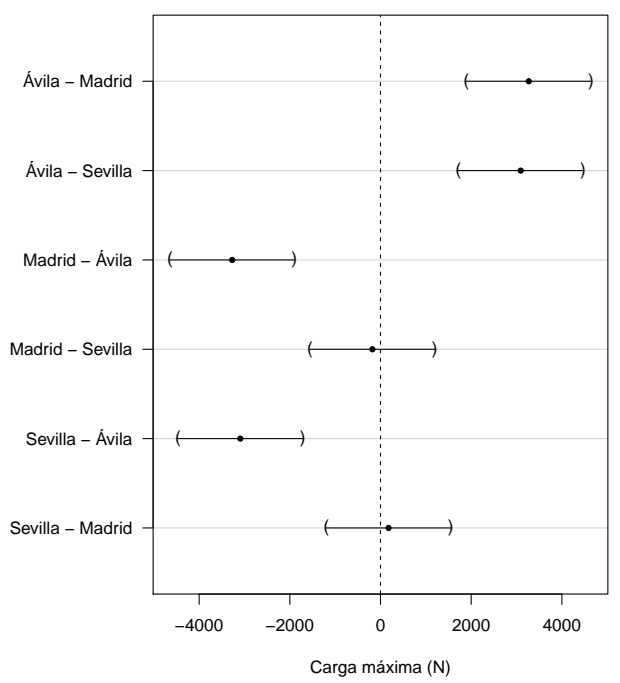

Figura 5.9: Intervalos de confianza del $95 \%$ de las diferencias de medias entre las distintas ubicaciones para el abeto según el análisis de Bonferroni

Cuadro 5.42: Análisis de efectos del modelo de la delaminación por ubicación y orientación según ubicación ${ }^{2}$

\begin{tabular}{lrrr}
\hline \multirow{2}{*}{ Source } & \multicolumn{3}{c}{ Type III } \\
\cline { 2 - 4 } & Wald Chi-Square & df & Sig. \\
\hline (Intercept) & 5422,697 & 1 &, 000 \\
\hline UBICACIÓN & 9,954 & 3 &, 019 \\
\hline ORIENTACIÓN (UBICACIÓN) & 16,446 & 9 &, 058 \\
\hline
\end{tabular}

Dependent Variable: tDELAMINACION

Model: (Intercept), UBICACION, ORIENTACIÓN (UBICACIÓN)

${ }^{a}$ Especie $=$ Abeto

tampoco puede despreciarse su efecto. Por esta razón y para estudiar la posición de la referencia frente a las ubicaciones físicas, se construye un efecto mixto ubicación*orientación (13 niveles, referencia, MadridEste, MadridOeste, etc.) y se plantea un test de ANOVA, y la realización posterior de un test de comparación múltiple de Dunnett que permita una comparación por pares de la referencia.

Cuadro 5.43: Prueba de homogeneidad de varianza de Levene de la delaminación por ubicación y orientación

\begin{tabular}{rrrrr}
\hline & Levene Statistic & df1 & df2 & Sig. \\
\hline tDELAMINACION & 1,791 & 12 & 117 &, 057 \\
\hline
\end{tabular}

${ }^{\mathrm{a}}$ Especie $=$ Abeto

Se realiza un análisis de Levene o de homogeneidad de varianzas (cuadro 5.43), y un test de ANOVA (cuadro 5.44), que muestra diferencias significativas entre las medias debidas al factor principal (UxO). 
Cuadro 5.44: Test ANOVA de la delaminación por ubicación y orientación ${ }^{\mathrm{a}}$

\begin{tabular}{rlrrrrr}
\hline & & Sum of Squares & df & Mean Square & F & Sig. \\
\hline \multirow{3}{*}{ tDELAMINACION } & Between Croups &, 802 & 12 &, 067 & 1,980 &, 032 \\
\cline { 2 - 7 } & Within Groups & 3,947 & 117 &, 034 & \\
\cline { 2 - 7 } & Total & 4,749 & 129 & & & \\
\hline
\end{tabular}

a Especie $=$ Abeto

Para poder discutir lo que está sucediendo en el abeto con respecto a la ubicación y la orientación se realiza análisis de comparación múltiple de Dunnett, en el que se analizan todas las ubicaciones con sus respectivas orientaciones frente a la referencia.

Cuadro 5.45: Análisis de comparación múltiple de Dunnett de la delaminación por ubicación y orientación ${ }^{\text {b }}$ Dunnett t (2-sided)a

\begin{tabular}{llllllll}
\hline \multirow{2}{*}{ Dependent Var. } & (I) ubi_ori & (J) ubi_ori & Mean Diff. (I-J) & Std. Err. & Sig. & \multicolumn{2}{c}{$95 \%$ Conf. Int. } \\
\cline { 6 - 8 } & & & & & & Lower B. & Upper B. \\
\hline & Avila oeste & Referencia &, 07310 &, 08214 &, 977 &,- 1579 &, 3041 \\
& Avila norte & Referencia &, $24711^{*}$ &, 08214 &, 029 &, 0161 &, 4781 \\
& Avila sur & Referencia &, 00808 &, 08214 & 1,000 &,- 2229 &, 2391 \\
& Avila este & Referencia &,- 01601 &, 08214 & 1,000 &,- 2470 &, 2150 \\
& Madrid oeste & Referencia &,- 02866 &, 08214 & 1,000 &,- 2597 &, 2023 \\
tDELAMINACION & Madrid norte & Referencia &,- 04808 &, 08214 &, 999 &,- 2791 &, 1829 \\
& Madrid sur & Referencia &,- 06924 &, 08214 &, 985 &,- 3002 &, 1618 \\
& Madrid este & Referencia &, 01827 &, 08214 & 1,000 &,- 2127 &, 2493 \\
& Sevilla oeste & Referencia &,- 05066 &, 08214 &, 999 &,- 2817 &, 1803 \\
& Sevilla norte & Referencia &, 02295 &, 08214 & 1,000 &,- 2080 &, 2540 \\
& Sevilla sur & Referencia &,- 04603 &, 08214 & 1,000 &,- 2770 &, 1850 \\
& Sevilla este & Referencia &,- 02333 &, 08214 & 1,000 &,- 2543 &, 2077 \\
\hline
\end{tabular}

${ }^{a}$ Dunnett t-tests treat one group as a control, and compare all other groups against it.

* The mean difference is significant at the 0.05 level

${ }^{\mathrm{b}}$ Especie $=$ Abeto

Como se observa en el cuadro 5.45 (en la figura 5.10 se representan gráficamente los intervalos de confianza de las diferencias entre las medias), la orientación no tiene influencia en la delaminación, excepto en el caso de Ávila norte y con un valor muy bajo.

Los resultados anteriores están referenciados a un control. En los análisis siguientes se trata de profundizar en las posibles diferencias que pueda haber en cada una de las Ubicaciones en función de la Orientación, en este caso sin tener en cuenta el valor de referencia o control mencionado anteriormente. Para ello se procede a llevar a cabo un análisis de las diferentes ubicaciones sin tener en cuenta a la referencia. 


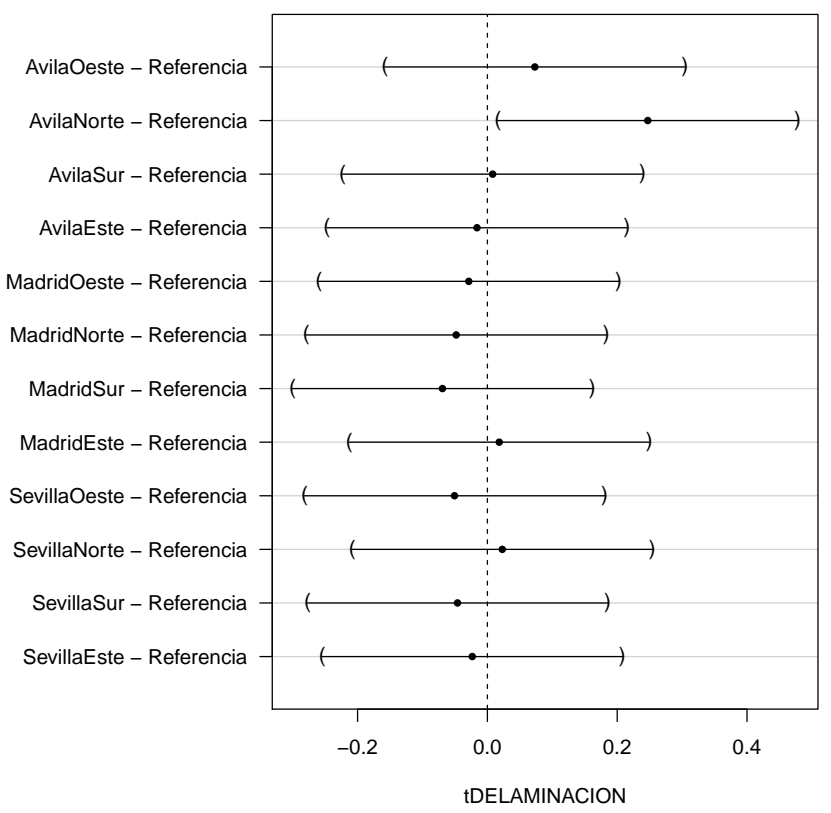

Figura 5.10: Intervalos de confianza del $95 \%$ de las diferencias de medias para el abeto según el análisis de Dunnett

\section{Ávila}

En primer lugar se lleva a cabo un test de Levene o de homogeneidad de la varianza (cuadro 5.46), y tras comprobar la homogeneidad de la muestra, se lleva a cabo un test de ANOVA, que compara cada una de las orientaciones entre ellas dentro de la misma ubicación (cuadro 5.47).

Cuadro 5.46: Prueba de homogeneidad de varianza de Levene de la delaminación por orientación ${ }^{\text {a }}$

\begin{tabular}{rrrrr}
\hline & Levene Statistic & df1 & df2 & Sig. \\
\hline tDELAMINACION & 1,238 & 3 & 36 &, 310
\end{tabular}

a. Especie $=$ Abeto, Ubicación $=$ Avila

Cuadro 5.47: Test ANOVA de la delaminación por orientación ${ }^{a}$

\begin{tabular}{rlrrrrr}
\hline & Sum of Squares & df & Mean Square & F & Sig. \\
\hline \multirow{3}{*}{ tDELAMINACION } & Between Croups &, 423 & 3 &, 141 & 4,332 &, 010 \\
\cline { 2 - 7 } & Within Groups & 1,173 & 36 & \multirow{2}{*}{, 033} & \\
\cline { 2 - 7 } & Total & 1,597 & 39 & & & \\
\hline
\end{tabular}

a Especie $=$ Abeto, Ubicación $=$ Avila

En el análisis ANOVA, observamos que existen diferencias significativas entre las distintas orientaciones para el abeto en la ubicación de Ávila, y debido a la homogeneidad de la varianza, se decide llevar a cabo un análisis de comparación múltiple de Bonferroni para evaluar lo que está sucediendo. 
Cuadro 5.48: Análisis de comparación múltiple de Bonferroni de la delaminación por orientación ${ }^{2}$ Bonferroni

\begin{tabular}{|c|c|c|c|c|c|c|c|}
\hline \multirow{2}{*}{ Dependent Variable } & \multirow{2}{*}{ (I) Orient. } & \multirow{2}{*}{ (J) Orient. } & \multirow{2}{*}{ Mean Diff. (I-J) } & \multirow{2}{*}{ Std. Error } & \multirow{2}{*}{ Sig. } & \multicolumn{2}{|c|}{$95 \%$ Conf. Interval } \\
\hline & & & & & & Lower B. & Upper B. \\
\hline \multirow{12}{*}{ tDELAMINACION } & \multirow{3}{*}{ Oeste } & Norte &,- 17401 & 08073 & 227 &,- 3994 & 0514 \\
\hline & & Sur &, 06502 & 08073 & 1,000 &,- 1604 & ,2904 \\
\hline & & Este & 08911 &, 08073 & 1,000 &,- 1363 & ,3145 \\
\hline & \multirow{3}{*}{ Norte } & Oeste & , 17401 & 08073 & .227 &,- 0514 & ,3994 \\
\hline & & Sur & $0,23903 *$ & 08073 & 032 &, 0136 &, 4644 \\
\hline & & Este & $0,26312^{*}$ & 08073 & 015 & 0377 &, 4885 \\
\hline & \multirow{3}{*}{ Sur } & Oeste &,- 06502 & 08073 & 1,000 &,- 2904 &, 1604 \\
\hline & & Norte & $-0,23903^{*}$ & 08073 &, 032 &,- 4644 &,- 0136 \\
\hline & & Este &, 02409 & 08073 & 1,000 &,- 2013 & ,2495 \\
\hline & \multirow{3}{*}{ Este } & Oeste &,- 08911 & 08073 & 1,000 &,- 3145 & , 1363 \\
\hline & & Norte & $-0,26312^{*}$ & 08073 &, 015 &,- 4885 &,- 0377 \\
\hline & & Sur &,- 02409 & 08073 & 1,000 &,- 2495 & ,2013 \\
\hline
\end{tabular}

* The mean difference is significant at the 0.05 level.

${ }^{a}$ Especie $=$ Abeto, Ubicación $=$ Avila

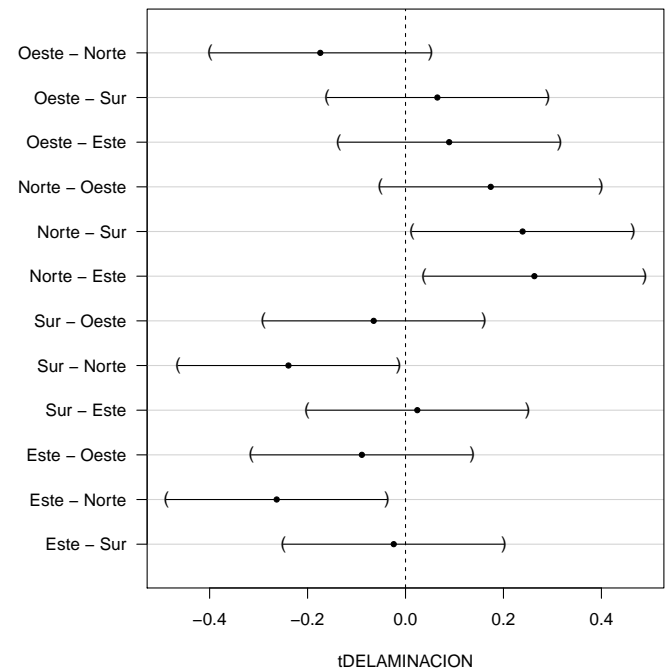

Figura 5.11: Intervalos de confianza del $95 \%$ de las diferencias de medias de delaminación entre las distintas orientaciones para el abeto en Ávila según el análisis de Bonferroni

Según este análisis (cuadro 5.48), en la ubicación de Ávila, la orientación que presenta diferencias significativas es la cara Norte, con respecto a la Este y a la Sur. En la figura 5.11 se muestran gráficamente los intervalos de confianza del $95 \%$ de las diferencias entre medias de las distintas ubicaciones. 


\section{Madrid}

En primer lugar se lleva a cabo un test de Levene o de homogeneidad de la varianza (cuadro 5.49), y tras comprobar la homogeneidad de la muestra, se lleva a cabo un test de ANOVA, que compara cada una de las orientaciones entre ellas dentro de la misma ubicación (cuadro 5.50).

Cuadro 5.49: Prueba de homogeneidad de varianza de Levene de la delaminación por orientación ${ }^{2}$

\begin{tabular}{rrrrr}
\hline & Levene Statistic & df1 & df2 & Sig. \\
\hline tDELAMINACION & 1,267 & 3 & 36 &, 300 \\
\hline
\end{tabular}

${ }^{\text {a }}$ Especie $=$ Abeto, Ubicación $=$ Madrid

Cuadro 5.50: Test ANOVA de la delaminación por orientación ${ }^{2}$

\begin{tabular}{rlrrrrr}
\hline & & Sum of Squares & df & Mean Square & F & Sig. \\
\hline \multirow{3}{*}{ tDELAMINACION } & Between Groups &, 042 & 3 &, 014 &, 583 &, 630 \\
\cline { 2 - 7 } & Within Groups &, 860 & 36 & \multicolumn{2}{c}{, 024} & \\
\cline { 2 - 6 } & Total &, 902 & 39 & & & \\
\hline
\end{tabular}

${ }^{a}$ Especie $=$ Abeto, Ubicación $=$ Madrid

En el test de ANOVA, observamos que no existen diferencias significativas entre las distintas orientaciones para el abeto en la ubicación de Madrid, por lo que no se procede a llevar a cabo otro tipo de análisis.

Sevilla

En primer lugar se lleva a cabo un test de Levene o de homogeneidad de la varianza (cuadro 5.51), y tras comprobar la homogeneidad de la muestra, se lleva a cabo un test de ANOVA que compara cada una de las orientaciones entre ellas dentro de la misma ubicación (cuadro 5.52).

Cuadro 5.51: Prueba de homogeneidad de varianza de Levene de la delaminación por orientación ${ }^{a}$

\begin{tabular}{rrrrr}
\hline & Levene Statistic & df1 & df2 & Sig. \\
\hline tDELAMINACION & 3,591 & 3 & 36 &, 023 \\
\hline
\end{tabular}

\footnotetext{
${ }^{\text {a }}$ Especie $=$ Abeto, Ubicación $=$ Sevilla
}

En el test de ANOVA, observamos que no existen diferencias significativas entre las distintas orientaciones para el abeto en la ubicación de Sevilla, por lo que no se procede a llevar a cabo otro tipo de análisis.

Por último y para confirmar si existe alguna ubicación preferente para el abeto en relación a la delaminación, se toman como muestra todos los datos de cada ubicación, es decir incluyendo las cuatro orientaciones, y se llevan a cabo análisis para valorar este efecto. 
Cuadro 5.52: Test ANOVA de la delaminación por orientación ${ }^{\mathrm{a}}$

\begin{tabular}{rlrrrrr}
\hline & & Sum of Squares & df & Mean Square & F & Sig. \\
\hline \multirow{3}{*}{ tDELAMINACION } & Between Croups &, 034 & 3 &, 011 &, 307 &, 820 \\
\cline { 2 - 7 } & Within Croups & 1,331 & 36 &, 037 & & \\
\cline { 2 - 7 } & Total & 1,365 & 39 & & & \\
\hline
\end{tabular}

${ }^{a}$ Especie = Abeto, Ubicación = Sevilla

Cuadro 5.53: Valores descriptivos de la delaminación por ubicación ${ }^{2}$

\begin{tabular}{|c|c|c|c|c|c|c|c|c|c|}
\hline & & \multirow{2}{*}{$\mathrm{N}$} & \multirow{2}{*}{ Mean } & \multirow{2}{*}{ Std. Dev. } & \multirow{2}{*}{ Std. Err. } & \multicolumn{2}{|c|}{$95 \%$ C. I. for Mean } & \multirow{2}{*}{ Min. } & \multirow{2}{*}{ Max. } \\
\hline & & & & & & Lower B. & Upper B. & & \\
\hline \multirow{4}{*}{ tDELAMINACION } & Avila & 40 & 1,27 &, 20 &, 03 & 1,20 & 1,33 &, 68 & 1,57 \\
\hline & Madrid & 40 & 1,16 & , 15 &, 02 & 1,11 & 1,21 & ,79 & 1,57 \\
\hline & Sevilla & 40 & 1,17 & ,19 &, 03 & 1,11 & 1,23 &, 89 & 1,57 \\
\hline & Total & 120 & 1,20 & ,19 &, 017 & 1,16 & 1,23 &, 68 & 1,57 \\
\hline
\end{tabular}

${ }^{\text {a }}$ Especie $=$ Abeto

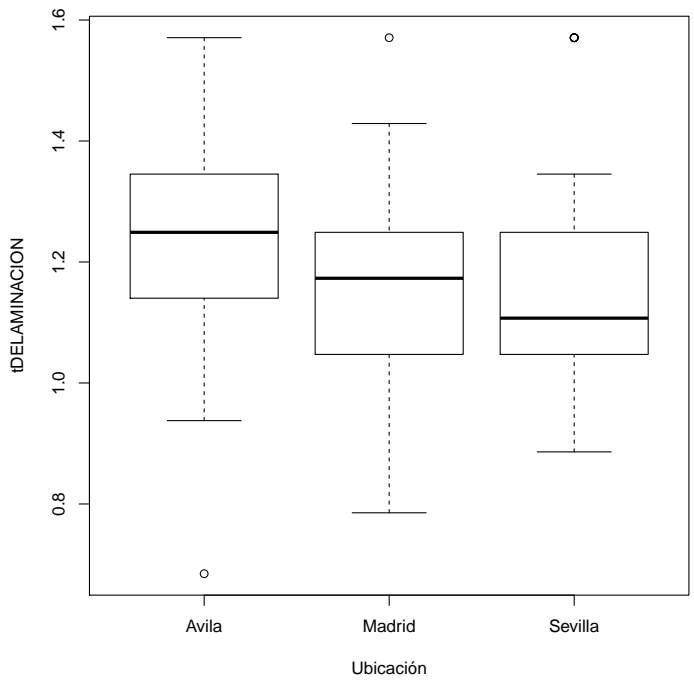

Figura 5.12: Diagramas de caja y bigotes de los valores descriptivos de la delaminación por ubicación del abeto

En el cuadro 5.53 se observan los datos de cada ubicación con sus correspondientes valores de media, desviación estándar, etc., que caracterizan la muestra analizada. En la figura 5.12 se muestran los diagramas de caja y bigotes para cada una de las ubicaciones.

En el test de ANOVA (cuadro 5.55), se observa que existen diferencias significativas entre las distintas ubicaciones para el abeto en relación a la delaminación, por lo que se procede a llevar a cabo un análisis de comparación multiple de Bonferroni. 
Cuadro 5.54: Prueba de homogeneidad de varianza de Levene de la delaminación por ubicación ${ }^{\text {a }}$

\begin{tabular}{lrrrr}
\hline & Levene Statistic & df1 & df2 & Sig. \\
\hline tDELAMINACION & 1,015 & 2 & 117 &, 366 \\
\hline${ }^{a}$ Especie = Abeto & & & &
\end{tabular}

Cuadro 5.55: Test ANOVA de la delaminación por ubicación ${ }^{\mathrm{a}}$

\begin{tabular}{rlrrrrr}
\hline & & Sum of Squares & df & Mean Square & $F$ & Sig. \\
\hline \multirow{3}{*}{ tDELAMINACION } & Between Croups &, 302 & 2 &, 151 & 4,568 &, 012 \\
\cline { 2 - 7 } & Within Groups & 3,864 & 117 &, 033 & \\
\cline { 2 - 7 } & Total & 4,165 & 119 & & & \\
\hline
\end{tabular}

${ }^{\mathrm{a}}$ Especie $=$ Abeto

Cuadro 5.56: Análisis de comparación múltiple de Bonferroni de la delaminación por ubicación ${ }^{2}$ Bonferroni

\begin{tabular}{|c|c|c|c|c|c|c|c|}
\hline \multirow{2}{*}{ Dependent Var. } & \multirow{2}{*}{ (I) Ubic. } & \multirow{2}{*}{ (J) Ubic. } & \multirow{2}{*}{ Mean Diff. (I-J) } & \multirow{2}{*}{ Std. Err. } & \multirow{2}{*}{ Sig. } & \multicolumn{2}{|c|}{$95 \%$ Conf. Int. } \\
\hline & & & & & & Lower B. & Upper B \\
\hline \multirow{6}{*}{ tDELAMINACION } & \multirow{2}{*}{ Avila } & Madrid & ,10999* &, 04063 &, 023 &, 0113 & 2087 \\
\hline & & Sevilla &, $10233^{*}$ &, 04063 & 039 &, 0036 & 2010 \\
\hline & \multirow{2}{*}{ Madrid } & Avila &,$- 10999 *$ &, 04063 &, 023 &,- 2087 &,- 0113 \\
\hline & & Sevilla &,- 00766 & ,04063 & 1,000 &,- 1064 &, 0910 \\
\hline & \multirow{2}{*}{ Sevilla } & Avila &,$- 10233^{*}$ &, 04063 &, 039 &,- 2010 &,- 0036 \\
\hline & & Madrid &, 00766 &, 04063 & 1,000 &,- 0910 &, 1064 \\
\hline
\end{tabular}

* The mean difference is significant at the 0.05 level

${ }^{\text {a }}$ Especie $=$ Abeto

Según muestra el cuadro 5.56, en el análisis de comparación múltiple de Bonferroni, la ubicación que produce esta diferencia significativa es Ávila, y según los valores de la tabla no solo es diferente, sino que es mejor en términos de delaminación. En la figura 5.13 se muestran gráficamente los intervalos de confianza del $95 \%$ de las diferencias entre medias de las distintas ubicaciones.

\subsubsection{Resumen de los resultados del CLT de abeto}

Según el análisis descriptivo, teniendo en cuenta los dos parámetros, carga máxima y delaminación, se puede apreciar que la peor orientación es la SUR de forma general. De forma puntual con respecto a la carga máxima la peor orientación sería la NORTE. Atendiendo a las ubicaciones, la mejor en los dos parámetros analizados sería Ávila.

Teniendo en cuenta el análisis de contraste de hipótesis, se observa que no se puede afirmar que haya influencia de la orientación en términos de delaminación, aunque en términos de carga máxima si se observan diferencias en la ubicación de Madrid para las caras NORTE y SUR frente a la ESTE, aun- 


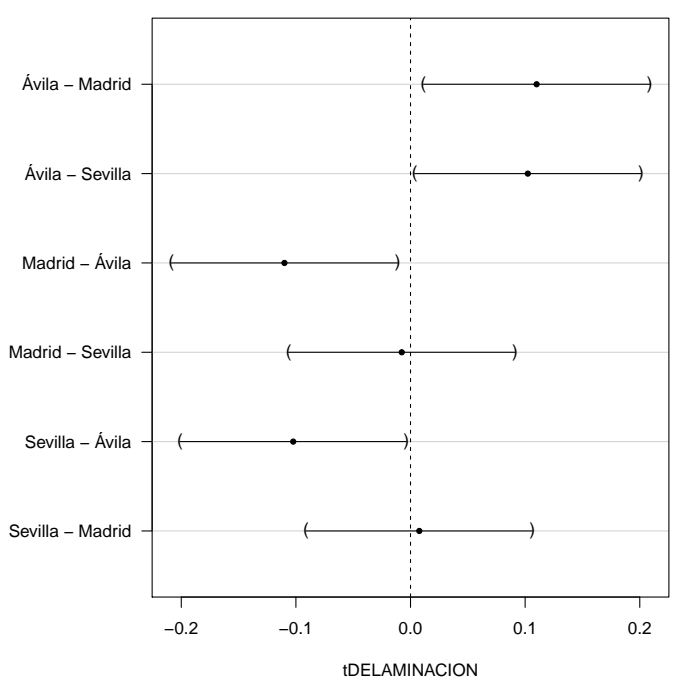

Figura 5.13: Intervalos de confianza del $95 \%$ de las diferencias de medias de delaminación entre las distintas ubicaciones para el abeto según el análisis de Bonferroni

que esto se debe a la protección parcial de la cara ESTE. Atendiendo a las ubicaciones, el análisis de contraste de hipótesis confirma estadísticamente el resultado del análisis descriptivo con Ávila como mejor ubicación.

\subsubsection{Resultados para el pino (Pinus sylvestris)}

A continuación se lleva a cabo un análisis descriptivo del envejecimiento natural en el que se comparan los resultados obtenidos en este método de envejecimiento con la referencia, para poder ver que está sucediendo en cada una de las ubicaciones y evaluar el efecto orientación, y un segundo análisis de contraste de hipótesis para ver la representatividad estadística de los resultados.

En el análisis de contraste de hipótesis se harán comparaciones con la referencia para evaluar la degradación, y sin la referencia para analizar las diferencias que existen entre los métodos aplicados y poder evaluar la degradación en cada uno de ellos.

\subsubsection{Análisis descriptivo del envejecimiento natural}

Con respecto al pino, cabe comentar que en referencia a los valores de delaminación, se va a considerar que un valor de delaminación es aceptable cuando se encuentre por encima del 70 \% de madera, según lo descrito en el ensayo de delaminación en el apartado 4.7 Ensayo de delaminación, cosa que en el pino sucede en todos los resultados obtenidos.

La primera comparación es una aproximación bastante somera en la que se puede ver que el valor de delaminación de referencia del pino 93,00 \% está por encima de la media de las delaminaciones de las diferentes ubicaciones y orientaciones $86,46 \%$, aunque en principio la diferencia no es significativa, lo 
Cuadro 5.57: Análisis descriptivo del envejecimiento natural (pino)

\begin{tabular}{|c|c|c|c|}
\hline & & DELAMINACIÓN (\%) & CARGA MÁX. (N) \\
\hline \multirow{2}{*}{ Referencia } & Media & 93,00 & 18423,09 \\
\hline & Desv. Estan. & 10,06 & 3361,91 \\
\hline \multirow{4}{*}{ Madrid } & Norte & 82,20 & 17628,13 \\
\hline & Sur & 78,70 & 17374,65 \\
\hline & Este & 86,90 & 17207,12 \\
\hline & Oeste & 83,20 & 18291,75 \\
\hline \multirow{4}{*}{ Sevilla } & Norte & 89,00 & 19760,69 \\
\hline & Sur & 87,50 & 20235,87 \\
\hline & Este & 81,00 & 20972,87 \\
\hline & Oeste & 82,00 & 18944,66 \\
\hline \multirow{4}{*}{ Avila } & Norte & 97,50 & 19108,67 \\
\hline & Sur & 88,50 & 17559,81 \\
\hline & Este & 89,50 & 17909,20 \\
\hline & Oeste & 91,50 & 16707,12 \\
\hline \multirow{2}{*}{ Media env. } & Media & 86,46 & 18475,04 \\
\hline & Desv. Estan. & 5,28 & 1330,32 \\
\hline \multirow{3}{*}{ Ciudades } & Madrid & EONS & ONSE \\
\hline & Sevilla & NSOE & ESNO \\
\hline & Avila & NOES & NESO \\
\hline \multirow{4}{*}{ Orientaciones } & Norte & ASM & SAM \\
\hline & Sur & ASM & SAM \\
\hline & Este & AMS & SAM \\
\hline & Oeste & AMS & SMA \\
\hline
\end{tabular}

que al igual que en el caso del abeto parece indicar que las muestras envejecidas como término medio están al menos igual que las de referencia, y las medias de cada envejecimiento no son muy dispares, ya que presentan una desviación estándar de 5,28.

Otra aproximación general pero que también nos puede servir de indicativo es el valor medio de la carga máxima, atendiendo a los datos se observa que la carga máxima media observada para el pino en las muestras de referencia es de 18.423,09 N, que se puede observar es aproximadamente igual a la carga máxima media de todas las ubicaciones y orientaciones, y la desviación estándar de la media de las cargas máximas de las ubicaciones y orientaciones es baja, y sensiblemente inferior a la desviación estándar de las muestras de referencia, 1330,32 frente a los 3361,91 de las muestras de referencia, lo que hace plantearse que la ubicación y orientación en el pino no influye en la pérdida de propiedades resistentes, a diferencia de lo que ocurría en el abeto.

De esta primera aproximación se puede extraer que no hay una influencia significativa en cuanto a términos de delaminación entre las muestras de referencia y las diferentes ubicaciones y orientaciones, ni tampoco entre los valores de resistencia en la tracción perpendicular a la fibra, para comprobar lo 
que sucede realizamos un análisis más detallado a continuación.

\subsection{Carga máxima pino}

Atendiendo a las orientaciones, se observa que la orientación Oeste es la peor de las cuatro orientaciones, teniendo en cuenta las tres ubicaciones, excepto en Madrid, aunque hay que tener en cuenta que en esta ubicación se encontraba protegida. La orientación Oeste presenta dos valores por debajo del valor de referencia, y uno de ellos incluso por debajo del valor medio de las ubicaciones y orientaciones.

Atendiendo a las ubicaciones, se observa que Sevilla es la mejor ubicación con respecto a los valores de carga máxima, ya que todos sus valores se sitúan por encima de la media de las ubicaciones y orientaciones y por encima de la carga máxima de referencia, además de tener los mejores valores en todas las orientaciones, incluida la Este que en Ávila se encuentra protegida, y en Sevilla no.

\subsection{Delaminación pino}

Atendiendo a las orientaciones, se observa que la orientación Sur es la peor de las cuatro orientaciones, teniendo en cuenta que en Sevilla no lo es, en todos los casos está por debajo del valor de delaminación de referencia y en Madrid incluso por debajo del valor de delaminación media de las ubicaciones y orientaciones

Atendiendo a las ubicaciones, se observa que Ávila es la mejor ubicación con respecto a los valores de delaminación, ya que todos sus valores se sitúan por encima de la media de las orientaciones y ubicaciones y muy cercanos al valor de delaminación de referencia, incluso superior en la cara Norte, y por tener los mejores valores en todas las orientaciones, incluso en la Oeste que en las otras ubicaciones se encuentra protegida y en Ávila no lo está.

\subsubsection{Análisis de contraste de hipótesis del envejecimiento natural}

Tras este primer análisis general descriptivo de los resultados, basado en los valores medios obtenidos, se procede a realizar un análisis de contraste de hipótesis para valorar la representatividad estadística de los resultados.

\subsection{Carga máxima pino}

Para evaluar la carga máxima, se plantean varios modelos en los que se contrastan los efectos principales, Ubicación (Referencia como control, Madrid, Ávila y Sevilla) y Orientación (Norte, Sur, Este y Oeste). El mejor modelo según su AIC (bondad de ajuste a través del índice de Akaike), es aquel que presenta Ubicación como efecto principal y Orientación como efecto jerarquizado a Ubicación. Los test de efectos del modelo aparecen en la tabla siguiente:

Según se muestra en cuadro 5.58, en el caso del pino, la ubicación es un efecto significativo sobre la carga máxima, mientras que no puede afirmarse que la orientación influya significativamente aunque 
Cuadro 5.58: Análisis de efectos del modelo de la carga máxima en función de ubicación y orientación según ubicación ${ }^{2}$

\begin{tabular}{lrrr}
\hline \multirow{2}{*}{ Source } & \multicolumn{3}{c}{ Type III } \\
\cline { 2 - 4 } & Wald Chi-Square & df & Sig. \\
\hline (Intercept) & 8027,780 & 1 &, 000 \\
\hline UBICACION & 29,338 & 3 &, 000 \\
\hline ORIENTACION(UBICACION) & 11,669 & 9 &, 233 \\
\hline Dependent Variable: CARCA MÁX. (N) & & \\
Model: (Intercept), UBICACION, ORIENTACION(UBICACION) \\
a Especie = Pino
\end{tabular}

tampoco puede despreciarse su efecto. Por esta razón y para estudiar la posición de la Referencia frente a las ubicaciones físicas se construye un efecto mixto ubicación*orientación (13 niveles, Referencia, MadridEste, MadridOeste, etc.) y se plantea un test de ANOVA, y la realización posterior de un análisis de comparación múltiple de Dunnett que permita una comparación por pares de la Referencia.

Cuadro 5.59: Prueba de homogeneidad de varianza de Levene de la carga máxima por ubicación*orientación ${ }^{a}$

\begin{tabular}{rrrrr}
\hline & Levene Statistic & df1 & df2 & Sig. \\
\hline CARGA MÁX. (N) & 1,272 & 12 & 117 &, 244 \\
\hline
\end{tabular}

${ }^{\mathrm{a}}$ Especie $=$ Pino

Cuadro 5.60: Test ANOVA de la carga máxima por ubicación”orientación ${ }^{a}$

\begin{tabular}{lllrrrr}
\hline & & Sum of Squares & df & Mean Square & F & Sig. \\
\hline \multirow{3}{*}{ CARGA MÁX. (N) $)$} & Between Groups & 204812156,586 & 12 & 17067679,715 & 3,075 &, 001 \\
\cline { 2 - 7 } & Within Groups & 649300923,949 & 117 & 5549580,547 & & \\
\cline { 2 - 7 } & Total & 854113080,534 & 129 & & & \\
\hline
\end{tabular}

${ }^{a}$ Especie $=$ Pino

El test de ANOVA muestra como resultado homogeneidad de varianzas (cuadro 5.59) y diferencias significativas entre las medias debidas al factor principal (UxO) (cuadro 5.60).

Para poder discutir lo que está sucediendo en el pino con respecto a la ubicación y la orientación se realiza un análisis de comparación múltiple de Dunnett.

Como se observa en el cuadro 5.61, según el análisis de Dunnett, la orientación no tiene influencia en la carga máxima para la especie pino en ninguno de los casos. En la figura 5.14 se muestran gráficamente los intervalos de confianza del $95 \%$ de las diferencias de medias.

Los resultados anteriores están referenciados a un control. En los análisis siguientes se trata de profundizar en las posibles diferencias que pueda haber en cada una de las Ubicaciones en función de la Orientación, en este caso sin tener en cuenta el valor de referencia o control mencionado anteriormente. 
Cuadro 5.61: Análisis de comparación múltiple de Dunnett de la carga máxima por ubicación y orientación ${ }^{b}$ Dunnett t (2-sided)

\begin{tabular}{lllrrrrrr}
\hline \multirow{2}{*}{ Dependent Var. } & (I) obi_ori & (J) obi_ori & Mean Diff. (I-J) & Std. Err. & Sig. & \multicolumn{2}{c}{$95 \%$ Conf. Int. } \\
\cline { 7 - 8 } & & & & & & Lower B. & Upper B. \\
\hline & Avila oeste & Referencia & $-2815,97$ & 1053,53 &, 071 & $-5778,80$ & 146,86 \\
& Avila norte & Referencia & $-414,42$ & 1053,53 & 1,000 & $-3377,25$ & 2548,41 \\
& Avila sur & Referencia & $-1963,28$ & 1053,53 &, 386 & $-4926,11$ & 999,55 \\
& Avila este & Referencia & $-1613,89$ & 1053,53 &, 624 & $-4576,72$ & 1348,94 \\
& Madrid oeste & Referencia & $-1231,34$ & 1053,53 &, 876 & $-4194,17$ & 1731,50 \\
CARCA MÁX. (N) & Madrid norte & Referencia & $-1894,96$ & 1053,53 &, 428 & $-4857,79$ & 1067,87 \\
& Madrid sur & Referencia & $-2148,44$ & 1053,53 &, 283 & $-5171,27$ & 814,39 \\
& Madrid este & Referencia & $-2375,97$ & 1053,53 &, 208 & $-5278,80$ & 646,86 \\
& Sevilla oeste & Referencia & $-578,43$ & 1053,53 & 1,000 & $-3541,26$ & 2384,40 \\
& Sevilla norte & Referencia & 237,60 & 1053,53 & 1,000 & $-2725,23$ & 3200,43 \\
& Sevilla sur & Referencia & 712,79 & 1053,53 &, 997 & $-2250,05$ & 3675,62 \\
& Sevilla este & Referencia & 1449,78 & 1053,53 &, 741 & $-1513,05$ & 4412,61 \\
\hline
\end{tabular}

${ }^{a}$ Dunnett t-tests treat one group as a control, and compare all other groups against it.

*The mean difference is significant at the 0.05 level.

${ }^{\mathrm{b}}$ Especie $=$ Pino

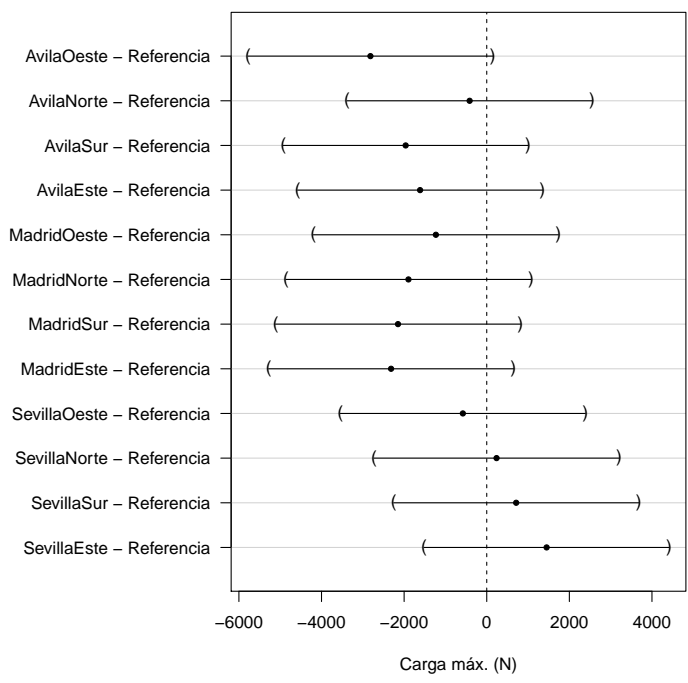

Figura 5.14: Intervalos de confianza del $95 \%$ de las diferencias de medias para el pino según el análisis de Dunnett

Ávila

En primer lugar se lleva a cabo un test de Levene o de homogeneidad de la varianza (cuadro 5.62), y tras comprobar la homogeneidad de la muestra, se lleva a cabo un test de ANOVA que compara cada una de las orientaciones entre ellas dentro de la misma ubicación (cuadro 5.63).

En el test de ANOVA, se observa que no existen diferencias significativas entre las distintas orientaciones para el pino en la ubicación de Ávila, por lo que no se procede a llevar a cabo otro tipo de análisis. 
Cuadro 5.62: Prueba de homogeneidad de varianza de Levene de la carga máxima por orientación ${ }^{\mathrm{a}}$

\begin{tabular}{rrrrr}
\hline & Levene Statistic & df1 & df2 & Sig. \\
\hline CARGA MÁX. (N) & 2,142 & 3 & 36 &, 112 \\
\hline
\end{tabular}

${ }^{\text {a }}$ Especie $=$ Pino, Ubicación $=$ Avila

Cuadro 5.63: Test ANOVA de la carga máxima por orientación ${ }^{a}$

\begin{tabular}{llrrrrr}
\hline & & Sum of Squares & df & Mean Square & F & Sig. \\
\hline & Between Croups & 29748235,192 & 3 & 9916078,397 & 1,678 &, 189 \\
\cline { 2 - 7 } CARCA MÁX. (N) & Within Groups & 212682083,571 & 36 & 5907835,655 & & \\
\cline { 2 - 6 } & Total & 242430318,763 & 39 & & & \\
\hline
\end{tabular}

${ }^{\text {a }}$ Especie $=$ Pino, Ubicación $=$ Avila

\section{Madrid}

En primer lugar se lleva a cabo un test de Levene o de homogeneidad de la varianza, y tras comprobar la homogeneidad de la muestra (cuadro 5.64), se lleva a cabo un test de ANOVA que compara cada una de las orientaciones entre ellas dentro de la misma ubicación (cuadro 5.65)

Cuadro 5.64: Prueba de homogeneidad de varianza de Levene de la carga máxima por orientación ${ }^{a}$

\begin{tabular}{rrrrr}
\hline & Levene Statistic & df1 & df2 & Sig. \\
\hline CARGA MÁX. (N) &, 164 & 3 & 36 &, 920 \\
\hline
\end{tabular}

${ }^{a}$ Especie $=$ Pino, Ubicación $=$ Madrid

Cuadro 5.65: Test ANOVA de la carga máxima por orientación ${ }^{a}$

\begin{tabular}{rlrrrrr}
\hline & & Sum of Squares & df & Mean Square & F & Sig. \\
\hline \multirow{3}{*}{ CARGA MÁX. (N) } & Between Croups & 6818708,509 & 3 & 2272902,836 & ,398 &, 755 \\
\cline { 2 - 7 } & Within Croups & 205484098,689 & 36 & 5707891,630 & & \\
\cline { 2 - 7 } & Total & 212302807,198 & 39 & & & \\
\hline
\end{tabular}

${ }^{a}$ Especie $=$ Pino, Ubicación = Madrid

En el test de ANOVA, se observa que no existen diferencias significativas entre las distintas orientaciones para el pino en la ubicación de Madrid, por lo que no se procede a llevar a cabo otro tipo de análisis.

\section{Sevilla}

En primer lugar se lleva a cabo un test de Levene o de homogeneidad de la varianza (cuadro 5.66), y tras comprobar la homogeneidad de la muestra, se lleva a cabo test de ANOVA que compara cada una de las orientaciones entre ellas dentro de la misma ubicación (cuadro 5.67). 
Cuadro 5.66: Prueba de homogeneidad de varianza de Levene de la carga máxima por orientación ${ }^{2}$

\begin{tabular}{rrrrr}
\hline & Levene Statistic & df1 & df2 & Sig. \\
\hline CARGA MÁX. (N) & 1,684 & 3 & 36 &, 188 \\
\hline
\end{tabular}

a Especie $=$ Pino, Ubicación $=$ Sevilla

Cuadro 5.67: Test ANOVA de la carga máxima por orientación ${ }^{2}$

\begin{tabular}{llrrrrr}
\hline & & Sum of Squares & df & Mean Square & F & Sig. \\
\hline \multirow{3}{*}{ CARCA MÁX. (N) } & Between Croups & 21712831,436 & 3 & 7237610,479 & 1,249 & 306 \\
\cline { 2 - 7 } & Within Croups & 208530461,825 & 36 & 5792512,828 & & \\
\cline { 2 - 7 } & Total & 230243293,262 & 39 & & & \\
\hline
\end{tabular}

${ }^{\text {a }}$ Especie $=$ Pino, Ubicación = Sevilla

En el test de ANOVA, se observa que no existen diferencias significativas entre las distintas orientaciones para el pino en la ubicación de Sevilla, por lo que no se procede a llevar a cabo otro tipo de análisis.

Por último y para confirmar si existe alguna ubicación preferente para el pino en relación a la carga máxima, se toman como muestra todos los datos de cada ubicación, es decir incluyendo las cuatro orientaciones, y se llevan a cabo análisis para valorar este efecto.

Cuadro 5.68: Valores descriptivos de la carga máxima por ubicación ${ }^{a}$

\begin{tabular}{|c|c|c|c|c|c|c|c|c|c|}
\hline & & \multirow{2}{*}{$\mathrm{N}$} & \multirow{2}{*}{ Mean } & \multirow{2}{*}{ Std. Dev. } & \multirow{2}{*}{ Std. Err. } & \multicolumn{2}{|c|}{$95 \%$ C. I. for Mean } & \multirow{2}{*}{ Min. } & \multirow{2}{*}{ Max. } \\
\hline & & & & & & Lower B. & Upper B. & & \\
\hline \multirow{4}{*}{ CARGA MÁX. (N) } & Avila & 40 & 17821,20 & 2493,22 & 394,21 & 17023,83 & 18618,57 & 12744,78 & 23977,38 \\
\hline & Madrid & 40 & 17625,41 & 2333,17 & 368,91 & 16879,23 & 18371,60 & 13053,01 & 21630,70 \\
\hline & Sevilla & 40 & 19978,52 & 2429,75 & 384,18 & 19201,45 & 20755,59 & 15324,30 & 24956,16 \\
\hline & Total & 120 & 18475,04 & 2627,22 & 239,83 & 18000,15 & 18949,93 & 12744,78 & 24956,16 \\
\hline
\end{tabular}

${ }^{\mathrm{a}}$ Especie $=$ Pino

En el cuadro 5.68 se observan los datos de cada ubicación con sus correspondientes valores de media, desviación estándar, etc., que caracterizan la muestra analizada. En la figura 5.15 se muestran gráficamente las distribuciones de la carga máxima mediante diagramas de caja y bigotes para las tres ubicaciones.

Cuadro 5.69: Prueba de homogeneidad de varianza de Levene de la carga máxima por ubicación ${ }^{a}$

\begin{tabular}{rrrrr}
\hline & Levene Statistic & df1 & df2 & Sig. \\
\hline CARGA MÁX. (N) &, 058 & 2 & 117 &, 944 \\
\hline
\end{tabular}

${ }^{\mathrm{a}}$ Especie $=$ Pino

En el test de ANOVA (cuadro 5.70), se observa que existen diferencias significativas entre las distintas ubicaciones para el pino en relación a la carga máxima, por lo que se procede a llevar a un cabo análisis 


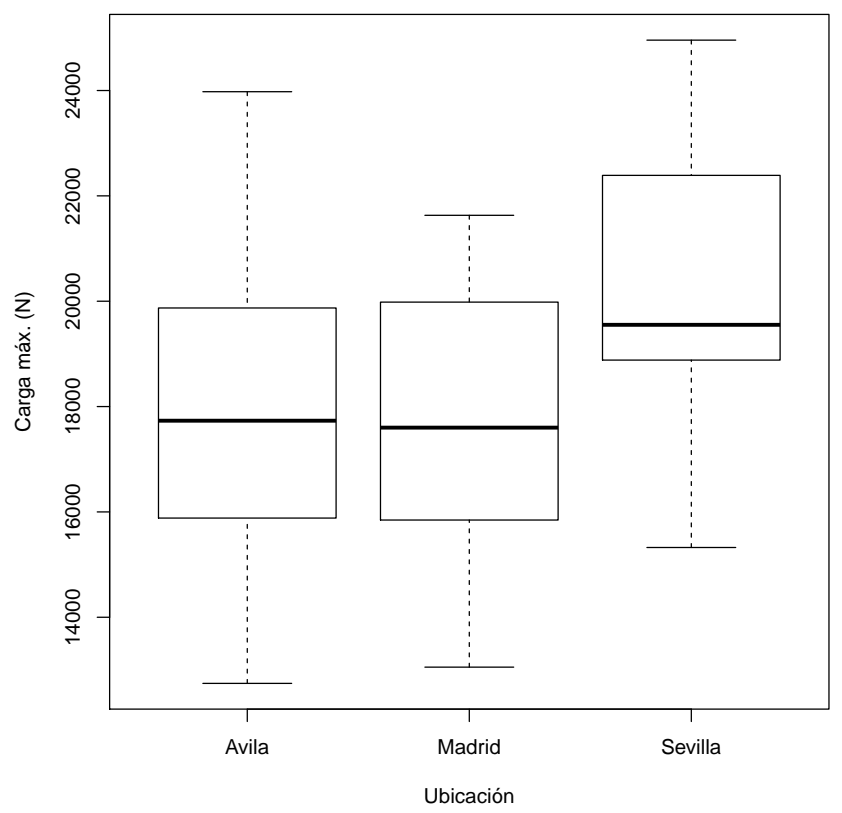

Figura 5.15: Diagramas de caja y bigotes de la carga máxima en función de la ubicación para el pino

Cuadro 5.70: Test ANOVA de la carga máxima por ubicación ${ }^{2}$

\begin{tabular}{llrrrrr}
\hline & & Sum of Squares & df & Mean Square & F & Sig. \\
\hline & Between Croups & 136393340,974 & 2 & 68196670,487 & 11,649 &, 000 \\
\cline { 2 - 7 } CARCA MÁX. (N) & Within Groups & 684976419,223 & 117 & 5854499,310 & & \\
\cline { 2 - 7 } & Total & 821369760,197 & 119 & & \\
\hline
\end{tabular}

${ }^{\mathrm{a}}$ Especie $=$ Pino

de comparación múltiple de Bonferroni.

Según muestra el cuadro 5.71, en el análisis de Bonferroni, la ubicación que produce esta diferencia significativa es Sevilla, y según los valores de la tabla no solo es diferente, sino que es mejor en términos de carga máxima. En la figura 5.16 se muestran gráficamente los intervalos de confianza del $95 \%$ de las diferencias entre medias de las distintas ubicaciones.

\subsection{Delaminación pino}

Para evaluar la delaminación, se plantean varios modelos en los que se contrastan los efectos principales, Ubicación (Referencia como control, Madrid, Ávila y Sevilla) y Orientación (Norte, Sur, Este y Oeste). El mejor modelo según su AIC (bondad de ajuste a través del índice de Akaike), es aquel que presenta Ubicación como efecto principal y Orientación como efecto jerarquizado a Ubicación. Los test de efectos del modelo aparecen en el cuadro 5.72 
Cuadro 5.71: Análisis de comparación múltiple de Bonferroni de la carga máxima por ubicación ${ }^{a}$ Bonferroni

\begin{tabular}{|c|c|c|c|c|c|c|c|}
\hline \multirow{2}{*}{ Dependent Var. } & \multirow{2}{*}{ (I) Ubic. } & \multirow{2}{*}{ (]) Ubic. } & \multirow{2}{*}{ Mean Diff. (I-J) } & \multirow{2}{*}{ Std. Err. } & \multirow{2}{*}{ Sig. } & \multicolumn{2}{|c|}{$95 \%$ Conf. Int. } \\
\hline & & & & & & Lower B. & Upper B. \\
\hline \multirow{6}{*}{ CARGA MÁX. (N) } & \multirow{2}{*}{ Avila } & Madrid & 195,78500 & 541,04 & 1,000 & $-7118,3424$ & 1509,9124 \\
\hline & & Sevilla & $-2157,324^{*}$ & 541,04 &, 000 & $-3471,4514$ & $-843,1966$ \\
\hline & \multirow{2}{*}{ Madrid } & Avila & $-195,78500$ & 541,04 & 1,000 & $-1509,9124$ & 1118,3424 \\
\hline & & Sevilla & $-2353,109 *$ & 541,04 &, 000 & $-3667,2364$ & $-1038,9816$ \\
\hline & \multirow{2}{*}{ Sevilla } & Avila & $2157,324^{*}$ & 541,04 &, 000 & 843,1966 & 3471,4514 \\
\hline & & Madrid & $2353,109^{*}$ & 541,04 &, 000 & 1038,9816 & 3667,2364 \\
\hline
\end{tabular}

* The mean difference is significant at the 0.05 level.

aspecie $=$ Pino

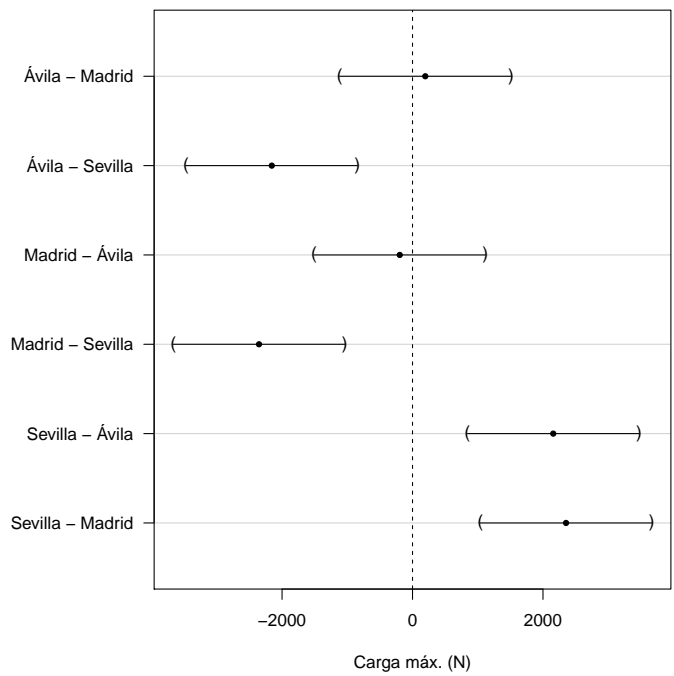

Figura 5.16: Intervalos de confianza del $95 \%$ de las diferencias de medias de carga máxima entre las distintas ubicaciones para el pino según el análisis de Bonferroni

Según se muestra en el cuadro 5.72, en el caso del pino, la ubicación es un efecto significativo sobre la delaminación, mientras que no puede afirmarse que la orientación influya significativamente, aunque tampoco puede despreciarse su efecto. Por esta razón y para estudiar la posición de la referencia frente a las ubicaciones físicas se construye un efecto mixto ubicación”orientación (13 niveles, Referencia, MadridEste, MadridOeste, etc.) y se plantea un ANOVA, y la realización posterior de un test de comparación múltiple de Dunnet que permita una comparación por pares de la referencia.

Se realiza un test de Levene o de homogeneidad de varianzas (cuadro 5.73), y un test de ANOVA, que muestra diferencias significativas entre las medias debidas al factor principal (UxO) (cuadro 5.74).

Para poder discutir lo que está sucediendo en el pino con respecto a la ubicación y la orientación se 
Cuadro 5.72: Análisis de efectos del modelo de la delaminación frente a la ubicación y a la orientación según ubicación ${ }^{\mathrm{a}}$

\begin{tabular}{lrrr}
\hline \multirow{2}{*}{ Source } & \multicolumn{3}{c}{ Type III } \\
\cline { 2 - 4 } & Wald Chi-Square & df & Sig. \\
\hline (Intercept) & 5381,622 & 1 &, 000 \\
\hline UBICACION & 28,910 & 3 &, 000 \\
\hline ORIENTACION(UBICACION) & 14,761 & 9 &, 098 \\
\hline Dependent Variable: tDELAMINACION & & \\
Model: (Intercept), UBICACION, ORIENTACION(UBICACION) \\
a Especie = Pino
\end{tabular}

Cuadro 5.73: Prueba de homogeneidad de varianza de Levene de la delaminación por ubicación y orientación según ubicación $^{\mathrm{a}}$

\begin{tabular}{lrrrr}
\hline & Levene Statistic & df1 & df2 & Sig. \\
\hline tDELAMINACION & 2,892 & 12 & 117 &, 002 \\
\hline a Especie = Pino & & & &
\end{tabular}

Cuadro 5.74: Test ANOVA de la delaminación por ubicación y orientación según ubicación ${ }^{2}$

\begin{tabular}{rlrrrrr}
\hline & & Sum of Squares & df & Mean Square & $F$ & Sig. \\
\hline \multirow{3}{*}{ tDELAMINACION } & Between Croups & 1,516 & 12 &, 126 & 3,275 &, 000 \\
\cline { 2 - 7 } & Within Groups & 4,514 & 117 &, 039 & & \\
\cline { 2 - 7 } & Total & 6,030 & 129 & & & \\
\hline
\end{tabular}

${ }^{\mathrm{a}}$ Especie $=$ Pino

realiza un análisis de comparación múltiple de Dunnett, en el que se analizan todas las ubicaciones con sus respectivas orientaciones frente a la referencia.

Como se observa en el cuadro 5.75, según el análisis de Dunnett, la orientación no tiene influencia en la delaminación, excepto en el caso de Madrid Sury con un valor muy bajo. En la figura 5.17 se muestran los intervalos de confianza correspondientes a las diferencias de medias de este análisis.

Los resultados anteriores están referenciados a un control. En los análisis siguientes se trata de profundizar en las posibles diferencias que pueda haber en cada una de las Ubicaciones en función de la Orientación, en este caso sin tener en cuenta el valor de referencia o control mencionado anteriormente. Para ello se procede a llevar a cabo un análisis de las diferentes ubicaciones sin tener en cuenta a la referencia.

\section{Ávila}

En primer lugar se lleva a cabo un test de Levene o de homogeneidad de la varianza (cuadro 5.76), y tras comprobar la homogeneidad de la muestra, se lleva a cabo un test de ANOVA, que compara cada una 
Cuadro 5.75: Análisis de comparación múltiple de Dunnett de la delaminación por ubicación y orientación ${ }^{\text {b }}$ Dunnett t (2-sided) $)^{2}$

\begin{tabular}{lllrrrrr}
\hline \multirow{2}{*}{ Dependent Var. } & (I) obi_ori & (J) obi_ori & Mean Diff. (I-J) & Std. Err. & Sig. & \multicolumn{2}{c}{$95 \%$ Conf. Int. } \\
\cline { 6 - 8 } & & & & & & Lower B. & Upper B. \\
\hline & Avila oeste & Referencia &,- 04582 &, 08784 & 1,000 &,- 2929 &, 2012 \\
& Avila norte & Referencia &, 12259 &, 08784 &, 727 &,- 1244 &, 3696 \\
& Avila sur & Referencia &,- 06924 &, 08784 &, 991 &,- 3163 &, 1778 \\
& Avila este & Referencia &,- 05765 &, 08784 &, 998 &,- 3047 &, 1894 \\
& Madrid oeste & Referencia &,- 21350 &, 08784 &, 127 &,- 4605 &, 0335 \\
tDELAMINACION & Madrid norte & Referencia &,- 21939 &, 08784 &, 109 &,- 4664 &, 0276 \\
& Madrid sur & Referencia & $-0,27788^{*}$ &, 08784 &, 019 &,- 5249 &,- 0308 \\
& Madrid este & Referencia &,- 16035 &, 08784 &, 471 &,- 4074 &, 0867 \\
& Sevilla oeste & Referencia &,- 21571 &, 08784 &, 120 &,- 4627 &, 0313 \\
& Sevilla norte & Referencia &,- 07920 &, 08784 &, 975 &,- 3262 &, 1678 \\
& Sevilla sur & Referencia &,- 06479 &, 08784 &, 995 &,- 3718 &, 1822 \\
& Sevilla este & Referencia &,- 20807 &, 08784 &, 146 &,- 4551 &, 0390 \\
\hline
\end{tabular}

${ }^{a}$ Dunnett t-tests treat one group as a control, and compare all other groups against it.

* The mean difference is significant at the 0.05 level.

${ }^{\mathrm{b}}$ Especie $=$ Pino

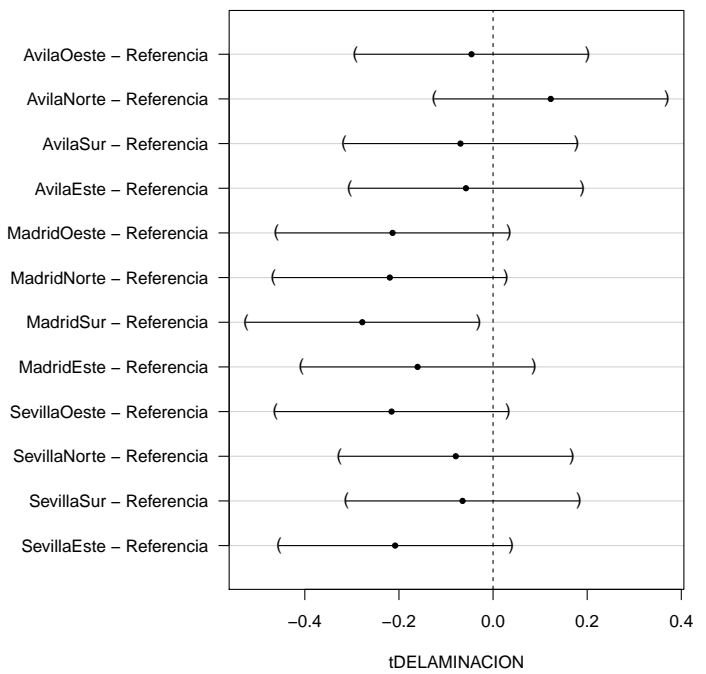

Figura 5.17: Intervalos de confianza del $95 \%$ de las diferencias de medias de delaminación para el pino según el análisis de Dunnett

de las orientaciones entre ellas dentro de la misma ubicación (cuadro 5.77).

En el test de ANOVA, se observa que no existen diferencias significativas entre las distintas orientaciones para el pino en la ubicación de Ávila, por lo que no se procede a llevar otro tipo de análisis. 
Cuadro 5.76: Prueba de homogeneidad de varianza de Levene de la delaminación por orientación ${ }^{\mathrm{a}}$

\begin{tabular}{rrrrr}
\hline & Levene Statistic & df1 & df2 & Sig. \\
\hline tDELAMINACION & 2,620 & 3 & 36 &, 066 \\
\hline
\end{tabular}

${ }^{\mathrm{a}}$ Especie $=$ Pino, Ubicación $=$ Avila

Cuadro 5.77: Test ANOVA de la delaminación por orientación ${ }^{a}$

\begin{tabular}{rlrrrrr}
\hline & & Sum of Squares & df & Mean Square & F & Sig. \\
\hline \multirow{3}{*}{ tDELAMINACION } & Between Groups &, 246 & 3 &, 082 & 1,857 &, 154 \\
\cline { 2 - 7 } & Within Groups & 1,591 & 36 & \multirow{2}{*}{, 044} & \\
\cline { 2 - 7 } & Total & 1,837 & 39 & & & \\
\hline
\end{tabular}

${ }^{a}$ Especie $=$ Pino, Ubicación = Avila

\section{Madrid}

En primer lugar se lleva a cabo un test de Levene o de homogeneidad de la varianza (cuadro 5.78), y tras comprobar la homogeneidad de la muestra, se lleva a cabo un test de ANOVA que compara cada una de las orientaciones entre ellas dentro de la misma ubicación (cuadro 5.79).

Cuadro 5.78: Prueba de homogeneidad de varianza de Levene de la delaminación por orientación ${ }^{a}$

\begin{tabular}{rrrrr}
\hline & Levene Statistic & df1 & df2 & Sig. \\
\hline tDELAMINACION &, 555 & 3 & 36 &, 648 \\
\hline
\end{tabular}

${ }^{a}$ Especie $=$ Pino, Ubicación $=$ Madrid

Cuadro 5.79: Test ANOVA de la delaminación por orientación ${ }^{\mathrm{a}}$

\begin{tabular}{rlrrrrr}
\hline & & Sum of Squares & df & Mean Square & F & Sig. \\
\hline \multirow{3}{*}{ tDELAMINACION } & Between Croups &, 069 & 3 &, 023 & 1,323 &, 282 \\
\cline { 2 - 7 } & Within Groups &, 629 & 36 &, 017 & \\
\cline { 2 - 7 } & Total &, 698 & 39 & & & \\
\hline
\end{tabular}

${ }^{a}$ Especie $=$ Pino, Ubicación = Madrid

En el test de ANOVA, se observa que no existen diferencias significativas entre las distintas orientaciones para el pino en la ubicación de Madrid, por lo que no se procede a llevar a cabo otro tipo de análisis.

Sevilla

En primer lugar se lleva a cabo un test de Levene o de homogeneidad de la varianza (cuadro 5.80), y tras comprobar la homogeneidad de la muestra, se lleva a cabo un test de ANOVA que compara cada una de las orientaciones entre ellas dentro de la misma ubicación (cuadro 5.81). 
Cuadro 5.80: Prueba de homogeneidad de varianza de Levene de la delaminación por orientación ${ }^{\mathrm{a}}$

\begin{tabular}{rrrrr}
\hline & Levene Statistic & df1 & df2 & Sig. \\
\hline tDELAMINACION & 2,412 & 3 & 36 &, 083 \\
\hline
\end{tabular}

${ }^{a}$ Especie $=$ Pino, Ubicación $=$ Sevilla

Cuadro 5.81: Test ANOVA de la delaminación por orientación ${ }^{2}$

\begin{tabular}{rlrrrrr}
\hline & & Sum of Squares & df & Mean Square & F & Sig. \\
\hline \multirow{3}{*}{ tDELAMINACION } & Between Groups &, 197 & 3 &, 066 & 1,233 &, 312 \\
\cline { 2 - 7 } & Within Groups & 1,918 & 36 &, 053 & & \\
\cline { 2 - 7 } & Total & 2,115 & 39 & & & \\
\hline
\end{tabular}

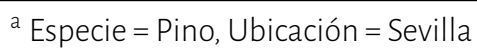

En el test de ANOVA, se observa que no existen diferencias significativas entre las distintas orientaciones para el pino en la ubicación de Sevilla, por lo que no se procede a llevar a cabo otro tipo de análisis.

Por último y para confirmar si existe alguna ubicación preferente para el pino en relación a la delaminación, se toman como muestra todos los datos de cada ubicación, es decir incluyendo las cuatro orientaciones, y se llevan a cabo análisis para valorar este efecto.

Cuadro 5.82: Valores descriptivos de la delaminación por ubicación ${ }^{2}$

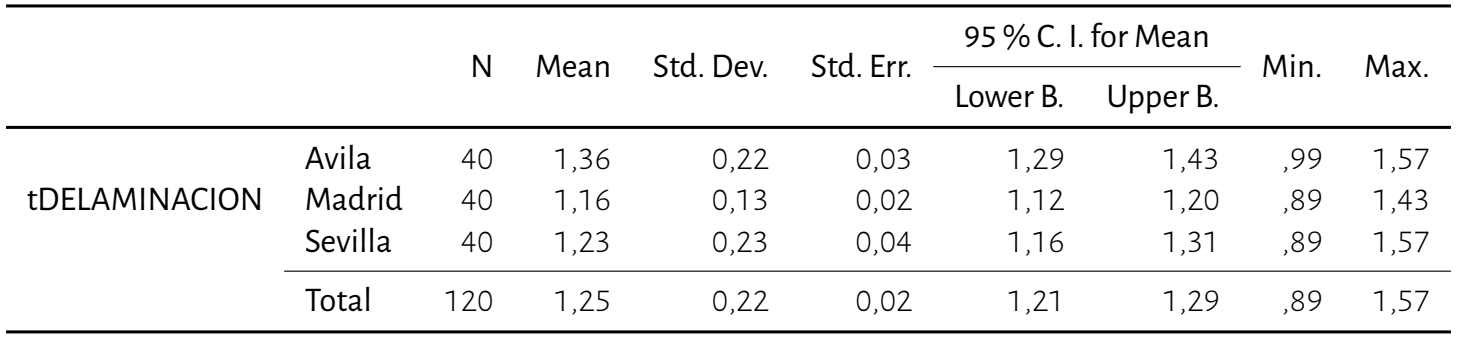

${ }^{\mathrm{a}}$ Especie $=$ Pino

En el cuadro 5.82 se observan los datos de cada ubicación con sus correspondientes valores de media, desviación estándar, etc., que caracterizan la muestra analizada y en la figura 5.18 sus diagramas de caja y bigotes.

Cuadro 5.83: Prueba de homogeneidad de varianza de Levene de la delaminación por ubicación ${ }^{\text {a }}$

\begin{tabular}{rrrrr}
\hline & Levene Statistic & df1 & df2 & Sig. \\
\hline tDELAMINACION & 12,163 & 2 & 117 &, 000 \\
\hline
\end{tabular}

${ }^{\mathrm{a}}$ Especie $=$ Pino

En el test de ANOVA (cuadro 5.84), se observa que existen diferencias significativas entre las distintas ubicaciones para el abeto en relación a la delaminación, por lo que se procede a llevar a cabo un análisis de comparación múltiple de Tamhane. 


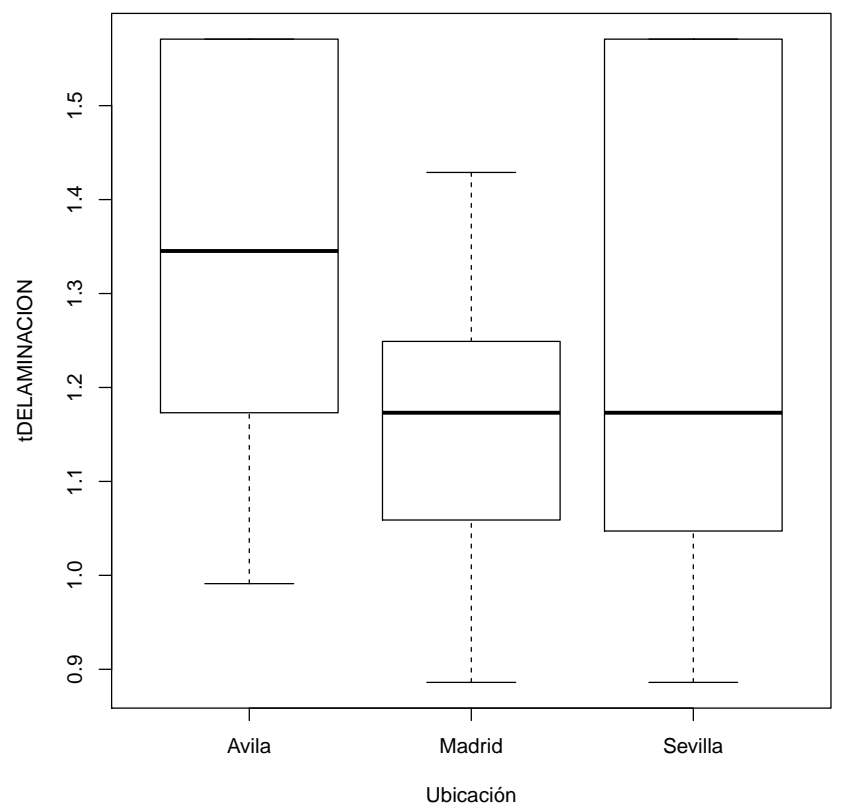

Figura 5.18: Diagramas de caja y bigotes de la delaminación por ubicación para el pino

Cuadro 5.84: Test ANOVA de la delaminación por ubicación ${ }^{2}$

\begin{tabular}{rlrrrrr}
\hline & Sum of Squares & df & Mean Square & F & Sig. \\
\hline \multirow{3}{*}{ tDELAMINACION } & Between Croups &, 862 & 2 &, 431 & 10,840 &, 000 \\
\cline { 2 - 7 } & Within Croups & 4,650 & 117 &, 040 & & \\
\cline { 2 - 7 } & Total & 5,512 & 119 & & & \\
\hline
\end{tabular}

${ }^{\mathrm{a}}$ Especie $=$ Pino

Según muestra el cuadro 5.85, en el análisis de comparación múltiple de Tamhane, la ubicación que produce esta diferencia significativa es Ávila, y según los valores de la tabla no solo es diferente, sino que es mejor en términos de delaminación.

\subsubsection{Resumen de los resultados del CLT de pino}

Según el análisis descriptivo, teniendo en cuenta los dos parámetros, no existe una orientación peor de forma general. De forma puntual con respecto a la carga máxima la peor orientación sería la OESTE, y con respecto a la delaminación sería la SUR. Atendiendo a las ubicaciones, la mejor en términos de delaminación sería ÁVILA y en términos de carga máxima sería SEVILLA.

Teniendo en cuenta el análisis de contraste de hipótesis, se observa que no se puede afirmar que haya influencia de la orientación en términos de delaminación ni de carga máxima. Atendiendo a las ubicaciones, el análisis de contraste de hipótesis confirma estadísticamente el resultado del análisis des- 
Cuadro 5.85: Análisis de comparación múltiple de Tamhane de la delaminación por ubicación ${ }^{2}$ Tamhane

\begin{tabular}{|c|c|c|c|c|c|c|c|}
\hline \multirow{2}{*}{ Dependent Var. } & \multirow{2}{*}{ (I) Ubic. } & \multirow{2}{*}{ (J) Ubic. } & \multirow{2}{*}{ Mean Diff. (I-J) } & \multirow{2}{*}{ Std. Err. } & \multirow{2}{*}{ Sig. } & \multicolumn{2}{|c|}{$95 \%$ Conf. Int. } \\
\hline & & & & & & Lower B. & Upper B. \\
\hline \multirow{6}{*}{ tDELAMINACION } & \multirow{2}{*}{ Avila } & Madrid & $0,205^{*}$ &, 040 &, 000 & , 106 & ,304 \\
\hline & & Sevilla & $0,129^{*}$ &, 050 &, 036 &, 007 &, 252 \\
\hline & \multirow{2}{*}{ Madrid } & Avila & $-0,205^{*}$ &, 040 &, 000 &,- 304 &,- 106 \\
\hline & & Sevilla & $-0,076$ &, 042 &, 219 &,- 180 &, 028 \\
\hline & \multirow{2}{*}{ Sevilla } & Avila & $-0,129 *$ &, 050 &, 036 &,- 252 &,- 007 \\
\hline & & Madrid & 0,076 &, 042 & ,219 &,- 028 &, 180 \\
\hline
\end{tabular}

* The mean difference is significant at the 0.05 level.

${ }^{\mathrm{a}}$ Especie $=$ Pino

criptivo con Ávila como mejor ubicación en términos de delaminación, y Sevilla en términos de carga máxima.

\subsection{Análisis del envejecimiento artificial}

Tras la primera aproximación llevada a cabo en el análisis general de los envejecimientos, en la que se han comparado los valores de referencia con los valores obtenidos para el abeto en todos los métodos de envejecimiento aplicados. Al igual que se ha hecho con el envejecimiento natural, se procede a un análisis más específico, centrando este análisis en el envejecimiento artificial.

Con esta intercomparación, se trata de evaluar las diferencias entre los distintos métodos de envejecimiento, y dentro de cada tipo de envejecimiento entre sus dos modalidades, y comprobar el efecto que cada uno tiene sobre la degradación del CLT.

\subsubsection{Resultados para el abeto (Picea abies)}

A continuación se lleva a cabo un análisis descriptivo del envejecimiento artificial en el que se comparan los resultados obtenidos los dos métodos de envejecimiento aplicados con sus dos modalidades con la referencia, para poder ver que está sucediendo en cada uno de los métodos, y si afectan o no las modalidades, y un segundo análisis de contraste de hipótesis para ver la representatividad estadística de los resultados.

En el análisis de contraste de hipótesis se harán comparaciones con la referencia para evaluar la degradación, y sin la referencia para analizar las diferencias que existen entre los métodos aplicados y poder evaluar la degradación en cada uno de ellos. 


\subsubsection{Análisis descriptivo FCBA}

Al observar los datos resultantes del envejecimiento llevado a cabo en las muestras de abeto tras el envejecimiento realizado en el FCBA mediante la Ageing Wheel (cuadro 5.86 y cuadro 5.87), se puede ver que la delaminación no depende del envejecimiento, ya que en el ciclo largo que debería ser mayor, en este caso no lo es, y además tampoco se observa influencia en la carga máxima. Aunque parece superior en el ciclo largo, se puede decir que simplemente no le afecta el envejecimiento, y que esta variación se puede deber a la variabilidad de la desviación estándar.

Cuadro 5.86: FCBA ciclo corto abeto

\begin{tabular}{lcccc}
\hline MEDIDA & CARCA MÁX. (N) & DESP. MÁX. (mm) & MÓDULO (Mpa) & DELAMINACIÓN (\%) \\
\hline Media & 10039,47 & 0,99 & 117,44 & 85,00 \\
\hline Desv. Estan. & 1764,22 & 0,12 & 13,64 & 8,49 \\
\hline \multicolumn{5}{c}{ Cuadro 5.87: FCBA ciclo largo abeto } \\
\hline MEDIDA & CARGA MÁX. (N) & DESP. MÁX. (mm) & MÓDULO (Mpa) & DELAMINACIÓN (\%) \\
\hline Media & 12251,68 & 1,12 & 126,23 & 91,00 \\
\hline Desv. Estan. & 2867,78 & 0,11 & 17,47 & 8,10 \\
\hline
\end{tabular}

Por tanto en este caso vemos que el envejecimiento aplicado no afecta a las muestras en términos de delaminación si lo comparamos con las muestras de referencia, y si afecta en la pérdida de propiedades estructurales, aunque no se puede afirmar que aumentar la duración del ciclo en este caso tenga algún efecto.

\subsubsection{Análisis descriptivo del método INIA}

A la vista de los datos resultantes del envejecimiento llevado a cabo en las muestras de abeto tras el envejecimiento realizado en el INIA mediante cámara climática (cuadro 5.88 y cuadro 5.89), se puede ver que ni la delaminación ni los valores de la resistencia a la tracción perpendicular, se ven significativamente influidas por la duración del tratamiento de envejecimiento en cámara. Este resultado es compatible con las reiteradas observaciones de campo según las cuales el grueso de las degradaciones por fendas se produce durante los primeros tiempos de la exposición.

Cuadro 5.88: INIA ciclo corto abeto

\begin{tabular}{lcccc}
\hline MEDIDA & CARCA MÁX. (N) & DESP. MÁX. (mm) & MÓDULO (Mpa) & DELAMINACIÓN (\%) \\
\hline Media & 7643,66 & 0,76 & 116,45 & 76,50 \\
\hline Desv. Estan. & 1831,95 & 0,14 & 14,31 & 18,57 \\
\hline
\end{tabular}

Sin embargo, en este caso vemos que el envejecimiento aplicado afecta a las muestras en términos de propiedades estructurales si lo comparamos con las muestras de referencia, y también afecta en términos de delaminación. No se puede afirmar que haya diferencias al aplicar los dos ciclos, pero sí que se 
Cuadro 5.89: INIA ciclo largo abeto

\begin{tabular}{lcccc}
\hline MEDIDA & CARGAMÁX. (N) & DESP. MÁX. (mm) & MÓDULO (Mpa) & DELAMINACIÓN (\%) \\
\hline Media & 7693,04 & 0,82 & 111,22 & 77,50 \\
\hline Desv. Estan. & 1237,67 & 0,09 & 12,33 & 5,89 \\
\hline
\end{tabular}

produce una pérdida notable en términos de resistencia estructural y de delaminación al aplicar este método de envejecimiento. Cabe plantearse en este caso siendo este el tipo de ensayo para caracterizar el material, si sería apto para el uso, aunque como producto al ser superior al 70 \% sería apto.

\subsubsection{Análisis de contraste de hipótesis}

Para ver cuáles de los resultados obtenidos en el análisis descriptivo son estadísticamente representativos del comportamiento que están teniendo las muestras de CLT de abeto, se lleva a cabo un análisis de contraste de hipótesis.

\subsection{Carga máxima}

Con el objeto de comprobar si hay diferencias en la carga máxima según el método de envejecimiento empleado se procede en primer lugar a realizar un test de Levene o de homogeneidad de la varianza, para comprobar la homogeneidad de la varianza de los datos analizados (cuadro 5.90) y posteriormente llevar a cabo un test de ANOVA.

Cuadro 5.90: Prueba de homogeneidad de varianza de Levene de la carga máxima por tipo de envejecimiento ${ }^{2}$

\begin{tabular}{rrrrr}
\hline & Levene Statistic & df1 & df2 & Sig. \\
\hline CARGA MÁX. (N) & 4,257 & 4 & 45 &, 005 \\
\hline
\end{tabular}

a Especie $=$ Abeto

Cuadro 5.91: Test ANOVA de la carga máxima por tipo de envejecimiento ${ }^{2}$

\begin{tabular}{lllrrrr}
\hline & & Sum of Squares & df & Mean Square & F & Sig. \\
\hline \multirow{3}{*}{ CARGA MÁX. (N) } & Between Groups & 327064230,734 & 4 & 81766057,683 & 23,011 &, 000 \\
\cline { 2 - 7 } & Within Groups & 159903012,666 & 45 & 3553400,281 & & \\
\cline { 2 - 7 } & Total & 486967243,400 & 49 & & \\
\hline
\end{tabular}

${ }^{\text {a }}$ Especie $=$ Abeto

Según muestra el test de ANOVA (cuadro 5.91), existen diferencias significativas entre los diferentes métodos de envejecimiento aplicados para la delaminación del CLT de abeto. Para profundizar en estas diferencias se decide llevar a cabo un análisis de comparación múltiple de Dunnett.

Según el análisis de Dunnett (cuadro 5.92), las diferencias que se mostraban en el test de ANOVA en el caso de la carga máxima son causadas por todos los métodos de envejecimiento excepto por el llevado 
Cuadro 5.92: Análisis de comparación múltiple de Dunnett de la carga máxima por tipo de envejecimiento ${ }^{\text {b }}$ Dunnett t (2-sided) $)^{\mathrm{a}}$

\begin{tabular}{|c|c|c|c|c|c|c|c|}
\hline \multirow{2}{*}{ Dependent Var. } & \multirow{2}{*}{ (I) Ubic. } & \multirow{2}{*}{ (J) Ubic. } & \multirow{2}{*}{ Mean Diff. (I-J) } & \multirow{2}{*}{ Std. Err. } & \multirow{2}{*}{ Sig. } & \multicolumn{2}{|c|}{$95 \%$ Conf. Int. } \\
\hline & & & & & & Lower B. & Upper B. \\
\hline \multirow{4}{*}{ CARGA MÁX. (N) } & FCBA Corto & Referencia & $-4132,887^{*}$ & 843,0184 &, 000 & $-6266,8204$ & $-1998,9536$ \\
\hline & FCBA Largo & Referencia & $-1920,668$ & 843,0184 &, 089 & $-4054,6014$ & 213,2654 \\
\hline & INIA Corto & Referencia & $-6528,695^{*}$ & 843,0184 &, 000 & $-8662,6284$ & $-4394,7616$ \\
\hline & INIA Largo & Referencia & $-6479,310^{*}$ & 843,0184 &, 000 & $-8613,2434$ & $-4345,3766$ \\
\hline
\end{tabular}

a cabo en el FCBA en su modalidad de ciclo largo, ya que en todos excepto en este último se muestran pérdidas significativas de carga máxima con respecto a los valores de referencia, o lo que es lo mismo, en todos excepto en este se produce degradación en términos de carga máxima.

A la vista de los resultados obtenidos, en el caso del abeto se encuentran diferencias significativas entre los distintos tipos de envejecimiento y la referencia, hay diferencias entre todos los tipos de envejecimiento excepto en el caso del FCBA en su modalidad de ciclo largo. Se puede afirmar a la luz de estos datos que los tipos de envejecimiento aplicados al abeto le afectan en términos de carga máxima, excepto en el envejecimiento llevado a cabo en el FCBA en su modalidad de ciclo largo, en el que la pérdida de capacidad resistente en términos de carga máxima no es significativa.

Para poder profundizar un poco más en lo que está sucediendo en los diferentes métodos de envejecimiento en el abeto en materia de carga máxima, se procede a llevar a cabo otros análisis excluyendo de estos la referencia.

Cuadro 5.93: Valores descriptivos de la carga máxima por tipo de envejecimiento ${ }^{2}$

\begin{tabular}{|c|c|c|c|c|c|c|c|c|c|}
\hline & & \multirow{2}{*}{$\mathrm{N}$} & \multirow{2}{*}{ Mean } & \multirow{2}{*}{ Std. Dev. } & \multirow{2}{*}{ Std. Err. } & \multicolumn{2}{|c|}{$95 \%$ C. I. for Mean } & \multirow{2}{*}{ Min. } & \multirow{2}{*}{ Max } \\
\hline & & & & & & Lower B. & Upper B. & & \\
\hline & FCBA Corto & 10 & 10039,47 & 1764,22 & 557,90 & 8777,42 & 11301,51 & 7522,34 & 13673,82 \\
\hline CARCA & FCBA Largo & 10 & 12251,68 & 2867,78 & 906,87 & 10200,20 & 14303,17 & 8842,68 & 16585,08 \\
\hline \multirow[t]{3}{*}{ MÁX. (N) } & INIA Corto & 10 & 7643,66 & 1831,95 & 579,31 & 6333,16 & 8954,15 & 5659,68 & 10555,30 \\
\hline & INIA Largo & 10 & 7693,04 & 1237,67 & 391,39 & 6807,67 & 8578,42 & 5560,19 & 9538,59 \\
\hline & Total & 40 & 9406,96 & 2733,52 & 432,21 & 8532,74 & 10281,18 & 5560,19 & 16585,08 \\
\hline
\end{tabular}

${ }^{\mathrm{a}}$ Especie $=$ Abeto

En el cuadro 5.93 se observan los datos de cada envejecimiento con sus correspondientes valores de media, desviación estándar, etc., que caracterizan la muestra analizada.

En el test de ANOVA, observamos que existen diferencias significativas entre los distintos métodos de envejecimiento para el abeto en relación a la carga máxima (cuadro 5.95), y teniendo en cuenta que la muestra no es homogénea (cuadro 5.94) se procede a llevar a cabo análisis de comparación múltiple de Tamhane. 
Cuadro 5.94: Prueba de homogeneidad de varianza de Levene de la carga máxima por tipo de envejecimiento (sin la referencia) $)^{\mathrm{a}}$

\begin{tabular}{rrrrr}
\hline & Levene Statistic & df1 & df2 & Sig. \\
\hline CARGA MÁX. (N) & 4,089 & 3 & 36 &, 013 \\
\hline
\end{tabular}

a Especie $=$ Abeto

Cuadro 5.95: Test ANOVA de la carga máxima por tipo de envejecimiento (sin la referencia) ${ }^{\mathrm{a}}$

\begin{tabular}{lllrrrr}
\hline & & Sum of Squares & df & Mean Square & F & Sig. \\
\hline & Between Groups & 145392695,917 & 3 & 48464231,972 & 11,948 &, 000 \\
\cline { 2 - 7 } CARGA MÁX. (N) & Within Groups & 146020403,395 & 36 & 4056122,317 & & \\
\cline { 2 - 7 } & Total & 291413099,313 & 39 & & & \\
\hline
\end{tabular}

${ }^{\mathrm{a}}$ Especie $=$ Abeto

Cuadro 5.96: Análisis de comparación múltiple de Tamhane de la carga máxima por tipo de envejecimiento artificial Tamhane

\begin{tabular}{|c|c|c|c|c|c|c|c|}
\hline \multirow{2}{*}{ Dependent Var. } & \multirow{2}{*}{ (I) Ubic. } & \multirow{2}{*}{ (J) Ubic. } & \multirow{2}{*}{ Mean Diff. (I-J) } & \multirow{2}{*}{ Std. Err. } & \multirow{2}{*}{ Sig. } & \multicolumn{2}{|c|}{$95 \%$ Conf. Int. } \\
\hline & & & & & & Lower B. & Upper B. \\
\hline \multirow{12}{*}{ CARGA MÁX. (N) } & \multirow{3}{*}{ FCBA Corto } & FCBA Largo & $-2212,22$ & 1064,74 & ,290 & $-5435,26$ & 1010,83 \\
\hline & & INIA Corto & $2395,81^{*}$ & 804,27 & 047 & 20,45 & 4771,17 \\
\hline & & INIA Largo & $2346,42^{*}$ & 681,49 &, 020 & 305,50 & 4387,34 \\
\hline & \multirow{3}{*}{ FCBA Largo } & FCBA Corto & 2212,22 & 1064,74 & ,290 & $-1010,83$ & 5435,26 \\
\hline & & INIA Corto & $4608,03 *$ & 1076,11 & ,004 & 1361,18 & 7854,88 \\
\hline & & INIA Largo & $4558,64^{*}$ & 987,72 &, 003 & 1467,49 & 7649,80 \\
\hline & \multirow{3}{*}{ INIA Corto } & FCBA Corto & $-2395,81^{*}$ & 804,27 & , 047 & $-4771,17$ & $-20,45$ \\
\hline & & FCBA Largo & $-4608,03 *$ & 1076,11 &, 004 & $-7854,88$ & $-1361,18$ \\
\hline & & INIA Largo & $-49,38$ & 699,13 & 1,000 & $-2149,15$ & 2050,38 \\
\hline & \multirow{3}{*}{ INIA Largo } & FCBA Corto & $-2346,42^{*}$ & 681,49 & ,020 & $-4387,34$ & $-305,50$ \\
\hline & & FCBA Largo & $-4558,64^{*}$ & 987,72 & ,003 & $-7649,80$ & $-1467,49$ \\
\hline & & INIA Corto & 49,38 & 699,13 & 1,000 & $-2050,38$ & 2149,15 \\
\hline
\end{tabular}

*The mean difference is significant at the 0.05 level.

${ }^{\mathrm{a}}$ Especie $=$ Abeto

Según muestra el cuadro 5.96, en el análisis de Tamhane, el método de envejecimiento que tiene diferencias significativas es el llevado a cabo en el FCBA en sus dos modalidades con el llevado a cabo en el INIA en sus dos modalidades. Pero más importante que esto es el hecho de que no hay diferencias significativas entre las dos modalidades del método aplicado en el FCBA, ni entre las dos modalidades del método aplicado en el INIA. 


\subsection{Delaminación}

Con el objeto de comprobar si hay diferencias en la delaminación según el método de envejecimiento empleado, se procede en primer lugar a realizar un test de Levene o de homogeneidad de la varianza (cuadro 5.97), para comprobar la homogeneidad de la varianza de los datos analizados, y posteriormente llevar a cabo un test de ANOVA (cuadro 5.98).

Cuadro 5.97: Prueba de homogeneidad de varianza de Levene de la delaminación por tipo de envejecimiento ${ }^{a}$

\begin{tabular}{rrrrr}
\hline & Levene Statistic & df1 & df2 & Sig. \\
\hline tDELAMINACION & 2,575 & 4 & 45 &, 050 \\
\hline
\end{tabular}

${ }^{\mathrm{a}}$ Especie $=$ Abeto

Cuadro 5.98: Test ANOVA de la delaminación por tipo de envejecimiento ${ }^{a}$

\begin{tabular}{|c|c|c|c|c|c|c|}
\hline & & Sum of Squares & $\mathrm{df}$ & Mean Square & $\mathrm{F}$ & Sig. \\
\hline \multirow{3}{*}{ tDELAMINACION } & Between Groups & ,394 & 4 & ,099 & 2,998 & 028 \\
\hline & Within Groups & 1,479 & 45 &, 033 & & \\
\hline & Total & 1,873 & 49 & & & \\
\hline
\end{tabular}

${ }^{a}$ Especie $=$ Abeto

Según muestra el test de ANOVA, existen diferencias significativas entre los diferentes métodos de envejecimiento aplicados en relación a la delaminación del CLT de abeto. Para profundizar en estas diferencias, y teniendo en cuenta la homogeneidad de las varianzas, se decide llevar a cabo un análisis de comparación múltiple de Bonferroni.

Según el análisis de Bonferroni (cuadro 5.99), las diferencias que se mostraban en el test de ANOVA son mínimas, ya que solo hay diferencias entre el envejecimiento llevado a cabo en el FCBA y en el INIA, ambos en su modalidad de ciclo largo, en términos de delaminación, no se presentan más diferencias, ni siquiera con las muestras de referencia.

A la vista de los resultados obtenidos, en el caso del abeto no se encuentran diferencias significativas entre los distintos tipos de envejecimiento y la referencia, por lo que no se produce degradación, y las diferencias entre ellos son mínimas, lo que quiere decir que los tipos de envejecimiento aplicados al abeto no le afectan en términos de delaminación.

Para poder profundizar un poco más en lo que está sucediendo en los diferentes métodos de envejecimiento en el abeto en materia de delaminación, se procede a llevar a cabo otros análisis excluyendo de estos la referencia.

En el cuadro 5.100 se observan los datos de cada envejecimiento con sus correspondientes valores de media, desviación estándar, etc., que caracterizan la muestra analizada.

En el test de ANOVA (cuadro 5.102), observamos que existen diferencias significativas entre los distintos métodos de envejecimiento para el abeto en relación a la delaminación. Teniendo en cuenta la no 
Cuadro 5.99: Análisis de comparación múltiple de Bonferroni de la delaminación por tipo de envejecimiento artificial ${ }^{2}$ Bonferroni

\begin{tabular}{|c|c|c|c|c|c|c|c|}
\hline \multirow{2}{*}{ Dependent Var. } & \multirow{2}{*}{ (I) Ubic. } & \multirow{2}{*}{ (J) Ubic. } & \multirow{2}{*}{ Mean Diff. (I-J) } & \multirow{2}{*}{ Std. Err. } & \multirow{2}{*}{ Sig. } & \multicolumn{2}{|c|}{$95 \%$ Conf. Int. } \\
\hline & & & & & & Lower B. & Upper B. \\
\hline \multirow{20}{*}{ tDELAMINACION } & \multirow{4}{*}{ Referencia } & FCBA Corto &, 00308 & ,08108 & 1,000 &,- 2363 & ,2424 \\
\hline & & FCBA Largo &,- 13183 & ,08108 & 1,000 &,- 3712 & , 1075 \\
\hline & & INIA Corto &, 10721 & ,08108 & 1,000 &,- 1322 & ,3466 \\
\hline & & INIA Largo &, 11001 & ,08108 & 1,000 &,- 1294 & ,3494 \\
\hline & \multirow{4}{*}{ FCBA Corto } & Referencia &,- 00308 & ,08108 & 1,000 &,- 2424 &, 2363 \\
\hline & & FCBA Largo &,- 13490 & ,08108 & 1,000 &,- 3743 & , 1045 \\
\hline & & INIA Corto &, 10413 & ,08108 & 1,000 &,- 1352 & ,3435 \\
\hline & & INIA Largo & ,10693 & ,08108 & 1,000 &,- 1324 & ,3463 \\
\hline & \multirow{4}{*}{ FCBA Largo } & Referencia & ,13183 & ,08108 & 1,000 &,- 1075 & ,3712 \\
\hline & & FCBA Corto & ,13490 & ,08108 & 1,000 &,- 1045 &, 3743 \\
\hline & & INIA Corto & 23903 & ,08108 &, 051 &,- 0003 & ,4784 \\
\hline & & INIA Largo &, $24183^{*}$ & ,08108 & ,046 &, 0025 & ,4812 \\
\hline & \multirow{4}{*}{ INIA Corto } & Referencia &,- 10721 & ,08108 & 1,000 &,- 3466 &, 1322 \\
\hline & & FCBA Corto &,- 10413 & ,08108 & 1,000 &,- 3435 &, 1352 \\
\hline & & FCBA Largo &,- 23903 & ,08108 &, 051 &,- 4784 &, 0003 \\
\hline & & INIA Largo &, 00280 & ,08108 & 1,000 &,- 2366 &, 2422 \\
\hline & \multirow{4}{*}{ INIA Largo } & Referencia &,- 11001 & ,08108 & 1,000 &,- 3494 & , 1294 \\
\hline & & FCBA Corto &,- 10693 & ,08108 & 1,000 &,- 3463 &, 1324 \\
\hline & & FCBA Largo & $-.24183^{*}$ & ,08108 &, 046 &,- 4812 &,- 0025 \\
\hline & & INIA Corto &,- 00280 & , 08108 & 1,000 &,- 2422 &, 2366 \\
\hline
\end{tabular}

*The mean difference is significant at the 0.05 level.

aspecie $=$ Abeto

Cuadro 5.100: Valores descriptivos de la delaminación de los tipos de envejecimiento artificial ${ }^{2}$

\begin{tabular}{|c|c|c|c|c|c|c|c|c|c|}
\hline & & \multirow{2}{*}{$\mathrm{N}$} & \multirow{2}{*}{ Mean } & \multirow{2}{*}{ Std. Dev. } & \multirow{2}{*}{ Std. Err. } & \multicolumn{2}{|c|}{$95 \%$ C. I. for Mean } & \multirow{2}{*}{ Min. } & \multirow{2}{*}{ Max } \\
\hline & & & & & & Lower B. & Upper B. & & \\
\hline \multirow{5}{*}{ tDELAMINACION } & FCBA Corto & 10 & 1,186 &, 1213 &, 0384 & 1,100 & 1,273 & 99 & 1,35 \\
\hline & FCBA Largo & 10 & 1,321 & , 1911 &, 0604 & 1,185 & 1,458 & 1,11 & 1,57 \\
\hline & INIA Corto & 10 & 1,082 & ,2085 &, 0659 & ,933 & 1,231 &, 58 & 1,25 \\
\hline & INIA Largo & 10 & 1,079 &, 0700 &, 0221 & 1,029 & 1,130 & 94 & 1,17 \\
\hline & Total & 40 & 1,167 & , 1817 & ,0287 & 1,109 & 1,225 &, 58 & 1,57 \\
\hline
\end{tabular}

${ }^{a}$ Especie $=$ Abeto

homogeneidad de las varianzas (cuadro 5.101), se procede a llevar a cabo un análisis de comparación múltiple de Tamhane.

Según muestra el cuadro 5.103, en el análisis de Tamhane, el método de envejecimiento que tiene diferencias significativas es el llevado a cabo en el FCBA en su modalidad de ciclo largo con el llevado a 
Cuadro 5.101: Prueba de homogeneidad de varianza de Levene de la delaminación por tipo de envejecimiento (sin la referencia) ${ }^{2}$

\begin{tabular}{rrrrr}
\hline & Levene Statistic & df1 & df2 & Sig. \\
\hline tDELAMINACION & 3,271 & 3 & 36 &, 032 \\
\hline
\end{tabular}

${ }^{a}$ Especie $=$ Abeto

Cuadro 5.102: Test ANOVA de la delaminación por tipo de envejecimiento (sin la referencia) ${ }^{a}$

\begin{tabular}{rlrrrrr}
\hline & Sum of Squares & df & Mean Square & F & Sig. \\
\hline \multirow{2}{*}{ tDELAMINACION } & Between Groups &, 390 & 3 &, 130 & 5,223 &, 004 \\
\cline { 2 - 7 } & Within Croups &, 897 & 36 &, 025 & \\
\cline { 2 - 7 } & Total & 1,287 & 39 & & & \\
\hline
\end{tabular}

a. Especie $=$ Abeto

Cuadro 5.103: Análisis de comparación múltiple de Tamhane de la delaminación por tipo de envejecimiento artificial ${ }^{2}$ Tamhane

\begin{tabular}{|c|c|c|c|c|c|c|c|}
\hline \multirow{2}{*}{ Dependent Var. } & \multirow{2}{*}{ (I) Ubic. } & \multirow{2}{*}{ (J) Ubic. } & \multirow{2}{*}{ Mean Diff. (I-J) } & \multirow{2}{*}{ Std. Err. } & \multirow{2}{*}{ Sig. } & \multicolumn{2}{|c|}{$95 \%$ Conf. Int. } \\
\hline & & & & & & Lower B. & Upper B. \\
\hline \multirow{12}{*}{ tDELAMINACION } & \multirow{3}{*}{ FCBA Corto } & FCBA Largo &,- 135 & 072 & 389 &,- 351 & 081 \\
\hline & & INIA Corto & ,104 & ,076 & ,724 &,- 128 &, 336 \\
\hline & & INIA Largo & ,107 &, 044 & , 165 &,- 028 & 242 \\
\hline & \multirow{3}{*}{ FCBA Largo } & FCBA Corto &, 135 & , 072 & ,389 &,- 081 & 351 \\
\hline & & INIA Corto &, 239 & ,089 & ,090 &,- 025 &, 503 \\
\hline & & INIA Largo &, $242 *$ &, 064 & 018 &, 038 &, 446 \\
\hline & \multirow{3}{*}{ INIA Corto } & FCBA Corto &,- 104 & ,076 &, 724 &,- 336 & , 128 \\
\hline & & FCBA Largo &,- 239 & 089 & ,090 &,- 503 &, 025 \\
\hline & & INIA Largo &, 003 & 070 & 1,000 &,- 219 & 225 \\
\hline & \multirow{3}{*}{ INIA Largo } & FCBA Corto &,- 107 &, 044 &, 165 &,- 242 &, 028 \\
\hline & & FCBA Largo &,$- 242^{*}$ &, 064 & ,018 &,- 446 &,- 038 \\
\hline & & INIA Corto &,- 003 &, 070 & 1,000 &,- 225 &, 219 \\
\hline
\end{tabular}

* The mean difference is significant at the 0.05 level

${ }^{\mathrm{a}}$ Especie $=$ Abeto

cabo en el INIA en la misma modalidad. Pero más importante que esto es el hecho de que no hay diferencias significativas entre las dos modalidades de los envejecimientos llevados a cabo en el FCBAy en el INIA. 


\subsubsection{Resultados para el pino (Pinus sylvestris)}

A continuación se lleva a cabo un análisis descriptivo del envejecimiento artificial en el que se comparan los resultados obtenidos los dos métodos de envejecimiento aplicados con sus dos modalidades con la referencia, para poder ver que está sucediendo en cada uno de los métodos, y si afectan o no las modalidades, y un segundo análisis de contraste de hipótesis para ver la representatividad estadística de los resultados.

En el análisis de contraste de hipótesis se harán comparaciones con la referencia para evaluar la degradación, y sin la referencia para analizar las diferencias que existen entre los métodos aplicados y poder evaluar la degradación en cada uno de ellos.

\subsubsection{Análisis descriptivo del método FCBA}

Al observar los datos resultantes del envejecimiento llevado a cabo en las muestras de pino tras el envejecimiento realizado en el FCBA mediante la Ageing Wheel (cuadro 5.104 y cuadro 5.105), se puede ver que la delaminación no depende del envejecimiento, ya que en el ciclo largo que debería ser mayor en este caso no lo es, y en este caso tampoco se ve influencia en la carga máxima, ya que es superior en el ciclo largo, esto se puede interpretar simplemente como que no le afecta la duración del ciclo de envejecimiento, y que esta variación se puede deber al valor de la desviación estándar.

Cuadro 5.104: FCBA ciclo corto pino

\begin{tabular}{lcccc}
\hline MEDIDA & CARGA MÁX. (N) & DESP. MÁX. (mm) & MÓDULO (Mpa) & DELAMINACIÓN (\%) \\
\hline Media & 16749,19 & 1,62 & 137,47 & 81,00 \\
\hline Desv. Estan. & 1823,84 & 0,49 & 12,72 & 10,73 \\
\hline
\end{tabular}

Cuadro 5.105: FCBA ciclo largo pino

\begin{tabular}{lcccc}
\hline MEDIDA & CARCA MÁX. (N) & DESP. MÁX. (mm) & MÓDULO (Mpa) & DELAMINACIÓN (\%) \\
\hline Media & 19603,80 & 1,66 & 146,20 & 81,70 \\
\hline Desv. Estan. & 1618,75 & 0,18 & 6,81 & 11,83 \\
\hline
\end{tabular}

Por tanto en este caso vemos que el envejecimiento aplicado no afecta a las muestras en términos de propiedades estructurales si lo comparamos con las muestras de referencia, y si afecta en la delaminación, aunque aún con la pérdida de propiedades se puede afirmar que el producto sigue siendo apto, ya que está por encima del $70 \%$ y no se puede afirmar que aumentar la duración del ciclo en este caso tenga algún efecto.

\subsubsection{Análisis descriptivo para el método INIA}

A la vista de los datos resultantes del envejecimiento llevado a cabo en las muestras de pino tras el envejecimiento realizado en el INIA mediante cámara climática (cuadro 5.106 y cuadro 5.107), se puede 
ver que la delaminación no depende del envejecimiento, ya que la diferencia entre las dos modalidades del método no es significativa. En este caso se puede ver influencia en la carga máxima, ya que hay una disminución de capacidad resistente en el ciclo largo. Se puede interpretar que el envejecimiento afecta a la pérdida de propiedades resistentes, aunque esto no se le puede achacar al producto si no al material.

Cuadro 5.106: INIA ciclo corto pino

\begin{tabular}{lcccc}
\hline MEDIDA & CARCA MÁX. (N) & DESP. MÁX. (mm) & MÓDULO (Mpa) & DELAMINACIÓN (\%) \\
\hline Media & 17278,93 & 1,34 & 147,43 & 89,50 \\
\hline Desv. Estan. & 2216,02 & 0,13 & 9,11 & 11,89 \\
\hline
\end{tabular}

Cuadro 5.107: INIA ciclo largo pino

\begin{tabular}{lcccc}
\hline MEDIDA & CARCA MÁX. (N) & DESP. MÁX. (mm) & MÓDULO (Mpa) & DELAMINACIÓN (\%) \\
\hline Media & 15866,58 & 1,29 & 134,55 & 88,50 \\
\hline Desv. Estan. & 2601,03 & 0,15 & 22,61 & 10,55 \\
\hline
\end{tabular}

El envejecimiento aplicado afecta a las muestras en términos de propiedades estructurales si lo comparamos con las muestras de referencia, se observa que en el primer envejecimiento las pérdidas no son significativas y en el segundo son algo mayores, en este caso no se puede garantizar que esta diferencia sea debida a la desviación estándar, como sucedía con el abeto.

\subsubsection{Análisis de contraste de hipótesis}

Para ver cuáles de los resultados obtenidos en el análisis descriptivo son estadísticamente representativos del comportamiento que están teniendo las muestras de CLT de pino, se lleva a cabo un análisis de contraste de hipótesis.

\subsection{Carga máxima}

Con el objeto de comprobar si hay diferencias en la carga máxima según el método de envejecimiento empleado se procede en primer lugar a realizar un test de Levene o de homogeneidad de la varianza (cuadro 5.108), para comprobar la homogeneidad de la varianza de los datos analizados, y posteriormente llevar a cabo un test de ANOVA (cuadro 5.109).

Cuadro 5.108: Prueba de homogeneidad de varianza de Levene de la carga máxima por tipo de envejecimiento ${ }^{a}$

\begin{tabular}{rrrrr}
\hline & Levene Statistic & df1 & df2 & Sig. \\
\hline CARGA MÁX. (N) & 1,115 & 4 & 45 &, 361 \\
\hline
\end{tabular}

\footnotetext{
${ }^{a}$ Especie $=$ Pino
} 
Cuadro 5.109: Test ANOVA de la carga máxima por tipo de envejecimiento ${ }^{\mathrm{a}}$

\begin{tabular}{lllrrrr}
\hline & & Sum of Squares & df & Mean Square & F & Sig. \\
\hline \multirow{3}{*}{ CARGA MÁX. (N) } & Between Groups & 113364733,173 & 4 & 28341183,293 & 7,038 & ,000 \\
\cline { 2 - 7 } & Within Croups & 181209679,999 & 45 & 4026881,778 & & \\
\cline { 2 - 7 } & Total & 294574413,173 & 49 & & & \\
\hline
\end{tabular}

${ }^{a}$ Especie $=$ Pino

Según muestra el test de ANOVA, existen diferencias significativas entre los diferentes métodos de envejecimiento aplicados para la carga máxima del CLT de pino. Para profundizar en estas diferencias, y debido a la homogeneidad de varianzas, se decide llevar a cabo un análisis de comparación múltiple de Bonferroni.

Cuadro 5.110: Análisis de comparación múltiple de Bonferroni de la carga máxima por tipo de envejecimiento artificial ${ }^{2}$ Bonferroni

\begin{tabular}{|c|c|c|c|c|c|c|c|}
\hline \multirow{2}{*}{ Dependent Var. } & \multirow{2}{*}{ (I) Ubic. } & \multirow{2}{*}{ (J) Ubic. } & \multirow{2}{*}{ Mean Diff. (I-J) } & \multirow{2}{*}{ Std. Err. } & \multirow{2}{*}{ Sig. } & \multicolumn{2}{|c|}{$95 \%$ Conf. Int. } \\
\hline & & & & & & Lower B. & Upper B. \\
\hline \multirow{20}{*}{ CARGA MÁX. (N) } & \multirow{4}{*}{ Referencia } & FCBA Corto & $2773,896^{*}$ & 897,428 & 034 & 124,619 & 5423,173 \\
\hline & & FCBA Largo & $-80,713$ & 897,428 & 1,000 & $-2729,990$ & 2568,564 \\
\hline & & INIA Corto & 2244,162 & 897,428 & ,161 & $-405,115$ & 4893,439 \\
\hline & & INIA Largo & $3656,510^{*}$ & 897,428 & 002 & 1007,233 & 6305,787 \\
\hline & \multirow{4}{*}{ FCBA Corto } & Referencia & $-2773,896^{*}$ & 897,428 & 034 & $-5423,173$ & $-124,619$ \\
\hline & & FCBA Largo & $-2854,609^{*}$ & 897,428 & 027 & $-5503,886$ & $-205,332$ \\
\hline & & INIA Corto & $-529,734$ & 897,428 & 1,000 & $-3179,011$ & 2719,543 \\
\hline & & INIA Largo & 882,614 & 897,428 & 1,000 & $-1766,663$ & 3531,891 \\
\hline & \multirow{4}{*}{ FCBA Largo } & Referencia & 80,713 & 897,428 & 1,000 & $-2568,564$ & 2729,990 \\
\hline & & FCBA Corto & $2854,609^{*}$ & 897,428 & 027 & 205,332 & 5503,886 \\
\hline & & INIA Corto & 2324,875 & 897,428 &, 129 & $-324,402$ & 4974,152 \\
\hline & & INIA Largo & $3737,223^{*}$ & 897,428 & ,001 & 1087,946 & 6386,500 \\
\hline & \multirow{4}{*}{ INIA Corto } & Referencia & $-2244,162$ & 897,428 & , 161 & $-4893,439$ & 405,115 \\
\hline & & FCBA Corto & 529,734 & 897,428 & 1,000 & $-2119,543$ & 3179,011 \\
\hline & & FCBA Largo & $-2324,875$ & 897,428 &, 129 & $-4974,152$ & 324,402 \\
\hline & & INIA Largo & 1412,348 & 897,428 & 1,000 & $-1236,929$ & 4061,625 \\
\hline & \multirow{4}{*}{ INIA Largo } & Referencia & $-3656,510^{*}$ & 897,428 &, 002 & $-6305,787$ & $-1007,233$ \\
\hline & & FCBA Corto & $-882,614$ & 897,428 & 1,000 & $-3531,891$ & 1766,663 \\
\hline & & FCBA Largo & $-3737,223^{*}$ & 897,428 &, 001 & $-6386,500$ & $-1087,946$ \\
\hline & & INIA Corto & $-1412,348$ & 897,428 & 1,000 & $-4061,625$ & 1236,929 \\
\hline
\end{tabular}

* The mean difference is significant at the 0.05 level.

${ }^{\mathrm{a}}$ Especie $=$ Pino

Según el análisis de Bonferroni (cuadro 5.110), las diferencias que se mostraban en el test de ANOVA en el caso de la carga máxima son relevantes. En primer lugar se observa que tanto el método de envejecimiento aplicado en el FCBA en su modalidad de ciclo corto, como el aplicado en el INIA en su modalidad de ciclo largo, tienen diferencias significativas con los valores de referencia, lo que quiere 
decir que se produce degradación en estos métodos de envejecimiento en comparación con la referencia. También hay diferencias entre el método aplicado en el FCBA en sus dos modalidades, y el aplicado en el FCBA en su modalidad de ciclo largo y el INIA en su modalidad de ciclo largo.

Para poder profundizar un poco más en lo que está sucediendo en los diferentes métodos de envejecimiento en el pino en materia de carga máxima, se procede a llevar a cabo otros análisis excluyendo de estos la referencia.

Cuadro 5.111: Valores descriptivos de la carga máxima por tipo de envejecimiento artificial (sin la referencia) ${ }^{a}$

\begin{tabular}{|c|c|c|c|c|c|c|c|c|c|}
\hline & & \multirow{2}{*}{$\mathrm{N}$} & \multirow{2}{*}{ Mean } & \multirow{2}{*}{ Std. Dev. } & \multirow{2}{*}{ Std. Err. } & \multicolumn{2}{|c|}{$95 \%$ C. I. for Mean } & \multirow{2}{*}{ Min. } & \multirow{2}{*}{ Max. } \\
\hline & & & & & & Lower B. & Upper B. & & \\
\hline & FCBA Corto & 10 & 16749,19 & 1823,84 & 576,75 & 15444,50 & 18053,89 & 14404,40 & 19806,29 \\
\hline CARGA & FCBA Largo & 10 & 19603,80 & 1618,75 & 511,89 & 18445,82 & 20761,78 & 16497,67 & 21698,95 \\
\hline \multirow[t]{3}{*}{ MÁX. (N) } & INIA Corto & 10 & 17278,93 & 2216,02 & 700,77 & 15693,68 & 18864,17 & 13879,67 & 20788,90 \\
\hline & INIA Largo & 10 & 15866,58 & 2601,03 & 822,52 & 14005,91 & 17727,24 & 11373,79 & 18745,85 \\
\hline & Total & 40 & 17374,62 & 2454,94 & 388,16 & 16589,50 & 18159,75 & 11373,79 & 21698,95 \\
\hline
\end{tabular}

a. Especie $=$ Pino

En el cuadro 5.171 se observan los datos de cada envejecimiento con sus correspondientes valores de media, desviación estándar, etc., que caracterizan la muestra analizada.

Cuadro 5.112: Prueba de homogeneidad de varianza de Levene de la carga máxima por tipo de envejecimiento (sin la referencia) $)^{a}$

\begin{tabular}{rrrrr}
\hline & Levene Statistic & df1 & df2 & Sig. \\
\hline CARGA MÁX. (N) & 1,017 & 3 & 36 &, 396 \\
\hline
\end{tabular}

a Especie $=$ Pino

Cuadro 5.113: Test ANOVA de la carga máxima por tipo de envejecimiento (sin la referencia) ${ }^{a}$

\begin{tabular}{llrrrrr}
\hline & & Sum of Squares & df & Mean Square & F & Sig. \\
\hline \multirow{3}{*}{ CARGA MÁX. (N) } & Between Croups & 76437561,293 & 3 & 25479187,098 & 5,783 &, 002 \\
\cline { 2 - 7 } & Within Groups & 158605400,136 & 36 & 4405705,559 & & \\
\cline { 2 - 6 } & Total & 235042961,428 & 39 & & & \\
\hline
\end{tabular}

${ }^{a}$ Especie $=$ Pino

En el test de ANOVA (cuadro 5.113), observamos que existen diferencias significativas entre los distintos métodos de envejecimiento para el pino en relación a la carga máxima, teniendo en cuenta la homogeneidad de las varianzas (cuadro 5.112) se procede a llevar a cabo análisis de comparación múltiple de Bonferroni.

Según muestra el cuadro 5.114, en el análisis múltiple de Bonferroni, hay diferencias entre el método empleado en el FCBA en sus dos modalidades, lo que quiere decir que en este caso si habría diferencias entre la duración del ciclo. También hay diferencias entre el FCBA y el INIA en su modalidad de ciclo 
Cuadro 5.114: Análisis de comparación múltiple de Bonferroni de la carga máxima por tipo de envejecimiento artificial (sin la referencia) ${ }^{2}$

Bonferroni

\begin{tabular}{|c|c|c|c|c|c|c|c|}
\hline \multirow{2}{*}{ Dependent Var. } & \multirow{2}{*}{ (I) Ubic. } & \multirow{2}{*}{ (J) Ubic. } & \multirow{2}{*}{ Mean Diff. (I-J) } & \multirow{2}{*}{ Std. Err. } & \multirow{2}{*}{ Sig. } & \multicolumn{2}{|c|}{$95 \%$ Conf. Int. } \\
\hline & & & & & & Lower B. & Upper B. \\
\hline \multirow{12}{*}{ CARGA MÁX. (N) } & \multirow{3}{*}{ FCBA Corto } & FCBA Largo & $-2854,61^{*}$ & 938,69 & ,026 & $-5475,41$ & $-233,81$ \\
\hline & & INIA Corto & $-529,73$ & 938,69 & 1,000 & $-3150,53$ & 2091,07 \\
\hline & & INIA Largo & 882,61 & 938,69 & 1,000 & $-1738,19$ & 3503,41 \\
\hline & \multirow{3}{*}{ FCBA Largo } & FCBA Corto & $2854,61 *$ & 938,69 & ,026 & 233,81 & 5475,41 \\
\hline & & INIA Corto & 2324,88 & 938,69 & , 109 & $-295,92$ & 4945,67 \\
\hline & & INIA Largo & $3737,22 *$ & 938,69 &, 002 & 1116,42 & 6358,02 \\
\hline & \multirow{3}{*}{ INIA Corto } & FCBA Corto & 529,73 & 938,69 & 1,000 & $-2091,07$ & 3150,53 \\
\hline & & FCBA Largo & $-2324,88$ & 938,69 & , 109 & $-4945,67$ & 295,92 \\
\hline & & INIA Largo & 1412,35 & 938,69 & ,847 & $-1208,45$ & 4033,15 \\
\hline & \multirow{3}{*}{ INIA Largo } & FCBA Corto & $-882,61$ & 938,69 & 1,000 & $-3503,41$ & 1738,19 \\
\hline & & FCBA Largo & $-3737,22^{*}$ & 938,69 &, 002 & $-6358,02$ & $-7116,42$ \\
\hline & & INIA Corto & $-1412,35$ & 938,69 &, 847 & $-4033,15$ & 1208,45 \\
\hline
\end{tabular}

* The mean difference is significant at the 0.05 level.

${ }^{\text {a }}$ Especie $=$ Pino

largo, lo que quiere decir que estos métodos de envejecimiento no son equivalentes en el caso del pino para evaluar su variable de carga máxima.

\subsection{Delaminación}

Con el objeto de comprobar si hay diferencias en la delaminación según el método de envejecimiento empleado se procede en primer lugar a realizar un test de Levene o de homogeneidad de la varianza (cuadro 5.115), para comprobar la homogeneidad de la varianza de los datos analizados y posteriormente llevar a cabo un test de ANOVA (cuadro 5.116).

Cuadro 5.115: Prueba de homogeneidad de varianza de Levene de la delaminación por tipo de envejecimiento ${ }^{\mathrm{a}}$

\begin{tabular}{lrrrr}
\hline & Levene Statistic & df1 & df2 & Sig. \\
\hline tDELAMINACION & 1,107 & 4 & 45 &, 365 \\
\hline${ }^{a}$ Especie = Pino & & & &
\end{tabular}

Según muestra el test de ANOVA, no existen diferencias significativas entre los diferentes métodos de envejecimiento aplicados para la delaminación del CLT de pino. Por tanto se decide no llevar otro tipo de análisis.

A la vista de los resultados obtenidos, en el caso del pino no se encuentran diferencias significativas entre los distintos tipos de envejecimiento y la referencia, lo que quiere decir que los tipos de envejeci- 
Cuadro 5.116: Test ANOVA de la delaminación por tipo de envejecimiento ${ }^{2}$

\begin{tabular}{llrrrrr}
\hline & & Sum of Squares & df & Mean Square & F & Sig. \\
\hline \multirow{3}{*}{ tDELAMINACION } & Between Groups &, 420 & 4 &, 105 & 2,498 &, 056 \\
\cline { 2 - 7 } & Within Croups & 1,891 & 45 &, 042 & \\
\cline { 2 - 7 } & Total & 2,311 & 49 & & & \\
\hline
\end{tabular}

${ }^{\mathrm{a}}$ Especie $=$ Pino

miento aplicados al pino no le afectan en términos de delaminación, es decir, no se produce envejecimiento en esta materia.

Para poder profundizar un poco más en lo que está sucediendo en los diferentes métodos de envejecimiento en el pino en materia de delaminación, se procede a llevar a cabo otros análisis excluyendo de estos la referencia.

Cuadro 5.117: Valores descriptivos de la delaminación de los tipos de envejecimiento artificial ${ }^{2}$

\begin{tabular}{|c|c|c|c|c|c|c|c|c|c|}
\hline & & \multirow{2}{*}{$\mathrm{N}$} & \multirow{2}{*}{ Mean } & \multirow{2}{*}{ Std. Dev. } & \multirow{2}{*}{ Std. Err. } & \multicolumn{2}{|c|}{95 \% C. I. for Mean } & \multirow{2}{*}{ Min. } & \multirow{2}{*}{ Max. } \\
\hline & & & & & & Lower B. & Upper B. & & \\
\hline \multirow{5}{*}{ tDELAMINACION } & FCBA Corto & 10 & 1,14 &, 15 &, 05 & 1,03 & 1,25 & 94 & 1,40 \\
\hline & FCBA Largo & 10 & 1,16 &, 20 &, 06 & 1,02 & 1,31 &, 94 & 1,57 \\
\hline & INIA Corto & 10 & 1,32 &, 24 &, 08 & 1,15 & 1,49 & 99 & 1,57 \\
\hline & INIA Largo & 10 & 1,29 &, 22 &, 07 & 1,13 & 1,45 & 1,05 & 1,57 \\
\hline & Total & 40 & 1,23 &, 21 &, 03 & 1,16 & 1,30 & 94 & 1,57 \\
\hline
\end{tabular}

${ }^{a}$ Especie $=$ Pino

En el cuadro 5.117 se observan los datos de cada envejecimiento con sus correspondientes valores de media, desviación estándar, etc., que caracterizan la muestra analizada.

Cuadro 5.118: Prueba de homogeneidad de varianza de Levene de la delaminación por tipo de envejecimiento (sin la referencia) ${ }^{a}$

\begin{tabular}{lrrrr}
\hline & Levene Statistic & df1 & df2 & Sig. \\
\hline tDELAMINACION & 1,585 & 3 & 36 &, 210 \\
\hline a Especie = Pino & & & &
\end{tabular}

Cuadro 5.119: Test ANOVA de la delaminación por tipo de envejecimiento (sin la referencia) ${ }^{a}$

\begin{tabular}{rlrrrrr}
\hline & & Sum of Squares & df & Mean Square & F & Sig. \\
\hline \multirow{3}{*}{ tDELAMINACION } & Between Croups &, 244 & 3 &, 081 & 1,930 &, 142 \\
\cline { 2 - 7 } & Within Croups & 1,516 & 36 & \multirow{2}{*}{042} & \\
\cline { 2 - 7 } & Total & 1,759 & 39 & & & \\
\hline
\end{tabular}

${ }^{a}$ Especie $=$ Pino 
En el test de ANOVA (cuadro 5.119), observamos que no existen diferencias significativas entre los distintos métodos de envejecimiento para el pino en relación a la delaminación, por lo que no se procede a llevar a cabo otro tipo de análisis.

Según muestra los resultados del análisis no hay diferencia entre los distintos métodos de envejecimiento con sus respectivas modalidades aplicados en el pino en relación a la delaminación.

\subsection{Análisis de variables climáticas y degradación}

Para poder analizar qué variables climáticas influyen en la degradación del CLT, se ha realizado una comparación de las medias de carga máxima y delaminación con las medias de las diferentes variables climáticas, teniendo en cuenta las tres ubicaciones utilizadas para el estudio del envejecimiento al exterior y sus correspondientes orientaciones.

En primer lugar se realiza un análisis descriptivo de lo que está sucediendo, para posteriormente llevar a cabo un análisis de componentes principales para datos categóricos, y comprobar cuáles de los resultados obtenidos en el análisis descriptivo tiene significación en términos estadísticos.

\subsubsection{Análisis descriptivo de clima y degradación}

En este análisis descriptivo, se procede a evaluar las principales variables climáticas, en relación a la humedad que presenta la madera de cada una de las especies objeto de estudio. Con esto se pretende explicar la humedad que presenta cada una de las maderas en las tres ubicaciones, y poder evaluar cómo se produce su entrada en la madera.

Cuadro 5.120: Medias anuales

\begin{tabular}{lccccc}
\hline Ciudad & Temp Med $\left({ }^{\circ} \mathrm{C}\right)$ & Hum Med $(\%)$ & Precip $(\mathrm{mm})$ & PINO Hp $(\%)$ & ABETO Hp $(\%)$ \\
\hline Ávila & 10,69 & 69,19 & 283,38 & 11,27 & 11,12 \\
Madrid & 14,89 & 62,45 & 316,96 & 9,41 & 9,15 \\
Sevilla & 17,40 & 78,08 & 494,81 & 10,23 & 10,23 \\
\hline
\end{tabular}

En el cuadro 5.120, se presentan los datos climáticos medios anuales de las variables más representativas de cada una de las ubicaciones, con las humedades medias anuales de las maderas de pino y abeto.

A la hora de evaluar la entrada de agua en la madera hay que tener en cuenta diferentes factores. Aunque el aporte de agua que más va a influir en la degradación del material o producto va a ser el agua en forma líquida (Fernández-Colfin et al., 2017), principalmente aportada por la precipitación, hay que tener en cuenta que la precipitación acaecida no siempre es la precipitación efectiva en términos de aporte de agua a la madera.

Como puede deducirse de las figuras 5.19, 5.20 y 5.21, este aporte de agua directo, se verá influenciado por la temperatura, ya que fenómenos como la evaporación hacen que el aporte de agua a la madera sea mayor o menor. Esto se puede ver en los datos, por ejemplo, Ávila es la ubicación que menor 


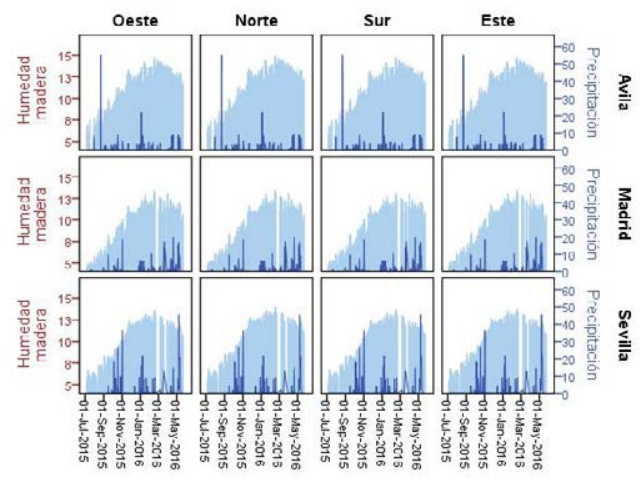

(a) abeto

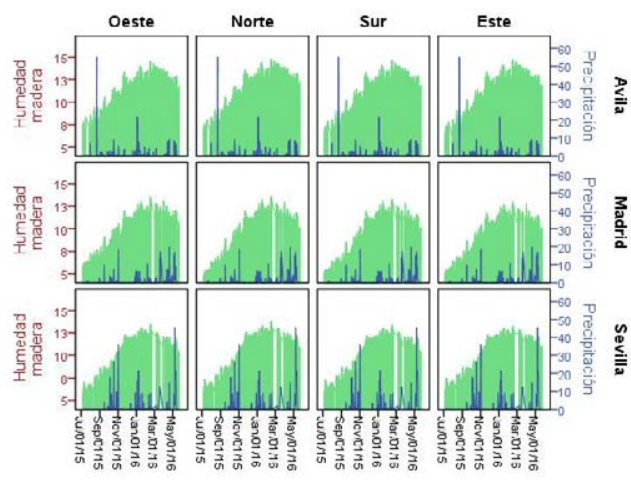

(b) pino

Figura 5.19: Cráficas de precipitación y de humedad de madera de abeto y pino en función de la ubicación

aporte de agua por precipitación tiene, sin embargo debido a su temperatura media, este aporte en términos de precipitación efectiva es mayor, ya que la evaporación del agua es menor, y esto se refleja en la humedad media, que es más alta que en Madrid donde llueve más, pero tiene una mayor temperatura, lo que hace que haya una mayor evaporación, por tanto en Ávila el aporte de agua que se realiza a la madera es mayor. En el caso de Sevilla nos encontramos con una alta precipitación y una alta temperatura, en este caso, la evaporación es muy alta, lo que hace que la humedad ambiental sea alta también, y aunque se produce un aporte de agua a la madera mayor que el de Madrid, no llega a ser tan alto como el de Ávila, puesto que su precipitación efectiva no es tan alta.

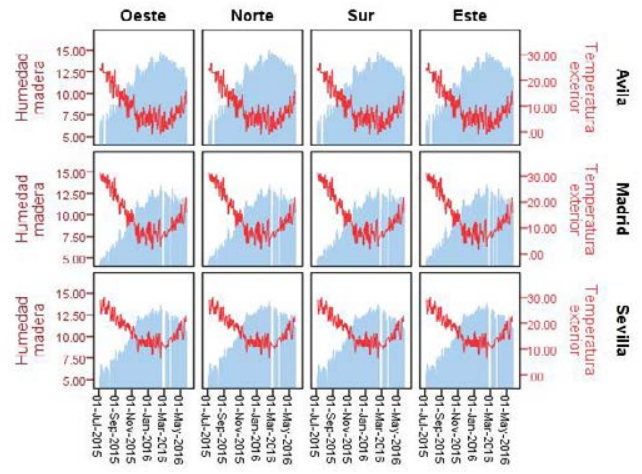

(a) abeto

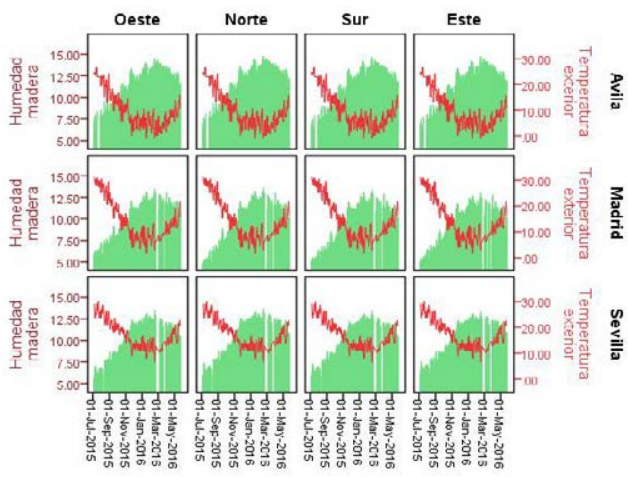

(b) pino

Figura 5.20: Cráficas de temperatura y de humedad de madera de abeto y pino en función de la ubicación

Pero para poder ver lo que está sucediendo a nivel global hay que dar un paso más y evaluar estos datos a la luz de los datos obtenidos en los ensayos de comportamiento estructural.

En el cuadro 5.121, se presentan los datos medios de pérdida de propiedades de carga máxima y dela- 


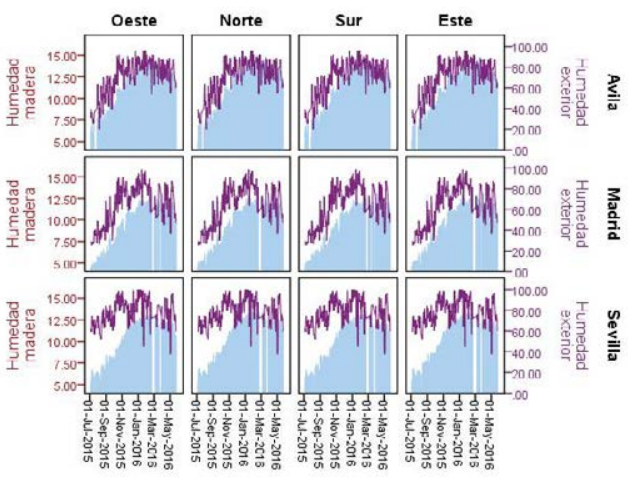

(a) abeto

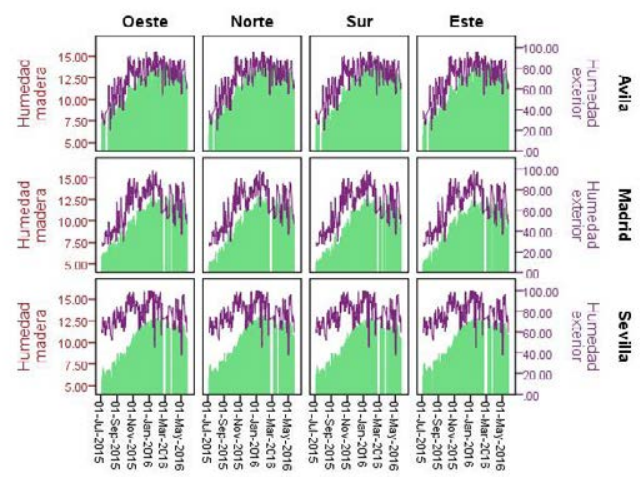

(b) pino

Figura 5.21: Cráficas de humedad exterior y de humedad de madera de abeto y pino en función de la ubicación

Cuadro 5.121: Datos medios de pérdida de propiedades de carga máxima y delaminación

\begin{tabular}{|c|c|c|c|c|c|}
\hline & \multirow{2}{*}{ ORIENTACIÓN } & \multicolumn{2}{|c|}{ ABETO } & \multicolumn{2}{|c|}{ PINO } \\
\hline & & DELAMINACIÓN (\%) & CARGA MÁX. (\%) & DELAMINACIÓN (\%) & CARGA MÁX. (\%) \\
\hline \multirow{2}{*}{ Ávila } & Media & 7,32 & 3,43 & $-1,34$ & $-3,27$ \\
\hline & Desv. Estan. & 6,81 & 10,65 & 4,33 & 5,41 \\
\hline \multirow{2}{*}{ Madrid } & Media & 0,40 & $-19,64$ & $-71,02$ & $-4,33$ \\
\hline & Desv. Estan. & 2,40 & 11,70 & 3,63 & 2,59 \\
\hline \multirow{2}{*}{ Sevilla } & Media & $-0,15$ & $-18,39$ & $-8,74$ & 8,44 \\
\hline & Desv. Estan. & 2,08 & 5,87 & 4,26 & 4,62 \\
\hline
\end{tabular}

minación en forma porcentual, para cada una de las especies objeto de estudio, en las tres ubicaciones evaluadas.

Para poder comparar las dos especies, teniendo en cuenta que parten de valores de referencia muy diferentes, se decide evaluar las pérdidas en tanto por ciento, así de forma relativa, se pueden comparar los resultados obtenidos para las dos especies.

Si tenemos en cuenta lo explicado anteriormente en referencia a las variables climáticas, y como estas influyen en la madera, y analizando las características de cada especie, los datos obtenidos en el cuadro 5.121, se pueden explicar de la siguiente forma:

- En Ávila se obtienen los mejores resultados para delaminación de las dos especies, y para carga máxima del abeto y del pino la segunda mejor. Esto se puede explicar porque aunque la incorporación del agua a la madera en esta ubicación es la mayor de las tres ubicaciones, sin embargo, el gradiente en la humedad que sufren las maderas expuestas al clima de Ávila se produce de una forma muy progresiva, debido a las características climáticas explicadas anteriormente.

- En Sevilla, como se ha comentado, el contenido de agua en la madera es intermedio, teniendo en 
cuenta las tres ubicaciones, y las pérdidas también son intermedias, sus valores de delaminación y carga máxima son valores medios con respecto a las tres ubicaciones. Aquí el gradiente de humedad es mayor que en Ávila, pero menor que en Madrid.

- En Madrid, se dan los peores resultados de las tres ubicaciones, porque a pesar de tener la menor incorporación de agua a la madera, sus características climáticas intermedias hacen que el gradiente de humedad haya sido alto, es decir ha habido mucho movimiento de agua, lo que ha generado estrés por los cambios volumétricos producidos en la madera y esto como consecuencia ha producido mayor degradación del material y del producto

Con respecto a las especies, cabe comentar que como producto, es decir en términos de delaminación, ambas reaccionan bien, algo mejor el caso del abeto, pero con buenos resultados en general. Sin embargo, en ambas especies aparece degradación del material en sí, es decir, aparecen pérdidas en la carga máxima, y por tanto hay pérdida en las propiedades estructurales, y en el caso del abeto, pérdidas importantes. Esto puede ser debido a la diferencia entre estas especies de madera, ya que las mayores pérdidas se producen donde se suponen unos mayores cambios volumétricos, es decir en Sevillay principalmente en Madrid, no así en Ávila.

La diferencia de comportamiento en este aspecto entre especies se atribuye a la elasticidad-plasticidad de cada una, como se explica en el apartado 2.1.3 Comportamiento de la madera, el abeto es una especie más rígida que el pino, y reacciona peor a los cambios de volumen, lo que hace que la degradación de la madera de abeto sea mayor.

\subsubsection{Análisis de componentes principales para datos categóricos abeto}

Una vez visto en el análisis descriptivo lo que está sucediendo con el CLT de abeto y pino en las tres ubicaciones con respeto a la influencia de los factores climáticos que se dan en cada una de las ubicaciones, se procede a llevar a cabo un análisis de componentes principales para datos categóricos para comprobar cuáles de estos resultados tienen significación en términos estadísticos.

Para seleccionar las variables que se van a estudiar, se realiza un análisis previo, en el que se eliminan del análisis variables que o bien no tienen ningún tipo de correlación con los datos objeto de estudio, o su correlación es de 1, por ejemplo, en el caso de la radiación solar y la precipitación, ya que como es habitual en episodios de lluvia la radiación solar es prácticamente inexistente y viceversa.

Cuadro 5.122: Resumen del modelo para el abeto incluyendo la delaminación y la carga máxima

\begin{tabular}{lrrr}
\hline \multirow{2}{*}{ Dimension } & Cronbach's Alpha & \multicolumn{2}{c}{ Variance Accounted For } \\
\cline { 3 - 4 } & & Total (Eigenvalue) & \% of Variance \\
\hline 1 & 0,765 & 2,760 & 45,998 \\
2 & 0,497 & 1,706 & 28,441 \\
\hline Total &, $931^{\text {a }}$ & 4,466 & 74,439 \\
\hline
\end{tabular}

a Total Cronbach's Alpha is based on the total Eigenvalue. 
En el cuadro 5.122, se observa un resumen del modelo analizado, y se muestra que este análisis de componentes principales llevado a cabo para el abeto explica el 74 \% de la varianza; esto cuantifica las interrelaciones de carga máxima, delaminación y las variables climáticas analizadas.

Cuadro 5.123: Matriz de correlaciones de las variables transformadas (para el abeto incluyendo delaminación y carga máxima)

\begin{tabular}{lrrrrrr}
\hline & $\begin{array}{c}\text { H. media } \\
\text { ext. }(\%)\end{array}$ & \multicolumn{1}{c}{$\begin{array}{c}\text { Precip. } \\
(\mathrm{mm})\end{array}$} & $\begin{array}{c}\text { Ta media } \\
\text { ext. }\end{array}$ & $\begin{array}{c}\text { DELAM. } \\
\text { (\%) }\end{array}$ & $\begin{array}{r}\text { H. Madera } \\
\text { Abeto }\end{array}$ & $\begin{array}{r}\text { CARCA } \\
\text { MÁX. (N) }\end{array}$ \\
\hline Humedad media exterior (\%) & 1,000 & 0,500 & 0,500 & $-0,016$ & 0,555 & 0,081 \\
Precipitación (mm) & 0,500 & 1,000 & 1,000 & $-0,222$ & $-0,437$ & $-0,412$ \\
Temperatura media exterior & 0,500 & 1,000 & 1,000 & $-0,222$ & $-0,431$ & $-0,412$ \\
DELAMINACIÓN (\%) & $-0,016$ & $-0,222$ & $-0,222$ & 1,000 & 0,196 & 0,076 \\
Humedad Madera Abeto & 0,555 & $-0,431$ & $-0,431$ & 0,196 & 1,000 & 0,457 \\
CARCA MÁX. (N) & 0,081 & $-0,412$ & $-0,412$ & 0,076 & 0,457 & 1,000 \\
Dimension & 1 & 2 & 3 & 4 & 5 & 6 \\
Eigenvalue & 2,760 & 1,706 & 0,943 & 0,582 & 0,009 & 0,000 \\
\hline
\end{tabular}

En el cuadro 5.123, se muestran las correlaciones para las variables transformadas. Teniendo en cuenta el modelo y los datos de los que se compone, se estima que las correlaciones tienen significación para valores por encima de 0,4 .

Según la tabla, la carga máxima está relacionada con factores como la humedad de la madera de abeto, la temperatura exterior y la precipitación. El parámetro más destacable en este caso sería la humedad de la madera de abeto, y este parámetro estaría influenciado por la precipitación y por la temperatura exterior, relación que ya se ve en el análisis descriptivo del apartado 5.4.1 Análisis descriptivo de climay degradación. En el caso de la delaminación no vemos ninguna relación con los parámetros analizados, ya que como se observa en los análisis previos la delaminación no es un problema para el CLT al exterior, especialmente en la madera de abeto.

Cuadro 5.124: Pesos de los componentes (para el abeto incluyendo delaminación y carga máxima)

\begin{tabular}{lcc}
\hline & \multicolumn{2}{c}{ Dimension } \\
\cline { 2 - 3 } & 1 & 2 \\
\hline Humedad media exterior (\%) & 0,349 & 0,928 \\
Precipitación (mm) & 0,965 & 0,195 \\
Temperatura media exterior & 0,965 & 0,195 \\
DELAMINACIÓN (\%) & $-0,335$ & 0,111 \\
Humedad Madera Abeto & $-0,555$ & 0,776 \\
CARCA MÁX. (N) & $-0,595$ & 0,393 \\
\hline
\end{tabular}

Variable Principal Normalization.

Como se observa en el cuadro 5.124, según el peso de las componentes de las dimensiones creadas, se observa que los parámetros analizados explican la variable carga máxima, pero no tienen relación significativa con la delaminación, que se corresponde con los resultados obtenidos anteriormente para el abeto, en los que se mostraba que la delaminación no se veía afectada por la degradación producida por los envejecimientos al exterior, pero la carga máxima sí. 


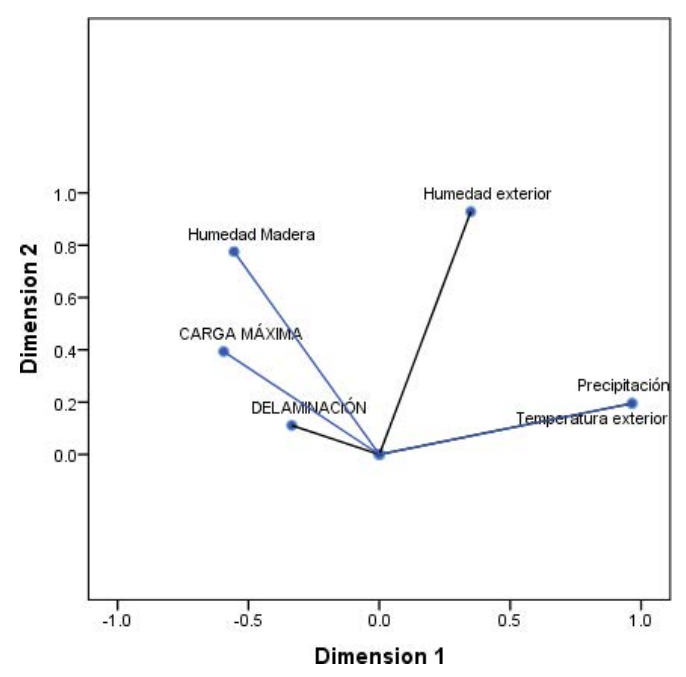

(a) Saturaciones en componentes

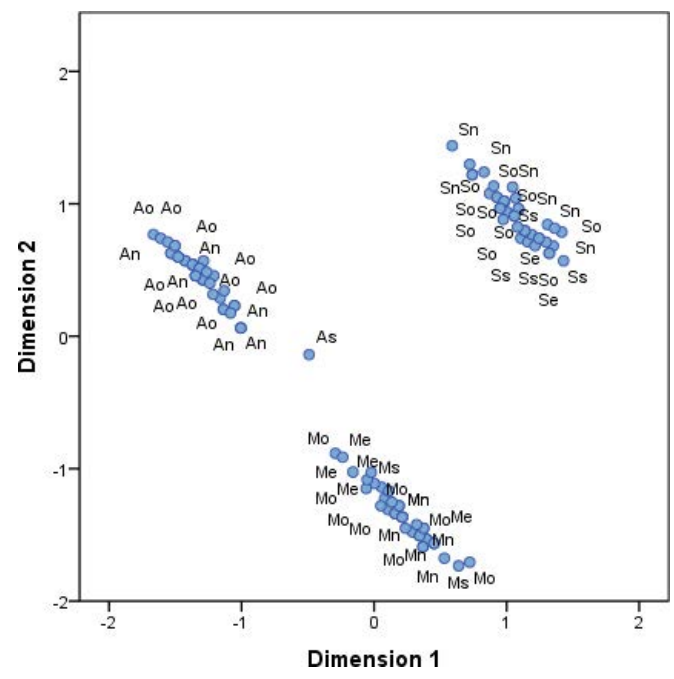

(b) Puntuaciones de los objetos

Figura 5.22: Gráficos del análisis de componentes principales (para el abeto incluyendo delaminación y carga máxima)

En la figura 5.22(a), que se corresponde con el cuadro 5.124 de peso de las componentes de las dimensiones creadas, se puede ver como la carga máxima y la delaminación tienen longitudes diferentes, lo que muestra incorrelación entre estos parámetros. Esto quiere decir que degradación del material y degradación del producto siguen caminos diferentes. En la gráfica se observa como se ha comentado, que la delaminación no está afectada por los parámetros climáticos analizados, es decir, que no le influye la exposición al exterior, o al menos no lo hace de manera significativa. Sin embargo en el caso de la carga máxima, se observa una relación fuerte con la temperatura media exterior y la precipitación, lo que quiere decir que si le afecta la exposición al exterior y que los principales factores climáticos que producen esta degradación son estos.

En la figura 5.22(b), se observa como las tres ubicaciones se agrupan en función de la carga máxima y la delaminación con respecto a las variables climáticas analizadas, lo que demuestra que las ubicaciones están claramente diferenciadas y que sus resultados de carga máxima y delaminación se ven afectadas por los factores climáticos que en ellas se producen.

Teniendo en cuenta lo analizado hasta el momento y para comprobar que sucede en cada una de las variables analizadas, se procede a realizar el análisis de componentes principales para datos categóricos de manera independiente a la delaminación y a la carga máxima.

\subsubsection{Análisis de componentes principales para datos categóricos de la carga máxima}

Como se observa en el cuadro 5.125, en el resumen del modelo analizado, en este análisis de componentes principales llevado a cabo para el abeto únicamente con la variable de carga máxima como medida de resistencia, la varianza explicada mejora al $88 \%$. Esto es debido a la incorrelación entre 
carga máxima y delaminación, por tanto se observa que mejora el modelo al dejar solo una de las dos variables en él.

Cuadro 5.125: Resumen del modelo para el abeto incluyendo únicamente la carga máxima

\begin{tabular}{lrrr}
\hline \multirow{2}{*}{ Dimension } & Cronbach's Alpha & \multicolumn{2}{c}{ Variance Accounted For } \\
\cline { 3 - 4 } & & Total (Eigenvalue) & \% of Variance \\
\hline 1 & 0,785 & 2,686 & 53,716 \\
2 & 0,515 & 1,700 & 34,003 \\
\hline Total &, $965^{\mathrm{a}}$ & 4,386 & 87,719 \\
\hline
\end{tabular}

a Total Cronbach's Alpha is based on the total Eigenvalue.

En el cuadro 5.126, se muestran las correlaciones para las variables transformadas. Teniendo en cuenta el modelo y los datos de los que se compone, se estima que las correlaciones tienen significación para valores por encima de 0,4 .

Cuadro 5.126: Matriz de correlaciones de las variables transformadas (para el abeto incluyendo únicamente la carga máxima)

\begin{tabular}{lrrrrr}
\hline & $\begin{array}{c}\text { H. media } \\
\text { ext. }(\%)\end{array}$ & \multicolumn{1}{c}{$\begin{array}{c}\text { Precip. } \\
(\mathrm{mm})\end{array}$} & $\begin{array}{c}\text { Ta media } \\
\text { ext. }\end{array}$ & $\begin{array}{c}\text { H. Madera } \\
\text { Abeto }\end{array}$ & $\begin{array}{r}\text { CARCA } \\
\text { MÁX. (N) }\end{array}$ \\
\hline Humedad media exterior (\%) & 1,000 & 0,500 & 0,500 & 0,555 & 0,081 \\
Precipitación (mm) & 0,500 & 1,000 & 1,000 & $-0,431$ & $-0,412$ \\
Temperatura media exterior & 0,500 & 1,000 & 1,000 & $-0,431$ & $-0,412$ \\
Humedad Madera Abeto & 0,555 & $-0,431$ & $-0,431$ & 1,000 & 0,457 \\
CARGA MÁX. (N) & 0,081 & $-0,412$ & $-0,412$ & 0,457 & 1,000 \\
Dimension & 1 & 2 & 3 & 4 & 5 \\
Eigenvalue & 2,686 & 1,700 & 0,605 & 0,009 & 0,000 \\
\hline
\end{tabular}

Según el cuadro 5.126, la carga máxima está relacionada con factores como la humedad de la madera de abeto, la temperatura exterior, y la precipitación. El parámetro más destacable en este caso sería la humedad de la madera de abeto, y este parámetro estaría influenciado por la precipitación y por la temperatura exterior, relación que ya se ve en el análisis descriptivo del apartado 5.4.1 Análisis descriptivo de clima y degradación. En el caso de la carga máxima se observa relación con los parámetros analizados, ya que como se muestra en los análisis previos la carga máxima es un problema para el CLT al exterior, especialmente en la madera de abeto.

Como se ha comentado en el análisis descriptivo, la precipitación tiene que ser precipitación efectiva, es decir, la cantidad de agua que finalmente se incorpora a la madera, teniendo en cuenta el gradiente de esta incorporación, ya que la velocidad de entrada y salida de esta agua es la que va a provocar los cambios volumétricos en la madera y por tanto su degradación. En el caso del abeto como material, como se ha venido observando en los diferentes análisis la delaminación no es un problema.

Como se observa en el cuadro 5.127, según el peso de las componentes de las dimensiones creadas, se observa que de los parámetros analizados, explican de forma relevante la variable carga máxima la humedad de la madera de abeto, y en mayor medida la precipitación y la temperatura, lo que confirma 
Cuadro 5.127: Pesos de los componentes (para el abeto incluyendo únicamente la carga máxima)

\begin{tabular}{lcc}
\hline & \multicolumn{2}{c}{ Dimension } \\
\cline { 2 - 3 } & 1 & 2 \\
\hline Humedad media exterior (\%) & 0,370 & 0,919 \\
Precipitación (mm) & 0,973 & 0,173 \\
Temperatura media exterior & 0,973 & 0,173 \\
Humedad Madera Abeto & $-0,540$ & 0,787 \\
CARGA MÁX. (N) & $-0,604$ & 0,418 \\
\hline
\end{tabular}

Variable Principal Normalization.

lo explicado en el análisis descriptivo del apartado 5.4.1 Análisis descriptivo de clima y degradación. Esto se corresponde con los resultados obtenidos anteriormente para el abeto, en los que se mostraba que la carga máxima, se veía afectada por la degradación producida por los envejecimientos al exterior.

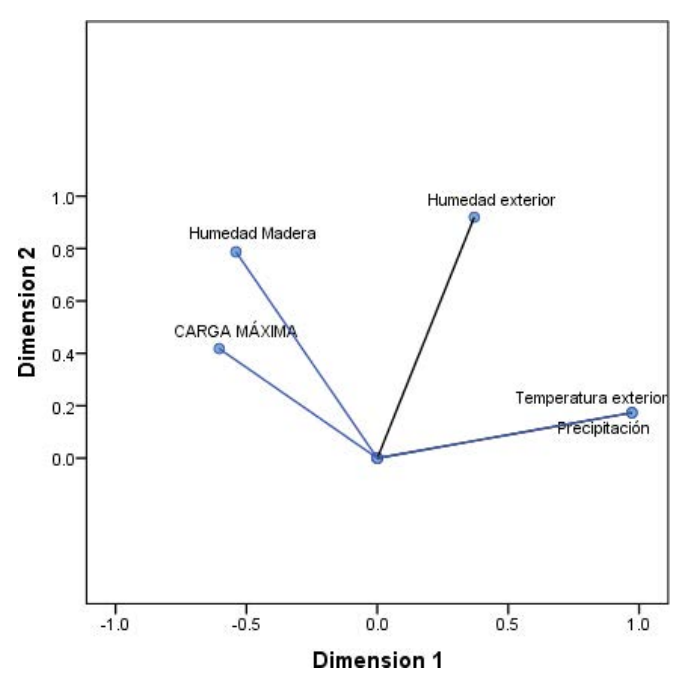

(a) Saturaciones en componentes

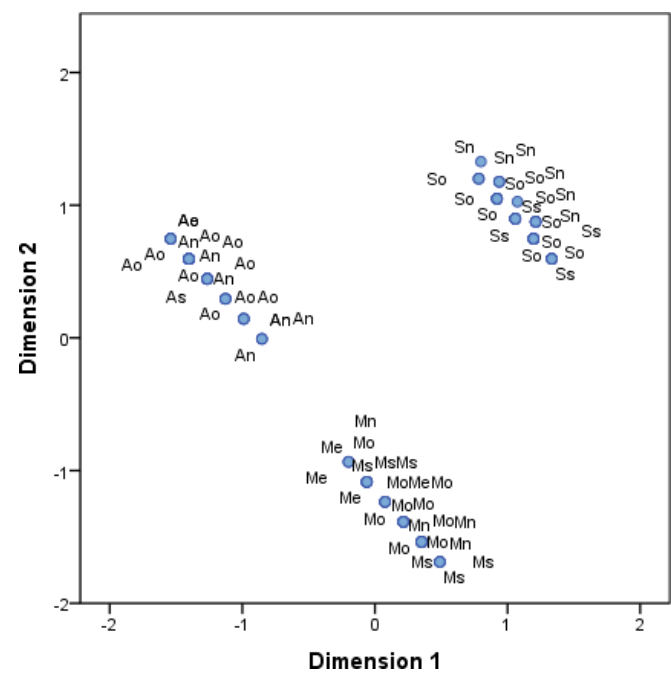

(b) Puntuaciones de los objetos

Figura 5.23: Gráficos del análisis de componentes principales (para el abeto incluyendo únicamente la carga máxima)

En la figura 5.23(a), que se corresponde con el cuadro 5.127 de peso de las componentes de las dimensiones creadas, se puede ver como la carga máxima tiene una longitud similar al resto de variables analizadas, lo que muestra la relación entre estas variables y la carga máxima, sin embargo forma prácticamente un ángulo recto con la humedad exterior, lo que quiere decir que no está relacionada con esta variable. Esto quiere decir que la carga máxima se ve afectada por los parámetros climáticos analizados, es decir, que le influye la exposición al exterior.

En la figura 5.23(b), se observa como las tres ubicaciones se agrupan en función de la carga máxima con respecto a las variables climáticas analizadas, lo que demuestra que las ubicaciones están claramente diferenciadas y que sus resultados de carga máxima, se ven afectados por los factores climáticos que en ellas se producen, y como se ha visto de una forma significativa, por tanto condiciona la durabilidad 
del material en materia de carga máxima.

\subsubsection{Análisis de componentes principales para datos categóricos de la delaminación}

Como se observa en el cuadro 5.128, en el resumen del modelo analizado, en este análisis de componentes principales llevado a cabo para el abeto únicamente con la variable de delaminación como medida de resistencia, la varianza explicada mejora al $82 \%$. Esto es debido a la incorrelación entre carga máxima y delaminación, por tanto se observa que mejora el modelo al dejar solo una de las dos variables en él.

Cuadro 5.128: Resumen del modelo para el abeto incluyendo únicamente la delaminación

\begin{tabular}{lrrr}
\hline \multirow{2}{*}{ Dimension } & Cronbach's Alpha & \multicolumn{2}{c}{ Variance Accounted For } \\
\cline { 3 - 4 } & & Total (Eigenvalue) & \% of Variance \\
\hline 1 & 0,753 & 2,517 & 50,339 \\
2 & 0,460 & 1,583 & 31,654 \\
\hline Total &, $945^{\mathrm{a}}$ & 4,100 & 81,993 \\
\hline
\end{tabular}

a Total Cronbach's Alpha is based on the total Eigenvalue.

Cuadro 5.129: Matriz de correlaciones de las variables transformadas (para el abeto incluyendo únicamente la delaminación)

\begin{tabular}{|c|c|c|c|c|c|}
\hline & $\begin{array}{l}\text { H. media } \\
\text { ext. (\%) }\end{array}$ & $\begin{array}{l}\text { Precip. } \\
(\mathrm{mm})\end{array}$ & $\begin{array}{l}T^{a} \text { media } \\
\text { ext. }\end{array}$ & $\begin{array}{l}\text { H. Madera } \\
\text { Abeto }\end{array}$ & $\begin{array}{l}\text { DELAM. } \\
(\%)\end{array}$ \\
\hline Humedad media exterior (\%) & 1,000 & 0,500 & 0,500 & 0,555 & $-0,016$ \\
\hline Precipitación (mm) & 0,500 & 1,000 & 1,000 & $-0,431$ & $-0,222$ \\
\hline Temperatura media exterior & 0,500 & 1,000 & 1,000 & $-0,431$ & $-0,222$ \\
\hline Humedad Madera Abeto & 0,555 & $-0,431$ & $-0,431$ & 1,000 & 0,196 \\
\hline DELAMINACIÓN (\%) & $-0,016$ & $-0,222$ & $-0,222$ & 0,196 & 1,000 \\
\hline Dimension & 1 & 2 & 3 & 4 & 5 \\
\hline Eigenvalue & 2,517 & 1,583 & 0,891 & 0,009 & 0,000 \\
\hline
\end{tabular}

En el cuadro 5.129, se muestran las correlaciones para las variables transformadas. Teniendo en cuenta el modelo y los datos de los que se compone, se estima que las correlaciones tienen significación para valores por encima del 0,4.

Según el cuadro 5.129, la delaminación no está relacionada de manera significativa con ninguno de los parámetros analizados, ya que ningún valor está por encima del 0,4, sin embargo vemos que los factores más relacionados siguen siendo la precipitación, la temperatura media exteriory la humedad de la madera de abeto. Aun así el que no afecten de manera significativa, confirma que la exposición al exterior no es un problema para la delaminación del CLT de abeto, o lo que es lo mismo no le influye como producto.

Como se observa en el cuadro 5.130, según el peso de las componentes de las dimensiones creadas, se observa que los parámetros analizados no explican de forma relevante la variable delaminación, lo que 
Cuadro 5.130: Pesos de los componentes (para el abeto incluyendo únicamente la delaminación)

\begin{tabular}{lcc}
\hline & \multicolumn{2}{c}{ Dimension } \\
\cline { 2 - 3 } & 1 & 2 \\
\hline Humedad media exterior (\%) & 0,501 & 0,860 \\
Precipitación (mm) & 0,990 & 0,017 \\
Temperatura media exterior & 0,990 & 0,017 \\
Humedad Madera Abeto & $-0,425$ & 0,881 \\
DELAMINACIÓN (\%) & $-0,351$ & 0,257 \\
\hline
\end{tabular}

Variable Principal Normalization.

se corresponde con los resultados obtenidos anteriormente para el abeto, en los que se mostraba que la delaminación no se veía afectada por la degradación producida por los envejecimientos al exterior.

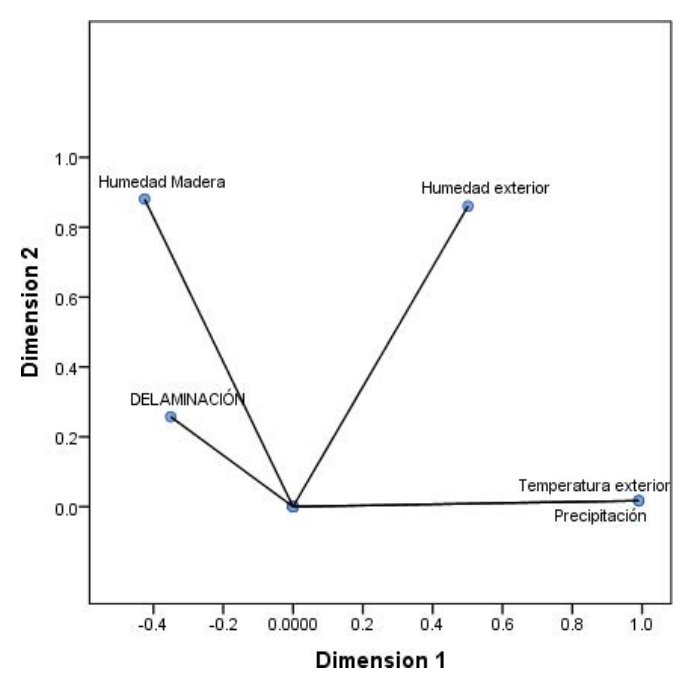

(a) Saturaciones en componentes

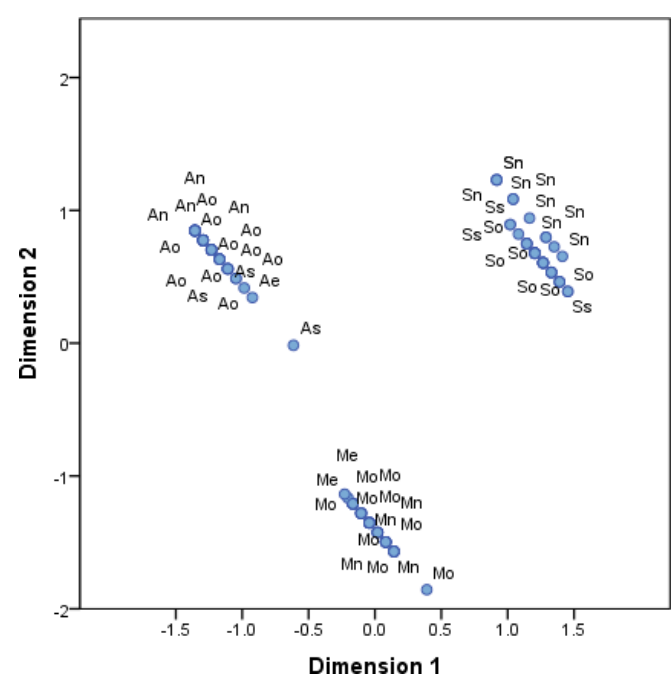

(b) Puntuaciones de los objetos

Figura 5.24: Cráficos del análisis de componentes principales (para el abeto incluyendo únicamente la delaminación)

En la figura 5.24(a), que se corresponde con el cuadro 5.130 de peso de las componentes de las dimensiones creadas, se puede ver como la delaminación tiene una longitud diferente que el resto de variables analizadas, lo que muestra la falta de relación entre estas variables y la delaminación. Esto quiere decir que la delaminación no se ve afectada por los parámetros climáticos analizados, es decir, que no le influye la exposición al exterior, o al menos no lo hace de manera significativa.

En la figura 5.24(b), se observa como las tres ubicaciones se agrupan en función de la delaminación con respecto a las variables climáticas analizadas, lo que demuestra que las ubicaciones están claramente diferenciadas y que sus resultados de delaminación, se ven afectadas por los factores climáticos que en ellas se producen, aunque no sea de una forma significativa, o que condicione la durabilidad del producto en materia de delaminación. 


\subsubsection{Análisis de los componentes principales para datos categóricos del pino}

Una vez visto en el análisis descriptivo lo que está sucediendo con el CLT de abeto y pino en las tres ubicaciones con respeto a la influencia de los factores climáticos que se dan en cada una de las ubicaciones, se procede a llevar a cabo un análisis de componentes principales para datos categóricos para comprobar cuáles de estos resultados tienen significación en términos estadísticos

Para seleccionar las variables que se van a estudiar, se realiza un análisis previo, en el que se eliminan del análisis variables que o bien no tienen ningún tipo de correlación con los datos objeto de estudio, o su correlación es de 1, por ejemplo, en el caso de la radiación solary la precipitación, ya que como es habitual en episodios de lluvia la radiación solar es prácticamente inexistente y viceversa.

Cuadro 5.131: Resumen del modelo para el pino incluyendo la delaminación y la carga máxima

\begin{tabular}{lrrr}
\hline \multirow{2}{*}{ Dimension } & Cronbach's Alpha & \multicolumn{2}{c}{ Variance Accounted For } \\
\cline { 3 - 4 } & & Total (Eigenvalue) & \% of Variance \\
\hline 1 & 0,762 & 2,742 & 45,701 \\
2 & 0,502 & 1,718 & 28,638 \\
\hline Total &, $937^{\mathrm{a}}$ & 4,460 & 74,339 \\
\hline
\end{tabular}

a Total Cronbach's Alpha is based on the total Eigenvalue.

En el cuadro 5.131, se observa un resumen del modelo analizado, y se muestra que este análisis de componentes principales llevado a cabo para el pino explica el 74 \% de la varianza; esto cuantifica las interrelaciones de Carga Máxima, Delaminación y las variables climáticas analizadas.

Cuadro 5.132: Matriz de correlaciones de las variables transformadas (para el pino incluyendo delaminación y carga máxima)

\begin{tabular}{lrrrrrr}
\hline & $\begin{array}{c}\text { H. Madera } \\
\text { Pino }\end{array}$ & $\begin{array}{c}\text { H. media } \\
\text { ext. }(\%)\end{array}$ & \multicolumn{1}{c}{$\begin{array}{c}\text { Precip. } \\
(\mathrm{mm})\end{array}$} & $\begin{array}{c}\text { Ta media } \\
\text { ext. }\end{array}$ & $\begin{array}{r}\text { DELAM. } \\
(\%)\end{array}$ & $\begin{array}{l}\text { CARGA } \\
\text { MÁX. (N) }\end{array}$ \\
\hline Humedad Madera Pino & 1,000 & 0,460 & $-0,526$ & $-0,526$ & 0,331 & 0,065 \\
Humedad media exterior (\%) & 0,460 & 1,000 & 0,500 & 0,500 & 0,078 & 0,361 \\
Precipitación (mm) & $-0,526$ & 0,500 & 1,000 & 1,000 & $-0,251$ & 0,298 \\
Temperatura media exterior & $-0,526$ & 0,500 & 1,000 & 1,000 & $-0,251$ & 0,298 \\
DELAMINACIÓN(\%) & 0,331 & 0,078 & $-0,251$ & $-0,251$ & 1,000 & 0,044 \\
CARCA MÁX. (N) & 0,065 & 0,361 & 0,298 & 0,298 & 0,044 & 1,000 \\
Dimension & 1 & 2 & 3 & 4 & 5 & 6 \\
Eigenvalue & 2,742 & 1,718 & 0,795 & 0,735 & 0,010 & 0,000 \\
\hline
\end{tabular}

En el cuadro 5.132, se muestran las correlaciones para las variables transformadas. Teniendo en cuenta el modelo y los datos de los que se compone, se estima que las correlaciones tienen significación para valores por encima de 0,4.

Según la tabla, ni la carga máxima, ni la delaminación están relacionadas con ninguno de los factores analizados, aunque se pueden ver ciertas influencias de los diferentes factores, no se aprecia ninguna relación significativa con ninguno de los factores analizados. 
Cuadro 5.133: Pesos de los componentes (para el pino incluyendo delaminación y carga máxima)

\begin{tabular}{lcc}
\hline & \multicolumn{2}{c}{ Dimension } \\
\cline { 2 - 3 } & 1 & 2 \\
\hline Humedad Madera Pino & $-0,513$ & 0,788 \\
Humedad media exterior (\%) & 0,499 & 0,788 \\
Precipitación (mm) & 0,984 & $-0,011$ \\
Temperatura media exterior & 0,984 & $-0,011$ \\
DELAMINACIÓN (\%) & $-0,349$ & 0,486 \\
CARGA MÁX. (N) & 0,413 & 0,489 \\
\hline
\end{tabular}

Variable Principal Normalization.

Como se observa en el cuadro 5.133, según el peso de las componentes de las dimensiones creadas, al contrario que sucedía con el abeto, los parámetros analizados no explican las variables delaminación y carga máxima con mucha significación, aunque se sigue observando que la temperatura exteriory la precipitación son los que más afectan, y que están más relacionados con la carga máxima que con la delaminación. Según esto la influencia de los factores se vé más clara en el caso del abeto que del pino, aunque existe en ambas especies.

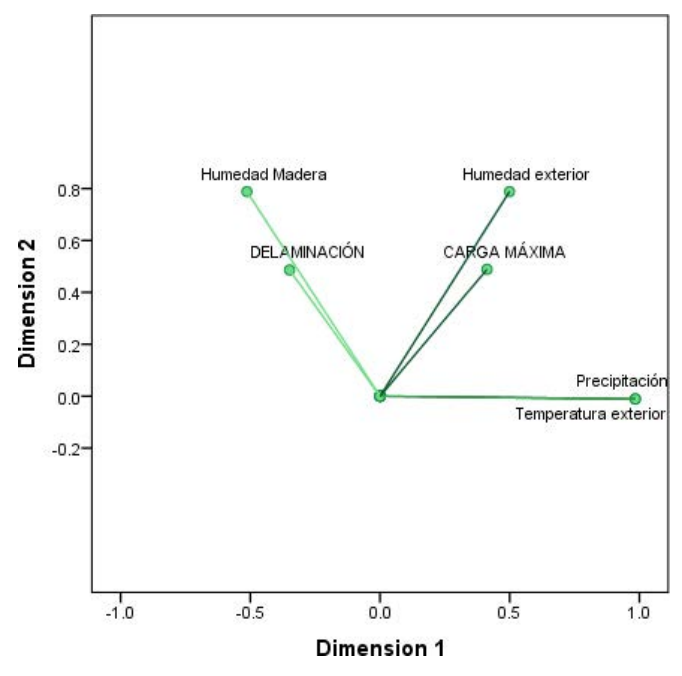

(a) Saturaciones en componentes

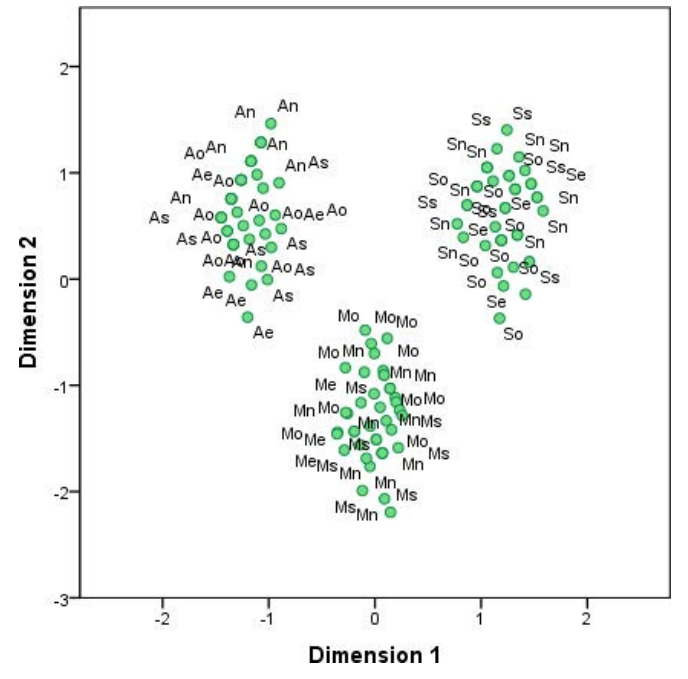

(b) Puntuaciones de los objetos

Figura 5.25: Gráficos del análisis de componentes principales (para el pino incluyendo delaminación y carga máxima)

En la figura 5.25(a), que se corresponde con el cuadro 5.133 de peso de las componentes de las dimensiones creadas, se puede ver que aunque carga máxima y delaminación tienen longitudes similares, forman un ángulo de prácticamente $90^{\circ}$, lo que muestra incorrelación entre estos parámetros. Esto quiere decir que degradación del material y degradación del producto siguen caminos diferentes. En la gráfica se observa como se ha comentado, que la delaminación no está afectada por los parámetros climáticos analizados, es decir, que no le influye la exposición al exterior, o al menos no lo hace de manera significativa. Sin embargo en el caso de la carga máxima, se observa una mayor relación 
con la temperatura media exterior y la precipitación, lo que quiere decir que si le afecta la exposición al exterior y que los principales factores climáticos que producen esta degradación son estos.

En la figura 5.25(b), se observa como las tres ubicaciones se agrupan en función de la carga máxima y la delaminación con respecto a las variables climáticas analizadas, lo que demuestra que las ubicaciones están claramente diferenciadas y que sus resultados de carga máxima y delaminación se ven afectadas por los factores climáticos que en ellas se producen, también se observa que los puntos que definen cada ubicación están más dispersos que en el caso del abeto, lo que demuestra que el abeto tiene una comportamiento más homogéneo.

Teniendo en cuenta lo analizado hasta el momento y para comprobar que sucede en cada una de las variables analizadas, se procede a realizar el análisis de componentes principales para datos categóricos de manera independiente a la delaminación y a la carga máxima.

\subsubsection{Análisis de componentes principales para datos categóricos de la carga máxima}

Como se observa en el cuadro 5.134, en el resumen del modelo analizado, en este análisis de componentes principales llevado a cabo para el pino únicamente con la variable de carga máxima como medida de resistencia, la varianza explicada mejora al $85 \%$. Esto es debido a la incorrelación entre carga máxima y delaminación, por tanto se observa que mejora el modelo al dejar solo una de las dos en él.

Cuadro 5.134: Resumen del modelo para el pino incluyendo únicamente la carga máxima

\begin{tabular}{lrrr}
\hline \multirow{2}{*}{ Dimension } & Cronbach's Alpha & \multicolumn{2}{c}{ Variance Accounted For } \\
\cline { 3 - 4 } & & Total (Eigenvalue) & \% of Variance \\
\hline 1 & 0,781 & 2,666 & 53,311 \\
2 & 0,459 & 1,580 & 31,601 \\
\hline Total &, $956^{\mathrm{a}}$ & 4,246 & 84,912 \\
\hline
\end{tabular}

${ }^{a}$ Total Cronbach's Alpha is based on the total Eigenvalue.

Cuadro 5.135: Matriz de correlaciones de las variables transformadas (para el pino incluyendo únicamente la carga máxima)

\begin{tabular}{lrrrrr}
\hline & $\begin{array}{c}\text { H. Madera } \\
\text { Pino }\end{array}$ & $\begin{array}{c}\text { H. media } \\
\text { ext. }(\%)\end{array}$ & \multicolumn{1}{c}{$\begin{array}{c}\text { Precip. } \\
(\mathrm{mm})\end{array}$} & $\begin{array}{c}\text { Ta media } \\
\text { ext. }\end{array}$ & $\begin{array}{r}\text { CARCA } \\
\text { MÁX. (N) }\end{array}$ \\
\hline Humedad Madera Pino & 1,000 & 0,460 & $-0,526$ & $-0,526$ & 0,065 \\
Humedad media exterior (\%) & 0,460 & 1,000 & 0,500 & 0,500 & 0,361 \\
Precipitación (mm) & $-0,526$ & 0,500 & 1,000 & 1,000 & 0,298 \\
Temperatura media exterior & $-0,526$ & 0,500 & 1,000 & 1,000 & 0,298 \\
CARGA MÁX. (N) & 0,065 & 0,361 & 0,298 & 0,298 & 1,000 \\
Dimension & 1 & 2 & 3 & 4 & 5 \\
Eigenvalue & 2,666 & 1,580 & 0,744 & 0,010 & 0,000 \\
\hline
\end{tabular}


En el cuadro 5.135, se muestran las correlaciones para las variables transformadas. Teniendo en cuenta el modelo y los datos de los que se compone, se estima que las correlaciones tienen significación para valores por encima de 0,4

Según el cuadro 5.135, la carga máxima está relacionada con factores como la humedad de la madera de pino, la temperatura exterior, y la precipitación, pero de una forma menos significativa que en el caso del abeto, ya que en ningún caso llega al 0.4. Sin embargo, la dinámica de relación entre las variables sería la misma que en el caso del abeto, solo que con una significación menor, es decir, el efecto en el pino es menos acusado. En este caso, el parámetro más destacable sigue siendo la humedad de la madera de pino, y este parámetro estaría influenciado por la precipitación y por la temperatura exterior, relación que ya se ve en el análisis descriptivo del apartado 5.4.1 Análisis descriptivo de clima y degradación. En el caso de la carga máxima se ve relación con los parámetros analizados, aunque es menor que en el caso del abeto, esto implica que aunque hay pérdidas, no se puede afirmar que la carga máxima sea un problema para el CLT al exterior en el caso del pino.

Como se ha comentado en el análisis descriptivo, la precipitación tiene que ser precipitación efectiva, es decir, la cantidad de agua que finalmente se incorpora a la madera, teniendo en cuenta el gradiente de esta incorporación, ya que la velocidad de entrada y salida de esta agua es la que va a provocar los cambios volumétricos en la madera y por tanto su degradación. En el caso del pino como material, este efecto es menos acusado que en el abeto.

Cuadro 5.136: Pesos de los componentes (para el pino incluyendo únicamente la carga máxima)

\begin{tabular}{lcc}
\hline & \multicolumn{2}{c}{ Dimension } \\
\cline { 2 - 3 } & $\mathbf{1}$ & $\mathbf{2}$ \\
\hline Humedad Madera Pino & $-0,447$ & 0,878 \\
Humedad media exterior (\%) & 0,566 & 0,762 \\
Precipitación (mm) & 0,984 & $-0,123$ \\
Temperatura media exterior & 0,984 & $-0,123$ \\
CARGA MÁX. (N) & 0,458 & 0,445 \\
\hline
\end{tabular}

Variable Principal Normalization.

Como se observa en el cuadro 5.136, vemos que todos los parámetros analizados, excepto la humedad ambiente, explican la variable carga máxima.

Como se observa en el cuadro 5.136, según el peso de las componentes de las dimensiones creadas, se observa que de los parámetros analizados, explican de forma relevante la variable carga máxima la humedad de la madera de pino, y en mayor medida la precipitación y la temperatura, lo que confirma lo explicado en el análisis descriptivo del apartado 5.4.1 Análisis descriptivo de clima y degradación. Esto se corresponde con los resultados obtenidos anteriormente para el pino, en los que se mostraba que la carga máxima, se veía afectada por la degradación producida por los envejecimientos al exterior.

En la figura 5.26(a), que se corresponde con el cuadro 5.136 de peso de las componentes de las dimensiones creadas, se puede ver como la carga máxima tiene una longitud diferente al resto de variables analizadas, lo que muestra que la relación entre estas variables y la carga máxima no es tan fuerte como lo era en el caso del abeto, y en este caso la humedad de la madera, tampoco es tan determinante, 


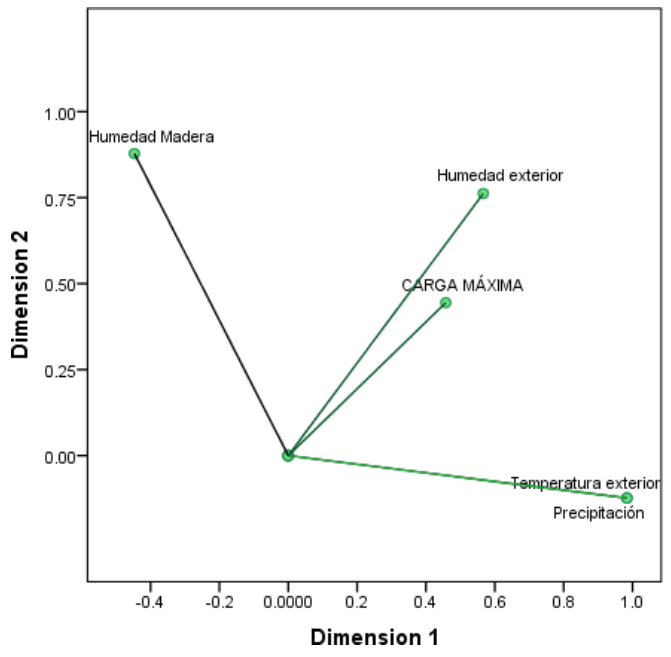

(a) Saturaciones en componentes

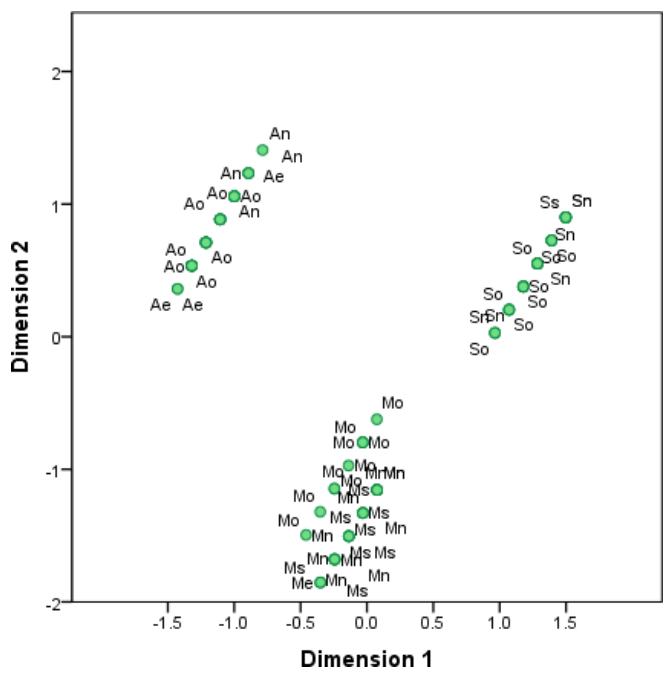

(b) Puntuaciones de los objetos

Figura 5.26: Cráficos del análisis de componentes principales (para el pino incluyendo únicamente la carga máxima)

según el peso de esta variable. Esto quiere decir que la carga máxima se ve afectada por los parámetros climáticos analizados, es decir, que le influye la exposición al exterior, pero en este caso a diferencia de en el resto la humedad de la madera de pino no tiene tanto peso en la pérdida de propiedades.

En la figura 5.26(b), se observa como las tres ubicaciones se agrupan en función de la carga máxima con respecto a las variables climáticas analizadas, lo que demuestra que las ubicaciones están claramente diferenciadas y que sus resultados de carga máxima, se ven afectados por los factores climáticos que en ellas se producen, y como se ha visto de una forma significativa, por tanto condiciona la durabilidad del material en materia de carga máxima. La agrupación de los valores, o su poca dispersión, muestran la homogeneidad de datos y por tanto de comportamiento de la madera de pino frente a la de abeto.

\subsubsection{Análisis de componentes principales para datos categóricos de la delaminación}

Como se observa en el cuadro 5.137, en el resumen del modelo analizado, en este análisis de componentes principales llevado a cabo para el pino únicamente con la variable de delaminación como medida de resistencia, la varianza explicada mejora al $84 \%$. Esto es debido a la incorrelación entre carga máxima y delaminación, por tanto se observa que mejora el modelo al dejar solo una de las dos variables en él.

En el cuadro 5.138, se muestran las correlaciones para las variables transformadas. Teniendo en cuenta el modelo y los datos de los que se compone, se estima que las correlaciones tienen significación para valores por encima del 0,4.

Según el cuadro 5.138, la delaminación no está relacionada de manera significativa con ninguno de los parámetros analizados, ya que ningún valor está por encima del 0,4, sin embargo vemos que los factores más relacionados siguen siendo la precipitación, la temperatura media exteriory la humedad 
Cuadro 5.137: Resumen del modelo para el pino incluyendo únicamente la delaminación

\begin{tabular}{lrrr}
\hline \multirow{2}{*}{ Dimension } & Cronbach's Alpha & \multicolumn{2}{c}{ Variance Accounted For } \\
\cline { 3 - 4 } & & Total (Eigenvalue) & \% of Variance \\
\hline 1 & 0,775 & 2,634 & 52,676 \\
2 & 0,452 & 1,566 & 31,328 \\
\hline Total &, $952^{\mathrm{a}}$ & 4,200 & 84,004 \\
\hline
\end{tabular}

a Total Cronbach's Alpha is based on the total Eigenvalue.

Cuadro 5.138: Matriz de correlaciones de las variables transformadas (para el pino incluyendo únicamente la delaminación)

\begin{tabular}{lrrrrr}
\hline & $\begin{array}{c}\text { H. Madera } \\
\text { Pino }\end{array}$ & $\begin{array}{c}\text { H. media } \\
\text { ext. }(\%)\end{array}$ & \multicolumn{1}{c}{$\begin{array}{c}\text { Precip. } \\
(\mathrm{mm})\end{array}$} & $\begin{array}{c}\text { Ta media } \\
\text { ext. }\end{array}$ & $\begin{array}{c}\text { DELAM. } \\
(\%)\end{array}$ \\
\hline Humedad Madera Pino & 1,000 & 0,460 & $-0,526$ & $-0,526$ & 0,331 \\
Humedad media exterior (\%) & 0,460 & 1,000 & 0,500 & 0,500 & 0,078 \\
Precipitación (mm) & $-0,526$ & 0,500 & 1,000 & 1,000 & $-0,251$ \\
Temperatura media exterior & $-0,526$ & 0,500 & 1,000 & 1,000 & $-0,251$ \\
DELAMINACIÓN (\%) & 0,331 & 0,078 & $-0,251$ & $-0,251$ & 1,000 \\
Dimension & 1 & 2 & 3 & 4 & 5 \\
Eigenvalue & 2,634 & 1,566 & 0,789 & 0,011 & 0,000 \\
\hline
\end{tabular}

de la madera de pino. Aun así el que no afecten de manera significativa, confirma que la exposición al exterior no es un problema para la delaminación del CLT de abeto, o lo que es lo mismo no le influye como producto, resultado que confirma los análisis previos.

Cuadro 5.139: Pesos de los componentes (para el pino incluyendo únicamente la delaminación)

\begin{tabular}{lcc}
\hline & \multicolumn{2}{c}{ Dimension } \\
\cline { 2 - 3 } & 1 & 2 \\
\hline Humedad Madera Pino & $-0,599$ & 0,740 \\
Humedad media exterior (\%) & 0,415 & 0,889 \\
Precipitación (mm) & 0,985 & 0,129 \\
Temperatura media exterior & 0,985 & 0,129 \\
DELAMINACIÓN (\%) & $-0,404$ & 0,441 \\
\hline
\end{tabular}

Variable Principal Normalization.

Como se observa en el cuadro 5.139, según el peso de las componentes de las dimensiones creadas, se observa que los parámetros analizados explican la variable delaminación, lo que se corresponde con los resultados obtenidos anteriormente para el pino, ya que si bien se determinó que la delaminación no se veía afectada por la degradación producida por los envejecimientos al exterior, si se observó que afectaba más al pino que al abeto.

En la figura 5.27(a), que se corresponde con el cuadro 5.139 de peso de las componentes de las dimensiones creadas, se puede ver como la delaminación tiene una longitud diferente que el resto de variables analizadas, lo que muestra la falta de relación entre estas variables y la delaminación. Esto 


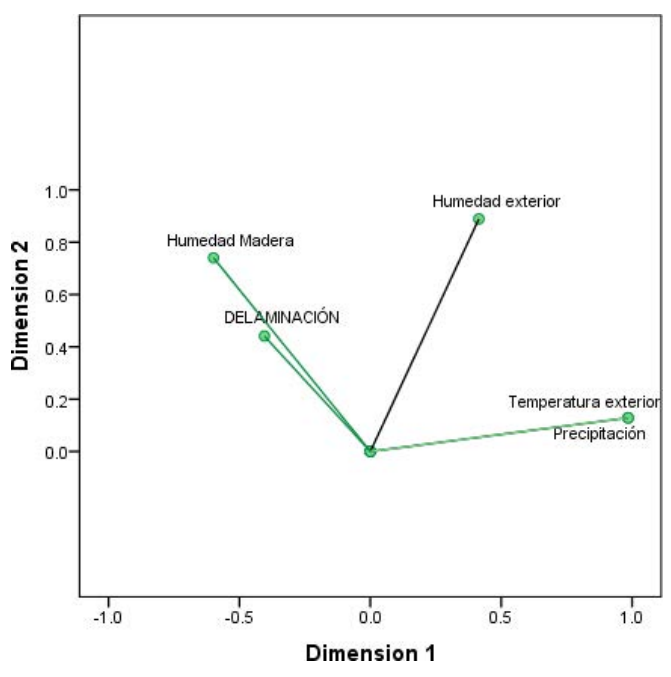

(a) Saturaciones en componentes

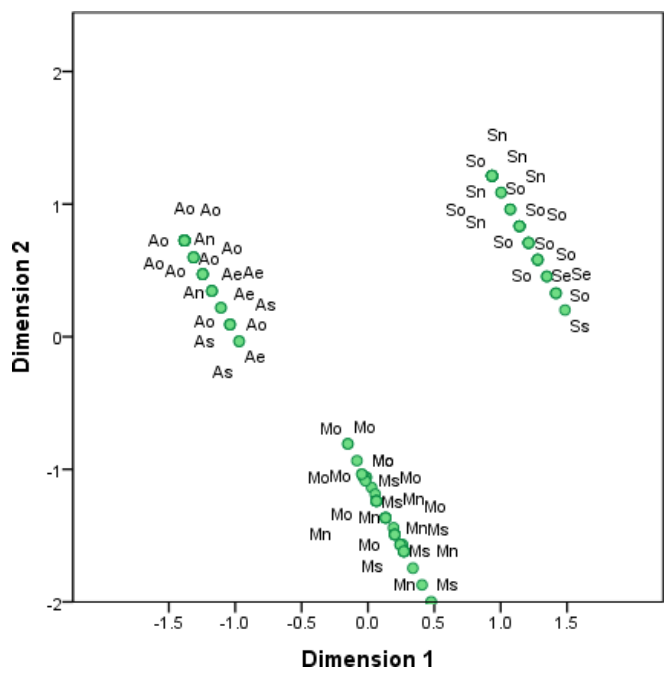

(b) Puntuaciones de los objetos

Figura 5.27: Gráficos del análisis de componentes principales (para el pino incluyendo únicamente la delaminación)

quiere decir que la delaminación no se ve afectada por los parámetros climáticos analizados, es decir, que no le influye la exposición al exterior, o al menos no lo hace de manera significativa, ya que como se ha explicado estas variables tienen más influencia en el pino que en el abeto.

En la figura 5.27(b), se observa como las tres ubicaciones se agrupan en función de la delaminación con respecto a las variables climáticas analizadas, lo que demuestra que las ubicaciones están claramente diferenciadas y que sus resultados de delaminación, se ven afectadas por los factores climáticos que en ellas se producen, aunque no sea de una forma significativa, o que condicione la durabilidad del producto en materia de delaminación.

\subsection{Análisis comparativo de la degradación respecto al método aplicado}

Como se ha comentado, los ensayos que se realizan para evaluar la aptitud al uso del CLT en clase de servicio 3 y clase de uso 3.7, se presumen muy agresivos para el material, debido a que en origen no han sido diseñados para el CLT, teniendo en cuenta sus particularidades.

Para comprobar si los métodos aplicados en este estudio son adecuados para la evaluación del CLT con respecto a su aptitud al uso como paramento al exterior, se decide llevar a cabo dos análisis. El primer análisis es la comparativa entre la referencia, el envejecimiento natural, y el envejecimiento artificial, con el objetivo de comprobar si se produce envejecimiento al aplicar los diferentes métodos. Y el segundo análisis consiste en la comparación de la referencia, el envejecimiento natural, el envejecimiento artificial Ilevado a cabo en el FCBA en su modalidad de ciclo corto, y el envejecimiento artificial llevado a cabo en el INIA es su modalidad de ciclo corto, con el objetivo de comprobar si son comparables estos métodos entre sí, y su adecuación para la evaluación del CLT. 
En estos análisis no se tendrán en cuenta los efectos que puedan producir las distintas ubicaciones, y dentro de estas las diferentes orientaciones en el envejecimiento natural, ni tampoco el efecto que puedan tener los distintos métodos de envejecimiento aplicados, así como las distintas duraciones de ciclo en el envejecimiento artificial.

Tampoco se realizará en este caso diferenciación entre las especies, ya que simplemente se pretende evaluar cuando se produce degradación, en que variables, ya sea delaminación o carga máxima, y discernir si los métodos aplicados son adecuados, y si podrían utilizarse para evaluar este material en las condiciones fijadas de clase de servicio 3 y clase de uso 3.1.

\subsubsection{Degradación según el método aplicado}

Para evaluar el efecto que tienen los diferentes métodos de envejecimiento, y poder discutir sobre los efectos del envejecimiento producido en el CLT tanto por su exposición al exterior, llevado a cabo mediante la metodología expuesta en el envejecimiento natural descrito en el apartado 4.4 Envejecimiento natural, como el producido por los diferentes procesos realizados en laboratorio, llevado a cabo mediante las metodologías expuestas en el envejecimiento artificial descrito en el apartado 4.5 Envejecimiento artificial, se decide llevar a cabo un análisis en que solo se tenga en cuenta el material sin ningún tipo de envejecimiento (no envejecido), el material envejecido mediante su exposición al exterior (envejecimiento natural), y el material envejecido en laboratorio (envejecimiento artificial).

Cuadro 5.140: Valores descriptivos de carga máxima y delaminación en función del método aplicado

\begin{tabular}{|c|c|c|c|c|c|c|c|c|c|}
\hline & & \multirow{2}{*}{$\mathrm{N}$} & \multirow{2}{*}{ Mean } & \multirow{2}{*}{ Std. Dev. } & \multirow{2}{*}{ Std. Err. } & \multicolumn{2}{|c|}{$95 \%$ C. I. for Mean } & \multirow{2}{*}{ Min. } & \multirow{2}{*}{ Max } \\
\hline & & & & & & Lower B. & Upper B. & & \\
\hline \multirow{4}{*}{ CARCA MÁX. (N) } & NO ENVEJECIDO & 20 & 16847,72 & 3074,85 & 687,56 & 15408,65 & 18286,79 & 12731,82 & 22813,78 \\
\hline & ARTIFICIAL & 80 & 13390,79 & 4768,21 & 533,10 & 12329,68 & 14451,91 & 5560,19 & 21698,95 \\
\hline & NATURAL & 240 & 15506,47 & 4067,82 & 262,58 & 14989,21 & 16023,73 & 7722,13 & 24956,16 \\
\hline & Total & 340 & 15087,56 & 4298,91 & 233,14 & 14628,98 & 15546,15 & 5560,19 & 24956,16 \\
\hline \multirow{4}{*}{ tDELAMINACION } & NO ENVEJECIDO & 20 & 1,28 & 0,24 & 0,05 & 1,17 & 1,40 & 0,84 & 1,57 \\
\hline & ARTIFICIAL & 80 & 1,20 & 0,20 & 0,02 & 1,15 & 1,24 & 0,58 & 1,57 \\
\hline & NATURAL & 240 & 1,22 & 0,20 & 0,01 & 1,20 & 1,25 & 0,68 & 1,57 \\
\hline & Total & 340 & 1,22 & 0,20 & 0,01 & 1,20 & 1,24 & 0,58 & 1,57 \\
\hline
\end{tabular}

En el cuadro 5.140, se observa una descripción de la muestra que se va a analizar, se puede ver que la cantidad de datos que tiene cada uno de los envejecimientos analizados es diferente, pero esto se tendrá en cuenta el los análisis realizados.

Además de esto cabe comentar que los datos de delaminación son más uniformes que los de carga máxima, debido a la homogeneidad de valores de la desviación estándar t del error estándar.

En la prueba de Levene o de homogeneidad de varianzas (cuadro 5.141), como se observaba en los datos anteriores, se da la homogeneidad de varianzas en los datos de la variable delaminación, pero no de la variable carga máxima.

Al realizar el test de Anova, se observa que existen diferencias significativas entre los parámetros analizados para la variable de carga máxima, pero no para la variable delaminación. Para poder saber a 
Cuadro 5.141: Prueba de homogeneidad de varianza de Levene de la carga máxima y delaminación en función del método aplicado

\begin{tabular}{lrrrr}
\hline & Levene Statistic & df1 & df2 & Sig. \\
\hline CARGA MÁX. (N) & 6,074 & 2 & 337 & 0,003 \\
\hline tDELAMINACION & 1,042 & 2 & 337 & 0,354 \\
\hline
\end{tabular}

Cuadro 5.142: Test ANOVA de la carga máxima y delaminación en función del método aplicado

\begin{tabular}{|c|c|c|c|c|c|c|}
\hline & & Sum of Squares & $d f$ & Mean Square & $\mathrm{F}$ & Sig. \\
\hline \multirow{3}{*}{ CARGA MÁX. (N) } & Between Groups & 334401826,755 & 2 & 167200913,378 & 9,501 & 0,000 \\
\hline & Within Croups & 5930529892,508 & 337 & 17598011,550 & & \\
\hline & Total & 6264931719,263 & 339 & & & \\
\hline \multirow{3}{*}{ tDELAMINACION } & Between Groups & 0,123 & 2 & 0,062 & 1,470 & 0,231 \\
\hline & Within Croups & 14,115 & 337 & 0,042 & & \\
\hline & Total & 14,238 & 339 & & & \\
\hline
\end{tabular}

qué se deben estas diferencias significativas mostradas en el test de Anova, se decide, debido a la no homogeneidad de las varianzas y a la diferencia de los tamaños muestrales, realizar un análisis de comparación múltiple de Tamhane.

Cuadro 5.143: multiple comparisons tambhane

Tamhane

\begin{tabular}{|c|c|c|c|c|c|c|c|}
\hline \multirow{2}{*}{ Dependent Var. } & & & \multirow{2}{*}{ Mean Diff. (I-J) } & \multirow{2}{*}{ Std. Err. } & \multirow{2}{*}{ Sig. } & \multicolumn{2}{|c|}{$95 \%$ Conf. Int. } \\
\hline & & & & & & Lower B. & Upper B. \\
\hline \multirow{6}{*}{ CARGA MÁX. (N) } & \multirow{2}{*}{ NO ENVE]. } & ARTIFICIAL & 3456,93 * & 870,02 & 0,001 & 1299,05 & 5614,80 \\
\hline & & NATURAL & 1341,25 & 735,99 & 0,222 & $-542,28$ & 3224,78 \\
\hline & \multirow{2}{*}{ ARTIFICIAL } & NO ENVE]. & $-3456,93^{*}$ & 870,02 & 0,001 & $-5614,80$ & $-1299,05$ \\
\hline & & NATURAL & $-2115,68^{*}$ & 594,26 & 0,002 & $-3554,75$ & $-676,61$ \\
\hline & \multirow{2}{*}{ NATURAL } & NO ENVE]. & $-1341,25$ & 735,99 & 0,222 & $-3224,78$ & 542,28 \\
\hline & & ARTIFICIAL & $2115,68^{*}$ & 594,26 & 0,002 & 676,61 & 3554,75 \\
\hline \multirow{6}{*}{ tDELAMINACION } & \multirow{2}{*}{ NO ENVE]. } & ARTIFICIAL & 0,09 & 0,06 & 0,408 & $-0,07$ & 0,24 \\
\hline & & NATURAL & 0,06 & 0,06 & 0,672 & $-0,09$ & 0,20 \\
\hline & \multirow{2}{*}{ ARTIFICIAL } & NO ENVE]. & $-0,09$ & 0,06 & 0,408 & $-0,24$ & 0,07 \\
\hline & & NATURAL & $-0,03$ & 0,03 & 0,656 & $-0,09$ & 0,04 \\
\hline & \multirow{2}{*}{ NATURAL } & NO ENVE]. & $-0,06$ & 0,06 & 0,672 & $-0,20$ & 0,09 \\
\hline & & ARTIFICIAL & 0,03 & 0,03 & 0,656 & $-0,04$ & 0,09 \\
\hline
\end{tabular}

*The mean difference is significant at the 0.05 level.

Según el análisis de comparación múltiple de Tamhane, no hay diferencias significativas para la variable delaminación en ninguno de los casos, lo que quiere decir que ninguno de los envejecimientos produce una delaminación significativa teniendo en cuenta los valores de referencia. Esto confirma los resultados obtenidos hasta el momento para la variable delaminación. En el caso de la carga máxima se 
observa que no hay diferencias significativas entre el envejecimiento al exterior o natural y los valores de referencia, sin embargo si las hay entre en el envejecimiento natural y el envejecimiento artificial, y el material no envejecido (valores de referencia) y el envejecimiento artificial.

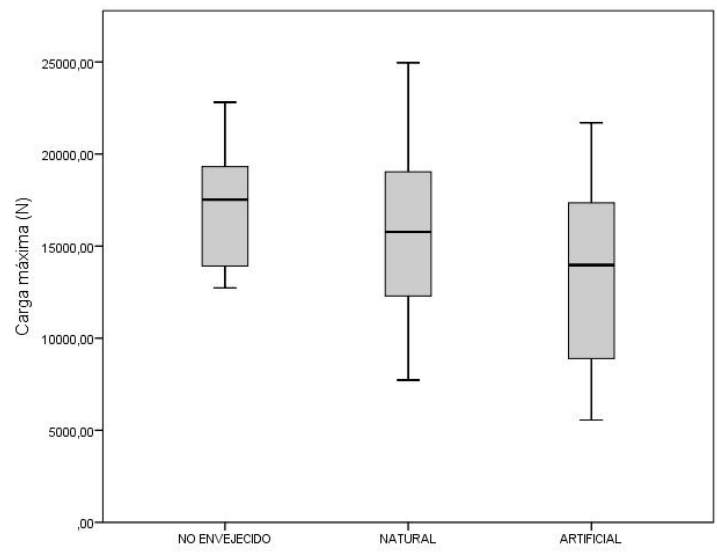

Figura 5.28: Diagramas de caja y bigotes de los resultados de carga máxima por método de aplicación

En la figura 5.28, se observa los resultados comentados anteriormente, la pérdida notable de propiedades del material se produce en el envejecimiento artificial, y aunque en el natural también se muestran pérdidas, no son significativas frente a la referencia.

Según esto, y como se ha observado anteriormente, la delaminación no se ve afectada por ninguno de los métodos de envejecimiento aplicado, o lo que es lo mismo, la degradación que se produce no es significativa. En el caso de la carga máxima se observa que la pérdida de propiedades no es significativa entre la exposición al exterior y la referencia, lo que nos confirma que el CLT como producto en principio sería apto para su uso exterior como paramento, teniendo en cuenta los condicionantes de la especie explicados anteriormente. Por último el envejecimiento artificial muestra que si produce envejecimiento, y que es más restrictivo que el envejecimiento natural, por tanto es apto para la evaluación del CLT en su uso como paramento al exterior.

\subsubsection{Comparativa entre métodos}

En principio los ciclos cortos realizados en laboratorio en las dos metodologías propuestas, se han diseñado tratando de hacerlos equivalentes a la degradación producida por la exposición al exterior durante un año. Para confirmar esta hipótesis se lleva a cabo una comparación con la referencia de los resultados obtenidos en el envejecimiento al exterior durante un año del CLT, con los envejecimientos de ciclo corto llevados a cabo en el FCBA y en el INIA.

En el cuadro 5.144 se observan los datos de cada una de las muestras que se van a analizary comparar, los tamaños muestrales son uniformes excepto en el tamaño de muestra del envejecimiento natural, que cuenta con los datos de las tres ubicaciones con sus correspondientes orientaciones. 
Cuadro 5.144: Valores descriptivos de la carga máxima y delaminación en función de los métodos equivalentes aplicados

\begin{tabular}{|c|c|c|c|c|c|c|c|c|c|}
\hline & & \multirow{2}{*}{$\mathrm{N}$} & \multirow{2}{*}{ Mean } & \multirow{2}{*}{ Std. Dev. } & \multirow{2}{*}{ Std. Err. } & \multicolumn{2}{|c|}{$95 \%$ C. I. for Mean } & \multirow{2}{*}{ Min. } & \multirow{2}{*}{ Max } \\
\hline & & & & & & Lower B. & Upper B. & & \\
\hline \multirow{5}{*}{ CARGA MÁX. (N) } & Referencia & 20 & 16847,72 & 3074,85 & 687,56 & 15408,65 & 18286,79 & 12731,82 & 22813,78 \\
\hline & NATURAL & 240 & 15506,47 & 4067,82 & 262,58 & 14989,21 & 16023,73 & 7722,13 & 24956,16 \\
\hline & FCBAC & 20 & 13394,33 & 3859,72 & 863,06 & 11587,92 & 15200,74 & 7522,34 & 19806,29 \\
\hline & INIAC & 20 & 12461,29 & 5324,19 & 1190,53 & 9969,49 & 14953,09 & 5659,68 & 20788,90 \\
\hline & Total & 300 & 15252,07 & 4189,21 & 241,86 & 14776,10 & 15728,04 & 5659,68 & 24956,16 \\
\hline \multirow{5}{*}{ tDELAMINACION } & Referencia & 20 & 1,28 & 0,24 & 0,05 & 1,17 & 1,40 & 0,84 & 1,57 \\
\hline & NATURAL & 240 & 1,22 & 0,20 & 0,01 & 1,20 & 1,25 & 0,68 & 1,57 \\
\hline & FCBAc & 20 & 1,16 & 0,14 & 0,03 & 1,10 & 1,23 & 0,94 & 1,40 \\
\hline & INIAC & 20 & 1,20 & 0,25 & 0,06 & 1,08 & 1,32 & 0,58 & 1,57 \\
\hline & Total & 300 & 1,22 & 0,21 & 0,01 & 1,20 & 1,25 & 0,58 & 1,57 \\
\hline
\end{tabular}

Cuadro 5.145: Prueba de homogeneidad de varianza de Levene de la carga máxima y delaminación en función de los métodos equivalentes aplicados

\begin{tabular}{lrrrr}
\hline & Levene Statistic & df1 & df2 & Sig. \\
\hline CARGA MÁX. (N) & 3,624 & 3 & 296 & 0,013 \\
\hline tDELAMINACION & 1,864 & 3 & 296 & 0,136 \\
\hline
\end{tabular}

En la prueba de Levene (cuadro 5.145), se muestra que en la variable carga máxima no hay homogeneidad de varianzas, y en la variable delaminación sí.

Cuadro 5.146: Test ANOVA de la carga máxima y delaminación en función de los métodos equivalentes aplicados

\begin{tabular}{|c|c|c|c|c|c|c|}
\hline & & Sum of Squares & $\mathrm{df}$ & Mean Square & $\mathrm{F}$ & Sig. \\
\hline \multirow{3}{*}{ CARGA MÁX. (N) } & Between Groups & 291247948,436 & 3 & 97082649,479 & 5,798 & 0,001 \\
\hline & Within Groups & 4956046002,194 & 296 & 16743398,656 & & \\
\hline & Total & 5247293950,630 & 299 & & & \\
\hline \multirow{3}{*}{ tDELAMINACION } & Between Groups & 0,155 & 3 & 0,052 & 1,218 & 0,303 \\
\hline & Within Groups & 12,534 & 296 & 0,042 & & \\
\hline & Total & 12,689 & 299 & & & \\
\hline
\end{tabular}

En el test de Anova (cuadro 5.146), no se muestran diferencias significativas en el caso de la delaminación, cosa lógica por los resultados obtenidos hasta el momento, sin embargo si se encuentran en el caso de la carga máxima. Para poder evaluar si se pueden comparar estos tres métodos, y ver porque se producen estas diferencias, debido a la no homogeneidad de las varianzas, y a la diferencia de tamaño muestral, se decide llevar a cabo un análisis de comparación múltiple de Tamhanne.

En el cuadro 5.147, se muestran los resultados del análisis de comparación múltiple de Tamhane, en el caso de la delaminación no se produce ningún tipo de diferencia con los tipos de envejecimiento, ni siquiera al compararlos con la referencia. En el caso de la carga máxima las diferencias se producen entre los envejecimientos artificiales y la referencia, lo que quiere decir que si se produce degradación con estos métodos, sin embargo con el envejecimiento natural y la referencia no hay, por lo que no se 
Cuadro 5.147: Análisis de comparación múltiple de Tamhane de la carga máxima y delaminación en función de los métodos equivalentes aplicados

\begin{tabular}{|c|c|c|c|c|c|c|c|}
\hline \multirow{2}{*}{ Dependent Var. } & & & \multirow{2}{*}{ Mean Diff. (I-J) } & \multirow{2}{*}{ Std. Err. } & \multirow{2}{*}{ Sig. } & \multicolumn{2}{|c|}{$95 \%$ Conf. Int. } \\
\hline & & & & & & Lower B. & Upper B. \\
\hline \multirow{12}{*}{ CARGA MÁX. (N) } & \multirow{3}{*}{ Referencia } & NATURAL & 1341,25 & 735,99 & 0,395 & $-761,34$ & 3443,84 \\
\hline & & FCBAC & $3453,39 \%$ & 1103,45 & 0,021 & 382,80 & 6523,98 \\
\hline & & INIAC & $4386,43^{*}$ & 1374,80 & 0,020 & 518,55 & 8254,30 \\
\hline & \multirow{3}{*}{ NATURAL } & Referencia & $-7341,25$ & 735,99 & 0,395 & $-3443,84$ & 761,34 \\
\hline & & FCBAC & 2112,14 & 902,12 & 0,159 & $-486,90$ & 4711,19 \\
\hline & & INIAC & 3045,18 & 1219,14 & 0,119 & $-495,53$ & 6585,89 \\
\hline & \multirow{3}{*}{ FCBAC } & Referencia & $-3453,39^{*}$ & 1103,45 & 0,021 & $-6523,98$ & $-382,80$ \\
\hline & & NATURAL & $-2112,14$ & 902,12 & 0,159 & $-4711,19$ & 486,90 \\
\hline & & INIAC & 933,04 & 1470,45 & 0,989 & $-3169,29$ & 5035,36 \\
\hline & \multirow{3}{*}{ INIAC } & Referencia & $-4386,43^{*}$ & 1374,80 & 0,020 & $-8254,30$ & $-518,55$ \\
\hline & & NATURAL & $-3045,18$ & 1219,14 & 0,119 & $-6585,89$ & 495,53 \\
\hline & & FCBAC & $-933,04$ & 1470,45 & 0,989 & $-5035,36$ & 3169,29 \\
\hline \multirow{12}{*}{ tDELAMINACION } & \multirow{3}{*}{ Referencia } & NATURAL & 0,06 & 0,06 & 0,892 & $-0,10$ & 0,22 \\
\hline & & FCBAC & 0,12 & 0,06 & 0,325 & $-0,06$ & 0,30 \\
\hline & & INIAC & 0,08 & 0,08 & 0,887 & $-0,14$ & 0,30 \\
\hline & \multirow{3}{*}{ NATURAL } & Referencia & $-0,06$ & 0,06 & 0,892 & $-0,22$ & 0,10 \\
\hline & & FCBAC & 0,06 & 0,03 & 0,356 & $-0,03$ & 0,16 \\
\hline & & INIAC & 0,02 & 0,06 & 0,999 & $-0,14$ & 0,19 \\
\hline & \multirow{3}{*}{ FCBAC } & Referencia & $-0,12$ & 0,06 & 0,325 & $-0,30$ & 0,06 \\
\hline & & NATURAL & $-0,06$ & 0,03 & 0,356 & $-0,16$ & 0,03 \\
\hline & & INIAC & $-0,04$ & 0,06 & 0,991 & $-0,22$ & 0,14 \\
\hline & \multirow{3}{*}{ INIAC } & Referencia & $-0,08$ & 0,08 & 0,887 & $-0,30$ & 0,14 \\
\hline & & NATURAL & $-0,02$ & 0,06 & 0,999 & $-0,19$ & 0,14 \\
\hline & & FCBAC & 0,04 & 0,06 & 0,991 & $-0,14$ & 0,22 \\
\hline
\end{tabular}

*The mean difference is significant at the 0.05 level.

puede afirmar que haya degradación con la exposición al exterior, o al menos no es significativa. Por último, en la comparativa entre los tres tipos de envejecimiento, no hay diferencias significativas, por lo que son comparables y se podrían utilizar los métodos de envejecimientos de laboratorio para simular la degradación producida por la exposición del producto al exterior durante un año.

En la figura 5.29, que se corresponde con los datos del cuadro 5.147, se observa de manera gráfica como afecta cada uno de los envejecimientos a la carga máxima. Cualquier tipo de exposición produce degradación, ya que como se observa el valor de la carga máxima va disminuyendo, sin embargo la pérdida de propiedades entre la referencia y el envejecimiento natural (exposición directa al exterior), no es significativa, por lo que en principio el CLT sería apto para su exposición al exterior. Con respecto a los tres métodos aplicados no hay diferencias estadísticamente significativas entre ellos, por lo que se podría decir que son equivalentes, y además vemos que tanto en el FCBA como en el INIA, ambos en su modalidad de ciclo corto, la pérdida de propiedades es mayor, por lo que en caso de aplicarlo, nos estaríamos quedando del lado de la seguridad, ya que es en todo caso más restrictivo que el envejeci- 


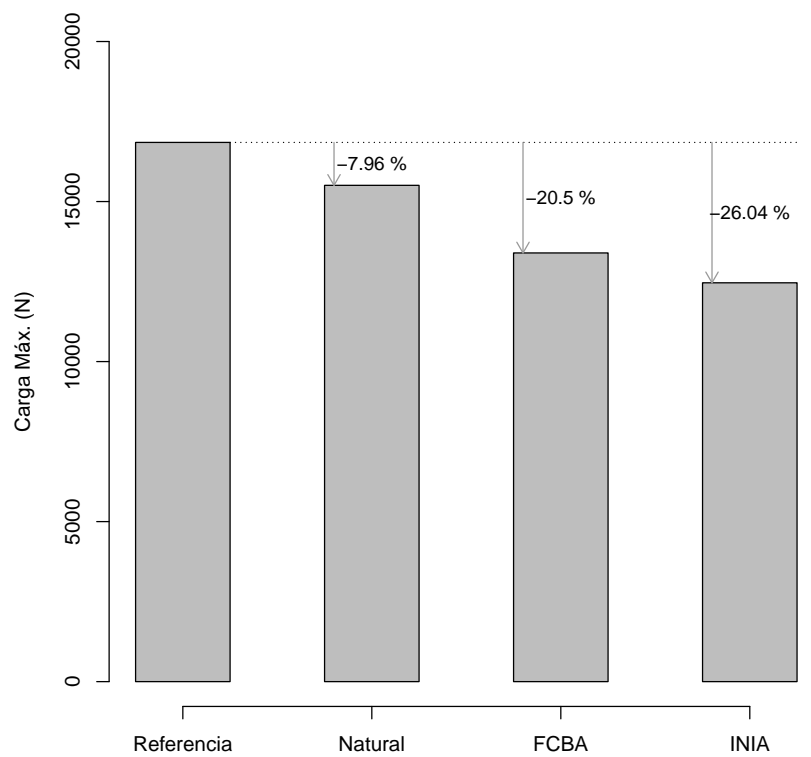

Figura 5.29: Comparación de métodos

miento natural, es decir, produce una degradación mayor a la esperada. 


\section{Capítulo 6}

\section{Conclusiones}

\subsection{Conclusiones parciales sobre el abeto}

Atendiendo al envejecimiento total, evaluado a través de un análisis comparativo entre todos los métodos de envejecimiento aplicados y la referencia, se puede afirmar que para el abeto no hay pérdidas por delaminación, ya que se muestra en el análisis descriptivo y se confirma estadísticamente con el análisis de contraste de hipótesis.

Analizando de forma independiente los envejecimientos natural y artificial, se observa que:

- Envejecimiento natural: no hay diferencias en la comparación del envejecimiento natural con la referencia, lo que quiere decir que no se produce envejecimiento o degradación en materia de delaminación, o al menos esta no es representativa. Tampoco se muestran diferencias en la comparación entre las distintas orientaciones, tanto en la comparación con la referencia como en la comparación sin esta, lo que quiere decir que no se puede afirmar que exista un efecto de orientación para la delaminación en su envejecimiento al exterior, ya que aunque en los valores medios del análisis descriptivo mostraba una tendencia a tener peores resultados la cara Sur, no se confirma estadísticamente con el análisis de contraste de hipótesis, por tanto no hay un patrón claro de efecto de orientación frente a la referencia, ni entre a las distintas orientaciones dentro de una misma ubicación. Lo que sí se demuestra en el análisis entre ubicaciones, es que la ubicación si influye en la delaminación y que la mejor ubicación en este caso es Ávila.

- Envejecimiento artificial: no hay diferencias en la comparación de los envejecimientos artificiales con la referencia, lo que quiere decir que no se produce envejecimiento o degradación en materia de delaminación, o al menos esta no es representativa. Dentro del mismo método de envejecimiento no se observan diferencias entre los dos ciclos aplicados con respecto a la delaminación, por lo que se puede afirmar que la duración del ciclo no influye en los envejecimientos aplicados. Lo que sí se demuestra es que hay diferencias significativas entre el ciclo llevado a cabo en el FCBA y el INIA.

Con todo esto se puede afirmar que la delaminación no es un problema para el CLT de abeto en los 
métodos ensayados, ya que no se produce degradación con respecto a la referencia, o al menos no es representativa, ya que no se puede demostrar estadísticamente. También se puede afirmar que la orientación no influye aunque la ubicación si, y que la duración de los ciclos aplicados no influye aunque si lo hace el método de envejecimiento aplicado.

Atendiendo al envejecimiento total, evaluado a través de un análisis comparativo entre todos los métodos de envejecimiento aplicados y la referencia, se puede afirmar que para el abeto hay pérdidas de resistencia expresado por el valor de la carga máxima, ya que se muestra en el análisis descriptivo y se confirma estadísticamente con el análisis de contraste de hipótesis. En este aspecto cabe comentar que esta degradación de capacidad resistente no se produce en Ávila ni en el método de envejecimiento llevado a cabo en el FCBA en su modalidad de ciclo largo.

Analizando de forma independiente los envejecimientos natural y artificial, se observa que:

- Envejecimiento natural: hay diferencias en la comparación del envejecimiento natural con la referencia, lo que quiere decir que se produce envejecimiento y por tanto hay degradación en materia de carga máxima. No se muestran diferencias en la comparación entre las distintas orientaciones, excepto en el caso de Madrid entre las caras Norte y Sur, aunque esto no permite afirmar que exista un efecto de orientación para la pérdida de resistencia en su envejecimiento al exterior, ya que aunque en los valores medios del análisis descriptivo se mostraba una tendencia a tener peores resultados en la cara Norte, no se confirma estadísticamente con el análisis de contraste de hipótesis, por tanto no hay un patrón claro de efecto orientación frente a la referencia, ni entre a las distintas orientaciones dentro de una misma ubicación. Lo que si se demuestra en el análisis entre ubicaciones, es que la ubicación si influye en la pérdida de resistencia y que la mejor ubicación en este caso es Ávila.

- Envejecimiento artificial: hay diferencias en la comparación de los envejecimientos artificiales con la referencia, lo que quiere decir que se produce envejecimiento y hay degradación en materia de carga máxima. Dentro del mismo método de envejecimiento no se observan diferencias entre los dos ciclos aplicados con respecto a la carga máxima, por lo que se puede afirmar que la duración del ciclo no influye en los envejecimientos aplicados. Lo que sí se demuestra es que hay diferencias significativas entre el ciclo llevado a cabo en el FCBA y el INIA.

Con todo esto se puede afirmar que la carga máxima es un problema para el CLT de abeto en los métodos ensayados, ya que se produce degradación con respecto a la referencia, tanto en el envejecimiento natural como en el artificial. También se puede afirmar que la orientación no influye aunque la ubicación si, y que la duración de los ciclos aplicados no influye aunque si lo hace el método de envejecimiento aplicado.

Por tanto no se puede confirmar con resultados estadísticamente significativos que la orientación influya en la degradación del CLT de abeto en términos de delaminación o de carga máxima, lo que sí se puede afirmar es que la ubicación influye, y que de las ubicaciones estudiadas la mejor es Ávila. También se puede afirmar estadísticamente que los envejecimientos aplicados no influyen en la delaminación, así como si lo hacen en la carga máxima. Y con respecto al envejecimiento artificial si se confirma que los envejecimientos aplicados son claramente diferentes, aunque no hay diferencia en la duración de los ciclos dentro de un mismo envejecimiento. 
Los factores climáticos que más influyen en la degradación del CLT de abeto son la precipitación y la temperatura exterior, que afectan directamente a la humedad de la madera, y sobre todo al gradiente de humedad, es decir, la velocidad con el agua entra y sale de la madera. Estos factores tienen un mayor efecto sobre la carga máxima, y por tanto sobre la degradación del material madera, ya que aunque también afectan a la delaminación y por tanto al CLT como producto, como se ha visto su influencia sobre este parámetro no es significativa.

Según esto el CLT de abeto sufre degradación en carga máxima o lo que es lo mismo, pérdida de resistencia, cosa que se le puede atribuir al material, en este caso madera de abeto, pero no en términos de delaminación, por lo tanto sería apto como producto, y según los ensayos llevados a cabo sería apto para su utilización en clase de servicio 3 con la restricción de clase de uso 3.1, es decir como paramento.

\subsection{Conclusiones parciales sobre el pino}

Atendiendo al envejecimiento total, evaluado a través de un análisis comparativo entre todos los métodos de envejecimiento aplicados y la referencia, se puede afirmar que para el pino no hay pérdidas por delaminación, ya que aunque aparecen unas pequeñas pérdidas en el análisis descriptivo, se confirma estadísticamente con el análisis de contraste de hipótesis que no hay pérdidas significativas.

Analizando de forma independiente los envejecimientos natural y artificial, se observa que:

- Envejecimiento natural: no hay diferencias en la comparación del envejecimiento natural con la referencia, lo que quiere decir que no se produce envejecimiento o degradación en materia de delaminación, o al menos esta no es representativa. Tampoco se muestran diferencias en la comparación entre las distintas orientaciones, tanto en la comparación con la referencia como sin esta, lo que quiere decir que no se puede afirmar que exista un efecto de orientación para la delaminación en su envejecimiento al exterior, ya que aunque en los valores medios del análisis descriptivo mostraba una tendencia a tener peores resultados la cara Sur, no se confirma estadísticamente con el análisis de contraste de hipótesis, por tanto no hay un patrón claro de efecto de orientación frente a la referencia, ni entre las distintas orientaciones de una misma ubicación. Lo que si se demuestra en el análisis entre ubicaciones, es que la ubicación si influye en la delaminación y que la mejor ubicación en este caso es Ávila.

- Envejecimiento artificial: no hay diferencias en la comparación de los envejecimientos artificiales con la referencia, lo que quiere decir que no se produce envejecimiento o degradación en materia de delaminación, o al menos esta no es significativa. Dentro del mismo método de envejecimiento no se observan diferencias entre los dos ciclos aplicados con respecto a la delaminación, por lo que se puede afirmar que la duración del ciclo no influye en los envejecimientos aplicados. Tampoco se demuestra que haya diferencias entre los métodos de envejecimiento llevados a cabo en el INIA y en el FCBA.

Con todo esto se puede afirmar que la delaminación no es un problema para el CLT de pino en los métodos ensayados, ya que no se produce degradación con respecto a la referencia, o al menos no es representativa, ya que no se puede demostrar estadísticamente. También se puede afirmar que la 
orientación no influye aunque la ubicación si, y que la duración de los ciclos aplicados no influye aunque si lo hace el método de envejecimiento aplicado.

Atendiendo al envejecimiento total, evaluado a través de un análisis comparativo entre todos los métodos de envejecimiento aplicados y la referencia, se puede afirmar que para el pino no hay pérdidas de resistencia expresado por el valor de la carga máxima, ya que aunque se muestran pequeñas pérdidas en el análisis descriptivo, no se confirma estadísticamente con el análisis de contraste de hipótesis, únicamente en el caso del envejecimiento artificial en el INIA en la modalidad de ciclo largo y en el FCBA en la modalidad de ciclo corto, presentan degradación significativa.

Analizando de forma independiente los envejecimientos natural y artificial, se observa que:

- Envejecimiento natural: no hay diferencias en la comparación del envejecimiento natural con la referencia, lo que quiere decir que no se produce envejecimiento y por tanto no hay degradación en materia de carga máxima. No se muestran diferencias en la comparación entre las distintas orientaciones, por lo que no se puede afirmar que exista un efecto de orientación para la pérdida de resistencia en su envejecimiento al exterior, ya que aunque en los valores medios del análisis descriptivo se mostraba una tendencia a tener peores resultados en la cara Oeste, no se confirma estadísticamente con el análisis de contraste de hipótesis, por tanto no hay un patrón claro de efecto orientación frente a la referencia, ni entre las distintas orientaciones dentro de una misma ubicación. Lo que si se demuestra en el análisis entre ubicaciones, es que la ubicación si influye en la pérdida de resistencia y que la mejor ubicación en este caso es Sevilla.

- Envejecimiento artificial: hay diferencias en la comparación de los envejecimientos artificiales con la referencia en el caso del FCBA en su modalidad de ciclo corto y en el INIA en su modalidad de ciclo largo. Interpretando los datos se puede afirmar que se produce envejecimiento y degradación en el caso del INIA, ya que según los datos se considera que en el FCBA no hay. Dentro del mismo método de envejecimiento se observan diferencias entre los dos ciclos aplicados con respecto a la carga máxima en el FCBA, aunque se considera que se produce por la heterogeneidad del material, en el caso del INIA no se producen, por tanto se puede afirmar que hay diferencias significativas entre el ciclo llevado a cabo en el FCBA y el INIA, pero no en las diferentes modalidades, duración del ciclo, dentro del mismo método de envejecimiento

Con todo esto se puede afirmar que la carga máxima no es un problema para el CLT de pino en los métodos ensayados, ya que no se produce degradación con respecto a la referencia en ningún método de envejecimiento, excepto en el llevado a cabo en el INIA en su modalidad de ciclo largo, y las pérdidas no son representativas. También se puede afirmar que la orientación no influye aunque la ubicación si, y que la duración de los ciclos aplicados no influye aunque si lo hace el método de envejecimiento aplicado.

Por tanto no se puede confirmar con resultados estadísticamente significativos que la orientación influya en la degradación del CLT de pino en términos de delaminación o de carga máxima, lo que sí se puede afirmar es que la ubicación influye, y que de las ubicaciones estudiadas la mejor es Ávila en el caso de la delaminación y Sevilla en el caso de la carga máxima. También se puede afirmar estadísticamente que los envejecimientos aplicados no influyen en la delaminación, así como si lo hacen en la carga máxima. Y con respecto al envejecimiento artificial si se confirma que los envejecimientos apli- 
cados son claramente diferentes, aunque no hay diferencia en la duración de los ciclos dentro de un mismo envejecimiento.

Los factores climáticos que más influyen en la degradación del CLT de pino son la precipitación y la temperatura exterior, que afectan directamente a la humedad de la madera, y sobre todo al gradiente de humedad, es decir, la velocidad con el agua entra y sale de la madera. Estos factores tienen un mayor efecto sobre la carga máxima, y por tanto sobre la degradación del material madera, ya que aunque también afectan a la delaminación y por tanto al CLT como producto, como se ha visto su influencia sobre este parámetro no es significativa.

Según esto el CLT de pino sufre un degradación en carga máxima o lo que es lo mismo, pérdida de resistencia, cosa que se le puede atribuir al material, en este caso madera de pino, pero no en términos de delaminación, por lo tanto sería apto como producto, y según los ensayos llevados a cabo sería apto para su utilización en clase de servicio 3 con la restricción de clase de uso 3.1, es decir como paramento.

\subsection{Conclusiones generales}

A la hora de verificar la aptitud al uso del CLT, hay que tener en cuenta que es un producto, y por tanto tiene componentes, en este caso madera, que es el material principal que lo compone, y cola, que es el agente aglomerante que hace que el material principal pueda ensamblarse y así diseñar la geometría y dimensiones del producto final.

Por tanto cuando hablamos de la degradación del CLT tenemos que tener en cuenta ambos factores, la degradación del material y del aglomerante. Según la investigación llevada a cabo, el aglomerante no presenta ningún tipo de problema frente a los envejecimientos a los que se ve sometido durante su experimentación, por lo que se puede afirmar que mantiene la integridad del producto respecto a la unión de las piezas de madera que lo conforman. En cambio, la respuesta del material que compone el CLT va a variar en función de la especie de la que proceda.

Con respecto a la influencia de los diferentes factores que afectan a la degradación del CLT, tanto en el envejecimiento natural como en el artificial se demuestra que el factor condicionante es el aporte de agua líquida, pero este factor está condicionado por otros factores adyacentes como la temperatura, que marcarán el ritmo de incorporación de esta agua a la madera o gradiente de entrada, que será el que realmente defina el comportamiento del material.

Durante su exposición al exterior, en las tres ubicaciones seleccionadas, el CLT de pino y de abeto utilizado en el estudio no ha sobrepasado el $15 \%$ de humedad de madera en el centro de la pieza, por lo que no ha cambiado de clase de uso y por tanto de clase de servicio.

Es muy importante la selección de la madera que va a conformar el CLT, ya que dependiendo de la climatología donde se vaya a exponer al exterior el resultado podrá variar, especies como el abeto que funcionan muy bien al exterior en climas nórdicos no se comportan de igual manera en la península ibérica.

Anatómicamente la madera de abeto tiene una estructura más uniforme, pero con respecto al comportamiento general que se observa según los datos de esta investigación, el comportamiento del pino con 
respecto a los envejecimientos aplicados en este estudio es más homogéneo y por tanto más predecible a la hora de modelizar su envejecimiento y en caso de querer predecir su vida útil como material de construcción.

Por último la ubicación es un factor fundamental en el comportamiento de la madera al exterior, ya que una misma clase de uso, tendrá comportamientos diferentes según la ubicación en la que se encuentre, lo que puede hacer que cumpla o no para la clase de servicio para la que ha sido prescrita.

A tenor de lo expuesto se concluye que:

- Los métodos de envejecimiento empleados para la verificación de la aptitud al uso del CLT en clase de servicio 3, son muy exigentes con el producto y con las condiciones reales a las que este se enfrenta en su uso al exterior como paramento.

- Los métodos propuestos para la evaluación de la aptitud al uso para el CLT en clase de servicio 3 como paramento, son adecuados, ya que generan un proceso degradativo que al menos iguala al proceso sufrido al exterior por este material.

- El CLT como producto es apto para su uso en clase de servicio 3 como paramento, siempre que la especie escogida para elaborarlo sea resistente a la degradación abiótica a la que se expone.

- Para asegurar la resistencia a la degradación abiótica de la madera, se deben usar especies adaptadas al medio en el que van a llevar a cabo su vida en servicio, en el caso de España es mejor la madera de pino que la de abeto.

- En el caso de la madera, la clase de servicio 3 debería tener una subdivisión en función de si el uso del producto se produce en posición horizontal, o en posición vertical, como paramento, ya que su comportamiento en estas dos circunstancias es muy diferente.

- Tanto para las definiciones de clase de uso como para las de clase de servicio hay que tener en cuenta la ubicación, o lo que es lo mismo, algún tipo de índice climático que permita subir o bajar la clase de uso en función de la exposición.

- Aunque no se ha podido demostrar estadísticamente, se puede intuir el efecto de la orientación en el comportamiento del CLT al exterior como paramento.

- El parámetro que más influye en la degradación de la madera es el aporte de agua líquida, al exterior este aporte se lleva a cabo principalmente en forma de precipitación. Esta precipitación y la degradación que va a producir en la madera va a estar condicionada por la cantidad de precipitación efectiva, y por el gradiente en que el agua procedente de esta precipitación se incorpora a la madera. 


\section{Capítulo 7}

\section{Futuras líneas de investigación}

A la luz de los resultados obtenidos en el desarrollo de la presente tesis doctoral, en materia de degradación del CLT. Se plantean las siguientes futuras líneas de investigación:

LINEA 1: Investigación de la degradación del CLT en función del grosor de las láminas que lo componen

El comportamiento frente a la degradación del CLT, entre otros factores está condicionado por el grosor de lámina utilizado para su fabricación. Esto es debido a que las tensiones generadas por el gradiente de humedad variarán en función de este parámetro y tendrán como consecuencia un diferente proceso degradativo.

LINEA 2: Investigación de la degradación abiótica de la madera que compone el CLT para diferentes especies en diferentes localizaciones representativas de la geografía española

Las maderas, en general, tienen una estructura común, que está claramente diferenciada entre coníferas y frondosas. Aunque dentro de estos dos grupos existen unas características anatómicas similares, que les confieren unas propiedades estructurales, también poseen otras características, que las hacen diferentes y que condicionan su comportamiento, como es el caso de la plasticidad/elasticidad en función de la especie.

LINEA 3: Investigación de la degradación del CLT en su exposición al exterior, aumentando su durabilidad con una capa de sacrificio compuesta por especies de madera de al ta durabilidad

Las especies de madera, como se ha comendo, tienen diferentes propiedades intrínsecas que les confieren una durabilidad biótica y abiótica característica. Lo que hace que la conformación del tablero con diferentes especies, usando la más durable como capa de sacrificio, que no compute en el cálculo estructural del producto, sirva para aumentar la vida útil del CLT en su uso exterior.

LINEA 4: Estudio de factores de corrección de las clases de uso de madera al exterior en función de la zona climática y las soluciones de diseño empleadas 
Es necesario investigar la influencia climática y las mejoras que el diseño puede aportar a la exposición al exterior de los productos derivados de la madera, para la reforma de las clases de servicio, ya que la clase de servicio 3 es demasiado amplia, y limita en exceso el uso de la madera al exterior. Es necesaria la subdivisión de esta clase y la ampliación de los usos de los productos derivados de la madera en clase de servicio 3.

LINEA 5: Optimización del comportamiento mecánico y funcional del tablero CLT seleccionando láminas de diferente espesory dirección dentro de un mismo tablero

Al igual que ya ocurre con el tablero de LVL, sería posible diseñar productos con direcciones y espesores de lámina seleccionados en función de las propiedades mecánicas buscadas y que, a la vez, minimicen las tensiones que se generan en las diferentes láminas de CLT, lo que ampliaría su durabilidad abiótica.

LINEA 6: Estudio de la protección del CLT en su exposición al exterior con propuestas arquitectónicas

Una vez demostrada la aptitud al uso del CLT para clase de servicio 3, en clase de uso 3.1, se debe estudiar su protección mediante propuestas arquitectónicas (aleros, detalles constructivos, etc.) y con tratamientos especiales para su uso al exterior, para conseguir minimizar su degradación abiótica y alargar su vida en servicio.

LINEA 7: Posibilidades del CLT como elemento estructural tanto en obra nueva como en rehabilitación

Cada día aparecen más ejemplos de utilización del CLT. En países como España se hace necesaria la investigación sobre las posibilidades que presenta este producto tanto en obra nueva como en rehabilitación. En este último caso se trata de un producto idóneo en construcciones históricas y en ampliaciones en altura de edificios existentes, debido a su ligereza y resistencia.

LINEA 8: Sostenibilidad y análisis de ciclo de vida del CLT

Con las políticas actuales de eficiencia energética, integradas actualmente en el Código Técnico de la Edificación, y con la previsible inclusión en el mismo de parámetros de sostenibilidad, se hace necesaria la investigación de las propiedades que este producto presenta en este campo, y de los beneficios en materia de sostenibilidad que puede aportar al proceso constructivo. 


\section{Capítulo 8}

\section{Índices de calidad de la tesis}

La valoración de los índices de calidad de la tesis doctoral, se basa en el rendimiento científico llevado a cabo durante el periodo de formación para la presentación de la tesis doctoral. A continuación se ofrece una relación de las aportaciones científicas correspondientes a dicho periodo.

\section{Contribuciones y Ponencias a Congresos}

1. Título: Vida en servicio en función de la durabilidad de la madera contralaminada Autores: Galván, J., Oteiza, I., Martínez, E., Fernández-Golfín, J.I., Anaya, J.J.

Congreso: I Jornadas LICNOMAD. Barcelona, Junio 2016.

Publicación: Resúmenes del Congreso, 3-4.

Tipo de participación: Presentación oral

2. Título: Effect of sawing pattern and species on the permeability to water of two conifers: radiata and scots pine

Autores: Fernández-Colfin, J.I.; Galvan, J.; Conde, M.; Conde, M.

Congreso: Fourth COST Action FP1303 International Conference. Designing with bio-based building materials - Challenges and opportunities. Madrid, Spain. 24-25 de Febrero de 2016.

Publicación: Actas del Congreso

ISBN: 978-91-88349-16-3

Tipo de participación: Presentación oral

3. Título: Methodological approach to the evaluation of the CLT for use in service class 3

Autores: Galván, J., Troya, T., Oteiza, I., Martinez, E., Fernández-Colfin, J.I.

Congreso: Fourth COST Action FP1303 International Conference. Designing with bio-based building materials - Challenges and opportunities. Madrid, Spain. 24-25 de Febrero de 2016.

Publicación: Actas del Congreso

ISBN: 978-91-88349-16-3

Tipo de participación: Presentación oral 
4. Título: A wireless system for monitoring the internal temperature and humidity values of different types of wood

Autores: S. Aparicio, J. Galván, M.G. Hernández, J.I. Fernandez-Colfin, J.J. Anaya.

Congreso: Fourth COST Action FP1303 International Conference. Designing with bio-based building materials - Challenges and opportunities. Madrid, Spain. 24-25 de Febrero de 2016.

Publicación: Actas del Congreso

ISBN: 978-91-88349-16-3

Tipo de participación: Presentación oral

5. Título: Construcción con madera, evolución de la sostenibilidad de materiales de construcción. El caso del CLT

Autores: Galván, J.; Oteiza, I.; Fernández-Colfín, J.I.; Martínez, E.

Congreso: Jornadas Internacionales Conmemorativas del 80 Aniversario del IETcc. Madrid, España. 12-14 de Noviembre de 2014.

Publicación: Actas del Congreso

ISBN:

Tipo de participación: Póster

6. Título: Durability and service class of CLT. The case of Spain

Autores: Galván, J.; Oteiza, I.; Fernández-Colfín, J.I.; Troya, M.T.; Martínez, E.

Congreso: COST ACTION FP1303 1st Conference Performance and maintenance of bio- based building materials influencing the life cycle and LCA. Kranjska Cora, Slovenia. 23-24 de Octubre de 2014.

Publicación: Actas del congreso

ISBN:

Tipo de participación: Presentación Oral

7. Título: Madera contralaminada (CLT), una alternativa real para una construcción sostenible en España Autores: Galván, J.; Carabaño, R.; Oteiza, I.; Martínez, E.

Congreso: I Congreso Internacional sobre Investigación en Construcción y Tecnología Arquitectónicas. Madrid, España. 11-12 y 13 de junio de 2014.

Publicación: Actas del Congreso.

ISBN:

Tipo de participación: Presentación Oral

8. Título: Evolución en la innovación de productos de madera para la construcción. A través del análisis de los productos con DITE

Autores: Oteiza, l.; Galván, ..; Cuerdo, T.

Congreso: Jornadas Internacionales de Investigación en Construcción "Viviendas; pasado, presente y futuro". Madrid, España. 21-22 de noviembre de 2013.

ISBN:

Tipo de participación: Presentación oral

Publicación de artículos en revistas especializadas 


\section{TESIS DOCTORAL}

1. Título: Wood decay hazard in Spain using the Scheffer index: proposal for an improvement Autores: Fernandez-Colfin, J.I.; Larrumbide, E.; Ruano, A.; Galvan, J.; Conde, M Referencia: European Journal of Wood and Wood Products. (2016). 74 (4): 591-599. DOI: 10.1007/s00107-016-1036-z

Pertenencia a redes de investigación

1. Título: LICNOMAD: Red para el impulso de la madera y otros materiales lignocelulósicos en el sector de la construcción

Temática: La red LIGNOMAD tiene como propósito impulsar el avance en la investigación y el intercambio de conocimientos y experiencias entre grupos de investigación multidisciplinar de diferentes regiones de España con objetivos e intereses de investigación comunes.

Ámbito: Nacional

Pertenencia: 2016 - Actualidad

2. Título: FPS COST Action FP1303 Performance of bio-based building materials

Temática: Plataforma de interconexión e intercambio científico entre diferentes disciplinas; tecnología de la madera, biología, biotecnología, física del edificio e ingeniería. Estudio de los estados límite para desarrollar la predicción de la vida útil y los modelos de rendimiento, teniendo en cuenta aspectos estéticos y funcionales en la construcción.

Ámbito: Europeo

Pertenencia: 2014 - Actualidad

Organización de actividades de investigación

1. Título: Designing with bio-based building materials -Challenges and opportunities

Tipo de actividad: Local Organizer

Ámbito: Europeo

Tema: COST Action FP1303

Lugar de celebración: Madrid

Fecha: Febrero 2016

Conferencias y cursos impartidos en seminarios, máster, etc.

1. Título: Construir com CLT

Ponencia: "Durabilidade de Construçoes em CLT"

Tipo de actividad: Ponente

Ámbito: Internacional

Lugar de celebración: Oporto

Año: 2016

2. Título: Master en Real State y Facility Management

Ponencia: "Estrategias Bioclimáticas en Edificación, Sistemas pasivos"

Tipo de actividad: Ponente 
Ámbito: Nacional

Lugar de celebración: Madrid

Año: 2016

3. Título: Have a Wood Day

Ponencia: "La Cadena de Suministro de Materiales Sostenibles en el sector de la Construcción"

Tipo de actividad: Ponente

Ámbito: Nacional

Lugar de celebración: Madrid

Año: 2015

4. Título: Escuela de Arquitectura - UPM

Ponencia: "Productos estructurales de madera para la construcción"

Tipo de actividad: Ponente

Ámbito: Nacional

Lugar de celebración: Madrid

Año: 2015

5. Título: Escuela de Arquitectura-UPM

Ponencia: "Productos estructurales de madera para la construcción"

Tipo de actividad: Ponente

Ámbito: Nacional

Lugar de celebración: Madrid

Año: 2014

6. Título: Grado en arquitectura de interiores - UPM

Ponencia: "Productos de madera para la construcción"

Tipo de actividad: Ponente

Ámbito: Nacional

Lugar de celebración: Madrid

Año: 2014

7. Título: Grado en arquitectura de interiores - UPM

Ponencia: "Productos de madera para la construcción"

Tipo de actividad: Ponente

Ámbito: Nacional

Lugar de celebración: Madrid

Año: 2013

Becas

1. Beca de investigación JAE_Predoc_CP

Beca de cuatro años para la realización de la presente tesis doctoral, Ilevada a cabo en el Instituto de Ciencias de la Construcción Eduardo Torroja del CSIC, Madrid. 


\section{TESIS DOCTORAL}

2. Beca de investigación Trees4Future

Beca para el acceso a laboratorios de alto nivel para investigaciones relevantes. Concedida para la investigación de la tesis doctoral en el FCBA, Burdeos (Francia). 



\section{Bibliografía}

Abrahamsen, R. B. y K. A. Malo (2014). «Structural design and assembly of "treet"-a 14-storey timber residential building in norway». En: World Conference on Timber Engineering 2014, pág. 8 (vid. pág. 81).

Aicher, S. y G. Dill-Langer (1997). «Climate induced stresses perpendicular to the grain in glulam». Otto CrafJournal 8, págs. 209-231 (vid. pág. 90).

Allue, J. (1966). «Subregiones fitoclimáticas de España». Instituto Forestal de Inv. y Exp. Madrid (vid. pág. 105).

Allué, ]. (1990). «Atlas fitoclimático de España». Taxonomías. Ministerio de Agricultura, Pesca y Alimentación. INIA Madrid (vid. pág. 105).

Alvarez, H.y ]. Fernández-Colfin (1996). «Humedad de la madera en la construcción: valores recomendados y riesgo de cambio dimensional». España. Centro de investigación forestal. CIFORINIA. AITIM 182, págs. 65-71 (vid. págs. 33, 38, 128).

ANSI/APA PRC 320 (2011). Standard for Performance-Rated Cross Laminated Timber. APA-The Engineered Wood Association (vid. pág. 64).

APA (2013). Engineered Wood Products for Superior Performance. The Engineered Wood Association (vid. pág. 59).

Aparicio, S., M. Martinez, J. Fuente, J. Ranz, R. Fort, M. Izquierdo y ]. Anaya (2014). Advances In Sensor Networks Research. Cap. Wireless sensor networks for concrete and architectural heritage applications, págs. 229-256. ISBN: 978-1-62948-679-6 (vid. págs. 125, 126).

Augusta, U., A. Rapp y D. Eckstein (2004). «Dauerhaftigkeit der wichtigsten heimischen Hölzer bei realitätsnaher Prüfung unter bautypischen Bedingungen». Abschlussbericht zum Forschungsprojekt 699-74 der Deutschen Cesellschaft für Holzforschung, München (vid. pág. 44).

Barber, N. (1968). «A theoretical model of shrinking wood». Holzforschung-International Journal of the Biology, Chemistry, Physics and Technology of Wood 22(4), págs. 97-103 (vid. pág. 29).

Barber, N. y B. Meylan (1964). «The anisotropic shrinkage of wood. A theoretical model». HolzforschungInternational Journal of the Biology, Chemistry, Physics and Technology of Wood 18(5), págs. 146-156 (vid. pág. 29).

Barrios, E., W. Contreras, M. O. De Cy M. Rondón (2011). «Sistema estructural de marco portante para edificaciones con madera, Araguaney-l». Revista Forestal Venezolana 55(1), págs. 75-90 (vid. pág. 74).

Beesley, ]., J. Creffield e I. Saunders (1983). «An Australian test for decay in painted timbers exposed to the weather». Forest Products Journal (USA) (vid. págs. 44, 45). 
Behnke, C. y K.-E. Militzer (1994). «A simulation model for timber drying checked by measurements at technical kilns». Drying Technology 12(8), págs. 1841-1862. DOI: 10.1080/07373939408962209 (vid. pág. 35).

Bodig, J. y B. Jayne (1993). Mechanics of Wood and Wood Composites. Krieger Publishing Company. ISBN: 9780894647772 (vid. págs. 28, 34).

Brandner, R., G. Flatscher, A. Ringhofer, G. Schickhofery A. Thiel (2016). «Cross laminated timber (CLT): overview and development». European Journal of Wood and Wood Products 74(3), págs. 331-351 (vid. págs. 58, 59, 61, 63, 65, 78, 80).

Brischke, C. (2007). «Investigation of decay influencing factors for service life prediction of exposed wooden components». Tesis doct. Dissertation, University of Hamburg (vid. pág. 45).

Brischke, C. y A. Rapp (2010). «Service life prediction of wooden components-Part 1: Determination of dose-response functions for above ground decay.» En: 41st Annual Meeting of the International Research Croup on Wood Protection, Biarritz, France, 9-13 May 2010. IRC Secretariat (vid. pág. 45).

Brischke, C., L. Meyer, G. Alfredsen, M. Humar, L. Francis, P. Flæte y P. Larsson-Brelid (2012). «Durability of timber products-Part 1: inventory and evaluation of above ground literature data on natural durability of timbers». The International Research Croup on Wood Protection, IRC/WP, págs. 12-20498 (vid. pág. 46).

Brischke, C. y E. F. Hansson (2011). «Modeling biodegradation of timber-Dose-response models for above-ground decay and its climate-dependent variability». En: International Conference on Structural Health Assessment of Timber Structures, Lisbon, Portugal. Citeseer (vid. pág. 93).

Brischke, C., R. Bayerbach y A. Otto Rapp (2006). «Decay-influencing factors: A basis for service life prediction of wood and wood-based products». Wood Material Science and Engineering 1 (3-4), págs. 91-107 (vid. págs. 47-44).

Brischke, C., A. O. Rapp, R. Bayerbach, N. Morsing, P. Fynholm y C. R. Welzbacher (2008). «Monitoring the "material climate" of wood to predict the potential for decay: Results from in situ measurements on buildings». Building and Environment 43(10), págs. 1575-1582 (vid. pág. 45).

Brischke, C., E. Frühwald, D. Kavurmaciy S. Thelandersson (2011). «Decay hazard mapping for Europe». eng. En: IRC 2017. Ed. por]. Jermer. International research group on wood protection (vid. págs. 45, 46, 93).

Brischke, C. et al. (2013a). «A critical view on early indicators for above ground field performance of wood». En: Jahresberichtskategorie: 13-S1. Stockholm: IRC Secretariat, págs. 1-24 (vid. pág. 93).

Brischke, C., L. Meyer, T. Bornemann, M. Bilstein, B. Lauenstein, J.-M. Lücky C. Wulf (2013b). «Service life of timber components: prognosis based on 3 years high-frequency monitoring». English. European Journal of Wood and Wood Products 71 (1), págs. 79-90. Dol: 10.1007/s00107-012-0640-9 (vid. pág. 93).

Bulcke, J. Van den, J. Van Acker y ]. De Smet (2009). «An experimental set-up for real-time continuous moisture measurements of plywood exposed to outdoor climate». Building and Environment 44(12), págs. 2368-2377 (vid. pág. 45).

Burgert, I., J. Keckes, K. Frühmann, P. Fratzl y S. E. Tschegg (2002). «A Comparison of Two Techniques for Wood Fibre Isolation - Evaluation by Tensile Tests on Single Fibres with Different Microfibril Angle». Plant Biology 4(1), págs. 9-12. ISSN: 1438-8677. DOI: 10.1055/s-2002-20430 (vid. pág. 28). 
Burgert, I. y D. Eckstein (2001). «The tensile strength of isolated wood rays of beech (Fagus sylvatica L.) and its significance for the biomechanics of living trees». Trees 15(3), págs. 168-170. ISSN: 14322285. DOI: $10.1007 /$ s004680000086 (vid. pág. 27).

Buxbaum, C., O. Pankratz, M. Schorery W. Thalhammer (2009). «Hygrothermal performance of habitable basements made in timber constructions». En: Proceedings of 4th International Building Physics Conference, Istanbul, Turkey, June 15-78 (vid. pág. 46).

Bylund, D. (2012). «Innovations in the use of engineered timber in Australian architecture: advanced Scandinavian engineered timber and industrialised construction techniques in an Australian setting». En: World Conference on Timber Engineering 2012, págs. 243-252 (vid. pág. 78).

Canadian Wood Council (2010). «The Design Possibilities of Engineered Wood Products». Canadian Wood Council (vid. pág. 59).

Carll, C. G. (2009). «Decay hazard (Scheffer) index values calculated from 1971-2000 climate normal data» (vid. pág. 93)

Cartwright, K. S. G. (1942). «The variability in resistance to decay of the heartwood of home-grown european larch, larix decidua, mill. ( L. Europaea) and its relation to position in the log». Forestry: An International Journal of Forest Research 16(1), pág. 49. Dol: 10.1093/forestry/16.1.49 (vid. pág. 43).

Casagrande, D., S. Rossi, T. Sartori y R. Tomasi (2016). «Proposal of an analytical procedure and a simplified numerical model for elastic response of single-storey timber shear-walls». Construction and Building Materials 102, págs. 1101-1112 (vid. pág. 79).

Cassinello, F. (1973). Construccion: carpintería. Rueda (vid. págs. 77, 85).

Cave, I. y ]. Walker (1994). «Stiffness of wood in fast-grown plantation softwoods: the influence of microfibril angle». Forest products journal 44(5), pág. 43 (vid. pág. 28).

Chapman, J. (2012). «Thirty level timber building concept based on cross-laminated timber construction» (vid. págs. 82, 83).

Chapman, ]. (2014). «Integrating cross-laminated timber panels to construct buildings to 20 levels». En: proceedings of the World Conference on Timber Engineering (WCTE), págs. 10-14 (vid. págs. 82, 83).

Chapman, J., T. Reynolds y R. Harris (2012). «A 30 level cross laminated timber building system and analysis of the eurocode dynamic wind loads». World 15, pág. 19 (vid. págs. 82, 83).

Cornick, S., W Dalgliesh y W. Maref (2010). «Sensitivity of hygrothermal analysis to uncertainty in rain data». En: Heat-Air-Moisture Transport, 2nd Volume: Measurements and Implications in Buildings. ASTM International (vid. pág. 51).

Creemers, J., M. De Meijer, T. Zimmermanny]. Sell (2002). «Influence of climatic factors on the weathering of coated wood». European Journal of Wood and Wood Products 60(6), págs. 417-420 (vid. págs. 44, 45).

Crespell, P. y S. Gagnon (2010). «Cross laminated timber: a primer». FPInnovations, Special Publication 52 (vid. pág. 67).

de Miguel, ]. (1985). «Legislación y normativa de la utilización de la madera en la construcción». En: Actas de las I Jornadas Nacionales de la Madera en la Construcción. Agrupación Nacional de Constructores de Obras (ANCOP) (vid. pág. 85).

Defraeye, T., B. Blocken y ]. Carmeliet (2013). «Influence of uncertainty in heat-moisture transport properties on convective drying of porous materials by numerical modelling». Chemical Engineering Research and Design 91 (1), págs. 36-42 (vid. pág. 51). 
Degroot, R. C. (1982). «An assessment of climate index in predicting wood decay in houses». Durability of building materials 1(2), págs. 169-174 (vid. pág. 45).

Derome, D., C. Desmarais y C. Thivierge (2007). «Large-scale experimental investigation of woodframe walls exposed to simulated rain penetration in a cold climate». En: Proceedings of Thermal Performance of the Exterior Envelopes of Whole Buildings X Conference, DOE/ORNL/ASHRAE/BETEC/ABAA, December, págs. 2-7 (vid. pág. 46).

Dietsch, P., A. Gamper, M. Merk y S. Winter (2012). «Building climate-long-term measurements to determine the effect on the moisture gradient in large-span timber structures». Proc. Iternational Counc. Res. Innov. Build. Constr. Work. Comm. W18-Timber Struct. Meet 45, págs. 1-14 (vid. pág. 126).

Dill-Langer, G. (2004). Schädigung von Brettschichtholz bei Zugbeanspruchung rechtwinklig zur Faserrichtung. Otto-Graf-Institut, Universität Stuttgart, Forschungs- und Materialprüfungsanstalt. Materialprüfungsanstalt Universität Stuttgart. ISBN: 9783980951203 (vid. pág. 35).

DIN-EN 1995-1-1 (2013). Nationaler Anhang - National festgelegte Parameter-Eurocode 5: Bemessung und Konstruktion von Holzbauten - Teil 7-7: Allgemeines - Allgemeine Regeln und Regeln für den Hochbau. DIN (vid. pág. 64).

Dinwoodie, J. (1975). «Timber - a review of the structure-mechanical property relationship». Journal of Microscopy 104(1), págs. 3-32 (vid. pág. 28).

Dinwoodie, J. (1989). Wood, nature's cellular, polymeric, fibre-composite. Book (Institute of Metals). Institute of Metals. ISBN: 9780901462350 (vid. págs. 28, 34).

Directiva 89/106/CEE de Productos de Construcción (1989). relativa a la aproximación de las disposicones legales, reglamentarias y administrativas de los Estados Miembros sobre los productos de construcción. Comisión Europea (vid. págs. 42, 63, 86, 87, 92).

Dröge, G.y K.-H. Stoy (1981). Crundzüge des neuzeitlichen Holzbaues. 1. Konstruktionselemente: Berechnung und Ausführung. Mit 30 Tabellen (Basics of contemporary timber engineering: construction elements, design and execution). Ernst (vid. pág. 59).

Dyken, T. y H. Klepp (2010). «Monitoring the moisture content of timber bridges». ICTB 2010 (vid. págs. 126, 127, 134, 137).

E. Hormias, S. B. y (2012). «Consolidación estructural del edificio patrimonial de C/Ripoll, 25 de Barcelona - Ca la Dona». Informes de la Construcción 64(Extra), págs. 79-94. ISSN: 1988-3234. DOI: 10.3989/ic.11.051 (vid. pág. 84).

Ellis, B. y A. Bougard (2001). «Dynamic testing and stiffness evaluation of a six-storey timber framed building during construction». Engineering Structures 23(10), págs. 1232-1242 (vid. pág. 79).

Engelund, E. T., L. G. Thygesen, S. Svensson y C. A. Hill (2013). «A critical discussion of the physics of wood-water interactions». Wood science and technology 47(1), págs. 141-161 (vid. pág. 51).

Eslyn, W. E., T. L. Highley y F. F. Lombard (1985). «Longevity of untreated wood in use above ground». Forest Products Journal 35(5), págs. 28-35 (vid. pág. 93).

Evans, L. (2013). «Cross-Laminated Timber: Taking wood buildings to the next level». Architectural Records (vid. págs. 61, 80).

Falk, A. (2013). «Cross-laminated timber: Driving forces and innovation». Structures and Architecture: Concepts, Applications and Challenges, págs. 511-518 (vid. págs. 78, 79).

Fengel, D. y G. Wegener (1989). Wood: chemistry, ultrastructure, reactions. 2nd ed. Walter de Gruyter (vid. pág. 43). 
Fernandez-Colfin, J., R. Diez y V. Sanchis (1988). «Mejora del ensayo de tracción perpendicular a las caras en tableros aglomerados». Boletín de información técnica (24), págs. 19-21. ISSN: 0044-9261 (vid. págs. 151, 157)

Fernandez-Golfin, J., E. Larrumbide, A. Ruano, J. Galvan y M. Conde (2016). «Wood decay hazard in Spain using the Scheffer index: proposal for an improvement». European Journal of Wood and Wood Products 74(4), págs. 591-599 (vid. pág. 145).

Fernández-Colfin, J., M. Conde, M. Diez, M. Conde, L. Acuña, E. Torres, E. Pereay M. Troya (2017). «Decay of wood in outdoor above ground applications: Preview of results on the effect of climate and species in Spain». eng. En: IRC 2017. Ed. por]. Jermer. International research group on wood protection (vid. págs. 38, 236).

Fernández-Colfín, J., M. Conde, J. Fernandez-Colfin, R. Calvo, M. Baonza y P. d. P. y Palacios (2012). «Curves for the estimation of the moisture content of ten hardwoods by means of electrical resistance measurements». Forest Systems 21 (1), págs. 121-127 (vid. pág. 127).

Filiatrault, A., I. P. Christovasilis, A. Wanitkorkul y ]. W. van de Lindt (2009). «Experimental seismic response of a full-scale light-frame wood building». Journal ofstructural engineering 136(3), págs. 246-254 (vid. pág. 79).

Fleming, P., S. Smith y M. Ramage (2014). «Measuring-up in timber: a critical perspective on midand high-rise timber building design». Architectural Research Quarterly 18(01), págs. 20-30 (vid. págs. 82-84).

Folz, B. y A. Filiatrault (2001). «Cyclic analysis of wood shear walls». Journal of Structural Engineering 127(4), págs. 433-441 (vid. pág. 79).

Fragiacomo, M., S. Fortino, D. Tononi, I. Usardi y T. Toratti (2011). «Moisture-induced stresses perpendicular to grain in cross-sections of timber members exposed to different climates». Engineering Structures 33(11). Modelling the Performance of Timber Structures, págs. 3071-3078. ISSN: 01410296. Dol: http://dx.doi.org/10.1016/j. engstruct.2011.06.018 (vid. págs. 38-41).

Frech, P. y K. Möhler (1987). Beurteilungskriterien für Rissbildungen bei Bauholz im konstruktiven Holzbau. Entwicklungsgemeinschaft Holzbau id Dt. Ces. für Holzforschung (vid. pág. 40).

Frühwald, E., E. Serrano, T. Toratti, A. Emilsson y S. Thelandersson (2007). «Design of Safe Timber Structures-How can we learn from structural failures in concrete, steel and timber?» (Vid. pág. 40).

Gagnon, S. y C. Pirvu (2011). CLT handbook: cross-laminated timber. FPInnovations Québec (vid. págs. 64, $65,79)$.

Gagnon, S. (2011). «CLT acoustic performance». En: Cross Laminated Timber Symposium, págs. 8-9 (vid. pág. 61).

Gandullo, J., O. Sánchez Palomares y L. Muñoz (1998). «Una nueva clasificación climática para España». Ecología (12), págs. 67-77 (vid. págs. 118, 119).

García, L. (1999). «Historia de la tecnología de la madera». Boletín de Información Técnica 198, págs. 67-71 (vid. págs. 52, 54, 60, 76).

García, L., A. Guindeo, C. Peraza y P. de Palacios (2003). La madera y su anatomía: anomalías y defectos, estructura microscópica de coníferas y frondosas, identificación de maderas, descripción de especies y pared ceIular. Fundación Conde del Valle de Salazar. ISBN: 9788484761532 (vid. pág. 25).

García-Navarro, J. y E. De la Peña (2001a). «Breve historia de la madera en la construcción (I)». Boletín de Información Técnica 211, págs. 70-75 (vid. págs. 67, 69). 
García-Navarro, J. y E. De la Peña (2001 b). «Breve historia de la madera en la construcción (II)». Boletín de Información Técnica 211, págs. 54-62 (vid. págs. 52, 59, 68).

Carcía-Navarro, J. y E. De la Peña (2002). «Breve historia de la madera en la construcción (III)». Boletín de Información Técnica 215, págs. $72-79$ (vid. pág. 68).

Carcía-Navarro, J. y E. De la Peña (2003). «Breve historia de la madera en la construcción (IV)». Boletín de Información Técnica 224, págs. 34-40 (vid. págs. 53, 67).

Carcía-Navarro, J. e I. Martínez (1996). «Aplicaciones innovadoras de la madera en la construcción». Informes de la Construcción 48(446), págs. 15-26 (vid. págs. 53-55, 58).

Gardino, P. (2011). «ll mercato italiano delle case in legno nel 2010». Promo Legno, Milano (vid. pág. 83).

Gardner, J. y G. Barton (1958). «The extraneous components of western red cedar». Forest Prod. 78 , págs. 3-6 (vid. pág. 43).

Gardner, ]. y G. Barton (1960). «The distribution of dihydroquercetin in Douglas-Fir and Western Larch.» Forest Products Journal 10(3), págs. 171-3 (vid. pág. 43).

Gasparri, E., A. Lucchini, G. Mantegazza y E. S. Mazzucchelli (2015). «Construction management for tall CLT buildings: From partial to total prefabrication of façade elements». Wood Material Science $\&$ Engineering 10(3), págs. 256-275 (vid. págs. 83, 84).

Gaussen, H. (1954). «Théorie et classification des climats et microclimats». VIlle Congrès international de botanique: 2-14 July 1954, págs. 125-130 (vid. pág. 105).

Cereke, T. y P. Niemz (2010). «Moisture-induced stresses in spruce cross-laminates». Engineering Structures 32(2), págs. 600-606 (vid. págs. 32, 41).

Geving, S. y S. Uvs|økk (2000). «Moisture conditions in timber frame roof and wall structures». Project report 273 (vid. pág. 46).

Ceving, S., T. H. Erichsen, K. Nore y B. Time (2006). Hygrothermal conditions in wooden claddings (vid. pág. 46).

Gigliotti, M., F. Jacquemin y A. Vautrin (2007). «Assessment of approximate models to evaluate transient and cyclical hygrothermoelastic stress in composite plates». International journal of solids and structures 44(3), págs. 733-759 (vid. pág. 52).

Class, S. V. y A. TenWolde (2007). Review of in-service moisture and temperature conditions in wood-frame buildings. US Department of Agriculture, Forest Service, Forest Products Laboratory Madison, WI (vid. pág. 46).

Cobakken, L. R. y P. K. Lebow (2010). «Modelling mould growth on coated modified and unmodified wood substrates exposed outdoors». Wood science and technology 44(2), págs. 315-333 (vid. pág. 45).

Coto, Y., K. C. Wakili, Y. Ostermeyer, T. Frank, N. Ando y H. Wallbaum (2011). «Preliminary investigation of a vapor-open envelope tailored for subtropical climate». Building and Environment 46(3), págs. 719-728 (vid. pág. 51).

Graciani García, A. (1995). La construcción después de la revolución industrial: una primera aproximación general. A. Craciani (vid. pág. 68).

Crinda, M. y ]. Carey (2004). «The COST euro index for fungal decay-five years results». In Proceedings of COST E22 Final Workshop (Portugal) (vid. págs. 44, 45).

Crosse, C. U. y M. Krüger (2006). «Inspection and monitoring of structures in civil engineering». NDT. net 17(1) (vid. pág. 126). 
Guinard, D. (2000). «La forêt au XXle siècle en France. Quel avenir pour la production et l'emploi du bois au siècle prochain ?»Comptes rendus de l'Académie d'agriculture de France (Paris) 86 (3), págs. 91-106 (vid. pág. 67).

Gustafsson, P. J. (2003). Fracture perpendicular to grain-structural applications. Wiley \& Sons, ISBN 0-47084469-8 (vid. pág. 50).

Gustafsson, P., P. Hoffmeyer y G. Valentin (1998). «DOL behaviour of end-notched beams». European Journal of Wood and Wood Products 56(5), págs. 307-317 (vid. pág. 50).

Guttmann, E. (2008). «Brettsperrholz: Ein Produktporträt [Cross laminated timber: a product profile]». Zuschnitt 31, págs. 12-14 (vid. pág. 59).

Cülzow, A., R. Steiger, D. Gsell, W. Wilson y G. Feltrin (2007). «Dynamic field performance of a wooden trough bridge». En: Proccedings of the International Conference on Experimental Vibration Analysis for Civil Engineering Structures (EVACES'07), (2nd, 2007, Porto, PT). Proccedings. Porto, PT, EVACES. Vol. 7, págs. 187-188 (vid. pág. 81).

Gülzow, A., K. Richter y R. Steiger (2011). «Influence of wood moisture content on bending and shear stiffness of cross laminated timber panels». European Journal of Wood and Wood Products 69(2), págs. 193-197 (vid. pág. 50).

Håkansson, H. (1998). Retarded sorption in wood (PhD Thesis). Inf. téc. Report TABK-98/1012. Sweden: Lund Institute of Technology (vid. pág. 51).

Hameury, S. (2005). «Moisture buffering capacity of heavy timber structures directly exposed to an indoor climate: a numerical study». Building and Environment 40(10), págs. 1400-1412 (vid. págs. 51, 78).

Hanhijärvi, A. (1995). Modelling of creep deformation mechanisms in wood. Disertación from Helsinki University of Technology. Espoo : Technical Research Centre of Finland (vid. págs. 33-35).

Harris, J. M. y B. Meylan (1965). «The influence of microfibril angle on longitudinal and tangential shrinkage in Pinus radiata». Holzforschung-International Journal of the Biology, Chemistry, Physics and Technology of Wood 19(5), págs. 144-153 (vid. pág. 29).

Harris, R., A. Ringhofer y G. Schickhofer (2013). «Focus solid timber solutions-European conference on cross laminated timber (CLT)». The University of Bath, Bath (vid. pág. 65).

Hartnack, R. (2005). «Langzeittragverhalten von druckbeanspruchten Bauteilen aus Holz». doctoralthesis. Bauhaus-Universität Weimar (vid. pág. 34)

Hasegawa, M. (1996). «Relationships between wood protection and climate indexes». Mokuzai Hozon 22, págs. 2-9 (vid. pág. 93).

Haupt, M., H. Leithoff, D. Meier, J. Puls, H. Richter y O. Faix (2003). «Heartwood extractives and natural durability of plantation-grown teakwood (Tectona grandis L.) - a case study». Holz als Roh-und Werkstoff 61(6), págs. 473-474 (vid. pág. 43).

He, M., F. Lam y R. O. Foschi (2001). «Modeling three-dimensional timber light-frame buildings». Journal ofStructural Engineering 127(8), págs. 901-913 (vid. pág. 79).

Hedenblad, C. (1996). «Material data for moisture transport calculations». Byggforskningsrådet: Stockholm (vid. pág. 52).

Hibbit, Karlsson \& Sorensen (2009). ABAQUS Standard User's Manual, Version 6.9 (vid. pág. 40).

Hillis, W. E. (2012). Heartwood and tree exudates. Vol. 4. Springer Science \& Business Media (vid. pág. 43).

Hoffmeyer, P. (1995a). «Holz als Baustoff». Holzbauwerke nach dem Eurocode 5, A4 (vid. pág. 50).

Hoffmeyer, P. (1995b). «Wood as a building material». Timber engineering step 1, A4 (vid. pág. 39). 
Holm, A. H. y H. M. Kuenzel (2002). «Practical application of an uncertainty approach for hygrothermal building simulations - drying of an AAC flat roof». Building and Environment 37(8), págs. 883-889 (vid. pág. 51).

Hough, R., J. Kell y]. Koopman (2012). «CLT Apartment Blocks for the Sydney Affordable Housing Market». En: World Conference on Timber Engineering (vid. pág. 83).

Hubbs, B. y M. Branch (2007). «Performance monitoring of rainscreen wall assemblies in Vancouver British Columbia». En: RDH Building Engineering Limited, Vancouver, BC, Canada (vid. pág. 46).

Hukka, A. (1999). «The effective diffusion coefficient and mass transfer coefficient of Nordic softwoods as calculated from direct drying experiments». Holzforschung 53(5), págs. 534-540 (vid. pág. 52).

Häglund, M. (2007). «Moisture content penetration in wood elements under varying boundary conditions». Wood Science and Technology 41 (6), págs. 477-490 (vid. págs. 50-52, 89).

ISO 15686-1 (2011). Building and constructed assets. Service life planning. Part 1: Ceneral principles. AENOR (vid. pág. 41).

Iwamae, A. y H. Suzuki (2008). «Durability of crawl space based on damage due to wood rot». En: Proceedings of 8th Symposium of Building Physics in the Nordic Countries, Copenhagen, June, págs. 16-18 (vid. pág. 45)

Jensen, F. (2013). «Wood structures - versatility and innovation». En: Structures and Architecture. New concepts, applications and challenges. ISBN: 978-0-415-66195-9 (vid. pág. 84).

Jermer, ]. (2011). WoodExter-Service life and performance of exterior wood above ground: Final report. Inf. téc. 2011:53. Updated 2012-09-03. SP - Sveriges Tekniska Forskningsinstitut, SP Trä (vid. págs. 92, 93).

Judd, J. P. y F. S. Fonseca (2005). «Analytical model for sheathing-to-framing connections in wood shear walls and diaphragms». Journal of Structural Engineering 131(2), págs. 345-352 (vid. pág. 79).

Jönsson, J. (2004). «Internal stresses in the cross-grain direction in glulam induced by climate variations». Holzforschung 58(2), págs. 154-159. ISSN: 1437-434X (vid. págs. 36, 90).

Jönsson, J. (2005a). «Internal stresses in glulam due to moisture gradients in the grain direction». Holzforschung 59(1), págs. 18-22 (vid. pág. 36).

Jönsson, J. (2005b). «Moisture Induced Stresses in Timber Structures». Tesis doct. Lund University, pág. 110 (vid. págs. 35, 36).

Jönsson, J. y S. Svensson (2004). «A contact free measurement method to determine internal stress states in glulam». Holzforschung 58(2), págs. 148-153. ISSN: 1437-434X (vid. pág. 36).

Kalamees, T.y ]. Vinha (2003). «Hygrothermal calculations and laboratory tests on timber-framed wall structures». Building and Environment 38(5), págs. 689-697 (vid. pág. 51).

Karacabeyli, E. y B. Douglas (2013). CLT Handbook: cross-laminated timber. FPInnovations (vid. págs. 65 , $79,80)$.

Kasal, B. y R. W. Anthony (2004). «Advances in in situ evaluation of timber structures». Progress in Structural Engineering and Materials 6(2), págs. 94-103 (vid. pág. 126).

Keunecke, D. (2008). «Elasto-mechanical characterisation of yew and spruce wood with regard to structure-property relationships». Tesis doct. ETH (vid. pág. 28).

Kollmann, F. y W. Côté (1968). Principles of Wood Science and Technology: Solid wood. Principles of Wood Science and Technology. Springer-Verlag (vid. pág. 28).

Kollmann, F. (1955). Technologie des Holzes und der Holzwerkstoffe. Springer-Verlag Berlin Heidelberg. ISBN: 978-3-642-52947-4. DOI: 10.1007/978-3-642-52947-4 (vid. pág. 31). 
Kottek, M., J. Crieser, C. Beck, B. Rudolf y F. Rubel (2006). «World map of the Köppen-Ceiger climate classification updated». Meteorologische Zeitschrift 15(3), págs. 259-263 (vid. pág. 40).

Kufner, M. (1978). «Elastizitätsmodul und Zugfestigkeit von Holz verschiedener Rohdichte in Abhängigkeit vom Feuchtigkeitsgehalt». European Journal of Wood and Wood Products 36(11), págs. 435-439 (vid. pág. 50).

Kuilen, J. Van de (2007). «Service life modelling of timber structures». Materials and structures 40(1), págs. 151-161 (vid. pág. 45).

Kutnik, M. (2008). «Assessment of the service life of outdoor timber constructions under various use conditions». En: Proceedings of COST E 37 Workshop: Enhanced durability focusing on differences in end-use related requirements, Heraklion, Greece (vid. pág. 45).

Köppen, W. y R. Geiger (1930). Handbuch der klimatologie. Vol. 3. 1. Cebrüder Borntraeger Berlin, Germany (vid. pág. 105).

Köppen, W. P. (1918). Klassifikation der klimate nach temperatur, Niederschlag und Jahreslauf. Perthes (vid. pág. 105).

Köppen, W. P. (1923). Die Klimate der Erde: Crundriss der Klimakunde. Walter de Gruyter \& Company (vid. pág. 105).

Künzel, H. M. y K. Kiessl (1996). «Calculation of heat and moisture transfer in exposed building components». International Journal of heat and mass transfer 40(1), págs. 159-167 (vid. pág. 51).

Lacasse, M., M. Manning, M. Rousseau, S. Cornick, S. Plescia, M. Nicholls y S. Nunes (2007). «Results on assessing the effectiveness of wall-window interface details to manage rainwater». En: 17th Canadian Building Science and Technology Conference. Banff Canada, págs. 1-14 (vid. pág. 45).

Lacasse, M. A. (2008). "Advances in service life prediction-an overview of durability and methods of service life prediction for non-structural building components». En: Proceedings of the annual Australasian Corrosion Association conference, Wellington Convention Centre, Wellington, NZ, págs. 1-13 (vid. pág. 45).

Laguarda Mallo, M. F. y O. Espinoza (2015). «Awareness, perceptions and willingness to adopt crosslaminated timber by the architecture community in the United States». Journal ofCleaner Production 94, págs. 198-210 (vid. págs. 60, 78, 79, 84).

Larkin, G. y P. Laks (2008). «To decay or not to decay: An accelerated field test of the validity of the Scheffer index». Document IRC/WP, págs. 08-20392 (vid. pág. 45).

Larrumbide, E., R. Villar, D. Jiménez, M. Gaviray ]. Tenorio (2013). «Clima alfa: una nueva zona climática de invierno para las islas Canarias». En: Jornadas Internacionales de Investigación en Construcción. Vivienda: Presente, pasado y futuro. (Madrid, 21-22 de nov. de 2013). Instituto Eduardo Torroja de Ciencias de la Construcción. ISBN: 978-84-7292-421-5 (vid. págs. 111, 118).

Larrumbide, E., M. Gavira y V. Sánchez (2014). «La problemática de las condensaciones intersticiales en la rehabilitación energética de edificios y su aplicación en el DB HE 2013 para las diferentes zonas climáticas peninsulares». En: Jornadas Internacionales Conmemorativas del 80 Aniversario del IETcc. (Madrid). Instituto Eduardo Torroja de Ciencias de la Construcción (vid. págs. 114-118).

Lebow, S. T. y T. Highley (2008). «Regional biodeterioration hazards in the United States». En: ACS Publications (vid. pág. 45).

Lehmann, S. (2012). «Sustainable construction for urban infill development using engineered massive wood panel systems». Sustainability 4(10), págs. 2707-2742 (vid. págs. 61, 83).

Lessing, J. (2006). «Industrialised house-building». Concept and Processes (vid. pág. 84). 
Li, Q., J. Rao y P. Fazio (2009). «Development of HAM tool for building envelope analysis». Building and environment 44(5), págs. 1065-1073 (vid. pág. 51).

Lindström, H., P. Harris y R. Nakada (2002). «Methods for measuring stiffness of young trees». Holz als Roh-und Werkstoff 60(3), págs. 165-174 (vid. pág. 28).

Lindt, J. W. Van de, S. E. Pryory S. Pei (2011). «Shake table testing of a full-scale seven-story steel-wood apartment building». Engineering Structures 33(3), págs. 757-766 (vid. pág. 79).

Liu, T. (1994). «Creep of wood under a large span of loads in constant and varying environments». Holz als Roh- und Werkstoff 52(1), págs. 63-70. ISSN: 1436-736X. DOI: 10.1007 / BF02615022 (vid. pág. 35).

Lynch, J. P. y K. J. Loh (2006). «A summary review of wireless sensors and sensor networks for structural health monitoring». Shock and Vibration Digest 38(2), págs. 91-130 (vid. pág. 126).

MacKenzie, C., C. Wang, Forest, W. P. Australia, T. Queensland, R. Leicester, G. Foliente y M. Nguyen (2007). Timber Service Life Design: Design Cuide for Durability. Market knowledge \& development. Foresty Wood Products Australia. ISBN: 9781920883164 (vid. págs. 45, 93).

Mårtensson, A. (1992). «Mechanical Behaviour of Wood Exposed to Humidity Variations.» TVBK-1006 (vid. pág. 35).

Martínez, S. R. (1980). «Les étages bioclimatiques de la végétation de la Péninsule Ibérique». En: Anales del Jardín Botánico de Madrid. Vol. 37. 2. Real Jardín Botánico, págs. 251-268 (vid. pág. 105).

Martínez, S. R.y y. M. Gandullo (1987). Memoria del mapa de series de vegetación de España: 1: 400.000 (vid. pág. 105).

Martínez Garrido, M., S. Aparicio, M. Izquierdo, R. Forty ]. Anaya (2011). «Propuesta de monitorización del deterioro en patrimonio construido mediante redes de sensores inalámbricas». En: $12^{\circ}$ Congreso Nacional de Ensayos No Destructivos, págs. 649-658 (vid. pág. 126).

McClung, R., H. Ce, J. Straubey ]. Wang (2014). «Hygrothermal performance of cross-laminated timber wall assemblies with built-in moisture: field measurements and simulations». Building and Environment 71, págs. 95-110 (vid. pág. 51).

McKeever, D. B. (1997). «Engineered wood products: a response to the changing timber resource». Pacific Rim Wood Market Report 123(5), pág. 15 (vid. pág. 59).

McMillen, J. M. (1955). «Drying Stresses in Red Oak». Forest ProductsJournal, págs. $71-76$ (vid. págs. 35-37).

Meyer, L., C. Brischke, J. Rieken, I. Morris y ]. Wang (2013). «Testing the performance of timber using 27 different field test methods». eng. En: Document IRG/WP 13-20517. Ed. por J. Jermer. International research group on wood protection (vid. pág. 93).

Miller, A. (1950). Austin, Climatology (vid. pág. 105).

Mohammad, M., S. Gagnon, B. Douglas y L. Podesto (2012). «Introduction to cross laminated timber». Wood Design Focus 22(2), págs. 3-12 (vid. págs. 59, 60, 64).

Moreno, ]. M. (2008). «Evaluación preliminar de los impactos en España por efecto del cambio climático». Boletín CF+S (38/39) (vid. págs. 108, 116).

Morlier, P. (2004). Creep in Timber Structures. Rilem Reports. Taylor \& Francis. ISBN: 9780203626573 (vid. pág. 34).

Morlier, P. y A. Ranta-Maunus (1998). «DOL effect of different sized timber beams». European Journal of Wood and Wood Products 56(5), págs. 279-284 (vid. pág. 50).

Morris, P. (2005). «Service life prediction based on hard data». En: Proceedings of COST E 37 Workshop: Service life prediction: The contribution to Sustainability, Oslo, Norway. Citeseer, págs. 19-21 (vid. pág. 45). 
Morris, P. y ]. Wang (2008a). «A new decay hazard map for North America using the Scheffer Index». Document IRC/WP, págs. 08-10672 (vid. pág. 45).

Morris, P. y ]. Wang (2008b). «Service life evaluation of wood-an engineering approach». eng. En: IRC 2008. Ed. por ]. Jermer. International research group on wood protection (vid. pág. 93).

Nadir, Y., P. Nagarajan y A. Midhun (2014). «Measuring elastic constants of Hevea brasiliensis using compression and losipescu shear test». European Journal of Wood and Wood Products 72(6), págs. 749-758. ISSN: 1436-736X. DOI: 10.1007/s00107-014-0842-4 (vid. pág. 95).

National Research Council (2010). National Building Code of Canada (NBCC) (vid. pág. 64).

NFP 23-305 (2014). Menuiseries en bois - Spécifications techniques des fenêtres, portes-fenêtres, portes extérieures et ensembles menuisés en bois - Menuiseries en bois - Spécifications techniques des fenêtres, portes-fenêtres et châssis fixes en bois. AFNOR (vid. pág. 142).

Niemz, P. (1993). Physik des Holzes und der Holzwerkstoffe. Holz: Anatomie - Chemie - Physik. DRWVerlag. ISBN: 9783871813245 (vid. pág. 34).

Niemz, P. y X. Wang (2002). «Spannungsausbildung in dreischichtigen Massivholzplatten bei Klimawechsel». Holzforschung und Holzverwertung 54(4), págs. 82-83 (vid. págs. 35, 50).

Niemz, P., H. Bärtschi y M. Howald (2005). «Untersuchungen zur Feuchteverteilung und Spannungsausbildung in Holzbauteilen bei Wechselklimalagerung| Investigation of moisture distribution and stress formation in timber construction materials under changing climatic conditions». Schweizerische Zeitschrift fur Forstwesen 156(3-4), págs. $92-99$ (vid. pág. 50).

Norén, $]$ (2001). «Assessment and mapping of environmental degradation factors in outdoor applications». Diss., KTH, Stockholm, 43p (vid. pág. 45).

Noves, H. A. y A. Guijarro (1984). Variación anual de la humedad de equilibrio de la madera de uso exterior en España. ISBN: 84-7498-188-3 (vid. pág. 117).

Nuere Matauco, E. (1998). «Ceometría y lazo en la carpintería hispano-musulmana». En: La arquitectura como diversidad. Institución Fernando el Católico, págs. 47-76 (vid. pág. 76)

Nuere Matauco, E. (2017). Conferencias y estudios sobre la carpintería de armar española. URL: http : / / enrique.nuere.es (vid. pág. 77).

Nájera, F. (1960). «Aplicaciones industriales de la madera de Chopo: estudio técnico y económico». spn. En: Conferencia en la Escuela Técnica Superior de Montes. (Madrid). Sección de publicaciones de la Escuela Técnica Superior de Ingenieros de Montes (vid. págs. 59, 95).

ONORM B 1995-1-7:2014 (2014). Eurocode 5: Design OfTimber Structures - Part 1-7: Ceneral - Common Rules And Rules For Buildings - National Specifications For The Implementation OfOnorm En 1995-7-7, National Comments And National Supplements. Osterreichisches Normungsinstitut (vid. págs. 64, 65).

Ormarsson, S. (1999). Numerical analysis of Moisture-Related Distortions in Sawn Timber. Publication Chalmers University of Technology, Department of Structural Engineering, no 99:7Doktorsavhandlingar vid Chalmers tekniska högskola. Ny serie, no: 1531. Department of Structural Mechanics, Chalmers University of Technology. ISBN: 91-7197-834-8 (vid. págs. 29, 30).

Ormazabal, M. (2017). Llegan a España los bloques de pisos de protección oficial de madera. Hondarribia construye la mayor edificación residencial del suroeste de Europa con toda la estructura de pino. El Pais. URL: http: //tinyurl.com/mh4md7q (vid. pág. 84).

Oteiza, I., J. Galván y T. Cuerdo (2013). «Evolución en la innovación de productos de madera para la construcción». En: Jornadas Internacionales de Investigación en Construcción. Vivienda: Presen- 
te, pasado y futuro. (Madrid, 21-22 de nov. de 2013). Instituto Eduardo Torroja de Ciencias de la Construcción (vid. págs. 59, 62, 75, 92).

Pallin, S. (2013). Risk Assessment of Hygrothermal Performance-Building Envelope Retrofit (PhD Thesis). Chalmers University of Technology (vid. pág. 51).

Papadakis, ]. et al. (1966). «Climates of the world and their agricultural potentialities.»Climates of the world and their agricultural potentialities. (Vid. pág. 105).

Peck, E. (1940). «A new approach to the formulation of hardwood dry kiln schedules». Southern Lumberman 161(2033), págs. 136-7 (vid. pág. 35).

Persson, K. (2000). «Micromechanical Modelling of Wood and Fibre Properties». eng. Tesis doct. Lund University, pág. 223. ISBN: 91-7874-094-0 (vid. pág. 28).

Phares, B. M., T. J. Wipf, L. F. Greimann e Y.-S. Lee (2005). Health monitoring of bridge structures and components using smart-structure technology. volume I. Inf. téc. (vid. pág. 126).

Piirto, D. D. y W. W. Wilcox (1981). Comparative properties of old and young growth giant sequoia of potential significance to wood utilization. English. Berkeley, Calif: Div. Of Agricultural Sciences, University Of California (vid. pág. 43).

Plackner, H. (2014). «Nicht mehrwegzudenken—Massivholz hat sich den Platz geschaffen [Undisputablesolid timber has created its market]». Holzkurier BSP Special 4, pág. 2014 (vid. pág. 61).

Pohlmann, J. y B. Mohr (1999). «Innovativer Plattenbalkenquerschnitt». Bauen Mit Holz101 (12), págs. 14-19 (vid. pág. 81).

pr-EN 16485 (2012). Round And Sawn Timber - Environmental Product Declarations - Product Category Rules For Wood And Wood-Based Products For Use In Construction. AENOR (vid. pág. 93).

Radovic, B. y T. Wiegand (2005). «Oberflächenqualität von Brettschichtholz». Sonderdruck aus Bauen mit Holz (vid. pág. 40).

Ranta-Manaus, A. (2001). «Effects of climate and climate variations on strength». Timber Engineering 2000 Course (vid. págs. 38-40).

Ranta-Maunus, A. (1990). «Einfluß des mechanisch-sorptiven Kriechens auf die Langzeitfestigkeit von Holz». Holzals Roh-und Werkstoff 48(2), págs. 67-71. ISSN: 1436-736X. DOI: 10.1007/BF02610709 (vid. pág. 35).

Ranta-Maunus, A. (1975). «The viscoelasticity of wood at varying moisture content». Wood Science and Technology 9(3), págs. 189-205. ISSN: 1432-5225. DOI: 10.1007/BF00364637 (vid. pág. 35).

Ranta-Maunus, A. (1999). «Round small-diameter timber for construction». Final report of project FAIR CT, págs. 95-0091 (vid. pág. 39).

Ranta-Maunus, A. (2003). «Effects of climate and climate variations on strength». Timber engineering, págs. 153-167 (vid. págs. 33, 38, 90).

Rapp, A., R. Peek y M. Sailer (2000). «Modelling the moisture induced risk of decay for treated and untreated wood above ground». Holzforschung 54(2), págs. 111-118 (vid. pág. 44).

Rasmussen, T. V.y A. Nicolajsen (2007). «Assessment of the performance of organic and mineral-based insulation products used in exterior walls and attics in dwellings». Building and Environment 42(2), págs. 829-839 (vid. pág. 46).

Reglamento Europeo de Productos de Construcción (UE) No 305/2011 (2011). por el que se establecen condiciones armonizadas para la comercialización de productos de construcción y se deroga la Directiva 89/706/CEE del Consejo. Comisión Europea (vid. págs. 63, 87). 
Reiterer, A., H. Lichtenegger, S. Tschegg y P. Fratzl (1999). «Experimental evidence for a mechanical function of the cellulose microfibril angle in wood cell walls». Philosophical Magazine A 79(9), págs. 2173-2184 (vid. pág. 28).

Reynolds, T., R. Harris, W.-S. Chang, J. Bregulla y J. Bawcombe (2015). «Ambient vibration tests of a cross-laminated timber building». Proceedings of the Institution ofCivil Engineers-Construction Materials 168(3), págs. 121-131 (vid. pág. 79).

Reynolds, T., D. Casagrande y R. Tomasi (2016). «Comparison of multi-storey cross-laminated timber and timber frame buildings by in situ modal analysis». Construction and Building Materials 102, págs. 1009-1017 (vid. pág. 82).

Rosenkilde, A. y]. Arfvidsson (1997). «Measurement and evaluation of moisture transport coefficients during drying of wood». Holzforschung-International Journal of the Biology, Chemistry, Physics and Technology of Wood 51(4), págs. 372-380 (vid. pág. 52).

Ross, R. J. (2010). «Wood handbook: wood as an engineering material» (vid. pág. 59).

Ruut, P. (2003). «Moisture dynamics in building envelopes (PhD Thesis)». Tesis doct. Report R-071. Technical University of Denmark (vid. pág. 51).

Rydell, Å., M. Bergström y T. Elowson (2005). «Mass loss and moisture dynamics of Scots pine (Pinus sylvestris L.) exposed outdoors above ground in Sweden». Holzforschung 59(2), págs. 183-189 (vid. pág. 44).

Saïd, M. N. A. (2007). «Measurement Methods of Moisture in Building Envelopes-A Literature Review». International Journal of Architectural Heritage 1(3), págs. 293-310 (vid. pág. 126).

Salonvaara, M., A. Karagiozis y A. Holm (2001). «Stochastic building envelope modeling-the influence of material properties». Thermal Performance of Exterior Envelopes of Whole Buildings VIII (vid. pág. 51).

Santana-Sosa, H., S. Zazo-Bello, I. A. Pérez-Álvarez, I. Raos, E. Mendieta-Otero y ]. López-Pérez (2006). «Validation of a HF spread spectrum multi-carrier technology through real-link measurements». Transactions on Emerging Telecommunications Technologies 17(6), págs. 651-657 (vid. pág. 126).

Sarja, A. (2003). Open and industrialised building. Routledge (vid. pág. 84).

Scheffer, T. C. (1971). «A climate index for estimating potential for decay in wood structures above ground». Forest products journal 21 (10), págs. 25-31 (vid. págs. 44, 45, 93).

Scheffer, T. C. y H. Hopp (1949). Decay resistance of black locust heartwood. Inf. téc. United States Department of Agriculture, Economic Research Service (vid. pág. 43).

Schickhofer, G. (2002). «Brettsperrholz: Anwendungen und Konstruktionsdetails im mehrgeschossigen Wohn-und Kommunalbau». Tagungsband: Ingenieurholzbau-Karlsruher Tage, Bruderverlag, Karlsruhe (vid. pág. 81)

Schickhofer, G. (2015). «CLT—European experience: idea \& development, technology \& applications». En: Presentation, CLT Seminar, Kochi, Japan, 5th February (vid. pág. 81).

Schickhofer, G. y A. Bernasconi (2002). «Der moderne Holzbrückenbau-Tragstrukturen und Fahrbahnkonstruktionen». Holzbau Kalender, Karlsruhe, Bruderverlag, págs. 704-739 (vid. pág. 81).

Schickhofer, G. y B. Hasewend (2000). «Solid timber construction: a construction system for residential houses, offices and industrial buildings». Cost Action E5 - proceedings of timber frame building systems: Seismic behavior of timber buildings, timber construction in the new millennium, Venice (vid. págs. 59, 81).

Schickhofer, C., T. Bogensperger y T. Moosbrugger (2010). BSPhandbuch: Holz-Massivbauweise in Brettsperrholz; Nachweise auf Basis des neuen europäischen Normenkonzepts: Einleitung, Einsatzbereiche, Tech- 
nologie, Modellbildung und Nachweisverfahren, Verbindungstechnik, Bauphysik, Anhang. Verlag der Technischen Universität Graz (vid. pág. 65).

Schmidt, H. (2005). «Vorbeugender baulicher Holzschutz-Außenbereich». Holzschutz im Hochbau, págs. 169-187 (vid. pág. 44).

Schmidt, J. y C. Criffin (2013). «Barriers to the design and use of cross-laminated timber structures in high-rise multi-family housing in the United States». Structures and Architecture, págs. 2225-2231 (vid. pág. 65).

Schmidt, O. (2006). Wood and Tree Fungi: Biology, Damage, Protection, and Use. SpringerLink: Springer e-Books. Springer Berlin Heidelberg. ISBN: 9783540321392 (vid. pág. 44).

Schoenauer, N. (1984). 6.000 años de hábitat: de los poblados primitivos a la vivienda urbana en las culturas de oriente y occidente. Editorial Gustavo Gili (vid. pág. 70).

Serrano, E., B. Enquist y ]. Vessby (2014). «Long term in-situ measurements of displacement, temperature and relative humidity in a multistorey residential clt-building». En: WCTE 2014-World Conference on Timber Engineering, Proceedings: Renaissance of Timber Construction; Quebec City; Canada; Aug. 10 through Aug. 142014 (vid. pág. 52).

Setliff, E. C. (1986). «Wood Decay Hazard in Canada Based on Scheffer's Climate Index Formula». The Forestry Chronicle 62(5), págs. 456-459. DOI: 10.5558/tf c62456-5 (vid. pág. 93).

Siau, ]. (1995). Wood: influence of moisture on physical properties. Dept. of Wood Science, Forest Products, Virginia Polytechnic Institute y State University (vid. pág. 31).

Siau, J. F. (1984). Transport Processes in Wood. Springer Berlin Heidelberg. ISBN: 978-3-642-69215-4. DOI: 10.1007/978-3-642-69213-0 (vid. pág. 31).

Simpson, W. y A. TenWolde (1999). «Wood handbook: Wood as an engineering material». USDA Forest Service General Technical Report FPL-GTR-173, Madison (vid. pág. 38).

Skaar, C. (1988). Wood-Water Relations. Hygroexpansion in Wood. Springer Berlin Heidelberg. ISBN: 9783-642-73685-8. DOI: 10.1007/978-3-642-73683-4 (vid. págs. 29-37).

Smith, A. (2014). «17-21 Wenlock Road. Building a ten-storey hybrid structure in London». En: 20 Internationales Holzbau Forum IHF 2014, pág. 9 (vid. pág. 81).

Smith, R. (2015). Prefabrication: discoveries in off-site construction techniques. Woodworks (vid. pág. 84).

Spalt, H. (1958). «The fundamentals of water vapor sorption by wood». Forest Products Journal 8(10), págs. 288-295 (vid. pág. 29).

Staib, G., A. Dörrhöfer y M. Rosenthal (2008). Components and Systems: Modular Construction-Design, Structure, New Technologies. Walter de Gruyter (vid. pág. 61).

Stamm, A. J. (1967a). «Movement of fluids in wood - Part I: Flow of fluids in wood». Wood Science and Technology 1(2), págs. 122-141. ISSN: 1432-5225. DOI: 10.1007/BF00353384 (vid. pág. 31).

Stamm, A. J. (1967b). «Movement of fluids in wood - Part II: Diffusion». Wood Science and Technology 1(3), págs. 205-230. ISSN: 1432-5225. DOI: 10.1007/BF00350462 (vid. pág. 31).

Steinhardt, N. S. y X. Fu (2002). Chinese architecture. Yale University Press (vid. pág. 72).

Steurer, A (1989). «Entwurfsgrundlagen und Konstruktionsprinzipien von Holzstegen (Design pronciples and construction pronciples of pedestrian timber bridges)». German. En: Fortbildungskurs der Schweizerische Arbeitsgemeinschaft für Holzforschung (SAH). Brücken und Stege aus Holz (vid. pág. 59).

Stirling, R. y P. Morris (2006). «The influence of extractives on western red cedar's equilibrium moisture content». Document IRG/WP, págs. 06-40331 (vid. pág. 43). 
Stürzenbecher, R. y K. Hofstetter (2011). «Bending of cross-ply laminated composites: An accurate and efficient plate theory based upon models of Lekhnitskii and Ren». Composite Structures 93(3), págs. 1078-1088 (vid. pág. 52).

Svensson, S. y T. Toratti (2002). «Mechanical response of wood perpendicular to grain when subjected to changes of humidity». Wood Science and Technology 36(2), págs. 145-156. ISSN: 1432-5225. DOI: 10.1007/s00226-001-0130-4 (vid. págs. 35-37).

Svensson, S. (1997). «Internal Stresses in Wood Caused by Climate Variations». eng. Tesis doct. Lund University, pág. 120 (vid. pág. 35).

Tannert, T., A. Müllery M. Vogel (2010). «Structural health monitoring of timber bridges». En: International Conference on Timber Bridges (ITCB), págs. 205-212 (vid. pág. 126).

Tannert, T., R. Berger, M. Vogel y A. Müller (2011). «Remote moisture monitoring of timber bridges: a case study». En: 5th International Conference on Structural Health Monitoring of Intelligent Infrastructure (SHMII-5), págs. 11-15 (vid. pág. 126).

Teischinger, A. (1987). «Feuchtigkeitsausgleichende Wirkung von Holz in Innenräumen». German. PhD thesis. Vienna: University of Natural Resources y Applied Life Sciences (vid. pág. 25).

Thelandersson, S., T. Isakson, A. Ekstrand-Tobin y P. Johansson (2009). «Modeling of onset of mould growth for wood exposed to varying climate conditions». Document IRC/WP, págs. 09-20414 (vid. pág. 45).

Thelandersson, S. (2013). «Service life evaluation of wood-an engineering approach». eng. En: IRC 2013. Ed. por]. Jermer. International research group on wood protection (vid. pág. 93).

Thelandersson, S., T. Isaksson, E. Suttie, E. Frühwald, T. Toratti, G. Crüll, H. Viitanen y ]. Jermer (2011) «Quantitative design guideline for wood in outdoor above ground applications». eng. En: IRC 2017. Ed. por ]. Jermer. International research group on wood protection (vid. págs. 92, 93).

Tiemann, H. D. (1906). Effect of moisture upon the strength and stiffness of wood. Washington, Cov't print. off., pág. 163 (vid. pág. 29).

Timmer, S. (2011). «Feasibility of tall timber buildings». Civil engineering and geosciences-structural engineering. Delft University of Technology: Delft University of Technology. Delft, Netherlands 269 (vid. pág. 81)

Tomasi, R., T. Sartori, D. Casagrande y M. Piazza (2015). «Shaking Table Testing of a Full-Scale Prefabricated Three-Story Timber-Frame Building». Journal of Earthquake Engineering 19(3), págs. 505-534 (vid. pág. 79).

Toratti, T. (1992). Creep of timber beams in a variable environment. Dissertation from Helsinki University of Technology: Teknillinen Korkeakoulu. na. ISBN: 9789512212514 (vid. págs. 33-35).

Toratti, T. y S. Svensson (2000). «Mechano-sorptive experiments perpendicular to grain under tensile and compressive loads». Wood Science and Technology 34(4), págs. 317-326. ISSN: 1432-5225. DOI: 10.1007/s002260000059 (vid. pág. 33).

UNE-CEN/TS 14464 (2010). Madera aserrada. Método de medición del cementado. AENOR (vid. pág. 36).

UNE-EN 1001-2 (2007). Durabilidad de la madera y de los materiales derivados de la madera. Terminología. Parte 2: Vocabulario. AENOR (vid. pág. 41).

UNE-EN 12775 (2001). Tableros de madera maciza. Clasificación y terminología. AENOR (vid. pág. 139).

UNE-EN 13353:2009+A1:2011 (2011). Tableros de madera maciza (SWP). Requisitos. AENOR (vid. pág. 139).

UNE-EN 13354 (2009). Tableros de madera maciza. Calidad de encolado. Método de ensayo. AENOR (vid. págs. $99,140,150)$.

UNE-EN 1339 (2003). Baldosas de hormigón. Especificaciones y métodos de ensayo. AENOR. 
UNE-EN 14081-1 (2011). Estructuras de madera. Madera estructural con sección transversal rectangular clasificada por su resistencia Parte 1: Requisitos generales. AENOR.

UNE-EN 15643-1 (2012). Sostenibilidad en la construcción. Evaluación de la sostenibilidad de los edificios. Parte 1: Marco general. AENOR (vid. pág. 93).

UNE-EN 15643-2 (2011). Sostenibilidad en la construcción. Evaluación de la sostenibilidad de los edificios. Parte 2: Marco para la evaluación del comportamiento ambiental. AENOR (vid. pág. 93).

UNE-EN 15643-3 (2012). Sostenibilidad en la construcción. Evaluación de la sostenibilidad de los edificios. Parte 3: Marco para la evaluación del comportamiento social. AENOR (vid. pág. 93).

UNE-EN 15643-4 (2012). Sostenibilidad en la construcción. Evaluación de la sostenibilidad de los edificios. Parte 4: Marco para la evaluación del comportamiento económico. AENOR (vid. pág. 93).

UNE-EN 15804 (2012). Sostenibilidad en la construcción. Declaraciones ambientales de producto. AENOR (vid. pág. 93).

UNE-EN 15978 (2011). Sostenibilidad en la construcción. Evaluación del comportamiento ambiental de los edificios. Métodos de cálculo. AENOR (vid. pág. 93).

UNE-EN 16351 (2016). Estructuras de madera. Madera contralaminada. Requisitos. AENOR (vid. págs. 65, $92,99,100,140,150,165)$.

UNE-EN 1995-1-1 (2016). Eurocódigo 5. Proyecto de estructuras de madera. Parte 1-1: Reglas generalesyreglas para edificación. AENOR (vid. págs. 23, 42, 47, 49, 87, 139, 140).

UNE-EN 301 (2014). Adhesivos fenólicos y aminoplásticos para estructuras de madera bajo carga. Clasificación y requisitos de comportamiento. AENOR (vid. pág. 167).

UNE-EN 302-3 (2013). Adhesivos para madera de uso estructural. Métodos de ensayo. Parte 3: Determinación del efecto del ataque ácido a las fibras de madera debido a los tratamientos cíclicos de temperatura y humedad sobre la resistencia a la tracción transversal. AENOR (vid. págs. 151, 157).

UNE-EN 316 (2009). Tableros de fibras. Definición, clasificación y símbolos. AENOR (vid. pág. 56).

UNE-EN 319 (1994). Tableros de partículas y tableros de fibras. Determinación de la resistencia a la tracción perpendicular a las caras del tablero. AENOR (vid. págs. 151, 152).

UNE-EN 335 (2013). Durabilidad de la madera y de los productos derivados de la madera. Clases de uso: definiciones, aplicación a la madera maciza y a los productos derivados de la madera. AENOR (vid. págs. 42, 44, $46,47,49,140,165)$.

UNE-EN 350 (2016). Durabilidad de la madera y de los productos derivados de la madera. Ensayos y clasificación de la resistencia a los agentes biológicos de la madera y de los productos derivados de la madera. AENOR (vid. págs. 41, 43).

UNE-EN 384 (2016). Madera estructural. Determinación de los valores característicos de las propiedades mecánicas y la densidad. AENOR (vid. págs. 39, 162).

UNE-EN 408 (2012). Estructuras de madera. Madera aserrada y madera laminada encolada para uso estructural. Determinación de algunas propiedades físicas y mecánicas. AENOR (vid. págs. 99, 100, 151, 153, 159, 164).

UNE-EN 408+A1 (2012). Estructuras de madera. Madera aserrada y madera laminada encolada para uso estructural. Determinación de algunas propiedades físicas y mecánicas. AENOR.

UNE-EN 460 (1995). Durabilidad de la madera y de los materiales derivados de la madera. Durabilidad natural de la madera maciza. Guía de especificaciones de durabilidad natural de la madera para su utilización según las clases de riesgo. AENOR (vid. pág. 44). 
UNE-EN 789 (2006). Estructuras de madera. Métodos de ensayo. Determinación de las propiedades mecánicas de los tableros derivados de la madera. AENOR (vid. pág. 100).

UNE-EN ISO 7500-1 (2016). Materiales metálicos. Calibración y verificación de máquinas de ensayos uniaxiales estáticos. Parte 1: Máquinas de ensayo de tracción/compresión. Calibración y verificación del sistema de medida de fuerza. (ISO 7500-1: 2015). AENOR (vid. pág. 164).

Viitanen, H. y A. Ritschkoff (1991). Brown Rot Decay in Wooden Constructions: Effect of Temperature, Humidity and Moisture. Institutionen för Virkeslära. Swedish University of Agricultural Sciences (vid. pág. 44).

Viitanen, H., R. Peuhkuri, T. Ojanen, T. Toratti y L. Makkonen (2008). «Service life of wooden materials: mathematical modelling as a tool for evaluating the development of mould and decay». En: Proceedings of the COST Action E 37 Final conference: Socio-economic perspectives of treated wood for the common European market, Bordeaux, September, págs. 97-106 (vid. pág. 45).

Viitanen, H., T. Toratti, R. Peuhkuri, T. Ojanen y L. Makkonen (2009). «Evaluation of exposure conditions for wooden facades and decking». Document IRG/WP, págs. 09-20408 (vid. pág. 45).

Von Kollmann, F. (1963). «Zur Theorie der Sorption». Forschung auf dem Cebiet des Ingenieurwesens A 29(2), págs. 33-41 (vid. pág. 31).

Wadel, G. (2009). «La sostenibilidad en la construcción industrializada. La construcción modular ligera aplicada a la vivienda (The sustainability of the industrialized architecture. Lightweight modular systems for housing)». Tesis doct. PhD thesis, UPC, Barcelona, Spain. (vid. pág. 74).

Wadsö, L. (1994). «Describing non-Fickian water-vapour sorption in wood». Journal of Materials Science 29(9), págs. 2367-2372 (vid. pág. 51).

Walker, ]. C. (2006). Primary wood processing: principles and practice. Springer Science \& Business Media (vid. pág. 27).

Wallner-Novak, M., J. Koppelhubery K. Pock (2013). «Brettsperrholz Bemessung-Grundlagen für Statik und Konstruktion nach Eurocode (Çross Laminated Timber Design-Construction and Design according to Eurocode")». Vienna, Austria (vid. pág. 65).

Walter, H. y H. Lieth (1960). «Ein Klimadiagramm Weltatlas». Fischer, Jena (vid. pág. 105).

Wang, C.-H., R. Leicester y M. NguyenWang (2008). Equations for use in a service life design guide. Market knowledge \& development. Foresty Wood Products Australia (vid. págs. 45, 46, 93).

Wang, J., X. Wu y M. Jiang (2007). «Decay Hazard Classifications in China for Exterior Above-Cround Wood». eng. En: IRG 2007. Ed. por]. Wang. International research group on wood protection (vid. págs. 45, 92).

Wang, J., P. Mukhopadhyaya y P. I. Morris (2014). «Sorption and capillary condensation in wood and the moisture content of red pine». Journal of Building Physics 37(4), págs. 327-347 (vid. pág. 51).

Wang, L. y H. Ge (2016). «Hygrothermal performance of cross-laminated timber wall assemblies: A stochastic approach». Building and Environment 97, págs. 11-25 (vid. pág. 51).

Wangaard, F. F. y L. A. Granados (1967). «The effect of extractives on water-vapor sorption by wood». Wood Science and Technology 1(4), págs. 253-277 (vid. pág. 29).

Wardrop, A. (1964). The structure and formation of the cell wall in xylem (vid. pág. 28).

Waugh, A., M. Wells y M. Lindegar (2010). «Tall timber buildings: application of solid timber constructions in multi-storey buildings». En: International Convention of Society of Wood Science and Technology and United Nations Economic Commission for Europe (vid. pág. 83). 
Welling, ]. (1988). «Die modellmäßige Erfassung von Trocknungsspannungen während der Kammertrocknung von Schnittholz». Holz als Roh-und Werkstoff 46(8), págs. 295-300. ISSN: 1436-736X. DOI: 10.1007/BF02615058 (vid. pág. 37).

Woodall, C. W., P. Ince, K. E. Skog, F. X. Aguilar, C. E. Keegan, C. Sorenson, D. C. Hodges y W. B. Smith (2011). «An overview of the forest products sector downturn in the United States». Forest Products Journal 61(8), págs. 595-603 (vid. pág. 59).

Yeh, B., S. Gagnon, T. Williamson y C. Pirvu (2012). «The cross-laminated timber standard in North America». World 15, pág. 19 (vid. pág. 64).

Zhao, J., R. Plagge, A. Nicolai, J. Grunewald y J. S. Zhang (2011). «Stochastic study of hygrothermal performance of a wall assembly - the influence of material properties and boundary coefficients». HVACER Research 17(4), págs. 591-601 (vid. pág. 51).

Zumbrunnen, P. y J. Fovargue (2012). «Mid rise CLT buildings-the UK's experience and potential for AUS and NZ». En: Proceedings of the World Conference on Timber Engineering 2012 (vid. págs. 65, 78, 80, $83,84)$. 


\section{Índice de figuras}

2.1. Esquema de las partes del tronco . . . . . . . . . . . . . . . . . . . 26

2.2. Lado izquierdo: Pinus radiata, (Walker, 2006). Lado derecho: Picea abies, muestra claramente las traqueidas de madera tardía de pared más gruesa y las traqueidas de madera temprana de pared más delgada . . . . . . . . . . . . . . . . . . 27

2.3. La estructura de la pared celular, Dinwoodie (1975) . . . . . . . . . . . . . . . . . 28

2.4. Deformaciones producidas por el secado en tablones procedentes de distintas partes del tronco (Ormarsson, 1999) . . . . . . . . . . . . . . . . . . . . . 30

2.5. Isotermas de sorción ( $\mathrm{M}$ : humedad de madera, $\mathrm{H}$ : humedad relativa) . . . . . . . 32

2.6. Direcciones de madera ortotrópicas (según Bodig y Jayne, 1993) . . . . . . . . . . . 34

2.7. Ilustración de fluencia . . . . . . . . . . . . . . . . . . . . . . . . . . . . . . . 34

2.8. Ilustración del efecto mecano-sortivo . . . . . . . . . . . . . . . . . . . 36

2.9. Equipo para cortar y medir deformaciones liberadas en madera, Svensson y Toratti (2002) . . . . . . . . . . . . . . . . . . . . . 37

2.10. Distribución de la deformación en roble rojo de $50 \mathrm{~mm}$ (Quercus rubra) durante el secado al aire, gráfico según McMillen (1955) . . . . . . . . . . . . . . . . 37

2.11. Recomendaciones americanas en contenidos de humedad . . . . . . . . . . . . . . 39

2.12. Esquema de la degradación de los productos encolados (elaboración propia) . . . . 42

2.13. Las grietas en las capas de recubrimiento después de secar las muestras CLT a un contenido de humedad del $10 \%$ (Cülzow et al., 2011) . . . . . . . . . . . . 50

2.14. Tablero contrachapado y mosquito segunda guerra mundial . . . . . . . . . . . . . 55

2.15. Tablero de partículas . . . . . . . . . . . . . . . . . . 56

2.16. Tablero de fibras duro . . . . . . . . . . . . . . . . . . . . . 56

2.17. Tablero de fibras de densidad media . . . . . . . . . . . . . . . . . 57

2.18. Tablero de virutas OSB . . . . . . . . . . . . . . . . . . . . 57

2.19. Tablero de partículas de madera-cemento . . . . . . . . . . . . . 58

2.20. Vista esquemática de la configuración de capas del CLT . . . . . . . . . . . . . . 60

2.21. Sección transversal de un panel de CLT de cinco capas . . . . . . . . . . . . . . . 60

2.22. Desarrollo del volumen mundial de producción de CLT hasta 2013 y las previsiones hasta el año 2015 en $\mathrm{m}^{3}$ (Brandner et al., 2016) (TSD: miles) . . . . . . . . . . . . . 61

2.23. Proceso de mecanizado de los paneles de CLT . . . . . . . . . . . . . . . . . . 62

3.1. Antiguo ayuntamiento de Esslingen . . . . . . . . . . . . . . . 68 
3.2. Skerm del desierto del Kalahari . . . . . . . . . . . . . . . . . . . . . . . . . . . . 69

3.3. Entramado de madera con relleno o nogging de ladrillo o barro . . . . . . . . . . . . 73

3.4. Ejemplo de la evolución de la construcción con CLT en Hackney (norte de Londres). Imagen cedida por Waugh Thistleton Architects Ltd. . . . . . . . . . . . . . . 79

3.5. (izquierda) Panel de CLT de 5 capas; (del medio a la derecha) Imágenes del proyecto Wittenbauerstraße/Graz/Austria: dos edificios residenciales de tres plantas (Brandner et al., 2016) . . . . . . . . . . . . . . . . . . . . . . . . . . 80

3.6. (arriba) Ejemplos de composición de capas para fines determinados; (Parte inferior) Ejemplos de estructuras de materiales compuestos de CLT y madera laminada encolada (GLT), de ultra alto rendimiento de madera contrachapada (UHPP), acero u hormigón; adaptado de Schickhofer (2015) . . . . . . . . . . . . . . . . . 81

3.7. Metropol parasol, "las Setas", Sevilla (Jürgen Mayer, 2011) _ . . . . . . . . . . . . . 82

3.8. Dos destacados edificios construidos con CLT . . . . . . . . . . . . . . . . . . 83

3.9. Operarios realizando tareas de montaje en las viviendas de Hondarribia, Gipuzkoa (Fotografía: Javier Hernández) ． . . . . . . . . . . . . . . . . . . . . 85

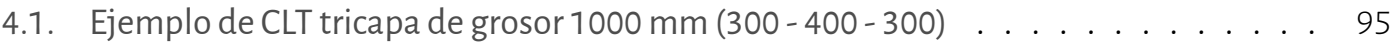

4.2. Despiece para la mecanización y optimización de los paneles de CLT de abeto . . . . 97

4.3. Despiece para la mecanización y optimización de los paneles de CLT (Fuente: Stora

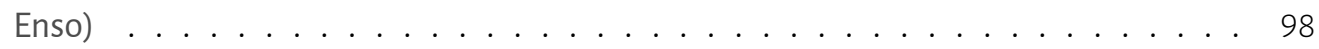

4.4. Probeta de abeto . . . . . . . . . . . . . . . . . . . 100

4.5. Probeta de pino . . . . . . . . . . . . . . . . . . . . 100

4.6. Despiece de los paneles de CLT expuestos al exterior para la obtención de probetas . 102

4.7. Probeta de pino, ubicada en Madrid, expuesta a la orientación Sur y situada en el panel en la posición C5, con su correspondiente nomenclatura . . . . . . . . . . 102

4.8. Defectos del material por gema y nudo saltadizo . . . . . . . . . . . . . . . . 103

4.9. Defectos del producto por fallo de encolado . . . . . . . . . . . . . . . . . . . 104

4.10. Temperatura media del aire en la Península Ibérica e Islas Baleares 1971-2000 (Ref. Atlas) . . . . . . . . . . . . . . . . . . . . 107

4.11. Precipitación media anual (mm)(1971-2000) (Elaborado por el INM) . . . . . . . . . 108

4.12. Zonas climáticas peninsulares con capitales de provincia y climas de referencia (Fuente: Larrumbide et al., 2014) . . . . . . . . . . . . . . . . . . . . . . 1175

4.13. Capitales de provincia con riesgo de formación de condensaciones intersticiales (Fuente: Larrumbide et al., 2014) ～. . . . . . . . . . . . . . . . . . . . . . . 1176

4.14. Situación de las probetas en los climas representativos seleccionados . . . . . . . 118

4.15. Dibujo de los paneles verticales (paramento) y el panel horizontal (cubierta) . . . . . 121

4.16. Prototipo de ensayo de CLT para su exposición al exterior . . . . . . . . . . . . . . 121

4.17. Bancada de hierro donde se colocan los prototipos al exterior . . . . . . . . . . . 122

4.18. Detalle de la placa de sujeción de los paneles de CLT . . . . . . . . . . . . . . 123

4.19. Fotografía de la bancada de hierro . . . . . . . . . . . . . . . . . 123

4.20. Angular de acero y sus variantes (utilizado para la unión de los paneles de CLT) . . . 123

4.21. Esquema de fijación del angular para su unión madera/madera . . . . . . . . . . 124

4.22. Valores estáticos para la unión de corte en el caso de un apuntalamiento total . . . 124 
4.23. Tornillo de acero y sus variantes (utilizado para la unión de los paneles de CLT) . . . . 124

4.24. Valores estáticos para los tornillos unión de corte madera - acero . . . . . . . . . . 124

4.25. Prototipos de CLT (Madrid) . . . . . . . . . . . . . . . . . . . . . . . . 125

4.26. Montaje manual de los prototipos exteriores (Ávila) . . . . . . . . . . . . . . . . 126

4.27. Vista desde el interior del prototipo de un sensor de temperatura y humedad embebido en la madera . . . . . . . . . . . . . . . . . . . . . . . . . . . . . . 129

4.28. Mote y multiplexor instalados en el interior de los prototipos . . . . . . . . . . . . . 129

4.29. A la izquierda el MOTE con la batería y a la derecha el circuito del mote . . . . . . . . 130

4.30. A la izquierda el Multiplexor, y a la derecha su circuito interno . . . . . . . . . . . . . 130

4.31. A la izquierda la base receptora, y a la derecha su circuito interno . . . . . . . . . . . . 130

4.32. Pantallazo del ordenador en el que se muestran todos los parámetros en tiempo real 131

4.33. Esquema de los prototipos y los sistemas de medición en Ávila . . . . . . . . . . . . . 132

4.34. Esquema de los prototipos y los sistemas de medición en Madrid . . . . . . . . . . . 132

4.35. Esquema de los prototipos y los sistemas de medición en Sevilla . . . . . . . . . . . 133

4.36. Curvas de ajuste de humedad de madera . . . . . . . . . . . . . . . . . . . . . 136

4.37. Mapa de color de la humedad de la madera . . . . . . . . . . . . . . . . . . . . . 138

4.38. Tablero de madera maciza tricapa (SWP) . . . . . . . . . . . . . . . . . . . . . 139

4.39. Tablero de madera contralaminada tricapa $(C L T)$. . . . . . . . . . . . . . . . . . 139

4.40. Esquema de la "Ageing wheel" o rueda de envejecimiento artificial, FCBA (Burdeos) . 142

4.41. Fotografía de la "Ageing wheel" o rueda de envejecimiento artificial, FCBA (Burdeos) 143

4.42. Lámpara OSRAM y gráfica de la potencia de radiación espectral de la lámpara . . . . 143

4.43. Disposición de las lámparas en el arco de irradiación . . . . . . . . . . . . . . . . . 144

4.44. Fotografía de la cámara climática utilizada en el ensayo (INIA) . . . . . . . . . . . . 147

4.45. Cotero de riego utilizado para la adaptación de la cámara e instalación del mismo . . 147

4.46. Mordaza de tipo cóncavo . . . . . . . . . . . . . . . . . . . . . . . . . . . . 151

4.47. Mordaza de tipo placa . . . . . . . . . . . . . . . . . . . . . . . . . 152

4.48. Mordaza de tipo ranura-lengüeta . . . . . . . . . . . . . . . . . . . . . 152

4.49. Ejemplo de fijación de la mordaza . . . . . . . . . . . . . . . . . . . . 153

4.50. Plano de mordazas tipo A de agarre plano . . . . . . . . . . . . . . . . . . . 153

4.51. Esfuerzo de tracción hasta falla de probeta 1 de CLT con mordazas tipo A . . . . . . 154

4.52. Rotura de la probeta 1 por ensayo de tracción perpendicular a la fibra con mordazas tipo A . . . . . . . . . . . . . . . . . . . 154

4.53. Esfuerzo de tracción hasta falla de probeta 2 de CLT con mordazas tipo A . . . . . . 155

4.54. Rotura de la probeta 2 por ensayo de tracción perpendicular a la fibra con mordazas tipo A . . . . . . . . . . . . . . . . . . 155

4.55. Esfuerzo de tracción hasta falla de probeta 3 de CLT con mordazas tipo A . . . . . . 155

4.56. Rotura de la probeta 3 por ensayo de tracción perpendicular a la fibra con mordazas tipo A . . . . . . . . . . . . . . . . . . 155

4.57. Esfuerzo de tracción hasta falla de probeta de CLT con la variante de mordazas tipo A 156

4.58. Rotura de la probeta por ensayo de tracción perpendicular a la fibra con la variante de mordazas tipo A . . . . . . . . . . . . . . . . 156

4.59. Plano de mordazas tipo B de agarre cóncavo . . . . . . . . . . . . . . . . . . 157

4.60. Intento de mecanización de las probetas . . . . . . . . . . . . . . . . . . . 158 
4.61. Plano de mordaza de tipo $\mathrm{C}$ de agarre químico . . . . . . . . . . . . . . . . 159

4.62. Esfuerzo de tracción hasta falla de probeta 1 de CLT con mordazas tipo C . . . . . . . 160

4.63. Rotura de la probeta 1 por ensayo de tracción perpendicular a la fibra con mordazas tipo C . . . . . . . . . . . . . . . . . 160

4.64. Esfuerzo de tracción hasta falla de probeta 2 de CLT con mordazas tipo C . . . . . . . 160

4.65. Rotura de la probeta 2 por ensayo de tracción perpendicular a la fibra con mordazas tipo C . . . . . . . . . . . . . . . . . 160

4.66. Esfuerzo de tracción hasta falla de probeta 3 de CLT con mordazas tipo C . . . . . . . 161

4.67. Rotura de la probeta 3 por ensayo de tracción perpendicular a la fibra con mordazas tipo C . . . . . . . . . . . . . . . . . . . 161

4.68. Muestras estabilizándose en cámara climática en ambiente normalizado . . . . . . 162

4.69. Adhesivo epoxi y su aplicación . . . . . . . . . . . . . . . . . . 163

4.70. Limpieza de las probetas . . . . . . . . . . . . . . . . . . . . 163

4.71. Detalle de rotura tras su impregnación con safranina . . . . . . . . . . . . 167

4.72. Plantilla para evaluación de fallo . . . . . . . . . . . . . . . . . . . 168

5.1. Diagramas de caja y bigotes de los valores descriptivos del abeto . . . . . . . . . . 180

5.2. Intervalos de confianza del $95 \%$ de las diferencias de medias entre los distintos envejecimientos y la referencia para el abeto según el análisis de Dunnett . . . . . . . 182

5.3. Diagramas de caja y bigotes de los valores descriptivos del pino . . . . . . . . . . 188

5.4. Intervalos de confianza del $95 \%$ de las diferencias de medias entre los distintos envejecimientos y la referencia para el pino según el análisis de Dunnett . . . . . . . 190

5.5. Intervalos de confianza del $95 \%$ de las diferencias de medias entre los distintos envejecimientos y la referencia para el abeto según el análisis de Dunnett . . . . . . . . 195

5.6. Intervalos de confianza del $95 \%$ de las diferencias de medias entre las distintas orientaciones para el abeto en Ávila según el análisis de Bonferroni . . . . . . . . . . . . 196

5.7. Intervalos de confianza del $95 \%$ de las diferencias de medias entre las distintas orientaciones para el abeto en Madrid según el análisis de Bonferroni . . . . . . . . . . 198

5.8. Diagramas de caja y bigotes de los valores descriptivos de carga máxima por ubicación del abeto . . . . . . . . . . . . . . . . . . . . . . . . . . . 199

5.9. Intervalos de confianza del $95 \%$ de las diferencias de medias entre las distintas ubicaciones para el abeto según el análisis de Bonferroni . . . . . . . . . . . . . . . 201

5.10. Intervalos de confianza del $95 \%$ de las diferencias de medias para el abeto según el análisis de Dunnett . . . . . . . . . . . . . . . . . . . . . . 203

5.11. Intervalos de confianza del $95 \%$ de las diferencias de medias de delaminación entre las distintas orientaciones para el abeto en Ávila según el análisis de Bonferroni . . . 204

5.12. Diagramas de caja y bigotes de los valores descriptivos de la delaminación por ubicación del abeto . . . . . . . . . . . . . . . . . . . . . . 206

5.13. Intervalos de confianza del $95 \%$ de las diferencias de medias de delaminación entre las distintas ubicaciones para el abeto según el análisis de Bonferroni . . . . . . . . . 208

5.14. Intervalos de confianza del $95 \%$ de las diferencias de medias para el pino según el análisis de Dunnett . . . . . . . . . . . . . . . . . . . . . . 212

5.15. Diagramas de caja y bigotes de la carga máxima en función de la ubicación para el pino 215 
5.16. Intervalos de confianza del $95 \%$ de las diferencias de medias de carga máxima entre las distintas ubicaciones para el pino según el análisis de Bonferroni . . . . . . . 216

5.17. Intervalos de confianza del $95 \%$ de las diferencias de medias de delaminación para el pino según el análisis de Dunnett . . . . . . . . . . . . . . . . . . . . . 218

5.18. Diagramas de caja y bigotes de la delaminación por ubicación para el pino . . . . . . 221

5.19. Cráficas de precipitación y de humedad de madera de abeto y pino en función de la ubicación . . . . . . . . . . . . . . . . . . . . . 237

5.20. Cráficas de temperatura y de humedad de madera de abeto y pino en función de la ubicación . . . . . . . . . . . . . . . . . . . . 237

5.21. Cráficas de humedad exterior y de humedad de madera de abeto y pino en función de la ubicación . . . . . . . . . . . . . . . . . . . . . . . 238

5.22. Cráficos del análisis de componentes principales (para el abeto incluyendo delaminación y carga máxima) . . . . . . . . . . . . . . . . . . . . . . . . . 241

5.23. Cráficos del análisis de componentes principales (para el abeto incluyendo únicamente la carga máxima) . . . . . . . . . . . . . . . . . . . . . . . . 243

5.24. Cráficos del análisis de componentes principales (para el abeto incluyendo únicamente la delaminación) . . . . . . . . . . . . . . . . . . . . . . . . . 245

5.25. Cráficos del análisis de componentes principales (para el pino incluyendo delaminación y carga máxima) . . . . . . . . . . . . . . . . . . . . . . . . . . . . . 247

5.26. Cráficos del análisis de componentes principales (para el pino incluyendo únicamente la carga máxima) . . . . . . . . . . . . . . . . . . . . . . 250

5.27. Gráficos del análisis de componentes principales (para el pino incluyendo únicamente la delaminación) . . . . . . . . . . . . . . . . . . . . . . 252

5.28. Diagramas de caja y bigotes de los resultados de carga máxima por método de aplicación . . . . . . . . . . . . . . . . . . . 255

5.29. Comparación de métodos . . . . . . . . . . . . . . . . . . . . . 258 



\section{Índice de tablas}

2.1. Coeficientes de contracción dimensional y riesgo de atejado de algunas especies (adaptado de Alvarez y Fernández-Golfin, 1996) . . . . . . . . . . . . . . . . . . . 33

2.2. Efecto del cambio de contenido de humedad a las propiedades mecánicas de las maderas blandas (\% / \%) entre 8 y $20 \%$ MC. Los valores de la madera clara y madera redonda son los efectos promedio, los valores de la madera aserrada son los valores característicos (Ranta-Manaus, 2001) . . . . . . . . . . . . . . . . . . . . 40

2.3. Köppen-Ceiger climate type classification of Europe (Kottek et al., 2006) _ . . . . . 40

2.4. Resumen de las clases de uso y de los agentes biológicos que atacan la madera y los materiales derivados de la madera . . . . . . . . . . . . . . . . . 48

2.5. Posible correspondencia entre clases de servicio y clases de uso . . . . . . . . . . . 48

4.1. Detalle de los paneles de abeto según su uso previsto . . . . . . . . . . . . . . . . . 97

4.2. Detalle de los paneles de pino . . . . . . . . . . . . . . . . . . . . . . . 98

4.3. Coeficientes de regresión para la severidad climática de invierno $(\mathrm{SCl})$. . . . . . . 1112

4.4. Coeficientes de regresión para la severidad climática de verano (SCV) . . . . . . . 113

4.5. Intervalos para la zonificación de invierno . . . . . . . . . . . . . . . . . 117

4.6. Intervalos para la zonificación de verano . . . . . . . . . . . . . . . . . . . . 1173

4.7. Esquema de agrupación climática de la Península Ibérica, islas Baleares, Canarias y ciudades autónomas de Ceuta y Melilla. DB HE 2006 . . . . . . . . . . . . . . . . . 114

4.8. Contenido crítico de agua . . . . . . . . . . . . . . . . . . . . . . . . . . . 114

4.9. Clasificación climática de las capitales de provincia (Fuente: Gandullo et al., 1998, Tabla VII) . . . . . . . . . . . . . . . . . . . . . . . . . . 119

4.10. Ciclos de humedad y temperatura para el ensayo . . . . . . . . . . . . . . . 135

4.11. Coeficientes para la ecuación de la humedad de la madera . . . . . . . . . . . . 137

4.12. Resumen del ciclo que realiza la rueda de envejecimiento (FCBA) . . . . . . . . . 144

4.13. Ciclo semanal seleccionado para el envejecimiento en cámara del CLT (INIA) . . . . 149

4.14. Resultados del ensayo a tracción perpendicular a la fibra con mordazas tipo A . . . . 154

4.15. Resultados del ensayo a tracción perpendicular a la fibra con mordazas tipo A, en su variante química madera-madera . . . . . . . . . . . . . . . . . . 156

4.16. Resultados del ensayo a tracción perpendicular a la fibra con mordazas tipo C . . . . 159

5.1. Ensayo de referencia Abeto . . . . . . . . . . . . . . . . . . . . . 175 
5.2. Exposición exterior abeto Madrid ． . . . . . . . . . . . . . . . . . . . . . 175

5.3. Exposición exterior abeto Sevilla ． . . . . . . . . . . . . . . . . . 176

5.4. Exposición exterior abeto Ávila . . . . . . . . . . . . . . . . . . . . . 177

5.5. FCBA ciclo corto abeto . . . . . . . . . . . . . . . . . . . . . . 177

5.6. FCBA ciclo largo abeto . . . . . . . . . . . . . . . . . . . . . . . 178

5.7. INIA ciclo corto abeto . . . . . . . . . . . . . . . . . . . . . . . . . 1778

5.8. INIA ciclo largo abeto . . . . . . . . . . . . . . . . . . . . . . . . . . . 178

5.9. Valores descriptivos del abeto . . . . . . . . . . . . . . . . . . . . . . . . . . . 179

5.10. Prueba de homogeneidad de varianza de Levene de la carga máxima y de la delaminación en función del envejecimiento (abeto) . . . . . . . . . . . . . . . 180

5.11. Test ANOVA de la carga máxima y de la delaminación en función del envejecimiento (abeto) . . . . . . . . . . . . . . . . . . . . . . . . . . 181

5.12. Análisis de comparación múltiple de Dunnett de la carga máxima y de la delaminación en función del envejecimiento (abeto) ‥ . . . . . . . . . . . . . 181

5.13. Ensayo de referencia pino . . . . . . . . . . . . . . . . . . . . 183

5.14. Exposición exterior pino Madrid ． . . . . . . . . . . . . . . . . . . 184

5.15. Exposición exterior pino Sevilla . . . . . . . . . . . . . . . . . . . . . 184

5.16. Exposición exterior pino Ávila . . . . . . . . . . . . . . . . . . . . . . . . . . . . . . 185

5.17. FCBA ciclo corto pino . . . . . . . . . . . . . . . . . . . 186

5.18. FCBA ciclo largo pino . . . . . . . . . . . . . . . . . . . . . . . 186

5.19. INIA ciclo corto pino . . . . . . . . . . . . . . . . . . . . . . 186

5.20. INIA ciclo largo pino . . . . . . . . . . . . . . . . . . . . . . . 187

5.21. Valores descriptivos del pino . . . . . . . . . . . . . . . . . . 187

5.22. Prueba de homogeneidad de varianza de Levene de la carga máxima y de la delaminación en función del envejecimiento (pino) . . . . . . . . . . . . 188

5.23. Test ANOVA de la carga máxima y de la delaminación en función del envejecimiento (pino) . . . . . . . . . . . . . . . . . . . . . . 189

5.24. Análisis de comparación múltiple de Dunnett de la carga máxima y de la delaminación en función del envejecimiento (pino) . . . . . . . . . . . . . . . . 189

5.25. Análisis descriptivo del envejecimiento natural del abeto . . . . . . . . . . . . . 192

5.26. Análisis de efectos del modelo de la carga máxima por ubicación y orientación según ubicación (abeto) . . . . . . . . . . . . . . . . . . . . 193

5.27. Prueba de homogeneidad de varianza de Levene de la carga máxima por ubicación y orientación (abeto) . . . . . . . . . . . . . . . . . . . 193

5.28. Test ANOVA de la carga máxima por ubicación y orientación (abeto) . . . . . . . . . 194

5.29. Análisis de comparación múltiple de Dunnett de la carga máxima por ubicación y orientación (abeto) . . . . . . . . . . . . . . . . . . . . 194

5.30. Prueba de homogeneidad de varianza de Levene de la carga máxima por orientación

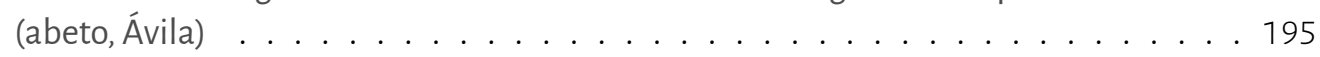

5.31. Test ANOVA de la carga máxima por orientación (abeto, Ávila) . . . . . . . . . . . . 195

5.32. Análisis de comparación múltiple de Bonferroni de la carga máxima por orientación (abeto, Ávila) . . . . . . . . . . . . . . . . . . . . . . 196 
5.33. Prueba de homogeneidad de varianza de Levene de la carga máxima por orientación (abeto, Madrid) . . . . . . . . . . . . . . . . . . . . . . . . . . 197

5.34. Test ANOVA de la carga máxima por orientación (abeto, Madrid) . . . . . . . . . . 197

5.35. Análisis de comparación múltiple de Bonferroni de la carga máxima por orientación (abeto, Madrid) . . . . . . . . . . . . . . . . . . . . . . . . 197

5.36. Prueba de homogeneidad de varianza de Levene de la carga máxima por orientación (abeto, Sevilla) . . . . . . . . . . . . . . . . . . . . . . 198

5.37. Test ANOVA de la carga máxima por orientación (abeto, Sevilla) . . . . . . . . . . . 199

5.38. Valores descriptivos de carga máxima por ubicación (abeto) . . . . . . . . . . . . . 199

5.39. Prueba de homogeneidad de varianza de Levene de la carga máxima por ubicación (abeto) ......................... 200

5.40. Test ANOVA de la carga máxima por ubicación (abeto) . . . . . . . . . . . . . . . 200

5.41. Análisis de comparación múltiple de Bonferroni de la carga máxima por ubicación

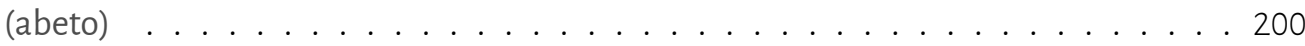

5.42. Análisis de efectos del modelo de la delaminación por ubicación y orientación según ubicación (abeto) . . . . . . . . . . . . . . . . . . . . . . . . . . . . 201

5.43. Prueba de homogeneidad de varianza de Levene de la delaminación por ubicación y orientación (abeto) . . . . . . . . . . . . . . . . . . . . . . . 201

5.44. Test ANOVA de la delaminación por ubicación y orientación (abeto) . . . . . . . . . 202

5.45. Análisis de comparación múltiple de Dunnett de la delaminación por ubicacióny orientación (abeto) . . . . . . . . . . . . . . . . . . . . . . . . 202

5.46. Prueba de homogeneidad de varianza de Levene de la delaminación por orientación (abeto, Ávila) . . . . . . . . . . . . . . . . . . . . . . . . . . . . . . . . . . 203

5.47. Test ANOVA de la delaminación por orientación (abeto, Ávila) . . . . . . . . . . . . 203

5.48. Análisis de comparación múltiple de Bonferroni de la delaminación por orientación (abeto, Ávila) . . . . . . . . . . . . . . . . . . . . . . . . . . . . . . . 204

5.49. Prueba de homogeneidad de varianza de Levene de la delaminación por orientación (abeto, Madrid) . . . . . . . . . . . . . . . . . . . . . . . 205

5.50. Test ANOVA de la delaminación por orientación (abeto, Madrid) . . . . . . . . . . . 205

5.51. Prueba de homogeneidad de varianza de Levene de la delaminación por orientación (abeto, Sevilla) . . . . . . . . . . . . . . . . . 205

5.52. Test ANOVA de la delaminación por orientación (abeto, Sevilla) . . . . . . . . . . 206

5.53. Valores descriptivos de la delaminación por ubicación (abeto) . . . . . . . . . . . . 206

5.54. Prueba de homogeneidad de varianza de Levene de la delaminación por ubicación (abeto) . . . . . . . . . . . . . . . . . . . 207

5.55. Test ANOVA de la delaminación por ubicación (abeto) . . . . . . . . . . . . . . . 207

5.56. Análisis de comparación múltiple de Bonferroni de la delaminación por ubicación (abeto) . . . . . . . . . . . . . . . . . . . . . 207

5.57. Análisis descriptivo del envejecimiento natural (pino) . . . . . . . . . . . . . . 209

5.58. Análisis de efectos del modelo de la carga máxima en función de ubicación y orientación según ubicación (pino) . . . . . . . . . . . . . . . . . . . . . . . . . . . . . 211

5.59. Prueba de homogeneidad de varianza de Levene de la carga máxima por ubicación“orientación

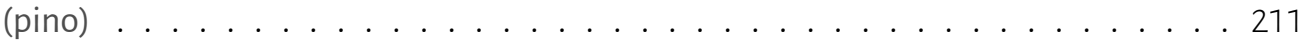


5.60. Test ANOVA de la carga máxima por ubicación*orientación (pino) . . . . . . . . 211

5.61. Análisis de comparación múltiple de Dunnett de la carga máxima por ubicación y orientación (pino) . . . . . . . . . . . . . . . . . . . . . 212

5.62. Prueba de homogeneidad de varianza de Levene de la carga máxima por orientación (pino, Ávila) . . . . . . . . . . . . . . . . . . . . . . . . 213

5.63. Test ANOVA de la carga máxima por orientación (pino, Ávila) . . . . . . . . . . 213

5.64. Prueba de homogeneidad de varianza de Levene de la carga máxima por orientación (pino, Madrid) . . . . . . . . . . . . . . . . . . . . . 213

5.65. Test ANOVA de la carga máxima por orientación (pino, Madrid) . . . . . . . . . . 213

5.66. Prueba de homogeneidad de varianza de Levene de la carga máxima por orientación (pino, Sevilla) . . . . . . . . . . . . . . . . . . . . . . . 214

5.67. Test ANOVA de la carga máxima por orientación (pino, Sevilla) . . . . . . . . . . 214

5.68. Valores descriptivos de la carga máxima por ubicación (pino) . . . . . . . . . . . . 214

5.69. Prueba de homogeneidad de varianza de Levene de la carga máxima por ubicación (pino) . . . . . . . . . . . . . . . . . . . . . . . . 214

5.70. Test ANOVA de la carga máxima por ubicación (pino) . . . . . . . . . . . . . . 215

5.71. Análisis de comparación múltiple de Bonferroni de la carga máxima por ubicación (pino) 216

5.72. Análisis de efectos del modelo de la delaminación frente a la ubicación y a la orientación según ubicación (pino) . . . . . . . . . . . . . . . . . . . 277

5.73. Prueba de homogeneidad de varianza de Levene de la delaminación por ubicación y orientación según ubicación (pino) ‥ . . . . . . . . . . . . . 217

5.74. Test ANOVA de la delaminación por ubicación y orientación según ubicación (pino) 217

5.75. Análisis de comparación múltiple de Dunnett de la delaminación por ubicacióny orientación (pino) . . . . . . . . . . . . . . . . . . . . . . . . . . 218

5.76. Prueba de homogeneidad de varianza de Levene de la delaminación por orientación (pino, Ávila) . . . . . . . . . . . . . . . . . . . . . . . . . . . . 219

5.77. Test ANOVA de la delaminación por orientación (pino, Ávila) . . . . . . . . . . . . . 219

5.78. Prueba de homogeneidad de varianza de Levene de la delaminación por orientación (pino, Madrid) . . . . . . . . . . . . . . . . . . . . . . . . . 219

5.79. Test ANOVA de la delaminación por orientación (pino, Madrid) . . . . . . . . . . 219

5.80. Prueba de homogeneidad de varianza de Levene de la delaminación por orientación (pino, Sevilla) . . . . . . . . . . . . . . . . . . . . . . 220

5.81. Test ANOVA de la delaminación por orientación (pino, Sevilla) . . . . . . . . . . 220

5.82. Valores descriptivos de la delaminación por ubicación (pino) . . . . . . . . . . . . 220

5.83. Prueba de homogeneidad de varianza de Levene de la delaminación por ubicación (pino) . . . . . . . . . . . . . . . . . . . . . . 220

5.84. Test ANOVA de la delaminación por ubicación (pino) . . . . . . . . . . . . . . 221

5.85. Análisis de comparación múltiple de Tamhane de la delaminación por ubicación (pino) 222

5.86. FCBA ciclo corto abeto . . . . . . . . . . . . . . . . . . . . . . . . . . . . 223

5.87. FCBA ciclo largo abeto . . . . . . . . . . . . . . . . . . . . . . . . . 223

5.88. INIA ciclo corto abeto . . . . . . . . . . . . . . . . . . . . . . . 223

5.89. INIA ciclo largo abeto . . . . . . . . . . . . . . . . . . . . . . . . . . . . 224 
5.90. Prueba de homogeneidad de varianza de Levene de la carga máxima por tipo de envejecimiento (abeto) . . . . . . . . . . . . . . . . . . . . 224

5.91. Test ANOVA de la carga máxima por tipo de envejecimiento (abeto) . . . . . . . . . 224

5.92. Análisis de comparación múltiple de Dunnett de la carga máxima por tipo de envejecimiento (abeto) . . . . . . . . . . . . . . . . . . . . . . . 225

5.93. Valores descriptivos de la carga máxima por tipo de envejecimiento (abeto) . . . . . 225

5.94. Prueba de homogeneidad de varianza de Levene de la carga máxima por tipo de envejecimiento (sin la referencia) (abeto) . . . . . . . . . . . . . . . . . . 226

5.95. Test ANOVA de la carga máxima por tipo de envejecimiento (sin la referencia) (abeto) 226

5.96. Análisis de comparación múltiple de Tamhane de la carga máxima por tipo de envejecimiento artificial (abeto) . . . . . . . . . . . . . . . . . . . 226

5.97. Prueba de homogeneidad de varianza de Levene de la delaminación por tipo de envejecimiento (abeto) . . . . . . . . . . . . . . . . . . . . . 227

5.98. Test ANOVA de la delaminación por tipo de envejecimiento (abeto) . . . . . . . . . 227

5.99. Análisis de comparación múltiple de Bonferroni de la delaminación por tipo de envejecimiento artificial (abeto) . . . . . . . . . . . . . . . . . . . . 228

5.100.Valores descriptivos de la delaminación de los tipos de envejecimiento artificial (abeto) 228

5.101.Prueba de homogeneidad de varianza de Levene de la delaminación por tipo de envejecimiento (sin la referencia) (abeto) . . . . . . . . . . . . . . . . . . . . 229

5.102.Test ANOVA de la delaminación por tipo de envejecimiento (sin la referencia) (abeto) 229

5.103.Análisis de comparación múltiple de Tamhane de la delaminación por tipo de envejecimiento artificial (abeto) . . . . . . . . . . . . . . . . . . . . . . . 229

5.104.FCBA ciclo corto pino . . . . . . . . . . . . . . . . . . . . 230

5.105.FCBA ciclo largo pino . . . . . . . . . . . . . . . . . . . . . . . . 230

5.106. INIA ciclo corto pino . . . . . . . . . . . . . . . . . . . . 231

5.107.INIA ciclo largo pino . . . . . . . . . . . . . . . . . . . . . . . . . . 231

5.108.Prueba de homogeneidad de varianza de Levene de la carga máxima por tipo de envejecimiento (pino) . . . . . . . . . . . . . . . . . . . . . . . . . 231

5.109.Test ANOVA de la carga máxima por tipo de envejecimiento (pino) . . . . . . . . . . 232

5.110.Análisis de comparación múltiple de Bonferroni de la carga máxima por tipo de envejecimiento artificial (pino) . . . . . . . . . . . . . . . . . . . . . 232

5.111. Valores descriptivos de la carga máxima por tipo de envejecimiento artificial (sin la referencia) (pino) . . . . . . . . . . . . . . . . . . . 233

5.112.Prueba de homogeneidad de varianza de Levene de la carga máxima por tipo de envejecimiento (sin la referencia) (pino) . . . . . . . . . . . . . . . . . . . 233

5.113.Test ANOVA de la carga máxima por tipo de envejecimiento (sin la referencia) (pino) 233

5.114.Análisis de comparación múltiple de Bonferroni de la carga máxima por tipo de envejecimiento artificial (sin la referencia) (pino) . . . . . . . . . . . . . . . . . . . 234

5.115.Prueba de homogeneidad de varianza de Levene de la delaminación por tipo de envejecimiento (pino) . . . . . . . . . . . . . . . . . . . . 234

5.116.Test ANOVA de la delaminación por tipo de envejecimiento (pino) . . . . . . . . . . 235

5.117.Valores descriptivos de la delaminación de los tipos de envejecimiento artificial (pino) 235 
5.118.Prueba de homogeneidad de varianza de Levene de la delaminación por tipo de envejecimiento (sin la referencia) (pino) . . . . . . . . . . . . . . . . . 235

5.119.Test ANOVA de la delaminación por tipo de envejecimiento (sin la referencia) (pino) 235

5.120 .Medias anuales . . . . . . . . . . . . . . . . . . . . 236

5.121. Datos medios de pérdida de propiedades de carga máxima y delaminación . . . . 238

5.122. Resumen del modelo para el abeto incluyendo la delaminación y la carga máxima . . 239

5.123. Matriz de correlaciones de las variables transformadas (para el abeto incluyendo delaminación y carga máxima) . . . . . . . . . . . . . . . . . . . 240

5.124.Pesos de los componentes (para el abeto incluyendo delaminación y carga máxima) . 240

5.125. Resumen del modelo para el abeto incluyendo únicamente la carga máxima . . . . 242

5.126. Matriz de correlaciones de las variables transformadas (para el abeto incluyendo únicamente la carga máxima) . . . . . . . . . . . . . . . . . . . . . 242

5.127.Pesos de los componentes (para el abeto incluyendo únicamente la carga máxima) 243

5.128. Resumen del modelo para el abeto incluyendo únicamente la delaminación . . . . . 244

5.129. Matriz de correlaciones de las variables transformadas (para el abeto incluyendo úni-

camente la delaminación) . . . . . . . . . . . . . . . . . . . . . . . . . 244

5.130.Pesos de los componentes (para el abeto incluyendo únicamente la delaminación) 245

5.131. Resumen del modelo para el pino incluyendo la delaminación y la carga máxima . 246

5.132. Matriz de correlaciones de las variables transformadas (para el pino incluyendo de-

laminación y carga máxima) . . . . . . . . . . . . . . . . . . . . . 246

5.133.Pesos de los componentes (para el pino incluyendo delaminación y carga máxima) 247

5.134. Resumen del modelo para el pino incluyendo únicamente la carga máxima . . . . . 248

5.135. Matriz de correlaciones de las variables transformadas (para el pino incluyendo úni-

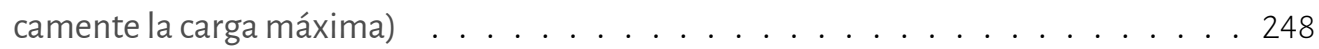

5.136.Pesos de los componentes (para el pino incluyendo únicamente la carga máxima) . 249

5.137. Resumen del modelo para el pino incluyendo únicamente la delaminación . . . . . 251

5.138. Matriz de correlaciones de las variables transformadas (para el pino incluyendo únicamente la delaminación) . . . . . . . . . . . . . . . . . . . . . . 251

5.139.Pesos de los componentes (para el pino incluyendo únicamente la delaminación) 251

5.140.Valores descriptivos de carga máxima y delaminación en función del método aplicado 253

5.141.Prueba de homogeneidad de varianza de Levene de la carga máxima y delaminación en función del método aplicado . . . . . . . . . . . . . . . . . . . . 254

5.142.Test ANOVA de la carga máxima y delaminación en función del método aplicado 254

5.143. multiple comparisons tambhane . . . . . . . . . . . . . . . . . . . . 254

5.144.Valores descriptivos de la carga máxima y delaminación en función de los métodos equivalentes aplicados . . . . . . . . . . . . . . . . . . 256

5.145.Prueba de homogeneidad de varianza de Levene de la carga máxima y delaminación en función de los métodos equivalentes aplicados . . . . . . . . . . . . . 256

5.146.Test ANOVA de la carga máxima y delaminación en función de los métodos equivalentes aplicados . . . . . . . . . . . . . . . . . . . . . 256

5.147.Análisis de comparación múltiple de Tamhane de la carga máxima y delaminación en función de los métodos equivalentes aplicados . . . . . . . . . . . . . . . . 257 